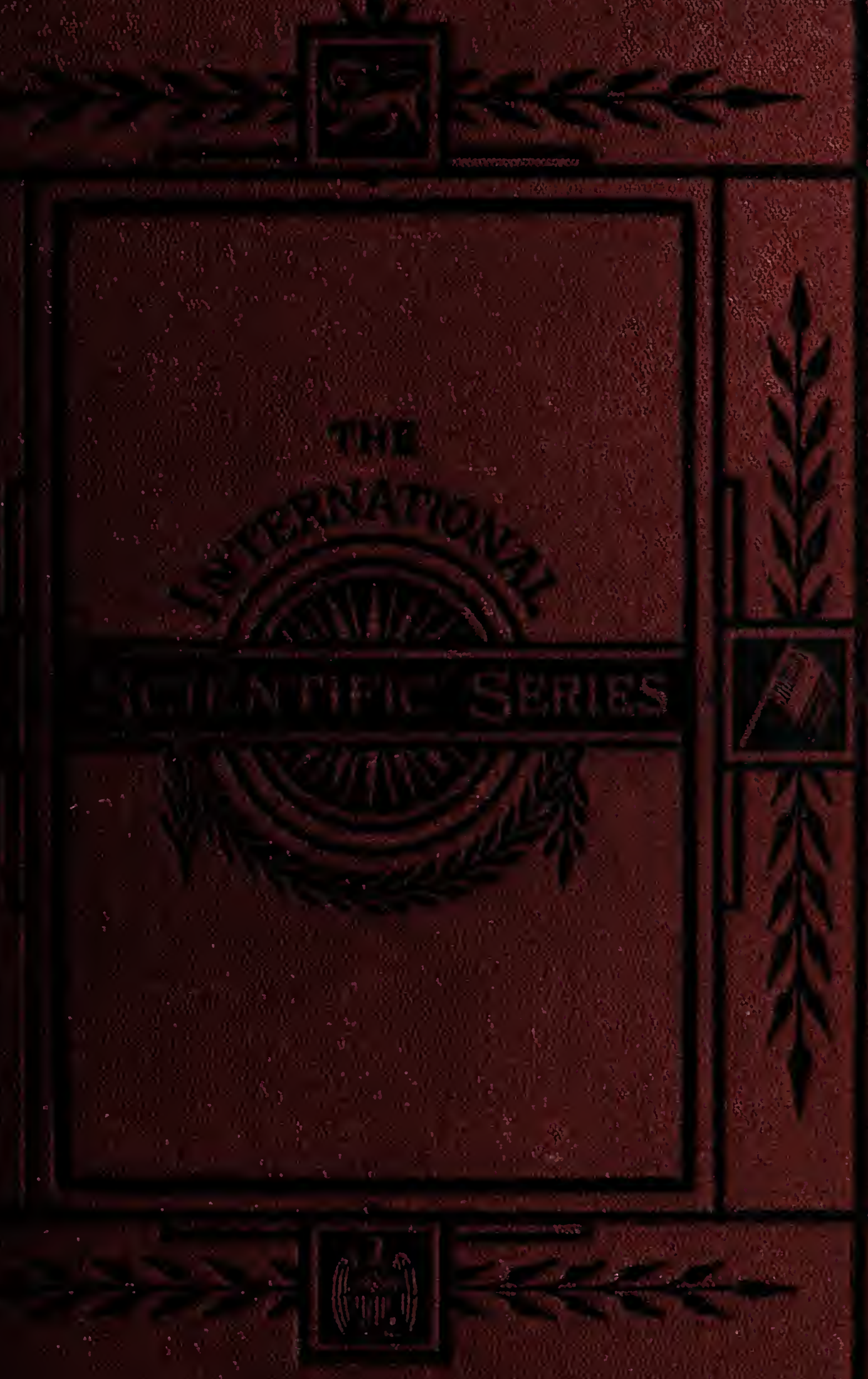




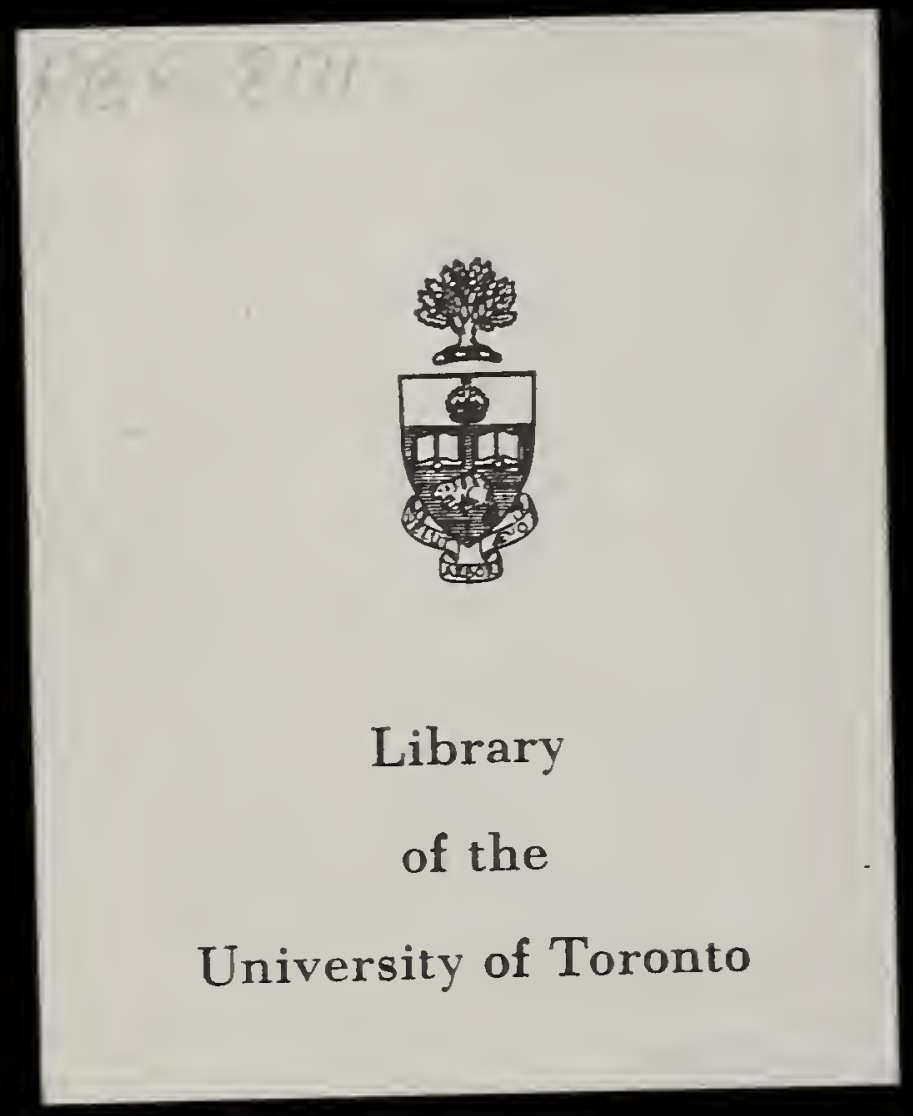




1. Colthenst

186 



\section{INTERNATIONAL SCIENTIFIC SERIES.}

Each Book Complete in One Volume. Crown 8ro. cloth.

I. FORMS of WATER : a Familiar Exposition of the Origin and Phenomena of GLAC.IFRS. B.y J. TYNDALL, LL.D., F.R.S. With 25 Illustrations." Eighth Edition. $5 s$.

II. PHYSICS and POLITICS; or, Thoughts on the Application of the Principles of 'Natural Selection' and 'Inheritance.' to Political Socièty. By Walter Bagehot." Sixth Edition. 4s.'

III. FOODS. By EDward Smith, M.D., LL.B , F.R.S. With numerous: Illustrations. Eighth Edition. 5s.

IV. MIND and BODY: the Theories of their Relation. By ALEXANDER BAIN, LL.D. WithFour Ilustrations. 'Seventh Edition. $4 s$.

V. The STUDY of SOCIOLOGY. By Herbert SPENCER. Eleventh Edition: " $5 s^{\prime}$

VI. On the CONSERVATION of ENERGY. By BALFOUR STEWART, M.A., LL.D., F.R.S. 'With 14 IIIustrations. 'Sixth Edition. " 5 s.

VII. ANIMAI LOCOMOTION; or, Walking, Swimming, and Flying. By J. B. PerTigrew, M.D., F.R.S., \&c. With 130 Illustrations. Third Edition. 5s.

VIII. RESPONSIBILITY in MENTAI DISEASE. By HENRY MAÚdsLiti, M.D. Fourth Edition." 5 s.

IX. The NEW CHEMISTRY. By Professor J. P. Cooke, of the Harvard Unlversity. With 31 Illustrations. Eighth Edition; remodelled and enlarged. $5 s$.

X. The SCIENCE of I.A.W. By:Professor Sheldon Amos. Fifth Edition. 5 s.

London: KEGAN PAUL, TRENCH, \& CO., 1 Paternoster Square. i. 
XI. ANIMAI MECHANISM: a Treatise on Terrestrial and Aërial Locomotion. BS Professor E. J. MAREY. With 117 Mllustrations. Third Edition. 5s.

XII. The DOCTRINE of DESCENT and DARWINISM. By Professor OSCAR SCHMDT (Strasburg University). With 26 Mlustrations. Sixth Edition. 5s.

XIII. The HISTORY of the CONFLICT between RELIGION and SCIENCE. By J. W. DRAPER, M.D., LL.D. Eighteenth Edition. 5s.

XIV. FUNGI: their Nature, Influences, Uses, \&c. By M. C. Cooke, M.A., LL.D. Edited by the Rev, M. J. BerkeLey, M.A., F.L.S. With numerous Illustrations. Third Edition. 5s.

XV. The CHEMICAL EFFECTS of IIGHT and PHOTOGRAPHY. By Dr. Hermain Vogel (Polytechnic Academy of Berlin). Translation thoroughly revised. With 100 Illustrations. Fourth Edition. 5s.

XVI. The LIFE and GROWTH of LANGUAGE. By WilliaM DWIGHT WHITNEY. Fourth Edition. 5s.

XVII. MONEY and the MECHANISM of EXCHANGE. By W. Staktey Jevons, M.A., F.R.S. Sixth Edition. 5s.

XVIII. The NATURE of LIGHT, with a General Account of PHYSICAL OPTICS. BY Dr. EUGENE LOMMEL. With 188 Illustrations and a Table of Spectra in Chromo-lithography. Third Edition. 5s.

XIX. ANIMAL PARASITES and MESSMATES. By Monsieur VAN BENEnEN. With 83 Illustrations. Third Edition. 5s.

XX. FERMENTAtion. By Professor Schützenberger. With 28 Illustrations. Fourth Edition. 5s.

XXI. The FIVE SENSES of MAN. By Professor Bernsteis, With 91 Illustrations. Fourth Edition. 5s.

London: KEGAN PAUL, TRENCH, \& CO, 1 Paternoster Square. 
The International Scientific Series-continued.

XXII. The THEORY of SOUND in its RELATION to MUSIC.

By Professor Pietro Blaserra. With numerous Illustrations. Third Edition. 5s.

XXIII. STUDIES in SPFCTRUM ANALYSIS. By J. NorMar LOCKYER, F.R.S. With Six Photographic Illustrations of Spectra, and numerous Engravings on Wood. Third Edition. 6s.6d.

XXIV. A HISTORY of the GROWTH of the STEAM ENGINE. By Professor R. H. THURstoN. With numerous Illustrations. Third Edition. 6s. 6d.

XXV. FDUCATION as a SCIFNCF. By ALEXANDRR BAIN, LL.D. Fourth Edition. $5 s$.

XXVI. The HUMAN gPECIES. By Professor A. De Quatrefages, Membre de l'Institut. Third Edition. $5 s$.

XXVII. MODERN CHROMATICS. With Application to Art and Industry. By OGDEN N. ROOD. Second Edition. With 130 original Illus. trations. $5 s$.

XXVIII. The CRAYFISH : an Introduction to the Study of Zoology. By T. H. HuxLeY, F.R.S. Fourth Edition. With 82 Illustrations. 5s.

XXIX. The BRAIN as an ORGAN of MIND. By H. CharLtos: Bastian, M.D. Third Edition. With 184 Illustrations. $5 s$.

XXX. The ATOMIC THEORY. By Professor A. Wortz. Translated by E. Cleminshaw, F.C.S. Third Edition. 5s.

XXXI. The NATURAL CONDITIONS of EXISTENCE as they affect Animal Life. By KARL SEMPER. Third Edition. With 2 Maps and 106 Woodcuts. 5s.

XXXII. GENERAL PHYSIOLOGY Of MUSCLES and NERVES By Prof. J. RosenthaL. Third Edition. With Illustrations. 5 s.

XXXIII. SIGHT: an Exposition of the Principles of Monocular and Binocular Vision. By JosePE LE CONTE, LL.D. Second Edition. With 132 Illustrations. $5 s$.

XXXIV. ILLUSIONS: a Psychological Study. By James Sully. Second Edition. $5 s$.

London: KEGAN PAUL TRENCH, \& CO, 1 Paternoster Square. 
XXX.V. VOLCANOES : what they are and what they teach.; By JoHN, W. JupD, F.R.S. Third Edition. With 92 Illustrations. 5s.

XXXVI. SUICIDE : an Essay on Comparative Moral Statistics. By Professor H. Monsell. Second. Edition. 5s.

XXXVII. THE BRAIN AND ITS FUNCTIONS. By J. LUYS, Physician to the Hospice de la, Salpêtrière. With numerous Illustrations. Second Edition. 5s.

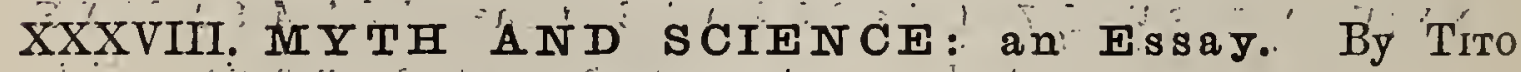
VIGxoli. Second Edition. 5s.

XXXIX. THE sUN. By C. A. Young, Ph.D., LL.D. Second Edition: With numerons'tllustrations.

XL. ANTS, BEES, and WAIPS. A Record of Observations

$\therefore$.. on the /Habits of the Social -Hymenoptera... By "Sir JoHN LuBBock, Bart.,.M.P:. Seventh Edition. With 5 Chromo-lithographic Plates, 5s.

XLI. ANIMAI INTELITGENCE. BY GEORGE J. ROMANES, IL.D., F.R.S. Third Edition. 5s.

XLII. The CONCEPTS and THEORIES of . MODERN PHYSICS. By J. B. STALLO. Third Edition. $5 s$.

XLIII. DISEAsts of MEMorY. An Essay in the Positive Psychology. By'TH. RIBOT. Second Edition. $5 s$.

XLIV. MAN BEFORE METALS: By N. JoLr, Correspondènt đe l'Institut de France. Third Edition. $5 s$.

XLV. THE : SCIENCE of POLITICS. By. Prof: SHELDON Amos. Third Edition. 5s.

XLVI. ELEMENTARY METPOROLOGY. By ROBERT H. ScoTt: Third Edition. 5s.

XLVII. THE ORGANS of SPEECH. 'By GEORG HERMANN VON MEYER. 5s.

XLVIII. FALIACIES. A View of Logic from the Practical Side. By AIFRKD SIDGWICK. $5 \dot{s}$.

XLIX. THE ORIGIN OF CULTIVATED PLANTS.' By ALPHONSE DE CANDOLLE.

L. JELIY FISH, STAR FISH, AND SEA URCHINS.

$\therefore$ Being a Research on Primitive Nervous Systems, By, G. J. Ronanef, LI.D., F.R.S.

London: KEGAN PAUL, TRENCH, \& CO., 1 Paternoster Square. 


\section{INTERNATIONAL SCIENTIFIC SERIES}

VOL. XXVIII. 



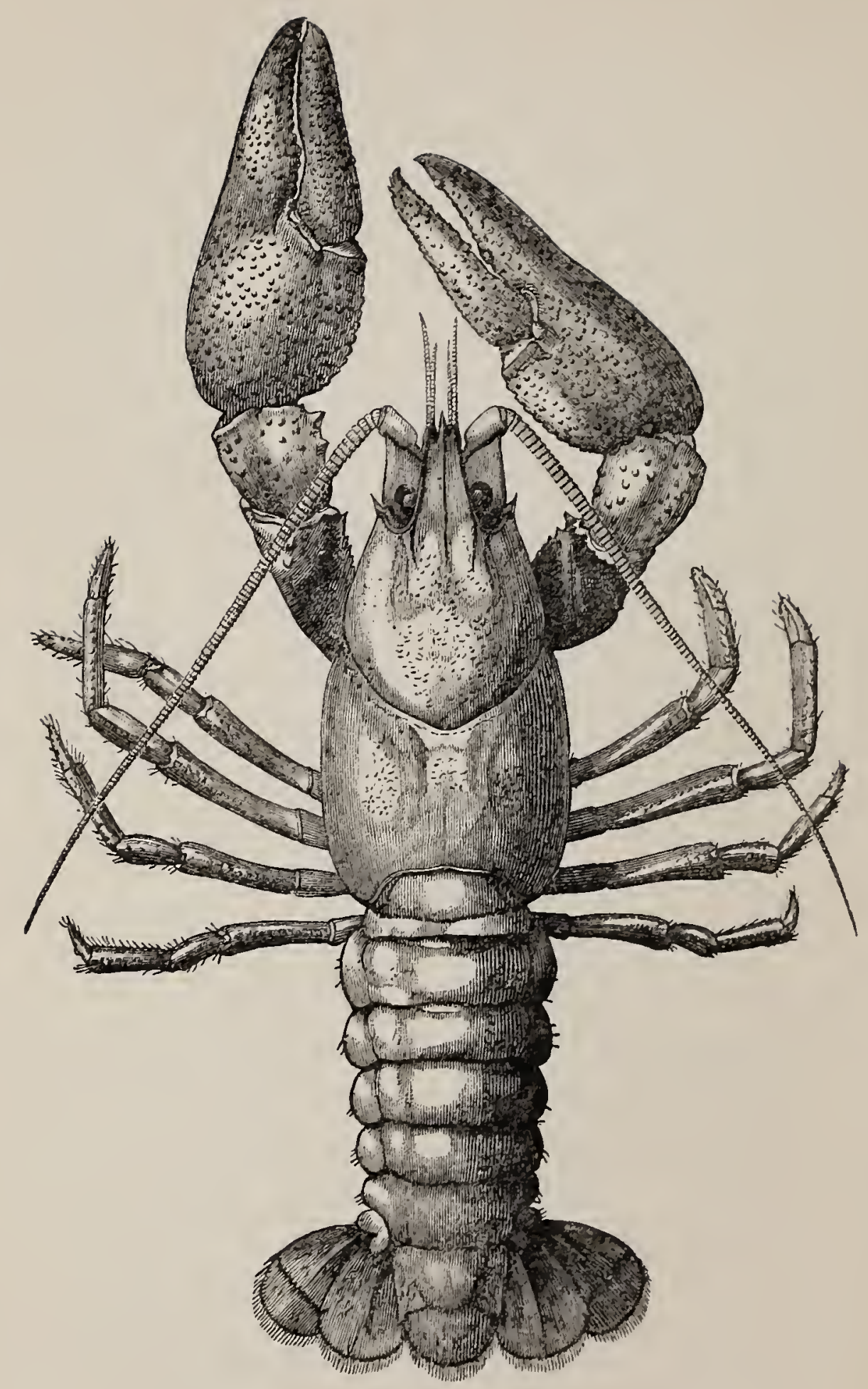

THE COMMON CRAYFISH.

(Asiacus furriatilis, Male.) 


\title{
THE CRAYFISH
}

\author{
AN INTRODUCTION TO
}

\section{THE STUDY OF ZOOLOGY}

T. H. HUXLEY, F.R.S.

WITH EIGHTY-TWO ILLUSTRATIONS

FOURTH EDITION.

LONDON :

KEGAN PAUL, TRENCH \& CO., 1, PATERNOSTER SQUARE 1884 . 


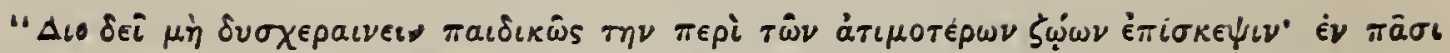

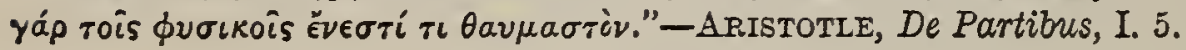

"Qui enim Autorum verba legentes, rerum ipsarum imagines (eorum verbis comprehensa) sensibus propriis non abstrahunt, hi non veras Ideas, sed falsa Idola et phantasmata inania mente concipiunt ......

"Insusurro itaque in aurem tibi (amice Lector!) ut quæcunque à nobis in hisce.... exercitationibus tractabuntur, ad exactam experientiæ trutinam pensites: fidemque iis non aliter adhibeas, nisi quatenus eadem indubitato sensuun testimonio firmissime stabiliri deprehenderis."-Hapver. Exercitationes de Generatione. Profatio.

"La seule et vraie Science est la connaissance des faits: l'esprit ne peut pas y suppléer et les faits sont dans les sciences ce qu'est l'expérience dans la vie civile."

"Le seul et le vrai moyen d'avancer la science est de travailler à la description et à l'histoire des differentes choses qui en font l'objet." - Buffos. Discours de la manière d'étudier et de traiter l'Histoire Naturelle.

"Ebenso hat mich auch die genäuere Untersuchung unsers Krebses gelehret, dass, so gemein und geringschätzig solcher auch den meisten zu seyn scheinet, sich an selbigem doch so viel Wunderbares findet, dass es auch den grossten Naturforscher schwer fallen sollte solches alles deutlich zu beschreiben."-ROESEL v. ROSENHOF. Insecten Belustigungen. - "Der Flusskrebs hiesiges Landes mit seinen merkwurdigen Eigenschaften." 


\section{PRE FACE.}

In writing this book about Crayfishes it has not been my intention to compose a zoological monograph on that group of animals. Such a work, to be worthy of the name, would require the devotion of years of patient study to a mass of materials collected from many parts of the world. Nor has it been my ambition to write a treatise upon our English crayfish, which should in any way provoke comparison with the memorable labours of Lyonet, Bojanus, or Strauss Durckheim, upon the willow caterpillar, the tortoise, and the cockchafer. What I have had in view is a much humbler, though perhaps, in the present state of science, not less useful object. I have desired, in fact, to show how the careful study of one of the commonest and most insignificant of animals, leads us, step by step, from every-day knowledge to the widest generalizations 
and the most difficult problems of zoology; and, indeed, of biological science in general.

It is for this reason that I have termed the book an "Introduction to Zoology." For, whoever will follow its pages, crayfish in hand, and will try to verify for himself the statements which it contains, will find himself brought face to face with all the great zoological questions which excite so lively an interest at the present day; he will understand the method by which alone we can hope to attain to satisfactory answers of these questions; and, finally, he will appreciate the justice of Diderot's remark, "Il faut être profond dans l'art ou dans la science pour en bien posséder les éléments."

And these benefits will accrue to the student whatever shortcomings and errors in the work itself may be made apparent by the process of verification. "Common and lowly as most may think the crayfish," well says Roesel von Rosenhof, "it is yet so full of wonders that the greatest naturalist may be puzzled to give a clear account of it." But only 
the broad facts of the case are of fundamental importance; and, so far as these are concerned, I venture to hope that no error has slipped into my statement of them. As for the details, it must be remembered, not only that some omission or mistake is almost unavoidable, but that new lights come with new methods of investigation; and that better modes of statement follow upon the improvement of our general views introduced by the gradual widening of our knowledge.

I sincerely hope that such amplifications and rectifications may speedily abound; and that this sketch may be the means of directing the attention of observers in all parts of the world to the crayfishes. Combined efforts will soon furnish the answers to many questions which a single worker can merely state; and, by completing the history of one group of animals, secure the foundation of the whole of biological science.

In the Appendix, I have added a few notes respecting points of detail with which I thought it 
unnecessary to burden the text; and, under the head of Bibliography, I have given some references to the literature of the subject which may be useful to those who wish to follow it out more fully.

I am indebted to Mr. T. J. Parker, demonstrator of my biological class, for several anatomical drawings; and for valuable aid in supervising the execution of the woodcuts, and in seeing the work through the press.

Mr. Cooper has had charge of the illustrations, and $\mathrm{I}$ am indebted to him and to $\mathrm{Mr}$. Coombs, the accurate and skilful draughtsman to whom the more difficult subjects were entrusted, for such excellent specimens of xylographic art as the figures of the Crab, Lobster, Rock Lobster, and Norway Lobster.

\section{T. H. H.}

\section{LONDON,}

-November, 1879. 


\section{CONTENTS.}

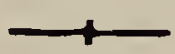

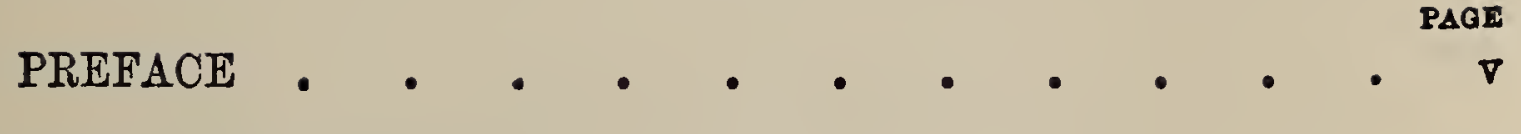

LIST OF WOODCOTS • • • • • • • • • xi

CHAPTER I.

The Natural History of the Common Craffish • • • 1

CHAPTER II.

The Physiology of the Common Crayfish. The Mechanism by which the Parts of the Living Engine are supplied WITH TIIE MATERIALS NECESSART FOR THEIR MAINTENANCE AND GROWTH . . • . • • • • • • 46

\section{CHAPTER III.}

The Physiology of the Common Crayfish. The Mechanism BX WHICH THE LIVING ORgaNisM ADJUSTS ITSELF TO SURROUNDING CONDITIONS AND REPRODUCES ITSELF • • • 87

\section{CHAPTER IV.}

The Morphology of the Common Crapfish. The structure AND THE DEVELOPMENT OF THE INDIVIDUAL • • • . 137 


\section{CHAPTER V.}

The Comparative Morphology of the Crayfish. The strucTURE AND THE DEVElopment of THE Crayfish CoMpared WITH THOSE OF OTHER LIVING BEINGS

CHAPTER VI.

The Distribution and the Etiology of the Crayfishes . 288

NOTES • • • • • • • • • • • • $\quad$ • 347

BIBLIOGRAPHY • • • • • • • • • 357

INDEX • • • • • • • • • • • 


\section{LIST OF WOODCUTS.}

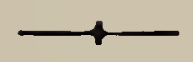

PAGE

Firontispiece. The Common Crayfish, Astacus fluviatilis, (MALE)

Fig. 1. Astacus fluviatilis. SIDE vIEW of THE MaLE. • 6

$" 2 . \quad " \quad " \quad$ Dorsal views of MaLe aNd Female 18

$" 3 . \quad " \quad " \quad$ Ventral VIEWS OF MALE AND FEMALE 21

" 4. " " $\quad$ The GILls . . . . . . 26

" 5. $" \quad$ DISSECTION FROM THE DORSAL SIDE

(MALE) • • • . . $\quad 28$

" $\quad$ 6. $" \quad$ LONGITUDINAL VERTICAL SECTION OF

THE ALIMENTARY CANAL • . 29

"7. " $\quad$ A GASTROLITH OR "CRAB"S EYE" . 30

" 8. " " $"$ ATTACHMENT OF TOUNG to SWIM-

MERET OF MOTHER . . • 41

Structure of the STOMaCH . . 53

LONGITUDINAL SECTION OF THE STO-

$\mathrm{MACH} \cdot \cdot \cdot \cdot \quad \cdot \quad \cdot 56$

"11. " " ROOF OF THE STOMACH, FroM WITHIN 60

$"$ 12. " $" \quad$ Dissection From the Side (MALE). 62

"13. " " ALIMENTARY CANAL From ABove . 65

"14. " " " BLOOD CORPUSCles . .

"15. " " " Transverse section of thorax $\quad . .70$

" $16 . \quad " \quad " \quad$ THE HEART . . . . . . 72

$"$ 17. $" \quad$ " STRUCTURE OF THE GILLS . . . 76

. 18. " . . $\quad$ " THE GREEN GLAND . . . . . 83 
Fig. 19. Astacus fluviatilis. MUSCULAR TISSUe • • • • 91

"20. , "

" 21.

, 22. , ,

"23. ,

"24. ,

, 25.

,26. ,

, $27 . \quad$,

, 28. , ,

,29. , ,

, 30. ",

"31. ,

"32. ",

, 33. ,"

"34. ,

, 35. ,

, 36. , ,

" 37. ",

" 38. ,

, 39. , ,

" 40. "

, 41. ,

" 42. "

" 43. "

" 44. ,
MUSCLES OF CHELA.

Articulation of abdominal so.

MITES • • . . • . 97

MUSCULAR STSTEM .. • . . 100

Nerve fibres . • • . . 102

Nerve ganglia • • . . 103

Nervous SYstem $\quad \cdot \quad \cdot \quad \cdot \quad \cdot 104$

Olfactory aNd AUDITORY ORgaNs 114

AUdITORY SAC • • • • • 117

StruCtURE OF EYE

Diagram of EYE • • • . 123

Female reproductive organs . 129

Male ReProductive organs . . 130

StruCtURE OF OVART. • . . 131

Structure of testis $\quad$ • . 132

SpermatozoA • . . . . 134

The Last thoracic Sternum IN THE

MALE AND FEMALE • • • 136

Transverse section of abdomen 142

Abdominal appendages • • • 144

CONNECTION BETWEEN THORAX AND

ABDOMEN • • • • • 151

Cephalothoracic sterna and eNDOPHRAGMAL STSTEMI • . . 153

OPhthalmic aNd antenNulari; so-

MITES . • . . • . 156

THE ROSTRUM • • . • . 157

A Segmest of the endophragmal SYSTEM • . . • • 159

LONGITUDINAL SECTION OF CEPHALO-

THORAX . . . . . 162

THE THIRD MAXILLIPEDE. • . 164 
FIG. 45. Astacus fluviatilis. THe FIRST AND SECOND MAXILLI-

PAGE PEDES • • . • . . 166

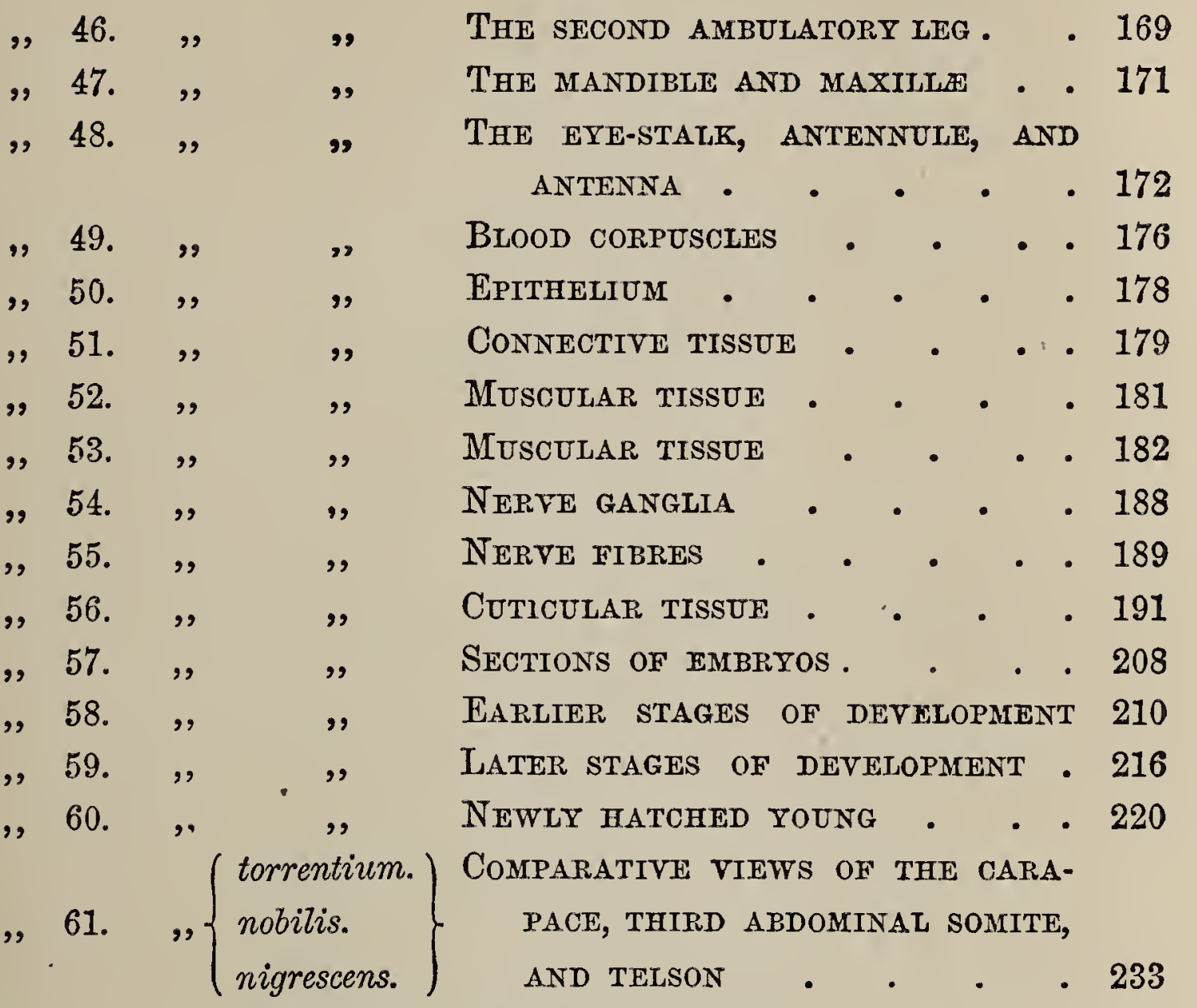

COMPARATIVE VIEWS OF THE FIRST AND SECOND ABDOMINAL APPENDAGES OF THE MALE • • • 245

" 63. Cambarus Clarkii .

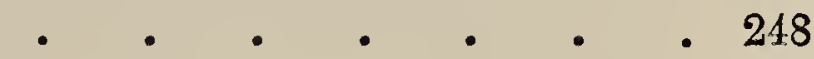

"64. Parastacus brasiliensis . • . • . • . . 250

"65. Astacoides madagascarensis . . . . . . 251

"66. Diagray OF THE MORPHOLOGical Relations OF the Astacidce • • • • • • • • • . 253

67. Homarus vulgaris . . • • • • . . 258 " 68. $\left\{\begin{array}{l}\text { Parastacus. } \\ \text { Nephrops. } \\ \text { Palamon. }\end{array}\right\}$ Ponobranchiæ.$\quad \cdot \quad \cdot \quad \cdot 259$ 
Fig. 69. Neptaps norregicus PAGE Fig. 69. Nephrops norvegicus . • • • • • • . 260 , 70. Palinurus vulgaris • • • • • • • . 262

"71. Palcomon jamaicensis • • • • • • . 269

"72. Cancer pagurus . • • • • • • • . 273

„73. Penceus . • . . • • • • • . 281

„74. Cancer pagurus. Development . . • . . . 282

„75. Astacus leptodactylis . . . . . . . . 301

„76. Austratian Crayfish . . . . . . . . 307

" 77. May of the distribution of Crayfishes . • . 309

"78. Cambarus. WALkiNg LEG. • • • • • . 312

„ 79. Paloemon jamaicensis . . . . . . . 329

"80. $\left\{\begin{array}{l}\text { Pserudastacus pustulosus } \\ \text { Eryma modestiformis }\end{array}\right\}$ • . . . . . 340

, 81. Hoploparia longimana . . . . . . 342 


\section{THE CRAYFISH:}

\section{AN INTRODUCTION TO THE STUDY OF ZOOLOGY.}

\section{CHAPTER I.}

TIIE NATURAL HISTORY OF THE COMMON CRAYFISH (Astacus fluviatilis.)

Many persons seem to believe that what is termed Science is of a widely different nature from ordinary knowledge, and that the methods by which scientific truths are ascertained involve mental operations of a recondite and mysterious nature, comprehensible only by the initiated, and as distinct in their character as in their subject matter, from the processes by which we discriminate between fact and fancy in ordinary life.

But any one who looks into the matter attentively will soon perceive that there is no solid foundation for the belief that the realm of science is thus shut off from that of common sense; or that the mode of investigation which yields such wonderful results to the sciertific investigator, is different in kind from that which is employed 38 
for the commonest purposes of everyday existence. Common sense is science exactly in so far as it fulfils the ideal of common sense; that is, sees facts as they are, or, at any rate, without the distortion of prejudice, and reasons from them in accordance with the dictates of sound judgment. And science is simply common sense at its best; that is, rigidly accurate in observation, and merciless to fallacy in logic.

Whoso will question the validity of the conclusions of sound science, must be prepared to carry his scepticism a long way; for it may be safely affirmed, that there is hardly any of those decisions of common sense on which men stake their all in practical life, which can justify itself so thoroughly on common sense principles, as the broad truths of science can be justified.

The conclusion drawn from due consideration of the nature of the case is verified by historical inquiry; and the historian of every science traces back its roots to the primary stock of common information possessed by all mankind.

In its earliest development knowledge is self-sown. Impressions force themselves upon men's senses whether they will or not, and often against their will. The amount of interest which these impressions awaken is determined by the coarser pains and pleasures which they carry in their train, or by mere curiosity; and reason deals with the materials supplied to it as far as that interest carries it, and no farther. Such common 
knowledge is rather brought than sought; and such ratiocination is little more than the working of a blind intellectual instinct.

It is only when the mind passes beyond this condition that it begins to evolve science. When simple curiosity passes into the love of knowledge as such, and the gratification of the æsthetic sense of the beauty of completeness and accuracy seems more desirable than the easy indolence of ignorance; when the finding out of the causes of things becomes a source of joy, and he is counted happy who is successful in the search; common knowledge of nature passes into what our forefathers called Natural History, from whence there is but a step to that which used to be termed Natural Philosophy, and now passes by the name of Physical Science.

In this final stage of knowledge, the phenomena of nature are regarded as one continuous series of causes and effects; and the ultimate object of science is to trace out that series, from the term which is nearest to us, to that which is at the furthest limit accessible to our means of investigation.

The course of nature as it is, as it has been, and as it will be, is the object of scientific inquiry; whatever lies beyond, above, or below this, is outside science. But the philosopher need not despair at the limitation of his field of labour : in relation to the human mind Nature is boundless; and, though nowhere inaccessible, she is everywhere unfathomable. 
The Biological Sciences embody the great multitude of truths which have been ascertained respecting living beings; and as there are two chief kinds of living things, animals and plants, so Biology is, for convenience sake, divided into two main branches, Zoology and Botany.

Each of these branches of Biology has passed through the three stages of development, which are common to all the sciences; and, at the present time, each is in these different stages in different minds. Every country boy possesses more or less information respecting the plants and animals which come under his notice, in the stage of common knowledge; a good many persons have acquired more or less of that accurate, but necessarily incomplete and unmethodised knowledge, which is understood by Natural History; while a few have reached the purely scientific stage, and, as Zoologists and Botanists, strive towards the perfection of Biology as a branch of Physical Science.

Historically, common knowledge is represented by the allusions to animals and plants in ancient literature; while Natural History, more or less grading into Biology, meets us in the works of Aristotle, and his continuators in the Middle Ages, Rondoletius, Aldrovandus, and their contemporaries and successors. But the conscious attempt to construct a complete science of Biology hardly dates further back than Treviranus and Lamarck, at the beginning of this century, while it has received its strongest impulse, in our own day, from Darwin. 
My purpose, in the present work, is to exemplify the general truths respecting the development of zoological science which have just been stated by the study of a special case ; and, to this end, I have selected an animal, the Common Crayfish, which, taking it altogether, is better fitted for my purpose than any other.

It is readily obtained,* and all the most important points of its construction are easily deciphered; hence, those who read what follows will have no difficulty in ascertaining whether the statements correspond with facts or not. And unless my readers are prepared to take this much trouble, they may almost as well shut the book; for nothing is truer than Harvey's dictum, that those who read without acquiring distinct images of the things about which they read, by the help of their own senses, gather no real knowledge, but conceive mere phantoms and idola.

It is a matter of common information that a number of our streams and rivulets harbour small animals, rarely more than three or four inches long, which are very similar to little lobsters, except that they are usually of a dull, greenish or brownish colour, generally diversified with pale yellow on the under side of the body, and sometimes with red on the limbs. In rare cases, their

* If crayfish are not to be had, a lobster will be found to answer to the description of the former, in almost all points ; but the gills and the abdominal appendages present differences ; and the last thoracic somite is united with the rest in the lobster. (See Chap. V.) 
general hue may be red or blue. These are "crayfishes," and they cannot possibly be mistaken for any other inhabitants of our fresh waters.

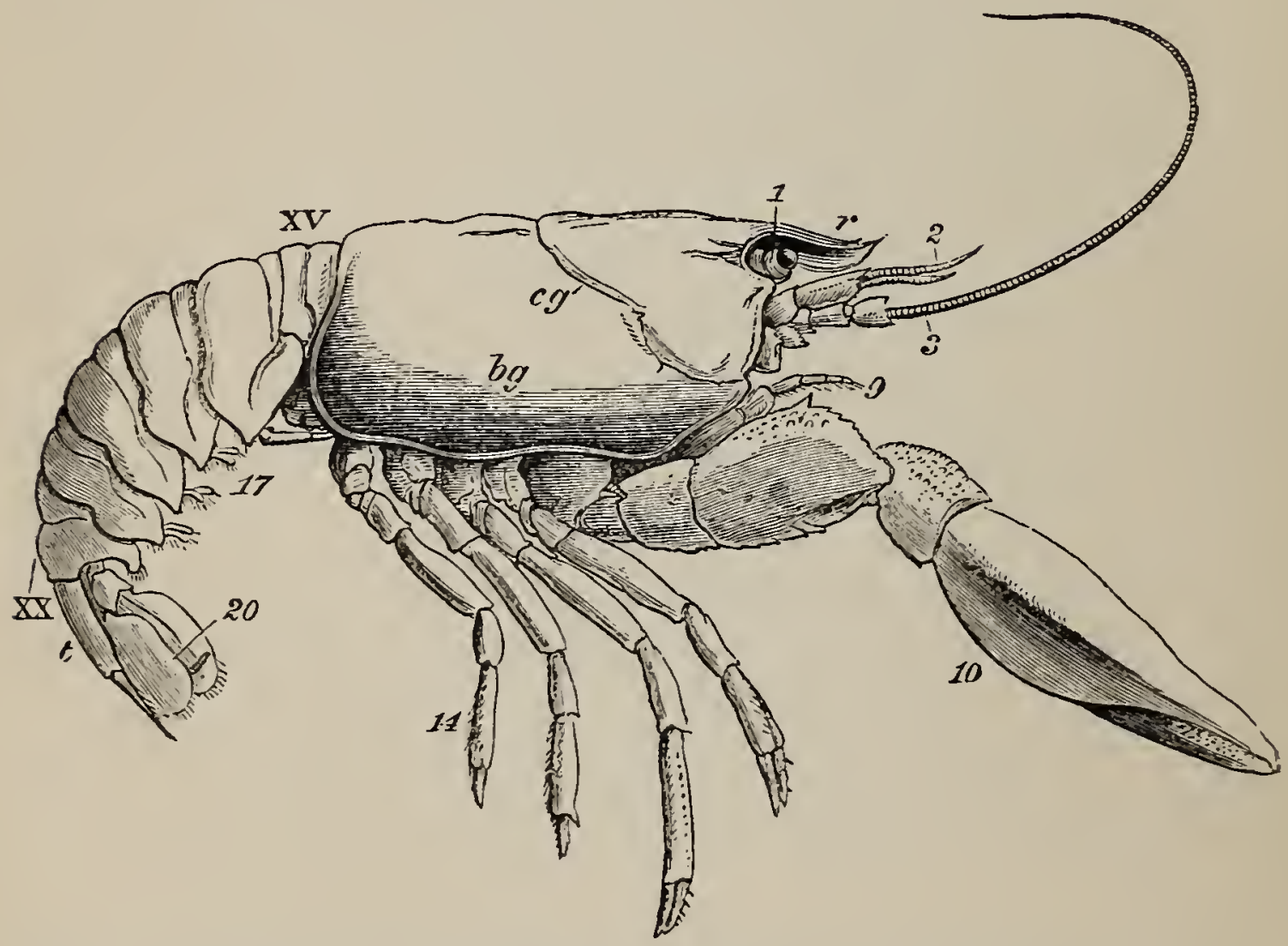

FIG. 1.-Astacus furiatilis.-Side view of a male specimen (nat. size) :-$b g$, branchiostegite; $c g$, cervical groove ; $r$, rostrum ; $t$, telson.1 , eye-stalk ; 2 , antennule ; 3 , antenna ; 9 , external maxillipede ; 10, forceps; 14, last ambulatory leg; 17 , third abdominal appendage; 20, lateral lobe of the tail-fin, or sixth abdominal appendage; $\mathrm{xv}$, the first; and $\mathrm{xx}$, the last abdominal somite. In this and in succeeding figures the numbers of the somites are given in Roman, those of the appendages in ordinary numerals.

The animals may be seen walking along the bottom of the shallow waters which they prefer, by means of four pairs of jointed legs (fig. 1); but, if alarmed, they swim 
backwards with rapid jerks, propelled by the strokes of a broad, fan-shaped flipper, which terminates the hinder end of the body (fig. 1, $t, 20$ ). In front of the four pairs of legs, which are used in walking, there is a pair of limbs of a much more massive character, each of which ends in two claws disposed in such a manner as to constitute a powerful pincer (fig. $1 ;$ 10). These claws are the chief weapons of offence and defence If the crayfish, and those who handle them incautiously will discover that their grip is by no means to be despised, and indicates a good deal of disposable energy. A sort of shield covers the front part of the body, and ends in a sharp projecting spine in the middle line $(r)$. On each side of this is an eye, mounted on a movable stalk (1), which can be turned in any direction: behind the eyes follow two pairs of feelers ; in one of these, the feeler ends in two, short, jointed filaments (2); while, in the other, it terminates in a single, many-jointed filament, like a whip-lash, which is more than half the length of the body (3). Sometimes turned backwards, sometimes sweeping forwards, these long feelers continually explore a considerable area around the body of the crayfish.

If a number of crayfishes, of about the same size, are compared together, it will easily be seen that they fall into two sets; the jointed tail being much broader, especially in the middle, in the one set than in the other (fig. 2). The broad-tailed crayfishes are the 
females, the others the males. And the latter may be still more easily known by the possession of four curved styles, attached to the under face of the first two rings of the tail, which are turned forwards between the hinder legs, on the under side of the body (fig. 3, A; 15, 16). In the female, there are mere soft filaments in the place of the first pair of styles (fig. $3, \mathrm{~B} ; 15$ ).

Crayfishes do not inhabit every British river, and even where they are known to abound, it is not easy to find them at all times of the year. In granite districts and others, in which the soil yields little or no calcareous matter to the waters which flow over it, crayfishes do not occur. They are intolerant of great heat and of much sunshine; they are therefore most active towards the erening, while they shelter themselves under the shade of stones and banks during the day. It has been observed that they frequent those parts of a river which run north and south, less than those which have an easterly and westerly direction, inasmuch as the latter yield more shade from the mid-day sun.

During the depth of winter, crayfishes are rarely to be seen about in a stream; but they may be found in abundance in its banks, in natural crevices and in burrows which they dig for themselves. The burrows may be from a few inches to more than a yard deep, and it has been noticed that, if the waters are liable to freeze, the burrows are deeper and further from the surface than otherwise. Where the soil, through 
which a strearn haunted by crayfishes runs, is soft and peaty, the crayfishes work their way into it in all directions, and thousands of them, of all sizes, may be dug out, even at a considerable distance from the banks.

It does not appear that crayfishes fall into a state of torpor in the winter, and thus "hybernate" in the strict sense of the word. At any rate, so long as the weather is open, the crayfish lies at the mouth of his burrow, barring the entrance with his great claws, and with protruded feelers keeps careful watch on the passers-by. Larvæ of insects, water-snails, tadpoles, or frogs, which come within reach, are suddenly seized and devoured, and it is averred that the water-rat is liable to the same fate. Passing too near the fatal den, possibly in search of a stray crayfish, whose flavour he highly appreciates, the vole is himself seized and held till he is suffocated, when his captor easily reverses the conditions of the anticipated meal.

In fact, few things in the way of food are amiss to the crayfish; living or dead, fresh or carrion, animal or vegetable, it is all one. Calcareous plants, such as the stoneworts (Chara), are highly acceptable; so are any kinds of succulent roots, such as carrots; and it is said that crayfish sometimes make short excursions inland, in search of vegetable food. Snails are devoured, shells and all; the cast coats of other crayfish are turned to account as supplies of needful calcareous matter; and the unprotected or weakly member of the family is 
not spared. Crayfishes, in fact, are guilty of cannibalism in its worst form; and a French observer pathetically remarks, that, under certain circumstances, the males "méconnaissent les plus saints devoirs;" and, not content with mutilating or killing their spouses, after the fashion of animals of higher moral pretensions, they descend to the lowest depths of utilitarian turpitude, and finish by eating them.

In the depth of winter, however, the most alert of crayfish can find little enough food; and hence, when they emerge from their hiding-places in the first warm days of spring, usually about March, the crayfishes are in poor condition.

At this time, the females are found to be laden with eggs, of which from one to two hundred are attached beneath the tail, and look like a mass of minute berries (fig. 3, B). In Nay or June, these eggs are hatched, and give rise to minute young, which are sometimes to be found attached beneath the tail of the mother, under whose protection they spend the first fer days of their existence.

In this country, we do not set much store upon crayfishes as an article of food, but on the Continent, and especially in France, they are in great request. Paris alone, with its two millions of inhabitants, consumes annually from five to six millions of crayfishes, and pays about $£ 16,000$ for them. The natural productivity of the rivers of France has long been inadequate to supply the 
demand for these delicacies; and hence, not only are large quantities imported from Germany, and elsewhere, but the-artificial cultivation of crayfish has been successfully attempted on a considerable scale.

Crayfishes are caught in various ways; sometimes the fisherman simply wades in the water and drags them out of their burrows; more commonly, hoop-nets baited with frogs are let down into the water and rapidly drawn up, when there is reason to think that crayfish have been attracted to the bait; or fires are lighted on the banks at night, and the crayfish, which are attracted, like moths, to the unwonted illumination, are scooped out with the hand or with nets.

Thus far, our information respecting the crayfish is such as would be forced upon anyone who dealt in crayfishes, or lived in a district in which they were commonly used for food. It is common knowledge. Let us now try to push our acquaintance with what is to be learned about the animal a little further, so as to be able to give an account of its Natural History, such as might have been furnished by Buffon if he had dealt with the subject.

There is an inquiry which does not strictly lie within the province of physical science, and yet suggests itself naturally enough at the outset of a natural history.

The animal we are considering has two names, one common, Crayfish, the other technical, Astacus fuviatilis. How has it come by these two names, and why, 
12 THE NATURAL HISTORY OF THE COMMON CRAYFISH.

having a common English name for it already, should naturalists call it by another appellation derived from a foreign tongue?

The origin of the common name, "crayfish," involves some curious questions of etymology, and indeed, of historv. It might readily be supposed that the rord "cray" had a meaning of its orm, and qualified the substantive "fish"-as "jelly" and "cod" in "jellyfish" and "codfish." But this certainly is not the case. The old English method of writing the word was "crevis" or "crevice," and the "cray" is simply a phonetic spelling of the syllable "cre," in which the "e" was formerly pronounced as all the world, except ourselves, now pronounce that vowel. While "fish" is the "vis" insensibly modified to suit our lnowledge of the thing as an aquatic animal.

Now "crevis" is clearly one of two things. Either it is a modification of the French name "écrerisse," or of the Low Dutch name "crevik," by which the crayfish is known in these languages. The former derivation is that usually giren, and, if it be correct, we must refer "crayfish" to the same category as "mutton," "beef," and " pork," all of which are French equivalents, introduced by the Normans, for the "sheep's flesh," "ox flesh," and "swine's flesh," of their English subjects. In this case, we should not have called a crayfish, a crayfish, except for the Norman conquest.

On the other hand, if "crevils" is the source of our 
word, it may have come to us straight from the Angle and Saxon contingent of our mixed ancestry.

As to the origin of the technical name; àotakós, astakos, was the name by which the Greeks knew the lobster; and it has been handed down to us in the works of Aristotle, who does not seem to have taken any special notice of the crayfish. At the revival of learning, the early naturalists noted the close general similarity between the lobster and the crayfish; but, as the latter lives in fresh water, while the former is a marine animal, they called the crayfish, in their Latin, Astacus fluviatilis, or the " river-lobster," by way of distinction; and this nomenclature was retained until, about forty-five years ago, an eminent French Naturalist, M. Milne-Edwards, pointed out that there are far more extensive differences between lobsters and crayfish than had been supposed; and that it would be advisable to mark the distinctness of the things by a corresponding difference in their names. Leaving Astacus for the crayfishes, he proposed to change the technical name of the lobster into Homarus, by latinising the old French name "Omar," or "Homar" (now Homard), for that animal.

At the present time, therefore, while the recognised technical name of the crayfish is Astacus fluviatilis, that of the lobster is Homarus vulgaris. And as this nomenclature is generally received, it is desirable that it should not be altered; though it is attended by the inconvenience, that Astacus, as we now employ the name, does not 
I4 THE NATURAL HISTORY OF THE COMMON CRAYFISH.

denote that which the Greeks, ancient and modern, signify, by its original, astakios; and does signify something quite different.

Finally, as to why it is needful to have two names for the same thing, one vernacular, and one technical. Many people imagine that scientific terminology is a needless burden imposed upon the novice, and ask us why we cannot be content with plain English. In reply, I would suggest to such an objector to open a conversation about his orn business with a carpenter, or an engineer, or, still better, with a sailor, and try how far plain English will go. The interview will not have lasted long before he will find himself lost in a maze of unintelligible technicalities. Every calling has its technical terminology; and every artisan uses terms of art, which sound like gibberish to those who know nothing of the art, but are exceedingly convenient to those who practise it.

In fact, every art is full of conceptions which are special to itself; and, as the use of language is to convey our conceptions to one another, language must supply signs for those conceptions. There are two ways of doing this: either existing signs may be combined in loose and cumbrous periphrases; or new signs, having a well-understood and definite signification, may be invented. The practice of sensible people shows the advantage of the latter course; and here, as elsewhere, science has simply followed and improved upon common sense. 
THE USE OF THE BINOMIAL NOMENCLATURE.

Moreover, while English, French, German, and Italian artisans are under no particular necessity to discuss the processes and results of their business with one another, science is cosmopolitan, and the difficulties of the study of Zoology would be prodigiously increased, if Zoologists of different nationalities used different technical terms for the same thing. They need a universal language; and it has been found convenient that the language shall be the Latin in form, and Latin or Greek in origin. What in English is Crayfish, is Ecrevisse in French; Flusskrebs, in German; Cammaro, or Gambaro, or Gammarello, in Italian : but the Zoologist of each nationality knows that, in the scientific works of all the rest, he shall find what he wants to read under the head of Astacus fluviatilis.

But granting the expediency of a technical name for the Crayfish, why should that name be double? The reply is still, practical convenience. If there are ten children of one family, we do not call them all Smith, because such a procedure would not help us to distinguish one from the other; nor do we call them simply John, James, Peter, William, and so on, for that would not help us to identify them as of one farnily. So we give them all two names, one indicating their close relation, and the other their separate individuality -as John Smith, James Smith, Peter Smith, William Smith, \&c. The same thing is done in Zoology; only, in accordance with the genius of the Latin language, 
we put the Christian name, so to speak, after the surname.

There are a number of kinds of Crayfish, so similar to one another that they bear the common surname of Astacus. One kind, by way of distinction, is called fluviatile, another slender-handed, another Dauric, from the region in which it lives; and these double names are rendered by-Astacus fluviatilis, Astacus leptodactylus, and Astacus dauricus; and thus we have a nomenclature which is exceedingly simple in principle, and free from confusion in practice. And I may add that, the less attention is paid to the original meaning of the substantive and adjective terms of this binomial nomenclature, and the sooner they are used as proper names, the better. Very good reasons for using a term may exist when it is first invented, which lose their validity with the progress of knowledge. Thus Astacus fluriatilis was a significant name so long as we knew of only one kind of crayfish; but now that we are acquainted with a number of kinds, all of which inhabit rivers, it is meaningless. Nevertheless, as changing it would involve endless confusion, and the object of nomenclature is simply to have a definite name for a definite thing, nobody dreams of proposing to alter it.

Having learned this much about the origin of the names of the crayfish, we may next proceed to consider those points which an observant Naturalist, who did not 
care to go far beyond the surface of things, would find to notice in the animal itself.

Probably the most conspicuous peculiarity of the crayfish, to any one who is familiar only with the higher animals, is the fact that the hard parts of the body are outside and the soft parts inside; whereas in ourselves, and in the ordinary domestic animals, the hard parts, or bones, which constitute the skeleton, are inside, and the soft parts clothe them. Hence, while our hard framework is said to be an endoskeleton, or internal skeleton; that of the crayfish is termed an exoskeleton, or external skeleton. It is from the circumstance that the body of the crayfishes is enveloped in this hard crust, that the name of Crustacea is applied to them, along with the crabs, shrimps, and other such animals. Insects, spiders, ana centipedes have also a hard exoskeleton, but it is usually not so hard and thick as in the Crustacea.

If a piece of the crayfish's skeleton is placed in strong vinegar, abundant bubbles of carbonic acid gas are given off from it, and it rapidly becomes converted into a soft laminated membrane, while the solution will be found to contain lime. In fact the exoskeleton is composed of a peculiar animal matter, so much impregnated with carbonate and phosphate of lime that it becomes dense and hard.

It will be observed that the body of the crayfish is naturally marked out into several distinct regions. There 

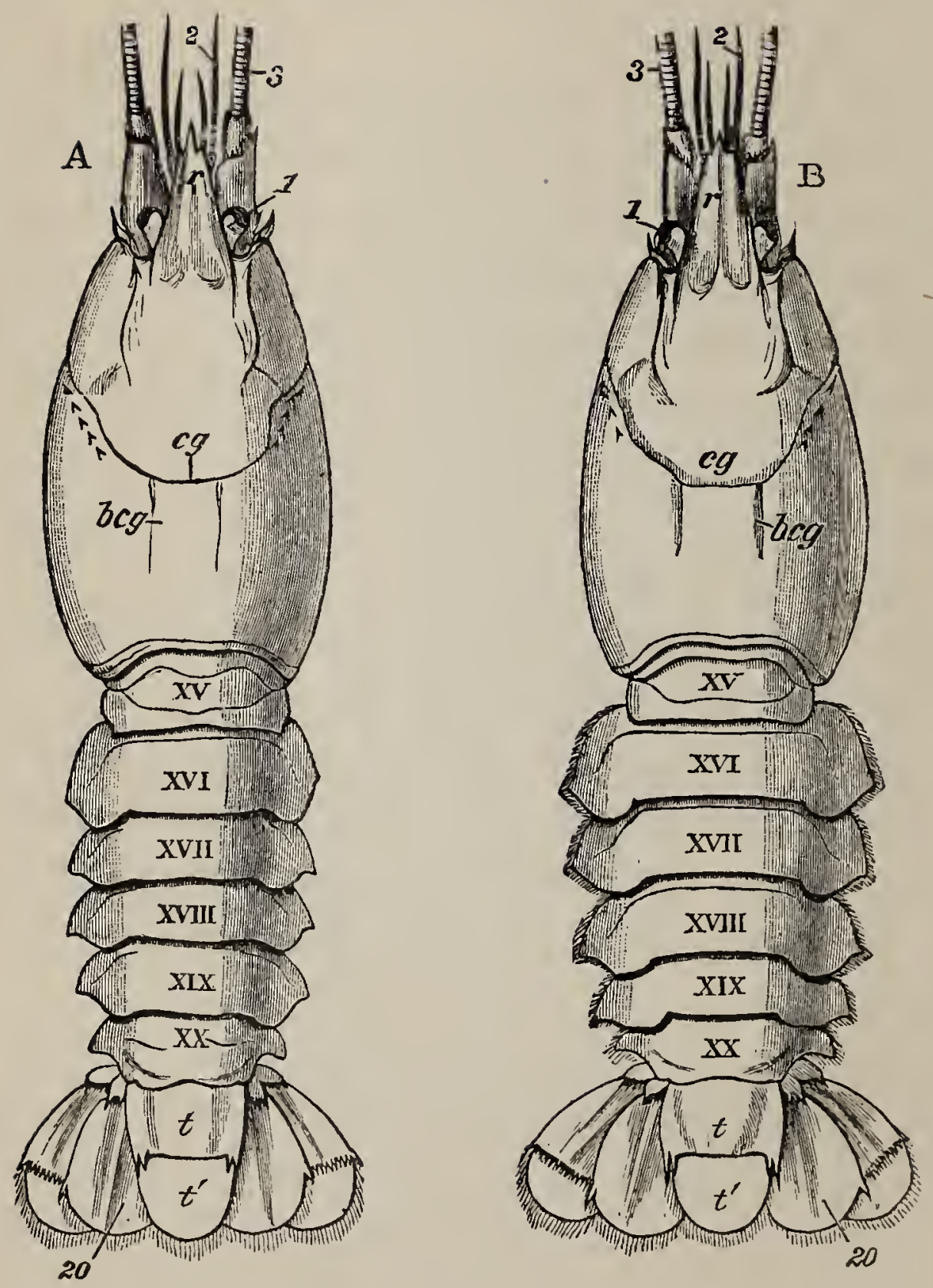

Frg. 2.-Astacus fuviatilis.-Dorsal or tergal views (nat. size). A, male; $\mathrm{B}$, female :- bcg, branchio-cardiac groove, which marks the boundary between the pericardial and the branchial cavities; $c g$, cervical groove ; these letters are placed on the carapace ; $r$, rostrum ; $t, t^{\prime}$, the two divisions of the telson; 1 , eye-stalks; 2 , antennules ; 3 , antennx; 20, lateral lobes of tail-fin; $\mathrm{xV}-\mathrm{xx}$, somites of the abdomen. 
is a firm and solid front part, covered by a large continuous shield, which is called the carapace; and a jointed hind part, commonly termed the tail (fig. 2). From the perception of a partially real, and partially fanciful, analogy with the regions into which the body is divided in the higher animals, the fore part is termed the cephalo-thorax, or head (cephalon) and chest (thorax) combined, while the hinder part receives the name of abdomen.

Now the exoskeleton is not of the same constitution throughout these regions. The abdomen, for example, is composed of six complete hard rings (fig. $2, \mathrm{xv}-\mathrm{xx}$ ), and a terminal flap, on the under side of which the vent (fig. $3, a$ ) is situated, and which is called the telson (fig. $2, t, t^{\prime}$ ). All these are freely moveable upon one another, inasmuch as the exoskeleton which connects them is not calcified, but is, for the most part, soft and flexible, like the hard exoskeleton when the lime salts have been removed by acid. The mechanism of the joints will have to be attentively considered by-and-by; it is sufficient, at present, to remark that, wherever a joint exists, it is produced in the same fashion, by the exoskeleton remaining soft in certain regions of the jointed part.

The carapace is not jointed; but a transverse groove is observed about the middle of it, the ends of which run down on the sides and then turn forwards (figs. 1 and 2 , $c g$ ). This is called the cervical groove, and it marks of 
the region of the head, in front, from that of the thorax behind.

The thorax seems at first not to be jointed at all; but if its under, or what is better called its sternal, surface is examined carefully, it will be found to be divided into as many transverse bands, or segments, as there are pairs of legs (fig. 3) ; and, moreover, the hindermost of these segments is not firmly united with the rest, but can be moved backwards and forwards through a small space (fig. $3, \mathrm{~B}$; xiv).

Attached to the sternal side of every ring of the abdomen of the female there is a pair of limbs, called swimmerets. In the five anterior rings, these are small and slender (fig. $3, \mathrm{~B} ; 15,19$ ); but those of the sixth ring are very large, and each ends in two broad plates (20). These two plates on each side, with the telson in the middle, constitute the flapper of the crayfish, by the aid of which it executes its retrograde swimming movements. The small swimmerets move together with a regular swing, like paddles, and probably aid in propelling the animal forwards. In the breeding female (B), the eggs are attached to them; while, in the male, the two anterior pairs $(\mathrm{A} ; 15,16)$ are converted into the peculiar styles which distinguish that sex.

The four pairs of legs which are employed for walling purposes, are divided into a number of joints, and the foremost two pairs are terminated by double claws, arranged so as to form a pincer, whence they are said to 


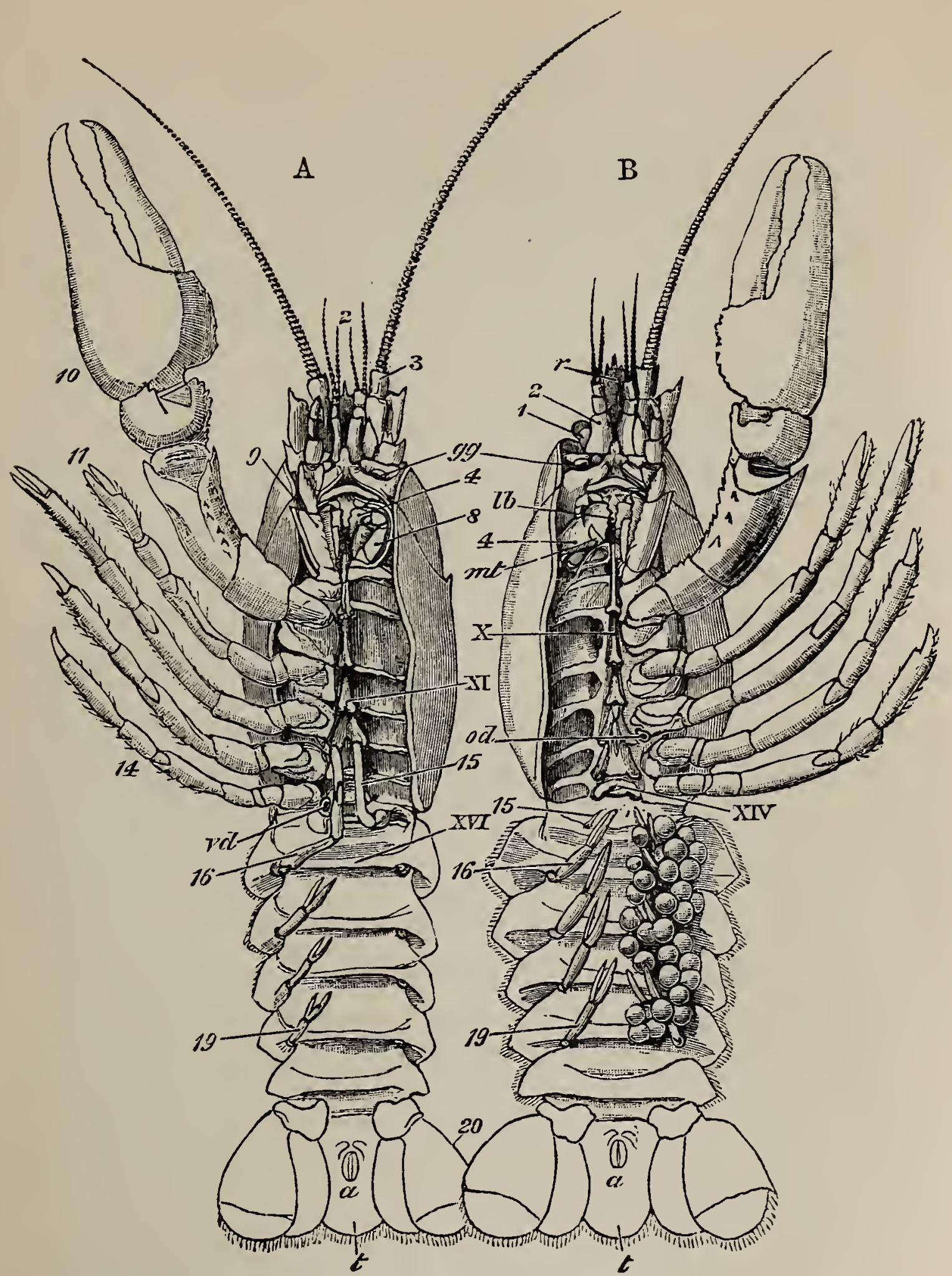

Fig. 3.-Astacus fluviatilis. -Ventral or sternal views (nat. size). A, male ; $\mathrm{B}$, female :$a$, vent; $g g$, opening of the green gland; $l b$, labrum; $m t$, metastoma or lower lip ; od, opening of the oviduct; $v d$, that of the vas deferens. 1 , eye-stalk; 2 , antennule ; 3 , antemna ; 4 , mandible ; 8 , second maxillipede; 9 , third or external maxillipede ; 10 , forceps ; 11 , first leg ; 14 , fourth leg; $15,16,19$, 20, first, second, fifth, and sixth abdominal appendages; X., Xr., XIv., sterna of the fourth, fifth, and eighth thoracic somite; Xvr., sternum of the second abdominal somite. In the male, the 9 th to the 14th and the 16th to the 19th appendages are removed on the animal's left side : in the female, the antenna (with the exception of its basal joint) and the 5th to the 14th appendages on the animal's right are removed; the eggs also are shown attached to the swimmerets of the left side of the body. 
be chelate. The two hindermost pairs, on the other hand, end in simple claws.

In front of these legs, come the great prehensile limbs (10), which are chelate, like those which immediately follow them, but vastly larger. They often receive the special name of chelce; and the large terminal joints are called the "hand." We shall escape confusion if we call these limbs the forceps, and restrict the name of chela to the two terminal joints.

All the limbs hitherto mentioned subserve locomotion and prehension in various degrees. The crayfish swims by the help of its abdomen, and the hinder pairs of abdominal limbs; walks by means of the four hinder pairs of thoracic limbs; lays hold of anything to fix itself, or to assist in climbing, by the two chelate anterior pairs of these limbs, which are also employed in tearing the food seized by the forceps and conveying it to the mouth; while it seizes its prey and defends itself with the forceps. The part which each of these limbs plays is termed its function, and it is said to be the organ of that function; so that all these limbs may be said to be organs of the functions of locomotion, of offence and defence.

In front of the forceps, there is a pair of limbs which have a different character, and take a different direction from any of the foregoing (9). These limbs, in fact, are turned directly forwards, parallel with one another, and with the middle line of the body. They are divided into a number of joints, of which one of those near the base 
is longer than the rest, and strongly toothed along the inner edge, or that which is turned towards its fellow. It is obvious that these two limbs are well adapted to crush and tear whatever comes between them, and they are, in fact, jaws or organs of manducation. At the same time, it will be noticed that they retain a curiously close general resemblance to the hinder thoracic legs; and hence, for distinction's sake, they are called outer footjaws, or external maxillipedes.

If the head of a stout pin is pushed between these external maxillipedes, it will be found that it passes without any difficulty into the interior of the body, through the mouth. In fact, the mouth is relatively rather a large aperture; but it cannot be seen without forcing aside, not only these external foot-jaws, but a number of other limbs, which subserve the same function of manducation, or chewing and crushing the food. We may pass by the organs of manducation, for the present, with the remark that there are altogether three pairs of maxillipedes, followed by two pairs of somewhat differently formed maxilla, and one pair of very stout and strong jaws, which are termed the mandibles (4). All these jaws work from side to side, in contradistinction to the jaws of vertebrated animals, which move up and down. In front of, and above the mouth, with the jaws which cover it, are seen the long feelers, which are called the antennce (3); above, and in front of them, follow the small feelers, or antennules (2); and over them, again, lie 
24. THE NATURAL HISTORY OF THE COMION CRAYFISH.

the eye stalks (1). The antennæ are organs of touch; the antennules, in addition, contain the organs of hearing; while, at the ends of the eyestalks, are the organs of vision.

Thus we see that the crayfish has a jointed and segmented body, the rings of which it is composed being very obvious in the abdomen, but more obscurely traceable elsewhere; that it has no fewer than twenty pairs of what may be called by the general name of appendages; and that these appendages are turned to different uses, or are organs of different functions, in different parts of the body. The crayfish is obviously a very complicated piece of living machinery. But we have not yet come to the end of all the organs that may be discovered even by cursory inspection. Every one who has eaten a boiled crayfish, or a lobster, knows that the great shield, or carapace, is very easily separated from the thorax and abdomen, the head and the limbs which belong to that region coming away with the carapace. The reason of this is not far to seek. The lower edges of that part of the carapace which belongs to the thorax approach the bases of the legs pretty closely, but a cleft-like space is left; and this cleft extends forwards to the sides of the region of the mouth, and backwards and upwards, between the hinder margin of the carapace and the sides of the first ring of the abdomen, which are partly overlapped by, and partly overlap, that margin. If the blade of a pair of scissors is care- 
fully introduced into the cleft from behind, as high up as it will go without tearing anything, and a cut is then made, parallel with the middle line, as far as the cervical groove, and thence following the cervical groove to the base of the outer foot-jaws, a large flap will be removed. This flap of the carapace is called the branchiostegite (fig. 1, bg), because it covers the gills or branchice (fig. 4), which are now exposed. They have the appearance of a number of delicate plumes, which take a direction from the bases of the legs upwards and forwards behind, upwards and backwards in front, their summits converging towards the upper end of the cavity in which they are placed, and which is called the branchial chamber. These branchiæ are the respiratory organs; and they perform the same functions as the gills of a fish, to which they present some similarity.

If the gills are cleared away, it is seen that the branchial cavity is bounded, on the inner side, by a sloping wall, formed by a delicate, but more or less calcified layer of the exoskeleton, which constitutes the proper outer wall of the thorax. At the upper limit of the branchial cavity, the layer of exoskeleton is very thin, and turning outwards, is continued into the inner wall or lining of the branchiostegite, which is also very thin (see fig. 15, p. 70).

Thus the branchial chamber is altogether outside the body, to which it stands in somewhat the same relation as the space between the flaps of a man's coat and his waistcoat would do to the part of the body enclosed by the 

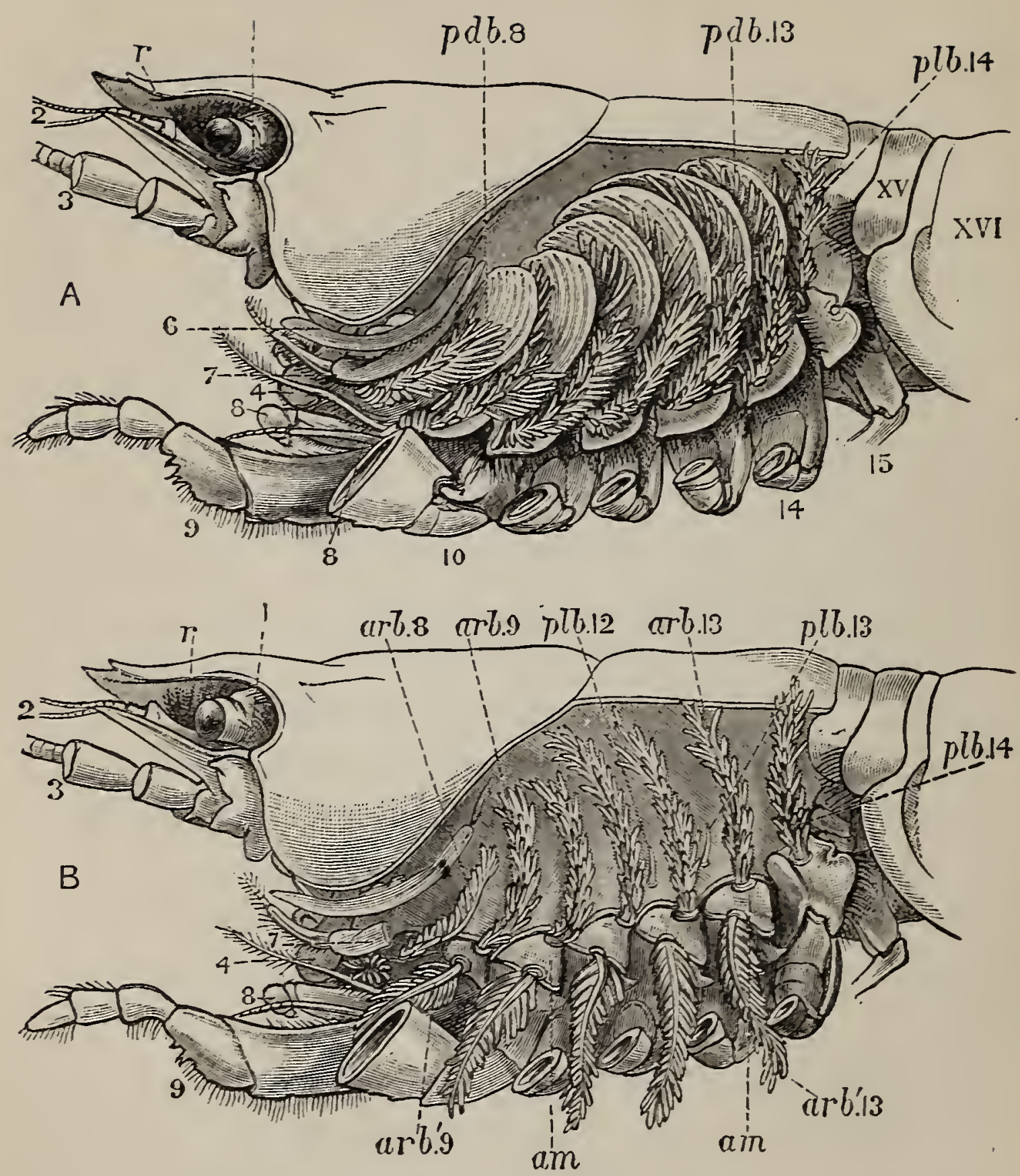

FIG. 4.-Astraces fuviatilis. -In A, the gills, exposed by the removal of the branchiostegite, are seen in their natural position; in $B$, the podobranchiæ ( $\sec \mathrm{p} .75$ ) are removed, and the anterior set of arthrobranchiæ turned downwards $(\times 2): 1$, eye-stalk ; 2 , antennule ; 3 , antenna ; 4 , mandible ; 6 , scaphoguatlite ; 7 , first maxillipede, in B the epipodite, to which the line points, is partly removed; 8 , second maxillipede; 9 , third maxillipede; 10 , forceps ; 14 , fourth ambulatory leg; 15 , first abdominal appendage; $\mathrm{xv}$., first, and xvr., second abdominal somite; arb. $S$, arb. 2 , arb. 13, the posterior arthrobranchiæ of the second and third maxillipedes and of the third ambulatory leg; $a r b^{\prime} .9$, $a r b^{\prime} .13$, the anterior arthrobranchice of the third maxillipede and of the third ambulatory leg; $p b d .8$, podobranchixe of the sccond maxillipede; $p b d$. 13, that of the third ambulatory leg: $p l b .1 \%, p l b .13$, the two rudimentary pleurobranchiæ; $p l b .14$, the functional pleurobranchia ; $r$, rostrum. 
waistcoat, if we suppose the lining of the flaps to be made in one piece with the sides of the waistcoat. Or a closer parallel still would be brought about, if the skin of a man's back were loose enough to be pulled out, on each side, into two broad flaps covering the flanks.

It will be observed that the branchial chamber is open behind, below, and in front; and, therefore, that the water in which the crayfish habitually lives has free ingress and egress. Thus the air dissolved in the water enables breathing to go on, just as it does in fishes. As is the case with many fishes, the crayfish breathes very well out of the water, if kept in a situation sufficiently cool and moist to prevent the gills from drying up; and thus there is no reason why, in cool and damp weather, the crayfish should not be able to live very well on land, at any rate among moist herbage, though whether our common crayfishes do make such terrestrial excursions is perhaps doubtful. We shall see, by-and-by, that there are some exotic crayfish which habitually live on land, and perish if they are long submerged in water.

With respect to the internal structure of the crayfish, there are some points which cannot escape notice, however rough the process of examination may be.

Thus, when the carapace is removed in a crayfish which has been just lilled, the heart is seen still pulsating. It is an organ of considerable relative size (fig. $5, h$ ), which is situated immediately beneath the 


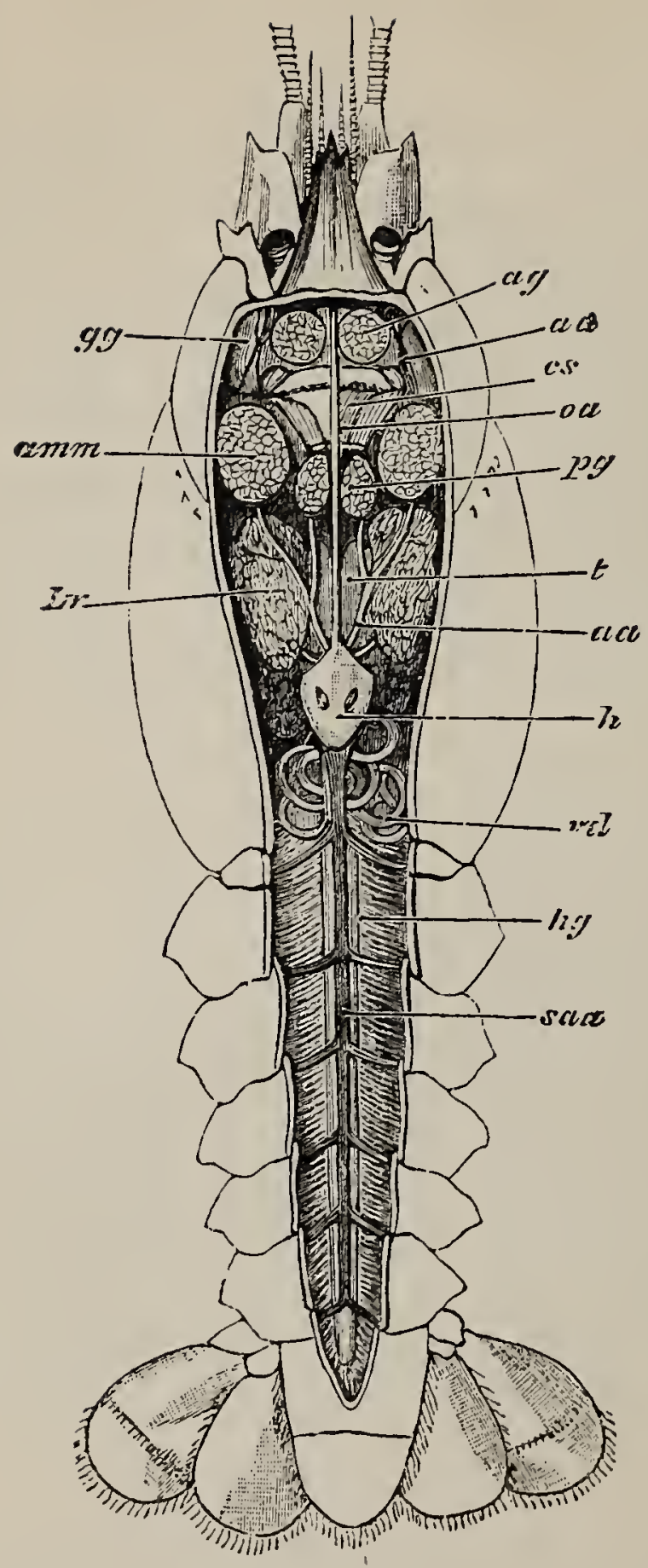

FiG. 5.-Astacus fluviatilis.-A male specimen, with the roof of the carapace and the terga of the abdominal somites removed to show the viscera (nat. size) :- $a \alpha$, antennary artery ; $a g$, anterior gastric muscles; amm, adductor muscles of the mandibles; $c s$, cardiac portion of the stomach ; $g g$, green glands ; $h$, heart ; $h g$, hind gut, or large intestine ; $I n$, liver ; $o \alpha$, ophthalmic artery ; $p g$ posterior gastric muscles; $s a u$, superior abdominal artery ; $t$, testis ; $v d$, vas deferens. 
the cavity of the stomach; while the opposite side, being convex and rough with irregular prominences, is something like a "brain-stone" coral.

Moreover, when the stomach is laid open, three large
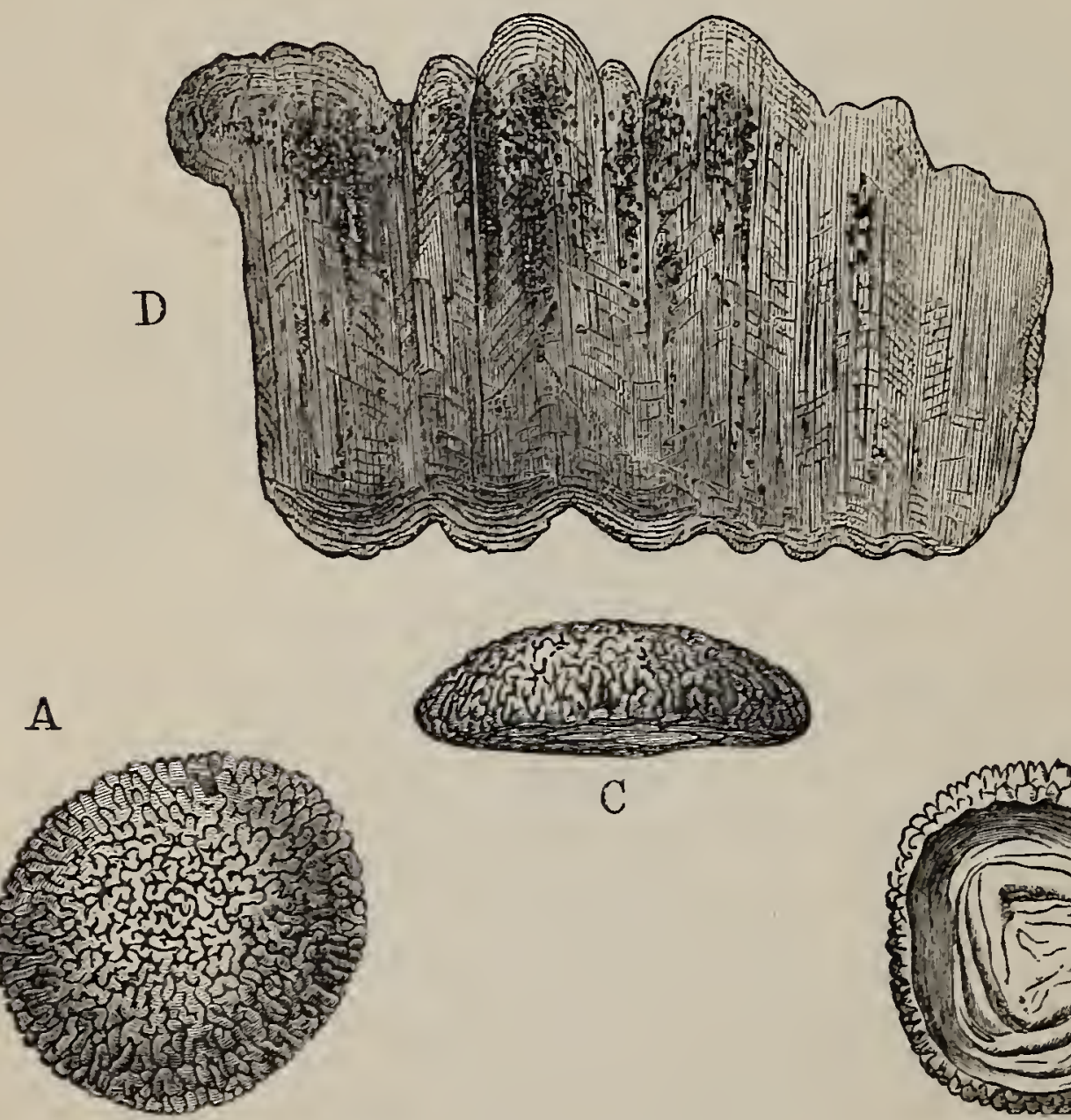

B

C

FIG. 7.-Astacus fluviatilis. $-\mathrm{A}$ gastrolith ; $\mathrm{A}$, from above; $\mathrm{B}$, from below ; $C$, from one side (all $\times 5)$; $D$, in vertical section $(\times 20)$.

reddish teeth are seen to project conspicuously into its interior (fig. $6, l t, m t$ ) ; so that, in addition to its six pairs of jaws, the crayfish has a supplementary crushing mill in its stomach. On each side of the stomach, there is a soft yellow or brown mass, commonly known as the 
liver (fig. 5, Lr); and, in the breeding season, the ovaries of the females, or organs in which the eggs are formed, are very conspicuous from the dark-coloured eggs which they contain, and which, like the exoskeleton, turn red when they are boiled. The corresponding part in a cooked lobster goes by the name of the "coral."

Beside these internal structures, the most noticeable are the large masses of flesh, or muscle, in the thorax and abdomen, and in the pincers; which, instead of being red, as in most of the higher animals, is white. It will further be observed that the blood, which flows readily when a crayfish is wounded, is a clear fluid, and is either almost colourless, or of a very pale reddish or neutral tint. Hence the older Naturalists thought that the crayfish was devoid of blood, and had merely a sort of ichor in place of it. But the fluid in question is true blood; and if it is received into a vessel, it soon forms a soft, but firm, gelatinous clot.

The crayfish grows rapidly in youth, but enlarges more and more slowly as age advances. The young animal which has just left the egg is of a greyish colour, and about one quarter of an inch long. By the end of the year, it may have reached nearly an inch and a half in length. Crayfishes of a year old are, on an average, two inches long; at two years, two inches and four-fifths; at three years, three inches and a half; at four years, four inches and a half nearly; and at five years, five inches. They 
32 THE NATURAL HISTORY OF THE COMMON CRAYFISH.

go on growing till, in exceptional cases, they may attain between seren inches and eight inches in length; but at what degree of longevity this unusual dimension is reached is uncertain. It seems probable, horrever, that the life of these animals may be prolonged to as much as fifteen or twenty years. They appear to reach maturity, so far as the power of reproduction is concerned, in their fifth or, more usually, their sixth year. Howerer, I have seen a female, with eggs attached under the abdomen, only tro inches long, and therefore, probably, in her second year. The males are commonly larger than females of the same age.

The hard skeleton of a crayfish, once formed, is incapable of being stretched, nor can it increase by interstitial addition to its substance, as the bone of one of the higher animals grows. Hence it follows, that the enlargement of the body, which actually takes place, involves the shedding and reproduction of its investment. This might be effected by insensible degrees, and in different parts of the body at different times, as we shed our hair; but, as a matter of fact, it occurs periodically and universally, somerhat as the feathers of birds are moulted. The whole of the old coat of the body is thrown off at once, and suddenly; and the new coat, which has, in the meanwhile, been formed beneath the old one, remains soft for a time, and allows of a rapid increase in the dimensions of the body before it 
hardens. This sort of moulting is what is technically termed ecdysis, or exuriation. It is commonly spoken of as the "shedding of the skin," and there is no harm in using this phrase, if we recollect that the shed coat is not the skin, in the proper sense of the rord, but only what is termed a cuticular layer, which is secreted upon the outer surface of the true integument. The cuticular skeleton of the crayfish, in fact, is not even so much a part of the skin as the cast of a snake, or as our own nails. For these are composed of coherent, formed parts of the epidermis; while the hard investment of the crayfish contains no such formed parts, and is developed on the outside of those structures which answer to the constituents of the epidermis in the higher animals. Thus the crayfish grows, as it were, by starts; its dimensions remaining stationary in the intervals of its moults, and then rapidly increasing for a few days, while the new exoskeleton is in the course of formation.

The ecdysis of the crayfish was first thoroughly studied a century and a half ago, by one of the most accurate observers who ever lived, the famous Réaumur, and the following account of this very curious process is given nearly in his words.*

A few hours before the process of exuviation com-

* See Réaumur's two MIemoirs, "Sur les diverses reproductions qui se font dans les écrevisses, les omars, les crabes, etc." "Histoire de l'Académie royale des Sciences," année 1712; and "Additions aux observations sur la mue des écrevisses données dans les liémoires de 1712." Ibid. 1718. 
mences, the crayfish rubs its limbs one against the other, and, without changing its place, moves each separately, throws itself on its back, bends its tail, and then stretches it out again, at the same time vibrating its antennæ. By these movements, it gives the various parts a little play in their loosened sheaths. After these preparatory steps, the crayfish appears to become distended; in all probability, in consequence of the commencing retraction of the limbs into the interior of the exoskeleton of the body. In fact, it has been remarked, that if, at this period, the extremity of one of the great claws is broken off, it will be found empty, the contained soft parts being retracted as far as the second joint. The soft membranous part of the exoskeleton, which connects the hinder end of the carapace with the first ring of the abdomen, gives way, and the body, covered with the new soft integument, protrudes; its dark brown colour rendering it easily distinguishable from the greenish-brown old integument.

Having got thus far, the crayfish rests for a while, and then the agitation of the limbs and body recommences. The carapace is forced upwards and forwards by the protrusion of the body, and remains attached only in the region of the mouth. The head is next drawn backwards, while the eyes and its other appendages are extracted from their old investment. Next the legs are pulled out, either one at a time, or those of one, or both, sides together. Sometimes a limb gives way and is left behind in its sheath. 
The operation is facilitated by the splitting of the old integument of the limb along one side longitudinally.

When the legs are disengaged, the animal draws its head and limbs completely out of their former covering; and, with a sudden spring forward, while it extends its abdomen, it extracts the latter, and leaves its old skeleton behind. The carapace falls back into its ordinary position, and the longitudinal fissures of the sheaths of the limbs close up so accurately, that the shed integument has just the appearance the animal had when the exuviation commenced. The cast exoskeleton is so like the crayfish itself, when the latter is at rest, that, except for the brighter colour of the latter, the two cannot be distinguished.

After exuviation, the owner of the cast skin, exhausted by its violent struggles, which are not unfrequently fatal, lies in a prostrate condition. Instead of being covered by a hard shell, its integument is soft and flabby, like wet paper; though Réaumur remarks, that if a crayfish is handled immediately after exuviation, its body feels hard; and he ascribes this to the violent contraction which its muscles have undergone, leaving them in a state of cramp. In the absence of the hard skeleton, however, there is nothing to bring the contracted muscles at once back into position, and it must be some time before the pressure of the internal fluids is so distributed as to stretch them out.

When the process of exuviation has proceeded so far 
that the carapace is raised, nothing stops the crayfish from continuing its struggles. If taken out of the water in this condition, they go on moulting in the hand, and even pressure on their bodies will not arrest their efforts.

The length of time occupied from the first giving way of the integuments to the final emergence of the animal, varies with its vigour, and the conditions under which it is placed, from ten minutes to several hours. The chitinous lining of the stomach, with its teeth, and the "crabs'-eyes," are shed along with the rest of the cuticular exoskeleton; but they are broken up and dissolved in the stomach.

The new integuments of the crayfish remain soft for a period which varies from one to three days; and it is a curious fact, that the animal appears to be quite aware of its helplessness, and governs itself accordingly.

An observant naturalist says: "I once had a domesticated crayfish (Astacus fluviatilis), which I kept in a glass pan, in water, not more than an inch and a half deep, previous experiment having shown that in deeper water, probably from want of sufficient aëration, this animal would not live long. By degrees my prisoner became very bold, and when I held my fingers at the edge of the vessel, he assailed them with promptness and energy. About a year after I had him, I perceived, as I thought, a second crayfish with him. On examination, I found it to be his old coat, which he had left in a most perfect state. My friend had now lost his heroism, and 
fluttered about in the greatest agitation. He was quite soft; and every time I entered the room during the next two days, he exhibited the wildest terror. On the third, he appeared to gain confidence, and ventured to use his nippers, though with some timidity, and he was not yet quite so hard as he had been. In about a week, however, he became bolder than ever; his weapons were sharper, and he appeared stronger, and a nip from him was no joke. He lived in all about two years, during which time his food was a very few worms at very uncertain times; perhaps he did not get fifty altogether." *

It would appear, from the best observations that have yet been made, that the young crayfish exuviate two or three times in the course of the first year; and that, afterwards, the process is annual, and takes place usually about midsummer. There is reason to suppose that very old crayfish do not exuviate every year.

It has been stated that, in the course of its violent efforts to extract its limbs from the cast-off exoskeleton, the crayfish sometimes loses one or other of them; the limb giving way, and the greater part, or the whole, of it remaining in the exuviæ. But it is not only in this way that crayfishes part with their limbs. At all times, if the animal is held by one of its pincers, so that it cannot get away, it is apt to solve the difficulty by casting off

* The late Mr. Robert Ball, of Dublin, in Bell's "British Crustacea," p. 239. 
the limb, which remains in the hand of the captor, while the crayfish escapes. This voluntary amputation is always effected at the same place; namely, where the limb is slenderest, just beyond the articulation which unites the basal joint with the next. The other limbs also readily part at the joints; and it is very common to meet with crayfish which have undergone such mutilation. But the injury thus inflicted is not permanent, as these animals possess the power of reproducing lost parts to a marvellous extent, whether the loss has been inflicted by artificial amputation, or voluntarily.

Crayfishes, like all the Crustacea, bleed very freely when wounded; and if one of the large joints of a leg is cut through, or if the animal's body is injured, it is very likely to die rapidly from the ensuing hæmorrhage. A crayfish thus wounded, however, commonly throws off the limb at the next articulation, where the cavity of the limb is less patent, and its sides more readily fall together; and, as we have seen, the pincer's are usually cast off at their narrowest point. When such amputation has taken place, a crust, probably formed of coagulated blood, rapidly forms over the surface of the stump; and, eventually, it becomes covered with a cuticle. Beneath this, after a time, a sort of bud grows out from the centre of the surface of the stump, and gradually takes on the form of as much of the limb as has been removed. At the next ecdysis, the corering cuticle is thrown off along with the rest of the exoskeleton; while the rudi- 
mentary limb straightens out, and, though very small, acquires all the organization appropriate to that limb. At every moult it grows; but, it is only after a long time that it acquires nearly the size of its uninjured and older fellow. Hence, it not unfrequently happens, that crayfish are found with pincers and other limbs, which, though alike useful and anatomically complete, are very unequal in size.

Injuries inflicted while the crayfish are soft after moulting, are apt to produce abnormal growths of the part affected; and these may be perpetuated, and give rise to various monstrosities, in the pincers and in other parts of the body.

In the reproduciion of their kind by means of eggs the co-operation of the males with the females is necessary. On the basal joint of the hindermost pair of legs of the male a small aperture is to be seen (fig. $3, \mathrm{~A} ; v d$ ). In these, the ducts of the apparatus in which the fecundating substance is formed terminate. The fecundating material itself is a thickish fluid, which sets into a white solid after extrusion. The male deposits this substance on the thorax of the female, between the bases of the hindermost pairs of thoracic limbs.

The eggs formed in the ovary are conducted to apertures, which are situated on the bases of the last pair of ambulatory legs but two, that is, in the hinder of the two pair which are provided with chelate extremities (fig. $3, \mathrm{~B}$; od). 
After the female has received the deposit of the spermatic matter of the male, she retires to a burrow, in the manner already stated, and then the process of laying the eggs commences. These, as they leave the apertures of the oviducts, are coated with a viscid matter, which is readily drawn out into a short thread. The end of the thread attaches itself to one of the long hairs, with which the swimmerets are fringed, and as the viscid matter rapidly hardens, the egg thus becomes attached to the limb by a stalk. The operation is repeated, until sometimes a couple of hundred eggs are thus glued on to the swimmerets. Partaking in the movements of the swimmerets, they are washed backwards and forwards in the water, and thus aërated and kept free of impurities; while the young crayfish is formed much in the same way as the chick is formed in a hen's egg.

The process of development, however, is very slow, as it occupies the whole winter. In late spring-time, or early summer, the young burst the thin shell of the egg, and, when they are hatched, present a general resemblance to their parents. This is rery unlike what takes place in crabs and lobsters, in which the young leave the egg in a condition very different from the parent, and undergo a remarkable metamorphosis before they attain their proper form.

For some time after they are hatched, the young hold on to the swimmerets of the mother, and are carried about, protected by her abdomen, as in a lind of nursery. 
That most careful naturalist, Roesel von Rosenhof, says of the young, when just hatched :-

"At this time they are quite transparent; and when

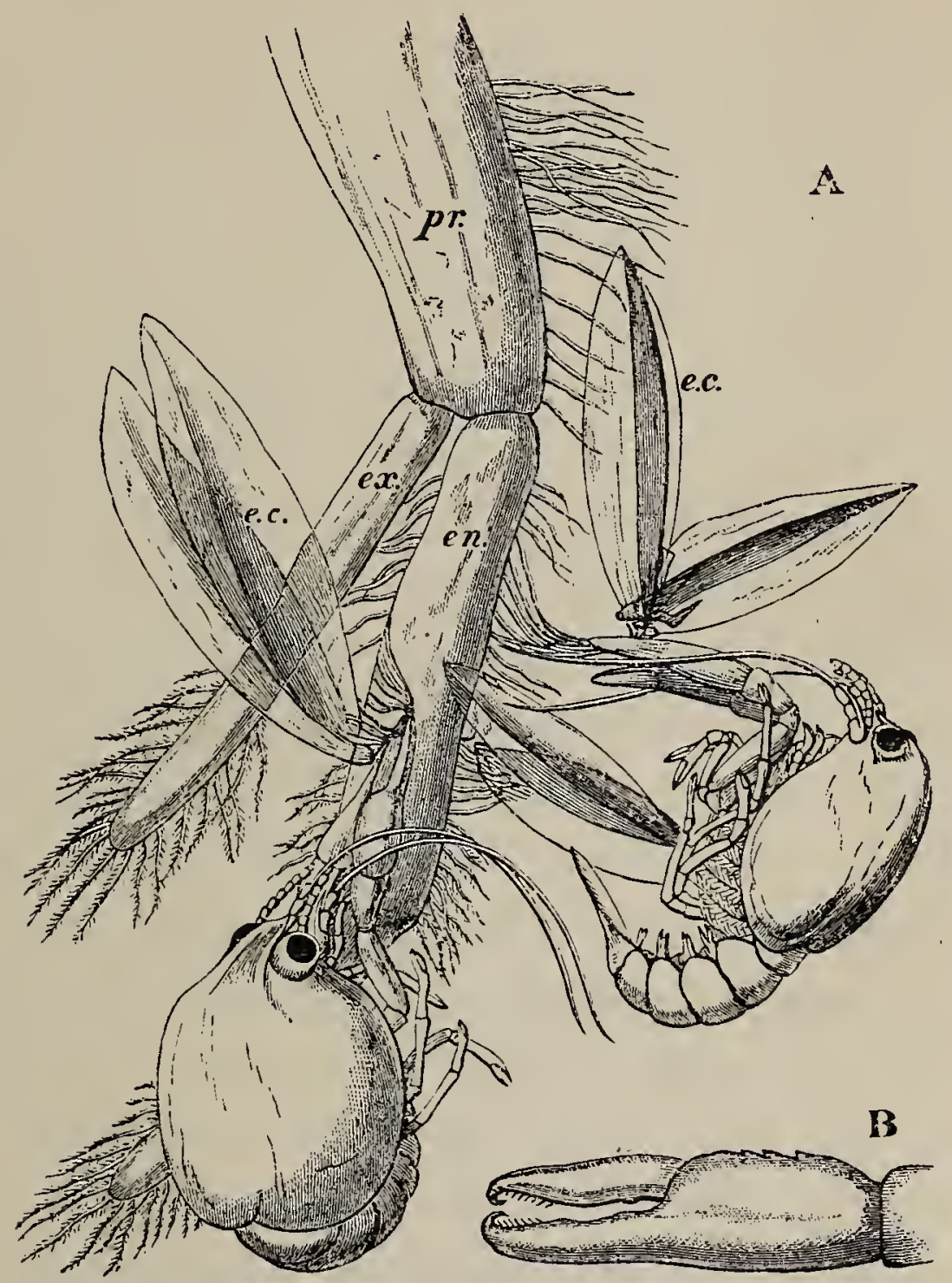

FIG. 8.-Astacus fluviatilis.-A, two recently hatched crayfish attached to one of the swimmerets of the mother $(\times 4)$. pr, protopodite; $c n$, endopodite ; and $e x$, exopodite of the swimmeret; $c c$, ruptured egg-cases. B, chela of a recently hatched crayfish $(\times 10)$.

such a crayfish [a female with young] is brought to table, it looks quite disgusting to those who do not know 
what the young are; but if we examine it more closely, especially with a magnifying-glass, we see with pleasure that the little crayfish are already perfect, and resemble the large one in all respects. When the mother of these little crayfish, after they have begun to be active, is quiet for a while, they leave her and creep about, a short way off. But, if they spy the least sign of danger, or there is any unusual movement in the water, it seems as if the mother recalled them by a signal; for they all at once swiftly return under her tail, and gather into a cluster, and the mother hies to a place of safety with them, as quickly as she can. A few days later, however, they gradually forsake her." *

Fishermen declare that "Hen Lobsters" protect their young in a similar manner.t Jonston, $\ddagger$ who wrote in the middle of the seventeenth century, says that the little crayfish are often to be seen adhering to the tail of the mother. Roesel's observations imply the same thing; but he does not describe the exact mode of adherence, and I can find no observations on the subject in the works of later writers.

It has been seen that the eggs are attached to the swimmerets by a viscid substance, which is, as it were, smeared over them and the hairs with which they are

* "Der Monatlich-herausgegeben Insecten Belustigung." Dritter Theil, p. 336.1755.

† Bell's "British Crustacea," p. 249.

¥ "Joannis Jonstoni Historiæ naturalis de Piscibus et Cetis Librj quinque. Tomus IV. 'De Cammaro seu Astaco fluviatili.'" 
fringed, and is continued by longer or shorter thread-like pedicles into the coat of the same material which invests each egg. It very soon hardens, and then becomes very firm and elastic.

When the young crayfish is ready to be hatched, the egg case splits into two moieties, which remain attached, like a pair of watch glasses, to the free end of the pedicle of the egg (fig. 8, A; ec). The young animal, though very similar to the parent, does not quite "resemble it in all respects," as Roesel says. For not only are the first and the last pairs of abdominal limbs wanting, while the telson is very different from that of the adult; but the ends of the great chelæ are sharply pointed and bent down into abruptly incurved hoolss, which overlap when the chelæ are shut (fig. 8, B). Hence, when the chelæ have closed upon anything soft enough to allow of the imbedding of these hooks, it is very difficult, if not impossible, to open them again.

Immediately the young are set free, they must instinctively bury the ends of their forceps in the hardened egg-glue which is smeared over the swimmerets, for they are all found to be holding on in this manner. They exhibit very little movement, and they bear rough shaking or handling without becoming detached; in consequence, I suppose, of the interlocking of the hooked ends of the chelæ imbedded in the egg-glue.

Even after the female has been plunged into alcohol, the young remain attached. I have had a female, with young affixed in this manner, under observation for five 
44 THE NATURAL HISTORY OF THE COMMON CRAYFISH.

days, but. none of them showed any signs of detaching themselves; and I am inclined to think that they are set free only at the first moult. After this, it would appear that the adhesion to the parent is only temporary.

The walking legs are also hooked at their extremities, but they play a less important part in fixing the young to the parent, and seem to be always capable of loosing their hold.

I find the young of a Mexican crayfish (Cambarus) to be attached in the same manner as those of the English crayfish; but, according to Mr. Wood-Mason's recent observations, the young of the New Zealand crayfishes fix themselres to the srimmerets of the parent by the hooked ends of their hinder ambulatory limbs.

Crayfishes, in every respect similar to those found in our English rivers, that is to say, of the species Astacus fluviatilis, are met with in Ireland, and on the Continent, as far south as Italy and northern Greece; as far east as restern Russia; and as far north as the shores of the Baltic. They are not known to occur in Scotlana; in Spain, except about Barcelona, they are either rare, or have remained unnoticed.

There is, at present, no proof of the occurrence of Astacus fluviatilis in the fossil state.

Curious myths have gathered about crayfishes, as about other animals. At one time "crabs'-eyes" were 
collected in rast numbers, and sold for medicinal purposes as a remedy against the stone, among other diseases. Their real utility, inasmuch as they consist almost entirely of carbonate of lime, with a little phosphate of lime and animal matter, is much the same as that of chalk, or carbonate of magnesia. It was, formerly, a current belief that crayfishes grow poor at the time of new moon, and fat at that of full moon; and, perhaps, there may be some foundation for the notion, considering the nocturnal habits of the animals. Van Helmont, a great dealer in wonders, is responsible for the stury that, in Brandenburg, where there is a great abundance of crayfishes, the dealers were obliged to transport them to market by night, lest a pig should run under the cart. For if such a misfortune should happen, every crayfish would be found dead in the morning: "Tam exitialis est porcus cancro." Another author improves the story, by declaring that the steam of a pig-stye, or of a herd of swine, is instantaneously fatal to crayfish. On the other hand, the smell of putrifying crayfish, which is undoubtedly of the strongest, was said to drive even moles out of their burrows. 


\section{CHAPTER II.}

THE PHYSIOLOGY OF THE CRAYFISH. THE MECHANISM BT WHICI THE PARTS OF THE LIVING ENGINE ARE SUPPLIED WITH THE MATERIALS NECESSARY FOR THEIR MAINTENANCE AND GROWTH.

Ax analysis of such a sketch of the "Natural History of the Crayfish" as is given in the preceding chapter, shows that it provides brief and general answers to three questions. First, what is the form and structure of the animal, not only when adult, but at different stages of its growth? Secondly, what are the various actions of which it is capable? Thirdly, where is it found? If we carry our investigations further, in such a manner as to give the fullest attainable answers to these questions, the knowledge thus acquired, in the case of the first question, is termed the Morphology of the crayfish; in the case of the second question, it constitutes the Physiology of the animal; while the answer to the third question would represent what we know of its Distribution or Chorology. There remains a fourth problem, which can hardly be regarded as seriously under discussion, so long as knowledge has advanced no further than the Natural History stage; the question, namely, 
how all these facts comprised under Morphology, Physiology, and Chorology have come to be what they are; and the attempt to solve this problem leads us to the crown of Biological effort, AEtiology. When it supplies answers to all the questions which fall under these four heads, the Zoology of Crayfish will have said its last word.

As it matters little in what order we take the first three questions, in expanding Natural History into Zoology, we may as well follow that which accords with the history of science. After men acquired a rough and general knowledge of the animals about them, the next thing which engaged their interest was the discovery in these animals of arrangements by which results, of a kind similar to those which their own ingenuity effects through mechanical contrivances, are brought about. They observed that animals perform various actions; and, when they looked into the disposition and the powers of the parts by which these actions are performed, they found that these parts presented the characters of an apparatus, or piece of mechanism, the action of which could be deduced from the properties and connections of its constituents, just as the striking of a clock can be deduced from the properties and connections of its weights and wheels.

Under one aspect, the result of the search after the vationale of animal structure thus set afoot is Teleology; or the doctrine of adaptation to purpose. Under another 
aspect, it is Physiology; so far as Physiology consists in the elucidation of complex vital phenomena by deduction from the established truths of Physics and Chemistry, or from the elementary properties of living matter.

We have seen that the crayfish is a voracious and indiscriminate feeder; and we shall be safe in assuming that, if duly supplied with nourishment, a full-grown crayfish will consume several times its own weight of food in the course of the year. Nevertheless, the increase of the animal's weight at the end of that time is, at most, \& small fraction of its total weight; whence it is quite clear, that a very large proportion of the food taken into the body must, in some shape or other, leave it again. In the course of the same period, the crayfish absorbs a rery considerable quantity of oxygen, supplied by the atmosphere to the water which it inhabits; while it gives out, into that water, a large amount of carbonic acid, and a larger or smaller quantity of nitrogenous and other excrementitious matters. From this point of riew, the crayfish may be regarded as a kind of chemical manufactory, supplied with certain alimentary raw materials, which it works up, transforms, and gives out in otheri shapes. And the first physiological problem which offers itself to us is the mode of operation of the apparatus contained in this factory, and the extent to which the products of its activity are to be accounted for by reasoning from known physical and chemical principles. 
We have learned that the food of the crayfish is made up of very diverse substances, both animal and vegetable; but, so far as they are competent to nourish the animal permanently, these matters all agree in containing a peculiar nitrogenous body, termed protein, under one of its many forms, such as albumen, fibrin, and the like. With this may be associated fatty matter's, starchy and saccharine bodies, and various earthy salts. And these, which are the essential constituents of the food, may be, and usually are, largely mixed up with other substances, such as wood, in the case of vegetable food, or skeletal and fibrous parts, in the case of animal prey, which are of little or no utility to the crayfish.

The first step in the process of feeding, therefore, is to reduce the food to such a state, that the separation of its nutritive parts, or those which can be turned to account, from its innutritious, or useless, constituents, may be facilitated. And this preliminary operation is the subdivision of the food into morsels of a convenient size for introduction into that part of the machinery in which the extraction of the useful products is performed.

The food may be seized by the pincers, or by the anterior chelate ambulatory limbs; and, in the former case, it is usually, if not always, transferred to the first, or second, or both of the anterior pairs of ambulatory limbs. These grasp the food, and, tearing it into pieces of the proper dimensions, thrust them between the external maxillipedes, which are, at the same time, 
worked rapidly to and fro sideways, so as to bring their toothed edges to bear upon the morsel. The other five pairs of jaws are no less active, and they thus crush and divide the food brought to them, as it is passed between their toothed edges to the opening of the mouth.

As the alimentary canal stretches from the mouth, at one end, to the vent at the other, and, at each of these limits, is continuous with the wall of the body, we may conceive the whole crayfish to be a hollow cylinder, the cavity of which is everywhere closed, though it is traversed by a tube, open at each end (fig. 6). The shut cavity between the tube and the walls of the cylinder may be termed the perivisceral carity; and it is so much filled up by the various organs, which are interposed between the alimentary canal and the body wall, that all that is left of it is represented by a system of irregular channels, which are filled with blood, and are termed blood sinuses. The rall of the cylinder is the outer wall of the body itself, to which the general name of integument may be given; and the outermost layer of this, again, is the cuticle, which gives rise to the whole of the exoskeleton. This cuticle, as we have seen, is extensively impregnated with lime salts; and, moreover, in consequence of its containing chitin, it is often spolsen of as the chitinous cuticula.

Having arrived at this general conception of the disposition of the parts of the factory, we may next proceed to consider the machinery of alimentation which is con- 
tained within it, and which is represented by the various divisions of the alimentary canal, with its appendages; by the apparatus for the distribution of nutriment; and by two apparatuses for getting rid of those products which are the ultimate result of the working of the whole organism.

And here we must trench somerwhat upon the province of Morphology, as some of these pieces of apparatus are complicated; and their action cannot be comprehended without a certain knowledge of their anatomy.

The mouth of the crayfish is a longitudinally elongated, parallel-sided opening, in the integument of the ventral or sternal aspect of the head. Just outside its lateral boundaries, the strong mandibles project, one on each side (fig $3, \mathrm{~B} ; 4$ ) ; their broad crushing surfaces, which are turned towards one another, are therefore completely external to the oral cavity. In front, the mouth is overliapped by a wide shield-shaped plate termed the upper lip, or labrum (figs. 3 and 6, $l b$ ); while, immediately behind the mandibles, there is, on each side, an elongated fleshy lobe, joined with its fellow by the posterior boundary of the mouth. These together constitute the metastoma (fig. $3, \mathrm{~B}$; $m$ t), which is sometimes called the lower lip. A short wide gullet, termed the œsophagus (fig. 6,oc), leads directly upwards into a spacious bag, the stomach, which occupies almost the whole cavity of the head. It is divided by a constriction into a large anterior chamber $(c s)$, into the under face of which the 
gullet opens, and a small posterior chamber ( $p s)$, from which the intestine $(\mathrm{hg})$ proceeds.

In a man's stomach, the opening by which the gullet communicates with the stomach is called the cardia, while that which places the stomach in communication with the intestine is named the pylorus ; and these terms liaving been transferred from human anatomy to that of the lower animals, the larger moiety of the crayfish's stomach is called the cardiac division, while the smaller is termed the pyloric division of the organ. It must be recollected, however, that, in the crayfish, the so-called cardiac division is that which is actually furthest from the heart, not that which is nearest to it, as in man.

The gullet is lined by a firm coat which resembles thin parchment. At the margins of the mouth, this strong lining is easily seen to be continuous with the cuticular exoskeleton; while, at the cardiac orifice, it spreads out and forms the imner or cuticular wall of the whole gastric cavity, as far as the pylorus, where it ends in certain valvular projections. The chitinous cuticle which forms the outermost layer of the integument is thus, as it were, turned in, to constitute the innermost layer of the walls of the stomach; and it confers upon them so great an amount of stiffness that they do not collapse when the organ is removed from the body. Furthermore, just as the cuticle of the integument is calcified to form the hard parts of the exoskeleton, so is the cuticle of the stomach calcified, or otherwise hardened, to give rise, in the first 
place, to the very remarkable and complicated apparatus which has already been spoken of, as a sort of gastric mill

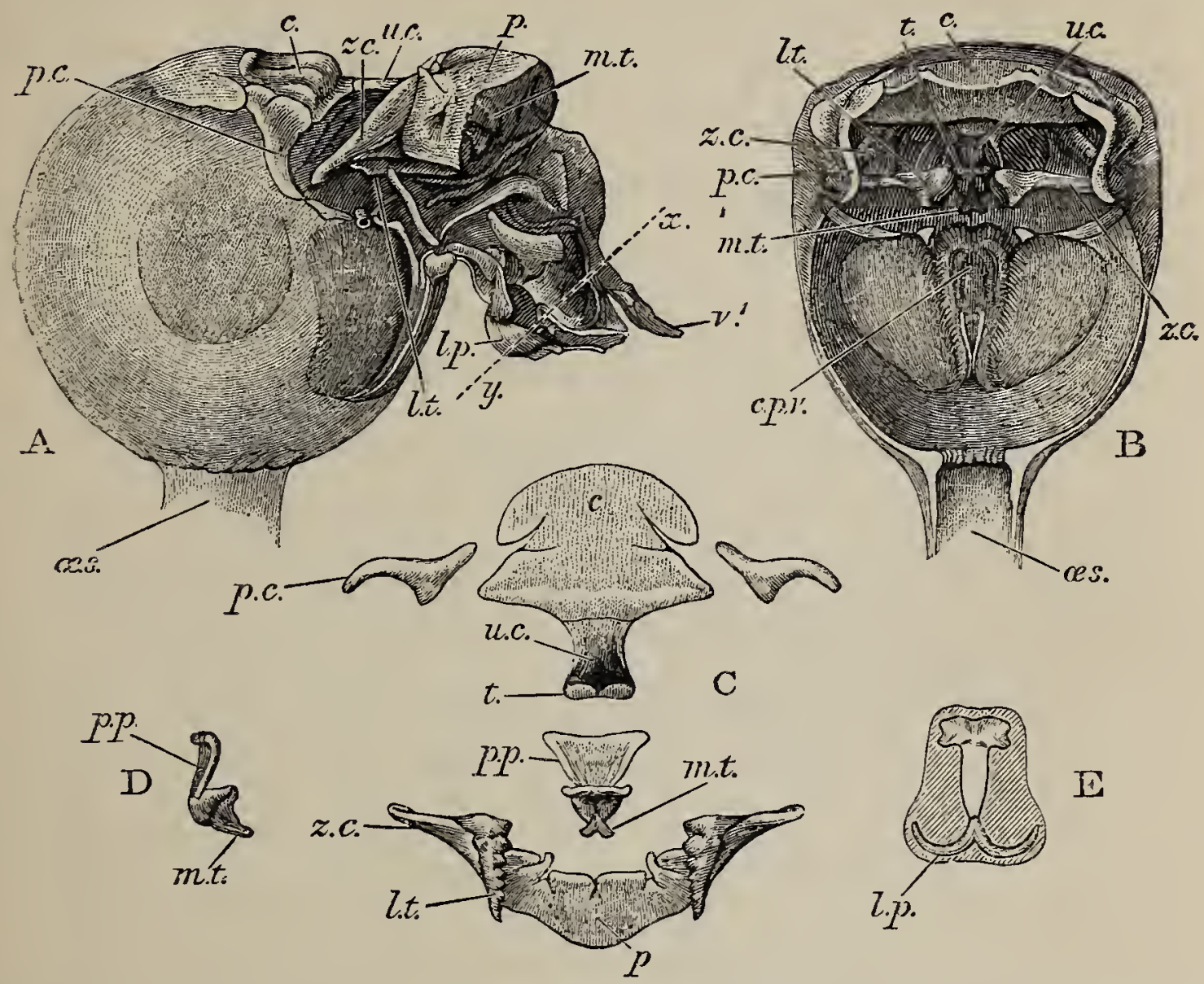

Fia. 9.-Astacus furiatilis. $\mathrm{A}$, the stomach with its outer coat removed, seen from the left side; $B$, the same viewed from the front, after removal of the anterior wall; $\mathrm{C}$, the ossicles of the gastric mill separated from one another; $\mathrm{D}$, the prefyloric ossicle and median tooth, seen from the right side; E, transverse section of the pyloric region along the line $x y$ in $\mathrm{A}$ (all $\times 2$ ). c, cardiac ossicle ; $c p v$, cardiopyloric valve; $l p$, lateral pouch; $l t$, lateral tooth, seen through the wall of the stomach in A; $m g$, mid-gut; $m t$, median tooth, seen through the wall of the stomach in $\mathrm{A}$; $\propto s$, , œsophagus; $p$, pyloric ossicle; $p c$, pterocardiac ossicle; $2 p$, prepyloric ossicle; $\imath c$, uro-cardiac process; $t$, convexities on the free surface of its hinder end; $v^{1}$, median pyloric valve; $z c$, zygocardiac ossicle.

or food-crusher; and, secondly, to a filter or strainer, whereby the nutritive juices are separated from the innutritious hard parts of the food and passed on into the intestine. 


\section{THE PHYSIOLOGY OF THE COMMON CRAYFISI.}

The gastric mill begins in the hinder half of the cardiac division. Here, on the upper wall of the stomach, we see a broad transverse calcified bar (figs. 9-11, c) from the middle of the hinder part of which another bar $(u c)$, united to the first by a flexible portion, is continued backwards in the middle line. The whole has, therefore, somewhat the shape of a cross-bow. Behind the firstmentioned piece, the dorsal wall of the stomach is folded in, in such a manner as to give rise to a kind of pouch; and the second piece, or what we may call the handle of the crossbow, lies in the front wall of this pouch. The end of this piece is dense and hard, and its free surface, which looks into the top of the cardiac chamber, is raised into two oval, flattened convex surfaces $(t)$. Connected by a transverse joint with the end of the handle of the crossbow, there is another solid bar, which ascends obliquely forwards in the back wall of the pouch $(p p)$. The end which is articulated with the handle of the crossbow is produced into a strong reddish conical tooth $(\mathrm{mt})$, curved forwards and bifurcated at the summit; consequently, when the cavity of the stomach is inspected from the fore part of the cardiac pouch (fig. 9, B), the twopointed curved tooth $(m t)$ is seen projecting behind the convex surfaces $(t)$, in the middle line, into the interior of that cavity. The joint which connects the handle of the crossbow with the hinder middle piece is elastic; hence, if the two are straightened out, they return to their bent disposition as soon as they are released. The upper end of 
the hinder middle piece $(p p)$ is connected with a second flat transverse plate which lies in the dorsal wall of the pyloric chamber $(p)$. The whole arrangement, thus far, may be therefore compared to a large cross-bow and a small one, with the ends of their handles fastened together by a spring joint, in such a manner that the handle of the one makes an acute angle with the handle of the other; while the middle of each bow is united with the middle of the other by the bent arm formed by the two handles. But, in addition to this, the outer ends of the two bows are also connected together. A small, curved, calcified bar ( $p c)$ passes from the outer end of the front crosspiece downwards and outwards in the wall of the stomach, and its hinder and lower extremity is articulated with another larger bar ( $z c$ ) which runs upwards and backwards to the hinder or pyloric crosspiece, with which it articulates. Internally, this piece projects into the cardiac cavity of the stomach as a stout elongated reddish elevation $(l t)$, the surface of which is produced into a row of strong sharp, transverse ridges, which diminish in size from before backwards, and constitute a crushing surface almost like that of the grinder of an elephant. Thus, when the front part of the cardiac cavity is cut away, not only are the median teeth already mentioned seen, but, on each side of them, there is one of these long lateral teeth.

There are two small pointed teeth, one under each of the lateral teeth, and each of these is supported by 


\section{THE PHYSIOLOGY OF THE COMMON CRAYFISH.}

a broad plate, hairy on its inner surface, which enters into the lateral wall of the cardiac chamber. There are various other smaller skeletal parts, but the most im-

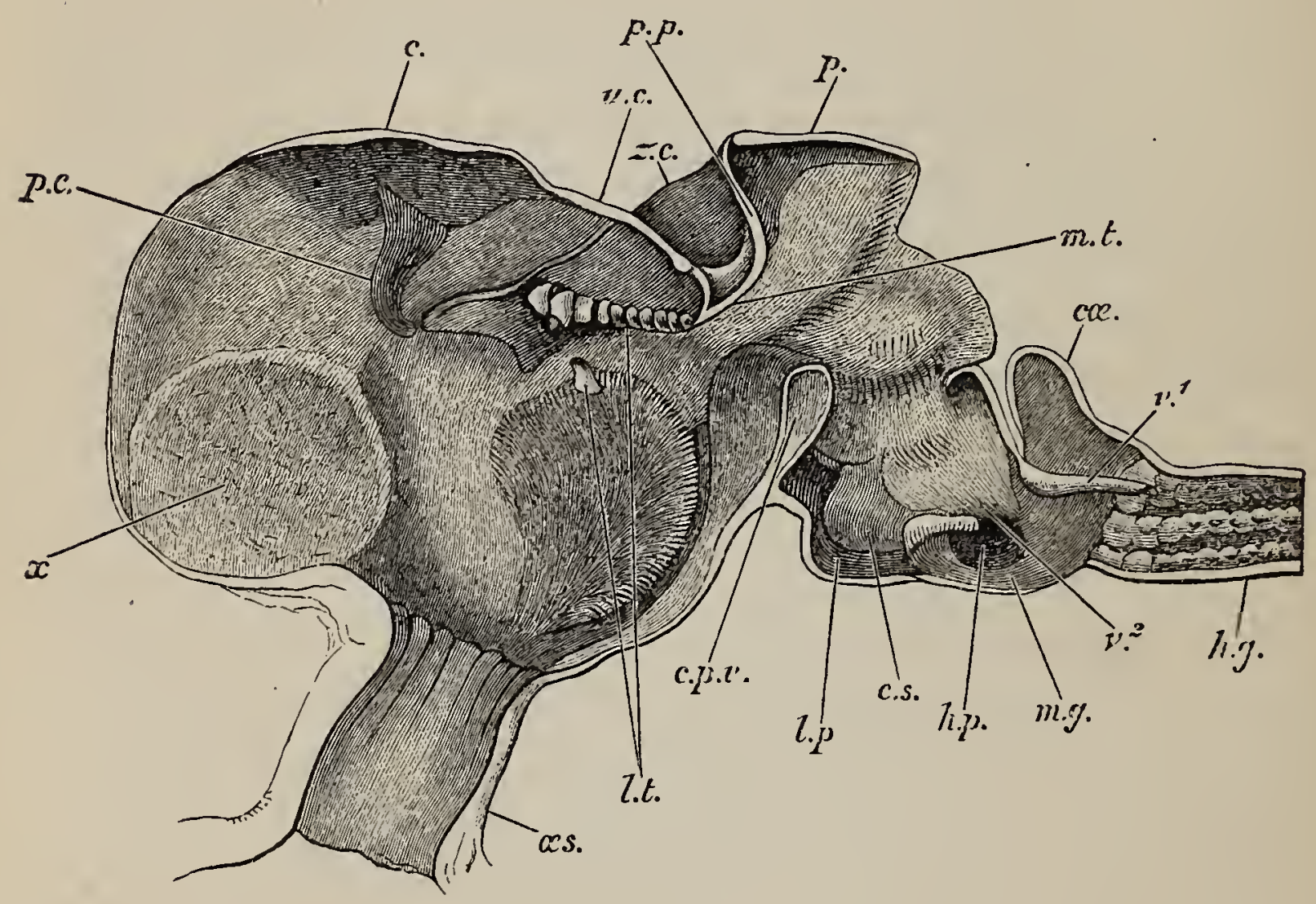

FIG. 10.-Astacus fluviatilis.-Longitudinal section of the stomach $(\times 4)$, $c$, cardiac ossicle; $c a$, cæcum ; $c . p . v$, cardio-pyloric valve; $c s$, cushionshaped surface; $/$ g , hind-gut ; $h p$, aperture of right bile duct ; lp, lateral pouch ; $l t$, lateral teeth ; $m g$, mid-gut ; $m t$, median tooth ; $c s$, œsophagus ; $p$, pyloric ossicle ; $p c$, pterocardiac ossicles ; $p p$, prepyloric ossicle ; $u c$, urocardiac process ; $v^{1}$, median pyloric valve; $\imath^{2}$, lateral pyloric valve; $x$, position of gastrolith; $z c$, zygocardiac ossicle.

portant are those which have been described; and these, from what has been said, will be seen to form a sort of hexagonal frame, with more or less flexible joints at the angles, and having the anterior and the posterior sides 
connected by a bent jointed middle bar. As all these parts are merely modifications of the hard skeleton, the apparatus is devoid of any power of moving itself. It is set in motion, however, by the same substance as that which gives rise to all the other bodily movements of the crayfish, namely, muscle. The chief muscles which move it are four very strong bundles of fibres. Two of these are attached to the front crosspiece, and proceed thence, upwards and forwards, to be fixed to the inner face of the carapace in the front part of the head (figs. 5, 6, and 12,ag). The two others, which are fixed into the hinder crosspiece and hinder lateral pieces, pass upwards and backwards, to be attached to the inner face of the carapace in the back part of the head $(p g)$. When these muscles shorten, or contract, they pull the front and back crosspieces further away from one another' consequently, the angle between the handles becomes more open and the tooth which is borne on their ends travels downwards and forwards. But, at the same time, the angle between the side bars becomes more open and the lateral tooth of each side movers inwards till it crosses in front of the middle tooth, and strikes against this and the opposite lateral tooth, which has undergone a corresponding change of place. The muscles being now relaxed, the elasticity of the joints suffices to bring the whole apparatus back to its first position, when a new contraction brings about a new clashing of the teeth. Thus, by the alternate contraction and relaxation of these two pair of muscles, the 
58 THE PHYSIOLOGY OF THE COMMON CRAYFISH.

three teeth are made to stir up and crush whatever is contained in the cardiac chamber. When the stomach is removed and the front part of the cardiac chamber is cut away, the front cross-piece may be seized with one pair of forceps and the hind cross-piece with another. On slightly pulling the two, so as to imitate the action of the muscles, the three teeth will be found to come together sharply, exactly in the manner described.

Works on mechanics are full of contrivances for the conversion of motion; but it would, perhaps, be difficult to discover among these a prettier solution of the problem; given a straight pull, how to convert it into three simultaneous convergent movements of as many points.

What I have called the filter is constructed mainly out of the chitinous lining of the pyloric chamber. The aper. ture of communication between this and the cardiac chamber, already narrow, on account of the constriction of the walls of the stomach at this point, is bounded at the sides by two folds; while, from below, a conical tongueshaped process (figs. 6, 10, and 11, cpv), the surface of which is covered with hairs, further obstructs the opening. In the posterior half of the pyloric chamber, its side walls are, as it were, pushed in; and, above, they so nearly meet. in the middle line, that a mere vertical chink is left between them; while even this is crossed by hairs set upors the two surfaces. In its lower half, however, each side wall curves outwards, and forms a cushion-shaped surface (fig. 10, cs) which looks downwards and inwards. If the 
floor of the pyloric chamber were flat, a wide triangular passage would thus be left open in its lower half. But, in fact, the floor rises into a ridge in the middle, while, at the sides, it adapts itself to the shape of the two cushionshaped surfaces; the result of which is that the whole cavity of the posterior part of the pyloric division of the stomach is reduced to a narrow three-rayed fissure. In transverse section, the vertical ray of this fissure is straight, while the two lateral ones are concave upwards (fig. 9, E). The cushions of the side walls are covered with short close-set hairs. The corresponding surfaces of the floor are raised into longitudinal parallel ridges, the edge of each of which is fringed with very fine hairs. As everything which passes from the cardiac sac to the intestine must traverse this singular apparatus, only the most finely divided solid matters can escape stoppage, so long as its walls are kept together.

Finally, at the opening of the pyloric sac into the intestine, the chitinous investment terminates in five symmetrically arranged processes, the disposition of which is such that they must play the part of valves in preventing any sudden return of the contents of the intestine to the stomach, while they readily allow of a passage the other way. One of these valvular processes is placed in the middle line above (figs. 10 and 11, $v^{1}$ ). It is longer than the others and concave below. The lateral processes $\left(v^{2},\right)$ of which there are two on each side, are triangular and flat. 
The cuticular lining which gives rise to all the complicated apparatus which has just been described, must

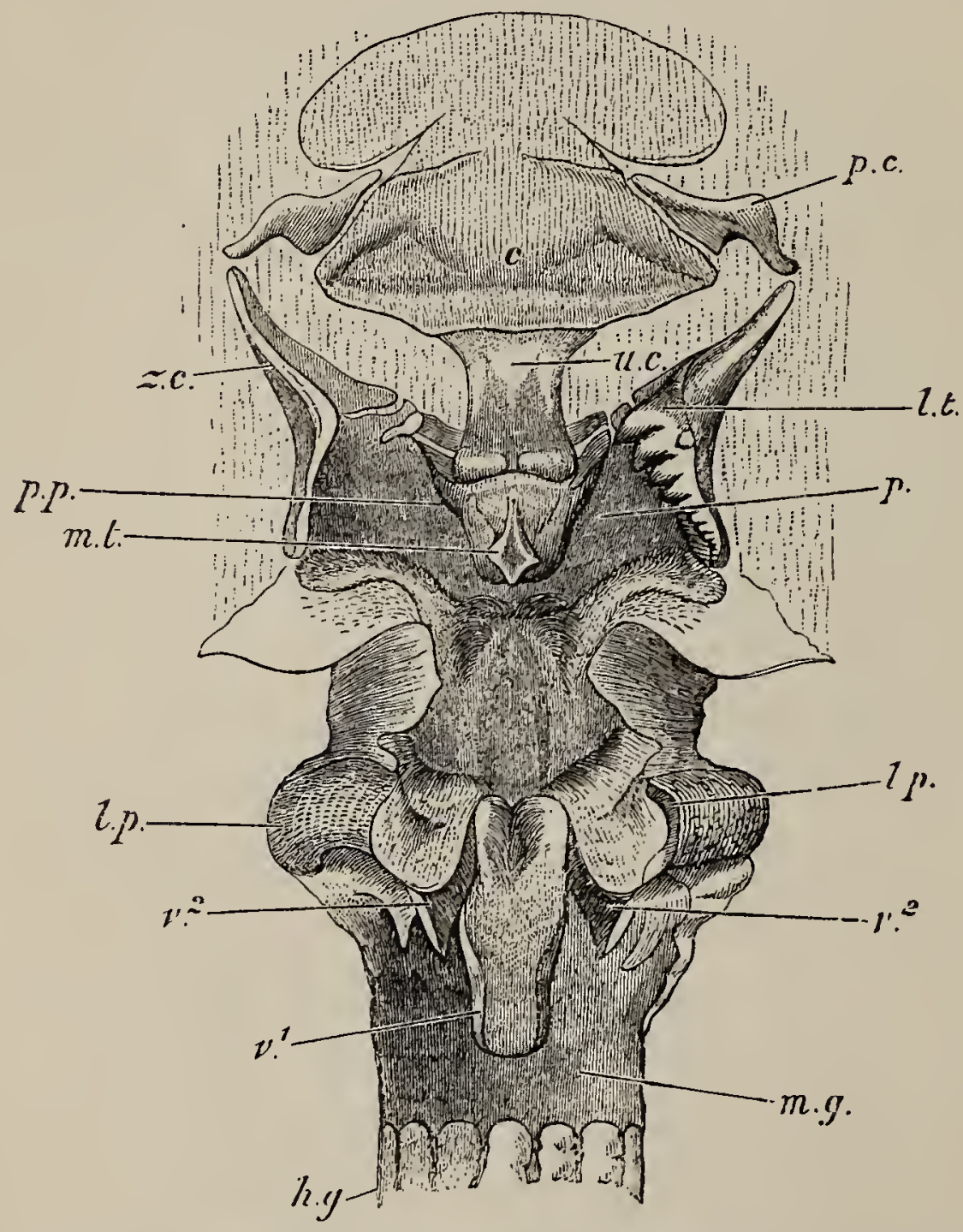

Fig. 11.-Astacus fluviatilis.--View of the roof of the stomach, tine ventral wall of which, and of the mid-gut, is laid open by a longitudinal incision $(\times 4)$. On the right side (the left in the figure), the lateral tooth is cut away: as well as the floor of the lateral pouch. The letters have the same signification as in fig. 10.

not be confounded with the proper wall of the stomach, which invests it, and to which it owes it origin, just as the cuticle of the integument is produced by the soft 
true skin which lies beneath it. The wall of the stomach is a soft pale membrane containing variously disposed muscular fibres ; and, beyond the pylorus, it is continued into the wall of the intestine.

It has already been mentioned that the intestine is a slender and thin-walled tube, which passes straight through the body almost without change, except that it becomes a little wider and thicker-walled near the vent. Immediately behind the pyloric valves, its surface is quite smooth and soft (figs. 9, 10, and 12, $\mathrm{mg}$ ), and its floor presents a relatively large aperture, the termination of the bile duct (fig. 12, bd, fig. 10, hp.), on each side. The roof is, as it were, pushed out into a short median pouch or cacum $(c a)$. Behind this, its character suddenly changes, and six squarish elevations, covered with a chitinous cuticle, encircle the cavity of the intestine $(r)$. From each of these, a longitudiual ridge, corresponding with a fold of the wall of the intestine, takes its rise, and passes, with a slight spiral twist, to its extremity ( $h g)$. Each of these ridges is beset with small papillæ, and the chitinous lining is continued over the whole to the vent, where it passes into the general cuticle of the integument, just as the lining of the stomach is continuous with the cuticle of the integument at the mouth. The alimentary canal may, therefore, be distinguished into a fore and a hind-gut $(\mathrm{hg})$, which have a thick internal lining of cuticular membrane; and a very short midgut ( $\mathrm{mg}$ ), which has no thick cuticular layer. It will be of 


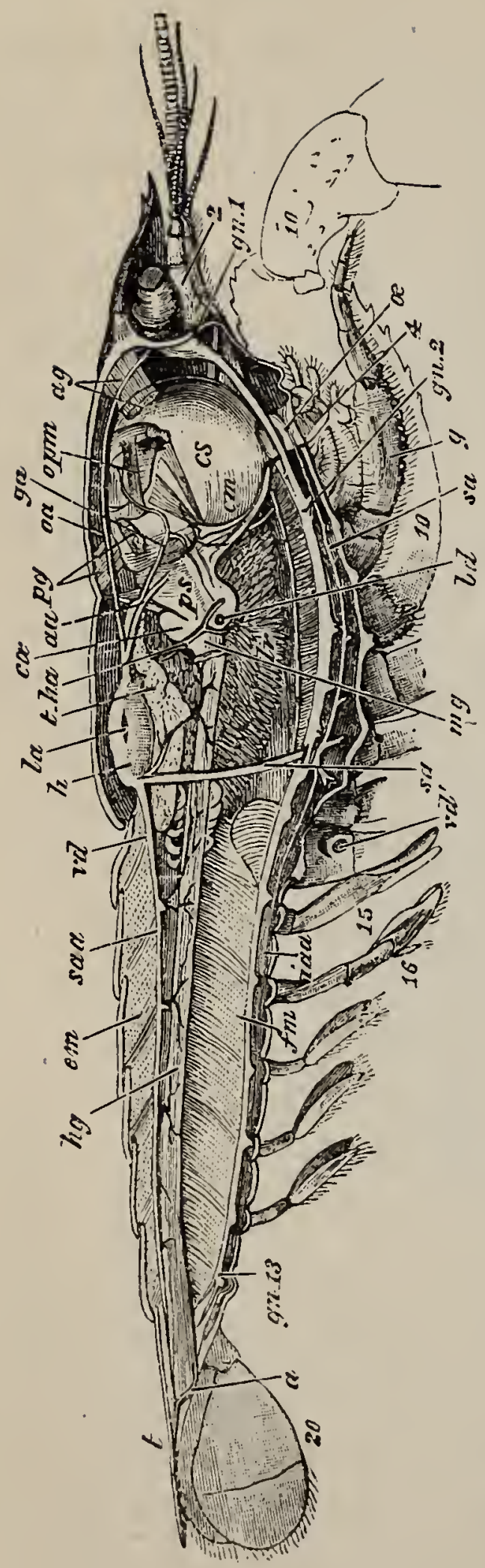

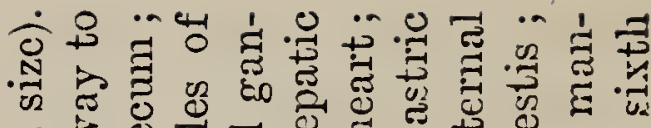

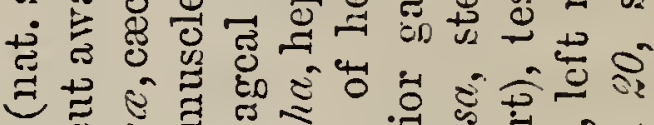

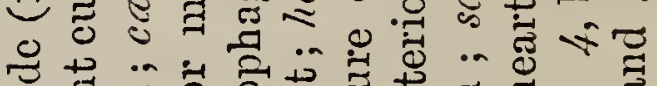

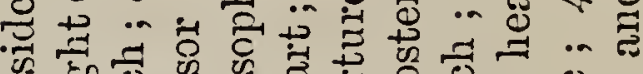

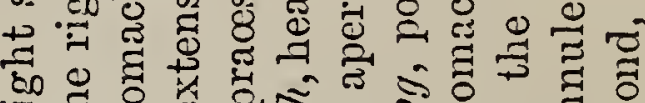
.70

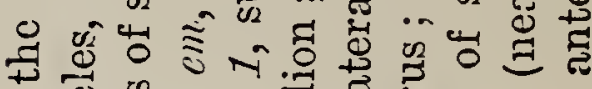
व ‡્0 4

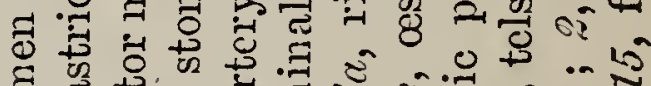
.

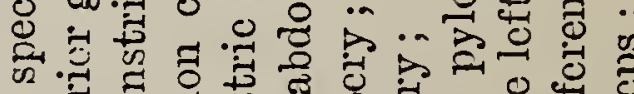

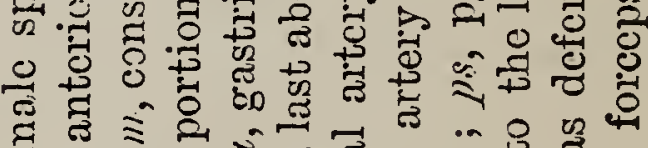
« 4 ป प్ర

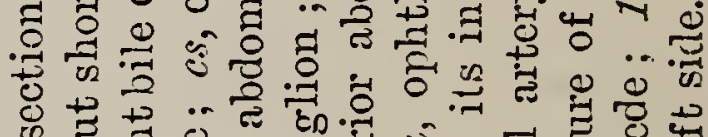

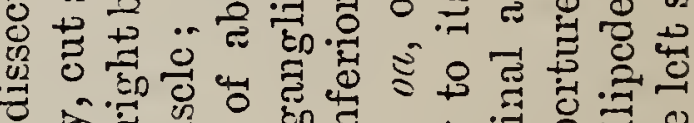

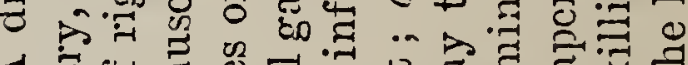

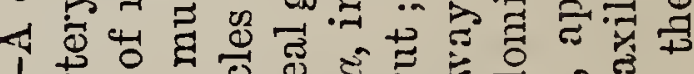

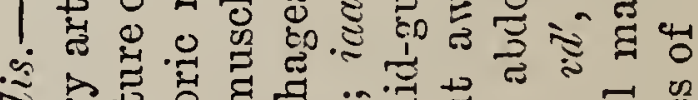

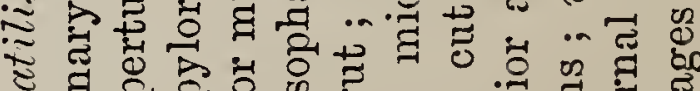

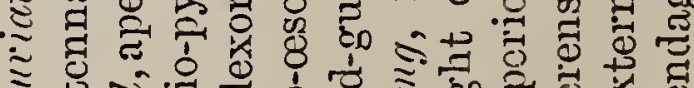

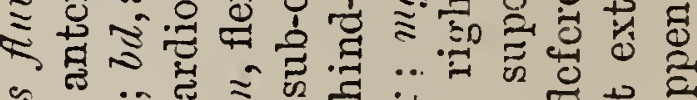

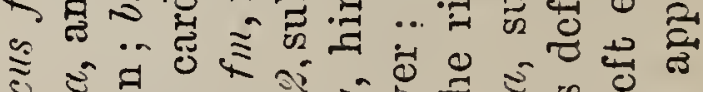

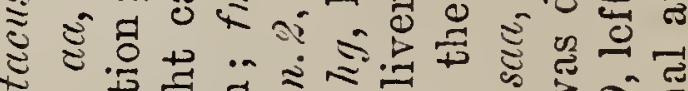

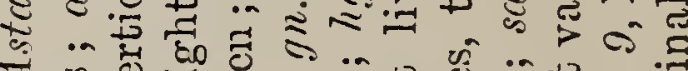

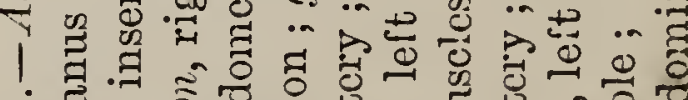

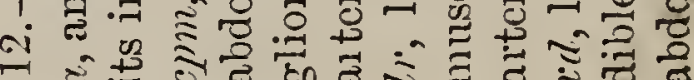
0 
importance to recollect this distinction by-and-by, when the development of the alimentary canal is considered.

If the treatment to which the food is subjected in the alimentary apparatus were of a purely mechanical nature, there would be nothing more to describe in this part of the crayfish's mechanism. But, in order that the nutritive matters may be turned to account, and undergo the chemical metamorphoses, which eventually change them into substances of a totally different character, they must pass out of the alimentary canal into the blood. And they can do this only by making their way through the walls of the alimentary canal; to which end they must either be in a state of extremely fine division, or they must be reduced to the fluid condition. In the case of the fatty matters, minute subdivision may suffice; but the amylaceous substances and the insoluble protein compounds, such as the fibrin of flesh, must be brought into a state of solution. Therefore some substances must be poured into the alimentary canal, which, when mixed with the crushed food, will play the part of a chemical agent, dissolving out the insoluble proteids, changing the amyloids into soluble sugar, and converting all the proteids into those diffusible forms of protein matter, which are known as peptones.

The details of the processes here indicated, which may be included under the general name of digestion, have only quite recently been carefully investigated in the crayfish; and we have probably still much to learn about 


\section{THE PHYSIOLOGY OF THE COMMON CRAYFISH.}

them; but what has been made out is very interesting, and proves that considerable differences exist between crayfishes and the higher animals in this respect.

The physiologist calls those organs, the function of which is to prepare and discharge substances of a special character, glands; and the matter which they elaborate is termed their secretion. On the one side, glands are in relation with the blood, whence they derive the materials which they convert into the substances characteristic of their secretion; on the other side, they have access, directly or indirectly, to a free surface, on to which they pour their secretion as it is formed.

Of such glands, the alimentary canal of the crayfish is provided with a pair, which are not only of very large size, but are further extremely conspicuous, on account of their yellow or brown colour. These two glands (figs. 12 and $13,\left({ }^{\circ}\right)$ are situated beneath, and on each side of, the stomach and the anterior part of the intestine, and answer in position to the glands termed liver and pancreas in the higher animals, inasmuch as they pour their secretion into the mid-gut. These glands have hitherto always been re. garded as the liver, and the name may be retained, though their secretion appears rather to correspond with the pancreatic fluid than with the bile of the higher animals.

Each liver consists of an immense number of short tubes, or caca, which are closed at one end, but open at the other into a general conduit, which is termed their duct. The mass of the liver is roughly divided into 


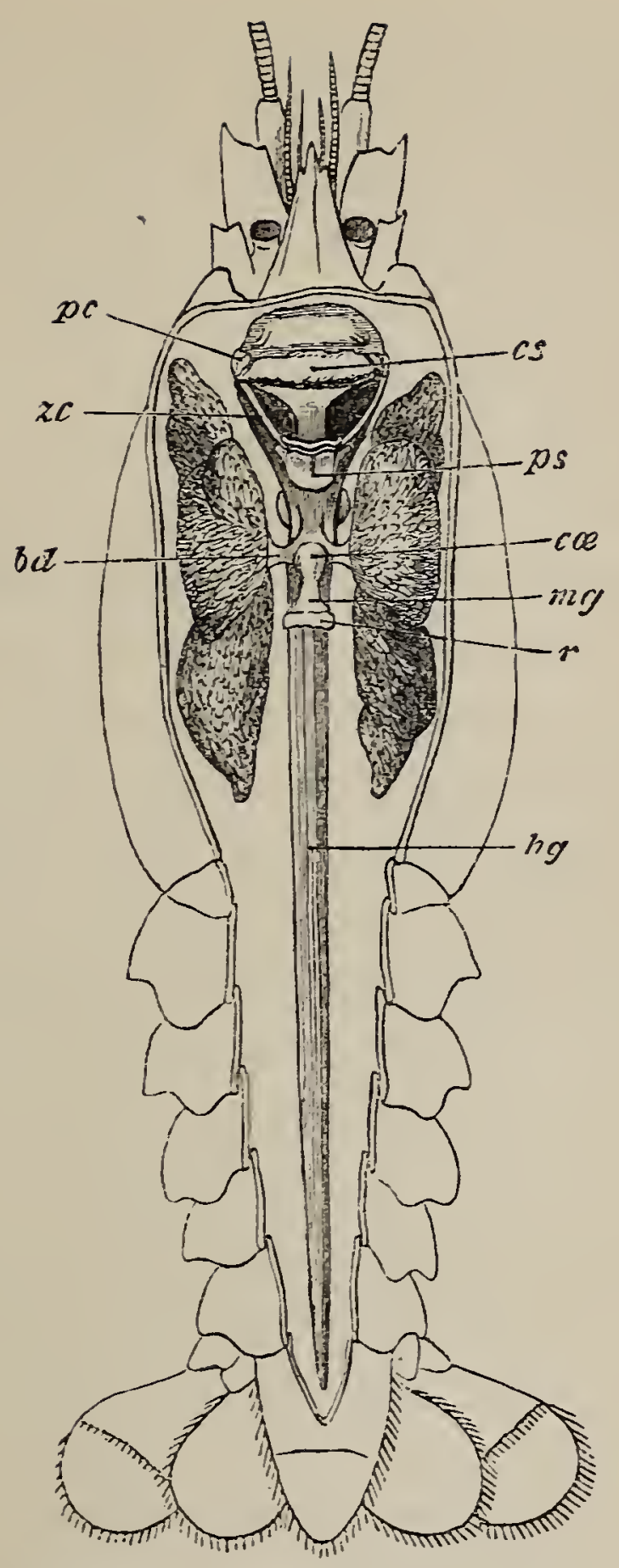

FIG. 13.-Astacus fluvicutilis. - The alimentary canal and livers seen from above (nat. size). $\quad b d$, bile-duct; $c \mathscr{e}$, cæcum ; $c s$, cardiac portion of stomach, the line pointing to the cardiac ossicle ; $/ \mathrm{g}$, hind-gut; $\mathrm{mg}$, mid-rut; pc, pterocardiac ossicle; $p s$, pyloric portion of stomach, the line pointing to the pyloric ossicle ; $r$, ridge separating mid-gut from hind-gut; $z c$, zygocardiac ossicle. 
three lobes, one anterior, one lateral, and one posterior ; and each lobe has its main duct, into which all the tubes composing it open. The three ducts unite together into a wide common duct $(b d)$, which opens, just behind the pyloric valves, into the floor of the mid-gut. Hence the apertures of the two hepatic ducts are seen, one on each side, in this part of the alimentary canal when it is laid open from above. Every cæcum of the liver has a thin outer wall, lined internally by a layer of cells, constituting what is termed an epithelium; and, at the openings of the hepatic ducts, this epithelium passes into a layer of somewhat similar structure, which lines the mid-gut, and is continued through the rest of the alimentary canal, beneath the cuticula. Hence the liver may be regarded as a much divided side pouch of the mid-gut.

The epithelium is made up of nucleated cells, which are particles of simple living matter, or protoplasm, in the midst of each of which is a rounded body, which is termed the nucleus. It is these cells which are the seat of the manufacturing process which results in the formation of the secretion; it is, as it were, their special business to form that secretion. To this end they are constantly being newly formed at the summits of the cæca. As they grow, they pass down towards the duct and, at the same time, separate into their interior certain special products, among which globules of yellow fatty matter are very conspicuous. When these products are fully formed, what remains of the substance of the cells dissolves away, and 
the yellow fluid accumulating in the ducts passes into the mid-gut. The yellow colour is due to the globules of fat. In the young cells, at the summit of the cæca, these are either absent, or very small, whence the part appears colourless. But, lower down, small yellow granules appear in the cells, and these become bigger and more numerous in the middle and lower parts. In fact, few glands are better fitted for the study of the manner in which secretion is effected than the crayfish's liver.

We may now consider the alimentary machinery, the general structure of which has been explained, in action.

The food, already torn and crushed by the jaws, is passed through the gullet into the cardiac sac, and there reduced to a still more pulpy state by the gastric mill. By degrees, such parts as are sufficiently fluid are drained off into the intestine, through the pyloric strainer, while the coarser parts of the useless matters are probably rejected by the mouth, as a hawk or an owl rejects his casts. There is reason to believe, though it is not certainly known, that fluids from the intestine mix with the food while it is undergoing trituration, and effect the transformation of the starchy and the insoluble protein compounds into a soluble state. At any rate, as soon as the strained-off fluid passes into the mid-gut it must be mixed with the secretion of the liver, the action of which is probably 
68 THE PHYSIOLOGY OF THE COMMON CRAYFISH.

similar to that of the pancreatic juice of the higher animals.

The mixture thus produced, which answers to the chyle of the higher animals, passes along the intestine, and the greater part of it, transuding through the walls of the alimentary canal, enters the blood, while the rest accumulates as dark coloured fæees in the hind gut, and

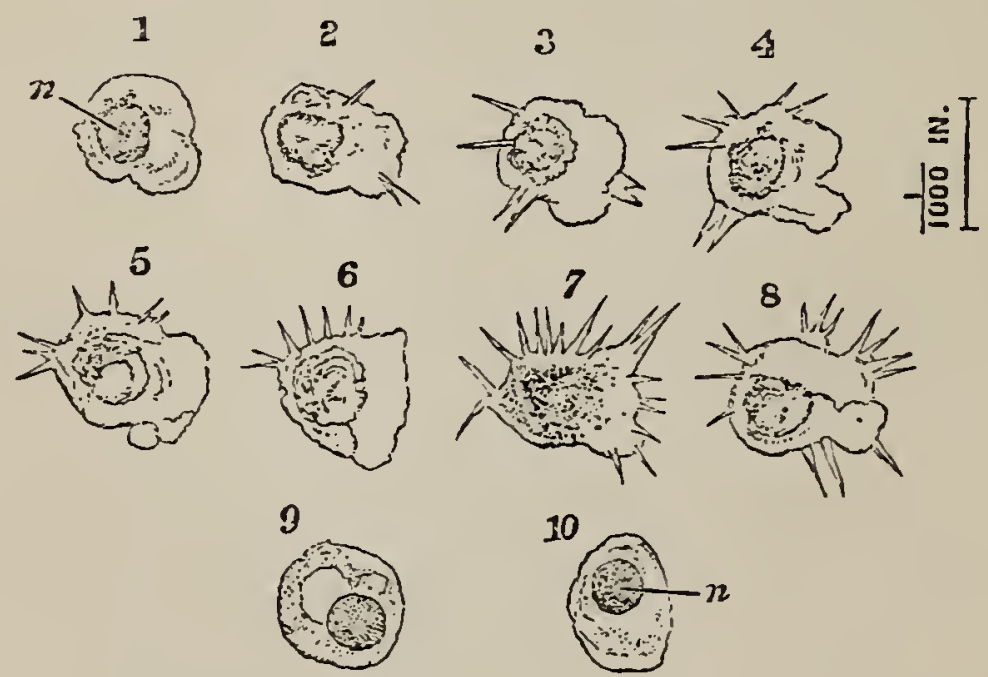

FIg. 14. - Astacus furiatilis. - The corpuscles of the blood (highly magnified). 1-8 show the changes undergone by a single corpuscle during a quarter of an hour; 9 and 10 are corpuscles killed by magenta, and having the nucleus deeply stained by the colouring matter. n, nucleus.

is eventually passed out of the body by the vent. The frecal matters are small in amount, and the strainer is so efficient that they rarely contain solid particles of sensible size. Sometimes, howerer, there are a good many minute fragments of regetable tissue.

The blood of which the nutritive elements of the food 
have thus become integral parts, is a clear fluid, either colourless, or of a pale neutral tint or reddish hue, which, to the naked eye, appears like so much water. But if subjected to microscopic examination, it is found to contain innumerable pale, solid particles, or corpuscles, which, when examined fresh, undergo constant changes of form (fig. 14). In fact, they correspond very closely with the colourless corpuscles which exist in our own blood; and, in its general characters, the crayfish's blood is such as ours would be if it were somewhat diluted and deprived of its red corpuscles. In other words, it resembles our lymph more than it does our blood. Left to itself it soon coagulates, giving rise to a pretty firm clot.

The sinuses, or cavities in which the greater part of the blood is contained, are disposed very irregularly in the intervals between the internal organs. But there is one of especially large size on the ventral or stemal side of the thorax (fig. 15, sc), into which all the blood in the body sooner or later makes its way. From this sternal sinus passages (av) lead to the gills, and from these again six canals $(b c v)$, pass up on the inner side of the inner wall of each branchial chamber to a cavity situated in the dorsal region of the thorax, termed the pericardium $(p)$, into which they open.

The blood of the crayfish is kept in a state of constant circulating motion by a pumping and distributing machinery, composed of the heart and of the arteries, with 


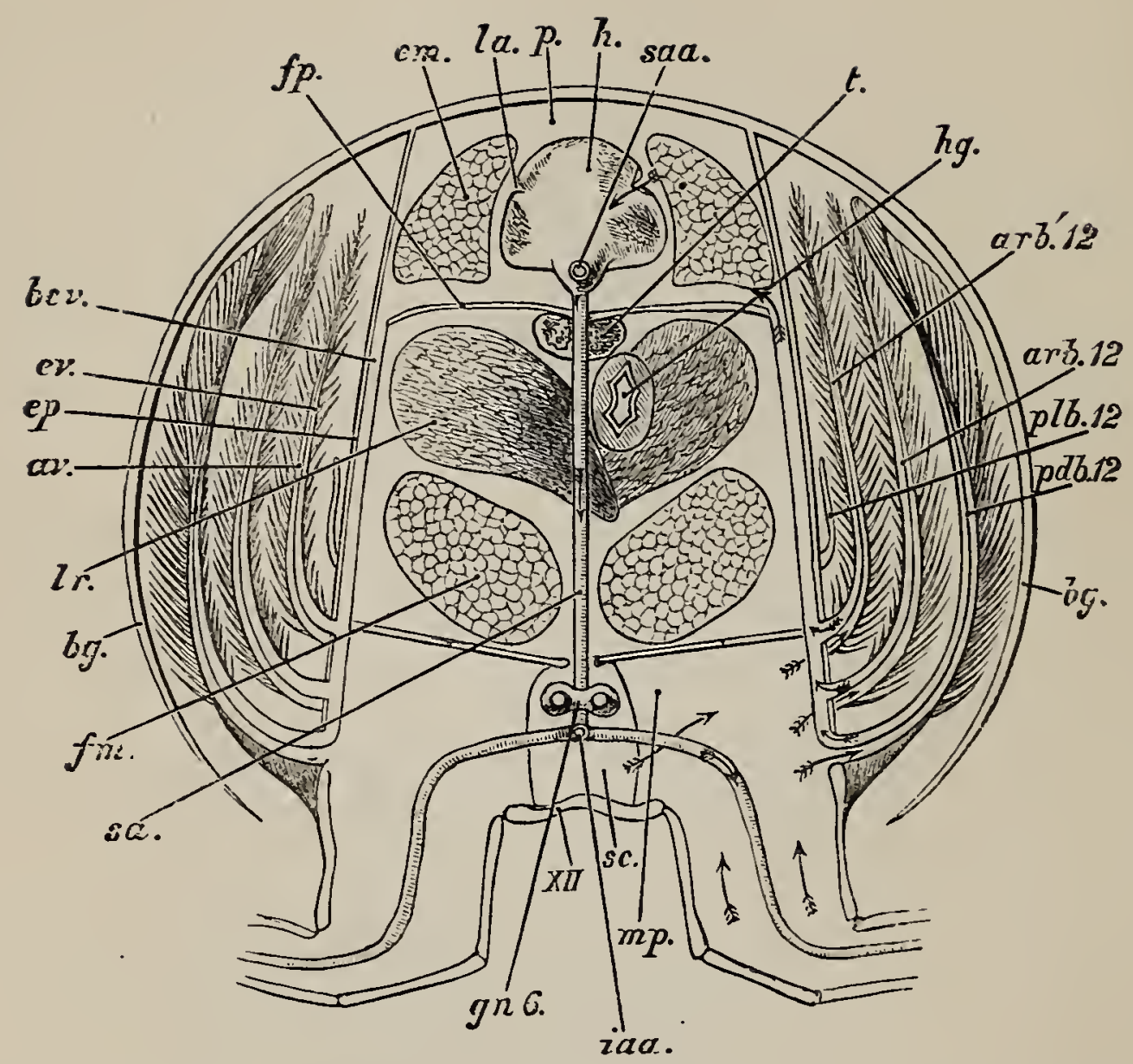

FIG. 15.-Astacus fluriatilis.-A diagrammatic transverse section of the thorax through the twelfth somite, showing the course of the circulation of the blood $(\times 3)$. arb. 12, the anterior or lower, and ar' $b^{\prime} .12$, the posterior or upper arthrobranchia of the twelfth somite ; $a v$, afferent branchial vessel ; $b c r$, branchio-cardiac vein ; $b g$, branchiostegite; $c m$, extensor muscles of abdomen; ('), epimeral wall of thoracic cavity; $e x$, efferent branchial vessel; fm, flexor muscles of abamen ; $f p$, floor of pericardium; $g n .6$, fifth thoracic ganglion ; $h$, heart ; $h g$, hind-gut ; ian, inferior abdominal artery, in cross section; $l a$, lateral valvular apertures of heart $; l l$, liver ; $m p$, indicates the position of the mesophragm by which the sternal canal is bounded laterally; $p$, pericardial sinus; $p l b .1 \%$, podobranchia, and $p l b .12$, pleurobranchia of the twelfth somite; $s a$,sternal artery; sila, superior abdominal artery ; $s c$, sternal canal ; $t$, testis; XII., sternum of twelfth somite. The arrows indicate the direction of the blood flow. 
their larger and smaller branches, which proceed from it and ramify through the body, to terminate eventually in the blood sinuses, which represent the reins of the higher animals.

When the carapace is removed from the middle of the region which lies behind the cervical groove, that is, when the dorsal or tergal wall of the thorax is taken away, a spacious chamber is laid open which is full of blood. This is the cavity already mentioned as the pericardium (fig. 15, p), though, as it differs in some respects from that which is so named in the higher animals, it will be better to term it the pericardial sinus.

The heart (fig. 15, $h$ ), lies in the midst of this sinus. It is a thick muscular body (fig. 16), with an irregularly hexagonal contour when viewed from above, one angle of the hexagon being anterior and another posterior. The lateral angles of the hexagon are connected by bands of fibrous tissue $(a c)$ with the walls of the pericardial sinus. Otherwise, the heart is free, except in so far as it is kept in place by the arteries which leave it and traverse the walls of the pericardium. One of these arteries (figs. 5, 12, and 16, sac), starting from the hinder part of the heart, of which it is a sort of continuation, runs along the middle line of the abdomen above the intestine, to which it gives off many branches. A second large artery starts from a dilatation, which is common to it with the foregoing, but passing directly downwards (figs. 12 and 15, sa, and fig. 16, st. a), either on the right or on the left side of the intestine, 
traverses the nervous cord (figs. 12 and 15), and divides into an anterior (fig. 12, sa) and a posterior (iaa) branch, both of which run beneath and parallel with that cord.

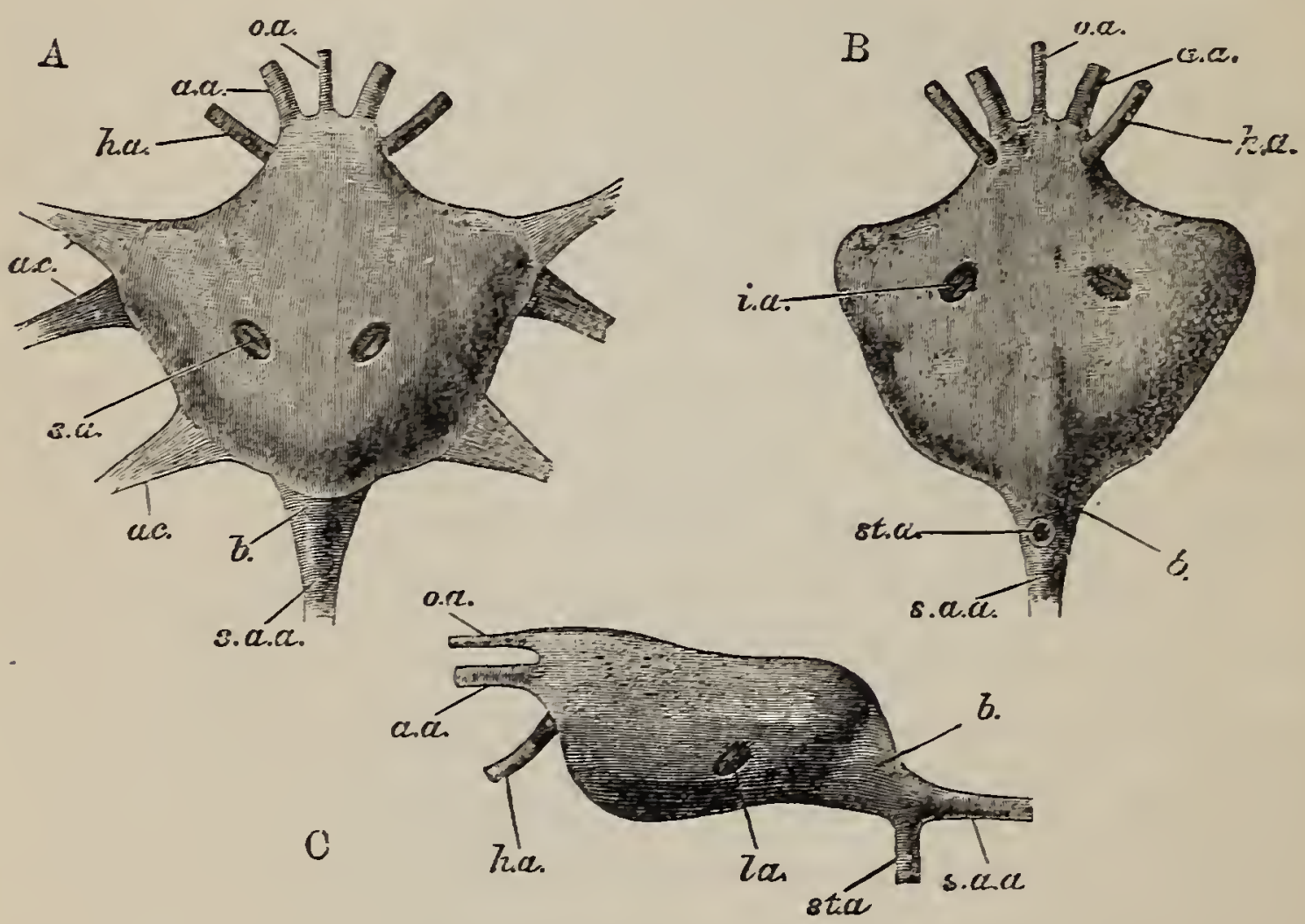

FIG. 16.-Astacus furiatilis. - The heart $(\times 4)$. A, from abore; B, from below; $\mathrm{C}$, from the left side. $a a$, antennary artery : $a c$, alæ cordis, or fibrous bands connecting the heart with the walls of the pericardial sinus; $b$, bulbous dilatation at the origin of the sternal arters ; ha, hepatic artery : la, lateral valvular apertures ; oa, ophthalmic artery; s.a, superior valvular apertures; s.a.a, superior abdominal artery; st.a, sternal artery, in B cut off close to its origin.

A third artery runs, from the front part of the heart, forwards in the middle line, over the stomach, to the eyes and fore part of the head (figs. 5, 12, and 16,oa); and two others diverge one on each side of this, and sweep 
round the stomach to the antennæ $(a a)$. Behind these, yet two other arteries are given off from the under side of the heart, and supply the liver $(h a)$. All these arteries branch out and eventually terminate in fire, so-called capillary, ramifications.

In the dorsal wall of the heart two small oval apertures are visible, provided with valvular lips (fig. 16, sa), which open inwards, or towards the internal cavity of the heart. There is a similar aperture in each of the lateral faces of the heart $(l a)$, and two others in its inferior face (ia), making six in all. These apertures readily admit fluid into the heart, but oppose its exit. On. the other hand, at the origins of the arteries, there are small valvular folds, directed in such a manner as to permit the exit of fluid from the heart, while they prevent its entrance.

'The walls of the heart are muscular, and, during life, they contract at intervals with a regular rhythm, in such a manner as to diminish the capacity of the internal cavity of the organ. The result is, that the blood which it contains is driven into the arteries, and necessarily forces into their smaller ramifications an equivalent amount of the blood which they already contained; whence, in the long run, the same amount of blood passes out of the ultimate capillaries into the blood sinuses. From the disposition of the blood sinuses, the impulse thus given to the blood which they contain is finally conveyed to the blood in the branchiæ, and a proportional quantity of that 


\section{THE PHYSIOLOGY OF THE COMMON CRAYFISA.}

blood leaves the branchiæ and passes into the sinuses which connect them with the pericardial sinus (fig. 15, bcv), and thence into that carity. At the end of the contraction, or systole, of the heart, its volume is of course diminisheci by the volume of the blood forced out, and the space between the walls of the heart and those of the pericardial sinus is increased to the same extent. This space, however, is at once occupied by the blood from the branchiæ, and perhaps by some blood which has not passed through the branchiæ, though this is doubtful. When the systole is over, the diastole follows; that it to say, the elasticity of the walls of the heart and that of the various parts which connect it with the walls of the pericardium, bring it back to its former size, and the blood in the pericardial sinus flows into its cavity by the six apertures. With a new systole the same process is repeated, and thus the blood is driven in a circular course through all parts of the body.

It will be observed that the branchire are placed in the course of the current of blood which is returning to the heart; which is the exact contrary of what happens in fishes, in which the blood is sent from the heart to the branchix, on its way to the body. It follows, from this arrangement, that the blood which goes to the branchim is blood in which the quantity of oxygen has undergone a diminution, and that of carbonic acid an increase, as compars with the blood in the heart itself. For the 
activity of all the organs, and especially of the muscles, is inseparably connected with the absorption of oxygen and the evolution of carbonic acid; and the only source from which the one can be derived, and the only receptacle into which the other can be poured, is the blood which bathes and permeates the whole fabric to which it is distributed by the arteries.

The blood, therefore, which reaches the branchix has lost oxygen and gained carbonic acid; and these organs constitute the apparatus for the elimination of the injurious gas from the economy on the one hand, and, on the other, for the taking in of a new supply of the needful "vital air," as the old chemists called it. It is thus that the branchiæ subserve the respiratory function.

The crayfish has eighteen perfect and two rudimentary branchiæ in each branchial chamber, the boundaries of which have been already described.

Of the eighteen perfect branchiæ, six (podobranchice) are attached to the basal joints of the thoracic limbs, from the last but one to the second (second maxillipede) inclusively (fig. 4, p. 26, pdb, and fig. 17, A, B); and eleven (arthrobranchice) are fixed to the flexible interarticular membranes, which connect these basal joints with the parts of the thorax to which they are articulated (fig. 4, arb, arb', fig. $17, \mathrm{C})$. Of these eleven branchiæ, two are attached to the interarticular membranes of all the ambulatory legs but the last, $(=6)$ and to those of the pincers and of the external maxillipedes, $(=4)$ and one to that of the 

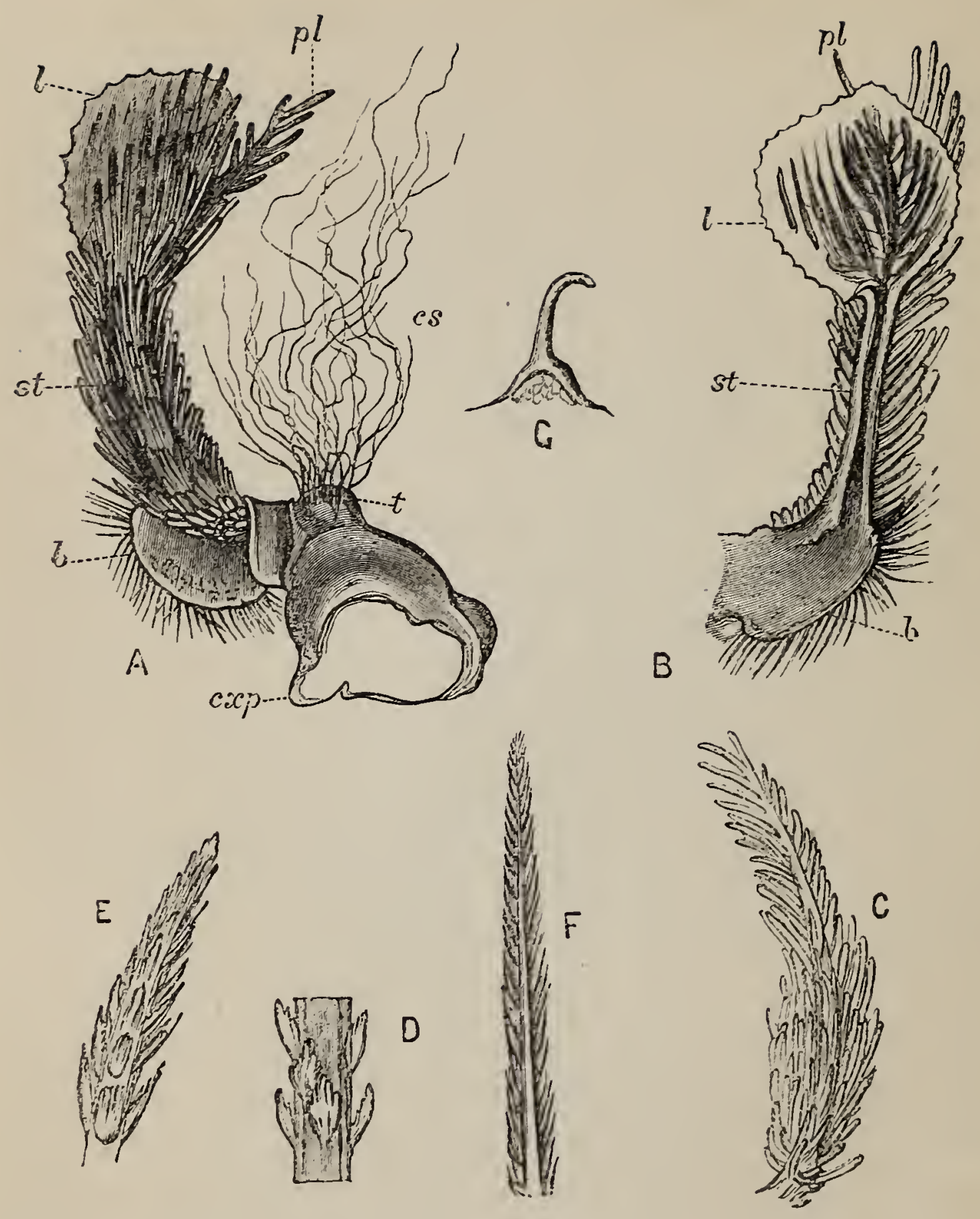

Frg. 17.-Astacus fluriatilis.-A, one of the podobranchiæ from the outer side; $\mathrm{B}$, the same from the inner side ; $\mathrm{C}$, one of the arthrobranchix ; D, a part of one of the coxopoditic setx ; E, extremity of the same seta; $F$, extremity of a seta from the base of the podobranchia ; $\mathrm{G}$, hooked seta of the lamina; (A-C, $\times 3$; D-G, highly magnified). $\quad$, base of podobranchia; (es, coxopoditic setæ; cxp, coxopodite : $l$, lamina, $p l$. plume, and st, stem of podobranchia; $t$, tubercle on the coxopodite, to which the setw arc attached. 
second maxillipede. The first maxillipede and the last ambulatory limb have none. Moreover, where there are two arthrobranchiæ, one is more or less in front of and external to the other.

'These eleven arthrobranchiæ are all very similar in structure (fig. 17, C). Each consists of a stem which contains two canals, one external and one internal, separated by a longitudinal partition. The stem is beset with a great number of delicate branchial filaments, so that it looks like a plume tapering from its base to its summit. Each filament is traversed by large vascular channels, which breals up into a net-work immediately beneath the surface. The blood driven into the external canals of the stem (fig. $15, a v)$ is eventually poured into the inner canal $(e v)$, which again communicates with the channels $(b c v)$ which lead to the pericardial sinus $(p)$. In its course, the blood traverses the branchial filaments, the outer investment of each of which is an excessively thin chitinous membrane, so that the blood contained in them is practically separated by a mere film from the aërated water in which the gills float. Hence, an exchange of gaseous constituents readily takes place, and as much oxygen is taken in as carbonic acid is given out.

The six podobranchiæ, or gills which are attached to the basal joints of the legs, play the same part, but differ a good deal in the details of their structure from those which are fixed to the interarticular membranes. Each consists of a broad base (fig. $17, A$ and $B ; b$ ) beset with many 
73 THE PHYSIOLOGY OF THL COMMION CRAYFISH.

fine straight hairs, or sete (F), whence a narrow stem (st) proceeds. At its upper end this stem divides into two parts, that in front, the plume $(p l)$, resembling the free end of one of the gills just described, while that behind, the lamina (l), is a broad thin plate, bent upon itself longitudinally in such a manner that its folded edge lies forwards, and covered with minute hooked setæ $(G)$. The gill which follows is received into the space included between the two lobes or halves of the folded lamina (fig. 4, p. 26). Each lobe is longitudinally plaited into about a dozen folds. The whole front and outer face of the stem is beset with branchial filaments; hence, we may compare one of these branchir to one of the preceding kind, in which the stem has become modified and has given off a large folded lamina from its inner and posterior face.

The branchiæ now described are arranged in sets of three for each of the thoracic limbs, from the third maxillipede to the last but one ambulatory limb, and two for the second maxillipede, thus making seventeen in all $(3 \times 5+2=17)$; and, between every two there is found a bundle of long twisted hairs (fig. 17, A, cx.s; D and $\mathrm{E})$, which are attached to a small elevation $(t)$ on the basal joint of each limb. These coxopoditic setce, no doubt, serve to prevent the intrusion of parasites and other foreign matter's into the branchial chamber. From the mode of attachment of the six branchiæe it is obvious that they must share in the movements of the basal joints of the 
PLEUROBRANCHIA, COMPLETE AND RUDIMENTARY. 79

legs; and that, when the crayfish walks, they must be more or less agitated in the branchial chamber.

The eighteenth branchia'resembles one of the eleven arthrobranchiæ in structure; but it is larger, and it is attached neither to the basal joint of the hindermost ambulatory limb, nor to its interarticular membrane, but to the sides of the thorax, above the joint. From this mode of attachment it is distinguished from the others as a pleurobranchia (fig. 4, pll. 14).

Finally, in front of this, fixed also to the walls of the thorax, above each of the two preceding pairs of ambulatory limbs, there is a delicate filament, about a sixteenth of an inch long, which has the structure of a branchial filament, and is, in fact, a rudimentary pleurobranchia (fig. 4, plb. 12, plb. 13).

The quantity of water which occupies the space left in the branchial chamber by the gills is but small, and as the respiratory surface offered by the gills is relatively wery large, the air contained in this water must be rapidly exhausted, even when the crayfish is quiescent; while, when any muscular exertion takes place, the quantity of carbonic acid formed, and the demand for fresh oxygen, is at once greatly increased. For the efficient performance of the function of respiration, therefore, the water in the branchial chamber must be rapidly renewed, and there must be some arrangement by which the supply of fresh water may be proportioned to the demand. In many animals, the respiratory surface is 
coveled with rapidly vibrating filaments, or cilia, by means of which a current of water is liept continually flowing over the gills, but there are none of these in the crayfish. The same object is attained, however, in another way. The anterior boundary of the branchial chamber corresponds with the cervical groove, which, as has been seen, curves downwards and then forwards, until it terminates at the sides of the space occupied by the jaws. If the branchiostegite is cut away along the groove, it will be found that it is attached to the sides of the head, which project a little beyond the anterior part of the thorax, so that there is a depression behind the sides of the head-just as there is a depression, behind a man's jaw, at the sides of the neck. Between this depression in front, the walls of the thorax internally, the branchiostegite externally, and the bases of the forceps and external foot-jaws below, a curved canal is included, by which the branchial cavity opens forwards as by a funnel. Attached to the base of the second maxilla there is a wide curved plate (fig. 4, 6) which fits against the projection of the head, as a shirt collar might do, to carry out our previous comparison ; and this scoopshaped plate (termed the scaphognathite), which is concave forwards and convex backwards, can be readily moved backwards and forwards.

If a living crayfish is taken out of the water, it will be found that, as the water drains away from the branchial cavity, bubbles of air are forced out of its anterior opening. 
Again, if, when a crayfish is resting quietly in the water, a little coloured fluid is allowed to run down towards the posterior opening of the branchial chamber, it will very soon be driven out from the anterior aperture, with considerable force, in a long stream. In fact, as the scaphognathite vibrates not less than three or four times in a second, the water in the funnel-shaped front passage of the branchial cavity is incessantly baled out; and, as fresh water flows in from behind to make up the loss, a current is kept constantly flowing over the gills. The rapidity of this current naturally depends on the more or less quick repetition of the strokes of the scaphograthite; and hence, the activity of the respiratory function can be accurately adjusted to the wants of the economy. Slow working of the scaphognathite answers to ordinary breathing in ourselves, quick working to panting.

A further self-adjustment of the respiratory apparatus is gained by the attachment of the six gills to the basal joints of the legs. For, when the animal exerts its muscles in walking, these gills are agitated, and thus not only bring their own surfaces more largely in contact with the water, but produce the same effect upon the other gills.

The constant oxidation which goes on in all parts of the body not only gives rise to carbonic acid; but, so far as it affects the proteinaceous constituents, it produces 
compounds which contain nitrogen, and these, like other waste products, must be eliminated. In the higher animals, such waste products take the form of urea, uric acid, hippuric acid, and the like; and are got rid of by the kidneys. We may, therefore, expect to find some organ which plays the part of a kidney in the crayfish; but the position of the structure, which there is much reason for regarding as the representative of the kidney, is so singular that very different interpretations have been put upon it.

On the basal joint of each antenna it is easy to see a small conical eminence with an opening on the inner side of its summit (fig. 18). The aperture $(x)$ leads by a short canal into a spacious sac, with extremely delicate walls $(s)$, which is lodged in the front part of the head, in front of and below the cardiac division of the stomach (cs). Beneath this, in a sort of recess, which corresponds with the epistoma, and with the base of the antenna, there is a discoidal body of a dull green colour, in shape somewhat like one of the fruits of the mallow, which is known as the green gland $(g g)$. The sac narrows below like a wide funnel, and the edges of its small end are continuous with the walls of the green gland; they surround an aperture which leads into the interior of the latter structure, and conveys its products into the sac, whence they are excreted by the opening in the antennary papilla. The green gland is said to contain a substance termed guanin (so named because it is found in the grano which is the accumulated 
excrement of birds), a nitrogenous body analogous in some respects to uric acid, but less highly oxidated;

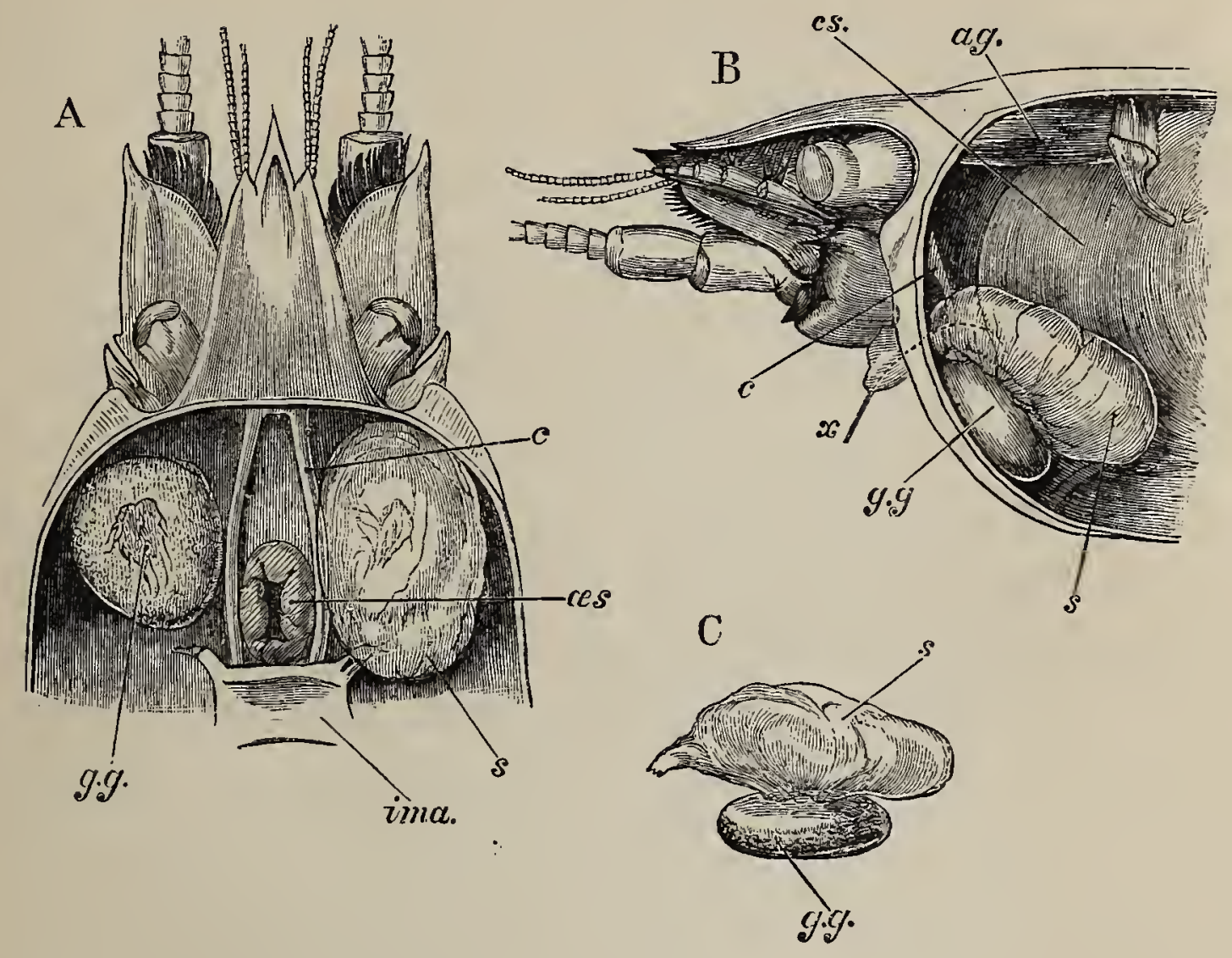

FIG. 18.-Astacus fluviatilis.-A, the anterior part of the body, with the dorsal portion of the carapace removed to show the position of the green glands ; B, the same, with the left side of the carapace removed; C, the green gland removed from the body (all $\times 2$ ). $a g$, left anterior gastric muscle ; $c$, circumœsophageal commissures; $c s$, cardiac portion of stomach ; $g g$, green gland, exposed in $\mathrm{A}$ on the left side by the removal of its sac; ima, intermaxillary or cephalic apodeme; $œ e, ~ œ s o p h a g u s$ seen in transverse section in A, the stomach being removed; $s$, sac of green gland; $x$, bristle passed from the aperture in the basal joint of the antenna into the sac.

and if this be the case, there can be little doubt that the green gland represents the kidney, and its secretion 
the urinary fluid, while the sac is a sort of urinary bladder.

Restricting our attention to the phenomena which have now been described, and to a short period in the life of the crayfish, the body of the animal may be regarded as a factory, provided with various pieces of machinery, by means of which certain nitrogenous and other matters are extracted from the animal and regetable substances which serve for food, are oxidated, and are then delivered out of the factory in the shape of carbonic acid gas, guanin, and probably some other products, with which we are at present unacquainted. And there is no doubt, that if the total amount of products given out could be accurately weighed against the total amount of materials taken in, the weight of the two would be found to be identical. To put the matter in its most general shape, the body of the crayfish is a sort of focus to which certain material particles converge, in which they move for a time, and from which they are afterwards expelled in new combinations. The parallel between a whirlpool in a stream and a living being, which has often been drawn, is as just as it is striking. The whirlpool is permanent, but the particles of water which constitute it are incessantly changing. Those which enter it, on the one side, are whirled around and temporarily constitute a part of its individuality; and as they leave it on the other side, their places are made good by new comers. 
Those who have seen the wonderful whirlpool, three miles below the Falls of Niagara, will not have forgotten the heaped-up wave which tumbles and tosses, a very embodiment of restless energy, where the swift stream hurrying from the Falls is compelled to make a sudden turn towards Lake Ontario. However changeful in the contour of its crest, this wave has been visible, approximately in the same place, and with the same general form, for centuries past. Seen from a mile off, it would appear to be a stationary hillock of water. Viewed closely, it is a typical expression of the conflicting impulses generated $b_{\vec{y}}$ a swift rush of material particles.

Now, with all our appliances, we cannot get within a good many miles, so to speak, of the crayfish. If we could, we should see that it was nothing but the constant form of a similar turmoil of material molecules which are constantly flowing into the animal on the one side, and streaming out on the other.

The chemical changes which take place in the body of the crayfish, are doubtless, like other chemical changes, accompanied by the evolution of heat. But the amount of heat thus generated is so small and, in consequence of the conditions under which the crayfish lives, it is so easily carried away, that it is practically insensible. The crayfish has approximately the temperature of the surrounding medium, and it is, therefore, reckoned among the cold-blooded animals.

If our investigation of the results of the process of 
86 THE PHYSIOLOGY OF THE COMMON CRAYFISH.

alimentation in a well-fed Crayfish were extended over a longer time, say a year or two, we should find that the products given out were no longer equal to the materials taken in, and the balance would be found in the increase of the animal's weight. If we inquired how the balance was distributed, we should find it partly in store, chiefly in the shape of fat; while, in part, it had been spent in increasing the plant and in enlarging the factory. That is to say, it would have supplied the material for the animal's growth. And this is one of the most remarkable respects in which the living factory differs from those which we construct. It not only enlarges itself, but, as we have seen, it is capable of executing its own repairs to a very considerable extent. 


\section{CHAPTER III.}

THE PHYSIOLOGY OF THE CRAYFISH-THE ILECHANISII BY WHICH THE LIVING ORGANISM ADJUSTS ITSELF TO SURROUNDING CONDITIONS AND REPRODUCES ITSELF.

IF the hand is brought near a vigorous crayfish, free to move in a large vessel of water, it will generally give a vigorous flap with its tail, and dart backwards out of reach; but if a piece of meat is gently lowered into the vessel, the crayfish will sooner or later approach and devour it.

If we ask why the crayfish behaves in this fashion, every one has an answer ready. In the first case, it is said that the animal is aware of danger, and therefore hastens away; in the second, that it knows that meat is good to eat, and therefore walks towards it and makes a meal. And nothing can seem to be simpler or more satisfactory than these replies, until we attempt to conceive clearly what they mean; and, then, the explanation, however simple it may be admitted to be, hardly retains its satisfactory character.

For example, when we say that the crayfish is "aware of danger," or "knows that meat is good to eat," what 


\section{THE PHYSIOLOGT OF THE COMMON CRAYFISH.}

do we mean by "being aware" and "knowing"? Certainly it camnot be meant that the crayfish says to himself, as we do, "This is dangerous," "That is nice;" for the crayfish, being devoid of language, has nothing to say either to himself or any one else. And if the crayfish has not language enough to construct a proposition, it is obviously out of the question that his actions should be guided by a logical reasoning process, such as that by which a man would justify similar actions. The crayfish assuredly does not first frame the syllogism, "Dangerous things are to be avoided; that hand is dangerous; therefore it is to be avoided;" and then act upon the conclusion thus logically drawn.

But it may be said that children, before they acquire the use of language, and we ourselres, long after we are familiar with conscious reasoning, perform a great variety of perfectly rational acts unconsciously. A child grasps at a sweetmeat, or cowers before a threatening gesture; before it can speak; and any one of us would start back from a chasm opening at our feet, or stoop to pick up a jewel from the ground, "without thinking about it." And, no doubt, if the crayfish has any mind at all, his mental operations must more or less resemble those which the human mind performs without giving them a spoken or unspoken verbal embodiment.

If we analyse these, we shall find that, in many cases, distinctly felt sensations are followed by a distinct desire to perform some act, which act is accordingly performed; 
while, in other cases, the act follows the sensation without one being aware of any other mental process; and, in yet others, there is no consciousness even of the sensation. As I wrote these last words, for example, I had not the slightest consciousness of any sensation of holding or guiding the pen, although my fingers were causing that instrument to perform exceedingly complicated movements. Moreover, experiments upon animals have proved that consciousness is wholly unnecessary to the carrying out of many of those combined movements by which the body is adjusted to varying external conditions.

Under these circumstances, it is really quite an open question whether a crayfish has a mind or not; moreover, the problem is an absolutely insoluble one, inasmuch as nothing short of being a crayfish would give us positive assurance that such an animal possesses consciousness; and, finally, supposing the crayfish has a mind, that fact does not explain its acts, but only shows that, in the course of their accomplishment, they are accompanied by phenomena similar to those of which we are aware in ourselves, under like circumstances.

So we may as well leave this question of the crayfish's mind on one side for the present, and turn to a more profitable investigation, namely, that of the order and connexion of the physical phenomena which intervene between something which happens in the neighbourhood of the animal and that other something which responds to it, as an act of the crayfish. 
Whatever else it may be, this animal, so far as it is acted upon by bodies around it and reacts on them, is a piece of mechanism, the internal works of which give rise to certain movements when it is affected by particular external conditions; and they do this in virtue of their physical properties and connexions.

Every movement of the body, or of any organ of the body, is an effect of one and the same cause, namely, muscular contraction. Whether the crayfish swims or walks, or mores its antennæ, or seizes its prey, the immediate cause of the movements of the parts which bring about, or constitute, these bodily motions is to be sought in a change which takes place in the flesh, or muscle, which is attached to them. The change of place which constitutes any movement is an effect of a previous change in the disposition of the molecules of one or more muscles; while the direction of that movement depends on the connexions of the parts of the skeleton with one another, and of the muscles with them.

The muscle of the crayfish is a clense, white substance; and if a small portion of it is subjected to examination it will be found to be very easily broken up into more or less parallel bundles of fine fibres. Each of these fibres is generally found to be ensheathed in a fine transparent membrane, which is called the sarcolemma, within which is contained the proper substance of the muscle. When quite fresh and living, this substance is soft and 
semi-fluid, but it hardens and becomes solid immediately after death.

Examined, with high magnifying powers, in this
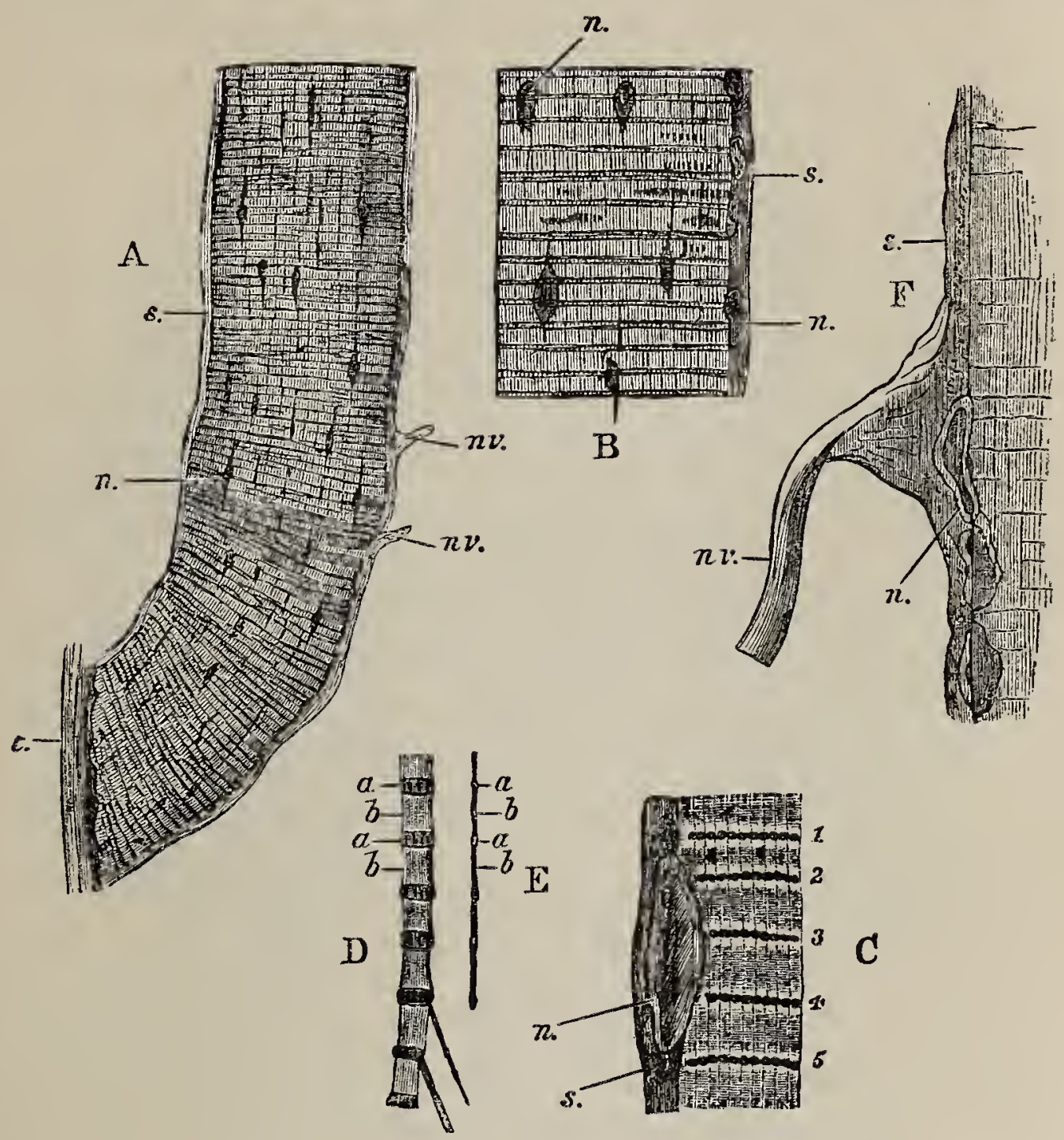

Fig. 19.-Astacus fluviatilis.-A, a single muscular fibre ; transverse diameter ${ }_{11}^{1}$ th of an inch; B, a portion of the same more highly magnified; $\mathrm{C}$, a smaller portion still more highly magnified; $\mathrm{D}$ and $\mathrm{E}$, the splitting up of a part of fibre into fibrillæ; $\mathrm{F}$, the connexion of a nervous with a muscular fibre which has been treated with acetic acid. $a$, darker, and $b$, clearer portions of the fibrillæ; $n$, nucleus of sarcolemma; $n v$, nerve fibre; $s$, sarcolemma; $t$, tendon; $1-5$, successive dark bands answering to the darker portions, $a$, of each fibrilla. 
92 THE PHYSIOLOGY OF THE COMMON CRAYFISH.

condition, the muscle-substance appears marked by very regular transverse bands, which are alternately opaque and transparent; and it is characteristic of the group of animals to which the crayfish belongs that their musclesubstance has this striped character in all parts of the body.

A greater or less number of these fibres, united into one or more bundles, constitutes a muscle; and, except when these muscles surround a cavity, they are fixed at each end to the hard parts of the skeleton. The attachment is frequently effected by the intermediation of a clense, fibrous, often chitinous, substance, which constitutes the tendon (fig. 19. A; t) of the muscle.

The property of the living muscle, which enables it to be the cause of motion, is this : Every muscular fibre is capable of suddenly changing its dimensions, in such a manner that it shortens and becomes proportionately thicker. Hence the absolute bulk of the fibre remains practically unchanged. From this circumstance, muscular contraction, as the change of form of a muscle is called, is radically different from the process which commonly goes by the same name in other things, and which involves a diminution of bulk.

The contraction of muscle takes place with great force, and, of course, if the parts to which its ends are fixed are both free to move, they are brought nearer at the moment of contraction: if one only is free to move that is approximated to the fixed part; and if the muscular 
fibre surrounds a cavity, the cavity is lessened when the muscle contracts. This is the whole source of motor power in the crayfish machine. The results produced by the exertion of that power depend upon the manner
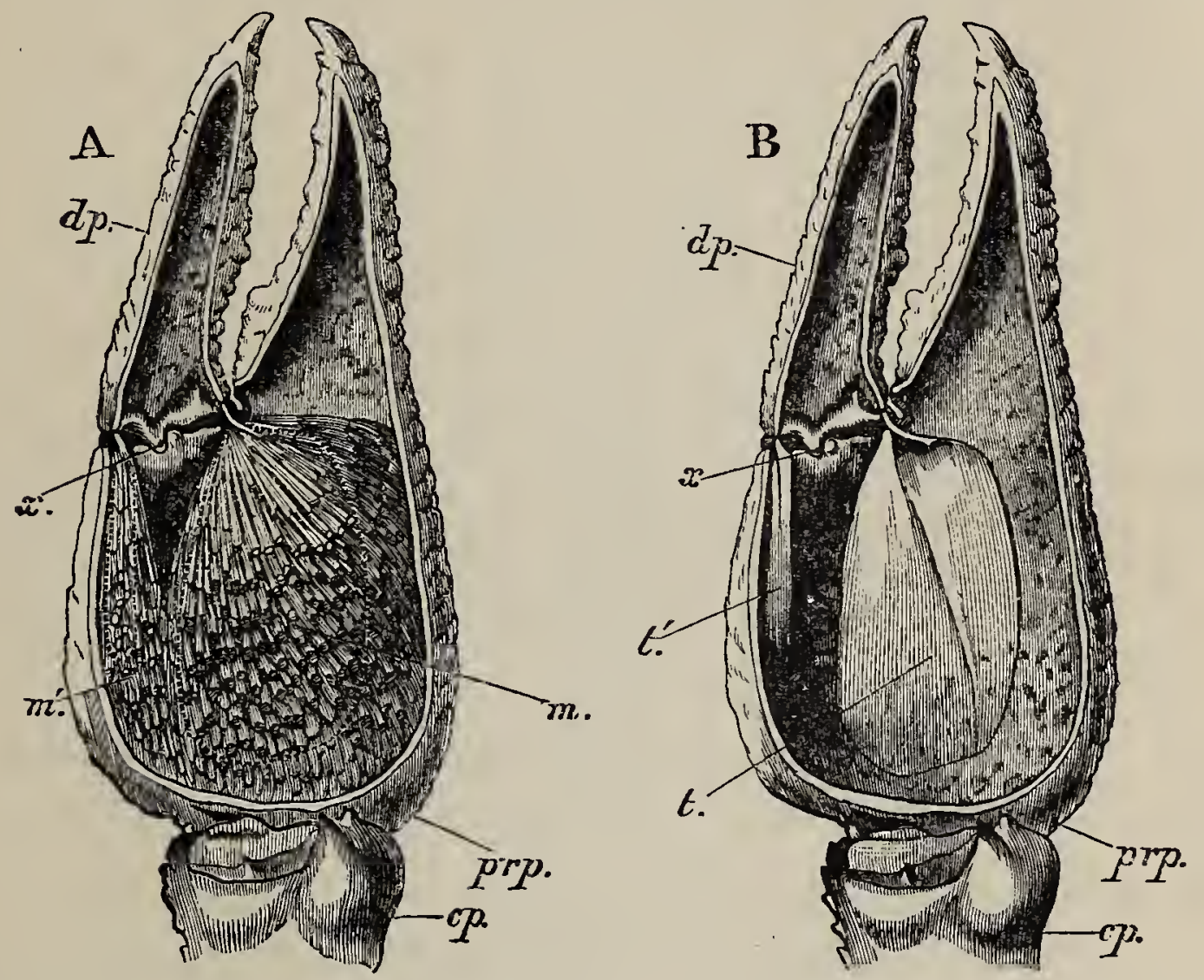

FIG. 20.-Astacus fluviatilis.-The chela of the forceps, with one side cut away to show, in $A$, the muscles, in B, the tendons ( $\times 2$ ). $c p$, carpopodite ; $p r p$, propodite ; $d p$, dactylopodite ; $m$, adductor muscle; $m^{\prime}$, abductor muscle; $t$, tendon of adductor muscle; $t$, tendon of abductor muscle; $x$, hinge.

in which the parts to which the muscles are attached are connected with one another.

One example of this has already been given in the curious mechanism of the gastric mill. Another may be found in the chela which terminates the forceps. If the 
94 THE PHYSIOLOGY OF THE COMMON CRAYFISH.

articulation of the last joint (fig. $20, d p$ ) with the one which precedes it ( $p r p)$ is examined, it will be found that the base of the terminal segment $(d p)$ turns on two hinges $(x)$, formed by the hard exoskeleton and situated at opposite points of the diameter of the base, on the penultimate segment; and these hinges are so disposed that the last joint can be moved only in one plane, to or from the produced angle of the penultimate segment ( $p r p$ ), which forms the fixed claw of the chela. Between the hinges, on both the inner and the outer sides of the articulation, the exoskeleton is "soft and flexible, and allows the terminal segment to play easily through a certain arc. It is by this arrangement that the direction and the extent of the motion of the free claw of the chela are determined. The source of the motion lies in the muscles which occupy the interior of the enlarged penultimate segment of the limb. Two muscles, one of very great size $(m)$, the other smaller $\left(m^{\prime}\right)$, are fastened by one end to the exoskeleton of this segment. The fibres of the larger muscle converge to be fixed into the two sides of a long flat process of the chitinous criticula, on the inner sicle of the base of the terminal segment, which serves as a tendon $(t)$; while those of the smaller muscle are similarly attached to a like process which proceeds from the outer side of the base of the terminal segment $\left(t^{\prime}\right)$. It is obvious that, when the latter muscle shortens it must move the apex of the terminal segment $(d p)$ away from the end of the fixed claw; while, 
when the former contracts, the end of the terminal segment is brought towards that of the fixed claw.

A living crayfish is able to perform very varied movements with its pincers. When it swims backwards, these limbs are stretched straight out, parallel with one another, in front of the head; when it walks, they are usually carried like arms bent at the elbow, the "forearm" partly resting on the ground; on being irritated, the crayfish sweeps the pincers round in any direction to grasp the offending body; when prey is seized, it is at once conveyed, with a circular motion, towards the region of the mouth. Nevertheless, these very varied actions are all brought about by a combination of simple flexions and extensions, each of which is effected in the exact order, and to the exact extent, needful to bring the chela into the position required.

The skeleton of the stem of the limb which bears the chela is, in fact, divided into four moveable segments; and each of these is articulated with the segments on each side of it by a hinge of just the same character as that which connects the moveable claw of the chela with the penultimate segment, while the basal segment is similarly articulated with the thorax.

If the axes of all these articulations * were parallel, it is obvious that, though the limb might be moved as a whole through a considerable arc, and might be bent in various

* By axis of the articulation is meant a line drawn through the pair of hinges which constitute it. 
degrees, yet all its movements would be limited to one plane. But, in fact, the axes of the successive articulations are nearly at right angles to one another; so that, if the segments are successively either extended or flexed, the chela describes a very complicated curve; and by rarying the extent of flexion or extension of each segment, this curve is susceptible of endless variation. It would probably puzzle a good mathematician to say exactly what position should be given to each segment, in order to bring the chela from any given position into any other; but if a lively crayfish is incautiously seized, the experimenter will find, to his cost, that the animal solves the problem both rapidly and accurately.

The mechanism by which the retrograde swimming of the crayfish is effected, is no less easily analysed. The apparatus of motion is, as we have seen, the abdomen, with its terminal five-pointed flapper. The rings of the abdomen are articulated together by joints (fig. 21, x) situated a little below the middle of the height of the rings, at opposite ends of transverse lines, at right angles to the long axis of the abdomen.

Each ring consists of a dorsal, arched portion, called the tergum (fig. 21 ; fig. 36, p. $142, t$. XIX), and a nearly flat ventral portion, which is the sternum (fig. 36, st. XIX). Where these two join, a broad plate is sent down on each side, which overlaps the bases of the abdominal appendages, and is known as the pleuron (fig. 36, pl. XIX). 
The sterna are all very narrow, and are connected together by wide spaces of flexible exoskeleton.

When the abdomen is made straight, it will be found that these intersternal membranes are stretched as far as they will yield. On the other hand. when the abdomen

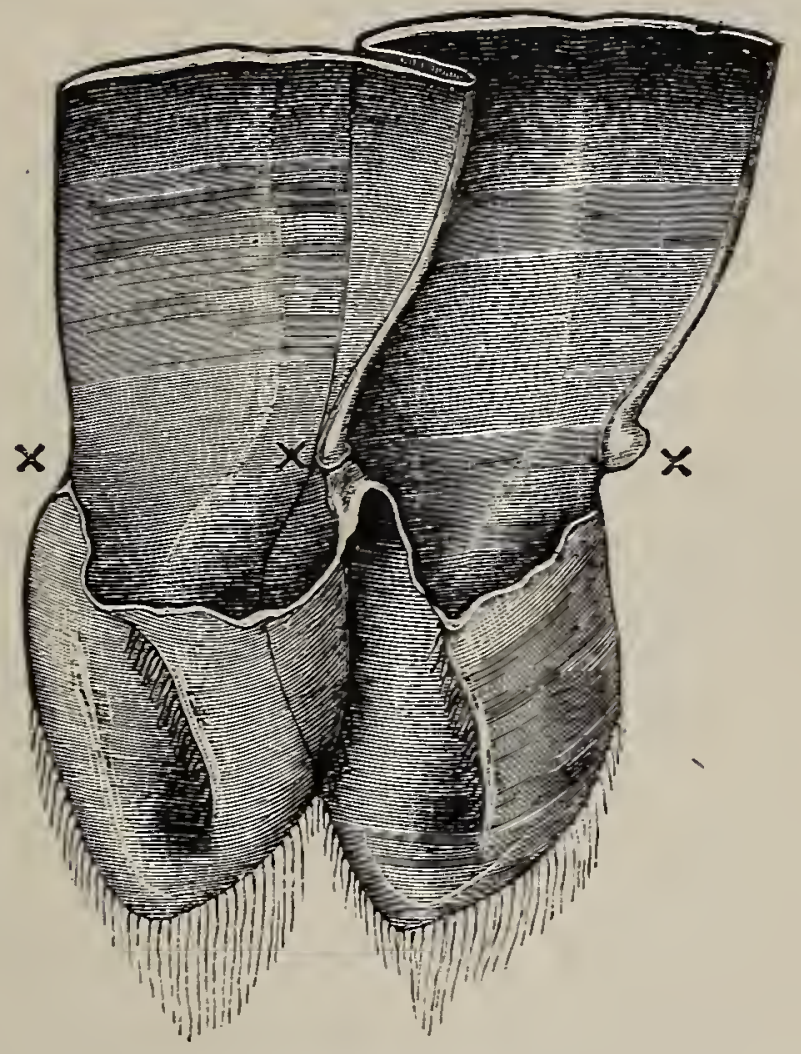

EIG. 21.-Astacus furiatilis.-Two of the abdominal somites, in vertical section, seen from the inner side, to show $x, x$, the hinges by which they are articulated with one another $(x 3)$. The anterior of the two somites is that to the right of the figure.

is bent up as far as it will go, the sterna come close together, and the intersternal membranes are folded.

The terga are very broad; so broad, in fact, that each orerlaps its successor, when the abdomen is straightened or extended, for nearly half its length in the middle line; and the overlapped surface is smooth, convex, and 
marked off by a transverse groove from the rest of the tergum as an articular facet. The front edge of the articular facet is continued into a sheet of flexible cuticula, which turns back, and passes as a loose fold to the hinder edge of the overlapping tergum (fig. 21). This tergal interarticular membrane allows the terga to move as far as they can go in flexion; whilst, in extreme extension, they are but slightly stretched. But, even if the intersternal membranes presented no obstacle to excessive extension of the abdomen, the posterior free edge of each tergum fits into the groove behind the facet in the next in such a manner, that the abdomen cannot be made more than very slightly concave upwards without breaking.

Thus the limits of motion of the abdomen, in the vertical direction, are from the position in which it is straight, or has even a very slight upward concavity, to that in which it is completely bent upon itself, the telson being brought under the bases of the hinder thoracic limbs. No lateral movement between the somites of the abdomen is possible in any of its positions. For, when it is straight, lateral movement is hindered not only by the extensive overlapping of the terga, but also by the manner in which the hinder edges of the pleura of each of the four middle somites overlap the front edges of their successors. The pleura of the second somite are much larger than any of the others, and their front edges overlap the small pleura of the first abdominal somite; and when the abdomen is much flexed, these pleura even 
THE EXTENSORS AND FLEXORS OF THE ABDOMEN. 99

ride over the posterior edges of the branchiostegites. In the position of extension, the overlap of the terga is great, while that of the pleura of the middle somites is small. As the abdomen passes from extension to flexion, the overlap of the terga of course diminishes; but any decrease of resistance to lateral strains which may thus arise, is compensated by the increasing overlap of the pleura, which reaches its maximum when the abdomen is completely flexed.

It is obvious that longitudinal muscular fibres fixed into the exoskeleton, above the axes of the joints, must bring the centres of the terga of the somites closer together, when they contract; while muscular fibres attached below the axes of the joints must approximate the sterna. Hence, the former will give rise to extension, and the latter to flexion, of the abdomen as a whole.

Now there are two pairs of very considerable muscles disposed in this manner. The dorsal pair, or the extensor's of the abdomen (fig. 22, e.m), are attached in front to the side walls of the thorax, thence pass backwards into the abdomen, and divide into bundles, which are fixed to the inner surfaces of the terga of all the somites. The other pair, or the flexors of the abdomen ( $f . m)$ constitute a very much larger mass of muscle, the fibres of which are curiously twisted, like the strands of a rope. The front end of this double rope is fixed to a series of processes of the exoskeleton of the thorax, called apodemata, some of which roof over the sternal blood-sinuses 


\section{THE PHYSIOLOGY OF THE COMMON CRAYFISH.}

and the thoracic part of the nerrous system; while, in the abdomen, its strands are attached to the sternal exoskeleton of all the somites and extend, on each side of the rectum, to the telson.

When the exoskeleton is cleaned by maceration, the

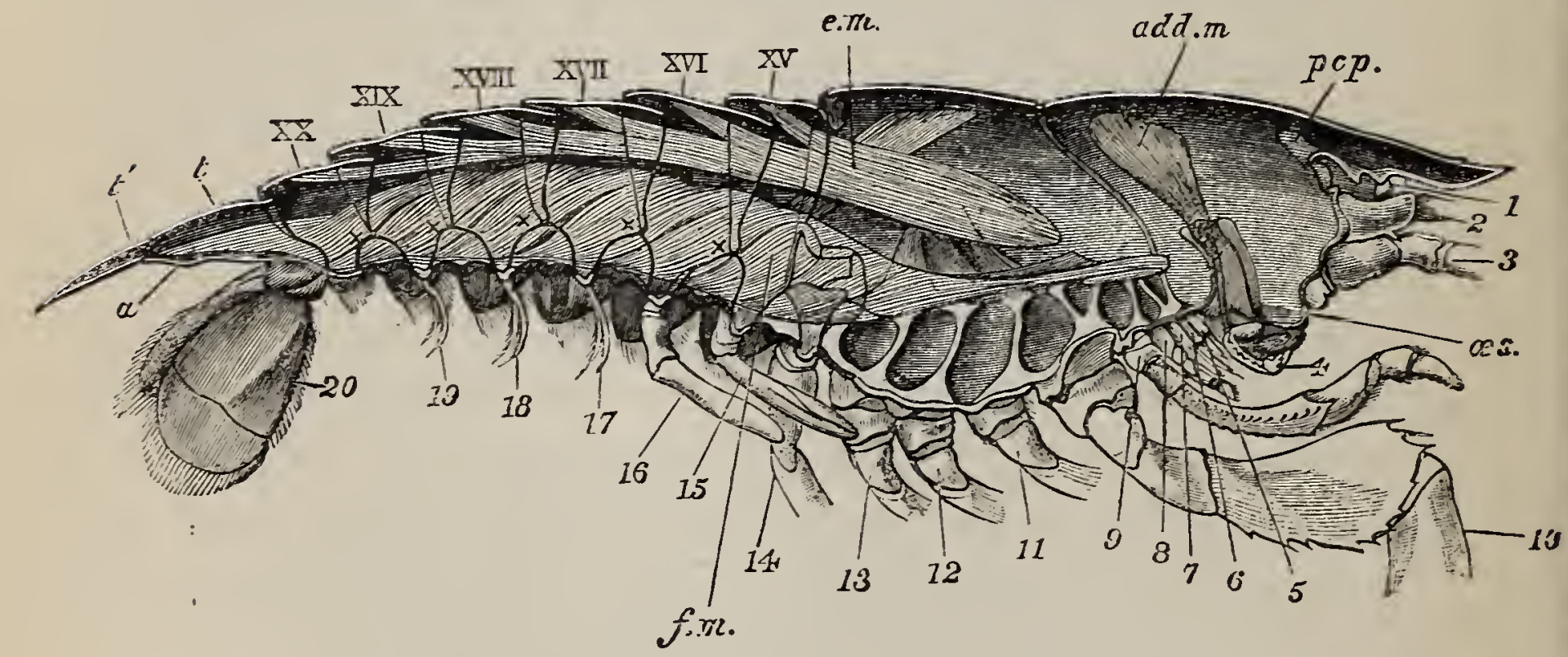

FIG. 22.-Astacus furiatilis.-A longitudinal section of the body to show the principal muscles and their relations to the exoskeleton (nat. size). $a$, the vent; add.m, adductor muscle of mandible; e.m, extensor, and $f . m$, flexor muscle of abdomen ; ${ }^{\circ} s$, œsophagus ; $p c p$, procephalic process; $t, t^{\prime}$, the trio segments of the telson; $x v-x x$, the abdominal somites; $1-20$, the appendages; $x, x$, hinges between the successive abdominal somites.

abdomen has a slight curve, dependent upon the form and the degree of elasticity possessed by its different parts; and, in a living crayfish at rest, it will be observed that the curvature of the abdomen is still more marled. Hence it is ready either for extension or for flexion.

A sudden contraction of the flexor muscles instantly increases the rentral curvature of the abdomen, and 
throws the tail fin, the two side lobes of which are spread out, forwards; while the body is propelled backwards by the reaction of the water against the stroke. Then the flexor muscles being relaxed, the extensor muscles come into play; the abdomen is straightened, but less violently and with a far weaker stroke on the water, in consequence of the less strength of the extensors and of the folding up of the lateral plates of the fin, until it comes into the position requisite to give full force to a new downward and forward stroke. The tendency of the extension of the abdomen is to drive the body forward; but from the comparative wealness and the obliquity of its stroke, its practical effect is little more than to check the backward motion conferred upon the body by the flexion of the abdomen.

Thus, every action of the crayfish, which involves motion, means the contraction of one or more muscles. But what sets muscle contracting? A muscle freshly removed from the body may be made to contract in various ways, as by mechanical or chemical irritation, or by an electrical shock; but, under natural conditions, there is only one cause of muscular contraction, and that is the activity of a nerve. Every muscle is supplied with one or more nerves. These are delicate threads which, on microscopic examination, prove to be bundles of fine tubular filaments, filled with an apparently structureless substance of gelatinous consistency, the nerve fibres 


\section{THE PHYSIOLOGY OF THE COMMON CRAYFISH.}

(fig. 23). The nerve bundle which passes to a muscle breaks up into smaller bundles and, finally, into separate fibres, each of which ultimately terminates by becoming continuous with the substance of a muscular fibre fig. 19, F.) Now the peculiarity of a muscle nerve, or motor nerve, as it is called, is that irritation of the nerve fibre at any part of its length, howerer distant from the muscle,

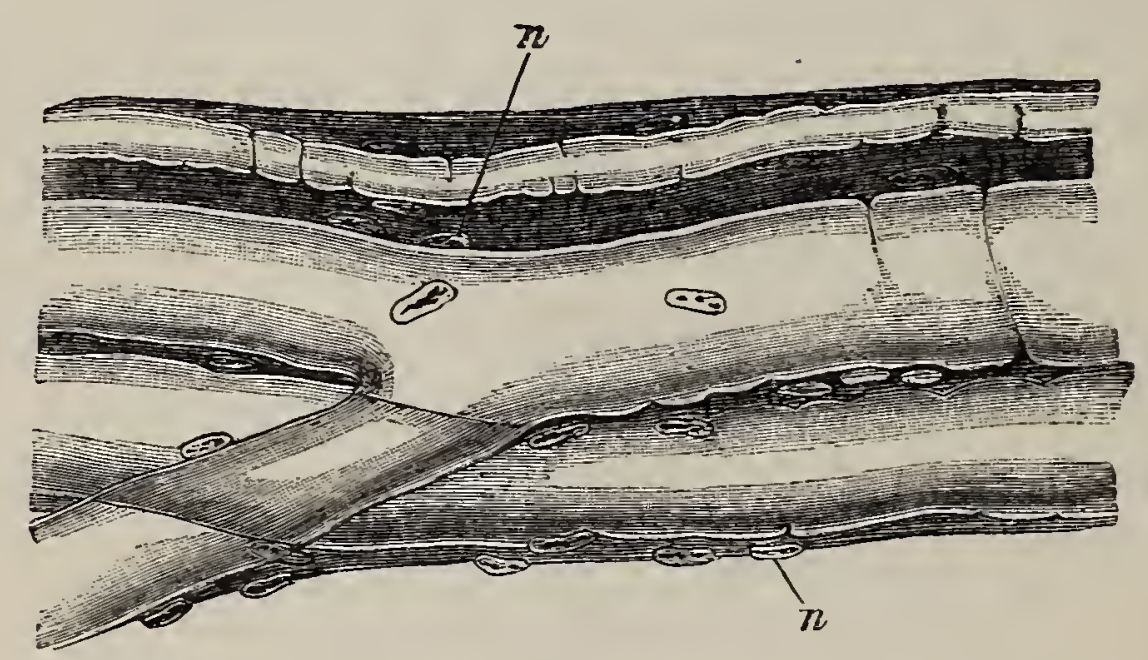

F1G. 23.-Astacus furiatilis.-Three nerve fibres, with the connective tissue in which they are imbedded. (Magnified about 250 diameters.) n, nuclei.

brings about muscular contraction, just as if the muscle itself were irritated. A change is produced in the molecular condition of the nerve at the point of irritation; and this change is propagated along the nerve, until it reaches the muscle, in which it gives rise to that change in the arrangement of its molecules, the most obvious effect of which is the sudden alteration of form which we call muscular contraction.

If we follow the course of the motor nerves in a 
direction away from the muscles to which they are distributed, they will be found, sooner or later, to terminate in ganglia (fig. 24 A. gl.c; fig. 25, gn. 1-13.) A ganglion is a body which is in great measure composed of

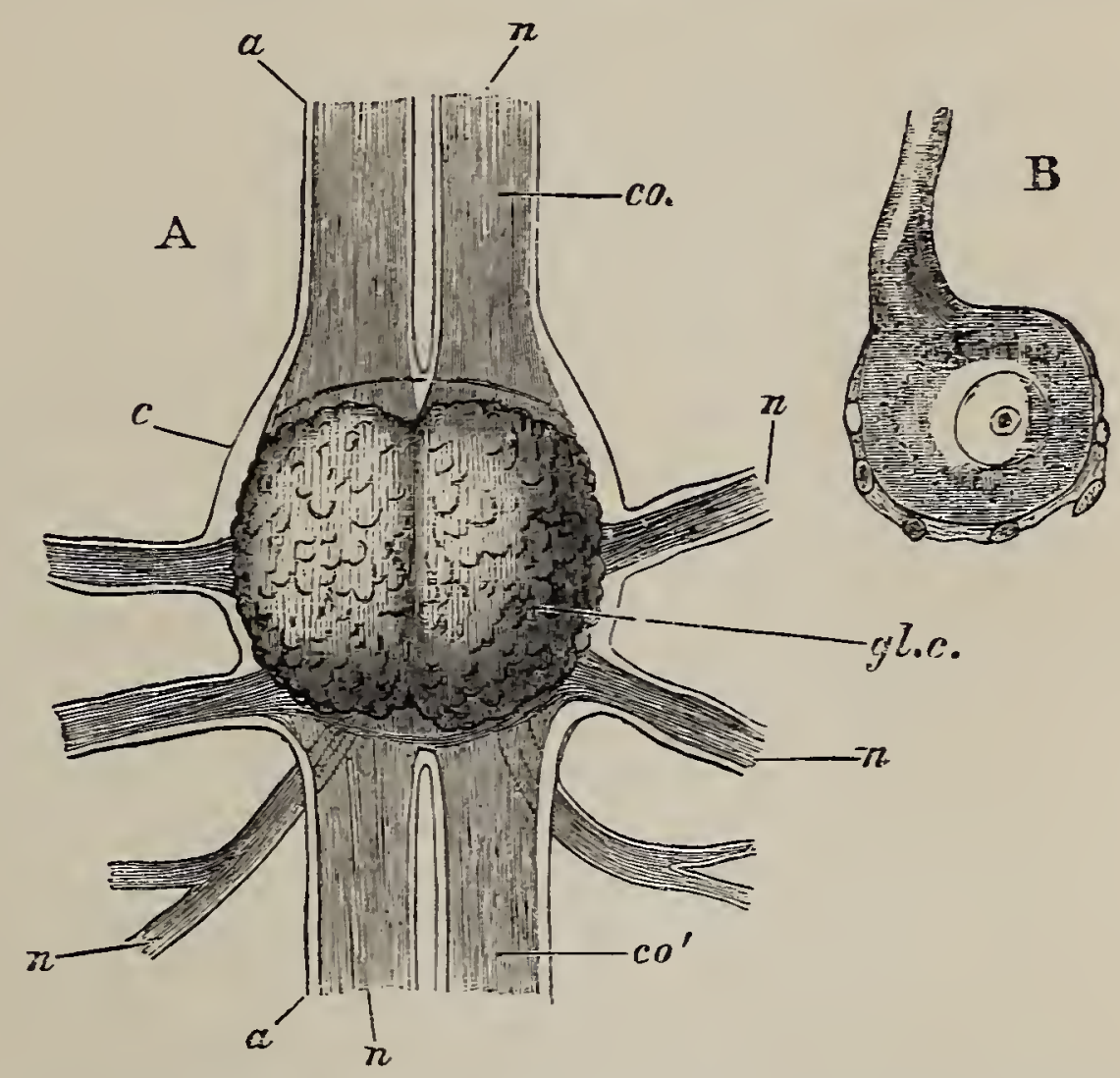

FIG. 24.-Astacus fluriatilis. -A, one of the (double) abdominal ganglia, with the nerves connected with it ( $\times 25)$; B, a nerve cell or ganglionic corpuscle $(\times 250)$. $a$, sheath of the nerves; $c$, sheath of the ganglion ; $c o, c o^{\prime}$, commissural cords connecting the ganglia with those in front, and those behind them. gl.c. points to the ganglionic corpuscles of the ganglia; $n$, nerve fibres.

nerve fibres; but, interspersed among these, or disposed around them, there are peculiar structures, which are termed ganglionic corpuscles, or nerve cells (fig. 24, B.) These are nucleated cells, not unlike the epithelial cells which have been already mentioned, but which are larger 


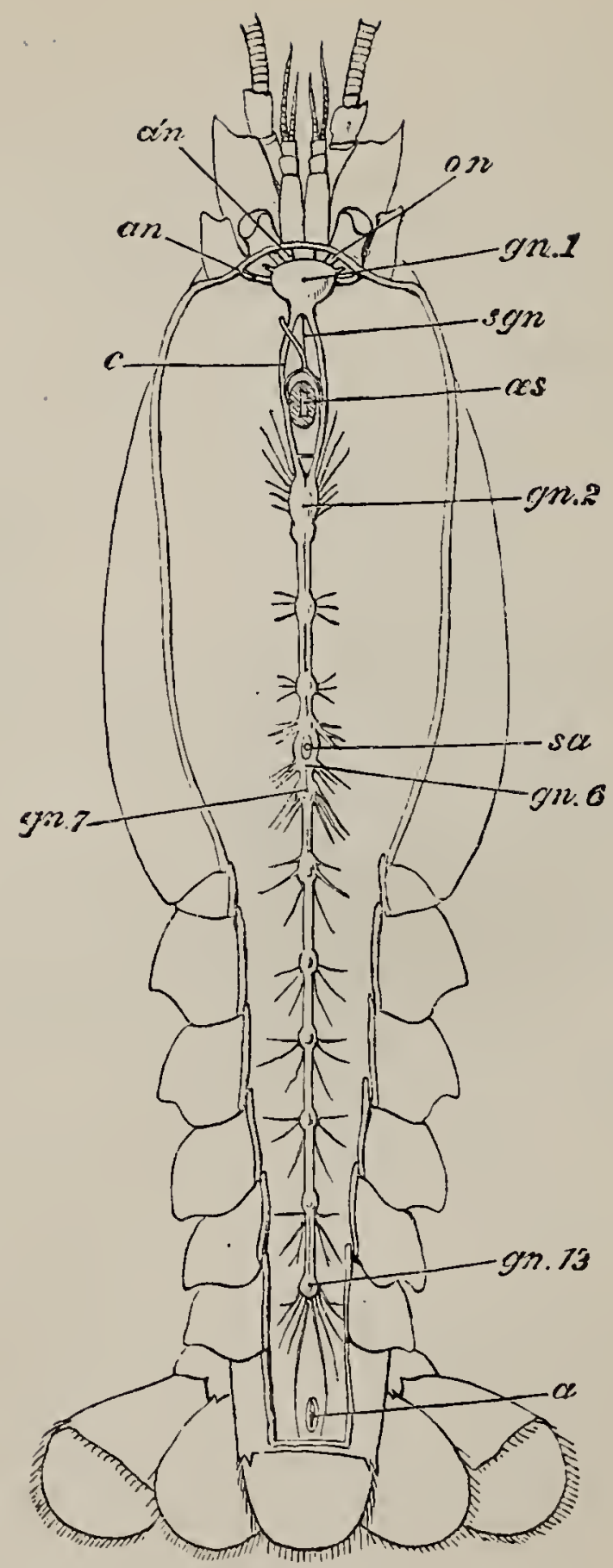

Frg. 25.-Astacus fluviatilis.-The central nervous system seen from above (nat. size). $a$, vent ; $a n$, antennary nerve; $a^{\prime} n$, antennulary nerve ; $c$, circumœsophageal commissures ; gn. 1, supraœsophageal ganglion; $g n .2$, infracesophageal ganglion; $g n .6$, fifth thoracic ganglion; $g n .7$, last thoracic ganglion; $g n .13$, last abdominal ganglion ; $a s$, œsophagus in cross section; on, optic nerve; $s a$, sternal artery in cross section ; $s g n$, stomatogastric nerve. 
and often give off one or more processes. These processes, under favourable circumstances, can be traced into continuity with nerve fibres.

The chief ganglia of the crayfish are disposed in a longitudinal series in the middle line of the ventral aspect of the body close to the integument (fig. 25). In the abdomen, for example, six ganglionic masses are readily observed, one lying over the sternum of each somite, connected by longitudinal bands of nerre fibres; and giving off branches to the muscles. On careful examination, the longitudinal connecting bands, or commissures (fig. 24, co), are seen to be double, and each. mass appears slightly bilobed. In the thorax, there are six, larger, double ganglionic masses, likewise connected by double commissures ; and the most anterior of these, which is the largest (fig. 25, gn. 2), is marked at the sides by notches, as if it were made up of several pairs of ganglia, run together into one continuous whole. In front of this, two commissures (c) pass forwards, separating widely, to give room for the gullet (ces), which passes between them; while in front of the gullet, just behind the eyes, they unite with a transversely elongated mass of ganglionic substance (gn. 1), termed the brain, or cerebral ganglion.

All the motor nerves, as has been said, are traceable, directly or indirectly, to one or other of these thirteen sets of ganglia; but other nerves are given off from the ganglia, which cannot be followed into any muscle. In 


\section{THE PHYSIOLOGY OF THE COMMON CRAYFISH.}

fact, these nerres go either to the integument or to the organs of sense, and they are termed sensory nerves.

When a muscle is connected by its motor nerve with a ganglion, irritation of that ganglion will bring about the contraction of the muscle, as well as if the motor nerve itself were irritated. Not only so; but if a sensory nerve, which is in connexion with the ganglion, is irritated, the same effect is produced; moreover, the sensory nerve itself need not be excited, but the same result will take place, if the organ to which it is distributed is stimulated. Thus the nervous system is fundamentally an apparatus by which two separate, and it may be distant, parts of the body, are brought into relation with one another; and this relation is of such a nature, that a change of state arising in the one part is followed by the propagation of changes along the sensory nerve to the ganglion, and from the ganglion to the other part; where, if that part happens to be muscle, it produces contraction. If one end of a rod of wood, twenty feet long, is applied to a sounding-board, the sound of a tuning-fork held against the opposite extremity will be very plainly heard. Nothing can be seen to happen in the wood, and yet its molecules are certainly set vibrating, at the same rate as the tuning-fork vibrates; and when, after travelling rapidly along the rood, these vibrations affect the sounding-board, they give rise to vibrations of the molecules of the air, which reaching the ear, are converted into an audible note. So in the nerve tract: 
no apparent change is effected in it by the irritation at one end; but the rate at which the molecular change produced travels can be measured; and, when it reaches the muscle, its effect becomes visible in the change of form of the muscle. The molecular change would take place just as much if there were no muscle connected with the nerve, but it would be no more apparent to ordinary observation than the sound of the tuning-fork is audible in the absence of the sounding-board.

If the nervous system were a mere bundle of nerve fibres extending between sensory organs and muscles, every muscular contraction would require the stimulation of that special point of the surface on which the appropriate sensory nerve ended. The contraction of several muscles at the same time, that is, the combination of movements towards one end, would be possible only if the appropriate nerves were severally stimulated in the proper order, and every movement would be the direct result of external changes. The organism would be like a piano, which may be made to give out the most complicated harmonies, but is dependent for their production on the depression of a separate key for every note that is sounded. But it is obvious that the crayfish needs no such separate impulses for the performance of highly complicated actions. The simple impression made on the organs of sensation in the two examples with which we started, gives rise to a train of complicated and accurately coordinated muscular contractions. To carry the analogy 
IOS THE PHYSIOLOGY OF THE COMMON CRAYFISH.

of the musical instrument further, striling a single key gives rise, not to a single note, but to a more or less elaborate tune; as if the hammer struck not a single string, but pressed down the stop of a musical box.

It is in the ganglia that we must look for the analogue of the musical box. A single impulse conveyed by a sensory nerve to a ganglion, may give rise to a single muscular contraction, but more commonly it originates a series of such, combined to a definite end.

The effect which results from the propagation of an impulse along a nerve fibre to a ganglionic centre, whence it is, as it were, reflected along another nerve fibre to a muscle, is what is termed a reflex action. As it is by no means necessary that sensation should be a concomitant of the first impulse, it is better to term the nerve fibre which carries it afferent rather than sensory; and, as other phenomena besides those of molar motion may be the ultimate result of the reflex action, it is better to term the nerve fibre which transmits the reflected impulse efferent rather than motor.

If the nervous commissures between the last thoracic and the first abdominal ganglia are cut, or if the thoracic ganglia are destroyed, the crayfish is no longer able to control the movements of the abdomen. If the forepart of the body is irritated, for example, the animal malies no effort to escape by swimming backwards. Nevertheless, the abdomen is not paralysed, for, if it be irritated, it will flap rigorously. This is a case of pure 
reflex action. The stimulus is conveyed to the abdominal ganglia through afferent nerves, and is reflected from them, by efferent nerves, to the abdominal muscles.

But this is not all. Under these circumstances it will be seen that the abdominal limbs all swing backwards and forwards, simultaneously, with an even stroke; while the vent opens and shuts with a regular rhythm. Of course, these movements imply correspondingly regular alternate contractions and relaxations of certain sets of muscles; and these, again, imply regularly recurring efferent impulses from the abdominal ganglia. The fact that these impulses proceed from the abdominal ganglia, may be shown in two ways: first, by destroying these ganglia in one somite after another, when the movements in each somite at once permanently cease; and, secondly, by irritating the surface of the abdomen, when the movements are temporarily inhibited by the stimulation of the afferent nerves. Whether these movements are properly reflex, that is, arise from incessant new afferent impulses of unknown origin, or whether they depend on the periodical accumulation and discharge of nervous energy in the ganglia themselves, or upon periodical exhaustion and restoration of the irritability of the muscles, is unknown. It is sufficient for the present purpose to use the facts as evidence of the peculiar co-ordinative function of ganglia. The crayfish, as we have seen, avoids light; and the slightest touch of one of its antennæ gives rise to active motions of the whole body. In fact, the animal's posi- 
110 THE PHYSIOLOGY OF THE COMMON CRAYFISH.

tion and movements are largely determined by the influences received through the feelers and the eyes. These receive their nerves from the cerebral ganglia; and, as might be expected, when these ganglia are extirpated, the crayfish exhibits no tendency to get away from the light, and the feelers may not only be touched, but sharply pinched, without effect. Clearly, therefore, the cerebral ganglia serve as a ganglionic centre, by which the afferent impulses derived from the feelers and the eyes are transmuted into efferent impulses. Another very curious result follows upon the extirpation of the cerebral ganglia. If an uninjured crayfish is placed upon its back, it makes unceasing and well-directed efforts to turn over; and if everything else fails, it will give a powerful flap with the abdomen, and trust to the chapter of accidents to turn over as it darts back. But the brainless crayfish behaves in a very different way. Its limbs are in incessant motion, but they are "all abroad;" and if it turns over on one side, it does not seem able to steady itself, but rolls on to its back again.

If anything is put between the chelæ of an uninjured crayfish, while on its back, it either rejects the object at once, or tries to make use of it for leverage to turn over. In the brainless crayfish a similar operation gives rise to a very curious spectacle.* If the object, whatever it be

* My attention was first drawn to these phenomena by my friend Dr. M. Foster, F.R.S., to whom I had suggested the desirableness of an experimental study of the nerve physiology of the crayfish. 
-a bit of metal, or wood, or paper, or one of the animal's own antennæ-is placed between the chelæ of the forceps, it is at once seized by them, and carried backwards; the chelate ambulatory limbs are at the same time advanced, the object seized is transferred to them, and they at once tuck it between the external maxillipedes, which, with the other jaws, begin vigorously to masticate it. Sometimes the morsel is swallowed; sometimes it passes out between the anterior jaws, as if deglutition were difficult. It is very singular to observe that, if the morsel which is being conveyed to the mouth by one of the forceps is pulled back, the forceps and the chelate ambulatory limbs of the other side are at once brought forward to secure it. The movements of the limbs are, in short, adjusted to meet the increased resistance.

All these phenomena cease at once, if the thoracic ganglia are destroyed. It is in these, therefore, that the simple stimulus set up by the contact of a body with, for example, one of the forceps, is translated into all the surprisingly complex and accurately co-ordinated movements, which have been described. Thus the nervous system of the crayfish may be regarded as a system of co-ordinating mechanisms, each of which produces a certain action, or set of actions, on the receipt of an appropriate stimulus.

When the crayfish comes into the world, it possesses in its neuro-muscular apparatus certain innate poten- 


\section{THE PHYSIOLOGY OF THE COMNON CRAYFISH.}

tialities of action, and will exhibit the corresponding acts, under the influence of the appropriate stimuli. A large proportion of these stimuli come from without through the organs of the senses. The greater or less readiness of each sense organ to receive impulses, of the nerres to transmit them, and of the ganglia to give rise to combined impulses, is dependent at any moment upon the physical condition of these parts; and this, again, is largely modified by the amount and the condition of the blood supplied. On the other hand, a certain number of these stimuli are doubtless originated by changes within the various organs which compose the body, including the nerve centres themselves.

When an action arises from conditions developed in the interior of an animal's body, inasmuch as we cannot perceive the antecedent phenomena, we call such an action "spontaneous;" or, when in ourselves we are aware that it is accompanied by the idea of the action, and the desire to perform it, we term the act "voluntary." But, by the use of this language, no rational person intends to express the belief that such acts are uncaused or cause themselves. "Self-causation" is a contradiction in terms; and the notion that any phenomenon comes into existence without a cause, is equivalent to a belief in chance, which one may hope is, by this time, finally exploded.

In the crayfish, at any rate, there is not the slightest reason to doubt that every action has its definite physical 
cause, and that what it does at any moment would be as clearly intelligible, if we only knew all the internal and external conditions of the case, as the striking of a clock is to any one who understands clockwork.

The adjustment of the body to varying external conditions, which is one of the chief results of the working of the nervous mechanism, would be far less important from a physiological point of view than it is, if only those external bodies which come into direct contact with the organism * could affect it; though very delicate influences of this kind take effect on the nervous apparatus through the integument.

It is probable that the seta, or hairs, which are so generally scattered over the body and the appendages, are delicate tactile organs. They are hollow processes of the chitinous cuticle, and their cavities are continuous with narrow canals, which traverse the whole thickness of the cuticle, and are filled by a prolongation of the subjacent proper integument. As this is supplied with nerves, it is likely that fine nerve fibres reach the bases of the hairs, and are affected by anything whick stirs, these delicately poised levers.

* It may be said that, strictly speaking, only those external bodies which are in direct contact with the organism do affect it-as the vibrating ether, in the case of luminous bodies; the vibrating air or water, in the case of sonorous bodies; odorous particles, in the case of odorous bodies: but I have preferred the ordinary phraseology to a pedantically accurate periphrasis. 
There is much reason to believe that odorous bodies affect crayfish; but it is very difficult to obtain experi-

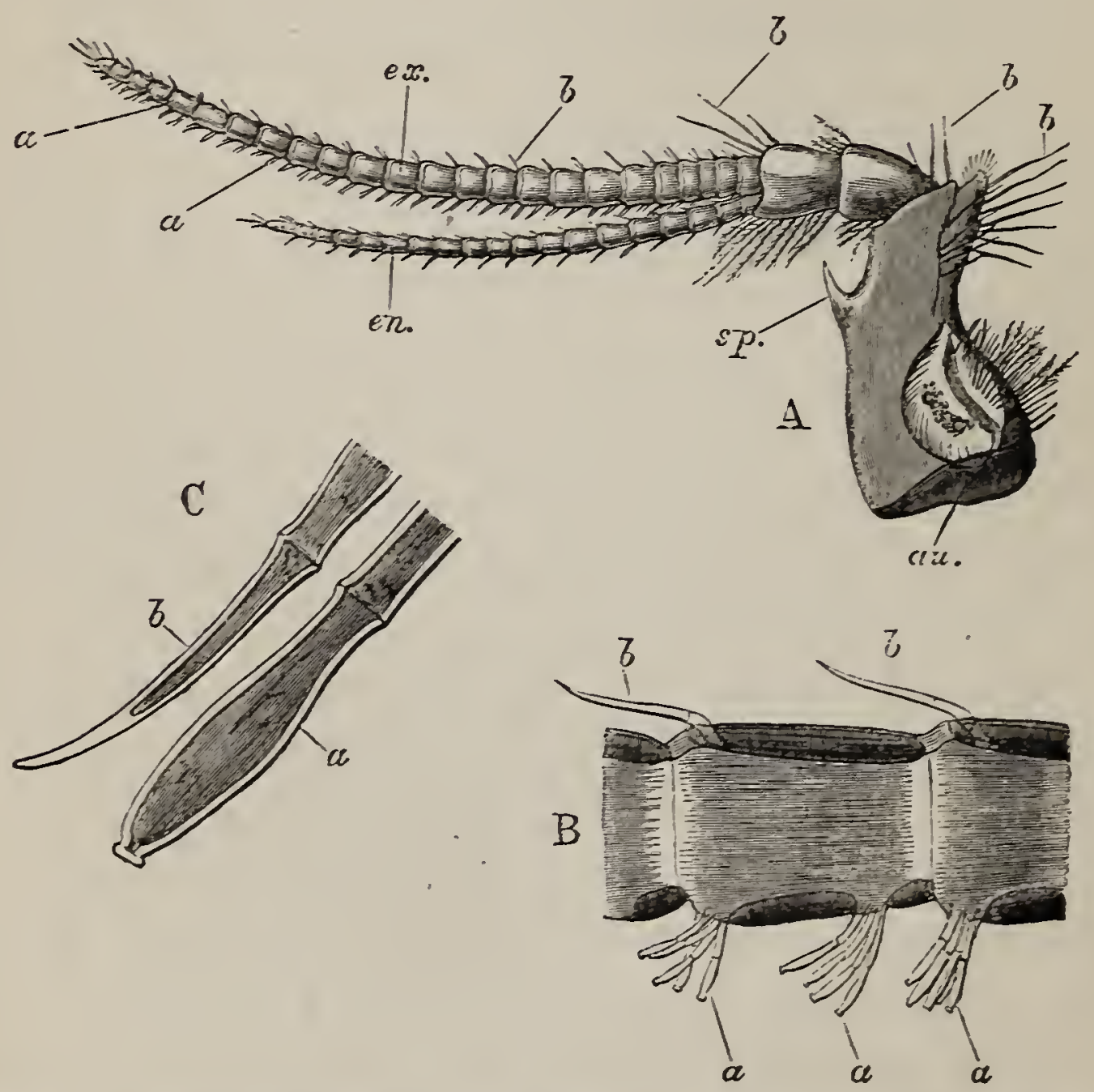

FIG. 26.-Astacus fluriatilis.-A, the right antennule seen from the inner side $(x 5)$; B, a portion of the exopodite enlarged; C, olfactory appendage of the exopodite; $a$, front view; $b$, side view $(\times 300)$; $a$, olfactory appendages; $a u$, auditory sac, supposed to be seen through the wall of the basal joint of the antennule; $b$, setx; $c n$, endopodite ; $e x$, exopodite; $s p$. spine of the basal joint.

mental eridence of the fact. Howerer, there is a good deal of analogical ground for the supposition that some peculiar structures, which are evidently of a sensory 
nature, developed on the under side of the outer branch of the antennule, play the part of an olfactory apparatus.

Both the outer (fig. $26 \mathrm{~A} . e x$ ) and the inner (en) branches of the antennule are made up of a number of delicate ring-like segments, which bear fine setæ $(b)$ of the ordinary character.

The inner branch, which is the shorter of the two, possesses only these setæ; but the under surface of each of the joints of the outer branch, from about the seventh or eighth to the last but one, is provided with two bundles of very curious appendages (fig. $27, \mathrm{~A}, \mathrm{~B}, \mathrm{C}, a$ ), one in front and one behind. These are rather more than 1-200th of an inch long, very delicate, and shaped like a spatula, with a rounded handle and a flattened somewhat curved blade, the end of which is sometimes truncated, sometimes has the form of a prominent papilla. There is a sort of joint between the handle and the blade, such as is found between the basal and the terminal parts of the ordinary setæ, with which, in fact, these processes entirely correspond in their essential structure. A soft granular tissue fills the interior of each of these problematical structures, to which Leydig, their discoverer, ascribes an olfactory function.

It is probable that the crayfish possesses something analogous to taste, and a very likely seat for the organ of this function is in the upper lip and the metastoma; but if the organ exists it possesses no structural peculiarities by which it can be identified. 
116 THE PHYSIOLOGY OF THE COMMON CRAYFISH.

There is no doubt, however, as to the special recipients of sonorous, and luminous vibrations; and these are of particular importance, as they enable the nervous machinery to be affected by bodies indefinitely remote from it, and to change the place of the organism in relation to such bodies.

Sonorous vibrations are enabled to act as the stimulants of a special nerve (fig. 25, $a^{\prime} n$ ) connected with the brain, by means of the very curious auditory sacs (fig. 26, A, au) which are lodged in the basal joints of the antennules.

Each of these joints is trihedral, the outer face being convex; the inner, applied to its fellow, flat; and the upper, on which the eyestalk rests, concave. On this upper face there is a narrow elongated oval aperture, the outer lip of which is beset with a flat brush of long close-set setæ, which lie horizontally over the aperture, and effectually close it. The aperture leads into a small sac (au) with delicate walls formed by a chitinous continuation of the general cuticula. The inferior and posterior wall of the sac is raised up along a curved line into a ridge which projects into its interior (fig. 27, A, r). Each side of this ridge is beset with a series of delicate setæ (as), the longest of which measures about $\frac{1}{30}$ th of an inch; they thus form a longitudinal band bent upon itself. These auditory sete project into the fluid contents of the sac, and their apices are for the most part imbedded in a gelatinous mass, which contains irregular particles of sand 
and sometimes of other foreign matter. A nerve $\left(n n^{\prime},\right)$ is distributed to the sac, and its fibres enter the bases of the hairs, and may be traced to their apices, where they end in peculiar elongated rod-like bodies (fig. 27, C). Here is an auditory organ of the simplest description.
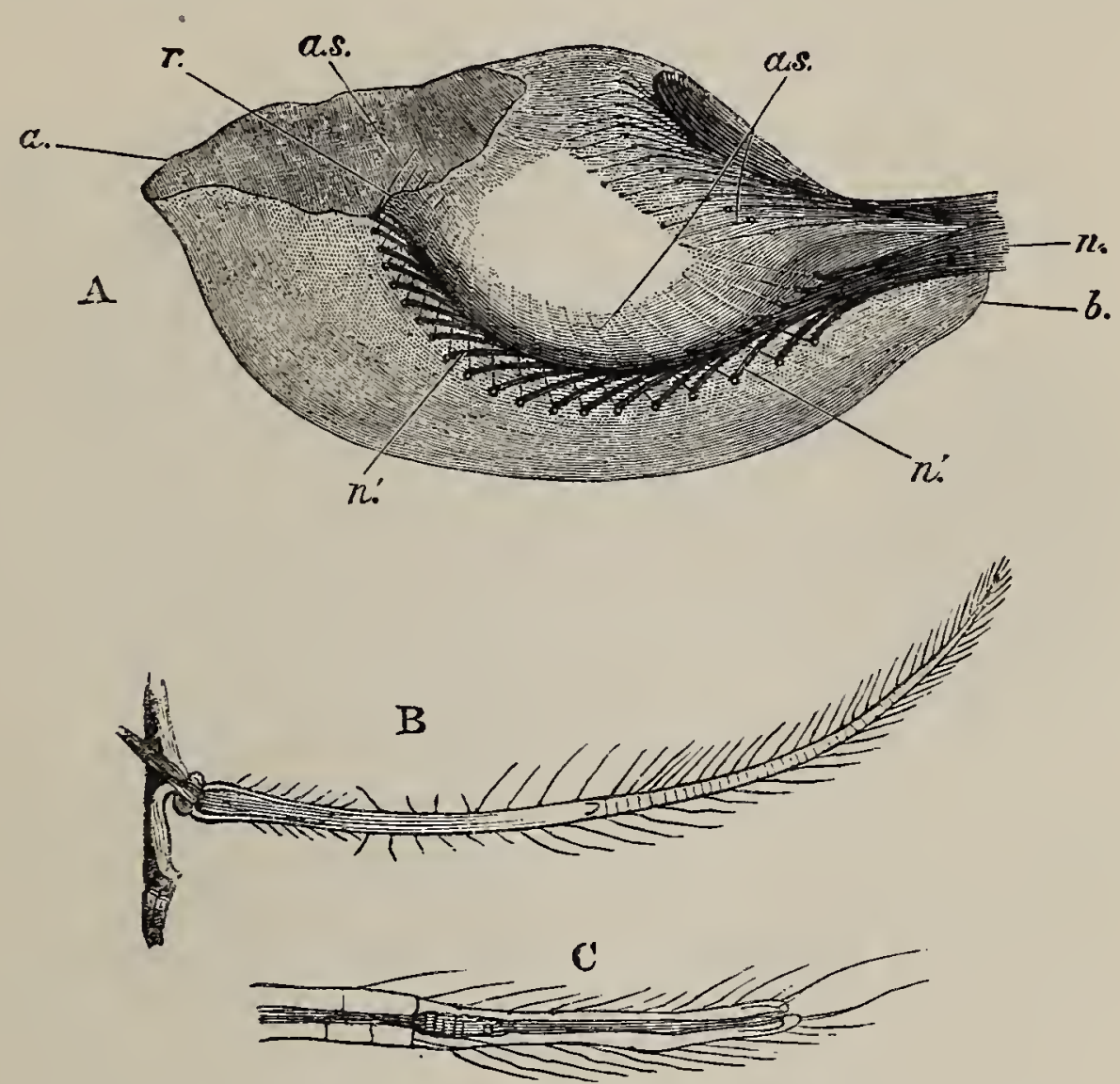

FIG. 27.-Astacus furiatilis. A, the auditory sac detached and seen from the outside $(\times 15)$; B, auditory hair $(\times 100)$; C, the distal extremity of the same more highly magnified. $a$, aperture of sac; as, auditory. setæ ; $b$, its inner or posterior extremity ; $n n$, nerves; $r$, ridge.

It retains, in fact, throughout life, the condition of a simple sac or involution of the integument, such as is that of the vertebrate ear in its earliest stage. 


\section{THE PHYSIOLOGY OF THE COMMON CRAYFISH.}

The sonorous vibrations transmitted through the water in which the crayfish lives to the fluid and solid contents of the auditory sac are taken up by the delicate hairs of the ridge, and give rise to molecular changes which traverse the auditory nerves and reach the cerebral ganglia.

The vibrations of the luminiferous ether are brought to bear upon the free ends of two large bundles of nerve fibres, termed the optic nerves (fig. 25, on), which proceed directly from the brain, by means of a highly complex eye. This is an apparatus, which, in part, sorts out the rays of light into as many very small pencils as there are separate endings of the fibres of the optic nerve, and, in part, serves as the medium by which the luminous vibrations are converted into molecular nerve changes.

The free extremity of the eyestall presents a convex, soft, and transparent surface, limited by an oval contour. The cuticle in this region, which is termed the cornea, (fig. 28,a), is, in fact, somewhat thinner and less distinctly laminated than in the rest of the eyestalk, and it contains no calcareous matter. But it is directly continuous with the rest of the exoskeleton of the eyestalk, to which it stands in somewhat the same relation as the soft integument of an articulation does to the adjacent hard parts.

The cornea is divided into a great number of minute, usually square facets, by faint lines, which cross it from side 
to side nearly at right angles with one another. A longitudinal section shows that both the horizontal and the vertical contours of the cornea are very nearly semicircular, and that the lines which mark off the facets merely arise from a slight modification of its substance between the facets. The outer contour of each facet forms part
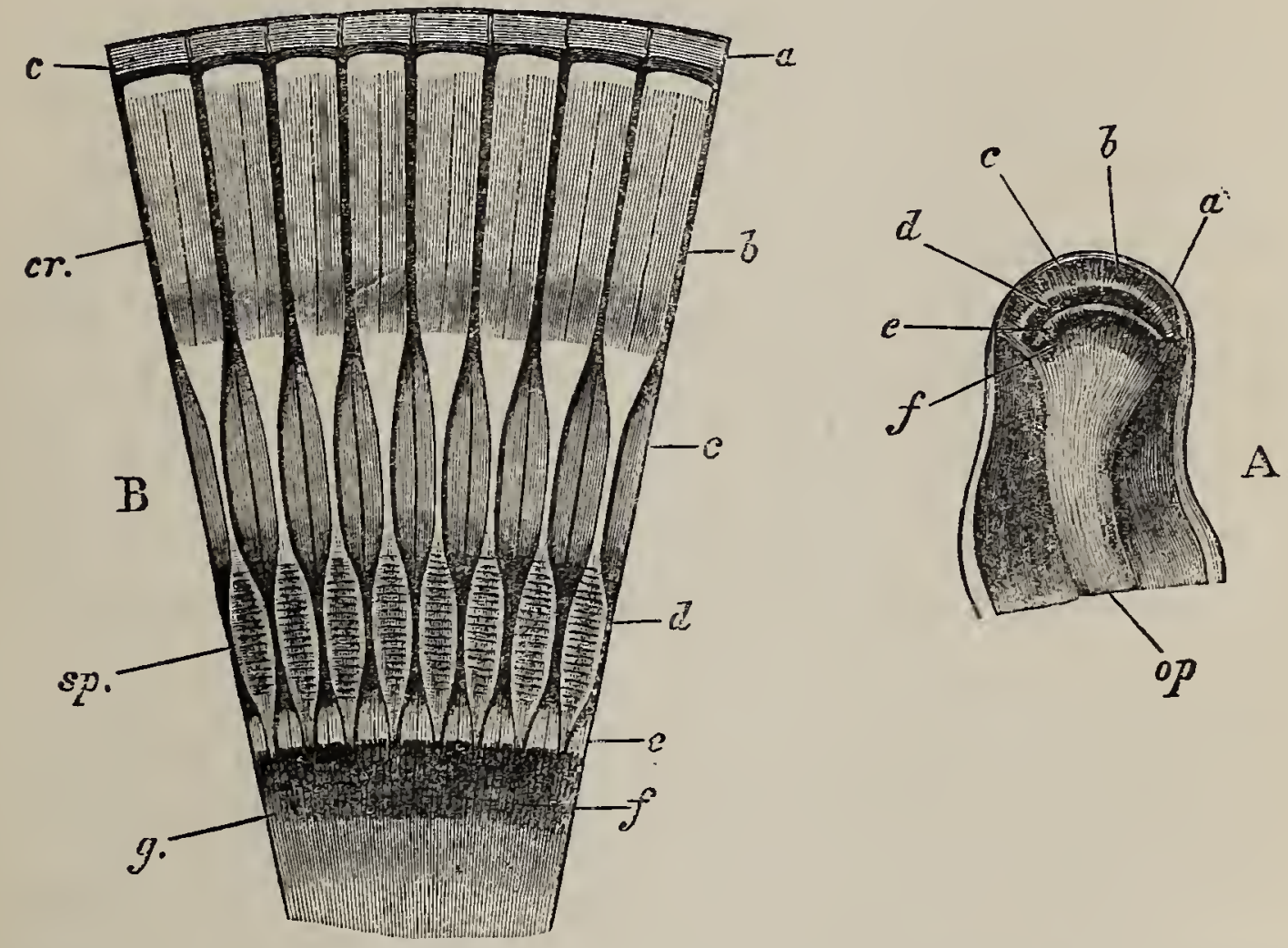

FIG. 28. - Astacus fluviatilis. $-\mathrm{A}$, a vertical section of the eye-stalk $(\times 6)$; B, a small portion of the same, showing the visual apparatus more highly magnified; $a$, cornea ; $b$, outer dark zone ; $c$, outer white zone; $d$, middle dark zone; $e$, inner white zone; $f$, inner dark zone ; $c r$, crystalline cones ; $g$, optic ganglion ; $o p$, optic nerve; $s p$, striated spindles.

of the general curvature of the outer face of the cornea; the inner contour sometimes exhibits a slight deviation 


\section{I20 THE PHYSIOLOGY OF THE COMMON CRAYFISH.}

from the general curvature of the inner face, but usually nearly coincides with it.

When a longitudinal or a transverse section is taken through the whole eyestalk, the optic nerve (fig. 28, A, $o p$ ) is seen to traverse its centre. At first narrow and cylindrical, it expands towards its extremity into a sort of bulb $(B, g)$, the outer surface of which is curved in correspondence with the inner surface of the cornea. The terminal half of the bulb contains a great quantity of dark colouring matter or pigment, and, in section, appears as what may be termed the inner clarl zone $(f)$. Outside this, and in connection with it, follows a white line, the inner white zone (e), then comes a middle dark zone $(d)$; outside this an outer pale band, which may be called the outer white zone $(c)$, and between this and the cornea $(a)$ is another broad band of dark pigment, the outer dark zone (b).

When viewed under a low power, by reflected light, this outer dark zone is seen to be traversed by nearly parallel straight lines, each of which starts from the boundary between two facets, and can be followed inwards through the outer white zone to the middle dark zone. Thus the whole substance of the eye between the outer surface of the bulb of the optic nerve and the inner surface of the cornea is marked out into as many segments as the cornea has facets; and each segment has the form of a wedge or slender pyramid, the base of which is four-sided, and is applied against the inner surface of 
one of the facets of the cornea, while its summit lies in the middle dark zone. Each of these visual pyramids consists of an axial structure, the visual rod, invested by a sheath. The latter extends inwards from the margin of each facet of the cornea, and contains pigment in two regions of its length, the intermediate space being devoid of pigment. As the position of the pigmented regions in relation to the length of the pyramid is always the same, the pigmented regions necessarily take the form of two consecutive zones when the pyramids are in their natural position.

The visual rod consists of two parts, an external crystalline cone (fig. $28, \mathrm{~B}, \mathrm{cr}$ ), and an internal striated spindle (sp). The crystalline cone consists of a transparent glassy-looking substance, which may be made to split up longitudinally into four segments. Its inner end narrows into a filament which traverses the outer white zone, and, in the middle dark zone, thickens into a foursided spindle-shaped transparent body, which appears transversely striated. The inner end of this striated spindle narrows again, and becomes continuous with nerve fibres which proceed from the surface of the optic bulb.

The exact mode of connection of the nerve-fibres with the visual rods is not certainly made out, but it is probable that there is direct continuity of substance, and that each rod is really the termination of a nerve fibre.

Eyes having essentially the same structure as that of 


\section{THE PHYSIOLOGY OF THE COMMON CRAYFISH.}

the crayfish are very widely met with among Crustacea and Insecta, and are commonly known as compound eyes. In many of these animals, in fact, when the cornea is removed, each facet is found to act as a separate lens; and when proper arrangements are made, as many distinct pictures of external objects are found behind it as there are facets. Hence the notion suggested itself that each visual pyramid is a separate eye, similar in principle of construction to the human eye, and forming a picture of so much of the external world as comes within the range of its lens, upon a retina supposed to be spread out on the surface of the crystalline cone, as the human retina is spread over the surface of the vitreous humour.

But, in the first place, there is no evidence, nor any probability, that there is anything corresponding to a retina on the outer face of the crystalline cone; and secondly, if there were, it is incredible that, with such an arrangement of the refractive media as exists in the cormea and crystalline cones, rays proceeding from points in the external world should be brought to a focus in correspondingly related points of the surface of the supposed retina. But without this no picture could be formed, and no distinct vision could take place. It is very probable, therefore, that the visual pyramids do not play the part of the simple eyes of the Vertebrata, and the only alternative appears to be the adoption of a modification of the theory of mosaic vision, propounded many years by Johannes Müller. 
Each visual pyramid, isolated from its fellows by its coat of pigment, may be supposed, in fact, to play the part of a very narrow straight tube, with blackened walls, one end of which is turned towards the external world, while the other incloses the extremity of one of the nerve fibres. The only light which can reach the latter, under these circumstances, is such as proceeds from points which lie in the

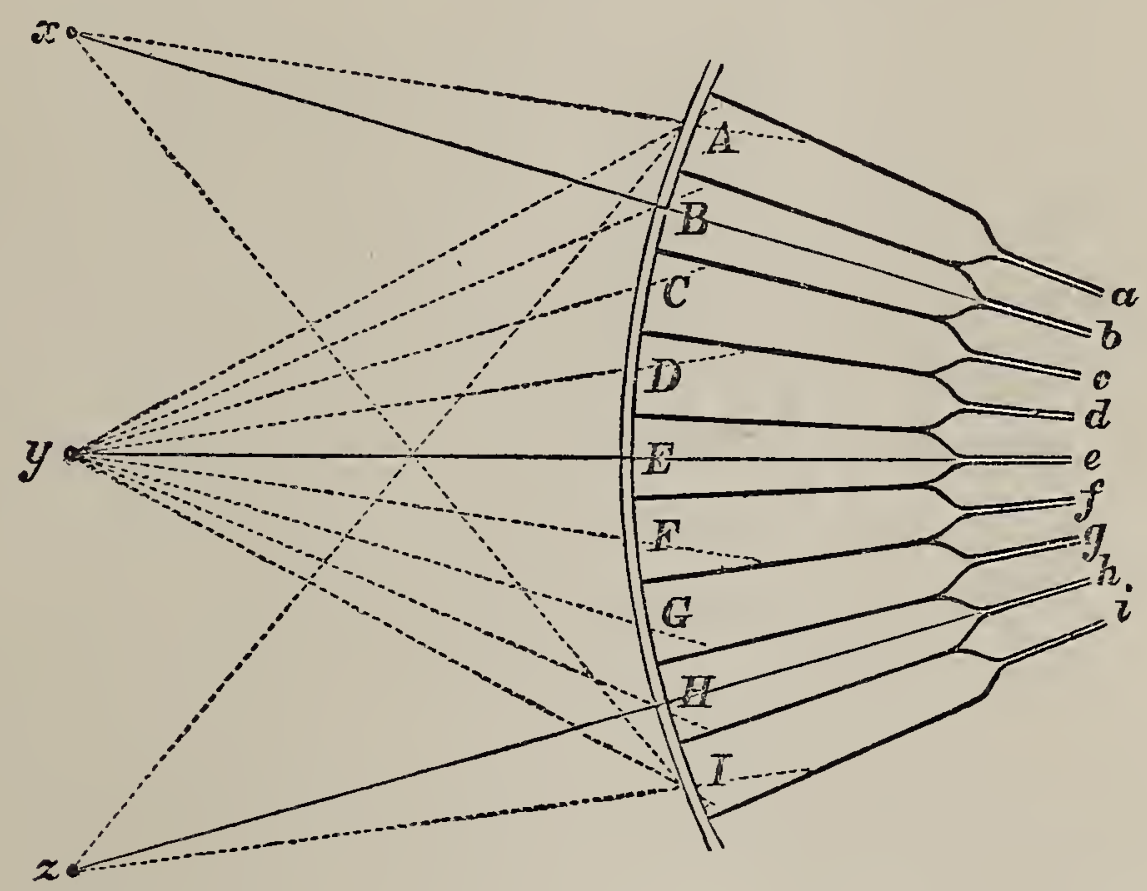

FIG. 29.-Diagram showing the course of rays of light from three points $x, y, z$, through the nine visual rods (supposed to be empty tubes) $\mathrm{A}-\mathrm{I}$ of a compound eye ; $a-i$, the nerve fibres connected with the visual rods.

direction of a straight line represented by the produced axis of the tubes.

Suppose A-I to be nine such tubes, $a-i$ the corresponding nerve fibres, and $x y z$ three points from which light proceeds. Then it will be obvious that the only light 


\section{THE PHYSIOLOGY OF THE COMMON CRAYFISH.}

from $x$ which will excite sensation, will be the ray which traverses $\mathrm{B}$ and reaches the nerve-fibre $b$, while that from $y$ will affect only $e$, and that from $x$ only $h$. The result, translated into sensation, will be three points of light on a dark ground, each of which answers to one of the luminous points, and indicates its direction in reference to the eye and its angular distance from the other two.*

The only modification needed in the original form of the theory of mosaic vision, is the supposition that part, or the whole, of the risual rod, is not merely a passive transmitter of light to the nerve-fibre, but is, itself, in someway concerned in transmuting the mode of motion, light, into that other mode of motion which we call nerrous energy. The visual rod is, in fact, to be regarded as the physiological end of the nerve, and the instrument by which the conversion of the one form of motion into the other takes place; just as the auditory hairs are instruments by which the sonorous wares are converted into molecular movements of the substance of the auditory nerres.

It is ronderfully interesting to observe that, when the so-called compound eye is interpreted in this manner,

* Since the risual rods are strongly refracting solids, and not empty tubes, the diagram given in fig. 29 does not represent the true course of the rays, indicated by dotted lines, which fall obliquely on any cornea of a crayfish's eye. Such rays will be more or less bent towards the axis of the risual rod of that cornea; but whether they reach its apex and so affect the nerve or not will depend on the curvature of the cornea ; its refractive index and that of the crystalline cone; and the relation between the length and the thickness of the latter. 
the apparent wide difference between it and the rertebrate eye gives place to a fundamental resemblance. The rods and cones of the retina of the vertebrate eye are extraordinarily similar in their form and their relations to the fibres of the optic nerve, to the visual rods of the arthropod eye. And the morphological discrepancy, which is at first so striking, and which arises from the fact that the free ends of the visual rods are turned towards the light, while those of the rods and cones of the vertebrate eye are turned from it, becomes a confirmation of the parallel between the two when the development of the vertebrate eye is taken into account. For it is demonstrable that the deep surface of the retina in which the rods and cones lie, is really a part of the outer surface of the body turned inwards, in the course of the singular developmental changes which give rise to the brain and the eye of vertebrate animals.

Thus the crayfish has, at any rate, two of the higher sense organs, the ear and the eye, which we possess ourselves; and it may seem a superfluous, not to say a frivolous, question, if any one should ask whether it can hear and see.

But, in truth, the inquiry, if properly limited, is a very pertinent one. That the crayfish is led by the use of its eyes and ears to approach some objects and avoid others, is beyond all doubt; and, in this sense, most indubitably it can both hear and see. But if the question 
126 THE PHYSIOLOGY OF THE COMNON CRAYFISH.

means, do luminous vibrations give it the sensations of light and darkness, of colour and form and distance, which they give to us? and do sonorous vibrations produce the feelings of noise and tone, of melody and of harmony, as in us ?-it is by no means to be answered hastily, perhaps cannot be answered at all, except in a tentative, probable way.

The phenomena to which we give the names of sound and colour are not physical things, but are states of consciousness, dependent, there is every reason to believe, on the functional activity of certain parts of our brains. Melody and harmony are names for states of consciousmess which arise when at least two sensations of sound have been produced. All these are manufactured articles, products of the human brain; and it would be exceedingly hazardous to affirm that organs capable of giving rise to the same products exist in the vastly simpler nervous system of the crustacean. It would be the height of absurdity to expect from a meat-jack the sort of work which is performed by a Jacquard loom; and it appears to me to be little less preposterous to look for the production of anything analogous to the more subtle phenomena of the human mind in something so minute and rude in comparison to the human brain, as the insignificant cerebral ganglia of the crayfish.

At the most, one may be justified in supposing the existence of something approaching dull feeling in ourselves; and, to return to the problem stated in the begin- 
ning of this chapter, so far as such obscure consciousness accompanies the molecular changes of its nervous substance, it will be right to speak of the mind of a crayfish. But it will be obvious that it is merely putting the cart before the horse, to speak of such a mind as a factor in the work done by the organism, when it is merely a dim symbol of a part of such work in the doing.

Whether the crayfish possesses consciousness or not, however, does not affect the question of its being an engine, the actions of which at any moment depend, on the one hand, upon the series of molecular changes excited, either by internal or by external causes, in its neuromuscular machinery; and, on the other, upon the disposition and the properties of the parts of that machinery. And such a self-adjusting machine, containing the immediate conditions of its action within itself, is what is properly understood by an automaton.

Crayfishes, as we have seen, may attain a considerable age; and there is no means of knowing how long they might live, if protected from the innumerable destructive influences to which they are at all ages liable.

It is a widely received notion that the energies of living matter have a natural tendency to decline, and finally disappear; and that the death of the body, as a whole, is the necessary correlate of its life. That all living things sooner or later perish needs no demonstration, but is would be difficult to find satisfactory grounds 


\section{THE PHYSIOLOGY OF THE COMMON CRAYFISH.}

for the belief that they must needs do so. The analogy of a machine that, sooner or later, must be brought to a standstill by the wear and tear of its parts, does not hold, inasmuch as the animal mechanism is continually renewed and repaired; and, though it is true that individual components of the body are constantly dying, yet their places are taken by vigorous successors. A city remains, notwithstanding the constant death-rate of its inhabitants; and such an organism as a crayfish is only a corporate unity, made up of innumerable partially independent individualities.

Whatever might be the longevity of crayfishes under imaginable perfect conditions, the fact that, notwithstanding the great number of eggs they produce, their number remains pretty much the same in a given district, if we take the average of a period of years, shows that about as many die as are born; and that, without the process of reproduction, the species would soon come to an end.

'There are many examples among members of the group of Crustacea to which the crayfish belongs, of animals which produce young from internally developed germs, as some plants throw off bulbs which are capable of reproducing the parent stock; such is the case, for example, with the common water flea (Daphnia). But nothing of this kind has been observed in the crayfish; in which, as in the higher animals, the reproduction of the species is dependent upon the combination of two kinds of living 
matter, which are developed in different individuals, termed males and females.

These two kinds of living matter are ova and sperma. tozoa, and they are developed in special organs, the ovary and the testis. The ovary is lodged in the female; the testis, in the male.

The ovary (fig. 30, ov) is a body of a trefoil form, which is situated immediately beneath, or in front of, the heart, between the floor of the pericardial sinus and the alimentary canal. From the ventral face of this

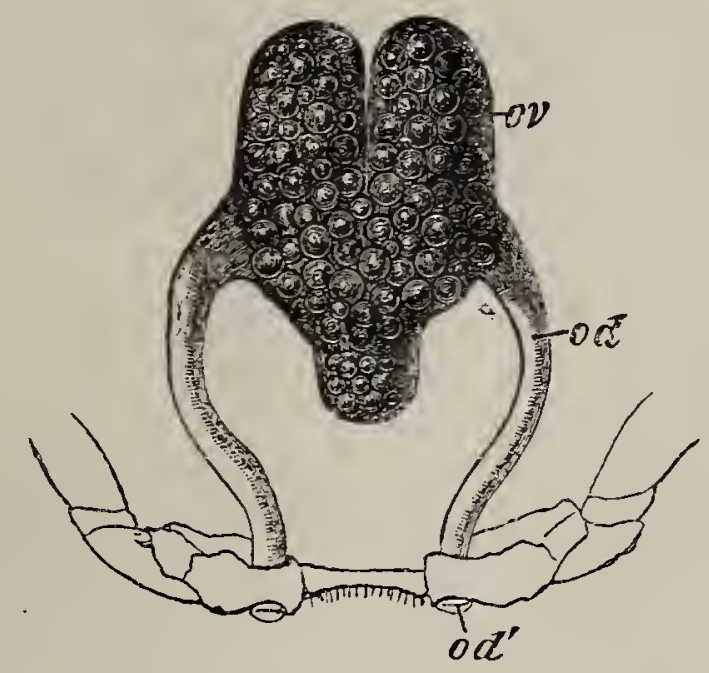

FIG. 30.-Astacus furiatilis. -The female reproductive organs $(\times 2)$; $o v$, ovary ; od, oviduct ; od', aperture of oviduct.

organ two short and wide canals, the oviducts (od), lead down to the bases of the second pair of wallking limbs, and terminate in the apertures (od') already noticed there.

The testis (fig. $31, t$ ) is somewhat similar in form to the ovary, but, the three divisions are much narrower. 
and more elongated: the hinder median division lies under the heart; the anterior divisions are situated between the heart behind, and the stomach and the liver in front (figs. 5 and 12, t). From the point at which the

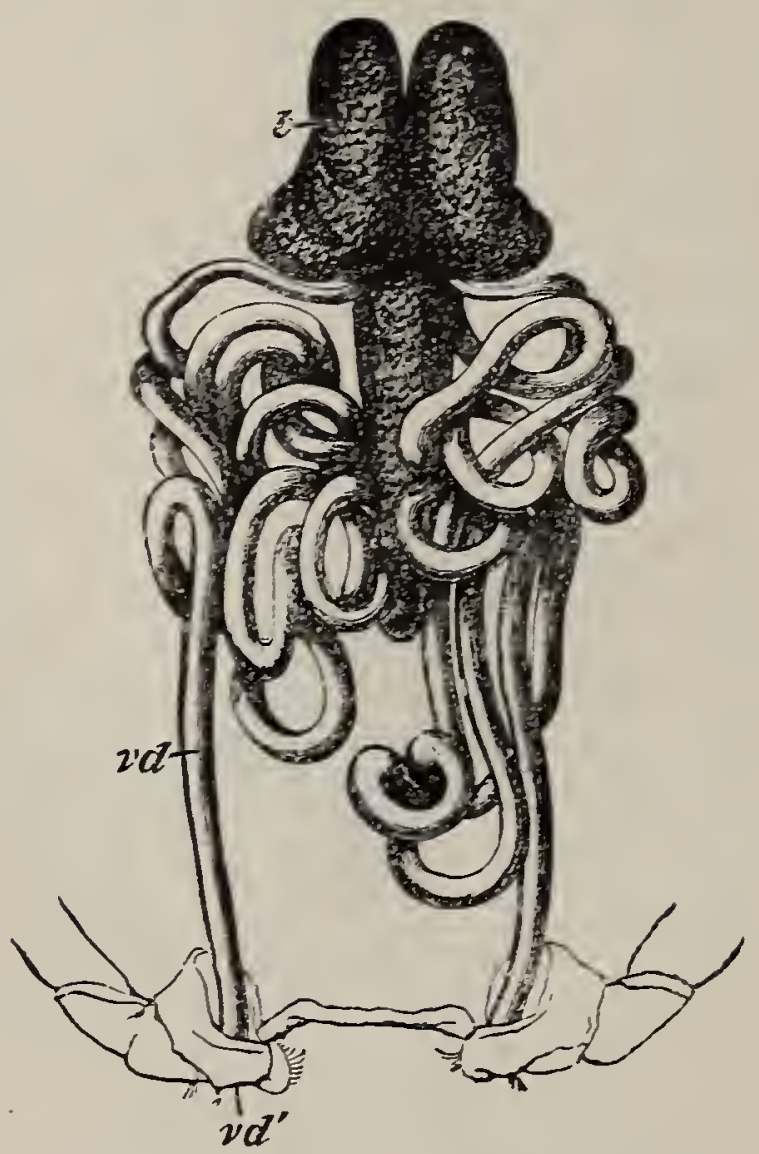

FIG. 31.-Astacus flviatilis. - The malc reproductive organs $(\times 2)$; $t$, testis ; $v d$, vas deferens ; $v d^{\prime}$, aperture of vas deferens.

three divisions join, proceed two ducts, which are termed the vasa deferentia (fig. 31, vd). These are very narrow, long, and make many coils before they reach the apertures upon the bases of the hindermost pair of walking limbs, by which they open externally (fig. 31, $v d^{\prime}$, and fig. $35, v d$ ). Both the ovary and the testis are very much larger 
during the breeding season than at other times; the large brownish-yellow eggs become conspicuous in the ovary,

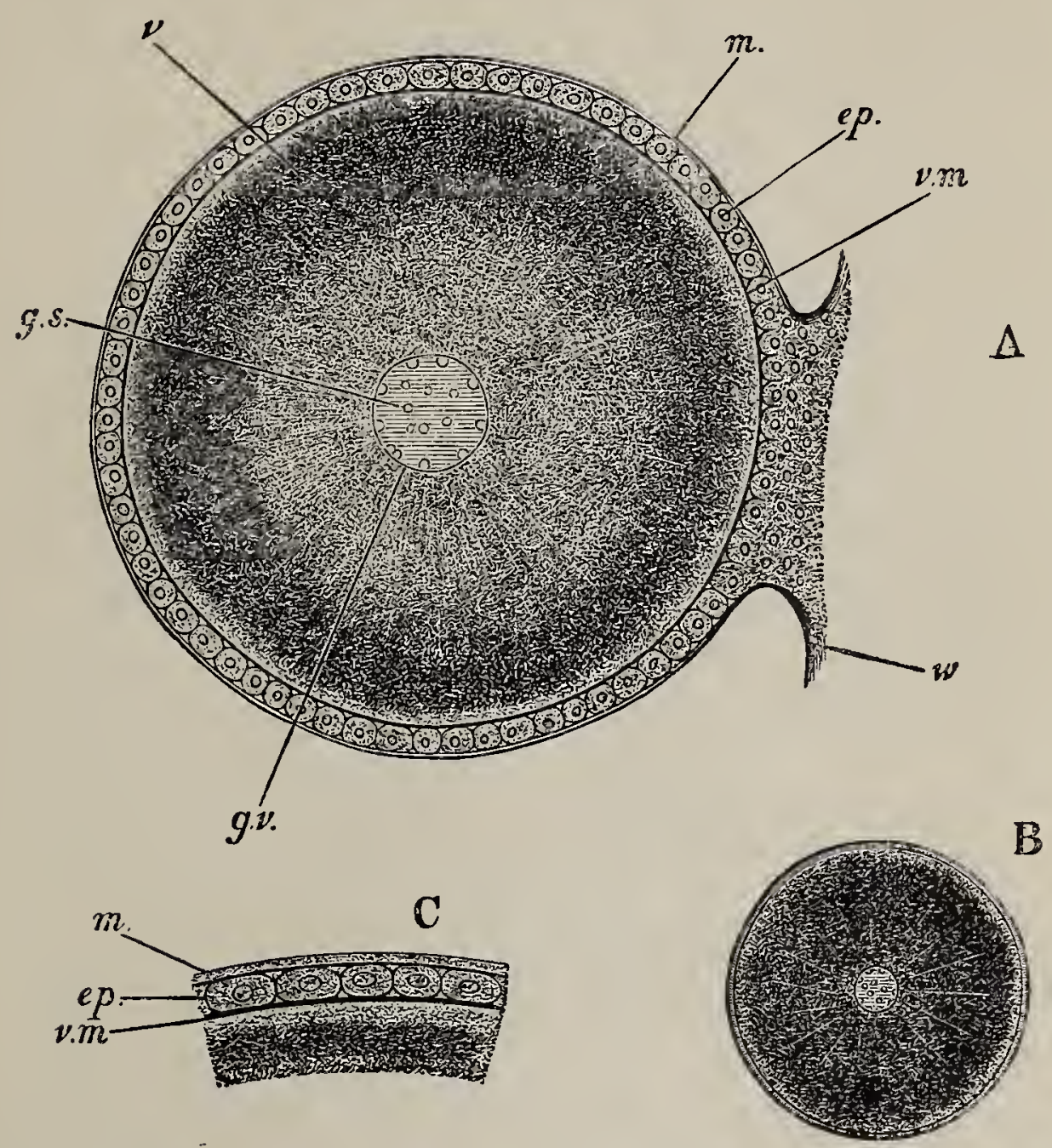

Fig. 32.-Astacus fluviatilis.-A, a two-thirds grown egg contained in its ovisac $(\times 50)$; $\mathrm{B}$, an egg removed from the ovisac $(\times 10)$; $\mathrm{C}$, a portion of the wall of an ovisac with the adjacent portion of the contained egg, highly magnified; $e p$, epithelium of ovisac; $g s$, germinal spots; $g v$, germinal vesicle; $m$, membrana propria; $v$, vitellus ; $v m$, vitelline membrane ; $v$, stalk of ovisac.

and the testis assumes a milk-white colour, at this period.

The walls of the ovary are lined internally by a layer of 


\section{I32 THE PHYSIOLOGY OF THE COMMON CRAYFISH.}

nucleated cells, separated from the cavity of the organ by a delicate structureless membrane. The growth of these cells gives rise to papillary elevations which project into the cavity of the ovary, and eventually become globular
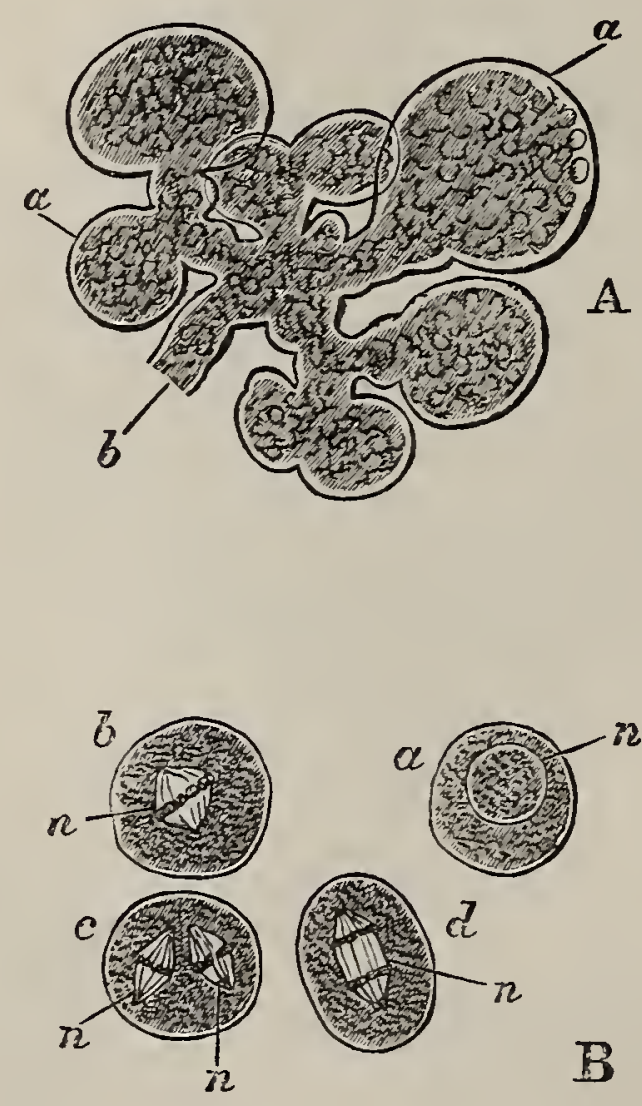

FIG. 33.-Astacus fluriatilis. -A, a lobule of the testis, showing $a$, acini, springing from $b$, the ultimate termination of a duct $(\times 50)$. B, spermatic cells; $a$, with an ordinary globular nucleus $n ; b$, with a spindle-shaped nucleus; $c$, with two similar nuclei; and $d$, with a nucleus undergoing division $(x 600)$.

bodies attached by short stalks, and invested by the structureless membrane as a membrana propria (fig. $32, \mathrm{~m}$ ). These are the ovisacs. In the mass of cells which becomes the ovisac, one rapidly increases in size and occupies the centre of the orisac, while the others 
surround it as a peripheral coat (ep.). This central cell is the ovum. Its nucleus enlarges, and becomes what is called the germinal vesicle (g.v.). At the same time numerous small corpuscles, flattened externally and convex internally, appear in it and are the germinal spots (g.s.). The protoplasm of the cell, as it enlarges, becomes granular and opaque, assumes a deep brownishyellow colour, and is thus converted into the yelk or vitellus (v.). As the egg grows, a structureless vitelline membrane is formed between the vitellus and the cells which line the ovisac, and incloses the egg, as in a bag. Finally, the ovisac bursts, and the egg, falling into the cavity of the ovary, makes its way down the oviduct, and sooner or later passes out by its aperture. When they leave the oviduct, the ova are invested by a viscous, transparent substance, which attaches them to the swimmerets of the female, and then sets; thus each egg, inclosed in a tough case, is firmly suspended by a stalk, which, on the one side, is continued into the substance of the case, while, on the other, it is fixed to the swimmeret. The swimmerets are kept constantly in motion, so that the eggs are well supplied with aerated water.

The testis consists of an immense number of minute spheroidal vesicles (fig. 33, A, a), attached like grapes to the ends of short stalks (b), formed by the ultimate ramifications of the vasa deferentia. The vesicles may, in fact, be regarded as dilatations of the ends and sides 

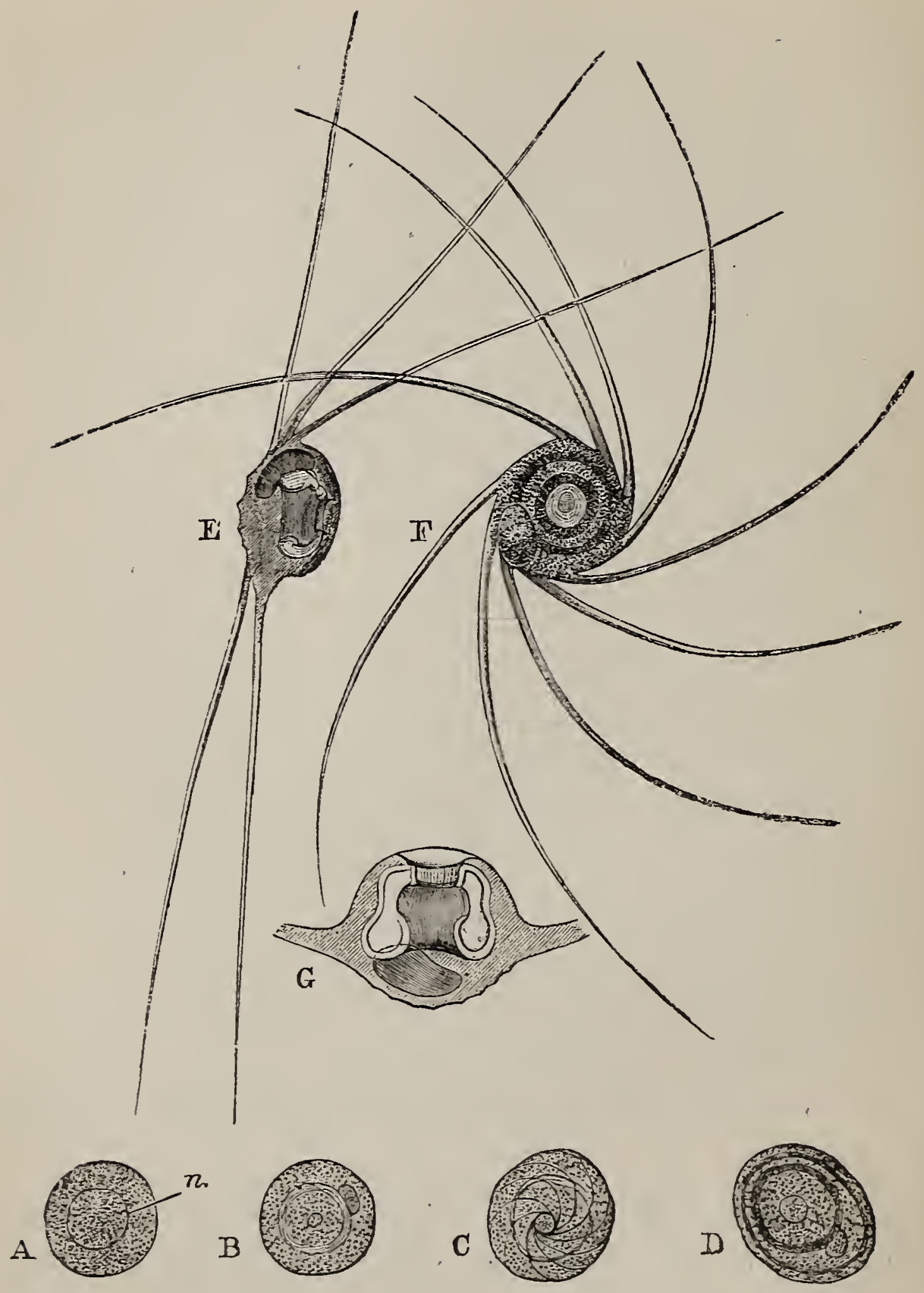

Fig. $3 \frac{4}{x}-$ Astacus fluviatilis. $-\mathrm{A}-\mathrm{D}$, different stages in the derelopment of a spermatozoon from a seminal cell; $E$, a mature spermatozoon seen from the side; $F$, the same viewed an face (all $\times 850) ; G$, a diagrammatic vertical section of the same. 
of the finest branches of the ducts of the testis. The cavity of each vesicle is filled by the large nucleated cells which line its walls (fig. 33, B), and, as the breeding season approaches, these cells multiply by division. Finally, they undergo some very singular changes of form and intermal structure (fig. 34, A-D), each becoming converted into a flattened spheroidal body, about $\frac{1}{1700}$ th of an inch in diameter, provided with a number of slender curved rays, which stand out from its sides (fig. 34, E-G). These are the spermatozoa.

The spermatozoa accumulate in the testicular vesicles, and give rise to a milky-looking substance, which traverses the smaller ducts, and eventually fills the vasa deferentia. This substance, however, consists, in addition to the spermatozoa, of a viscid material, secreted by the walls of the vasa deferentia, which envelopes the spermatozoa, and gives the secretion of the testis the form and the consistency of threads of vermicelli.

The ripening and detachment of both the ova and the spermatozoa take place immediately after the completion of ecdysis in the early autumn; and at this time, which is the breeding season, the males seek the females with great avidity, in order to deposit the fertilizing matter contained in the vasa deferentia on the sterna of their hinder thoracic and anterior abdominal somites. There it adheres as a whitish, chalky-looking mass ; but the manner in which the contained spermatozoa reach and enter the ova is unknown. The analogy 
of what occurs in other animals, however, leaves no doubt that an actual mixture of the male and female elements takes place and constitutes the essential part of the process of impregnation.

Ova to which spermatozoa have had no access, give rise to no progeny; but, in the impregnated ovum, the young crayfish talies its origin in a manner to be described below, when the question of development is dealt with.
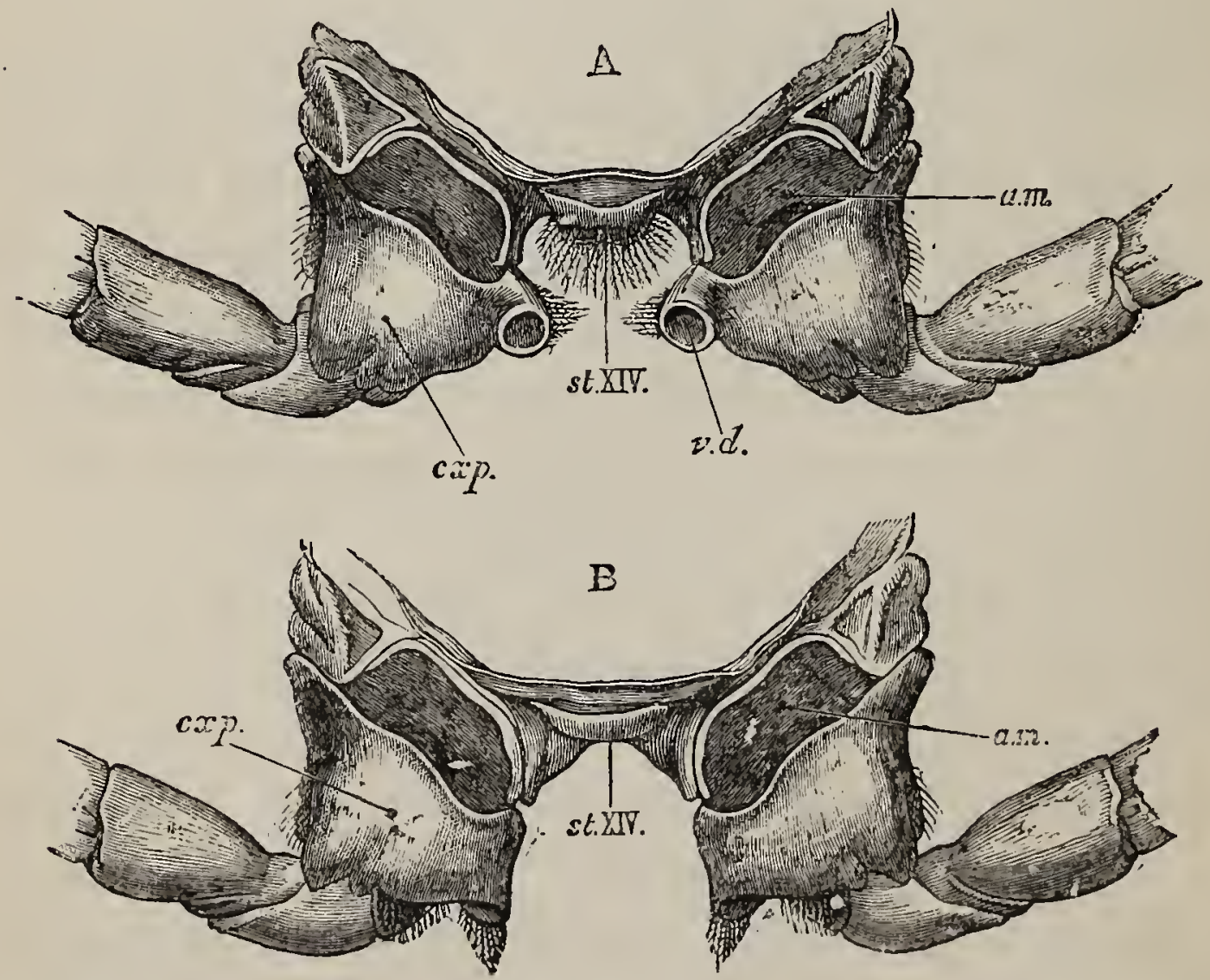

FiG. 35.-Astacus fluviatilis.-The last thoracic sternum, seen from behind, with the proximal ends of the appendages, $A$, in the male, $\mathrm{B}$, in the female, $(\times 3)$. am, articular membrane; cxp, coxopodite; st $X I V$, last thoracic sternum; $v d$, aperture of vas deferens. 


\section{CHAPTER IV.}

THE MORPHOLOGY OF THE COMIMON CRAYFISH: THE STRUC. TURE AND THE DEVELOPMENT OF THE INDIVIDUAL.

In the two preceding chapters the crayfish has been studied from the point of view of the physiologist, who, regarding an animal as a mechanism, endeavours to discover how it does that which it does. And, practically, this way of looking at the matter is the same as that of the teleologist. For, if all that we know concerning the purpose of a mechanism is derived from observation of the manner in which it acts, it is all one, whether we say that the properties and the connexions of its parts account for its actions, or that its structure is adapted to the performance of those actions.

Hence it necessarily follows that physiological phenomena can be expressed in the language of teleology. On the assuinption that the preservation of the individual, and the continuance of the species, are the final causes of the organization of an animal, the existence of that organization is, in a certain sense, explained, when it is shown that it is fitted for the attainment of those ends; although, perhaps, the importance of de- 
138 THE MORPHOLOGY OF THE COMMON CRAYFISII.

monstrating the proposition that a thing is fitted to do that which it does, is not very great.

But whatever may be the value of teleological explanations, there is a large series of facts, which have as yet been passed over, or touched only incidentally, of which they take no account. These constitute the subject matter of Morphology, which is related to physiology much as, in the not-living world, crystallography is related to the study of the chemical and physical properties of minerals.

Carbonate of lime, for example, is a definite compound of calcium, carbon, and oxygen, and it has a great variety of physical and chemical properties. But it may be studied under another aspect, as a substance capable of assuming crystalline forms, which, though extraordinarily various, may all be reduced to certain geometrical types. It is the business of the crystallographer to work out the relations of these forms; and, in so doing, he takes no note of the other properties of carbonate of lime.

In like manner, the morphologist directs his attention to the relations of form between different parts of the same animal, and between different animals; and these relations would be unchanged if animals were mere dead matter, devoid of all physiological properties-a. kind of mineral capable of a peculiar mode of growth.

A familiar exemplification of the difference between teleology and morphology may be found in such works of human art as houses. 
A house is certainly, to a great extent, an illustration of adaptation to purpose, and its structure is, to that extent, explicable by teleological reasonings. The roof and the walls are intended to keep out the weather; the foundation is meant to afford support and to exclude damp; one room is contrived for the purpose of a kitchen; another for that of a coal-cellar; a third for that of a dining-room; others are constructed to serve as sleeping rooms, and so on ; doors, chimneys, windows, drains, are all more or less elaborate contrivances directed towards one end, the comfort and health of the dwellers in the house. What is sometimes called sanitary architecture, now-a-days, is based upon considerations of house teleology. But though all houses are, to begin with and essentially, means adapted to the ends of shelter and comfort, they may be, and too often are, dealt with from a point of view, in which adaptation to purpose is largely disregarded, and the chief attention of the architect is given to the form of the house. A house may be built in the Gothic, the Italian, or the Queen Anne style; and a house in any one of these styles of architecture may be just as convenient or inconvenient, just as well or as ill adapted to the wants of the resident therein, as any of the others. Yet the three are exceedingly different.

To apply all this to the crayfish. It is, in a sense a house with a great variety of rooms and offices, in which the work of the indwelling life in feeding, breathing, moving, and reproducing itself, is done. But the 
same may be said of the crayfish's neighbours, the perch and the water-smail; and they do all these things neither better nor worse, in relation to the conditions of their existence, than the crayfish does. Yet the most cursory inspection is sufficient to show that the "styles of architecture" of the three are even more widely different than are those of the Gothic, Italian, and Queen Anne houses.

That which Architecture, as an art conversant with pure form, is to buildings, Morphology, as a science conversant with pure form, is to animals and plants. And we may now proceed to occupy ourselves exclusively with the morphological aspect of the crayfish.

As I have already mentioned, when dealing with the physiology of the crayfish, the entire body of the animal, when reduced to its simplest morphological expression, may be represented as a cylinder, closed at each end, except so far as it is perforated by the alimentary apertures (fig. 6); or we may say that it is a tube, inclosing another tube, the edges of the two being continuous at their extremities. The outer tube has a chitinous outer coat or cuticle, which is continued on to the imner face of the inner tube. Neglecting this for the present, the outermost part of the wall of the outer tube, which answers to the epidermis of the higher animals, and the innermost part of the wall of the inner tube, which is an epithelium, are formed by a layer of nucleated cells. A continuous layer of cells, therefore, is everywhere to 
be found on both the external and the internal free surfaces of the body. So far as these cells belong to the proper external wall of the body, they constitute the ectoderm, and so far as they belong to its proper internal wall, they compose the endoderm. Between these two layers of nucleated cells lie all the other parts of the body, composed of connective tissue, muscles, vessels, and nerves; and all these (with the exception of the ganglionic chain, which we shall see properly belongs to the ectoderm) may be regarded as a single thick stratum, which, as it lies between the ectoderm and the endoderm, is called the mesoderm.

If the intestine were closed posteriorly instead of opening by the vent, the crayfish would virtually be an elongated sac, with one opening, the mouth, affording an entrance into the alimentary cavity: and, round this cavity, the three layers just referred to-endoderm, mesoderm, and ectoderm-would be disposed concentrically.

We have seen that the body of the crayfish thus composed is obviously separable into three regions-the cephalon or head, the thorax, and the abdomen. The latter is at once distinguished by the size and the mobility of its segments: while the thoracic region is marked off from that of the head, outwardly, only by the cervical groove. But, when the carapace is removed, the lateral depression already mentioned, in which the 


\section{THE MORPHOLOGY OF THE COMMON CRAYFISH.}

scaphognathite lies, clearly indicates the natural boundary between the head and the thorax. It has further been observed that there are, in all, twenty pairs of appendages, the six hindermost of which are attached to the abdomen. If the other fourteen pairs are carefully removed, it will be found that the six anterior belong to the head, and the eight posterior to the thorax.

The abdominal region may now be studied in further detail. Each of its seven movable segments, except the telson, represents a sort of morphological unit, the repetition of which makes up the whole fabric of the body.

If the abdomen is divided transversely between the

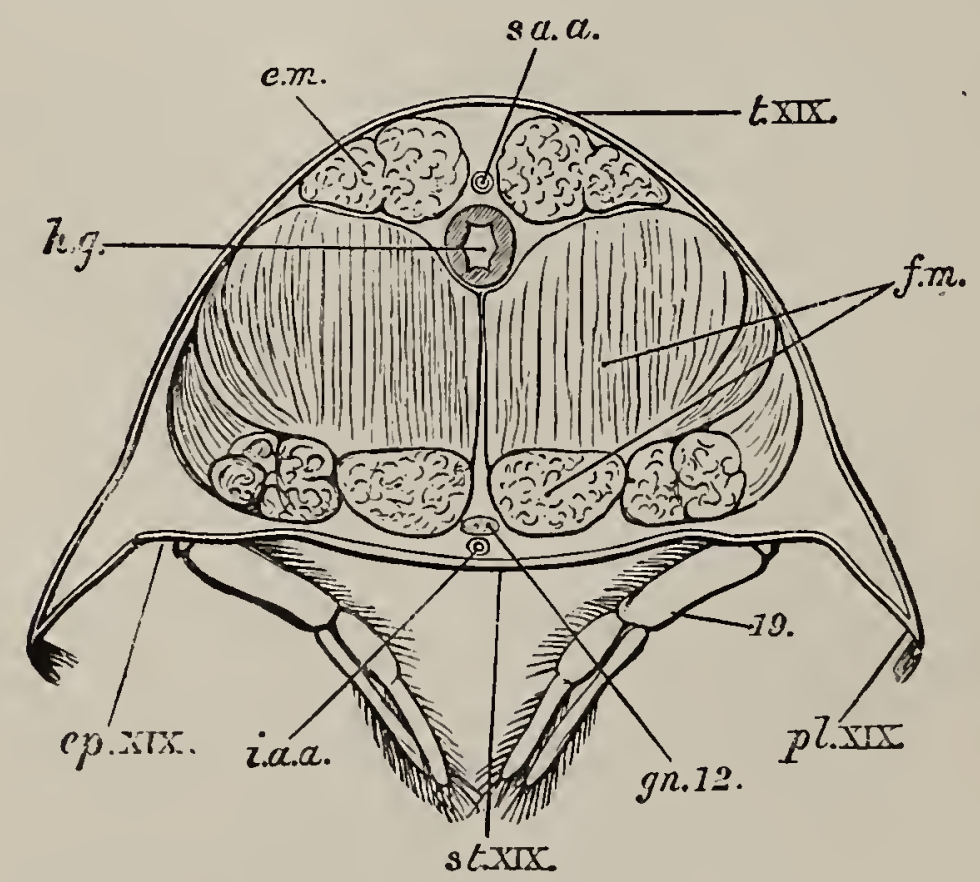

Fig. 36. - Astacus fluviatilis. - A transverse section througn the nineteenth (fifth abdominal) somite $(\times 2)$. c.m., extensor muscles; f.m., flexor muscles; $g n .12$, the fifth abdominal ganglion; $\pi . g$., hind-gut; i.a.a., inferior abdominal artery ; s.a.a, superior abdominal artery ; $p t . X I X$, pleura of the somite; st. $X I X$, its sternum ; $t . X I X$, its tergum ; $е p . X I X$, its epimera; 19 , its appendages. 
fourth and fifth, and the fifth and sixth segments, the fifth will be isolated, and can be studied apart. It constitutes what is called a metamere; in which are distinguishable a central part termed the somite, and two appendages (fig. 36).

In the exoskeleton of the somites of the abdomen several regions have already been distinguished; and although they constitute one continuous whole, it will be convenient to speak of the sternum (fig. 36, st. XIX), the tergum ( $t$. XIX), and, the pleura ( $p l$. XIX), as if they were separate parts, and to distinguish that portion of the sternal region, which lies between the articulation of the appendage and the pleuron, on each side, as the epimeron (ep. XIX). Adopting this nomenclature, it may be said of the fifth somite of the abdomen, that it consists of a segment of the exoskeleton, divisible into tergum, pleura, epimera, and sternum, with which two appendages are articulated; that it contains a double ganglion ( $g n .12)$, a section of the flexor $(\mathrm{fm})$ and extensor $(\mathrm{em})$ muscles, and of the alimentary $(\mathrm{hg})$ and vascular (s.a.a, i.a.a) systems.

The appendage (fig. 36, 19), which is attached to an articular cavity situated between the sternum and the epimeron, is seen to consist of a stalk or stem, which is made up of a very short basal joint, the coxopodite (fig. 37, $\mathrm{D}$ and $\mathrm{E}, c x . p)$, followed by a long cylindrical second joint, the basipodite (b.p), and receives the name of protopodite. At its free end, it bears two flattened narrow 

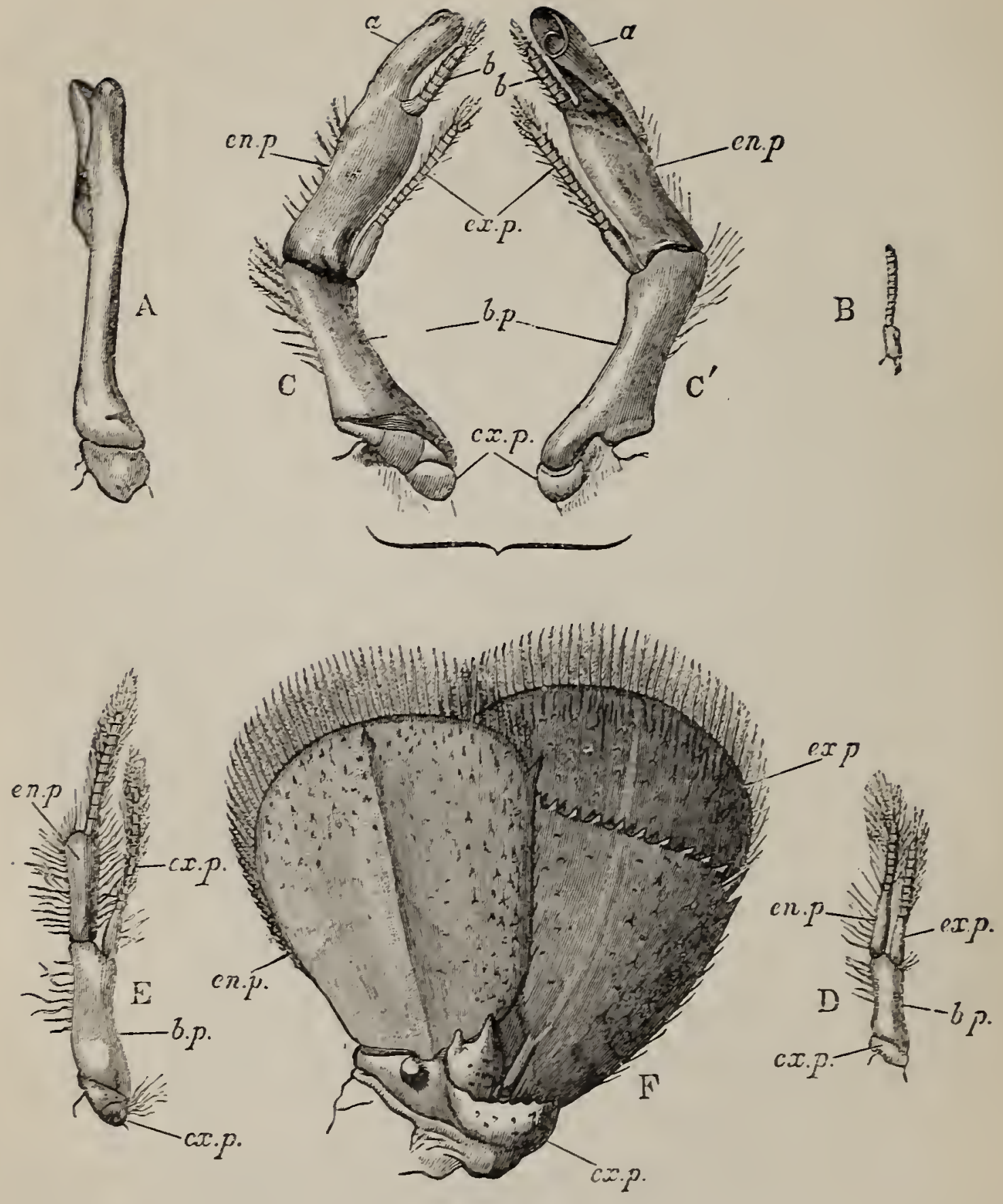

FIG. 37.-Astacus fluriatilis.-Appendages of the left side of the abdomen $(\times 3)$. A, the posterior face of the first appendage of the male ; $\mathrm{B}$, the same of the female; $\mathrm{C}$, posterior. and $\mathrm{C}^{\prime}$, anterior faces of the second appendage of the male; $\mathrm{D}$, the third appendage of the male; $\mathrm{E}$, the same of the female; $\mathrm{F}$, the sixth appendare. $a$, the rolled plate of the endopociis: $b$, the jointed extremity of the same; $7 p$., basipodite ; cx.p., coxopodite ; cr.p., endopodite ; cx.p., exopodite. 
plates, of which one is attached to the inner side of the extremity of the protopodite, and is called the endopodite (en.p), while the other is fixed a little higher up to the outer side of that extremity, and is the exopodite (ex.p). The exopodite is shorter than the endopodite. The endopodite is broad and is undivided for about half its length, from the attached end; the other half is narrower. and is divided into a number of small segments, which, however, are not united by definite articulations, but are merely marked off from one another by slight constrictions of the exoskeleton. The exopodite has a similar structure, but its undivided portion is shorter and narrower. The edges of both the exopodite and the endopodite are fringed with long setæ.

In the female crayfish, the appendages of this and of the fourth and third somites are larger than in the male (compare $D$ and $E$, fig. 37 ).

The fourth and fifth somites, with their appendages, may be described in the same terms as the third, and in the sixth there is no difficulty in recognising the corresponding parts of the somite; but the appendages (fig. 37, $F$ ), which constitute the lateral portions of the caudal fin, at first sight appear very different. In their size, no less than in their appearance, they depart widely from the appendages of the preceding somites. Nevertheless, each will be found to consist of a basal stalk, answering to the protopodite (cx.p), which however is very broad and thick, and is not divided into two 
joints ; and of two terminal oval plates, which represent the endopodite (en.p) and the exopodite (ex.p). The latter is divided by a transverse suture into two pieces; and the edge of the larger or basal moiety is beset with short spines, of which two, at the outer end of the series, are larger than the rest.

The second somite is longer than the first (fig. 1); it has very broad pleura, while those of the first somite are small and hidden by the overlapping front margins of the pleura of the second somite.

In the female, the appendages of the second somite of the abdomen are similar to those of the third, fourth, and fifth somites; but in those of the first somite (fig. $37, B$ ), there is a considerable variation. Sometimes, in fact, the appendages of this somite are altogether wanting; sometimes one is present, and not the other; and sometimes both are found. But, when they exist, these appendages are always small; and the protopodite is followed by only one imperfectly jointed filament, which appears to represent the endopodite of the other appendages.

In the male, the appendages of the first and second somites of the abdomen are not only of relatively large size, but they are widely different from the rest, those of the first somite departing from the general type further than those of the second. In the latter $\left(C, C^{\prime}\right)$ there is a protopodite $(c x \cdot p, b p)$ with the ordinary structure, and it is followed by an endopodite (en.p) and an exopodite 
(ex.p) ; but the former is singularly modified. The undivided basal part is large, and is produced on the inner side into a lamella $(a)$, which extends slightly beyond the end of the terminal jointed portion $(b)$. The inner half of this lamella is rolled upon itself, in such a manner as to give rise to a hollow cone, something like an extinguisher $\left(C^{\prime}, a\right)$.

The appendage of the first somite $(A)$ is an unjointed styliform body, which appears to represent the protopodite, together with the basal part and the inner prolongation of the endopodite of the preceding appendage. The terminal half of the appendage is really a broad plate, slightly bifid at the summit, but the sides of the plate are rolled in, in such a manner that the anterior half bends round and partially incloses the posterior half. They thus give rise to a canal, which is open at each end, and only partially closed behind.

These two pairs of curiously modified appendages are ordinarily turned forwards and applied against the sterna of the posterior part of the thorax, in the interval between the bases of the hinder thoracic limbs (see fig. 3, A). They serve as conduits by which the spermatic matter of the male is conveyed from the openings of the ducts of the testes to its destination.

If we confine our attention to the third, fourth, and fifth metameres of the abdomen of the crayfish, it is obvious that the several somites and their appendages, and the rarious regions or parts into which they are 


\section{S THE MORPHOLOGY OF THE COMMION CRAYFISH.}

divisible, correspond with one another, not only in form, but in their relations to the general plan of the whole abdomen. Or, in other words, a diagrammatic plan of one somite will serve for all the three somites, with insignificant variations in detail. The assertion that these somites are constructed upon the same plan, involves no more hypothesis than the statement of an architect, that three houses are built upon the same plan, though the façades and the internal decorations may differ more or less.

In the language of morphology, such conformity in sthe plan of organisation is termed homology. Hence, the several metameres in question and their appendages, are homologous with one another; while the regions of the somites, and the parts of their appendages, are also homologues.

When the comparison is extended to the sixth metamere, the homology of the different parts with those of the other metameres, is undeniable, notwithstanding the great differences which they present. To recur to a previous comparison, the ground plan of the building is the same, though the proportions are varied. So with regard to the first and second metameres. In the second pair of appendages of the male, the difference from the ordinary type of appendage is comparable to that produced by adding : portico or a turret to the building; while, in the first pair of appendages of the female, it is as if one wing of the edifice were left unbuilt; 
and, in those of the male, as if all the rooms were run into one.

It is further to be remarked, that, just as of a row of houses built upon the same plan, one may be arranged so as to serve as a dwelling-house, another as a warehouse, and another as a lecture hall, so the homologous appendages of the crayfish are made to subserve various functions. And as the fitness of the dwelling-house, the warehouse, and the lecture-hall for their several purposes would not in the least help us to understand why they should all be built upon the same general plan; so, the adaptation of the appendages of the abdomen of the crayfish to the discharge of their several functions does not explain why those parts are homologous. On the contrary, it would seem simpler that each part should have been constructed in such a manner as to perform its allotted function in the best possible manner, without reference to the rest. The proceedings of an architect, who insisted on con. structing every building in a town on the plan of a Gothic cathedral, would not be explicable by considerations of fitness or convenience.

In the cephalothorax, the division into somites is not at first obvious, for, as we have seen, the dorsal or tergal surface is covered over by a continuous shield, distinguished into thoracic and cephalic regions only by the cervical groove. Even here, however, when a transverse section of the thorax is compared with that of the abdo- 
men (figs. 15 and 36), it will be obvious that the tergal and the sternal regions of the two answer to one another; while the branchiostegites correspond with greatly developed pleura; and the inner wall of the branchial chamber, which extends from the bases of the appendages to the attachment of the branchiostegite, represents an immensely enlarged epimeral region.

On examination of the sternal aspect of the cephalothorax the signs of division into somites become plain (figs. 3 and $39, A$ ). Between the last two ambulatory limbs there is an easily recognisable sternum (XIV.), though it is considerably narrower than any of the sterna of the abdominal somites, and differs from them in shape.

The deep transverse fold which separates this hindermost thoracic sternum from the rest of the sternal wall of the cephalothorax, is continued upwards on the inner or epimeral wall of the branchial carity; and thus the sternal and the epimeral portions of the posterior thoracic somite are naturally marked off from those of the more anterior somites.

The epimeral region of this somite presents a rery curious structure (fig. 38). Immediately above the articular cavities for the appendages there is a shieldshaped plate, the posterior, convex edge of which is sharp, prominent, and setose. Close to its upper boundary the plate exhibits a round perforation ( $p l b$.$) ,$ to the margins of which the stem of the hindermost 
pleurobranchia (fig. 4, plb. 14) is attached; and in front of this, it is connected, by a narrow neck, with an elongated triangular piece, which takes a vertical direction, and lies in the fold which separates the posterior thoracic somite from the next in front. The base of this

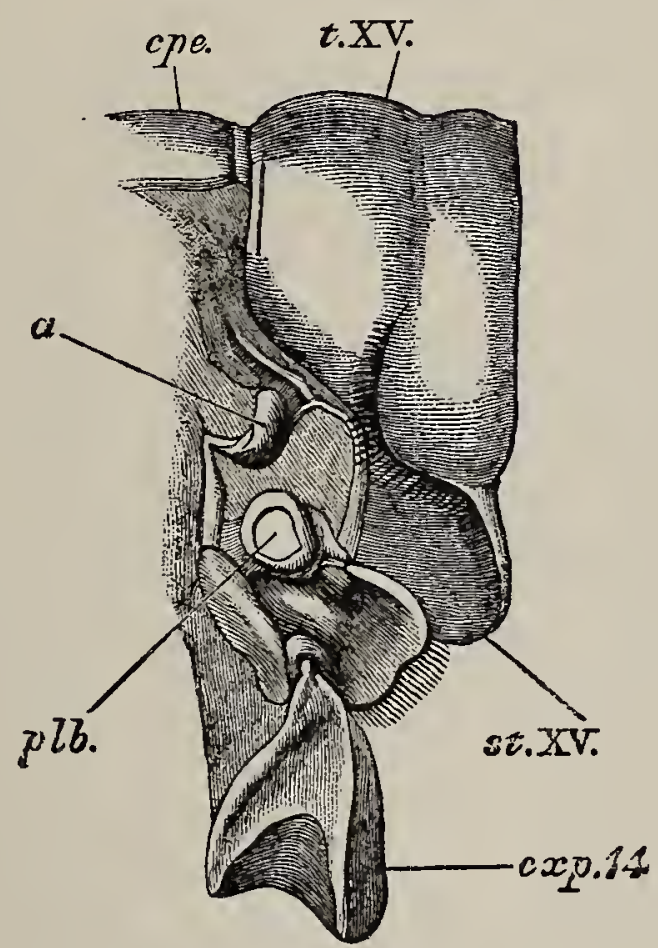

FIG. 38. - Astacus fuviatilis.-The mode of connexion between the last thoracic and the first abdominal somites $(x)$ ). $a$, L-shaped bar ; cpe, carapace ; $\exp .14$, coxopodite of the last ambulatory leg; plb., place of attachment of the pleurobranchia; st. $X \mathrm{~V}$, sternum, and $t$. $X V$, tergum of the first abdominal somite.

piece unites with the epimeron of the penultimate somite. Its apex is connected with the anterior end of the horizontal arm of an L-shaped calcified bar (fig. 38, a), the upper end of the vertical arm of which is firmly, but moveably, connected with the anterior and lateral edge of the tergum of the first abdominal somite $(t . X V$.). The tendon of one 


\section{THE MORPHOLOGY OF THE COMMON CRAYFISH.}

of the large extensor muscles of the abdomen is attached close to it.

The sternum and the shield-shaped epimeral plates constitute a solid, continuously calcified, ventral element of the skeleton, to which the posterior pair of legs is attached; and as this structure is united with the somites in front of and behind it only by soft cuticle, except where the shield-shaped plate is connected, by the intermediation of the triangular piece, with the epimeron which lies in front of it, it is freely movable backwards and forwards on the imperfect hinge thus constituted.

In the same way, the first somite of the abdomen, and, consequently, the abdomen as a whole, moves upon the hinges formed by the union of the L-shaped pieces with the triangular pieces.

In the rest of the thorax, the sternal and the epimeral regions of the several somites are all firmly united together. Nevertheless, shallow grooves answering to folds of the cuticle, which run from the intervals between the articular cavities for the limbs towards the tergal end 'of the inner wall of the branchial chamber, mark off the epimeral portions of as many somites as there are sterna, from one another.

A short distance above the articular cavities a transverse groove separates a nearly square area of the lower part of the epimeron from the rest. Towards the antericr and upper angle of this area, in the two somites 
which lie immediately in front of the hindermost, there is a small round aperture for the attachment of the
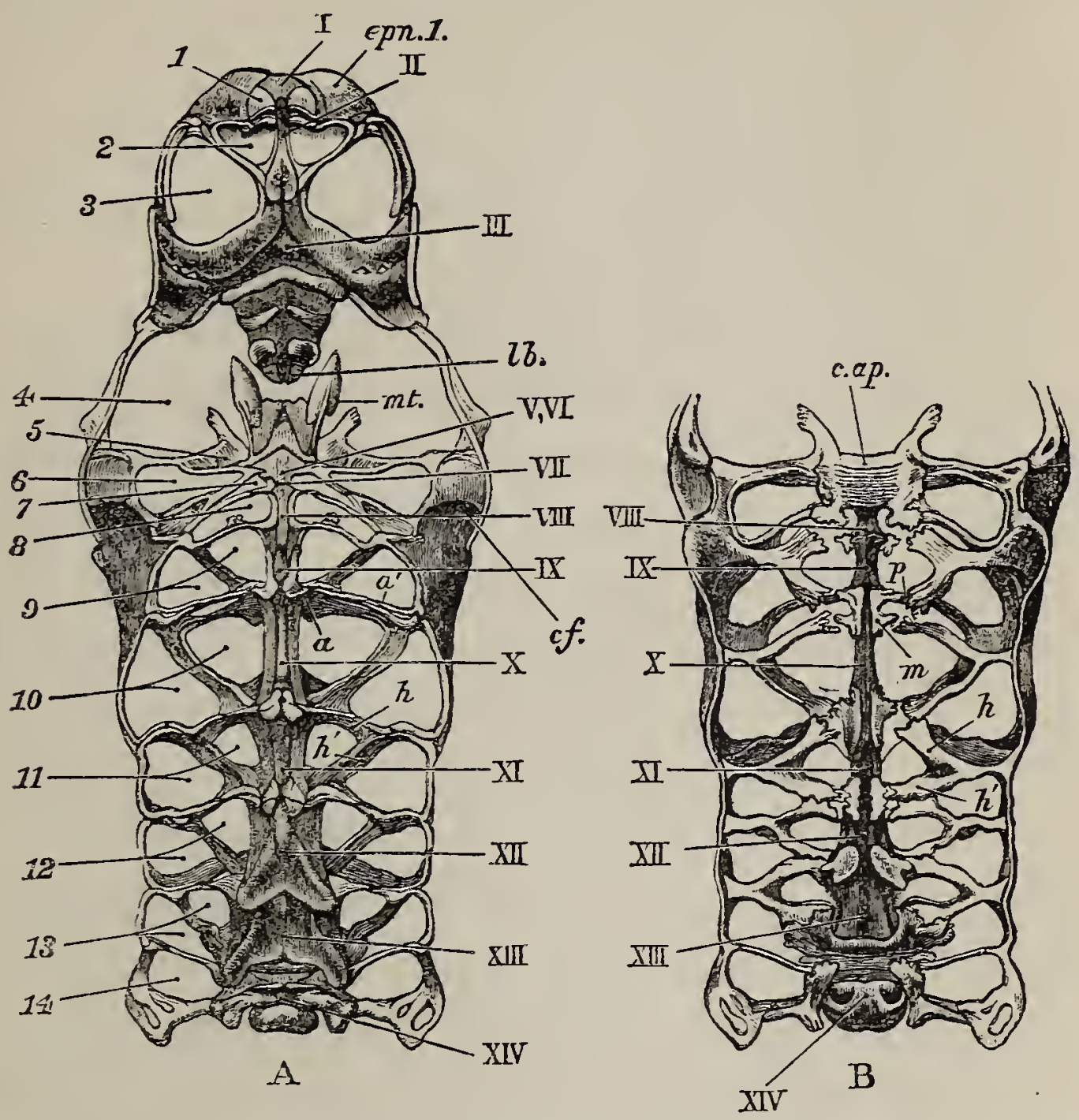

FIG. 39.-Astacus furiatilis.-The cephalothoracic sterna and the endophragmal system ( $\times 2$ ). $A$, from beneath; $B$, from above. $a, a^{\prime}$, arthrophragms or partitions between the articular cavities for the limbs ; c.ap, cephalic apodeme; $c f$, cervical fold ; $c p n$. 1, epimeron of the antennulary somite; $h$, anterior, and $h^{\prime}$, posterior horizontal process of endopleurite: $l b$, labrum ; $m$, mesophragm ; $m t$, metastoma ; $p$, paraphragm ; 1-XIV, cephalothoracic sterna ; 1-14, articular cavities of the cephalothoracic appendages. (The anterior cephalic sterna are bent downwards in $\mathrm{A}$ so as to bring them into the same plane with the remaining cephalothoracic sterna; in $\mathrm{B}$ these sterna are not shown.) 


\section{THE MORPHOLOGY OF THE COMMON CRAYFISH.}

rudimentary branchia. These areæ of the epimera, in fact, correspond with the shield-shaped plate of the hindermost somite. In the next most anterior somite (that which bears the first pair of ambulatory legs) there is only a small elevation in the place of the rudimentary branchia; and in the anterior four thoracic somites nothing of the kind is visible.

On the sternal aspect of the thorax (figs. 3 and 39, A) a triangular space is interposed between the basal joints or coxopodites of the penultimate and the ante-penultimate pairs of ambulatory legs, while the coxopodites of the more anterior limbs are closely approximated. The triangular area in question is occupied by two sterna (fig. 39, A, XII, XIII), the lateral margins of which are raised into flange-like ridges. The next two sterna ( $X$, $X I)$ are longer, especially that which lies between the forceps $(X)$, but they are very narrow; while the lateral processes are reduced to mere tubercles at the posterior ends of the sterna. Between the three pairs of maxillipedes, the sterna (VII, VIII, IX) are yet narrorer, and become gradually shorter; but traces of the tubercles at their posterior ends are still discernible. The most anterior of these sternal rods passes into a transrersely elongated plate, shaped like a broad arrow $(V, V I)$, which is constituted by the conjoined sterna of the tro posterior somites of the head.

Anteriorly to this, and between it and the posterior end of the elongated oral aperture, the sternal region is 
occupied only by soft or imperfectly calcified cuticle, which, on each side of the hinder part of the mouth, passes into one of the lobes of the metastoma $(m t)$. At the base of each of these lobes there is a calcified plate, united by an oblique suture with another, which occupies the whole length of the lobe and gives it firmness. The soft narrow lip which constitutes the lateral boundary of the oral aperture, and lies between it and the mandible, passes, in front, into the posterior face of the labrum (lb).

In front of the mouth, the sternal region which appertains, in part, to the antennæ, and, in part, to the mandibles, is obvious as a broad plate (III), termed the epistoma. The middle third of the posterior edge of the epistoma gives rise to a thickened transverse ridge, with rounded ends, slightly excavated behind, and is then continued into the labrum (lb), which is strengthened by three pairs of calcifications, arranged in a longitudinal series. The sides of the front edge of the epistoma are excarated, and bound the articular cavities for the basal joints of the antennæ (3); but, in the middle line, the epistoma is continued forwards into a spear-head shaped process (figs. 39 and 40,II), to which the posterior end of the antennulary sternum contributes. The antennulary sternum is very narrow, and its anterior or upper end runs into a small but distinct conical median spine (fig. 40,t.). Upon this follows an uncalcified plate, bent into the form of a half cylinder $(I)$, which lies between the inner ends of 
the eye-stalks and is united with adjacent parts only by flexible cuticle, so that it is freely. movable. This represents the whole of the sternal region, and probabiy more, of the ophthalmic somite.

The sterna of fourteen somites are thus identifiable in the cephalothorax. The corresponding epimera are

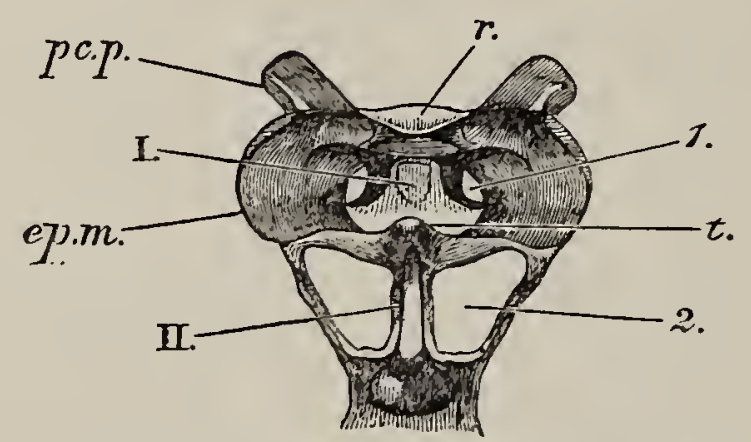

FIG. 40.-Astacus furiatilis.-The ophthalmic and antennulary somites $(\times 3)$. I, ophthalmic, and $I I$, antennulary sternum; 1 , articular surface for eyestalk; 2, for antennule; cpm, epimeral plate; $p c p$, procephalic process; $r$, base of rostrum ; $t$, tubercle.

represented, in the thorax, by the thin inner walls of the branchial chamber; the pleura, by the branchiostegites; and the terga, by so much of the median region of the carapace as lies behind the cervical groove. That part of the carapace which is situated in front of this groove occupies the place of the terga of the head; while the low ridge, skirting the oral and præ-oral region, in which it terminates laterally, represents the pleura of the cephalic somites.

The epimera of the head are, for the most part, very narrow; but those of the antennulary somite are broad plates (fig. 40, epm.), which constitute the posterior 
wall of the orbits. I am inclined to think that a transverse ridge, which unites these under the base of the rostrum, represents the tergum of the antennulary somite, and that the rostrum itself belongs to the next or antennary somite.*

The sharp convex rentral edge of the rostrum (fig. 41) is produced into a single, or sometimes two divergent spines, which descend, in front of the ophthalmic somite, towards the conical tubercle mentioned above: it thus gives rise to an imperfect partition between the orbits.

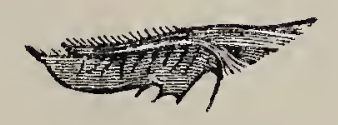

FIG. 41.-Astacus fluviatilis.-The rostrum, seen from the left side.

The internal face of the sternal wall of the whole of the thorax and of the post-oral part of the head, presents a complicated arrangement of hard parts, which is known as the endophragmal system (figs. 39, $B, 42$, and 43 ), and which performs the office of an internal skeleton by affording attachment to muscles, and serving to protect important viscera, while at the same time it ties the somites together, and unites them into a solid whole. In reality, however, the curious pillars and bulkheads which enter into the composition of the endophragmal system are all

* There are some singular marine crustacea, the Squillide, in which both the ophthalmic and the antennary somites are free and movable, while the rostrum is articulated with the tergum of the antennary somite. 


\section{THE MORPHOLOGY OF THE COMIION CRAYFISH.}

mere infoldings of the cuticle, or apodemes; and, as such, they are shed along with the other cuticular structures during the process of ecdysis.

Without entering into unnecessary details, the general principle of the construction of the endophragmal skeleton may be stated as follorrs. Four apodemes are dereloped between erery two somites, and as every apodeme is a fold of the cuticle, it follows that the anterior wall of each belongs to the somite in front, and the posterior wall to the somite behind. All four apodemes lie in the rentral half of the somite and form a single transverse series; consequently there are two nearer the middle line, which are termed the endosternites, and two further off, which are the endopleurites. The former lie at the inner, and the latter at the outer ends of the partitions or arthrophragms (fig. 39, A, $a, a^{\prime}$, fig. 42, aph), between the articular carities for the basal joints of the limbs, and they spring partly from the latter and partly from the sternum and the epimera respectively.

The endosternite (fig. 42 , ens.) ascends vertically, with a slight inclination forwards, and its summit narrows and assumes the form of a pillar, with a flat, transrersely elongated capital. The inner prolongation of the capital is called the mesophragm (mph.), the outer the paraphragm $(p p h$.$) . The mesophragms of the two endosternites of a$ somite usually unite by a median suture, and thus form a complete arch orer the stermal canal (s.c.), which lies between the endosternites. 
The endopleurites (en.p $c^{7}$ ) are also vertical plates, but they are relatively shorter, and their inner angles give off two nearly horizontal processes, one of which passes obliquely forwards (fig. 39, B, $h$, fig. $42, h . p$. ) and unites with the paraphragm of the endosternite of the somite in front, while the other, passing obliquely backwards (fig. $39, h^{\prime}$ ), becomes similarly connected with the endo. sternite of the somite behind.

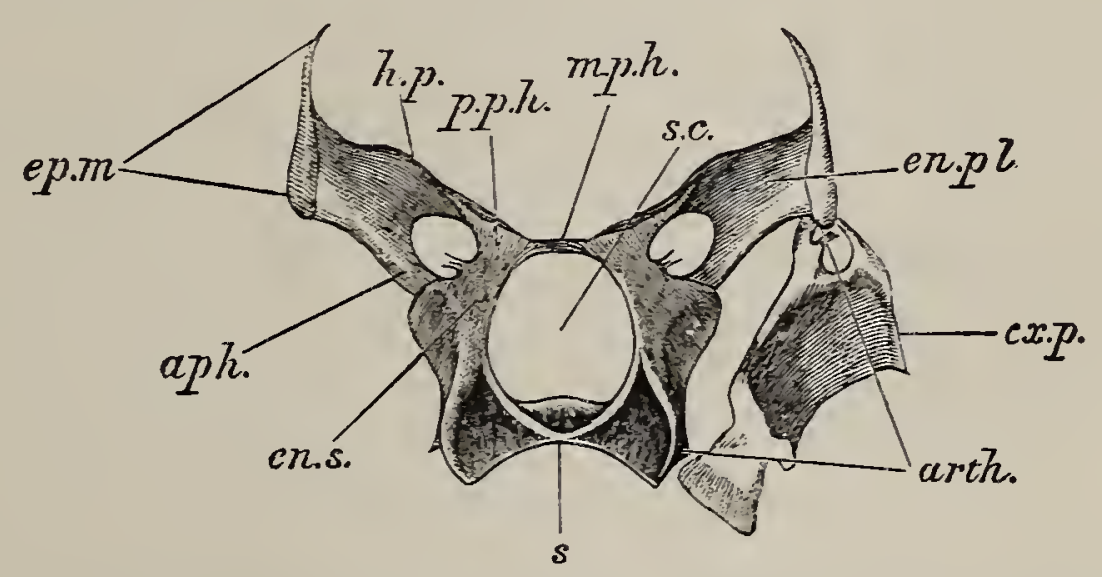

EIG. 42.-Astacus fluriatilis. - A segment of the endophragmal system ( $\times 3)$. aph, arthrophragm; arth, arthrodial or articular cavity; cxp, coxopodite of the ambulatory leg; enpl, endopleurite; ens, endosternite ; epm, epimeron ; $h p$, horizontal process of endopleurite; $m p h$, mesophragm ; $p p h$, paraphragm ; $s$, sternum of somite ; $s c$, sternal canal.

The endopleurites of the last thoracic somite are :udimentary, and its endosternites are small. On the other hand, the mesophragmal processes of the endosternites of the two posterior somites of the head (fig. 39, B, c.ap), by which the endophragmal system terminates in front, are particularly strong and closely united together. They thus, with their endopleurites, form a solid partition between the stomach, which lies upon them, and the mass of 
coalesced anterior thoracic and posterior cephalic ganglia situated beneath them. Strong processes are given off from their anterior and outer angles, which curve round the tendons of the adductor muscles of the mandibles, and give attachment to the abductors.

In front of the mouth there is no such endophragmal system as that which lies behind it. But the anterior gastric muscles are attached to two flat calcified plates, which appear to lie in the interior of the head (though they are really situated in its upper and front wall) on each side of the base of the rostrum, and are called the procephalic processes (figs. 40, 43, p.cp). Each of these plates constitutes the posterior wall of a narrow cavity which opens externally into the roof of the orbit, and has been regarded (though, as it appears to me, without sufficient reason) as an olfactory organ. I am disposed to think, though I have not been able to obtain complete evidence of the fact, that the procephalic processes are the representatives of the "procephalic lobes" which terminate the anterior end of the body in the embryo crayfish. At any rate, they occupy the same position relatively to the eyes and to the carapace; and the hidden position of these processes, in the adult, appears to arise from the extension of the carapace at the base of the rostrum over the fore part of the originally free sternal surface of the head. It has thus covered over the procephalic processes, in which the sternal wall of the body terminated; and the cavities which lie in front of them are 
simply the interspaces left between the inferior or posterior wall of the prolongation of the carapace and the originally exposed external faces of these regions of the cephalic integument.

Fourteen somites having thus been distinguished in the cephalothorax, and six being obvious in the abdomen, it is clear that there is a somite for every pair of appendages. And, if we suppose the carapace divided into segments answering to these sterna, the whole body will be made up of twenty somites, each having a pair of appendages. As the carapace, however, is not actually divided into terga in correspondence with the sterna which it covers, all we can safely conclude from the anatomical facts is that it represents the tergal region of the somites, not that it is formed by the coalescence of primarily distinct terga. In the head, and in the greater part of the thorax, the somites are, as it were, run together, but the last thoracic somite is partly free and to a slight extent moveable, while the abdominal somites are all free, and moveably articulated together. At the anterior end of the body, and, apparently, from the antennary somite, the tergal region gives rise to the rostrum, which projects between and beyond the eyes. At the opposite extremity, the telson is a corresponding median outgrowth of the last somite, which has become moveably articulated therewith. The narrowing of the sternal moieties of the anterior thoracic somites, to- 
gether with the sudden widening of the same parts in the posterior cephalic somites, gives rise to the lateral depression (fig. 39, cf) in which the scaphognathite lies. The limit thus indicated corresponds with that marked by the cervical groove upon the surface of the carapace, and separates the head from the thorax. The three pair of maxillipedes $(7,8,9)$, the forceps (10), the ambulatory

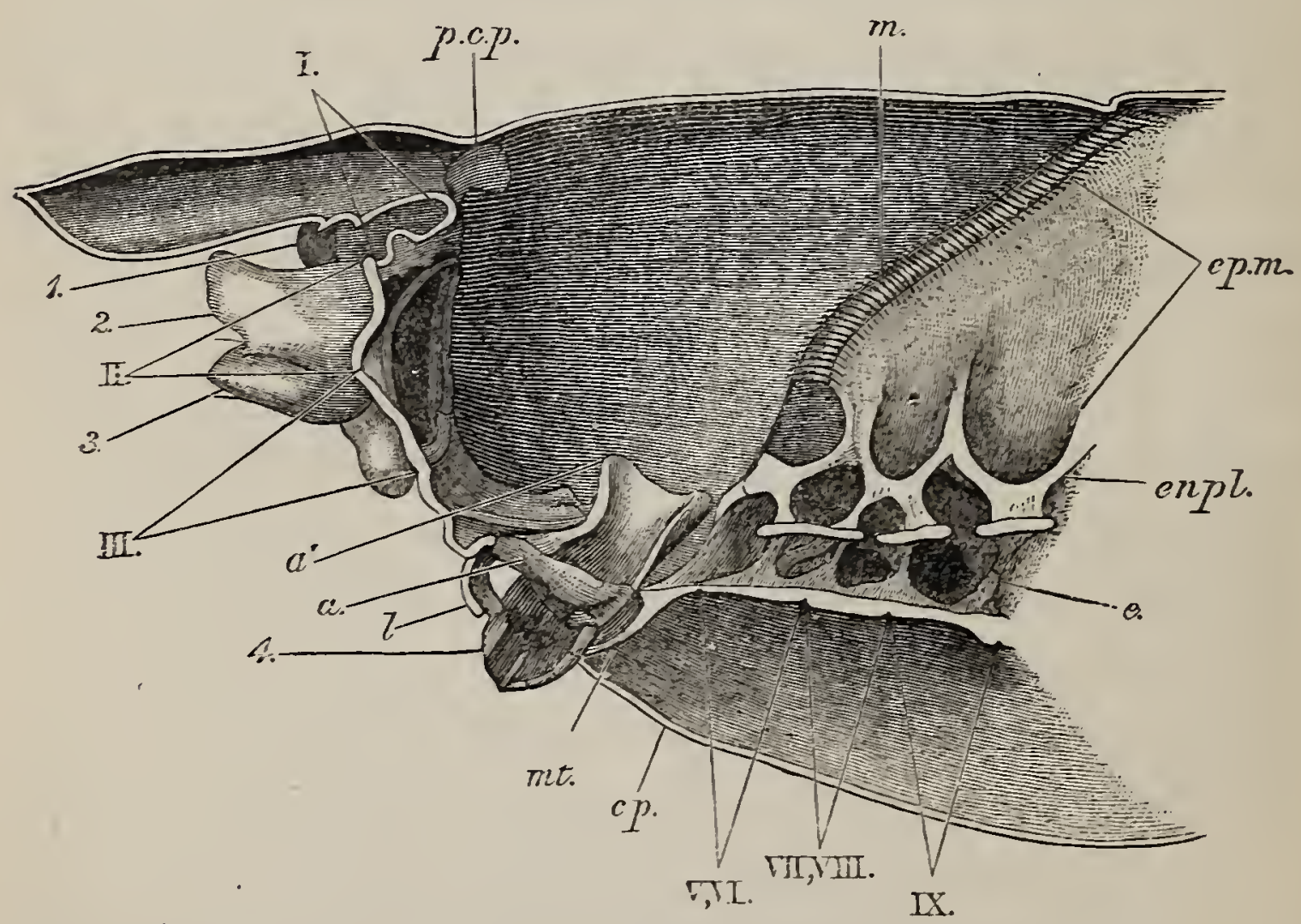

FIG. i3.-Astacus furviatilis.-Longitudinal section of the anterior part of the cephalothorax ( $\times 3)$. $I-I X$, sterna of first nine cephalothoracic somites; 1 , eyestalk ; 2 , basal joint of antennule ; 3 , basal joint of antenna; 4 , mandible; $a$, inner division of the masticatory surface of the mandible; $a^{\prime}$, apophysis of the mandible for muscular attachment ; $c p$, free edge of carapace ; $c$, endosternite : $c n p l$, endopleurite; cpm, epimeral plate; 7 , labrum; $m$, muscular fibres connecting epimera with interior of carapace; $m t$, metastoma ; pcp. procephalic process. 
Iimbs $(11-14)$, and the eight somites of which they are the appendages $(V I I-X I V)$, lie behind this boundary and belong to the thorax. The two pairs of maxillæ $(5,6)$ the mandibles (4), the antennæ (3), the antennules (2), the eyestalks (1), and the six somites to which they are attached $(I-V I)$, lie in front of the boundary and compose the head.

Another important point to be noticed is that, in front of the mouth, the sternum of the antennary somite (fig. $43, I I I)$ is inclined at an angle of $60^{\circ}$ or $70^{\circ}$ to the direction of the sterna behind the mouth. The sternum of the antennulary somite (II) is at right angles to the latter ; and that of the eyes $(I)$ looks upwards as well as forwards. Hence, the front of the head beneath the rostrum, though it looks forwards, or even upwards, is homologous with the sternal aspect of the other somites. It is for this reason that the feelers and the eyestalks take a direction so different from that of the other appendages. The change of aspect of the sternal surface in front of the mouth, thus effected, is what is termed the cephalic flexure.

Since the skeleton which invests the trunk of the crayfish is made up of a twenty-fold repetition of somites, homologous with those of the abdomen, we may expect to find that the appendages of the thorax and of the head, however unlike they may seem to be to those of the abdomen, are nevertheless reducible to the same fundamental plan. 
164 THE MORPHOLOGY OF THE COMMON CRAYFISH.

The third maxillipede is one of the most complete of these appendages, and may be advantageously made the starting point of the study of the whole series.

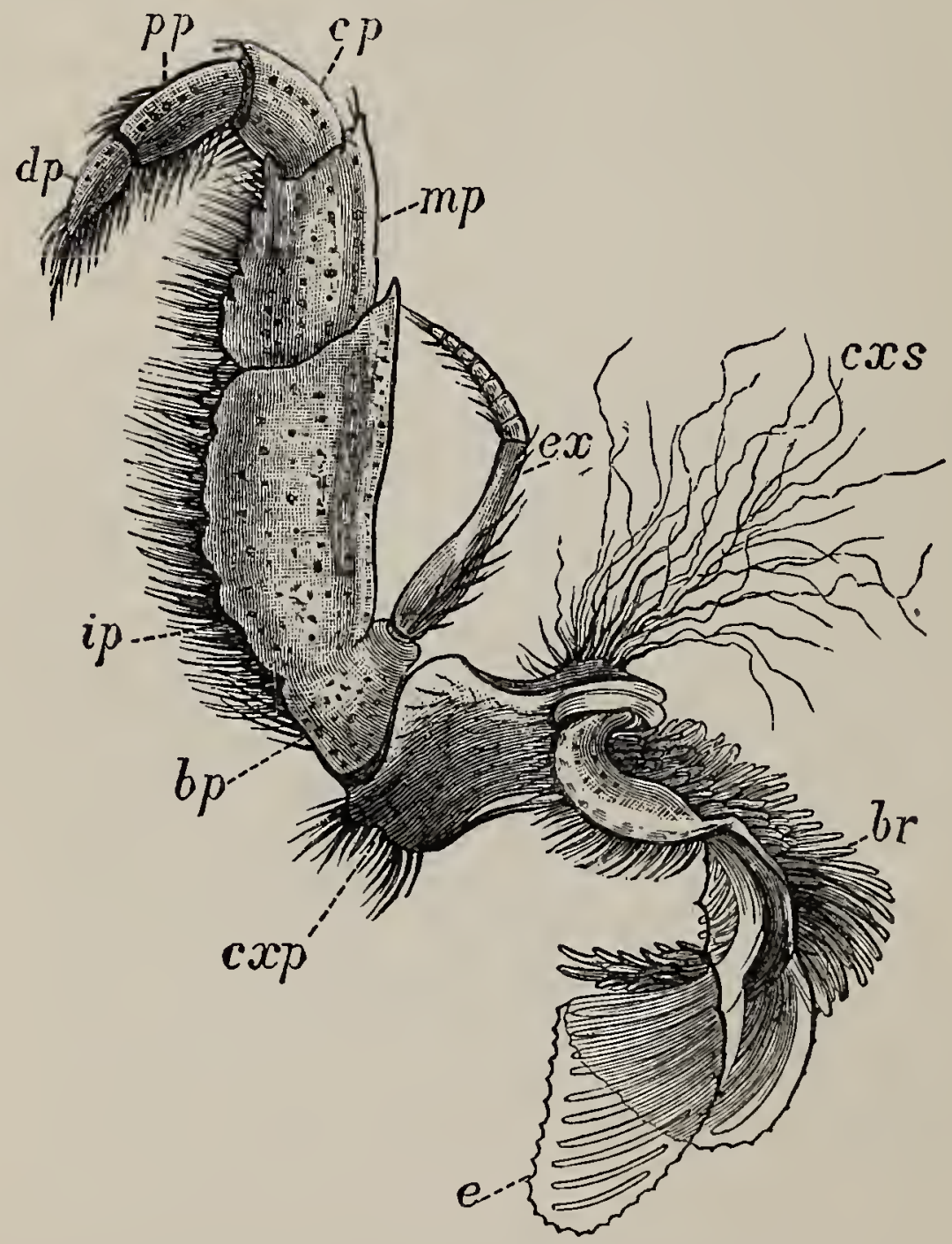

FIG. 44.-Astacus fuviatilis. - The third or external maxillipede of the left side $(\times 3) . e$, lamina, and $b r$, branchial filaments of the podobranchia ; $c x p$, coxopodite ; $c x s$, coxopoditic setæ ; $b p$, basipodite ; $c x$, exopodite ; $i p$, ischiopodite ; $m p$, meropodite; $c p$, carpopodite ; $p p$, propodite; $d p$, dactylopodite.

Neglecting details for the moment, it may be said that the appendage consists of a basal portion (fig. 44, cxp, bp), 
with two terminal divisions (ip to $d p$, and $e x$ ), which are directed forwards, below the mouth, and a third, lateral appendage $(e, b r)$, which runs up, beneath the carapace, into the branchial chamber. The latter is the gill, or podobranchia, attached to this limb, and it is something not represented in the abdominal limbs. But, with regard to the rest of the maxillipede, it is obvious that the basal portion $(c x p, b p)$ represents the protopodite, and the two terminal divisions the endopodite and the exopodite respectively. It has been observed that, in the abdominal appendages, the extent to which segmentation occurs in homologous parts varies indefinitely; an endopodite, for example, may be a continuous plate, or may be subdivided into many joints. In the maxillipede, the basal portion is divided into two joints; and, as in the abdominal limb, the first, or that which articulates with the thorax, is termed the coxopodite (cxp), while the second is the basipodite (bp). The stout, leg-like endopodite appears to be the direct continuation of the basipodite; while the much more narrow and slender exopodite articulates with its outer side. The exopodite $(e x)$ is by no means unlize one of the exopodites of the abdominal limbs, consisting as it does of an undivided base and a many-jointed terminal filament. The endopodite, on the contrary, is strong and massive, and is divided into five joints, named, from that nearest to the base onwards, ischiopodite (ip), meropodite ( $m p)$, carpopodite (cp), propodite $(p p)$, and dactylopodite (dp). 
The second maxillipede (fig. 45, B) has essentially the same composition as the first, but the exopodite $(e x)$ is relatively larger, the endopodite $(i p-d p)$ smaller and softer; and, while the ischiopodite (ip) is the longest joint in the third maxillipede, it is the meropodite $(\mathrm{mp})$ which is longest in the second. In the first maxillipede
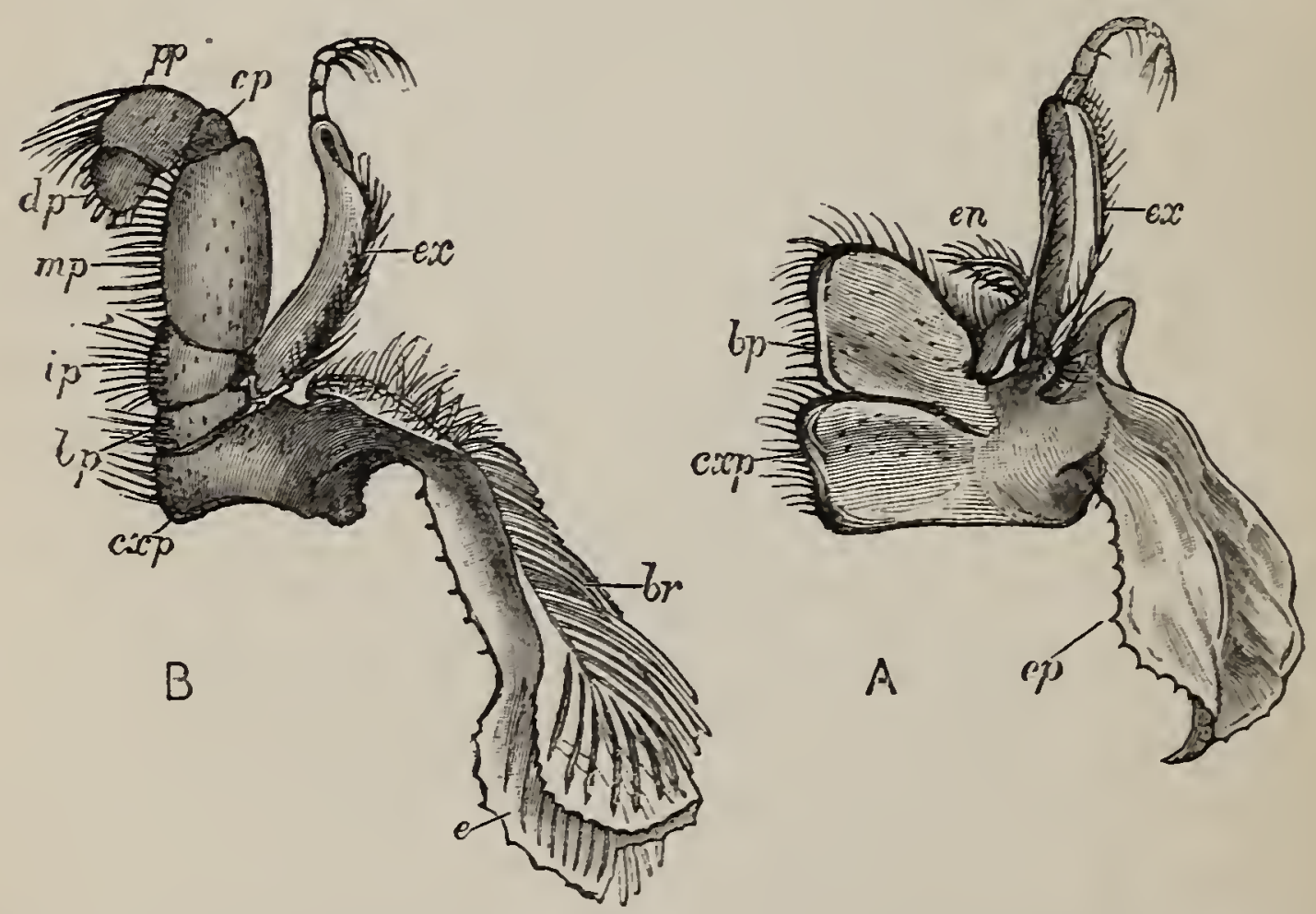

FIG. 45.-Astacus fluriatilis. $-\mathrm{A}$, the first; $\mathrm{B}$, the second maxillipede of the left side ( $\times 3)$. cxp, coxopodite; $b p$, basipodite ; $e, b r$, podobranchia ; $c p$, epipodite; $e n$, endopodite; $e x$, exopodite ; ip, ischiopodite; $m p$, meropodite; $c p$, carpopodite : $p p$, propodite ; $d p$, dactylopodite.

(fig. 45, A) a great modification has taken place. The coxopodite (cxp) and the basipodite (bp) are broad thin plates with setose cutting edges, while the endopodite $(e n)$ is short and only two-jointed, and the undivided portion of the exopodite $(e x)$ is very long. The place of 
the podobranchia is taken by a broad soft membranous plate entirely devoid of branchial filaments (ep). Thus, in the series of the thoracic limbs, on passing forwards from the third maxillipede, we find that though the plan of the appendages remains the same; $(1)$ the protopodite increases in relative size; (2) the endopodite diminishes; (3) the exopodite increases; (4) the podobranchia finally takes the form of a broad membranous plate and loses its branchial filaments.

Writers on descriptive Zoology usually refer to the parts of the maxillipedes under different names from those which are employed here. The protopodite and the endopodite taken together are commonly called the stem of the maxillipede, while the exopodite is the palp, and the metamorphosed podobranchia, the real nature of which is not recognised, is termed the flagellum.

When the comparison of the maxillipedes with the abdominal members, however, had shown the fundamental uniformity of composition of the two, it became desirable to invent a nomenclature of the homologous parts which should be capable of a general application. The names of protopodite, endopodite, exopodite, which I have adopted as the equivalents of the "stem" and the "palp," were proposed by Milne-Edwards, who at the same time suggested epipodite for the "flagellum." And the lamellar process of the first maxillipede is now very generally termed an epipodite; while the podobranchiæ, which have exactly the same relations to the following 
limbs, are spoken of as if they mere totally different structures, under the name of branchiæ or gills.

The flagellum or epipodite of the first maxillipede, however, is nothing but the slightly modified stem of a podobranchia, which has lost its branchial filaments; but the term "epipodite" may be conveniently used for podobranchiæ thus modified. Unfortunately, the same term is applied to certain lamelliform portions of the branchiæ of other crustacea, which answer to the laminæ of the crayfishes' branchiæ; and this ambiguity must be borne in mind, though it is of no great moment.

On examining an appendage from that part of the thorax which lies behind the third maxillipede, say, for example, the sixth thoracic limb (the second walking leg) (fig. 46), the two joints of the protopodite and the five joints of the endopodite are at once identifiable, and so is the podobranchia; but the exopodite has vanished altogether. In the eighth, or last, thoracic limb, the podobranchia has also disappeared. The fifth and sixth limbs also differ from the seventh and eighth, in being chelate; that is to say, one angle of the distal end of the propodite is prolonged and forms the fixed le? of the pincer. The produced angle is that which is turned downwards when the limb is fully extended (fig. 46). In the forceps, the great chela is formed in just the same way; the only important difference lies in the fact that, as in the external maxillipede, the basipodite and the ischiopodite are immoveably united. Thus, 


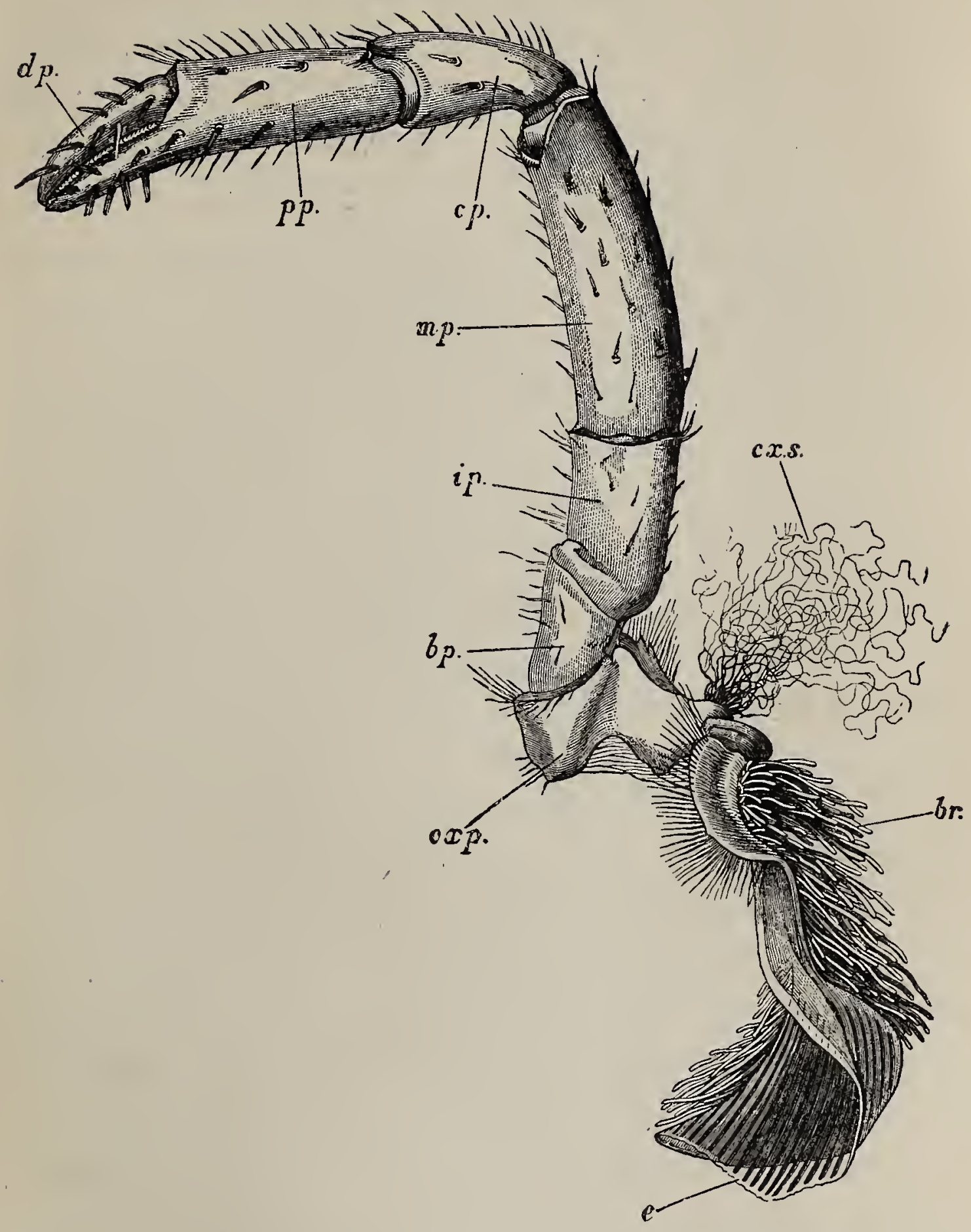

FIG. 46.-Astacus furiatilis.-The second ambulatory leg of the left side ( $\times 3$ ). cxp, coxopodite ; $b p$, basipodite ; $b r$, gill ; cxs, coxo. poditic setæ ; $e$, lamina of gill or epipodite; $i p$, ischiopodite ; $m p$, meropodite; $c p$, carpopodite ; $p p$, propodite ; $d p$, dactylopodite. 
170 THE MORPHOLOGY OF THE COMMON CRAYFISH.

the limbs of the thorax are all reducible to the same type as those of the abdomen, if we suppose that, in the posterior five pair, the exopodites are suppressed; and that, in all but the last, podobranchire are superadded.

Turning to the appendages of the head, the second maxilla (fig. $47, \mathrm{C}$ ) presents a further modification of the disposition of the parts seen in the first maxillipede. The coxopodite (cxp) and the basipodite (bp) are still thinner and more lamellar, and are subdivided by deep fissures which extend from their inner edges. The endopodite $(e n)$ is very small and undivided. In the place of the exopodite and the epipodite there is only one great plate, the scaphognathite $(s g)$ which either is such an epipodite as that of the first maxillipede with its anterior basal process much enlarged, or represents both the exopodite and the epipodite. In the first maxilla (B), the exopodite and the epipodite have disappeared, and the endopodite $(e n)$ is insignificant and unjointed. In the mandibles (A), the representative of the protopodite is strong and transversely elongated. Its broad inner or oral end presents a semicircular masticatory surface divided by a deep longitudinal groove into two toothed ridges. The one of these follows the convex anterior or inferior contour of the masticatory surface, projects far beyond the other, and is provided with a sharp serrated edge; the other (fig.43,a) gives rise to the straight posterior or superior contour of the masticatory surface, and is more obtusely tuberculated. In front, the inner 
ridge is continued into a process by which the mandible articulates with the epistoma (fig. 47, A, ar). The endo-
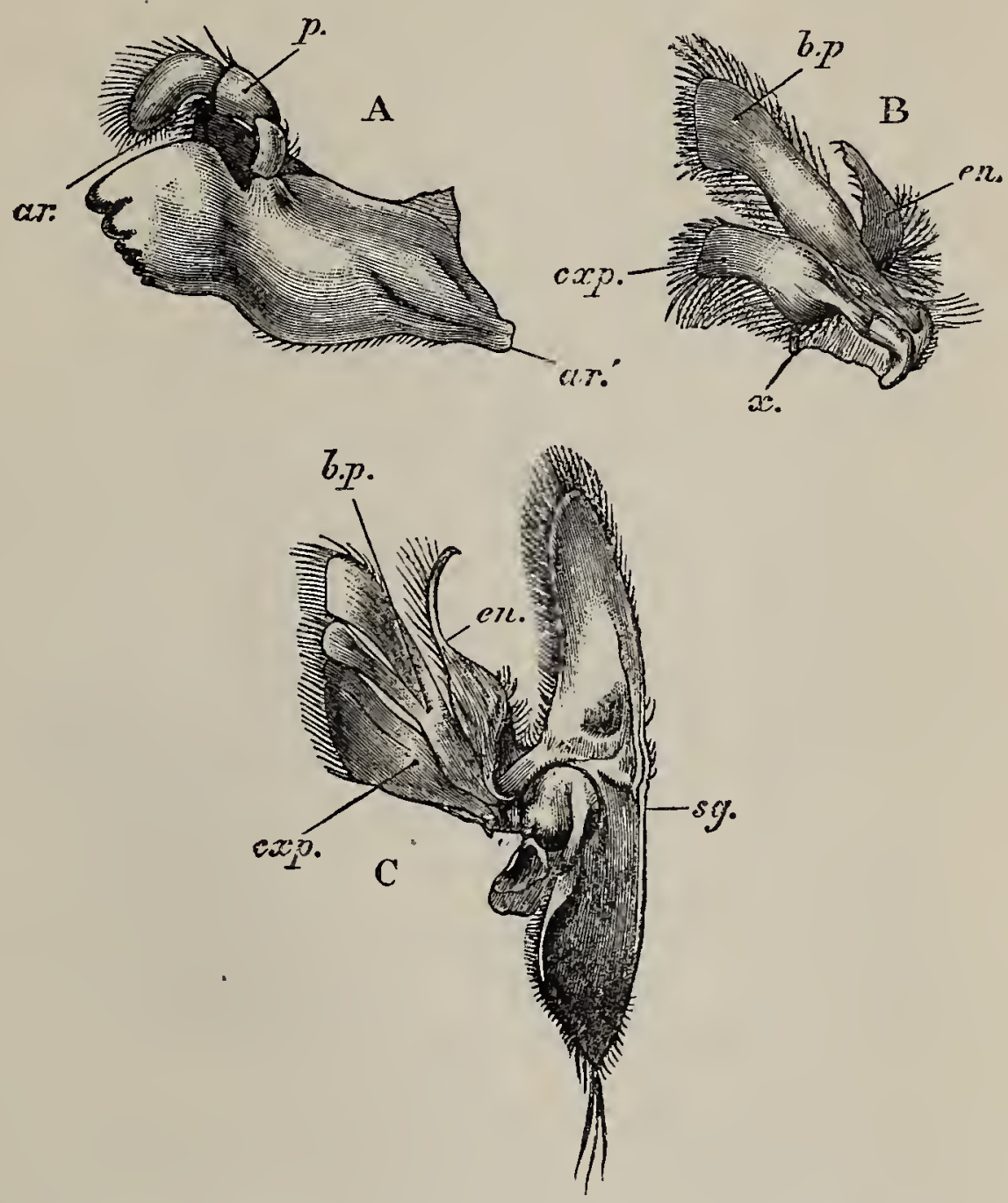

FIG. 47.-Astacus fiuviatilis -A, mandible ; B, first maxilla ; C, second maxilla of the left side $(\times 3)$. $a r$, internal, and $a r^{\prime}$, external articular process of the mandible; $b p$, basipodite ; cxp, coxopodite; $e n$, endopodite ; $p$, palp of the mandible; $s g$, scaphognathite; $x$, internal process of the first maxilla.

podite is represented by the three-jointed palp $(p)$, the terminal joint of which is oval and beset with numerous strong setæ, which are especially abundant along its anterior edge. 
In the antenna (fig. 48, C) the protopodite is twojointed. The basal segment is small, and its ventral face presents the conical prominence on the posterior aspect of which is the aperture of the duct of the renal gland $(g g)$. The terminal segment is larger and is subdivided by deep longitudinal folds, one upon the dorsal and
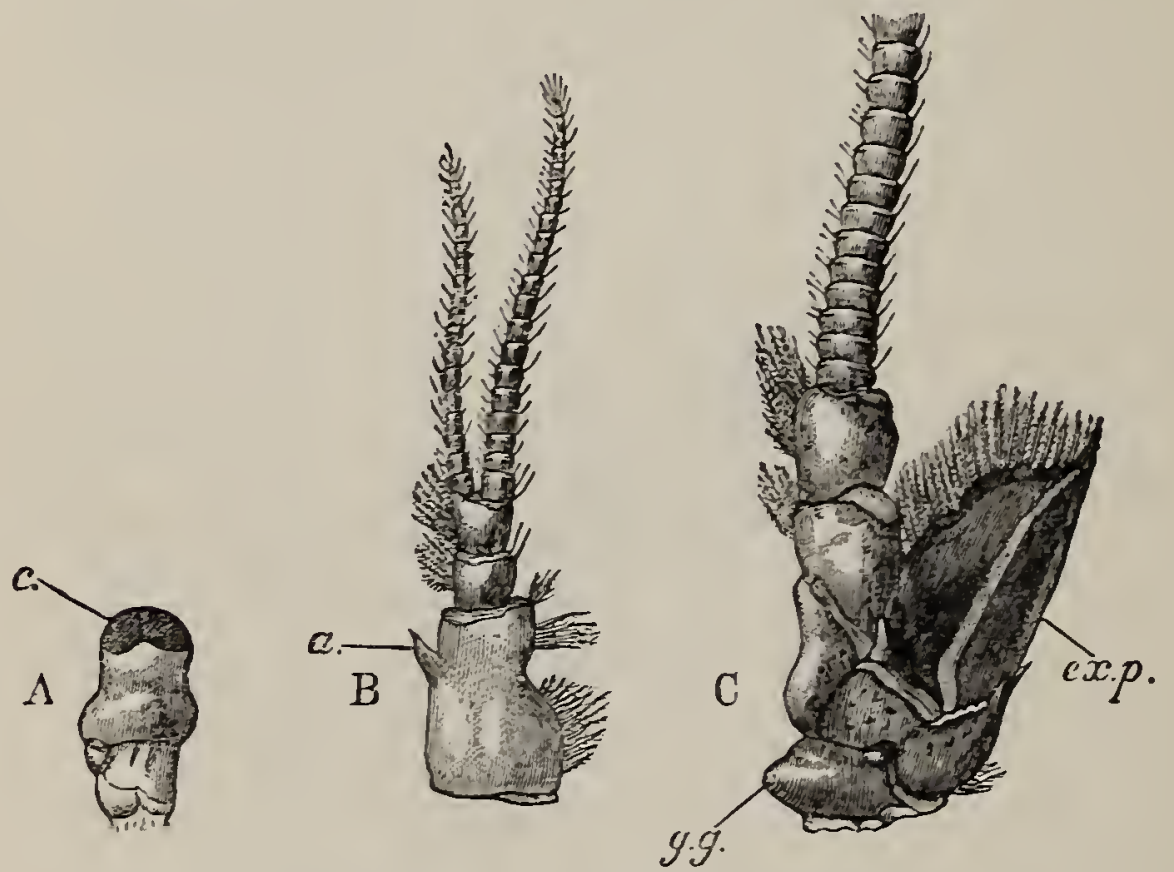

FIG. 48.-Astacus furiatilis.-A, eye-stalk; B, antennule ; C, antenna of the left side $(\times 3) . \quad a$, spine of the basal joint of the antennule; $c$, corneal surface of the eye; exp, exopodite or squame of the antenna; $g g$, aperture of the duct of the green gland.

one upon the ventral face, into two moieties which are more or less moreable upon one another. In front and externally it bear's the broad flat squame (exp) of the antenna, as an exopodite. Internally, the long annulated "feeler" which represents the endopodite, is connected with it by two stout basal segments. 
The antennule (fig. 48, B) has a three-jointed stem and two terminal annulated filaments, the outer of which is thicker and longer than the inner, and lies rather above as well as external to the latter. The peculiar form of the basal segment of the stem of the antennule has already been adverted to (p. 116). It is longer than the other two segments put together, and near the anterior end its sternal edge is produced into a single strong spine $(a)$. The stem of the antennule answers to the protopodite of the other limbs, though its division into three joints is unusual ; the two terminal annulated filaments represent the endopodite and the exopodite.

Finally, the eyestalk (A) has just the same structure as the protopodite of an abdominal limb, having a short basal and a long cylindrical terminal joint.

From this brief statement of the characters of the appendages, it is clear that, in whatever sense it is allowable to say that the appendages of the abdomen are constructed upon one plan, which is modified in execution by the excess of development of one part over another, or by the suppression of parts, or by the coalescence of one part with another, it is allowable to say that all the appendages are constructed on the same plan, and are modified on similar principles. Given a general type of appendage consisting of a protopodite, bearing a podobranchia, an endopodite and an exopodite, all the actual appendages are readily derivable from that type. 
174 THE MORPHOLOGY OF THE COMMON CRAYFISH.

In addition, therefore, to their adaptation to the purposes which they subserve, the parts of the skeleton of the crayfish show a unity in diversity, such as, if the animal were a piece of human worlmanship, would lead us to suppose that the artificer was under an obligation not merely to make a machine capable of doing certain kinds of work, but to subordinate the nature and arrangement of the mechanism to certain fixed architectural conditions.

The lesson thus taught by the skeletal organs is reiterated and enforced by the study of the nervous and the muscular systems. As the skeleton of the whole body is capable of resolution into the skeletons of iwenty separate metameres, variously modified and combined; so is the entire ganglionic chain resolvable into twenty pairs of ganglia various in size, distant in this region and approximated in that; and so is the muscular system of the trunk conceivable as the sum of twenty myctomes or segments of the muscular system appropriate to a metamere, variously modified according to the degree of mobility of the different regions of the organism.

The building up of the body by the repetition and the modification of a few similar parts, which is so obvious from the study of the general form of the somites and of their appendages, is still more remarkably illustrated, if we pursue our investigations further, and trace 
out the more intimate structure of these parts. The tough, outer coat, which has been termed the cuticula, except so far as it presents different degrees of hardness, from the presence or absence of calcareous salts, is obviously everywhere of the same nature; and, by macerating a crayfish in caustic alkali, which destroys all its other components of the body, it will be readily enough seen that a continuation of the cuticular layer passes in at the mouth and the vent, and lines the alimentary canal; furthermore, that processes of the cuticle covering various parts of the trunk and limbs extend inwards, and afford surfaces of attachment to the muscles, as the apodemata and tendons. In technical language, the cuticular substance which thus enters so largely into the composition of the bodily fabric of the erayfish is called a tissue.

The flesh, or muscle, is another kind of tissue, which is readily enough distinguished from cuticular tissue by the naked eye; but, for a complete discrimination of all the different tissues, recourse must be had to the microscope, the application of which to the study of the ultimate optical characters of the morphological constituents of the body has given rise to that branch of morphology which is known as Histology.

If we count every formed element of the body, which is separable from the rest by definite character's, as a tissue, there are no more than eight kinds of such tissues in the crayfish; that is to say, every solid constituent 
of the body consists of one or more of the following eight histological groups :-

1. Blood corpuscles; 2. Epithelium; 3. Connective tissue ; 4. Muscle; 5. Nerve; 6. Ova; 7. Spermatozoa; 8. Cuticle.

1. A drop of freshly-drawn blood of the crayfish contains multitudes of small particles, the blood corpuscles,

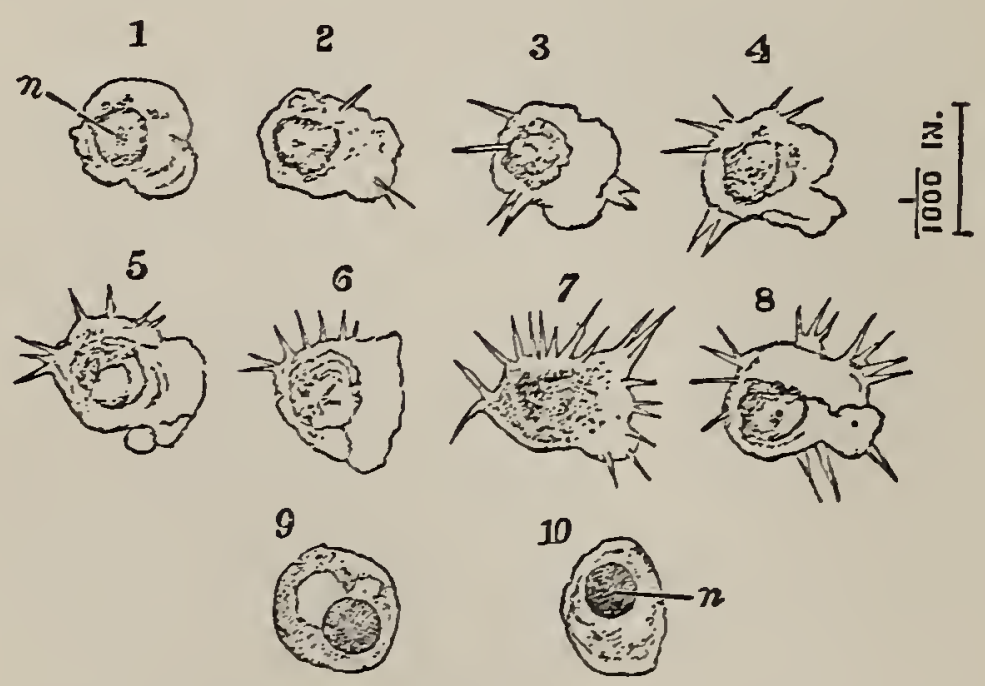

FIG. 49.-Astacus fluriatilis. - The corpuscles of the blood, highly magnified. 1-8, show the changes undergone by a single corpuscle during a quarter of an hour; $n$, the nucleus; 9 and 10 are corpuscles killed by magenta, and having the nucleus deeply stained by the colouring matter.

which rarely exceed 1-700th, and usually are about 1-1000th, of an inch in diameter (fig. 49). They are sometimes pale and delicate, but generally more or less dark, from containing a number of minute strongly refracting granules, and they are ordinarily exceedingly irregular in form. If one of them is watched continu- 
ously for two or three minutes, its shape will be seen to undergo the constant but slow. changes to which passing reference has already been made (p.69). One or other of the irregular prolongations will be drawn in, and another thrown out elsewhere. The corpuscle, in fact, has an inherent contractility, like one of those low organisms, known as an Amoba, whence its motions are frequently called amobiform. In its interior, an ill-marked oval contour may be seen, indicating the presence of a spheroidal body, about 1-2000th of an inch in diameter, which is the nucleus of the corpuscle (n). The addition of some re-agents, such as dilute acetic acid, causes the corpuscles at once to assume a spherical shape, and renders the nucleus very conspicuous (fig. 49,9 and 10). The blood corpuscle is, in fact, a simple nucleated cell, composed of a contractile protoplasmic mass, investing a nucleus; it is suspended freely in the blood; and, though as rnuch a part of the crayfish organism as any other of its histological elements, leads a quasi-independent existence in that fluid.

2. Under the general name of epithelium, may be included a form of tissue, which everywhere underlies the exoskeleton (where it corresponds with the epidermis of the higher animals), and the cuticular lining of the alimentary canal, extending thence into the hepatic cæca. It is further met with in the generative organs, and in the green gland. Where it forms the subcuticular layer of the integument and of the alimentary canal, it is found to 
178 THE MORPHOLOGY OF THE COMMON CRAYFISH.

consist of a protoplasmic substance (fig. 50), in which close set nuclei $(n)$ are imbedded. If a number of blood corpuscles could be supposed to be closely aggregated together into a continuous sheet, they would gire rise to such a structure as this; and there can be no doubt that it really is an aggregate of nucleated cells, though the limits between the individual cells are rarely visible in the fresh state. In the liver, howerer, the cells grow, and become detached from one another in the wider and lower

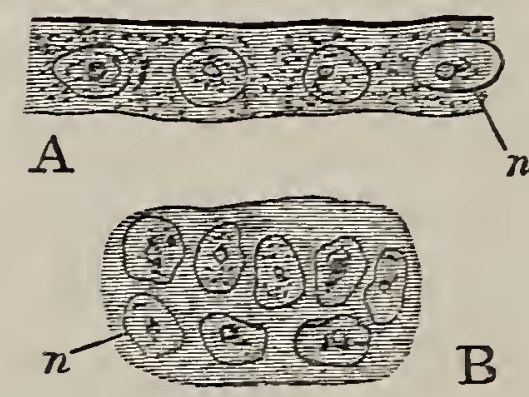

FIG. 50.-Astacus fuviatilis.-Epithelium, from the epidermic layer subjacent to the cuticle, highly magnified. $A$, in vertical section; $B$, from the surface. $n$, nuclei.

parts of the crea, and their essential nature is thus obrious.

3. Immediately beneath the epithelial layer follows a tissue, disposed in bands or sheets, which extend to the subjacent parts, invest them, and connect one with another. Hence this is called connective tissue.

The connectire tissue presents itself under three forms. In the first there is a transparent homogeneous-looking matrix, or ground substance, through which are scattered many nuclei. In fact, this form of connective tissue 
very closely resembles the epithelial tissue, except that the intervals between the nuclei are wider, and that the substance in which they are imbedded cannot be broken up into a separate cell-body for each nucleus. In the second form (fig. 51,A) the matrix exhibits fine wavy parallel lines, as if it were marked out into imperfect
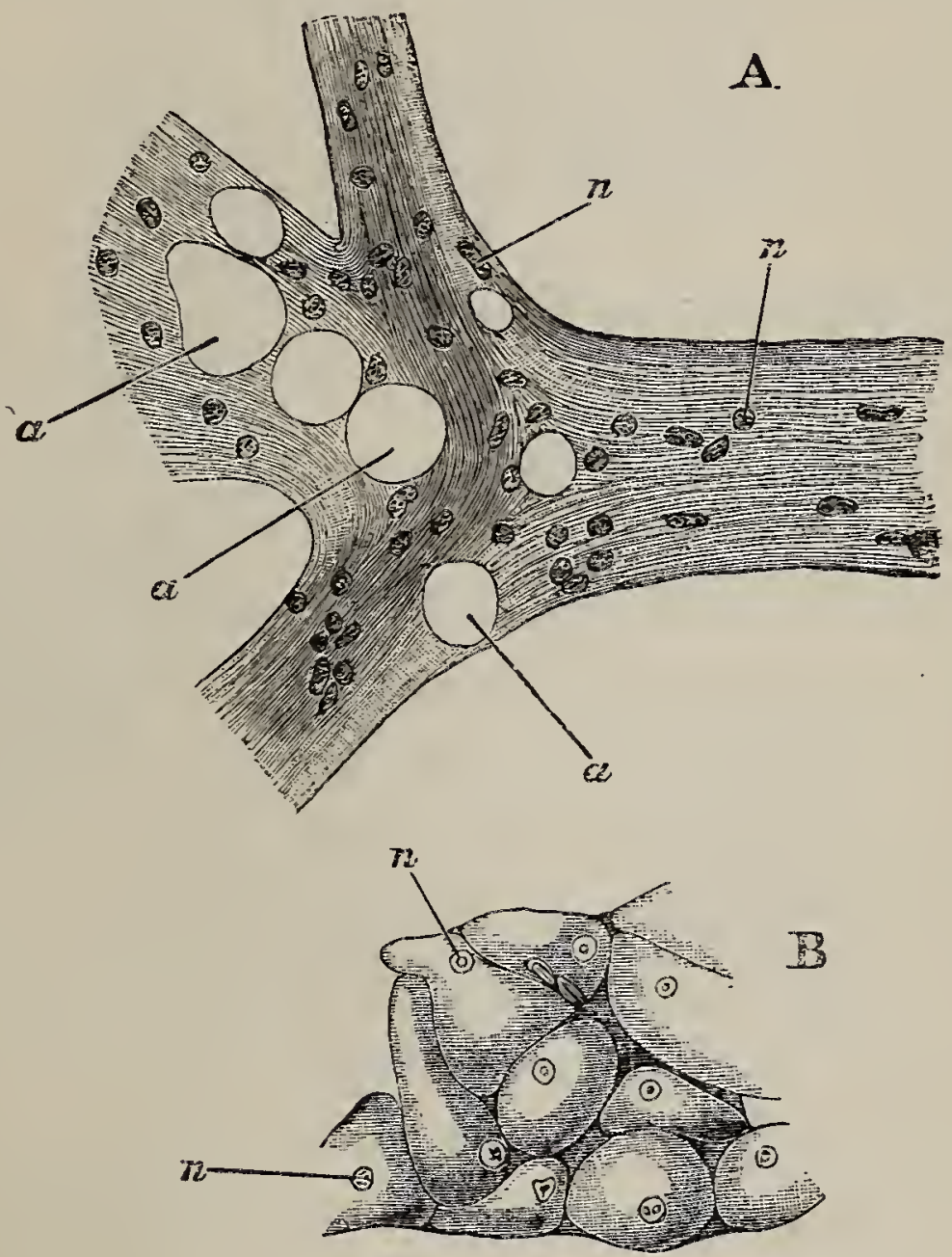

FIG. 51.-Astacus fluriatilis.-Connective tissue ; $A$, second form ; $B$, third form. a, cavities; $n$, nuclei. Highly magnified.

fibres. In this form, as in the next to be described, more or less spherical cavities, which contain a clear fluid, are excavated in the matrix; and the number of 


\section{THE MORPHOLOGY OF THE COMMON CRAYFISH.}

these is sometimes so great, that the matrix is proportionally very much reduced, and the structure acquires a close superficial similarity to that of the parenchyma of plants. This is still more the case with a third form, in which the matrix itself is marked off into elongated or rounded masses, each of which has a nucleus in its interior (fig. 51, B). Under one form or another, the connective tissue extends throughout the body, ensheathing the various organs, and forming the walls of the blood sinuses.

The third form is particularly abundant in the outer investment of the heart, the arteries, the alimentary canal, and the nervous centres. About the cerebral and anterior thoracic ganglia, and on the exterior of the heart, it usually contains more or less fatty matter. ' In these regions, many of the nuclei, in fact, are hidden by the accumulation round them of granules of various sizes, some of which are composed of fat, while others consist of a proteinaceous material. These aggregates of granules are usually spheroidal; and, with the matrix in which they are imbedded and the nucleus which they surround, they are often readily detached when a portion of the connective tissue is teased out, and are then known as fat cells. From what has been said respecting the distribution of the connective tissue, it is obvious that if all the other tissues could be removed, this tissue would form a continuous whole, and represent a sort of model, or cast, of the whole body of the crayfish. 
4. The muscular tissue of the crayfish always has the form of bands or fibres, of very various thickness, marked, when viewed by transmitted light, by alternate darker and

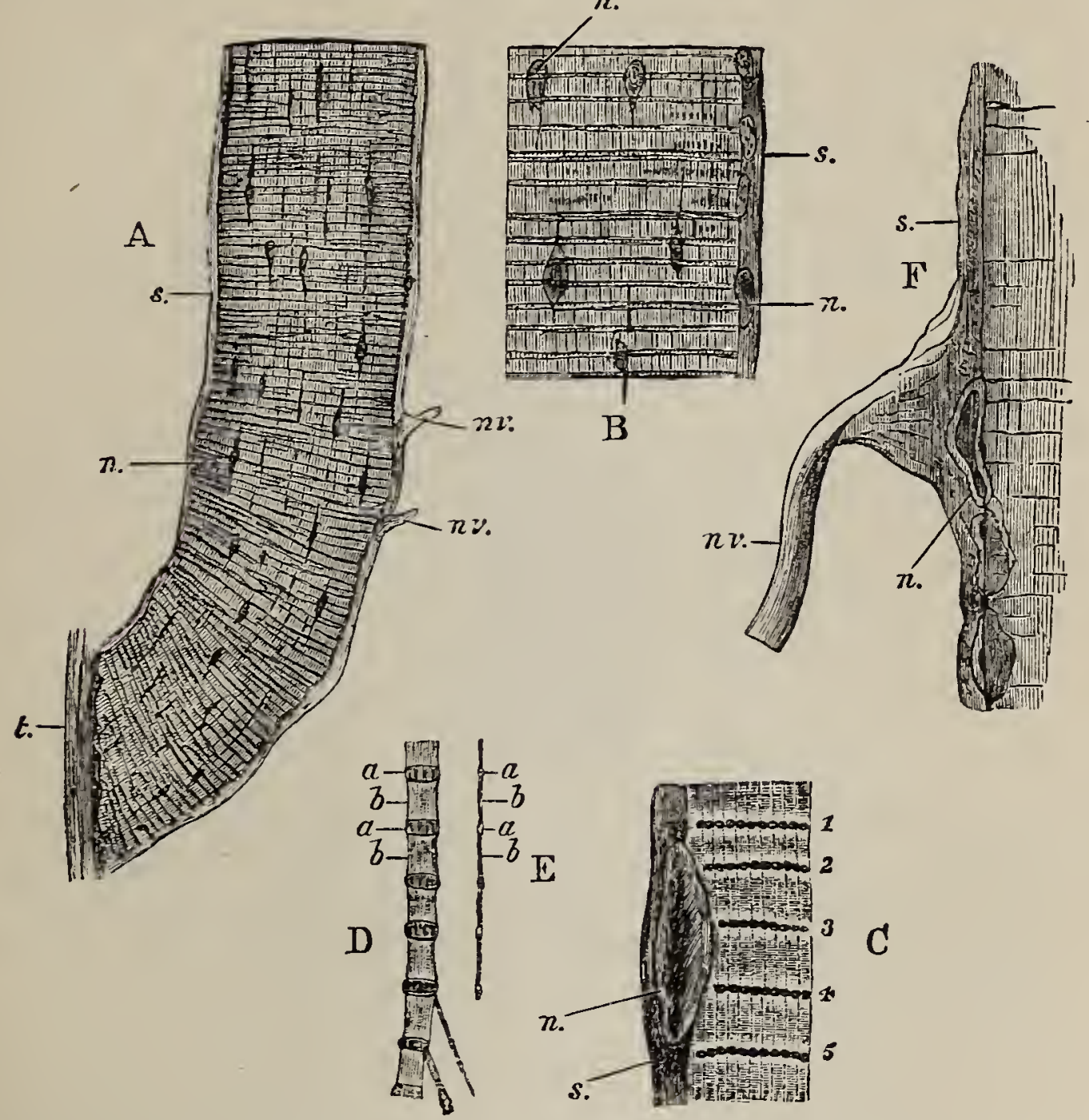

FIF. 52.-Astacus fluriatilis.-A, a single muscular fibre, transverse diameter $\frac{1}{110}$ th of an inch; $\mathrm{B}$, a portion of the same more highly magnified; C, a smaller portion treated with alcohol and acetic acid still more highly magnified; D and $\mathrm{E}$, the splitting up of a part of a fibre, treated with picro-carmine, into fibrillæ; $F$, the connection of a nervous with a muscular fibre which has been treated with alcohol and acetic acid. $a$, darker, and $b$, clearer portions of the fibrillæ; $n$, nuclei ; $n v$, nerve fibre ; $s$, sarcolemma ; $t$, tendon ; $1-5$, successive dark granular striæ answering to the granular portions, $a$, of each fibrilla. 


\section{THE MORPHOLOGY OF THE COMMON CRAYFISH.}

lighter striæ, transversely to the axis of the fibres (fig. $52 \mathrm{~A}$ ). The distance of the transverse striæ from one another varies with the condition of the muscle, from $1-4,000$ th of an inch in the quiescent state to as little as 1-30,000th of an inch in that of extreme contraction. The more delicate muscular fibres, like those of the heart and those of the intestine, are imbedded in the connective tissue of the organ, but have no special sheaths.

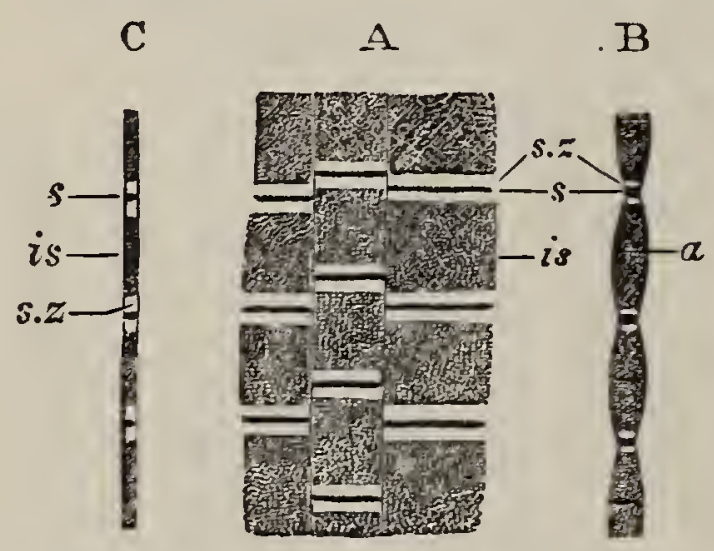

FIG. 53.-Astacus furiatilis. $-A$, living muscular fibres very highly magnified; $B$, a fibrilla treated with solution of sodiun chloride ; $C$, a fibrilla treated with strong nitric acid. $s$, septal lines; $s z$, septal zones; $i s$, interseptal zones; $a$, transverse line in the interseptal zone.

The fibres which make up the more conspicuous muscles of the trunk and limbs, on the other hand, are much larger, and are invested by a thin, transparent, structureless sheath, which is termed the sarcolemma. Nuclei are scattered, at intervals, through the striated substance of the muscle; and, in the larger muscular fibres, a layer of nucleated protoplasm lies between the sarcolemma and the striated muscle substance. 
This much is readily seen in a specimen of muscular fibre taken from any part of the body, and whether alive or dead. But the results of the ultimate optical analysis of these appearances, and the conclusions respecting the normal structure of striped muscle which may be legitimately drawn from them, have been the subjects of much controversy.

Quiescent muscular fibres from the chela of the forceps of a crayfish, examined while still living, without the addition of any extraneous fluid, and with magnifying powers of not less than seven or eight hundred diameters, exhibit the following appearance. At intervals of about 1-4000th of an inch, very delicate but dark and welldefined transverse lines are visible; and these, on careful focussing, appear beaded, as if they were made of a series of close-set minute granules not more than 1-20,000th to 1-30,000th of an inch in diameter. These may be termed the septal lines (fig. 52, D and E, $a ; \mathrm{C}, 1-5$; fig. 53, s). On each side of every septal line there is a very narrow perfectly transparent band, which may be distinguished as the septal zone (fig. 53, sz). Upon this follows a relatively broad band of a substance which has a semi-transparent aspect, like very finely ground glass, and hence appears somewhat dark relatively to the septal zone. Upon this inter-septal zone $(i s)$ follows another septal zone, then a septal line, another septal zone, an inter-septal zone, and so on throughout the whole length of the fibre. 


\section{S4 THE MORPHOLOGY OF THE COMMON CRAYFISH.}

In the perfectly unaltered state of the muscle no other transverse markings than these are discernible. But it is always possible to observe certain longitudinal markings; and these are of three kinds. In the first place, the nuclei which, in the perfectly fresh muscle, are delicate transparent oval bodies, are lodged in spaces which taper off at each end into narrow longitudinal clefts (fig. 52, A, B). Prolongations of the protoplasmic sheath of the fibre extend inwards and fill these clefts. Secondly, there are similar clefts interposed between these, but narrow and merely linear throughout. Sometimes these clefts contain fine granules. Thirdly, even in the perfectly fresh muscle, extremely faint parallel longitudinal striæ 1-7,000th of an inch, or thereabouts, apart, traverse the several zones, so that longer or shorter segments of the successive septal lines are inclosed between them. A transverse section of the muscle appears divided into rounded or polygonal areæ of the same diameter, separated from one another here and there by minute interstices. Moreover, on examination of perfectly fresh muscle with high magnifying powers, the septal lines are hardly ever straight for any distance, but are broken up into short lengths, which answer to one or more of the longitudinal divisions, and stand at slightly different heights.

The only conclusion to be drawn from these appearances seems to me to be that the substance of the muscle is composed of distinct fibrils; and that the longitudinal 
striæ and the rounded areæ of the transverse section are simply the optical expressions of the boundaries of these fibrils. In the perfectly unaltered state of the tissue, however, the fibrils are so closely packed that their boundaries are scarcely discernible.

Thus each muscular fibre may be regarded as composed of larger and smaller bundles of fibrils imbedded in a nucleated protoplasmic framework which ensheaths the whole and is itself invested by the sarcolemma.

As the fibre dies, the nuclei acquire hard, dark contours and their contents become granular, while at the same time the fibrils acquire sharp and well-defined boundaries. In fact, the fibre may now be readily teased out with needles, and the fibrils isolated.

In muscle which has been treated with various reagents, such as alcohol, nitric acid, or solution of common salt, the fibrils themselves may be split up into filaments of extreme tenuity, each of which appears to answer to one of the granules of the septal lines. Such an isolated muscle filament looks like a very fine thread carrying minute beads at regular intervals.

The septal lines resist most reagents, and remain risible in muscular fibres which have been subjected to various modes of treatment; but they may have the appearance of continuous bars, or be more or less completely resolved into separate granules, according to circumstances. On the other hand, what is to be seen in 


\section{THE MORPHOLOGY OF THE COMMON CRAYFISH.}

the interspace between every two septal lines depends upon the reagent employed. With dilute acids and strong solutions of salt, the inter-septal substance swells up and becomes transparent, so that it ceases to be distinguishable from the septal zone. At the same time a distinct but faint transverse line may appear in the middle of its length. Strong nitric acid, on the contrary, renders the inter-septal substance more opaque, and the septal zones consequently appear very well defined.

In living and recently dead muscle, as well as in muscles which have been preserved in spirit or hardened with nitric acid, the inter-septal zones polarize light; and hence, in the dark field of the polarizing microscope, the fibre appears crossed by bright bands, which correspond with the inter-septal zones, or at any rate, with the middle parts of them. The substance which forms the septal zones, on the contrary, produces no such effect, and consequently remains dark; while the septal lines again have the same property as the inter-septal substance, though in a less degree.

In fibres which have been acted upon by solution of salt, or dilute acids, the inter-septal zones have lost their polarizing property. As we know that the reagents in question dissolve the peculiar constituent of muscle, myosin, it is to be concluded that the inter-septal substance is chiefly composed of myosin.

Thus a fibril may be considered to be made up of 
segments of different material arranged in regular order; S-sz-IS-sz-S-sz-IS-sz-S : S representing the septal line; sz, the septal zone; IS, the inter-septal zone. Of these, IS is the chief if not the only seat of the myosin; what the composition of $\mathrm{sz}$ and of $\mathrm{S}$ may be is uncertain, but the supposition, that, in the living muscle, sz is a mere fluid, appears to me to be wholly inadmissible.

When living muscle contracts, the inter-septal zones become shorter and wider and their margins darker, while the septal zones and the septal lines tend to become effaced-as it appears to me simply in consequence of the approximation of the lateral margins of the inter-septal zones. It is probable that the substance of the intermediate zone is the chief, if not the only, seat of the activity of the muscle during contraction.

5. The elements of the nervous tissue are of two kinds, nerve-cells, and nerve fibres; the former are found in the sanglia, and they vary very much in size (fig. $54, \mathrm{~B}$ ). Each ganglionic corpuscle consists of a cell body produced into one or more processes which sometimes, if not always, end in nerve fibres. A large, clear spherical nucleus is seen in the interior of the nerve-cell; and in the centre of this is a well defined, small round particle, the nucleolus. The corpuscle, when isolated, is often surrounded by a sort of sheath of small nucleated cells. 
188 THE MORPHOLOGY OF THE COMMON CRAYFISH.

The nerve fibres (fig. 55) of the crayfish are remarkable for the large size which some of them attain. In the central nervous system a few reach as much as 1-200th of an inch in diameter; and fibres of 1-300th or 1-400th of

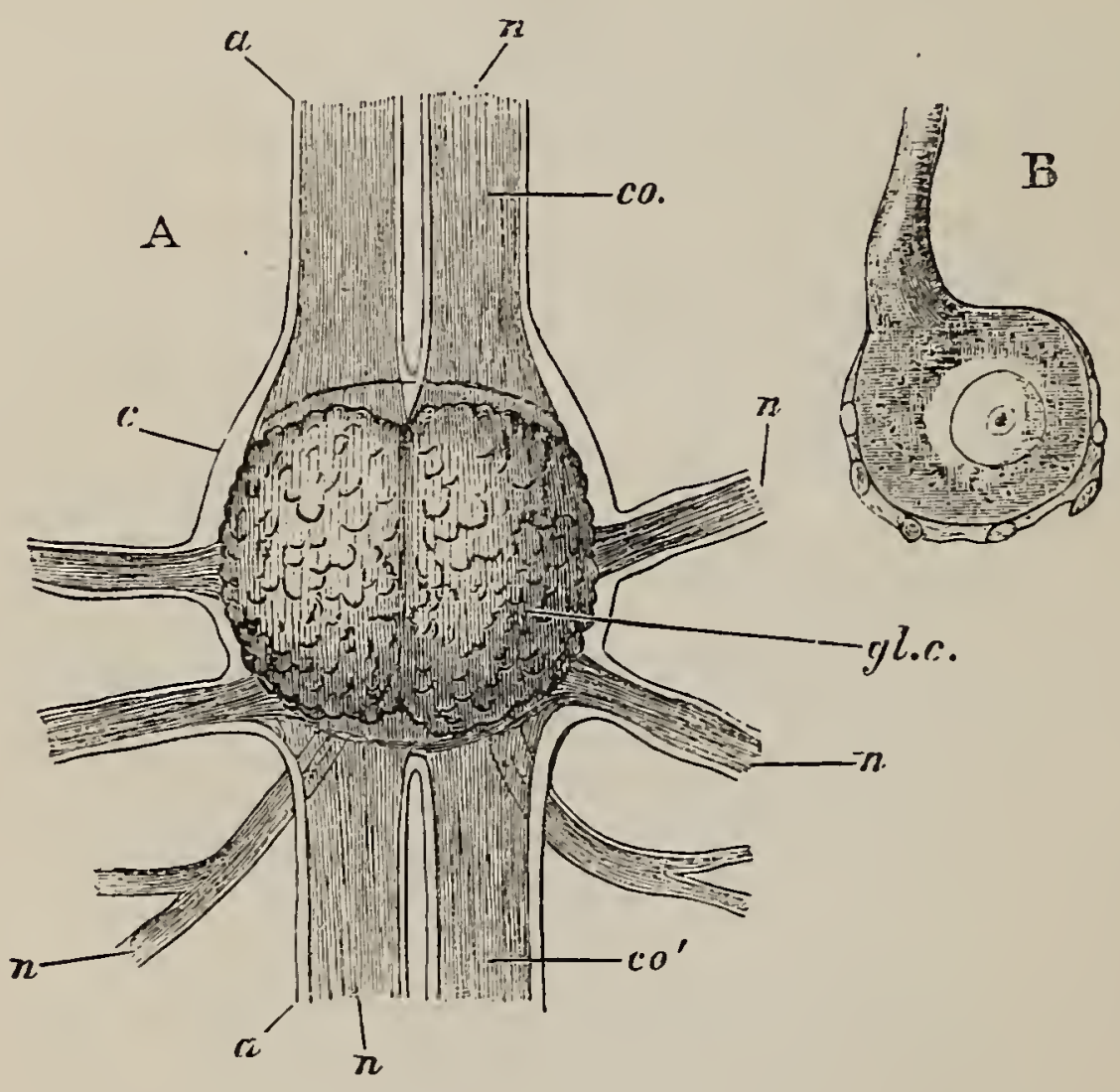

Fig. 54.-Astacus fuviatilis. - A, one of the (double) abdominal ganglia, with the nerves connected with it ( $\times 25) ; B$, a nerve cell or ganglionic corpuscle $(\times 250)$. $a$, sheath of the nerves; $c$, sheath of the ganglion ; $c o, c o^{\prime}$. commissural cords connecting the ganglia with those in front, and those behind them. gl.c. points to the ganglionic corpuscles of the ganglia; $n$, nerve fibres.

an inch in diameter are not rare in the main branches. Each fibre is a tube, formed of a strong and elastic, sometimes fibrillated, sheath, in which nuclei are imbedded at irregular intervals; and, when the nerve trunk gives 
off a branch, more or fewer of these tubes divide, sending off a prolongation into each branch.

When quite fresh, the contents of the tubes are perfectly pellucid, and without the least indication of structure; and, from the manner in which the contents

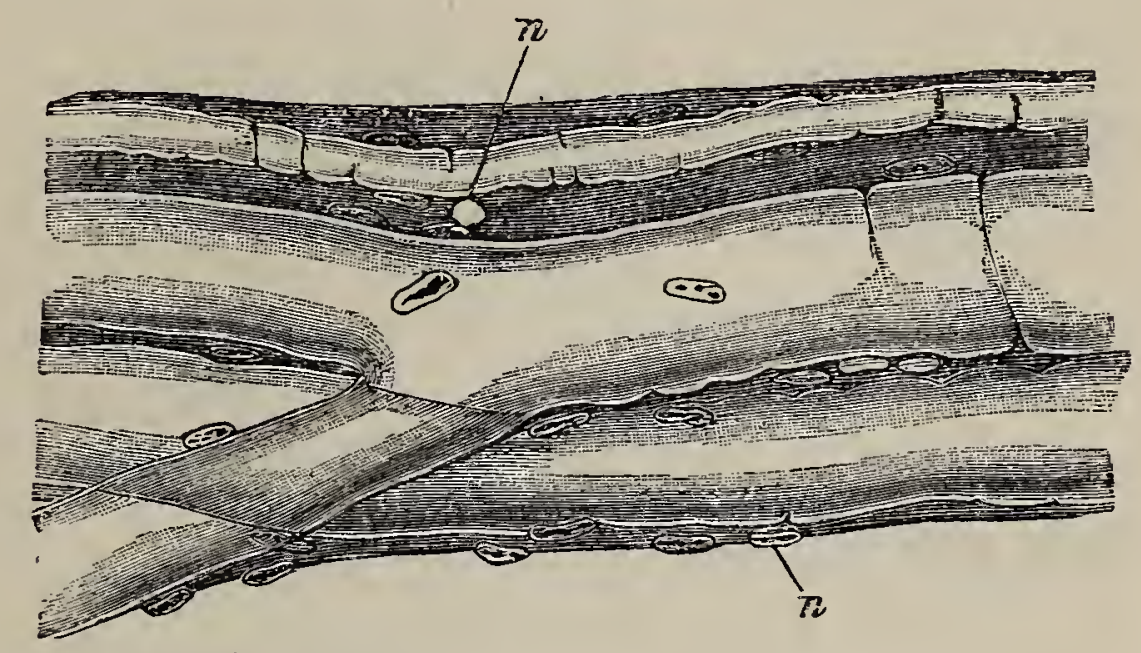

FIG. 55.-Astacus fuciatilis.-Three nerve fibres, with the sonnective tissue in which they are imbedded (magnified about 250 diameters); $n$, nuclei.

exude from the cut ends of the tubes, it is evident that they consist of a fluid of gelatinous consistency. As the fibre dies, and under the influence of water and of many chemical re-agents, the contents break up into globules or become turbid and finely granular.

Where motor nerve fibres terminate in the muscles to which they are distributed, the sheath of each fibre becomes continuous with the sarcolemma of the muscle, and the subjacent protoplasm is commonly raised into a small prominence which contains several nuclei (fig. 52, F). These are called the terminal or motor plates. 
190 THE MORPHOLOGY OF THE COMMON CRAYFISH.

6, 7. The ova and the spermatozoa have already been described (pp. 132-135).

It will be observed that the blood corpuscles, the epithelial tissues, the ganglionic corpuscles, the ora and the spermatozoa, are all demonstrably nucleated cells, more or less modified. The first form of connective tissue is so similar to epithelial tissue, that it may obviously be regarded as an aggregate of as many cells as it presents nuclei, the matrix representing the more or less modified and confluent bodies of the cells, or products of these. But if this be so, then the second and third forms have a similar composition, except so far as the matrix of the cells has become fibrillated, or vacuolated, or marked off into masses corresponding with the several nuclei. By a parity of reasoning, muscular tissue may also be considered a cell aggregate, in which the internuclear substance has become converted into striated muscle; while, in the nerve fibres, a like process of metamorphosis may have given rise to the pellucid gelatinous nerve substance. But, if we accept the conclusions thus suggested by the comparison of the various tissues with one another, it follows that every histological element, which has now been mentioned, is either a simple nucleated cell, a modified nucleated cell, or a more or less modified cell aggregate. In other words, every tissue is resolvable into nucleated cells. 

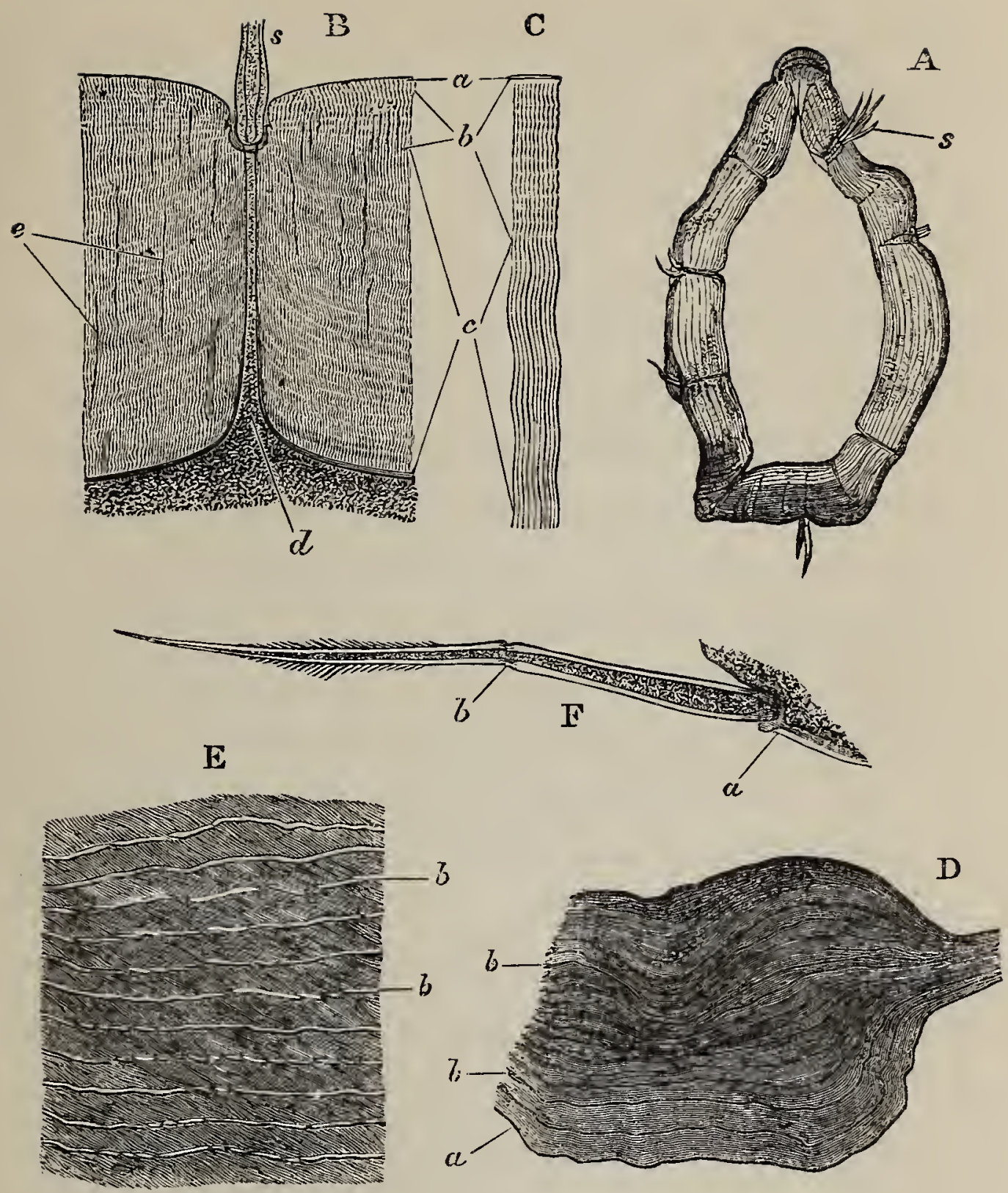

Frg. 56.-Astacus fluriatilis.--The structure of the cuticle. A, transverse section of a joint of the forceps $(\times 4)$; $s$, setæ ; $B$, a portion of the same $(\times 30) ; C$, a portion of $\mathrm{B}$ more highly magnified. $a$, epiostracum ; $b$, ectostracum ; $c$, endostracum ; $d$, canal of seta ; $e$, canals filled with air ; $s$, seta. $D$, section of an intersternal membrane of the abdomen, the portion to the right in the natural condition, the remainder pulled apart with needles $(\times 20) ; E$, small portion of the same, highly magnified; $a$, intermediate sub. stance; $b$, laminæ. $F$, a seta, highly magnified ; $a$ and $b$, joints. 


\section{THE MORPHOLOGI OF THE COMION CRAYFISH.}

A notable exception to this generalisation, however, obtains in the case of the cuticular structures, in which no cellular components are discoverable. In its simplest form, such as that presented by the lining of the intestine, the cuticle is a delicate, transparent membrane, thrown off from the surface of the subjacent cells, either by a process of exudation, or by the chemical transformation of their superficial layer. No pores are discernible in this membrane, but scattered orer its surface there are oval patches of extremely minute, sharp conical processes, which are rarely more than 1-5,000th of an inch long. Where the cuticle is thicker, as in the stomach and in the exoskeleton, it presents a stratified appearance, as if it were composed of a number of laminæ, of varying thickness, which had been successively thrown off from the subjacent cells.

Where the cuticular layer of the integument is uncalcified, for example, between the sterna of the abdominal somites, it presents an external, thin, dense, wrinkled lamina, the epiostracum, followed by a soft substance, which, on vertical section, presents numerous alternately more transparent and more opaque bands, which run parallel with one another and with the free surfaces of the slice (fig. 56, D). These bands are very close-set, often not more than 1-5000th of an inch apart near the outer and the inner surfaces, but in the middle of the section they are more distant.

If a thin rertical slice of the soft cuticle is gently 
pulled with needles in the direction of its depth, it stretches to eight or ten times its previous diameter, the clear intervals between the dark bands becoming proportionally enlarged, especially in the middle of the slice, while the dark bands themselves become apparently thinner, and more sharply defined. The dark bands may then be readily drawn to a distance of as much as $1-300$ th of an inch from one another; but if the slice is stretched further, it splits along, or close to, one of the dark lines. The whole of the cuticular layer is stained by such colouring matters as hæmatoxylin; and, as the dark bands become more deeply coloured than the intermediate transparent substance, the transverse stratifcation is made very manifest by this treatment.

Examined with a high magnifying power, the transparent substance is seen to be traversed by close-set, faint, vertical lines, while the dark bands are shown to be produced by the cut edges of delicate laminæ, having a finely striated appearance, as if they were composed of delicate parallel wavy fibrillæ.

In the calcified parts of the exoskeleton a thin, tough, wrinkled epiostracum (fig. 56, B, a), and, subjacent to this, a number of alternately lighter and darker strata are similarly discernible: though all but the innermost laminæ are hardened by a deposit of calcareous salts, which are generally evenly diffused, but sometimes take the shape of rounded masses with irregular contours.

Immediately beneath the epiostracum, there is a zone 
194 THE MORPHOLOGY OF THE COMMON CRAYFISH.

which may occupy a sixth or a seventh of the thickness of the whole, which is more transparent than the rest, and often presents hardly any trace of horizontal or vertical striation. When it appears laminated, the strata are very thin. This zone may be distinguished as the ectostracum (b), from the endostracum (c), which makes up the rest of the exoskeleton. In the outer part of the endostracum, the strata are distinct, and may be as much as 1-500th of an inch thick, but in the inner part they become very thin, and the lines which separate them may be not more than 1-8000th of an inch apart. Fine, parallel, close-set, vertical striæ $(e)$ traverse all the strata of the endostracum, and may usually be traced through the ectostracum, though they are always faint, and sometimes hardly discernible, in this region. When a high magnifying power is employed, it is seen that these striæ, which are about 1-7000th of an inch apart, are not straight, but that they present regular short undulations, the alternate convexities and concavities of which correspond with the light and the dark bands respectively.

If the hard exoskeleton has been allowed to become partially or wholly dry before the section is made, the latter will look white by reflected and black by transmitted light, in consequence of the places of the strix being taken by threads of air of such extreme tenuity, that they may measure not more than 1-30,000th of an inch in diameter. It is to be concluded, therefore, that 
the strix are the optical indications of parallel undulating canals which traverse the successive strata of the cuticle, and are ordinarily occupied by a fluid. When this dries up, the surrounding air enters, and more or less completely fills the tubes. And that this is really the case may be proved by making very thin sections parallel with the face of the exoskeleton, for these exhibit innumerable minute perforations, set at regular distances from one another, which correspond with the intervals between the striæ in the vertical section; and sometimes the contours of the areæ which separate the apertures are so well defined as to suggest a pavement of minute angular blocks, the corners of which do not quite meet.

When a portion of the hard exoskeleton is decalcified, a chitinous substance remains, which presents the same structure as that just described, except that the epiostracum is more distinct; while the ectostracum appears made up of very thin laminæ, and the tubes are represented by delicate striæ, which appear coarser in the region of the dark zones. As in the naturally soft parts of the exoskeleton, the decalcified cuticle may be split into flakes, and the pores are then seen to be disposed in distinct areæ circumscribed by clear polygonal borders. These perforated areæ appear to correspond with individual cells of the ectoderm, and the canals thus answer to the so-called "pore-canals," which are common in cuticular structures and in the walls of many cells which bound free surfaces. 
The whole exoskeleton of the crayfish is, in fact, produced by the cells which underlie it, either by the exudation of a chitinous substance, which subsequently hardens, from them; or, as is more probable, by the chenical metamorphosis of a superficial zone of the bodies of the cells into chitin. However this may be, the cuticular products of adjacent cells at first form a simple, continuous, thin pellicle. A continuation of the process by which it was originated increases the thickness of the cuticle; but the material thus added to the inner surface of the latter is not always of the same nature, but is alternately denser and softer. The denser material gives rise to the tough laminæ, the softer to the intermediate transparent substance. But the quantity of the latter is at first very small, whence the more external laminæ are in close apposition. Subsequently the quantity of the intermediate substance increases, and gives rise to the thick stratification of the middle region, while it remains insignificant in the inner region of the exoskeleton.

The cuticular structures of the crayfish differ from the nails, hairs, hoofs, and similar hard parts of the higher animals, insomuch as the latter consist of aggregations of cells, the bodies of which have been metamorphosed into horny matter. The cuticle, with all its dependencies, on the contrary, though no less dependent on cells for its existence, is a derivative product, the formation of which does not involve the complete meta- 
morphosis and consequent destruction of the cells to which it owes its origin.

The calcareous salts by which the calcified exoskeleton is hardened can only be supplied by the infiltration of a fluid in which they are dissolved from the klood; while the distinctive structural characters of the epiostracum, the ectostracum, and the endostracum, are the results of a process of metamorphosis which goes on pari passu with this infiltration. To what extent this metamorphosis is a properly vital process ; and to what extent it is explicable by the ordinary physical and chemical properties of the animal membrane on the one hand, and the mineral salts on the other, is a curious, and at present, unsolved problem.

The outer surface of the cuticle is rarely smooth. Generally it is more or less obviously ridged or tuberculated; and, in addition, presents coarser or finer hairlike processes which exhibit every gradation from a fine microscopic down to stout spines. As these processes, though so similar to hairs in general appearance, are essentially different from the structures known as hairs in the higher animals, it is better to speak of them as setce.

These setæ (fig. 56, F) are sometimes short, slender, conical filaments, the surface of which is quite smooth; sometimes the surface is produced into minute serrations, or scale-like prominences, disposed in two or more series; in other setæ, the axis gives off slender lateral 
branches; and in the most complicated form the branches are ornamented with lateral branchlets. For a certain distance from the base of the seta, its surface is usually smooth, even when the rest of its extent is ornamented with scales or branches. Moreover, the basal part of the seta is marked off from its apical moiety by a sort of joint which is indicated by a slight constriction, or by a peculiarity in the structure of the cuticula at this point. A seta almost always takes its origin from the bottom of a depression or pit of the layer of cuticle, from which it is developed, and at its junction with the latter it is generally thin and flexible, so that the seta moves easily in its socket. Each seta contains a carity, the boundaries of which generally follow the outer contours of the seta. In a good many of the setæ, however, the parietes, near the base of the seta, are thickened in such a manner as almost, or completely, to obliterate the central cavity. Howerer thick the cuticle may be at the point from which the setæ take their origin, it is always traversed by a funnel-shaped canal (fig. 56, B, d), which usually expands beneath the base of the seta. Through this canal the subjacent ectoderm extends up to the base of the seta, and can even be traced for some distance into its interior.

It has already been mentioned that the apodemata and the tendons of the muscles are infoldings of the cuticle, embraced and secreted by corresponding involutions of the ectoderm. 
Thus the body of the crayfish is resolvable, in the first place, into a repetition of similar segments, the metameres, each of which consists of a somite and two appendages; the metameres are built up out of a few simple tissues; and, finally, the tissues are either aggregates of more or less modified nucleated cells, or are products of such cells. Hence, in ultimate morphological analysis, the crayfish is a multiple of the histological unit, the nucleated cell.

What is true of the crayfish, is certainly true of all animals, above the very lowest. And it cannot yet be considered certain that the generalization fails to hold good even of the simplest manifestations of animal life; since recent investigations have demonstrated the presence of a nucleus in organisms in which it had hitherto appeared to be absent.

However this may be, there is no doubt that in the case of man and of all vertebrated animals, in that of all arthropods, mollusks, echinoderms, worms, and inferior organisms down to the very lowest sponges, the process of morphological analysis yields the same result as in the case of the crayfish. The body is built up of tissues, and the tissues are either obviously composed of nucleated cells; or, from the presence of nuclei, they may be assumed to be the results of the metamorphosis of such cells; or they are cuticular structures.

The essential character of the nucleated cell is that it consists of a protoplasmic substance, one part of which differs somewhat in its physical and chemical characters 
from the rest, and constitutes the nucleus. What part the nucleus plays in relation to the functions, or vital activities, of the cell is as yet unknown; but that it is the seat of operations of a different character from those which go on in the body of the cell is clear enough. For, as we have seen, however different the several tissues may be, the nuclei which they contain are very much alike; whence it follows, that if all these tissues were primitively composed of simple nucleated cells, it must be the bodies of the cells which have undergone metamorphosis, while the nuclei have remained relatirely unchanged.

On the other hand, when cells multiply, as thcy do in all growing parts, by the division of one cell into two, the signs of the process of internal change which ends in fission are apparent in the nucleus before they are manifest in the body of the cell; and, commonly, the division of the former precedes that of the latter. Thus a single cell body may possess two nuclei, and may become divided into two cells by the subsequent aggregation of the two moieties of its protoplasmic substance round each of them, as a centre.

In some cases, very singular structural changes talie place in the nuclei in the course of the process of celldivision. The granular or fibrillar contents of the nucleus, the wall of which becomes less distinct, arrange themselves in the form of a spindle or double cone, formed of extremely delicate filaments; and in the plane 
of the base of the double cone the filaments present knots or thickenings, just as if they were so many threads with a bead in the middle of each. When the nuclear spindle is viewed sideways, these beads or thickenings give rise to the appearance of a disk traversing the centre of the spindle. Soon each bead separates into two, and these move away from one another, but remain connected by a fine filament. Thus the structure which had the form of a double cone, with a disk in the middle, assumes that of a short cylinder, with a disk and a cone at each end. But as the distance between the two disks increases, the uniting filaments lose their parallelism, converge in the middle, and finally separate, so that two separate double cones are developed in place of the single one. Along with these changes in the nucleus, others occur in the protoplasm of the cell body, and its parts commonly display a tendency to arrange themselves in radii from the extremities of the cones as a centre; while, as the separation of the two secondary nuclear spindles becomes complete, the cell body gradually splits from the periphery inwards, in a direction at right angles to the common axis of the spindles and between their apices. Thus two cells are formed, where, previously, only one existed; and the nuclear spindles of each soon revert to the globular form and confused arrangement of the contents, characteristic of nuclei in their ordinary state. The formation of these nuclear spindles is very beautifully seen in the epithelial cells of the testis of the 
crayfish (fig. 33, p. 132); but I have not been able to find distinct evidence of it elsewhere in this animal; and although the process has now been proved to take place in all the divisions of the animal kingdom, it would seem that nuclei may, and largely do, undergo division, without becoming converted into spindles.

The most cursory examination of any of the higher plants shows that the vegetable, like the animal body, is made up of various kinds of tissues, such as pith, woody fibre, spiral vessels, ducts, and so on. But even the most modified forms of regetable tissue depart so little from the type of the simple cell, that the reduction of them all to that common type is suggested still more strongly than in the case of the animal fabric. And thus the nucleated cell appears to be the morphological unit of the plant no less than of the animal. Moreover, recent inquiry has shown that in the course of the multiplication of vegetable cells by division, the nuclear spindles may appear and run through all their remarkable changes by stages precisely similar to those which occur in animals.

The question of the universal presence of nuclei in cells may be left open in the case of Plants, as in that of Animals; but, speaking generally, it may justly be affirmed that the nucleated cell is the morphological foundation of both divisions of the living world; and the great generalisation of Schleiden and Schwann, that there is a fundamental agreement in structure and 
development between plants and animals, has, in substance, been merely confirmed and illustrated by the labours of the half century which has elapsed since its promulgation.

Not only is it true that the minute structure of the crayfish is, in principle, the same as that of any other animal, or of any plant, however different it may be in detail; but, in all animals (save some exceptional forms) above the lowest, the body is similarly composed of three layers, ectoderm, mesoderm, and endoderm, disposed around a central alimentary cavity. The ectoderm and the endoderm always retain their epithelial character; while the mesoderm, which is insignificant in the lower organisms, becomes, in the higher, far more complicated even than it is in the crayfish.

Moreover, in the whole of the Arthropoda, and the whole of the Vertebrata, to say nothing of other groups of animals, the body, as in the crayfish, is susceptible of distinction into a series of more or less numerous segments, composed of homologous parts. In each segment these parts are modified according to physiological requirements; and by the coalescence, segregation, and change of relative size and position of the segments, well characterized regions of the body are marked out. And it is remarkable that precisely the same principles are illustrated by the morphology of plants. A flower with its whorls of sepals, petals, stamens and carpels has the same relation to a stem 
with its whorls of leaves, as a crayfish's head has to its abdomen, or a dog's skull to its thorax.

It may be objected, however, that the morphological generalisations which have now been reached, are to a considerable extent of a speculative character; and that, in the case of our crayfish, the facts warrant no more than the assertion that the structure of that animal may be consistently interpreted, on the supposition that the body is made up of homologous somites and appendages, and that the tissues are the result of the modification of homologous histological elements or cells; and the objection is perfectly valid.

There can be no doubt that blood corpuscles, liver cells, and ora are all nucleated cells; nor any that the third, fourth, and fifth somites of the abdomen are constructed upon the same plan; for these propositions are mere statements of the anatomical facts. But when, from the presence of nuclei in connective tissue and muscles, we conclude that these tissues are composed of modified cells; or when we say that the ambulatory limbs of the thorax are of the same type as the abcominal limbs, the exopodite being suppressed, the statement, as the evidence stands at present, is no more than a convenient way of interpreting the facts. The question remains, has the muscle actually been formed out of nucleated cells? Has the ambulatory limb ever possessed an exopodite, and lost it ? 
The answer to these questions is to be sought in the facts of individual and ancestral development.

An animal not only is, but becomes; the crayfish is the product of an egg, in which not a single structure visible in the adult animal exists : in that egg the different tissues and organs make their appearance by a gradual process of evolution; and the study of this process can alone tell us whether the unity of composition suggested by the comparison of adult structures, is borne out by the facts of their development in the individual or not. The hypothesis that the body of the crayfish is made up of a series of homologous somites and appendages, and that all the tissues are composed of nucleated cells, might be only a permissible, because a useful, mode of colligating the facts of anatomy. The investigation of the actual manner in which the evolution of the body of the crayfish has been effected, is the only means of ascertaining: whether it is anything more. And, in this sense, development is the criterion of all morphological speculations.

The first obvious change which takes place in an impregnated ovum is the breaking up of the yelk into smaller portions, each of which is provided with a nucleus, and is termed a blastomere. In a general morphological sense, a blastomere is a nucleated cell, and differs trom an ordinary cell only in size, and in the usual, though by no means invariable, abundance of granular contents; and blastomeres insensibly pass into ordinary cells, as 
206 THE MURPHOLOGY OF THE COMMON CRAYFISH.

the process of division of the yelk into smaller and smaller portions goes on.

In a great many animals, the splitting-up into blastomeres is effected in such a manner that the yelk is, at first, divided into equal, or nearly equal, masses; that each of these again divides into two; and that the number of blastomeres thus increases in geometrical progression until the entire yelk is converted into a mulberry-like body, termed a morula, made up of a great number of small blastomeres or nucleated cells. The whole organism is subsequently built up by the multiplication, the change of position, and the metamorphosis of these products of yell division.

In such a case as this, yelk division is said to be complete. An unessential modification of complete yelk division is seen when, at an early period, the blastomeres produced by division are of unequal sizes; or when they become unequal in consequence of division taking place much more rapidly in one set than in another.

In many animals, especially those which have large ova, the inequality of division is pushed so far that only a portion of the yelk is affected by the process of fission, while the rest serves merely as food-yelk, for nutriment to the blastomeres thus produced. Over a greater or less extent of the surface of the egg, the protoplasmic substance of the yelk segregates itself from the rest, and, constituting a germinal layer, breaks up into the blastomeres, which multiply at the expense of the food- 
yelk, and fabricate the body of the embryo. This process is termed partial or incomplete yelk division.

The crayfish is one of those animals in the egg of which the yelk undergoes partial division. The first steps of the process have not yet been thoroughly worked out, but their result is seen in ova which have been but a short time laid (fig. 57, A). In such eggs, the great mass of the substance of the vitellus is destined to play the part of food-yelk; and it is disposed in conical masses, which radiate from a central spheroidal portion to the periphery of the yelk $(v)$. Corresponding with the base of each cone, there is a clear protoplasmic plate, which contains a nucleus; and as these bodies are all in contact by their edges, they form a complete, though thin, investment to the food-yelk. This is termed the blastoderm (bl).

Each nucleated protoplasmic plate adheres firmly to the corresponding cone of granular food-yelk, and, in all probability, the two together represent a blastomere; but, as the cones only indirectly subserve the growth of the embryo, while the nucleated peripheral plates form an independent spherical sac, out of which the body of the young crayfish is gradually fashioned, it will be convenient to deal with the latter separately.

Thus, at this period, the body of the developing crayfish is nothing but a spherical bag, the thin walls of which are composed of a single layer of nucleated cells, while its cavity is filled with food-yell. The first modification 

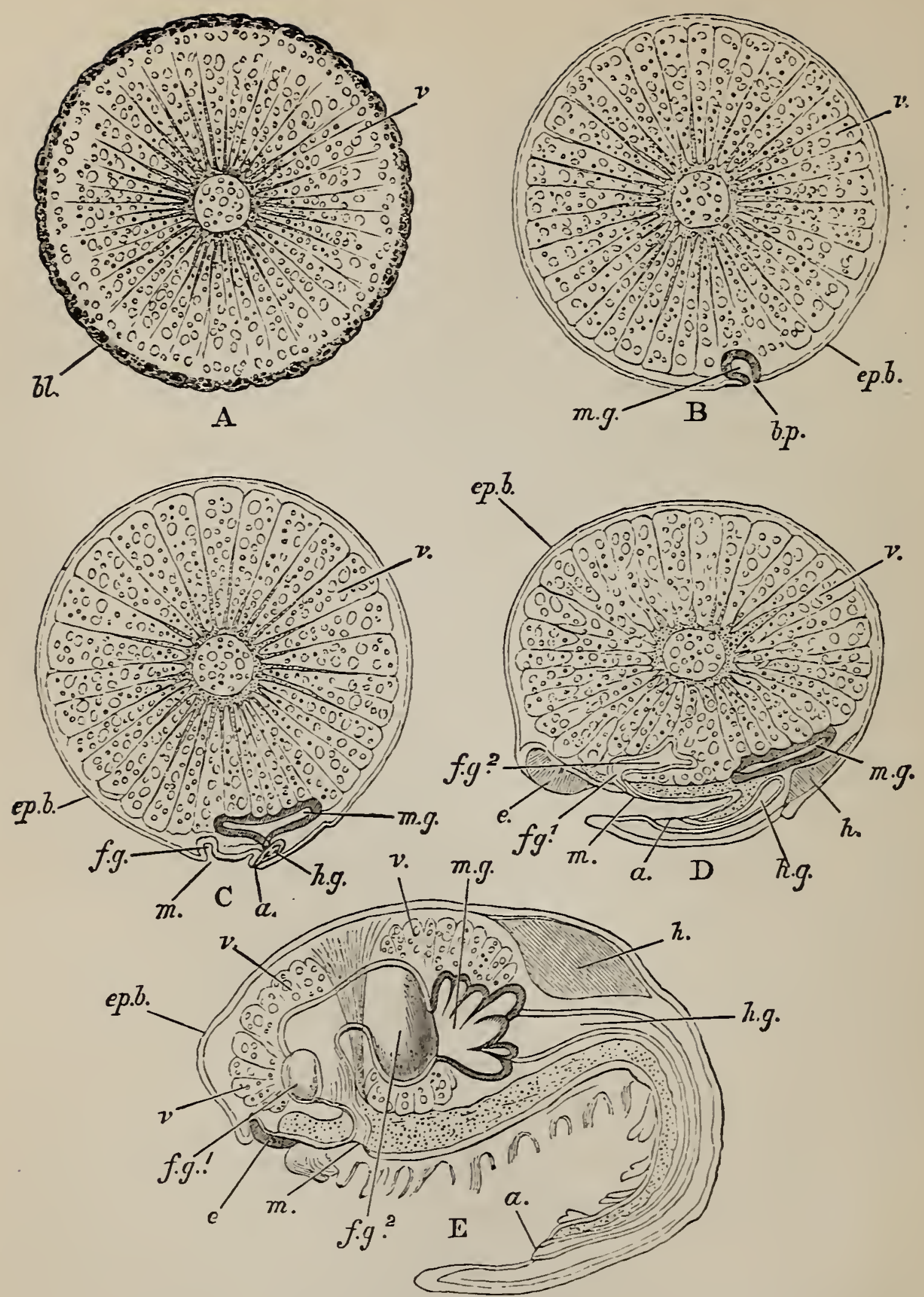

FIG. 57.-Astacus furicetilis. - Diagrammatic sections of cmbryos; partly after Reichenbach, partly original $(\times 20)$. A. An ovum in which the blastoderm is just formed. B. An orum in which the invagination of the blastoderm to constitute the hypoblast or rudiment of the mid-gut has taken place. (This nearly answers to the stage represented in fig. $5 \mathrm{~S}, A$.) C. A longitudinal section of an ovum, in which the rudiments of the abdomen, of the hind-gut, and of the foregut have 'aypeared. (This nearly answers to the stage represented in fig. 58, E.) D. A similar section of an embryo in nearly the same stage of development as that represented in $\mathrm{C}$, fig. 59 . E. An embryo just hatched, in longitudinal section; $\alpha$, anus; $b l$, blastoderm ; $b p$, blastopore; e, eye; ep.b., epriblast; $f g$, fore-gut; $f g^{1}$, its osoplageal, and $f g^{2}$, its gastric nortion ; $h$, 'heart; $h g$, hind-gut ; $m$, inouth ; mg, hypoblast, archenteron, or nid-gut; $r$, relk. The dotted portions in $\mathrm{D}$ and $\mathrm{E}$ represent the nervous system. 
whicis is effected in the vesicular blastoderm manifests itself on that face of it which is turned towards the pedicle of the egg. Here the layer of cells becomes thickened throughout an oval area about 1-25th of an inch in diameter. Hence, when the egg is viewed by reflected light, a whitish patch of corresponding form and size appears in this region. This may be termed the germinal disk. Its long axis corresponds with that of the future crayfish.

Next, a depression (fig. 58, A, $b p$ ) appears in the hinder third of the germinal disk, in consequence of this part of the blastoderm growing inwards, and thus giving rise to a small wide-mouthed pouch, which projects into the food-yelk with which the cavity of the blastoderm is filled (fig. 57, B, mg). As this infolding, or invagination of the blastoderm, goes on, the pouch thus produced increases, while its external opening, termed the blastopore (fig. $57, \mathrm{~B}$, and $58, \mathrm{~A}-\mathrm{E}, b p$ ), diminishes in size. Thus the body of the embryo crayfish, from being a simple bag becomes a double bag, such as might be produced by pushing in the wall of an incompletely distended india-rubber ball with the finger. And, in this case, if the interior of the bag contained porridge, the latter would very fairly represent the food-yelk.

By this invagination a most important step has been taken in the development of the crayfish. For, though the pouch is nothing but an ingrowth of part of the blastoderm, the cells of which its wall is composed 

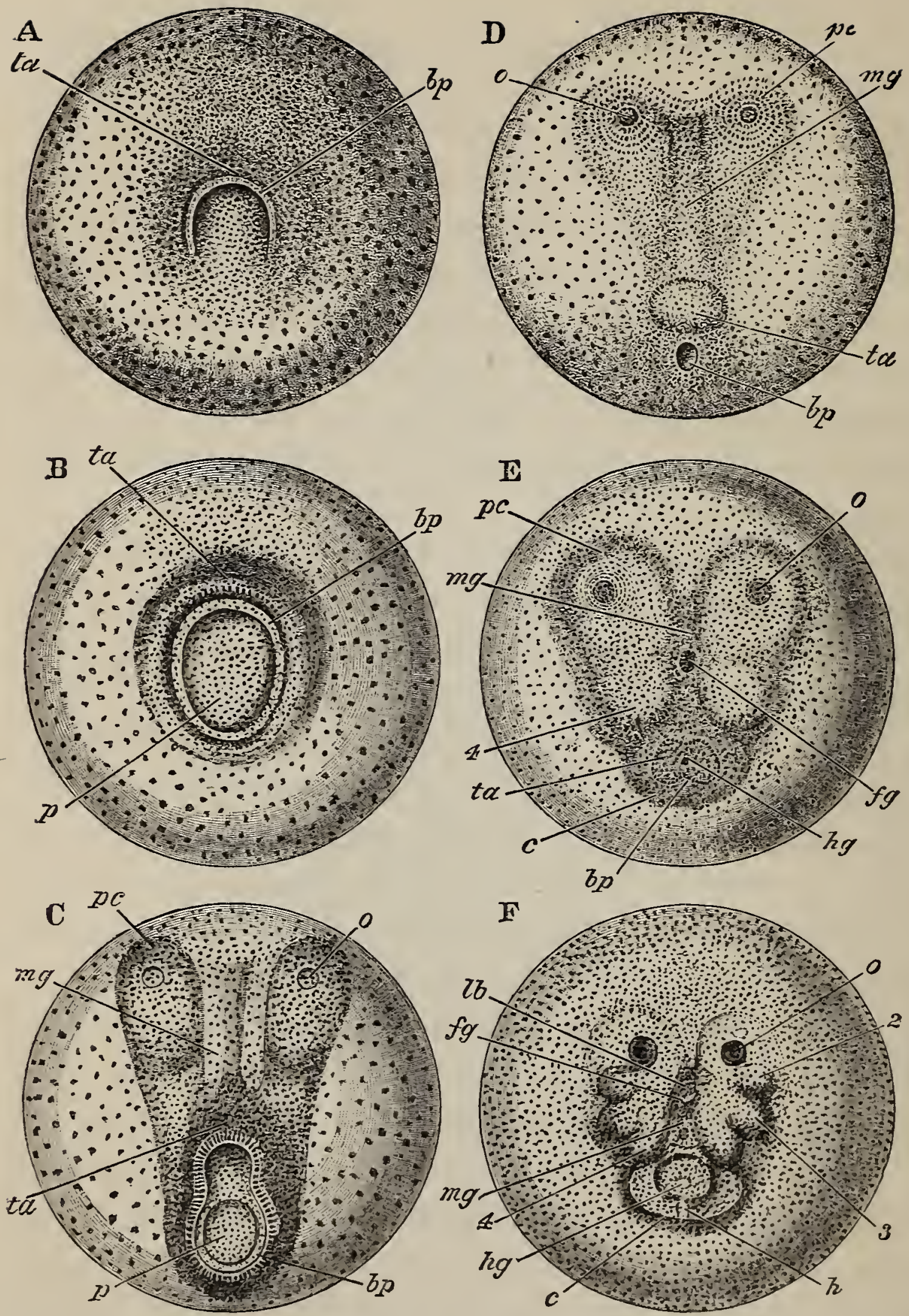

FIG. 5S.-Astacus furviatilis.-Surface views of the earlier stages in the development of the embrro, from the appearance of the blastopore (A) to the assumption of the nauplius form (F) (after Reichenbach, $\times$ about 23 ). bp, blastolore ; c, carapace ; $f g$, fore-gut involution; $h$, heart ; $h g$, hind-gut involution; $l b$, labrum; $m g$, medullary groove; $o$, optic pit; $p$, endodermal plug partly filling up the blastopore; $p c$, procephalic processes; ta, abclominal eleration; 2 , autemules; 3 , antennæ 4 , mandibles. 
henceforward exhibit different tendencies from those which are possessed by the rest of the blastoderm. In fact, it is the primitive alimentary apparatus or archenteron, and its wall is termed the hypoblast. The rest of the blastoderm, on the contrary, is the primitive epidermis, and receives the name of epiblast. If the foodyelk were away, and the archenteron enlarged until the hypoblast came in contact with the epiblast, the entire body would be a double-walled sac, containing an alimentary cavity, with a single external aperture. This is the gastrula condition of the embryo; and some animals, such as the common fresh-water polype, are little more than permanent gastrula.

Although the gastrula has not the slightest resemblance to a crayfish, yet, as soon as the hypoblast and the epiblast are thus differentiated, the foundations of some of the most important systems of organs of the future crustacean are laid. The hypoblast will give rise to the epithelial lining of the mid-gut; the epiblast (which answers to the ectoderm in the adult) to the epithelia of the fore-git and hind-gut, to the epidermis, and to the central nervous system.

The mesodermal structures, that is to say the connective tissue, the muscles, the heart and vessels, and the reproductive organs, which lie between the ectoderm and the endoderm, are not derived directly from either the epiblast or the hypoblast, but have a quasi-independent origin, from a mass of cells which first makes its appear- 


\section{THE MORPHOLOGY OF THE COMMON CRAYFISH.}

ance in the neighbourhood of the blastopore, betreen the hypoblast and the epiblast, though they are probably derived from the former. From this region they gradually spread, first over the sternal, and then on to the tergal aspect of the embryo, and constitute the mesoblast.

Epiblast, hypoblast, and mesoblast are at first alike constituted of nothing but nucleated cells, and they increase in dimensions by the continual fission and growth of these cells. The several layers become gradually modelled into the organs which they constitute, before the cells undergo any notable modification into tissues. A limb, for example, is, at first, a mere cellular out. growth, or bud, composed of an outer coat of epiblast with an inner core of mesoblast; and it is only subsequently that its component cells are metamorphosed into well-defined epidermic and connective tissues, ressels and muscles.

The embryo crayfish remains only a short while in the gastrula stage, as the blastopore soon closes up, and the archenteron takes the form of a sac, flattened out between the epiblast and the food-yelk, with which its cells are in close contact (fig. 57, C and D).* Indeed, as development proceeds, the cells of the hypoblast actually feed upon the substance of the food-yelk; and turn it to account for the general nutrition of the body.

* Whether, as some observers state, the hypoblastic cells grow orer and inclose the food-yelk or not, is a question that may be left open. I have not been able to satisfy myself of this fact. 
The sternal area of the embryo gradually enlarges until it occupies one hemisphere of the yelk; in other words, the thickening of the epiblast gradually extends outwards. Just in front of the blastopore, as it closes, the middle of the epiblast grows out into a rounded elevation (fig. 58, $t a$; fig. 59, $a b$ ), which rapidly increases in length, and at the same time turns forwards. This is the rudiment of the whole abdomen of the crayfish. Further forwards, two broad and elongated, but flatter thickenings appear; one on each side of the middle line (fig. 58, $p c$ ). As the free end of the abdominal papilla now marks the hinder extremity of the embryo, so do these two elevations, which are termed the procephalic lobes, define its anterior termination. The whole sternal. region of the body will be produced by the elongation of that part of the embryo which lies between these two limits.

A narrow longitudinal groove-like depression appears on the surface of the epiblast, in the middle line, between the procephalic lobes and the base of the abdominal papilla (fig. 58, C-F, $m g$ ). About its centre, this groove becomes further depressed by the ingrowth of the epiblast, which constitutes its floor, and gives rise to a short tubular sac, which is the rudiment of the whole foregut (fig. 57, C, and fig. 58, E, fg). At first, this epiblastic ingrowth does not communicate with the archenteron, but, after a while, its blind end combines with the front and lower part of the hypoblast, and an opening is formed by 


\section{THE MORPHOLOGY OF THE COMMON CRAYFISH.}

which the cavity of the fore-gut communicates with that of the mid-gut (fig. 57, E). Thus a gullet and stomach, or rather the parts which will eventually give rise to all these, are constituted. And it is important to remark that, in comparison with the mid-gut, they are, at first, very small.

In the same way, the epiblast covering the sternal face of the abdominal papilla undergoes invagination and is converted into a narrow tube which is the origin of the whole hind-gut (fig. 57, C, and fig. 58, E, hg). This, like the fore-gut, is at first blind ; but the shut front end soon applying itself to the hinder wall of the archenteric sac, the two coalesce and open into one another (fig. 57, E). Thus the complete alimentary canal, consisting of a very narrow, tubular, fore- and hind-gut, derived from the epiblast, and a wider and more sac-like mid-gut, formed of the whole hypoblast, is constituted.

The procephalic lobes become more convex; while, behind them, the surface of the epiblast rises into six elevations disposed in pairs, one on each side of the median groove. The hindermost of these, which lie at the sides of the mouth, are the rudiments of the mandibles (fig. 58, E and F,4); the other two become the antennæ (3) and the antennules (2), while, at a later period, processes of the procephalic lobes give rise to the eyestalks.

A short distance behind the abdomen, the epiblast rises into a transverse ridge, which is concave forwards, 
while its ends are prolonged on each side nearly as far as the mouth. This is the commencement of the free edge of the carapace (fig. 58, $\mathrm{E}$ and $\mathrm{F}$, and fig. 59, A, c) - the lateral parts of which, greatly enlarging, become the branchiostegites (fig. 59, D, c).

In many animals allied to crayfish, the young, when it has reached a stage in its development, which answers to this, undergoes rapid changes of outward form and of internal structure, without making any essential addition to the number of the appendages. The appendages which represent the antennules, the antennæ, and the mandibles elongate and become oar-like locomotive organs; a single median eye is developed, and the young leaves the egg as an active larva, which is known as a Nauplius. The crayfish, on the other hand, is wholly incapable of an independent existence at this stage, and continues its embryonic life within the egg case; but it is a remarkable circumstance that the cells of the epiblast secrete a delicate cuticula, which is subsequently shed. It is as if the animal symbolized a nauplius condition by the development of this cuticle, as the fotal whalebone whale symbolizes a toothed condition by developing teeth which are subsequently lost and never perform any function.

In fact, in the crayfish, the nauplius condition is soon left behind. The sternal disk spreads more and more over the yelk; as the region between the mouth and the root of the abdomen elongates, slight transverse 

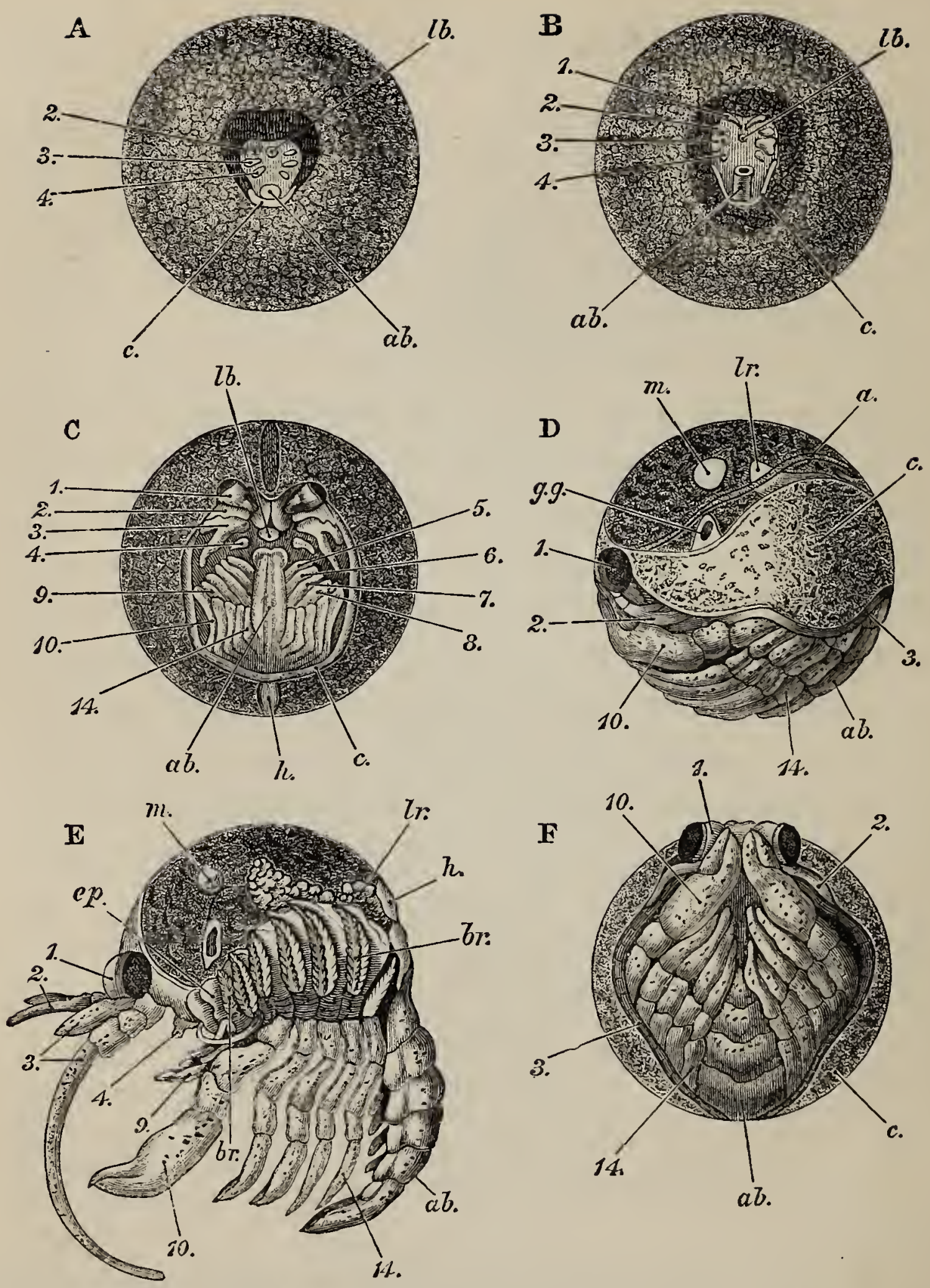

FiG. 59.-Astecus fluviatilis.-Ventral (A, B, C, F) and lateral (D, E) views of the embryo in successive stages of development (after Rathke, $\times 15$ ). $\Lambda$ is a little more advanced than the embryo represented in fig. $5 \mathrm{~S}, \mathrm{~F}: \mathrm{D}, \mathrm{E}$, and $\mathrm{F}$ are views of the young crayfish when nearly ready to be hatched: in $\mathrm{E}$, the carapace is removed, and the limbs and abdomen are spread out. $1-14$, the cephalic and thoracic appendages; $a$ ), abdomen ; br, branchix; $c$, carapace ; $c p$, cpipoditc of the first maxillipede; $g g$, green gland; $h$, lieart; $l b$, labrum ; lr; lirer; $m$, mandibular muscles. 
depressions indicate the boundaries of the posterior cephalic and the thoracic somites; and pairs of elevations, similar to the rudiments of the antennules and antennæ, appear upon them in regular order from before backwards (fig. 59, C).

In the meanwhile, the extremity of the abdomen flattens out and takes on the form of an oval plate, the middle of the posterior margin of which is slightly truncated or notched; while, finally, transverse constrictions mark off six segments, the somites of the abdomen, in front of this. Along with these changes, four pairs of tubercles grow out from the sternal faces of the four middle abdominal somites, and constitute the rudiments of the four middle pairs of abdominal appendages. The first abdominal somite exhibits only two hardly perceptible elevations in place of the appendages of the others, while the sixth seems, at first, to have none. The appendages of the sixth somite, however, are already formed, though, singularly enough, they lie beneath the cuticle of the telson and are set free only after the first ecdysis.

The rostrum grows out between the procephalic lobes; it remains relatively very short up to the time that the young crayfish quits the egg, and is directed more downwards than forwards. The lateral portions of the carapacial ridge, becoming deeper, are converted into the branchiostegites, and the cavities which they overarch are the branchial chambers. The transverse portion of 
the ridge, on the other hand, remains relatively short, and constitutes the free posterior margin of the carapace.

As these changes take place, the abdomen and the sternal region of the thorax are constantly enlarging in proportion to the rest of the ovum; and the food-yelk which lies in the cephalothorax is, pari passu, being diminished. Hence the cephalothorax constantly becomes relatively smaller and the tergal aspect of the carapace less spherical; although, even when the young crayfish is ready to be hatched, the difference between it and the adult in the form of the cephalothoracic region, and in the size of the latter relatively to the abdomen, is very marked.

The simple bud-like outgrowths of the somites, in which all the appendages take their origin, are rapidly metamorphosed. The eyestalks (fig. 59, 1) soon attain a considerable relative size. The extremities of the antennules (2) and of the antennæ (3) become bifurcated; and the two divisions of the antennule remain broad, thick, and of nearly the same size up to birth. On the other hand, the inner or endopoditic division of the antenna becomes immensely lengthened, and at the same time annulated, while the outer or exopoditic division remains relatively short, and acquires its characteristic scale-like form.

The labrum $(l b)$ arises as a prolongation of the middle sternal region in front of the mouth, while the bilobed metastoma is an outgrowth of the sternal region behind it. 
The posterior cephalic and the thoracic appendages (5-14) elongate and gradually approach the form which they possess in the adult. I have not been able to discover, at any period of development, an outer division or exopodite in any of the five posterior thoracic limbs. And this is a very remarkable circumstance, inasmuch as such an exopodite exists in the closely allied lobster in the larval state; and, in many of the shrimp and prawn-like allies of the crayfish, a complete or rudimentary exopodite is found in these limbs, even in the adult condition.

When the crayfish is hatched (fig. 60) it differs from the adult in many ways-not only is the cephalothorax more convex and larger in proportion to the abdomen; but the rostrum is short and bent down between the eyes. The sterna of the thorax are wider relatively, and hence there is a greater interval between the bases of the legs than in the adult. The proportion of the limbs to one another and to the body are nearly the same as in the adult, but the chelæ of the forceps are more slender. The tips of the chelæ are all strongly incurved (fig. 8, B, p. 41), and the dactylopodites of the two posterior thoracic limbs are hooklike. The appendages of the first abdominal somite are undeveloped, and those of the last are inclosed within the telson, which is, as has already been said, of a broad oval form, usually notched in the middle of its hinder margin, and devoid of any indication of transverse division. Its margins are produced into a single series of short conical 
processes, and the disposition of the vascular canals in its interior gives it the appearance of being radially striated.

The setæ, so abundant in the adult, are very scanty in the newly hatched young; and the great majority of those which exist are simple conical prolongations of the un-

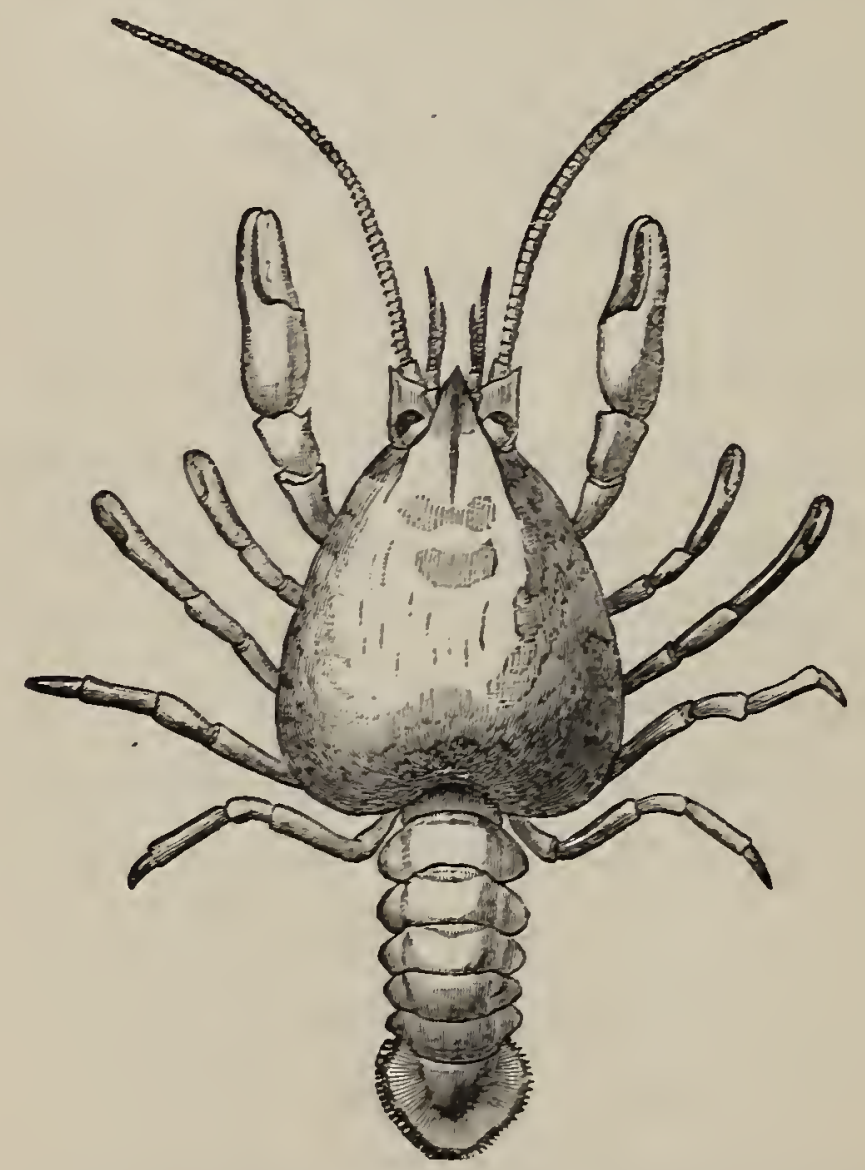

FIG. 60.-Astacus fluviatilis.-Xewly-hatched joung ( $\times 6)$.

calcified cuticle, the bases of which are not sunk in pits and which are devoid of lateral scales or processes.

The young animals are firmly attached to the $a b$ dominal appendages of the parent in the manner already described. They are rery sluggish, though they move when touched; and at this period they do not feed, but 
are nourished by the food-yelk, of which a considerable store still remains in the cephalothorax.

I imagine that they are set free during the first ecdysis, and that the appendages of the sixth abdominal somite are at that time expanded, but nothing is definitely known at present of these changes.

The foregoing sketch of the general nature of the changes which take place in the egg of the crayfish suffice to show that its development is, in the strictest sense of the word, a process of evolution. The egg is a relatively homogeneous mass of living protoplasmic matter, containing much nutritive material; and the development of the crayfish means the gradual conversion of this comparatively simple body into an organism of great complexity. The yelk becomes differentiated into formative and nutritive portions. The formative portion is subdivided into histological units: these arrange themselves into a blastodermic vesicle; the blastoderm becomes differentiated into epiblast, hypoblast, and mesoblast; and the simple vesicle assumes the gastrula condition. The layers of the gastrula shape themselves into the body of the crayfish and its appendages, while along with this, the cells of which all the parts are built, become metamorphosed into tissues, each with its characteristic properties. And all these wonderful changes are the necessary consequences of the interaction of the molecular forces resident in the substance of the 
222 THE MORPHOLOGY OF THE COMMON CRAYFISH.

impregnated ovum, with the conditions to which it is exposed; just as the forms evolved from a crystallising fluid are dependent upon the chemical composition of the dissolved matter and the influence of surrounding conditions.

Without entering into details which lie beyond the scope of the present work, something must be said respecting the manner in which the complicated internal organisation of the crayfish is evolved from the cellular double sac of the gastrula stage.

It has been seen that the fore-gut is at first an insignificant tubular involution of the epiblast in the region of the mouth. It is, in fact, a part of the epiblast turned inwards, and the cells of which it is composed secrete a thin cuticular layer, as do those of the rest of the epiblast, which gives rise to the ectodermal or epidermic part of the integument. As the embryo grows, the foregut enlarges much faster than the mid-gut, increasing in height and from before backwards, while its side-walls remain parallel, and are separated by only a narrow cavity. At length, it takes on the shape of a triangular bag (fig. $57, \mathrm{D}, f g$ ), attached by its narrow end around the mouth and immersed in the food-yelk, which it gradually divides into two lobes, one on the right and one on the left side. At the same time a vertical plate of mesoblastic tissue, from which the great anterior and posterior muscles are eventually developed, connects it with the roof and with the front wall of the carapace. 
Becoming constricted in the middle, the fore-gut next appears to consist of two dilatations of about equal size, connected by a narrower passage (fig. 57, E, $f g^{1}, f g^{2}$ ). The front dilatation becomes the cesophagus and the cardiac division of the stomach; the hinder one, the pyloric division. At the sides of the front end of the cardiac division two small pouches are formed shortly after birth; in each of these a thick laminated deposit of chitin takes place, and constitutes a minute crab's-eye or gastrolith, which has the same structure as in the adult, and is largely calcified. This fact is the more remarkable as, at this time, the exoskeleton contains very little calcareous deposit. In the position of the gastric teeth, folds of the cellular wall of corresponding shape are formed, and the chitinous cuticle of which the teeth are composed is, as it were, modelled upon them.

The hind-gut occupies the whole length of the abdomen, and its cells early arrange themselves into six ridges, and secrete a cuticular layer.

The mid-gut, or hypoblastic sac, very soon gives off numerous small prolongations on each side of its hinder extremity, and these are converted into the cæca of the liver (fig. 57, E, mg). The cells of its tergal wall are in close contact with the adjacent masses of food-yelk; and it is probable that the gradual absorption of the foodyelk is chiefly effected by these cells. At birth, however, the lateral lobes of the food-yelk are still large, and occupy the space left between the stomach and liver 
224 THE MORPHOLOGY OF THE COMMON CRAYFISH.

on the one hand, and the cephalic integument on the other.

The mesoblastic cells give rise to the layer of connective tissue which forms the deeper portion of the integument, and to that which invests the alimentary canal; to all the muscles; and to the heart, the ressels, and the corpuscles of the blood. The heart appears very early as a solid mass of mesoblastic cells in the tergal region of the thorax, just in front of the origin of the abdomen (figs. 57, 58, 59, $h$ ). It soon becomes hollow, and its walls exhibit rhythmical contractions.

The branchiæ are, at first, simple papillæ of the integument of the region from which they take their rise. These papillæ elongate into stems, which give off lateral filaments. The podobranchix are at first similar to the arthrobranchiæ, but an outgrowth soon takes place near the free end of the stem, and becomes the lamina, while the attached end enlarges into the base.

The renal organ is stated to arise by a tubular involution of the epiblast, which soon becomes convoluted, and gives rise to the green gland.

The central nerrous system is wholly a product of the epiblast. The cells which lie at the sides of the longitudinal groove already mentioned (fig. 58, $\mathrm{mg}$ ), grow inwards, and give rise to two cords which are at first separate from one another and continuous with the rest of the epiblast. At the front end of the groore a 
depression arises, and its cells form a mass which connects these two cords in front of the mouth, and gives rise to the cerebral ganglia. The epiblastic linings of two small pits (fig. 58, o) which appear very early on the surface of the procephalic lobes, are also carried inwards in the same way, and, uniting with the foregoing, produce the optic ganglia.

The cells of the longitudinal cords become differentiated into nerre fibres and nerve cells, and the latter, gathering towards certain points, give rise to the ganglia which erentually unite in the middle line. By degrees, the ingrowth of epiblastic cells, from which all these structures are developed, becomes completely separated from the rest of the epiblast, and is invested by mesoblastic cells. The central nervous system, therefore, in a crayfish, as in a vertebrated animal, is at first, as a part of the ectoderm, morphologically one with the epidermis; and the deep and protected position which it occupies in the adult is only a consequence of the mode in which the nervous portion of the ectoderm grows inwards and becomes detached from the epidermic portion.

The visual rods of the eye are merely modified cells of the ectoderm. The auditory sac is formed by an involution of the ectoderm of the basal joint of the antennule. At birth it is a shallow wide-mouthed depression, and contains no otoliths.

Lastly, the reproductive organs result from the segregation and special modification of cells of the mesoblast 
behind the liver. Rathke states that the sexual apertures are not visible until the young crayfish has attained the length of an inch; and that the first pair of abdominal appendages of the male appear still later in the form of two papillæ, which gradually elongate and take on their characteristic forms. 


\section{CHAPTER V.}

THE COMPARATIVE MORPHOLOGY OF THE CRAYFISH.-THE STRUCTURE AND THE DEVELOPMENT OF THE CRAYFISH COMPARED WITH THOSE OF OTHER IIVING BEINGS.

UP to this point, our attention has been directed almost exclusively to the common English crayfish. Except in so far as the crayfish is dependent for its maintenance upon other animals, or upon plants, we might have ignored the existence of all living things except crayfishes. But, it is hardly necessary to observe, that innumerable hosts of other forms of life not only tenant the waters and the dry land, but throng the air; and that all the crayfishes in the world constitute a hardly appreciable fraction of its total living population.

Common observation leads us to see that these multitudinous living beings differ from not-living things in many ways; and when the analysis of these differences is pushed as far as we are at present able to carry it, it shews us that all living beings agree with the crayfish and differ from not-living things in the same particulars. Like the crayfish, they are constantly wasting away by 
228 THE COMPARATIVE MIORPHOLOGY OF THE CRAYFISH.

oxidation, and repairing themselves by taking into their substance the matters which serve them for food; like the crayfish, they shape themselves according to a definite pattern of external form and internal structure; like the crayfish, they give off germs which grow and develope into the shapes characteristic of the adult. No mineral matter is maintained in this fashion; nor grows in the same way; nor undergoes this kind of development; nor multiplies its kind by any such process of reproduction.

Again, common observation early leads to the discrimination of living things into two great divisions. Nobody confounds ordinary animals with ordinary plants, nor doubts that the crayfish belongs to the former category and the waterweed to the latter. If a living thing moves and possesses a digestive receptacle, it is held to be an animal; if it is motionless and draws its nourishment directly from the substances which are in contact with its outer surface, it is held to be a plant. We need not inquire, at present, how far this rough definition of the differences which separate animals from plants holds good. Accepting it for the moment, it is obvious that the crayfish is unquestionably an animal, -as much an animal as the vole, the perch, and the pond-snail, which inhabit the same waters. Moreover, the crayfish has, in common with these animals, not merely the motor and digestive power's characteristic of animality, but they all, like it, possess a complete alimentary canal; special appa- 
ratus for the circulation and the aerration of the blood; a nervous system with sense-organs; muscles and motor mechanisms; reproductive organs. Regarded as pieces of physiological apparatus, there is a striking similarity between all three. But, as has already been hinted in the preceding chapter, if we look at them from a purely morphological point of view, the differences between the crayfish, the perch, and the pond-snail, appear at first sight so great, that it may be difficult to imagine that the plan of structure of the first can have any relation to that of either of the last two. On the other hand, if the crayfish is compared with the water-beetle, notwithstand-ing wide differences, many points of similarity between the two will manifest themselves; while, if a small lobster is set side by side with a crayfish, an unpractised observer, though he will readily see that the two animals are somewhat different, may be a long time in making out the exact nature of the differences.

Thus there are degrees of likeness and unlikeness among animals, in respect of their outward form and internal structure, or, in other words, in their morphology. The lobster is very like a crayfish, the beetle is remotely like one; the pond-snail and the perch are extremely unlike crayfishes. Facts of this kind are commonly expressed in the language of zoologists, by saying that the lobster and the crayfish are closely allied forms; that the beetle and the crayfish present a remote affinity; and that there is no affinity between the 
230 THE COMPARATIVE MORPHOLOGY OF THE CRAYFisH.

crayfish and the pond-snail, or the crayfish and the perch.

The exact determination of the resemblances and differences of animal forms by the comparison of the structure and the development of one with those of another, is the business of comparative morphology. Morphological comparison, fully and thoroughly worked out, furnishes us with the means of estimating the position of any one animal in relation to all the rest; while it shews us with what forms that animal is nearly, and with what it is remotely, allied: applied to all animals, it furnishes us with a kind of map, upon which animals are arranged in the order of their respective affinities; or a classification, in which they are grouped in that order. For the purpose of dereloping the results of comparative morphology in the case of the crayfish, it will be convenient to bring together, in a summary form, those points of form and structure, many of which have already been referred to and which characterise it as a separate kind of animal.

Full-grown English crayfishes usually measure about three inches and a half from the extremity of the rostrum in front to that of the telson behind. The largest specimen I have met with measured four inches.* The

* The dimensions of crayfishes at successive ages given at p. 31, beginning at the words "By the end of the year," refer to the "écrevisse à pieds rouges" of France; not to the English crayfish, which is 
males are commonly somewhat larger, and they almost always have longer and stronger forceps than the females. The general colour of the integument varies from a light reddish-brown to a dark olive-green; and the hue of the tergal surface of the body and limbs is always deeper than that of the sternal surface, which is often light vellowish-green, with more or less red at the extremities of the forceps. The greenish hue of the sternal surface occasionally passes into yellow in the thorax and into blue in the abdomen.

The distance from the orbit to the posterior margin of the carapace is nearly equal to that from the posterior margin of the carapace to the base of the telson, when the abdomen is fully extended, but this measurement of the carapace is commonly greater than that of the abdomen in the males and less in the females.

The general contour of the carapace (fig. 61 ), without the rostrum, is that of an oval, truncated at the ends: the anterior end being narrower than the posterior. Its surface is evenly arched from side to side. The greatest. breadth of the carapace lies midway between the cervical groove and its posterior edge. Its greatest vertical depth is on a level with the transverse portion of the cervical groove.

The length of the rostrum, measured from the orbit

considerably smaller. Doubtless, the proportional rate of increment is much the same, in the two kinds; but in the English crayfish it has not been actually ascertained. 
232 THE COMPARATIVE MORPHOLOGY OF THE CRAYFISH.

to its extremity, is greater than half the distance from the orbit to the cervical groove. It is trihedral in section, and its free end is slightly curved upwards (fig. 41). It gradually becomes narrower for about three-fourths of its whole length. At this point it has rather less than half the width which it has at its base (fig. 61, A); and its raised, granular and sometimes distinctly serrated margins are produced into two obliquely directed spines, one on each side. Beyond these, the rostrum rapidly narrows to a fine point; and this part of the rostrum is equal in length to the width between the two spines.

The tergal surface of the rostrum is flattened and slightly excavated from side to side, except in its anterior half, where it presents a granular or finely serrated median ridge, which gradually passes into a low elevation in the posterior half, and, as such, may generally be traced on to the cephalic region of the carapace. The inclined sides of the rostrum meet ventrally in a sharp.edge, convex from before backwards; the posterior half of this edge gives rise to a small, usually bifurcated, spine, which descends between the eye-stalks (fig. 41). The raised and granulated lateral margins of the rostrum are continued back on to the carapace for a short distance, as two linear ridges (fig. 61, A). Parallel with each of these ridges, and close to it, there is another longitudinal elevation $(a, b)$, the anterior end of which is raised into a prominent spine $(a)$, which is situated immediately behind the orbit, and may, therefore, be termed the post-orbital 
spine. The elevation itself may be distinguished as the post-orbital ridge. The flattened surface of this ridge is marked by a longitudinal depression or groove. The
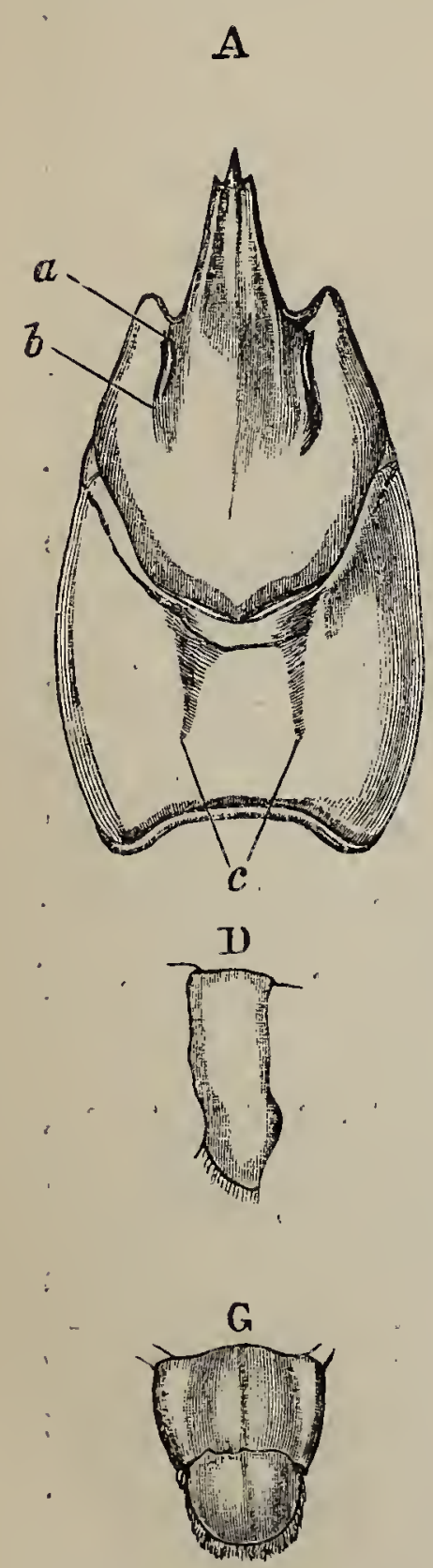

B
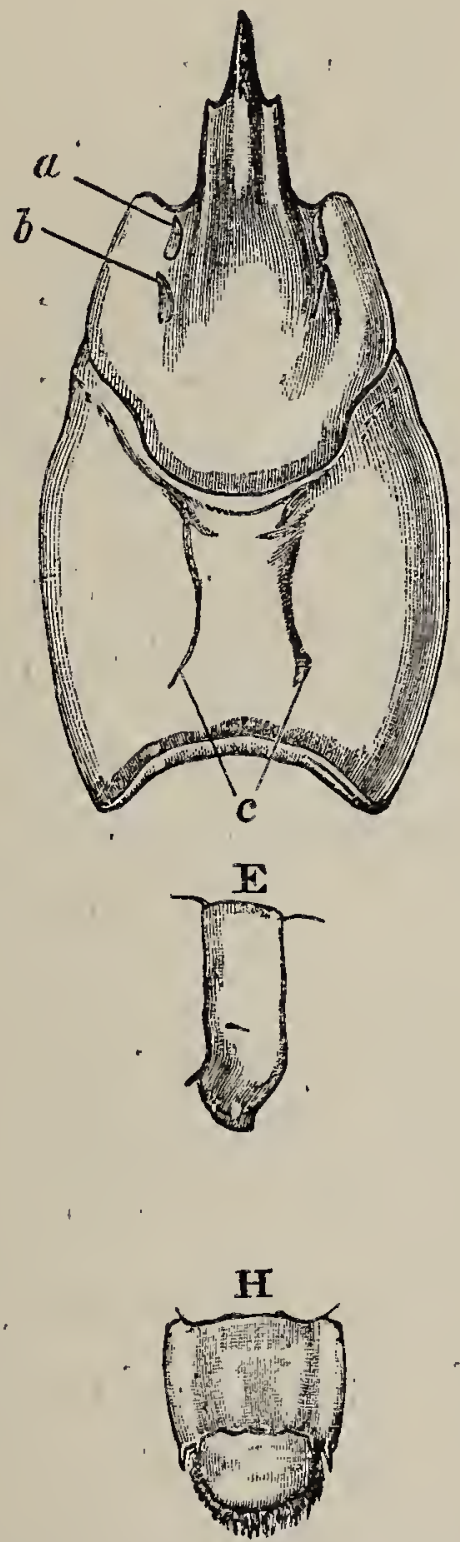
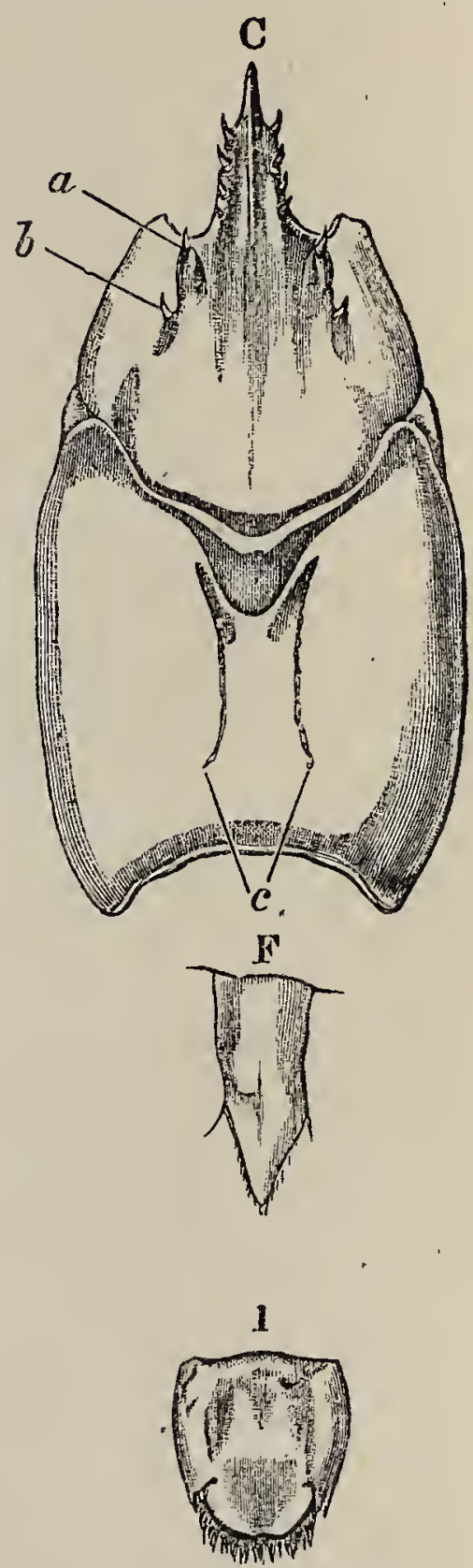

FIG. 61.-A, D, \& G, Astacus torrentium; $\mathrm{B}, \mathrm{E}, \& \mathrm{H}, \mathrm{A}$. notilis; C, F, \& I, A. nigrescens (nat. size). A-C, Dorsal views of carapace; $\mathrm{D}-\mathrm{F}$, side views of third abdominal somites ; G-I, Dorsal views of telson. $a, b$, post-orbital ridge and spines; $c$, branchio-cardiac grooves inclosing the areola. 
234 TIIE COMPARATIVE MORPHOLOGT OF THE CRAYHISH.

posterior end of the ridge passes into a somewhat broader and less marked elevation, the hinder end of which turns inwards, and then comes to an end at a point midway between the orbit and the cervical groove. Generally this hinder elevation appears like a mere continuation of the post-orbital ridge; but, sometimes, the two are separated by a distinct depression. I have never seen any prominent spine upon the posterior elevation, though it is sometimes minutely spinulose. The post-orbital ridges of each side, viewed together, give rise to a characteristic lyrate mark upon the cephalic region of the carapace.

A faintly marked, curved, linear depression runs from the hinder end of the post-orbital ridge, at first directly downwards, and then curves backwards to the cervical groove. It corresponds with the anterior and inferior boundary of the attachment of the adductor muscle of the mandible.

Below the level of this, and immediately behind the cervical groove, there are usually three spines, arranged in a series, which follow the cervical groove. The points of all are directed obliquely forwards, and the lowest is the largest. Sometimes there is only one prominent spine, with one or two very small ones; sometimes there are as many as five of these cervical spines.

The cardiac region is marked out by two grooves which run backwards from the cervical groove (fig. $61, \mathrm{~A}, \mathrm{c}$ ), and terminate at a considerable distance from the posterior 
edge of the carapace. Each groove runs, at first, obliquely inwards, and then takes a straight course parallel with its fellow. The area thus defined is termed the areola; its breadth is equal to about one-third of the total transverse diameter of the carapace in this region.

No such distinct lines indicate the lateral boundary of the region in front of the cervical gronve which answers to the stomach. But the middle part of the carapace, or that which is comprised in the gastric and cardiac regions, has its surface sculptured in a different way from the branchiostegites and the lateral regions of the head. In the former, the surface is excavated by shallow pits, separated by relatively broad flat-topped ridges; but, in the latter, the ridges become more prominent, and take the form of tubercles, the apices of which are directed forwards. Minute setæ spring from the depressions between these tubercles.

The branchiostegite has a thickened rim, which is strongest below and behind (fig. 1). The free edge of this rim is fringed with close-set setæ.

The pleura of the second to the sixth abdominal somites are broadly lanceolate and obtusely pointed at their free ends (fig. 61, D); the anterior edge is longer and more convex than the posterior edge. In the females, the pleura are larger, and are directed more outwards and less downwards than in the males. The pleura of the second somite are much larger than the rest, and overlap the very small pleura of the first somite (fig.1). The 


\section{THE COMPARATIVE MORPHOLOGY OF THE CRAYFISH.}

pleura of the sixth somite are narrow, and their posterior edges are concare.

The pits and setæ of the cuticle which clothes the tergal surfaces of the abdominal somites are so few and scattered, that the latter appear almost smooth. In the telson, however, especially in its posterior division, the markings are coarser and the setre more apparent.

The telson (fig. 61, G) presents an anterior quadrate division and a posterior half-oval part, the free curred edge of which is beset with long setæ, and is sometimes slightly notched in the middle. The posterior division is freely movable upon the anterior, in consequence of the thinness and pliability of the cuticle along a transrerse line which joins the postero-external angles of the anterior division, each of which is produced into two strong spines, of which the outer is the longer. The length of the posterior division of the telson, measured from the middle of the suture, is equal to, or but very little less than, that of the anterior division.

On the under side of the head, the basal joints of the antennules are visible, internal to those of the antennæ, but the attachment of the latter is behind and below that of the former (fig. 3, A). Behind these, and in front of the mouth, the epistoma (fig. 39, A, II, III) presents a broad area of a pentagonal form. The posterior boundary of this area is formed ivy two thickened transverse ridges, which meet on the middle line at a very open angle, the apex of which is turned forwards. 
The posterior edges of these ridges are continuous with the labrum. The anterior margin is produced in the middle into a fleur de lys shaped process, the summit of which terminates between the antennules. At the sides of this process, the anterior margin of the epistoma is deeply excavated to receive the basal joints of the antennæ. Following the contours of these excavated margins, the surface of the epistoma presents two lateral convexities. The widest and most prominent part of each of these lies towards the outer edge of the epistoma, and is produced into a conical spine. Sometimes there is a second smaller spine beside the principal one. Between the two convexities lies a triangular median depressed area.

The distance from the apex of the anterior median process to the posterior ridge is equal to a little more than half the width of the epistoma.

The corneal surface of the eye is transversely elongated and reniform, and its pigment is black. The eye-stalks are much broader at their bases than at their cormeal ends (fig. 48, A). The antennules are about twice as long as the rostrum. The tergal surface of the trihedral basal joint of the antennule, on which the eye-stalk rests, is concare; the outer surface is convex, the inner flat (figs. 26, A, and 48, B). Near the anterior end of the sternal edge which separates the two latter faces, there is a strong curved spine directed forwards (fig. 48, B, a). When the setæ, which proceed from the outer edge of 
the auditory aperture and hide it, are remored, it is seen. to be a wide, somewhat triangular cleft, which occupies the greater part of the hinder half of the tergal surface of the basal joint (fig. 26, A).

The exopodites, or squames, of the antennæ extend as far as the apex of the rostrum, or even project beyond it, when they are turned forwards, while they reach to the commencement of the filament of the endopodite (Frontispiece). The squame is fully twice as long as it is broad, with a general convexity of its tergal and concavity of its sternal surface. The outer edge is straight and thick, the inner, which is fringed with long setæ, is convex and thin (fig. 48, C). Where these two edges join in front, the squame is produced into a strong spine. A thick outer portion of the squame is marked off from the thinner inner portion by a longitudinal groove on the tergal side, and by a strong ridge on the sternal side. One or two small spines generally project from the posterior and external angle of the squame; but they may be very small or absent in individual specimens. Close beneath these, the outer angle of the next joint is produced into a strong spine. When the abdomen is straightened out, if the antennæ are turned back as far as they will go without damage, the ends of their filaments usually reach the tergum of the third somite of the abdomen (Frontispicce). I have not observed any difference between the sexes in this respect.

The inner edge of the ischiopodite of the third maxilli- 
pede is strongly serrated and wider in front than behind (fig. 44); the meropodite possesses four or five spines in the same region; and there are one or two spines at the distal end of the carpopodite. When straightened out, the maxillipedes extend as far as, or even beyond, the end of the rostrum.

The inner or sternal edge of the ischiopodite of the forceps is serrated; that of the meropodite presents two rows of spines, the inner small and numerous, the outer large and few. There are several strong spines at the anterior end of the outer or tergal face of this joint. The carpopodite has two strong spines on its under or sternal surface, while its sharp inner edge presents many strong spines. Its upper surface is marked by a longitudinal depression, and is beset with sharp tubercles. The length of the propodite, from its base to the extremity of the fixed claw of the chela, measures rather more than twice as much as the extreme breadth of its base, the thickness of which is less than a third of this length (fig. 20, p. 93). The external angular process, or fixed claw, is of the same length as the base, or a little shorter. Its inner edge is sharp and spinose, and the outer more rounded and simply tuberculated. The apex of the fixed claw is produced into a slightly incurved spine. Its inner edge has a sinuous curvature, convex posteriorly, concave anteriorly, and bears a series of rounded tubercles, of which one near the summit of the conrexity, and one near the apex of the claw are the most prominent. 
240 THE COMPARATIVE MYRPHOLOGY OF THE CRAYFISH.

The apex of the dactylopodite, like that of the propodite, is formed by a slightly incurved spine (fig. 20), while its outer, sharper, edge presents a curvature, the inverse of that of the edge of the fixed claw against which it is applied. This edge is beset with rounded tubercles, the most prominent of which are one at the beginning, and one at the end of the concave posterior moiety of the edge. When the dactylopodite is brought up to the fixed claw, these tubercles lie, one in front of and one behind the chief tubercle of the convexity of the latter. The whole surface of the propodite and dactylopodite is corered with minute elevations, those of the upper surface being much more prominent than those of the lower surface.

The length of the fully extended forceps generally equals the distance between the posterior margin of the orbit and the base of the telson, in well characterized males; and, in individual examples, they are even longer ; while it may not be greater than the distance between the orbit and the hinder edge of the fourth abdominal somite, in females; and, in massiveness and strength, the difference of the forceps in the two sexes is still more p. 19. $\times$ remarkable (fig. 2).+ Moreover there is a good deal of variation in the form and size of the chelæ in individual males. The right and left chelæ present no important differences.

The ischiopodites of the four succeeding thoracic limbs are devoid of any recurred spines in either sex (Front., P. 168 . fig. 46).x The first pair are the stoutest, the second the 
longest: and when the latter are spread out at right angles to the body, the distance from tip to tip of the dactylopodites is equal to, or rather greater than, the extreme length of the body from the apex of the rostrum to the posterior edge of the telson, in both sexes. In both sexes, the length of the swimmerets hardly exceeds half the transverse diameter of the somites to which they are attached.

The exopodites of the appendages of the sixth abdominal somite (the extreme length of which is rather greater than that of the telson) are divided into a larger proximal, and a smaller distal portion (fig. 37, F, p. 144). The latter is about half as long as the former, and has a rounded free edge, setose like that of the telson. There is a complete flexible hinge between the two portions, and the overlapping free edge of the proximal portion, which is slightly concave, is beset with conical spines, the outermost of which are the longest. The endopodite has a spine at the junction of its outer straight edge with the terminal setose convex edge. A faintly marked longitudinal median ridge, or keel, ends close to the margin in a minute spine. The tergal distal edge of the protopodite is deeply bilobed, and the inner lobe ends in two spines, while the outer, shorter and broader lobe, is minutely serrated.

In addition to the characters distinctive of sex, which have already been fully detailed (pp. 7, 20, and 145), there is a marked difference in the form of the sterna of the three posterior thoracic somites between the males and females. 
Comparing a male and a female of the same size, the triangular area between the bases of the penultimate and ante-penultimate thoracic limbs is considerably broader at the base in the female. In both sexes, the hinder part of the penultimate sternum is a rounded transverse ridge separated by a groove from the anterior part; but this ridge is much larger and more prominent in the female than in the male, and it is often obscurely divided into two lobes by a median depression. Moreover, there are but few setæ on this region in the female; while, in the male, the setæ are long and numerous.

The sternum of the last thoracic somite of the female is divided by a transverse groove into two parts, of which the posterior, viewed from the sternal aspect, has the form of a transverse elongated ridge, which narrows to each end, is moderately convex in the middle, and is almost free from setæ. In the male, the corresponding posterior division of the last thoracic sternum is produced downwards and forwards into a rounded eminence which gives attachment to a sort of brush of long setæ (fig. 35 , p. 136).

The importance of this long enumeration of minute details* will appear by and by. It is simply a statement of the more obvious external characters in which all the full-grown English crayfishes which have come under my

* The student of systematic zoology will find the comparison of a lobster with a crayfish in all the points mentioned to be an excellent training of the faculty of observation. 
notice agree. No one of these individual crayfishes was exactly like the other; and to give an account of any single crayfish as it existed in nature, its special peculiarities must be added to the list of characters given above; which, considered together with the facts of structure discussed in previous chapters, constitutes a definition, or diagnosis, of the English kind, or species, of crayfish. It follows that the species, regarded as the sum of the morphological characters in question and nothing else, does not exist in nature; but that it is an abstraction, obtained by separating the structural characters in which the actual existences-the individual crayfishes-agree, from those in which they differ, and neglecting the latter.

A diagram, embodying the totality of the structural characters thus determined by observation to be common to all our crayfishes, might be constructed; and it would be a picture of nothing which ever existed in nature; though it would serve as a very complete plan of the structure of all the crayfishes which are to be found in this country. The morphological definition of a species is, in fact, nothing but a description of the plan of structure which characterises all the individuals of that species.

California is separated from these islands by a third of the circumference of the globe, one-half of the interval being occupied by the broad North Atlantic ocean. The fresh waters of California, however, contain crayfishes which are 


\section{THE COMPARATIVE MORPHOLOGY OF THE CRAYFISH.}

so like our own, that it is necessary to compare the two in every point mentioned in the foregoing description in order to estimate the value of the differences which they present. Thus, to take one of the kinds of crayfishes found in California, which has been called Astacus nigrescens; the general structure of the animal may be described in precisely the same terms as those used for the English crayfish. Even the branchiæ present no important difference, except that the rudimentary pleurobranchiæ are rather more conspicuous; and that there is a third small one, in front of the two which correspond with those possessed by the English crayfish.

The Californian crayfish is larger and somewhat differently coloured, the undersides of the forceps particularly presenting a red hue. The limbs, and especially the forceps of the males, are relatively longer; the chelæ of the forceps have more slender proportions; the areola is narrower relatively to the transverse diameter of the carapace (fig. 61, C). More definite distinctions are to be found in the rostrum, which is almost parallel-sided for two-thirds of its length, then gives off two strong lateral spines and suddenly narrows to its apex. Behind these spines, the raised lateral edges of the rostrum present five or six other spines which diminish in size from before backwards. The postorbital spine is very prominent, but the ridge is represented, in front, by the base of this spine, which is slightly grooved; and behind, by a distinct spine which is not so strong as the postorbital spine. 
There are no cervical spines, and the middle part of the cervical groove is angulated backwards instead of being transverse.
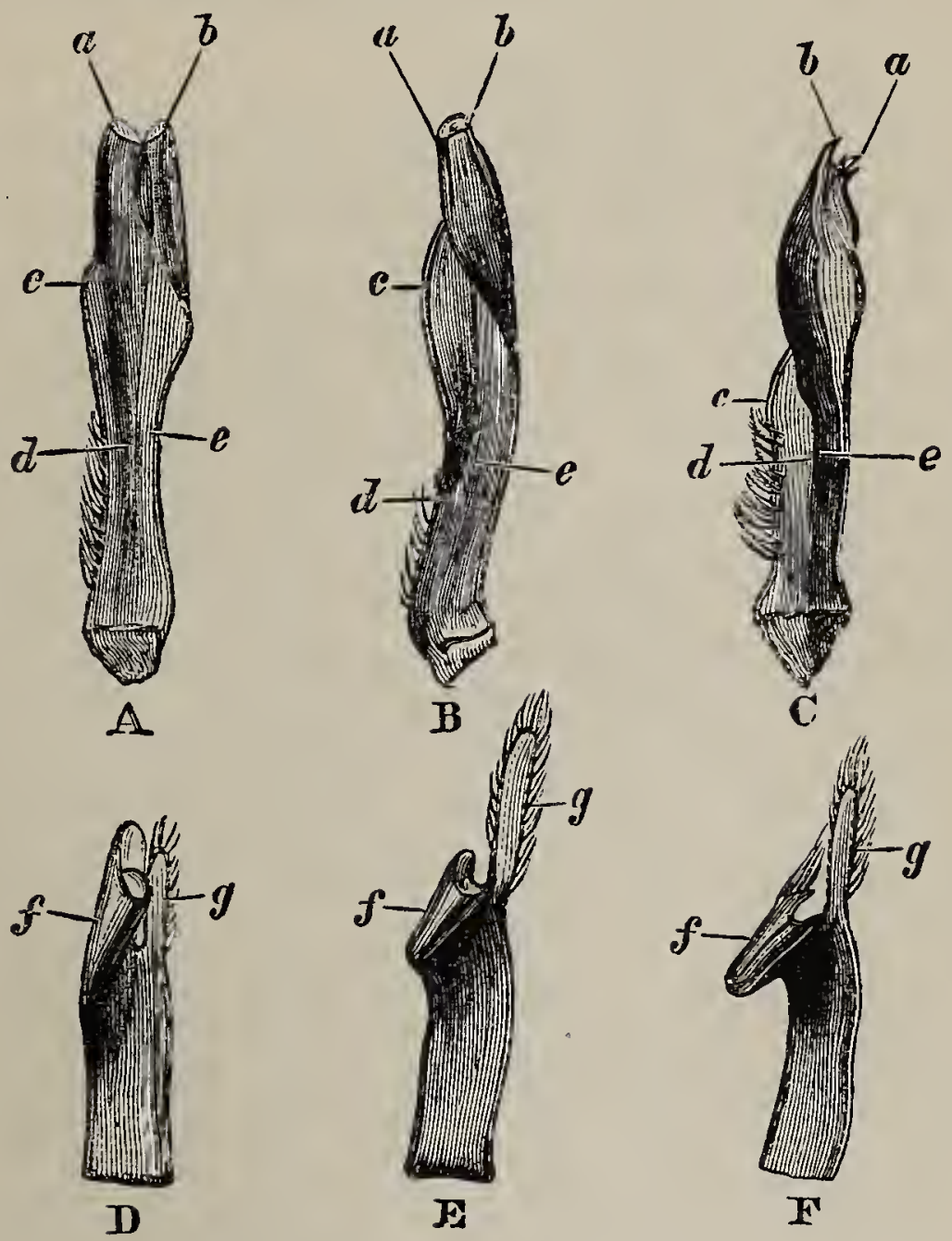

FIg. 62. A \& D, Astacus torrentium; $\mathrm{B} \& \mathrm{E}$, A. noonlis; $\mathrm{C} \& \mathrm{~F}$, A. nigrescens. A-C, 1st abdominal appendage of the male; $\mathrm{D}-\mathrm{F}$, endopodite of second appendage ( $\times 3$ ). $a$, anterior, and $b$, posterior rolled edge; $c, d, e$, corresponding parts of the appendages in each species; $f$, rolled plate of endopodite; $g$, terminal division of endopodite.

The abdominal pleura are narrow, equal-sided, and acutely pointed in the males (fig. 61, F) - slightly broader, more obtuse, and with the anterior edges 


\section{THE COMPARATIVE MORPHOLOGY OF THE CRAYFISH.}

rather more convex than the posterior, in the females. The tergal surface of the telson is not divided into two parts by a suture (fig. 61, I). The anterior process of the epistoma is of a broad rhomboidal shape, and there are no distinct lateral spines.

The squame of the antenna is not so broad relatively. to its length; its inner edge is less convex, and its outer edge is slightly concave; the outer basal angle is sharp but not produced into a spine. The opposed edges of the fixed and movable claws of the chelæ of the forceps are almost straight and present no conspicuous tubercles. In the males, the forceps are vastly larger than in the females, and the two claws of the chelæ are bowed out, so that a wide interval is left when their apices are applied together ; in the females, the claws are straight and the edges fit together, leaving no interval. Both the upper and the under surfaces of the claws are almost smooth. The median ridge of the endopodite of the sixth abdominal appendage is more marked, and ends close to the margin in a small prominent spine.

In the females, the posterior division of the sternum of the penultimate thoracic somite is prominent and deeply bilobed; and there are some small differences in form in the abdominal appendages of the males. More especially, the rolled inner process of the endopodite of the second appendage (fig. $62 \mathrm{~F}, f$ ) is disposed very obliquely, and its open mouth is on a level with the base of the jointed part of the endopodite $(g)$ instead of reaching almost to 
the free end of the latter and being nearly parallel with it. In the first appendage (C), the anterior rolled edge (a) more closely embraces the posterior $(b)$, and the groove is more completely converted into a tube.

It will be observed that the differences between the English and the Californian crayfishes amount to exceedingly little; but, on the assumption that these differences are constant, and that no transitional forms between the English and the Californian crayfishes are to be net with, the individuals which present the characteristic peculiarities of the latter are said to form a distinct species, Astacus nigrescens; and the definition of that species is, like that of the English species, a morphological abstraction, embodying an account of the plan of that species, so far as it is distinct from that of other crayfishes.

We shall see by and by that there are sundry other kinds of crayfishes, which differ no more from the English or the Californian kinds, than these do from one another; and, therefore, they are all grouped as species of the one genus, Astacus.

If, leaving California, we cross the Rocky Mountains and enter the eastern States of the North American Union, many sorts of crayfishes, which would at once be recognised as such by any English visitor, will be found to be abundant. But on careful examination it will be discovered that all of these differ, both from the English crayfish, and from Astacus nigrescens, to a much greater 
248 THE COMPARATIVE MORPHOLOGY OF THE CRAYFISH.

extent than those do from one another. The gills are, in fact, reduced to seventeen on each side, in consequence

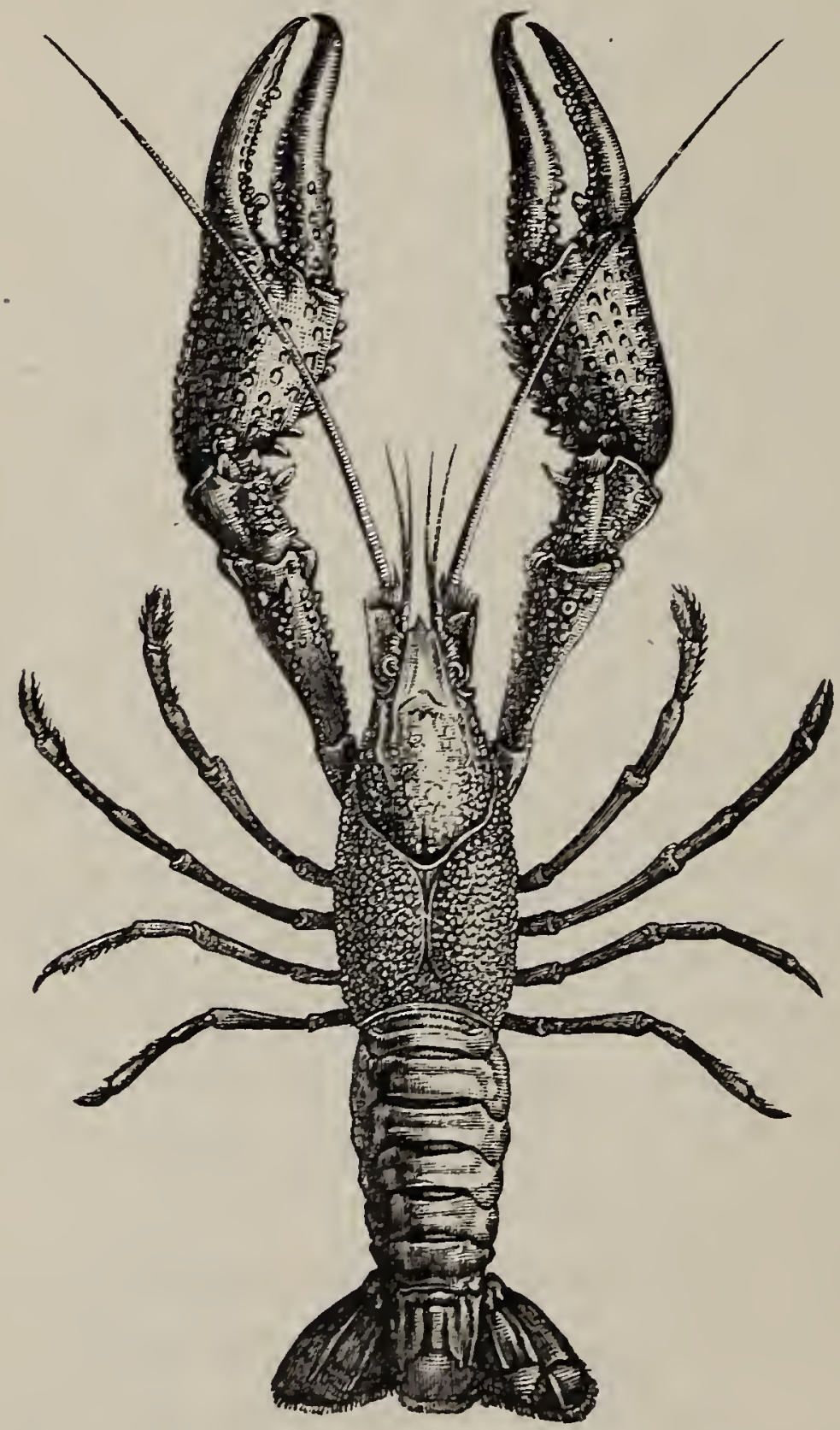

FIG. 63. Cambarus Clarkii, male ( $\frac{1}{2}$ nat. size), after Hagen. of the absence of the pleuro-branchia of the last thoracic somite; and there are some other differences to which it is not needful to refer at present. It is convenient to 
distinguish these seventeen-gilled crayfishes, as a whole, from the eighteen-gilled species; and this is effected by changing the generic name. They are no longer called Astacus, but Cambarus (fig. 63).

All the individual crayfish referred to thus far, therefore, have been sorted out, first into the groups termed species; and then these species have been further sorted into two divisions, termed genera. Each genus is an abstraction, formed by summing up the common characters of the species which it includes, just as each species is an abstraction, composed of the common characters of the individuals which belong to it; and the one has no more existence in nature than the other. The definition of the genus is simply a statement of the plan of structure which is common to all the species included under that genus; just as the definition of the species is a statement of the common plan of structure which runs throughout the individuals which compose the species.

Again, crayfishes are found in the fresh waters of the Southern hemisphere; and almost the whole of what has been said respecting the structure of the English crayfish applies to these; in other words, their general plan is the same. Bit, in these southern crayfishes, the podobranchiæ have no distinct lamina, and the first somite of the abdomen is devoid of appendages in both sexes. The southern crayfishes, like those of the Northern hem1sphere, are divisible into many species; and these species 
are susceptible of being grouped into six genera-Astacoides (fig. 65), Astacopsis, Charaps, Parastacus (fig. 64),

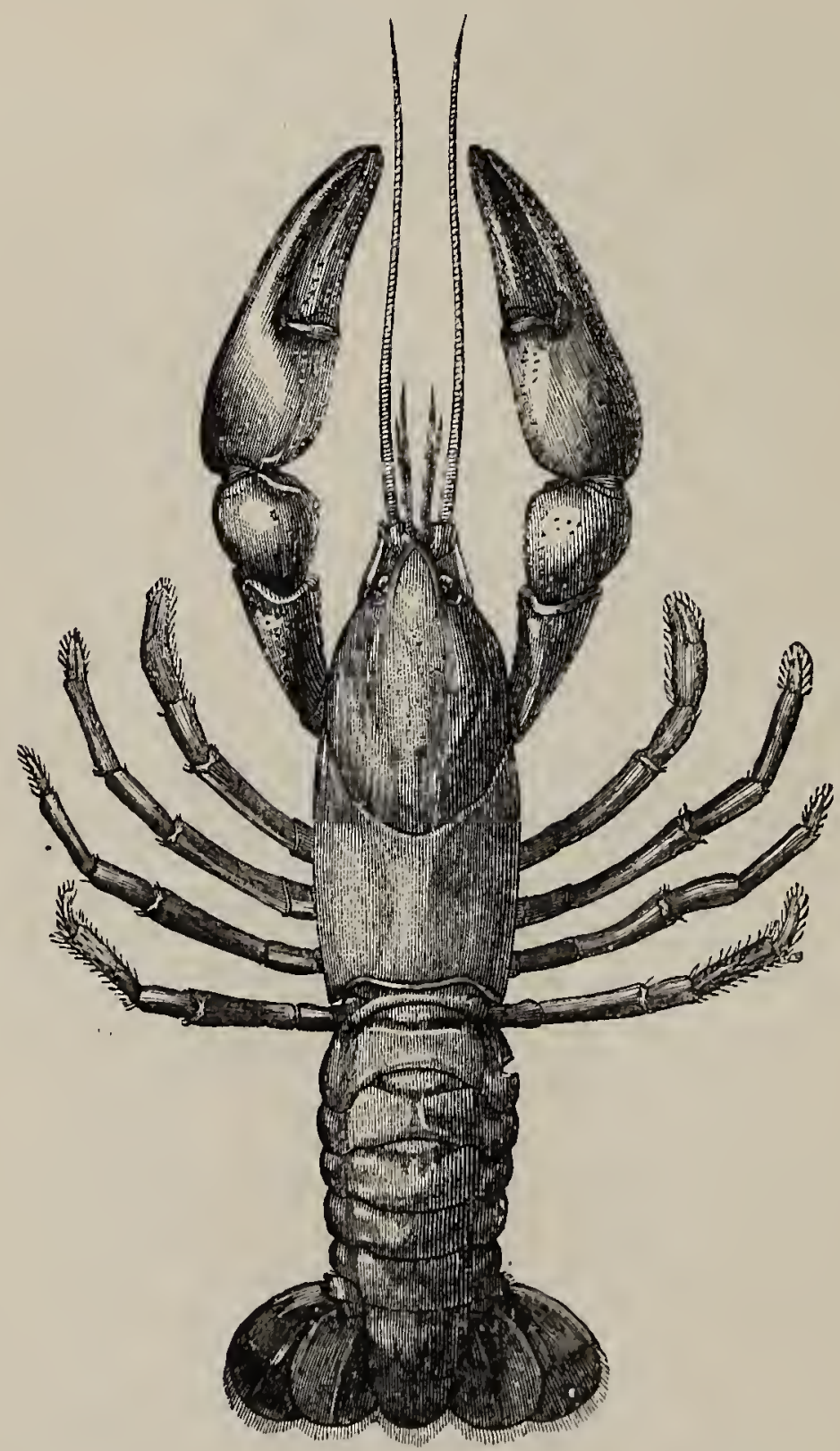

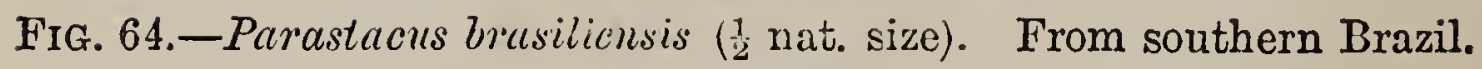

Engceus, and Paranephrops-on the same principle as that which has led to the grouping of the Northern forms into two genera. But the same convenience which has 


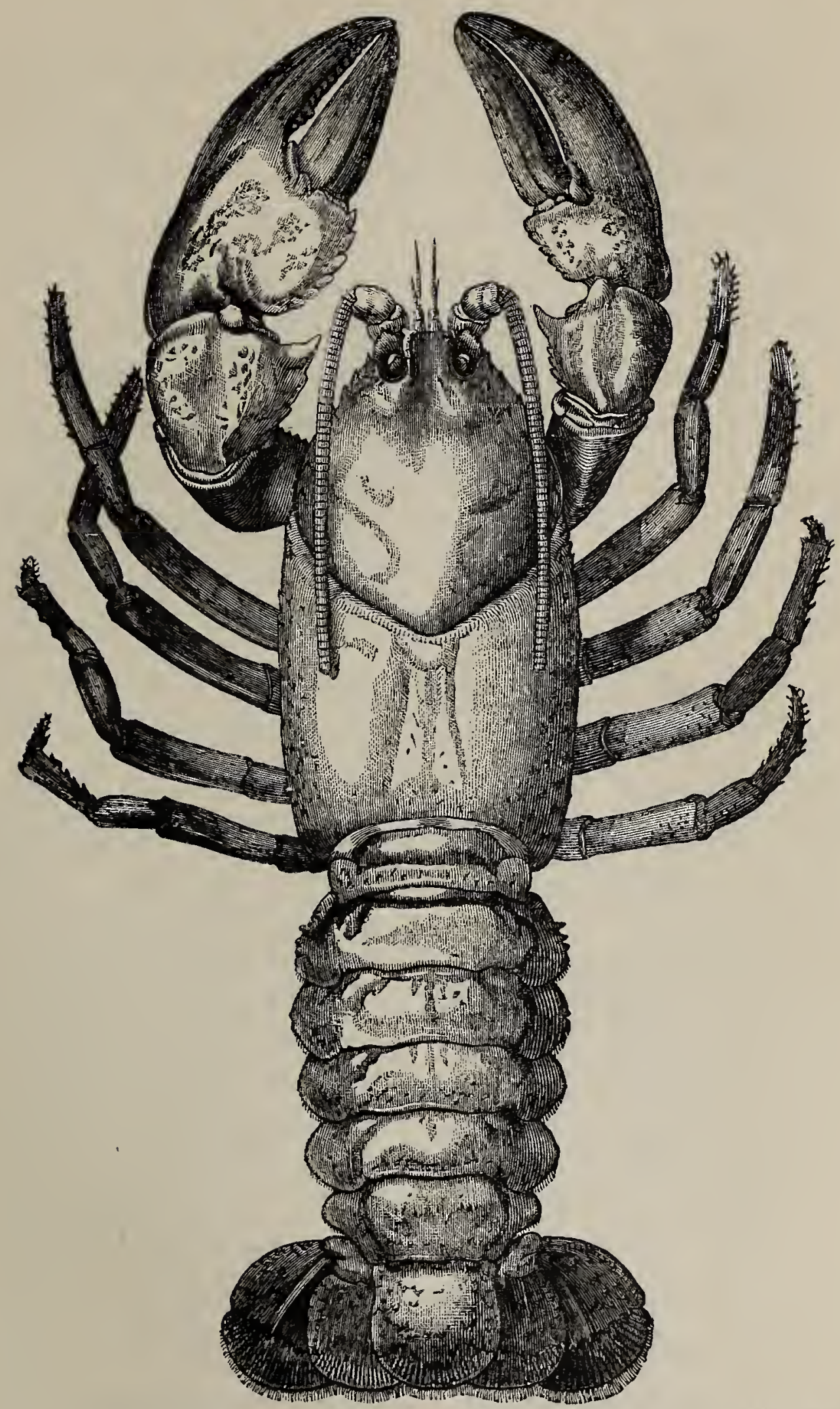

FIG. 65.-Astacoides madagascarensis ( $\frac{2}{3}$ nat. size). From Madagascar. 


\section{THE COMPARATIVE MORPHOLOGY OF THE CRAYFISH.}

led to the association of groups of similar species into genera, has given rise to the combination of allied genera into higher groups, which are termed Families. It is obvious that the definition of a family, as a statement of the characters in which a certain number of genera agree, is another morphological abstraction, which stands in the same relation to generic, as generic do to specific abstractions. Moreover, the definition of the family is a statement of the plan of all the genera comprised in that family.

The fauily of the Northern crayfishes is termed Potamobiida; that of the Southern crayfishes, Parastacida. But these tro families have in common all those structural characters which are special to neither; and, carrying out the metaphorical nomenclature of the zoologist a stage further, we may say that the two form a Tribe-the definition of which describes the plan which is common to both families.

It may conduce to intelligibility if these results are put into a graphic form. In fig. 66, A. is a diagram represent. ing the plan of an animal in which all the externally visible parts which are found, more or less modified, in the natural objects which we call individual crayfishes are roughly sketched. It represents the plan of the tribe. B. is a diagram exhibiting such a modification of $\mathrm{A}$. as converts it into the plan common to the whole family of the Parastacida. C. stands in the same relation to the Potamobiida. If the scheme were thoroughly worked out, diagrams representing the peculiarities of 


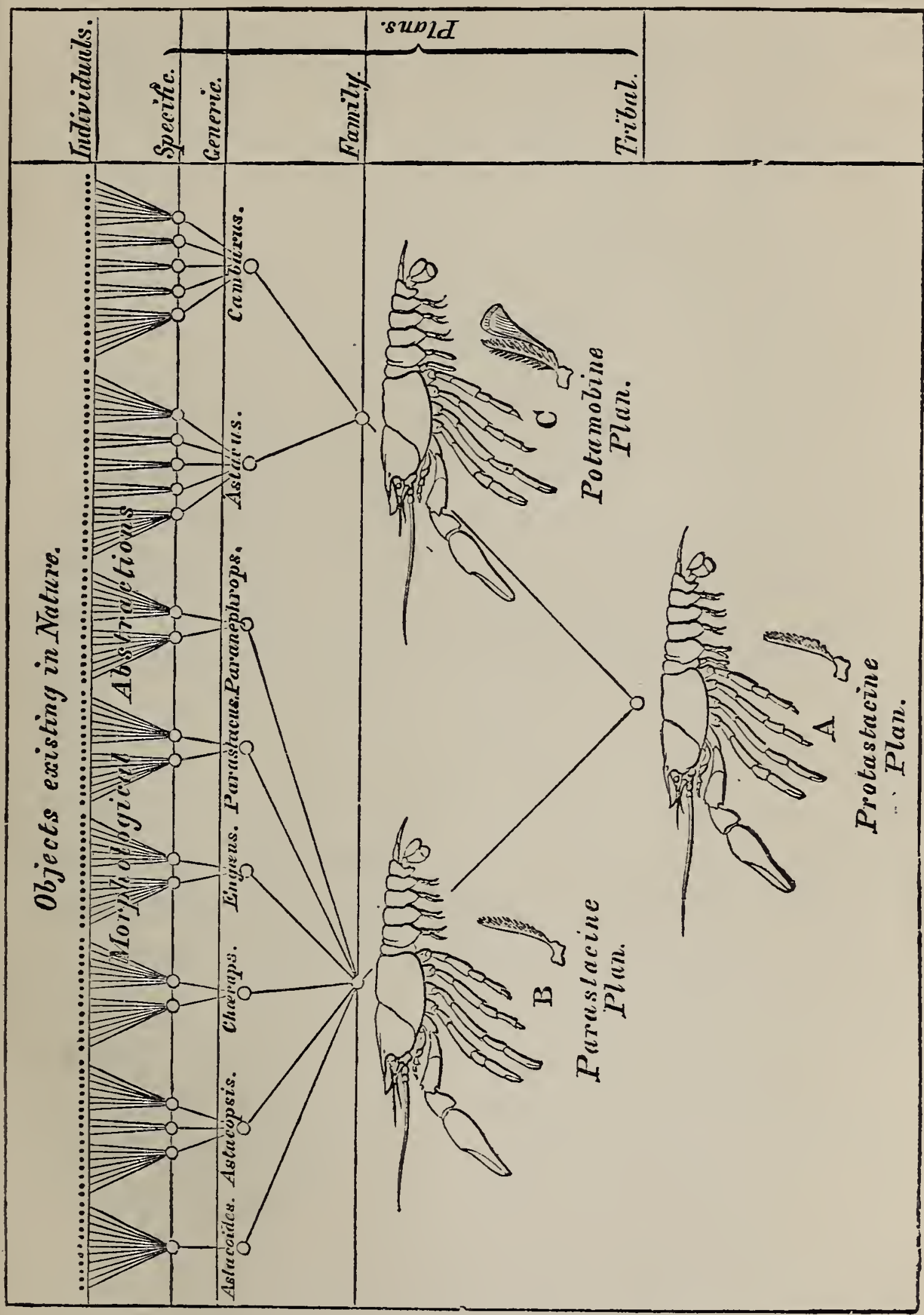

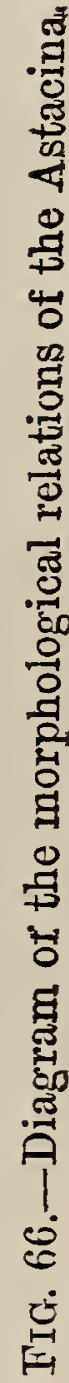


254 THE COMPARATIVE MORPHOLOGY OF THE CRAYFISH.

form which characterize each of the genera and species, would appear in the place of the names of the former, or of the circles which represent the latter. All these figures would represent abstractions - mental images which have no existence outside the mind. Actual facts would begin with drawings of individual animals, which we may suppose to occupy the place of the dots above the upper line in the diagram.

That all crayfishes may be regarded as modifications of the common plan A, is not an hypothesis, but a generalization obtained by comparing together the observations made upon the structure of individual crayfishes. It is simply a graphic method of representing the facts which are commonly stated in the form of a definition of the tribe of crayfishes, or Astacina.

This definition runs as follows :-

Multicellular animals provided with an alimentary canal and with a chitinous cuticular exoskeleton; with a ganglionated central nervous system traversed by the csophagus ; possessing a heart and branchial respiratory organs.

The body is bilaterally symmetrical, and consists of twenty metameres (or somites and their appendages), of which six are associated into a head, eight into a thorax, and six into an abdomen. A telson is attached to the last abdominal somite.

The somites of the abdominal region are all free, those of the head and thorax, except the hindermost, which is 
partially free, are united into a cephalothorax, the tergal wall of which has the form of a continuous carapace. The carapace is produced in front into a rostrum, at the sides into branchiostegites.

The eyes are placed at the ends of movable stalks. The antennules are terminated by two filaments. The exopodite of the antenna has the form of a mobile scale. The mandible has a palp. The first and second maxillæ are foliaceous; the second being provided with a large scaphognathite. There are three pairs of maxillipedes, and the endopodites of the third pair are narrow and elongated. The next pair of thoracic appendages is much larger than the rest, and is chelate, as are the two following pairs, which are slender ambulatory limbs. The hindmost two pairs of thoracic appendages are ambulatory limbs, like the foregoing, but not chelate. The abdominal appendages are small swimmerets, except the sixth pair, which are very large, and have the exopodite divided by a transverse joint.

All the crayfishes have a complex gastric armature. The seven anterior thoracic limbs are provided with podobranchix, but the first of these is always more or less completely reduced to an epipodite. More or fewer arthrobranchiæ always exist. Pleurobranchiæ may be present or absent.

In this tribe of Astacina there are two families, the Potamobiidee and the Parastacida; and the definition of each of these families is formed by superadding to the 
definition of the tribe the statement of the special peculiarities of the family.

Thus, the Potamobiidle are those Astacina in which the podobranchiæ of the second, fourth, fifth, and sixth thoracic appendages are always provided with a plaited lamina, and that of the first is an epipodite devoid of branchial filaments. The first abdominal somite invariably bears appendages in the males, and usually in both sexes. In the males these appendages are styliform, and those of the second somite are always peculiarly modified. The appendages of the four following somites are relatively small. The telson is very generally divided by a transverse incomplete hinge. None of the branchial filaments are terminated by hoolss; nor are any of the coxopoditic setæ, or the longer setæ of the podobranchiæ hooked, though hooked tubercles occur on the stem and on the laminæ of the latter. The coxopoditic setæ are always long and tortuous.

In the Parastacida, on the other hand, the podobranchiæ are devoid of more than a rudiment of a lamina, though the stem may be alate. The podobranchia of the first maxillipede has the form of an epipodite; but, in almost all cases, it bears a certain number of well developed branchial filaments. The first abdominal somite possesses no appendages in either sex : and the appendages of the four following somites are large. The telson is never divided by a transverse hinge. More or fewer of the branchial filaments of the podo- 
branchiæ are terminated by short hooked spines; and the coxopoditic setæ, as well as those which beset the stems of the podobranchiæ, have hooked apices.

The definitions of the genera would in like manner be given by adding the distinctive characters of each genus to the definitions of the family; and those of the species by adding its character to those of the genus. But at present it is unnecessary to pursue this topic further.

There are no other inhabitants of the fresh waters, or of the land, which could be mistaken for crayfishes; but certain marine animals, familiar to every one, are so strikingly similar to them, that one of these was formerly included in the same genus, Astacus; while another is very often known as the "Sea-crayfish." These are the "Common Lobster," the "Norway Lobster," and the "Rock Lobster" or " Spiny Lobster."

The common lobster (Homarus vulgaris, fig. 67) presents the following distinctive characters. The last thoracic somite is firmly adherent to the rest; the exopodite of the antenna is so small as to appear like a mere movable scale; all the abdominal appendages are well developed in both sexes; and, in the males, the two anterior pairs are somewhat like those of the male Astacus, but less modified.

The principal difference from the Astacina is exhibited by the gills, of which there are twenty on each side; namely, six podobranchiæ, ten arthrobranchiæ, and four 


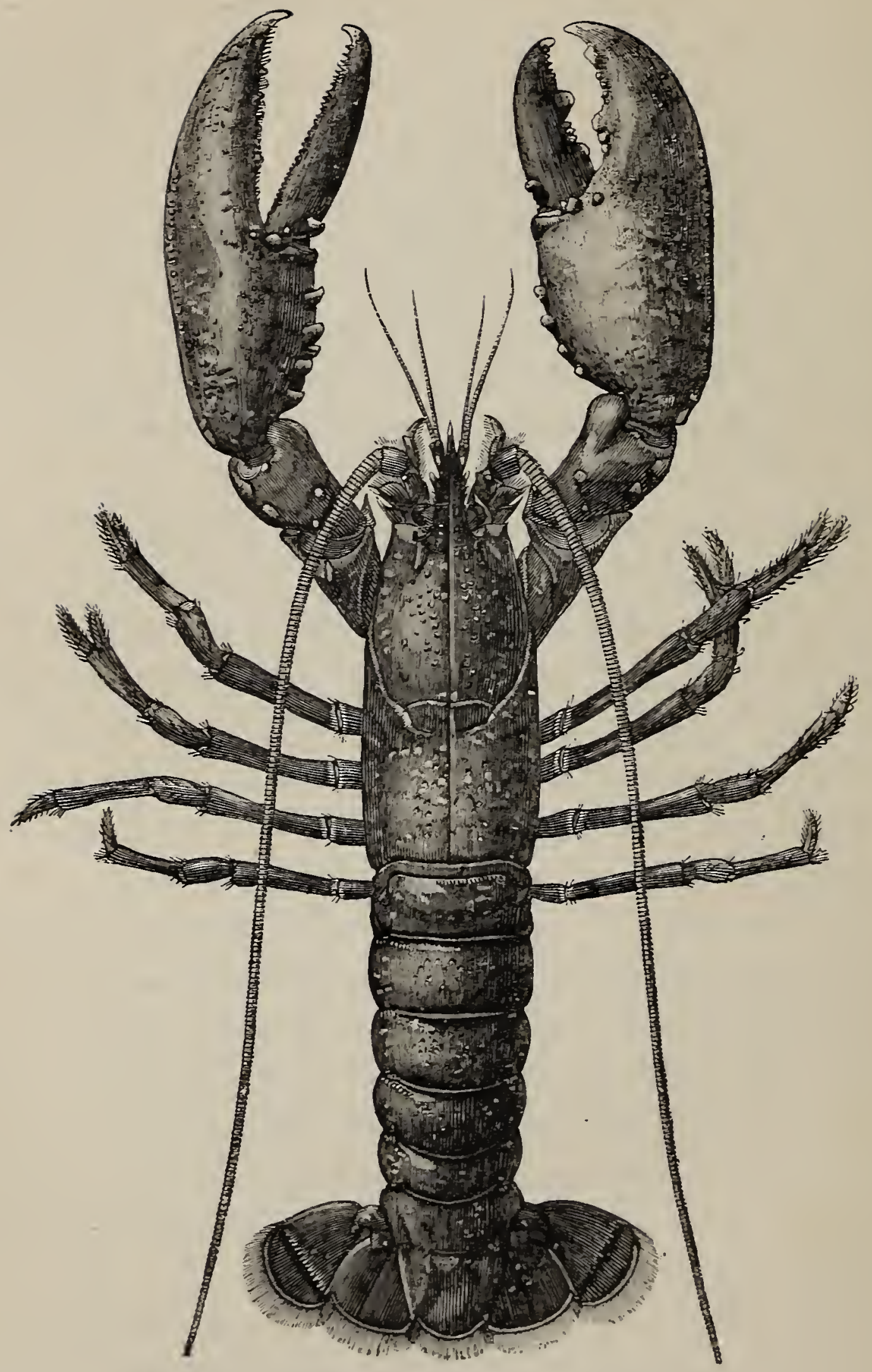

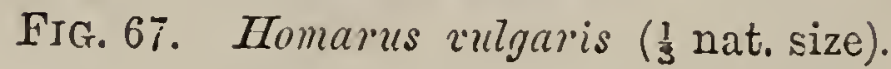


fully developed pleurobranchiæ. Moreover, the branchial filaments of these gills are much stiffer and more closely set than in most crayfishes. But the most important distinction is presented by the podobranchire, in which the stem is, as it were, completely split into two parts longitudinally (as in fig. 68, B); one half (ep)

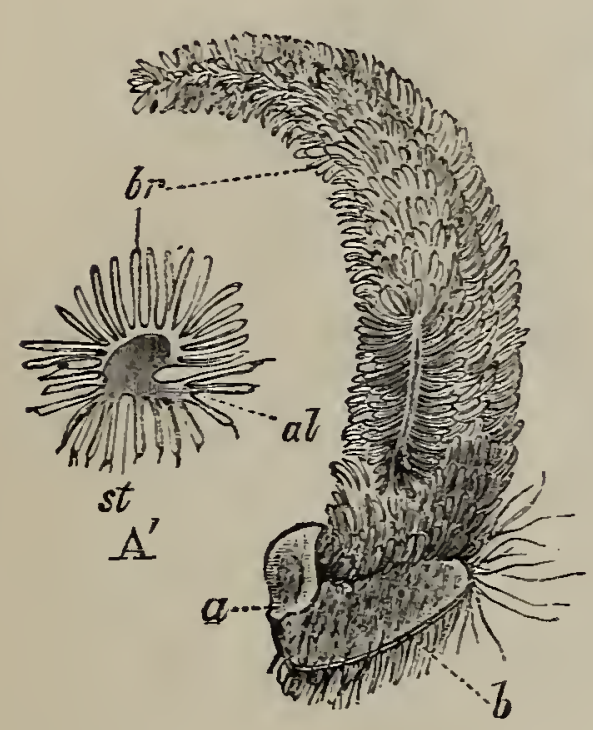

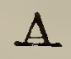
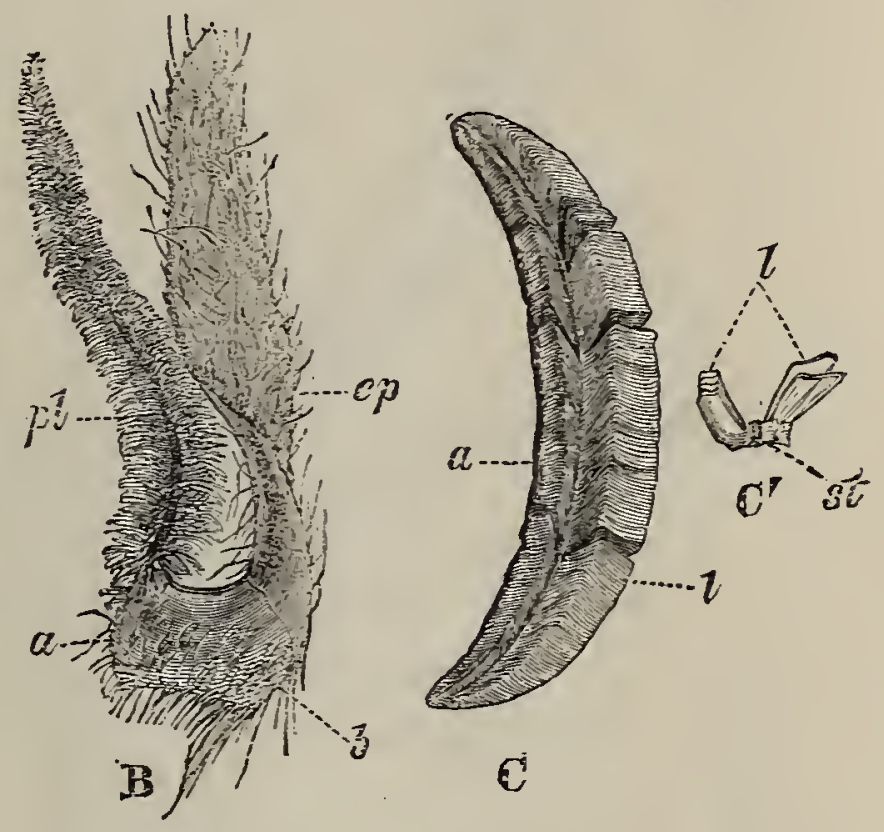

c

FIG.68. Podobranchiæ of A, Parastacus; B, Nephrops; C, Palamon. $\mathrm{A}^{\prime}, \mathrm{C}^{\prime}$, transverse sections of $\mathrm{A}$ and $\mathrm{C}$ respectively. $a$, point of attachment; al, wing-like expansion of the stem; $b$, base; $b r$, branchial filaments ; $e p$, epipodite ; $l$, branchial laminæ ; $p l$, plume ; st, stem.

corresponding with the lamina of the crayfish gill, and the other $(p l)$ with its plume. Hence the base $(b)$ of the podobranchia bears the gill in front; while, behind, it is continued into a broad epipoditic plate $(e p)$ slightly folded upon itself longitudinally but not plaited, as in the crayfish.

'The Norway Lobster (Nephrops norvegicus, fig. 69) 


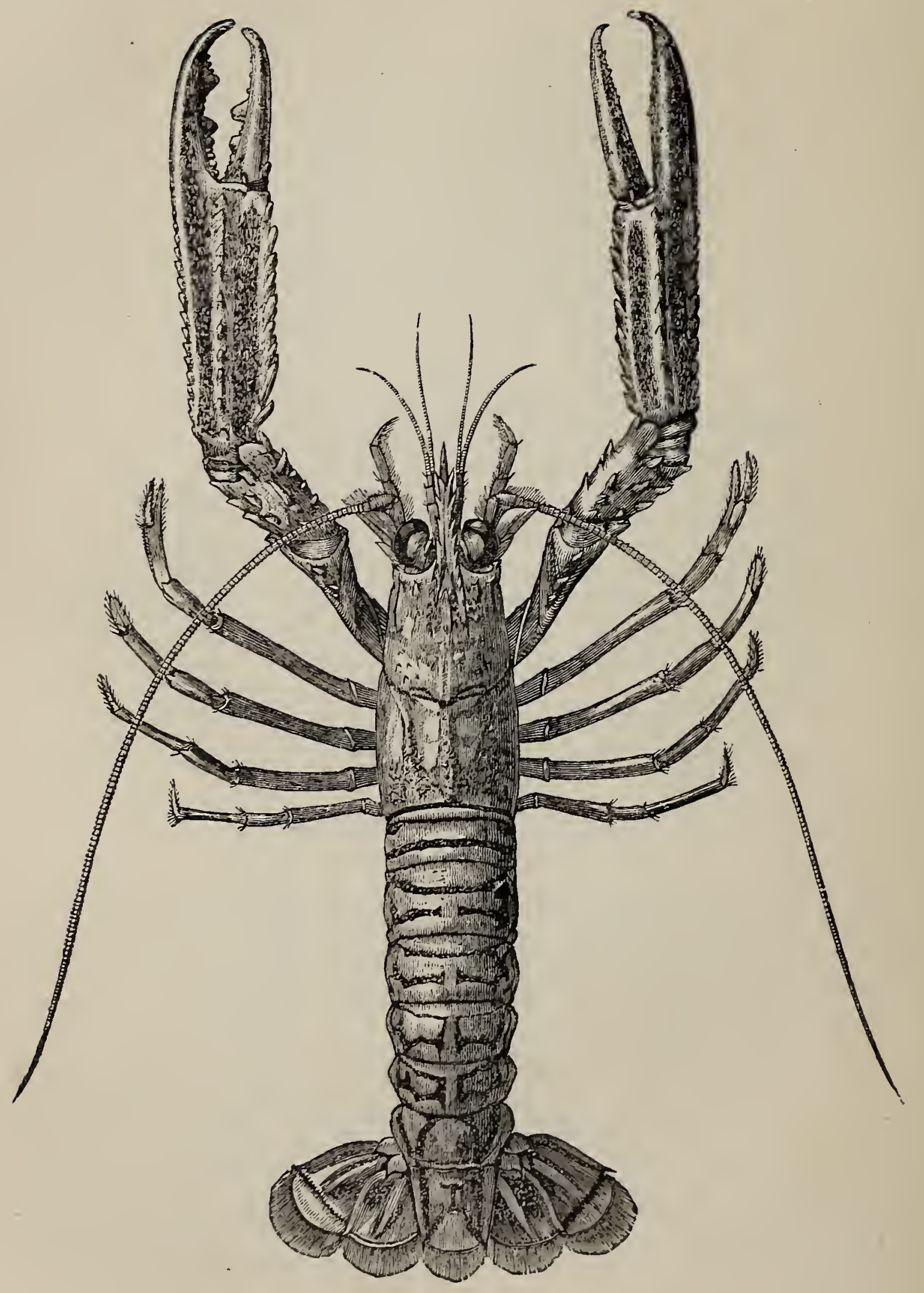

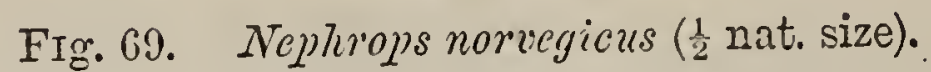


resembles the lobster in those respects in which the latter differs from the crayfishes: but the antennary squame is large; and, in addition, the branchial plume of the podobranchia of the second maxillipede is very small or absent, so that the total number of functional branchiæ is reduced to nineteen on each side.

These two genera, Homarus and Nephrops, therefore, represent a family, Homarina, constructed upon the same common plan as the crayfishes, but differing so far from the Astacina in the structure of the branchiæ and in some other points, that the distinction must be expressed by putting them into a different tribe. It is obvious that the special characteristics of the plan of the Homarina give it much more likeness to that of the Potamobiide than to that of the Parastacida.

The Rock Lobster (Palinurus, fig. 70) differs much more from the crayfishes than either the common lobster or the Norway lobster does. Thus, to refer only to the more important distinctions, the antennæ are enormous; none of the five posterior pairs of thoracic limbs are chelate, and the first pair are not so large in proportion to the rest as in the crayfishes and lobsters. The posterior thoracic sterna are very broad, not comparatively narrow, as in the foregoing genera. There are no appendages to the first somite of the abdomen in either sex. In this respect, it is curious to observe that, in contradistinction from the Homarina, the Rock Lobsters are more closely allied to the Parastacida than to the Potamobiida. 


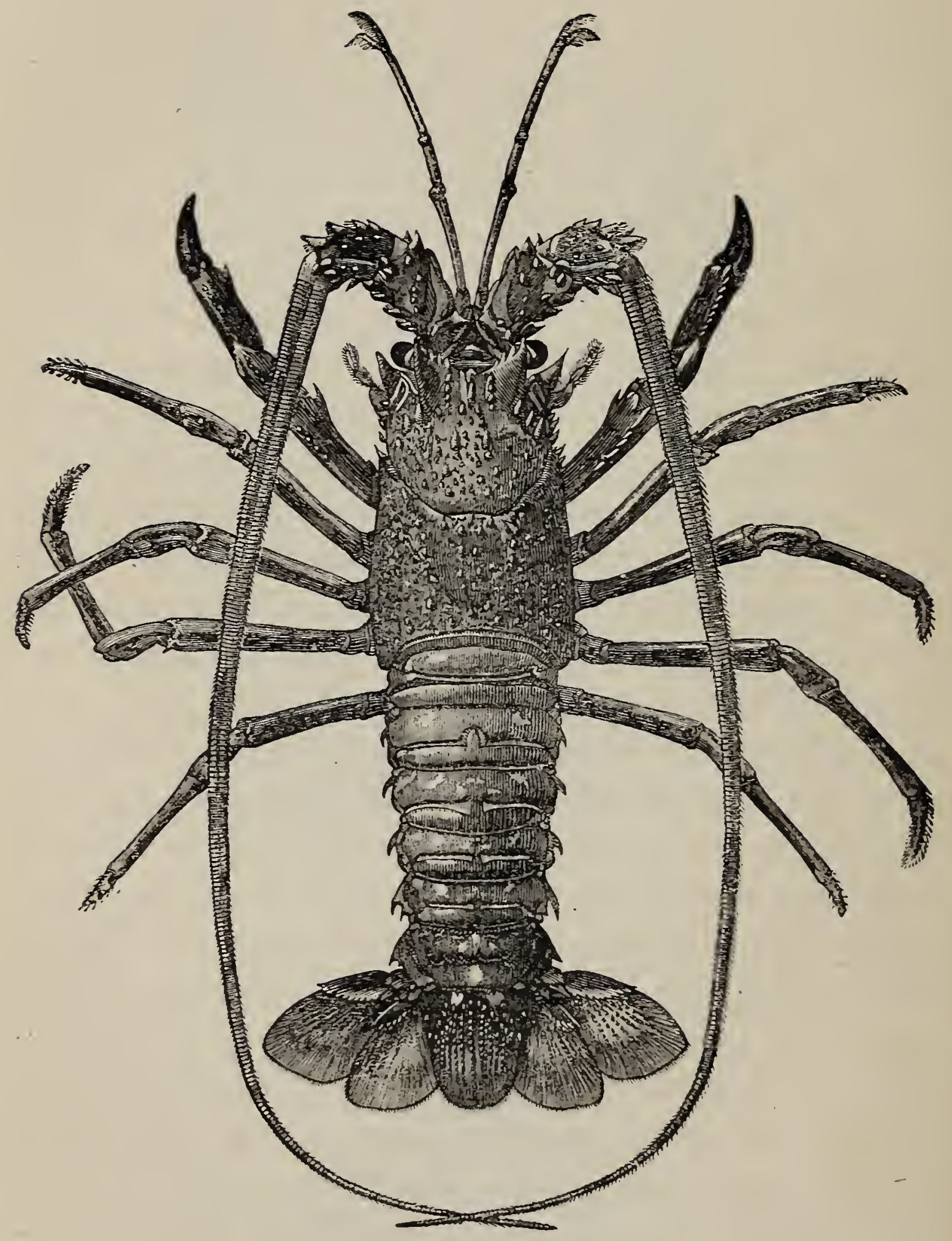

FIG. 70. Palinurus vulgaris (about $\frac{1}{4}$ nat. size). 
The gills are similar to those of the lobsters, but reach the number of twenty-one on each side.

In their fundamental structure the rock lobsters agree with the crayfishes; hence the plans of the two may be regarded as modifications of a plan common to both. To this end, the only considerable changes needful in the tribal plan of the crayfishes, are the substitution of simple for chelate terminations to the middle thoracic limbs and the suppression of the appendages of the first somite of the abdomen.

Thus not only all the crayfishes, but all the lobsters and rock lobsters, different as they are in appearance, size, and habits of life, reveal to the morphologist unmistakable signs of a fundamental unity of organization; each is a comparatively simple variation of the general theme-the common plan.

Eren the branchix, which vary so much in number in different members of these groups, are constructed upon a uniform principle, and the differences which they present are readily intelligible as the result of various modifications of one and the same primitive arrangement.

In all, the gills are trichobranchie; that is, each gill is somewhat like a bottle-brush, and presents a stem beset, more or less closely, with many series of branchial filaments. The largest number of complete branchiæ possessed by any of the Potamobiida, Parastacida, Homarida, or Palinurida, is trenty-one on each side; 
264 THE COMPARATIVE MORPHOLOGY OF THE CRAYFISH.

and when this number is present, the total is made up of the same numbers of podobranchiæ, arthrobranchiæ, and pleurobranchiæ attached to corresponding somites. In Palinurus and in the gemus Astacopsis (which is one of the Parastacida), for example, there are six podobranchiæ attached to the thoracic limbs from the second to the seventh inclusively; five pairs of arthrobranchiæ are attached to the interarticular membranes of the thoracic limbs from the third to the serenth inclusively, and one to that of the second, making eleren in all; while four pleurobranchix are fixed to the epimera of the four hindmost thoracic somites. Moreover, in Astacopsis, the epipodite of the first thoracic appendage (the first maxillipede) bears branchial filaments, and is a sort of reduced gill.

These facts may be stated in a tabular form as follows :-

\section{The branchial formula of Astacopsis.}

\begin{tabular}{|c|c|c|c|c|c|c|c|c|c|}
\hline \multirow{2}{*}{$\begin{array}{l}\text { Somites and } \\
\text { thir } \\
\text { Appendages. }\end{array}$} & \multicolumn{8}{|c|}{ Arthrobranchiæ. } & \multirow[b]{3}{*}{0 (cp. r.) } \\
\hline & \multicolumn{2}{|c|}{$\begin{array}{l}\text { Podo- } \\
\text { branchix. }\end{array}$} & Anterior. & & osterio & & \multicolumn{2}{|c|}{$\begin{array}{l}\text { Pleuro-- } \\
\text { branchie. }\end{array}$} & \\
\hline & 0 (ep. r & & 0 & $\ldots$ & 0 & $\ldots$ & 0 & $=$ & \\
\hline VIII. $\ldots$ & 1 & $\ldots$ & 1 & $\ldots$ & 0 & $\ldots$ & 0 & $=$ & \\
\hline IX. $\ldots$ & 1 & $\ldots$ & 1 & $\ldots$ & 1 & $\ldots$ & 0 & $=$ & 3 \\
\hline x. $\ldots$ & 1 & $\ldots$ & 1 & $\ldots$ & 1 & $\ldots$ & 0 & $=$ & 3 \\
\hline XI. $\ldots$ & 1 & $\ldots$ & 1 & $\ldots$ & 1 & $\ldots$ & 1 & $=$ & 4 \\
\hline XII. $\ldots$ & 1 & $\ldots$ & 1 & $\ldots$ & 1 & $\ldots$ & 1 & $=$ & 4 \\
\hline xirl. $\ldots$ & 1 & $\ldots$ & 1 & $\ldots$ & 1 & $\ldots$ & 1 & $=$ & 4 \\
\hline XIV. & 0 & ... & 0 & ... & 0 & $\ldots$ & 1 & $=$ & 1 \\
\hline & $\bar{c}$ & & $\bar{c}$ & & $=$ & & - & & $\overline{0}$ \\
\hline
\end{tabular}


This tabular " branchial formula" exhibits at a glance not only the total number of branchir, but that of each kind of branchia; and that of all kinds connected with each somite; and it further indicates that the podobranchia of the first thoracic somite has become so far modified, that it is represented only by an epipodite, with branchial filaments scattered upon its surface.

In Palinu'us, these branchial filaments are absent and the branchial formula therefore becomes-

\begin{tabular}{|c|c|c|c|c|c|c|c|c|}
\hline \multirow{3}{*}{$\begin{array}{c}\text { Somites and } \\
\text { their } \\
\text { Appendages. } \\
\text { vII. .. }\end{array}$} & \multicolumn{7}{|c|}{ Arthrobranchiæ. } & \multirow[b]{3}{*}{0 (ep.) } \\
\hline & \multicolumn{2}{|l|}{$\begin{array}{l}\text { Podo- } \\
\text { branchix. }\end{array}$} & nterior. & Posterior & & \multicolumn{2}{|c|}{$\begin{array}{l}\text { Pleuro- } \\
\text { branchix. }\end{array}$} & \\
\hline & 0 (ep.) & & 0 & ... 0 & . & 0 & $=$ & \\
\hline vIII. ... & 1 & $\ldots$ & 1 & $\ldots$ & $\ldots$ & 0 & $=$ & \\
\hline IX. ... & 1 & ... & 1 & $\ldots$ & $\ldots$ & 0 & $=$ & 3 \\
\hline x. $\ldots$ & 1 & ... & 1 & $\ldots$ & $\ldots$ & 0 & $=$ & 3 \\
\hline XI. $\ldots$ & 1 & $\cdots$ & 1 & ... 1 & $\ldots$ & 1 & $=$ & 4 \\
\hline XII. $\quad \ldots$ & 1 & ... & 1 & $\ldots$ & $\ldots$ & 1 & $=$ & 4 \\
\hline XIII. ... & 1 & $\ldots$ & 1 & ... 1 & $\ldots$ & 1 & $=$ & 4 \\
\hline XIV. ... & 0 & $\ldots$ & 0 & ... 0 & $\ldots$ & 1 & $=$ & 1 \\
\hline & $\overline{6}+\mathrm{ep}$. & & $\overline{6}$ & $+\overline{5}$ & + & $\overline{4}$ & $=$ & 21. \\
\hline
\end{tabular}

In the lobster, the solitary arthrobranchia of the eighth somite disappears, and the branchiæ are reduced to twenty on each side.

In Astacus, this branchia remains; but, in the English crayfish, the most anterior of the pleurobranchiæ has vanished, and mere rudiments of the two next remain. It has been mentioned that other Astaci present a rudiment of the first pleurobranchia. 


\section{The branchial formula of Astacus.}

Somites and their
Appendazes. branchiz. Anterior. Posterior. branchiæ.

$$
\begin{aligned}
& \begin{array}{llllllll}
\text { viI. } \ldots & 0 \text { (ep.) } \ldots & 0 & \ldots & 0 & \ldots & 0 & =0
\end{array} \\
& \text { VIII. } \ldots \begin{array}{llllllll} 
& 1 & \ldots & 1 & \ldots & 0 & \ldots & 0
\end{array}
\end{aligned}
$$

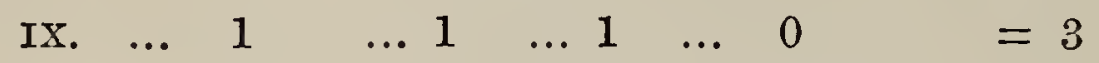

$$
\begin{aligned}
& \begin{array}{lllllllllll}
\mathrm{x} & \ldots & 1 & \ldots & 1 & \ldots & 1 & \ldots & 0 & =3
\end{array} \\
& \mathrm{XI} . \quad \ldots \quad 1 \quad \ldots .1 \quad \ldots \quad 1 \quad \ldots \quad 0 \text { or } r \quad=3 \text { or } 3+r \\
& \begin{array}{lllllllll}
\text { XII. } & \ldots & 1 & \ldots & 1 & \ldots & 1 & \ldots & r
\end{array}
\end{aligned}
$$

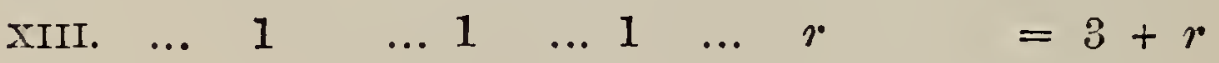

$$
\begin{aligned}
& \text { XIV. } \ldots \begin{array}{lllllllll} 
& 0 & \ldots & 0 & \ldots & 0 & \ldots & 1 & =1
\end{array} \\
& -\overline{6}+\mathrm{cp} \cdot+\overline{6}+\overline{5}+\overline{1}+2 \text { or } 3 r=\overline{18}+\mathrm{ep} .+2 \text { or } 3 r .
\end{aligned}
$$

In Cambarus, the number of the branchir is reduced to serenteen by the disappearance of the last pleurobranchia; while, in Astacoides, the process of reduction is carried so far, that only twelve complete branchiæ are left, the rest being either represented by mere rudiments, or disappearing altogether:

\section{The branchial formula of A stacoides.}

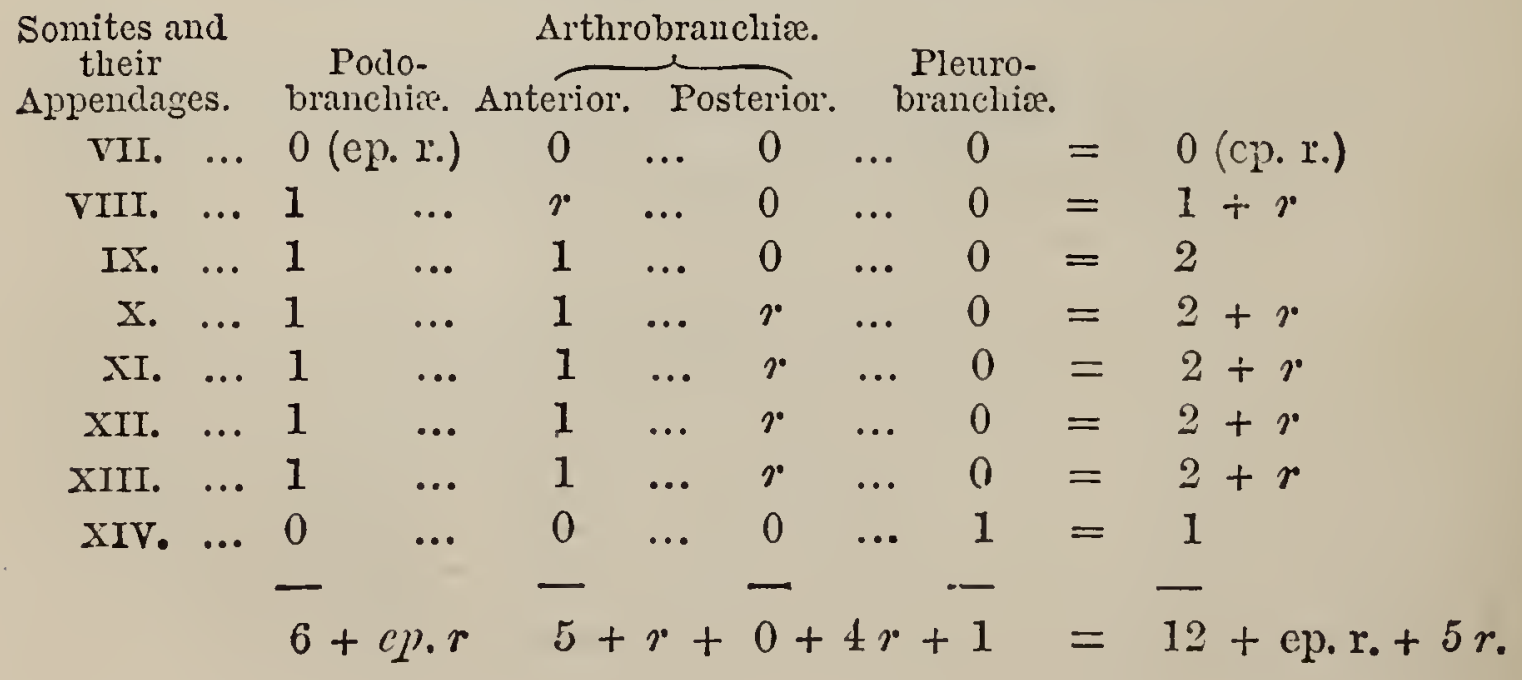


As these formulæ show, those trichobranchiate crustacea, which possess fewer than twenty-one complete branchiæ on each side, commonly present traces of the missing ones, either in the shape of epipodites, as in the case of the podobranchiæ, or of minute rudiments, in the case of the arthrobranchiæ and the pleurobranchiæ.

In the marine, prawn-like, genus Pencus (fig. 73, Chap. VI.), the gills are curiously modified trichobranchiæ. The number of functional branchiæ is, as in the lobster, twenty; but the study of their disposition shows that the total is made up in a very different way.

\section{The branchial formula of Penceus.}

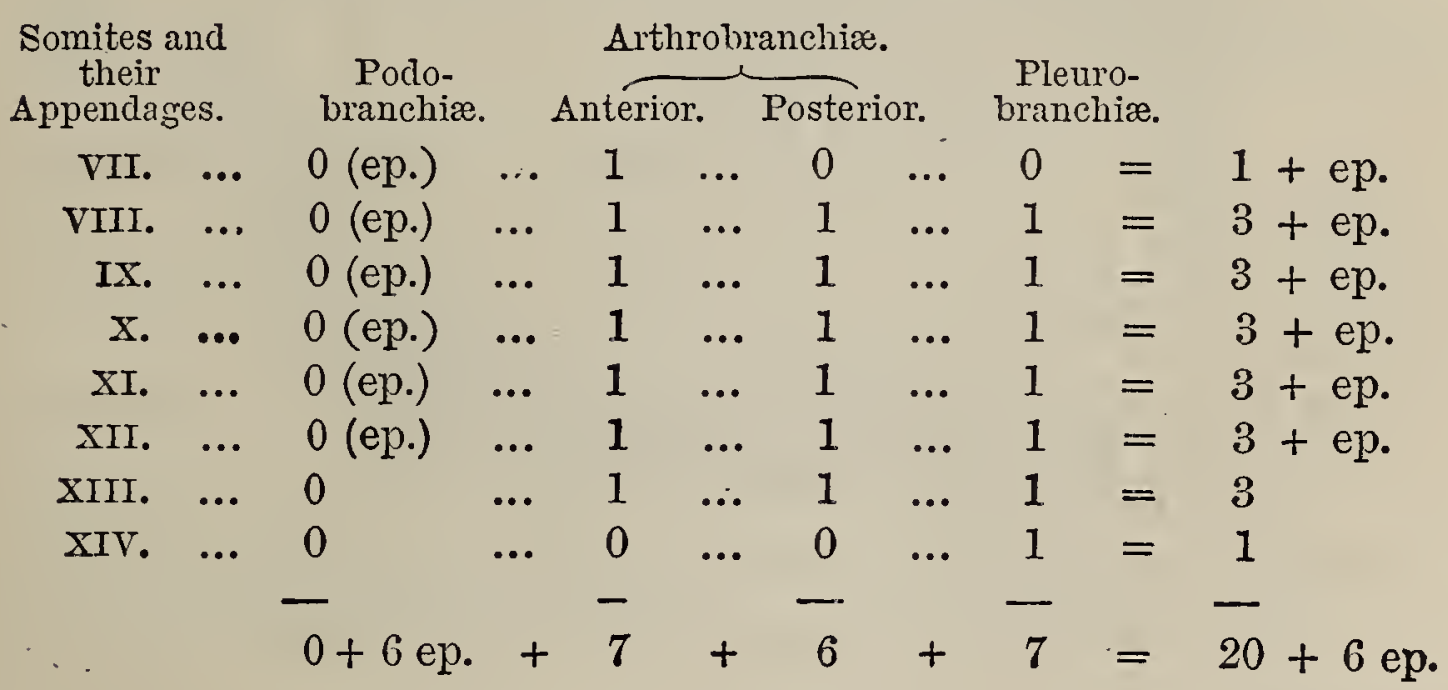

This case is very interesting; for it shows that the whole of the podobranchiæ may lose their branchial character, and be reduced to epipodites, as is the case with the first in the crayfish and lobster, and indeed in most of the forms under consideration. And since all but one of the somites bear both arthrobranchiæ and pleurobranchiæ, 
the suggestion arises that each hypothetically complete thoracic somite should possess four gills on each side, giving the following

Hypothetically complete branchial formula.

\begin{tabular}{|c|c|c|c|c|c|c|c|c|c|c|}
\hline \multirow{2}{*}{$\begin{array}{l}\text { Somites and } \\
\text { their } \\
\text { Appendages. }\end{array}$} & \multirow{2}{*}{\multicolumn{2}{|c|}{$\begin{array}{l}\text { Podo- } \\
\text { branchix. }\end{array}$}} & \multicolumn{5}{|c|}{ Arthrobranchiæ. } & & \\
\hline & & & & iterior & & sterior & & $\begin{array}{l}\text { Preut } \\
\text { brane }\end{array}$ & & \\
\hline VII. & $\ldots$ & 1 & $\ldots$ & 1 & $\ldots$ & 1 & & 1 & $\dot{=}$ & 4 \\
\hline viII. & $\ldots$ & 1 & $\ldots$ & 1 & $\ldots$ & 1 & $\ldots$ & 1 & $=$ & \\
\hline IX. & $\ldots$ & 1 & $\ldots$ & 7 & $\ldots$ & 1 & $\cdots$ & 1 & $=$ & \\
\hline$x$. & $\ldots$ & 1 & $\ldots$ & 1 & $\ldots$ & 1 & $\ldots$ & 1 & $=$ & \\
\hline XI. & $\ldots$ & 1 & $\ldots$ & 1 & $\ldots$ & 1 & $\cdots$ & 1 & $=$ & \\
\hline XII. & $\ldots$ & 1 & $\ldots$ & 1 & $\ldots$ & 1 & $\ldots$ & 1 & $=$ & \\
\hline$x I$ & $\ldots$ & 1 & $\ldots$ & 1 & $\ldots$ & 1 & & 1 & $=$ & 4 \\
\hline XIV. & $\ldots$ & 1 & $\ldots$ & 1 & $\ldots$ & 1 & .. & 1 & $=$ & 4 \\
\hline & & $\overline{8}$ & $t$ & $\overline{8}$ & . & $\overline{8}$ & + & $\overline{8}$ & $=$ & \\
\hline
\end{tabular}

Starting from this hypothetically complete branchial formula, we may regard all the actual formulæ as produced from it by the more or less complete suppression of the most anterior, or of the most posterior branchiæ, or of both, in each series. In the case of the podo branchiæ, the branchire are converted into epipodites; in that of the other branchix, they become rudimentary, or disappear.

In general appearance a common prawn (Palcemon, fig. 71) is very similar to a miniature lobster or crayfish. Nor does a closer examination fail to reveal a complete fundamental likeness. The number of the somites, and of the appendages, and their general character and dispo- 
sition, are in fact the same. But, in the prawn, the abdomen is much larger in proportion to the cephalothorax; the

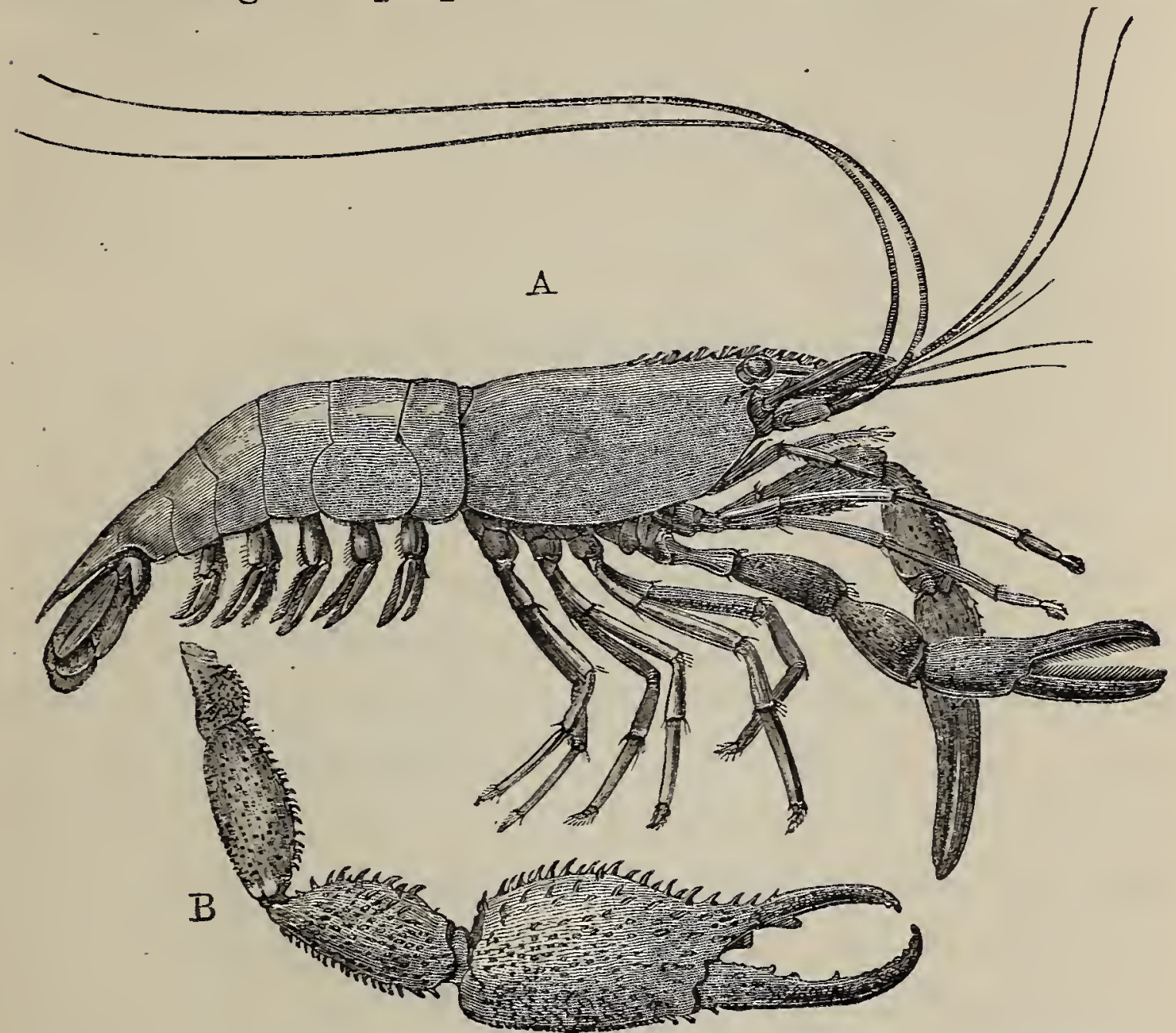

FIG. 71. Palcemon jamaicensis (about $\frac{5}{7}$ nat. size). A, female; $B$, fifth thoracic appendage of male.

basal scale, or expodite of the antemna, is much larger; ihe external maxillipedes are longer, and differless from the succeeding thoracic appendages. The first pair of these, which answers to the forceps of the crayfish, is chelate, but it is very slender; the second pair, also chelate, is always larger than the first, and is sometimes exceedingly 
long and strong (fig. $71, \mathrm{~B}$ ); the remaining thoracic limbs are terminated by simple claws. The five anterior abdominal somites are all provided with large swimmerets, which are used like paddles, when the animal swims quietly; and, in the males, the first pair is only slightly different from the rest. The rostrum is very large, and strongly serrated.

None of these differences from the crayfish, however, is so great, as to prepare us for the remarkable change observable in the respiratory organs. The total number of the gills is only eight. Of these, five are large pleurobranchiæ, attached to the epimera of the five hinder thoracic somites; two are arthrobranchiæ, fixed to the interarticular membrane of the external maxillipede; and one, which is the only complete podobranchia, belongs. to the second maxillipede. The podobranchir of the first and third maxillipedes are represented only by small epipodites. The branchial formula therefore is :-

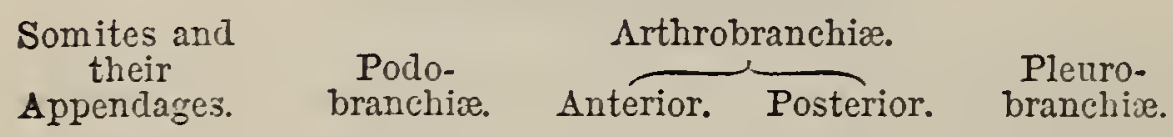

\begin{tabular}{|c|c|c|c|c|c|}
\hline VII. & $\ldots$ & 0 (ep.) & & $=$ & 0 (ep.) \\
\hline viIr. & $\ldots$ & 1 & & $=$ & \\
\hline IX. & $\ldots$ & 0 (ep.) & & $=$ & 2 (ep.) \\
\hline$x$. & $\ldots$ & 0 & & $=$ & 1 \\
\hline XI. & $\ldots$ & 0 & & $=$ & 1 \\
\hline XII. & $\ldots$ & 0 & & . & 1 \\
\hline XIII. & $\ldots$ & 0 & & $=$ & 1 \\
\hline XIV. & $\ldots$ & 0 & & $=$ & 1 \\
\hline & & $\overline{1}+2 \mathrm{cp}$ & & $=$ & \\
\hline
\end{tabular}


The prawn, in fact, presents us with an extreme case of that kind of modification of the branchial system, of which Pencus has furnished a less complete example. The series of the podobranchiæ is reduced almost to nothing, while the large pleurobranchiæ are the chief organs of respiration.

But this is not the only difference. The prawn's gills are not brush-like, but are foliaceous. They are not trichobranchice, but phyllobranchice; that is to say, che central stem of the branchia, instead of being beset with numerous series of slender filaments, bears only two rows of broad flat lamellæ (fig. $68, \mathrm{C}, \mathrm{C}^{\prime}, l$ ), which are attached to opposite sides of the stem $\left(\mathrm{C}^{\prime}, s\right)$, and gradually diminish in size from the region of the stem by which it is fixed, upwards and downwards. These lamellæ are superimposed closely upon one another, like the leaves of a book; and the blood traversing the numerous passages by which their substance is excavated, comes into close relation with the currents of aerated water, which are driven between the branchial leaflets by a respiratory mechanism of the same nature as that of the crayfish.

Different as these phyllobranchire of the prawns are in appearance from the trichobranchir of the preceding Crustacea, they are easily reduced to the same type. For in the genus Axius, which is closely allied to the lobsters, each branchial stem bears a single series of filaments on its opposite sides; and if these biserial filaments are supposed to widen out into broad leaflets, the transition from 
272 THE COMFARATIVE MORPHOLOGY OF THE CRAYFISH.

the trichobranchia to the phyllobranchia will be rery easily effected.

The shrimp (Crangon) also possesses phyllobranchiæ, and differ's from the prawn chiefly in the character of its locomotive and prehensile thoracic limbs.

There are yet other very well-known marine animals, which, in common appreciation, are always associated with the lobsters and crayfishes, although the difference of general appearance is vastly greater than in any of the cases which hare yet been considered. These are the Crabs.

In all the forms we have hitherto been considering, the abdomen is as long as, or longer than, the cephalothorax, while its width is the same, or but little less. The sixth somite has very large appendages, which, together with the telson, make up a porrerful tail-fin; and the large abdomen is thus fitted for playing an important part in locomotion.

Again, the length of the cephaluthorax is much greater than its width, and it is produced in front into a long rostrum. The bases of the antennæ are freely movable, and they are provided with a morable exopodite. Moreorer, the eye-stalks are not inclosed in a carity or orbit, and the eyes themselves appear abore and in front of the antennules. The extermal maxillipedes are narrow, and their endopodites are more or less leg-like.

None of these statements apply to the crabs. In these 
animals the abdomen is short, flattened, and apt to escape immediate notice, as it is habitually kept closely applied against the under surface of the cephalothorax. It is
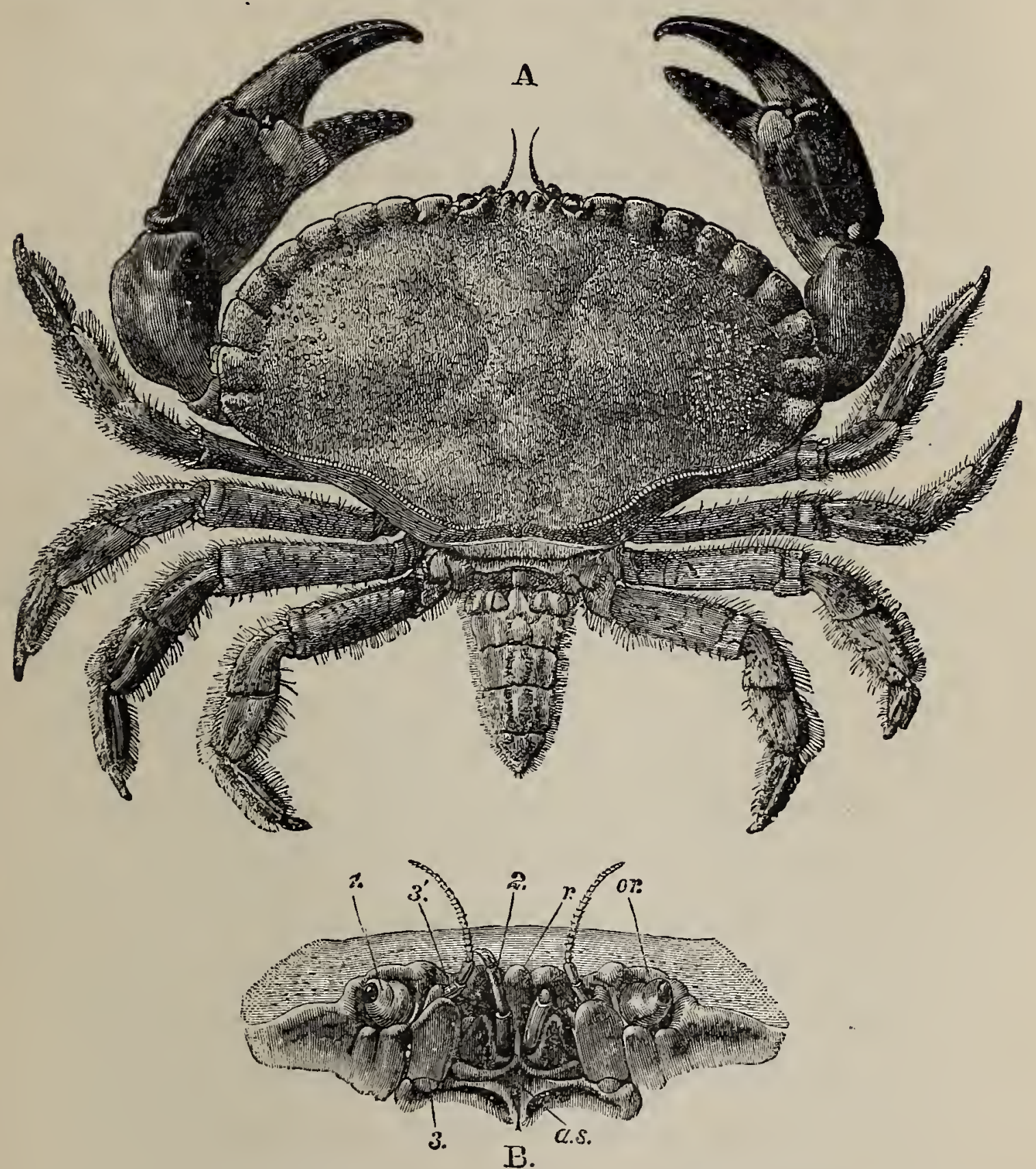

FIG. 72. Cancer paguirus, male ( $\frac{1}{3}$ nat. size). A, dorsal view, with the 2.bdomen extended; B, front view of "face." as, antennary sternum; or, orbit ; 2 ', rostrum ; 1 . ejestalk ; 2 . antennule ; 3 . base of antenna; $\jmath^{\prime}$, free portion of antenna. 
274 THE COMPARATIVE MORPHOLOGY OF THE CRAYFISH.

not used as a swimming organ; and the sixth somite possesses no appendages whatever. The breadth of the cephalothorax is often greater than its length, and there is no prominent rostrum. In its place there is a truncated process (fig. 72, B, r), which sends down a rertical partition, and divides from one another two carities, in which the swollen basal joints of the small antennules (2) are lodged. The outer boundary of each of these carities is formed by the basal part of the antenna (3), which is firmly fixed to the edge of the carapace. There is no exopoditic scale; and the free part of the antenna $\left(3^{\prime}\right)$ is rery small. The convex corneal surface of the eye appears outside the base of the antenna, lodged in a sort of orbit (or), the inner margin of which is formed by the base of the antenna, while the upper and outer boundaries are constituted by the carapace. Thus, while in all the preceding forms, the eye is situated nearest the middle line, and is most forward, while the antennule lies outside and behind it, and the antenna comes next; in the crab, the antennule occupies the innermost place, the antenna comes next, and the eye appears to be external to and behind the other two. But there is no real change in the attachments of the eye-stalls. For if the antennule and the basal joint of the antenna are removed, it will be seen that the base of the eye-stalk is attached, as in the crayfish, close to the middle line, on the inner side, and in front of the antennule. But it is very long and extends outwards, behind the antemnule and the antenna; 
its corneal surface alone being visible, as it projects into the orbit.

Again, the ischiopodites of the external maxillipedes are expanded into broad quadrate plates, which meet in the middle line, and close over the other manducatory organs, like two folding-doors set in a square doorway. Behind these there are great chelate forceps, as in the srayfish; but the succeeding four pairs of ambulatory limbs are terminated by simple claws.

When the abdomen is forcibly turned back, its sternal surface is seen to be soft and membranous. There are no swimmerets; but, in the female, the four anterior pairs of abdominal limbs are represented by singular appendages, which give attachment to the eggs; while in the males there are two pairs of styliform organs attached to the first and second somites of the abdomen, which correspond with those of the male crayfishes.

The ventral portions of the branchiostegites are sharply bent inwards, and their edges are so closely applied throughout the greater part of their length to the bases of the ambulatory limbs, that no branchial cleft is left. In front of the bases of the forceps, however, there is an elongated aperture, which can be shut or opened by a sort of valve, connected with the external maxillipede, which serves for the entrance of water into the branchial cavity. The water employed in respiration, and kept in constant motion by the action of the scaphognathite, is baled out through two apertures, which 
276 THE COMPARATIVE MORPHOLUGY OF THE CRAYFISH.

are separated from the foregoing by the external maxillipedes, and lie at the sides of the quadrate space in which these organs are set.

There are only nine gills on each side, and these, as in the prawn and shrimp, are phyllobranchiæ. Seven of the branchiæ are pyramidal in shape, and for the most part of large size. When the branchiostegite is removed, they are seen lying close against its inner walls, their apices converging towards its summit. 'The two hindermost of these gills are pleurobranchix, the other five are arthrobranchiæ. The two remaining gills are podobranchix, and belong to the second and the third maxillipedes respectively. Each is divided into a branchial and an epipoditic portion, the latter having the form of a long curved blade. The branchial portion of the podobranchia of the second maxillipede is long, and lies horizontally under the bases of the four anterior arthrobranchiæ; while the gill of the podobranchia of the third maxillipede is short and triangular, and fits in between the bases of the second and the third arthrobranchiæ. The epipodite of the third maxillipede is rery long, and its base furnishes the valve of the afferent aperture of the branchial cavity, which has been mentioned above. The podobranchia of the first maxillipede is represented only by a long curved epipoditic blade, which can sweep orer the outer surface of the gills, and doubtless serves to keep them clear of foreign bodies. 


\section{The branchial formula of Cancer pagurus.}

Somites and

\begin{tabular}{|c|c|c|c|c|c|c|c|c|c|c|}
\hline Somites an & & & & Arth & $o b$ & ranchis & & & & \\
\hline $\begin{array}{c}\text { their } \\
\text { Appendage }\end{array}$ & & $\begin{array}{r}\mathrm{P} \\
\text { bral }\end{array}$ & iiæ. & Anteric & & Poster & & $\begin{array}{r}\text { Pl } \\
\text { bral }\end{array}$ & & \\
\hline VII. & $\ldots$ & 0 & & 0 & ... & 0 & ... & 0 & $=$ & 0 \\
\hline VIII. & ... & 1. & ... & 1 & ... & 0 & $\ldots$ & 0 & $=$ & 2 \\
\hline IX. & $\ldots$ & 1. & ... & 1 & $\ldots$ & 1 & $\ldots$ & 0 & $=$ & 3 \\
\hline$x$. & $\ldots$ & 0 & $\ldots$ & 1 & ... & 1 & $\ldots$ & 0 & $=$ & 2 \\
\hline $\mathrm{XI}$. & $\ldots$ & 0 & ... & 0 & $\ldots$ & 0 & ... & 1 & $=$ & 1 \\
\hline XII. & ... & 0 & ... & 0 & ... & 0 & ... & 1 & $=$ & 1 \\
\hline XIII. & $\ldots$ & 0 & ... & 0 & ... & 0 & ... & 0 & $=$ & 0 \\
\hline XIV. & ... & 0 & ... & 0 & ... & 0 & $\ldots$ & 0 & $=$ & 0 \\
\hline & & - & & - & & - & & - & & - \\
\hline & & $2+$ & ep. & 3 & + & 2 & + & 2 & $=$ & $9+$ \\
\hline
\end{tabular}

It will be observed that the suppression of branchire has here taken place in all the series, and at both the anterior and the posterior ends of each. But the defect in total number is made up by the increase of size, not of the pleurobranchiæ alone, as in the case of the prawns, but of the arthrobranchiæ as well. At the same time the whole apparatus has become more specialized and perfected as a breathing organ. The close fitting of the edges of the carapace, and the possibility of closing the inhalent and exhalent apertures, render the crabs much more independent of actual immersion in water than most of their congeners; and some of them habitually live on dry land and breathe by means of the atmospheric air which they take into and expel from their branchial cavities.

Notwithstanding all these wide departures from the structure and habits of the crayfishes, however, attentive examination shows that the plan of construction of the 
278 THE COMPARATIVE MORPHOLOGY OF THE CRAYFISH.

crab is, in all fundamental respects, the same as that of the crayfish. The body is made up of the same number of somites. The appendages of the head and of the thorax are identical in number, in function, and even in the general pattern of their structure. But two pairs of abdominal appendages in the female, and four pairs in the male, have disappeared. The exopodites of the antennæ have vanished, and not even epipodites remain to represent the podobranchiæ of the posterior five pairs of thoracic limbs. The exceedingly elongated eyestalks are turned backwards and outwards, above the bases of the antennules and the antennæ, and the bases of the latter have become united with the edges of the carapace in front of them. In this manner the extraordinary face, or metope (fig. $72, \mathrm{~B}$ ) of the crab results from a simple modification of the arrangement of parts, every one of which exists in the crayfish. The same common plan serves for both.

The foregoing illustrations are taken from a few of our commonest and most easily obtainable Crustacea; but they amply suffice to exemplify the manner in which the conception of a plan of organization, common to a multitude of animals of extremely diverse outward forms and habits, is forced upon us by mere comparative anatomy.

Nothing would be easier, were the occasion fitting, than to extend this method of comparison to the whole of the several thousand species of crab-like, crayfish-like, or 
prawn-like animals, which, from the fact that they all have their eyes set upon movable stalks, are termed the Podophthalmia, or stalk-eyed Crustacea; and by arguments of similar force to prove that they are all modifications of the same common plan. Not.only so, but the sand-hoppers of the sea-shore, the wood-lice of the land, and the water-fleas or the monoculi of the ponds, nay, even such remote forms as the barnacles which adhere to floating wood, and the acorn shells which crowd every inch of rock on many of our coasts, reveal the same fundamental organization. Further than this, the spiders and the scorpions, the millipedes and the centipedes, and the multitudinous legions of the insect world, show us, amid infinite diversity of detail, nothing which is new in principle to any one who has mastered the morphology of the crayfish.

Given a body divided into somites, each with a pair of appendages; and given the power to modify those somites and their appendages in strict accordance with the principles by which the common plan of the Podsphthalmia is modified in the actually existing members of that order; and the whole of the Arthropoda, which probably make up two-thirds of the animal world, might readily be educed from one primitive form.

And this conclusion is not merely speculative. As a matter of observation, though the Arthropocla are not all evolved from one primitive form, in one sense of the words, jet they are in another. For each can be traced 
$2 S 0$ THE COMPARATIVE MORPHOLOGY OF THE CRAYFISH.

back in the course of its development to an ovum, and that ovum gives rise to a blastoderm, from which the parts of the embryo arise in a manner essentially similar to that in which the young crayfish is developed.

Moreover, in a large proportion of the Crustacea, the embryo leaves the egg under the form of a small oval body, termed a Nauplius (fig. 73, D), provided with (usually) three pairs of appendages, which play the part of swimming limbs, and with a median eye. Changes of form accompanied by sheddings of the cuticle take place, in virtue of which the larva passes into a new stage, when it is termed a Zocea (C). In this, the three pairs of locomotive appendages of the Nauplius are metamorphosed into rudimentary antennules, antennæ, and mandibles, while two or more pairs of anterior thoracic appendages provided with exopodites and hence appearing bifurcated, subserve locomotion. The abdomen has grown out and become a notable feature of the Zoæa, but it has no appendages.

In some Podophthalmia, as in Penceus (fig. 73), the young leaves the egg as a Nauplius, and the Nauplius becomes a Zora. The hinder thoracic appendages, each provided with an epipodite, appear ; the stalked eyes and the abdominal members are developed, and the larva passes into what is sometimes called the Mysis or Schizopod stage. The adult state differs from this chiefly in the presence of branchiæ and the rudimentary character of the exopodites of the five posterior thoracic limbs. 
In the Opossum-shrimps (Mysis) the young does not leave the pouch of the mother until it is fully

A.
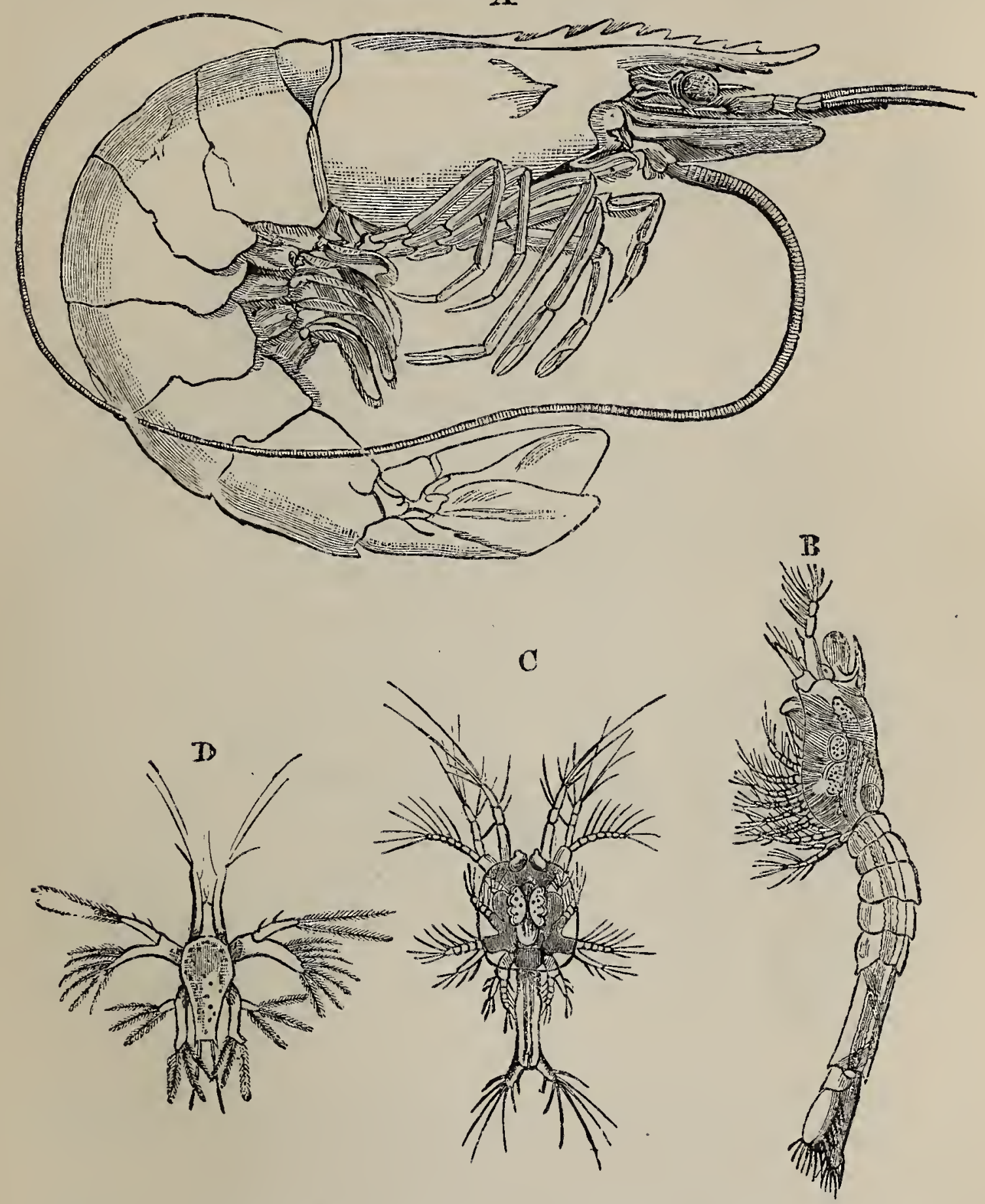

FIG. 73. Pencus semisulcatus. A, adult (after de Haan, $\frac{1}{2}$ nat. size); B, Zoæa, and C, less advanced Zoæa of a species of Pencus. D, Nauplius. (B, C, and D, after Fritz Müller.) 
developed; and, in this case, the Nauplius state is passed through so rapidly and in so early and imperfect a condition of the embryo, that it would not be recognized

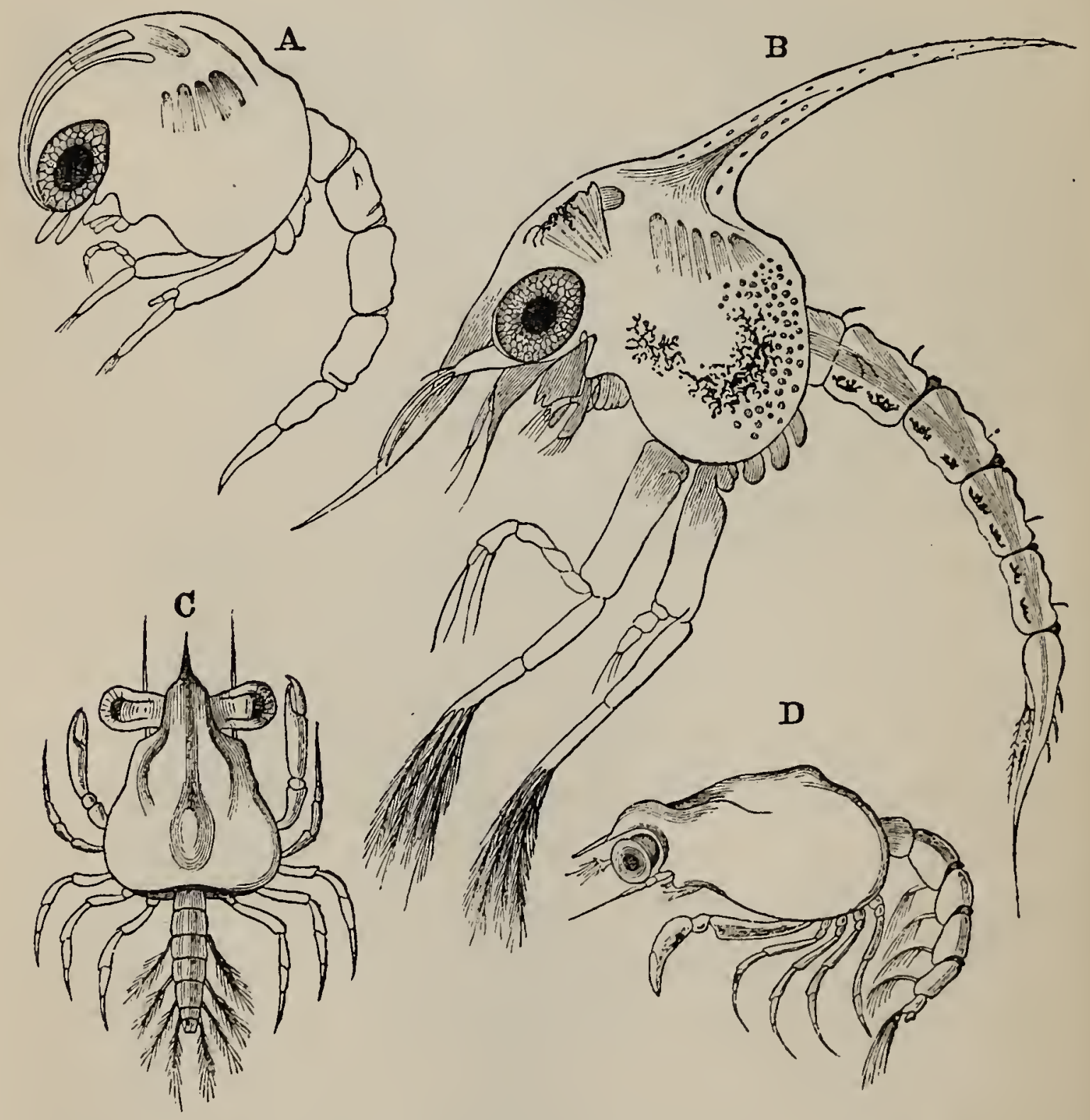

Fig. 74. Cancer pagurus. A, newly hatched Zoxa ; B, more advanced Zoæa; C, dorsal, and D, side view of Megalopa (after Spence Bate). The figures $A$ and $B$ are more magnified than $C$ and D.)

except for the cuticle which is developed and is subsequently shed. 
In the great majority of the Podophthalmia, the Nauplius stage seems to be passed over without any such clear evidence of its occurrence, and the young is set free as a Zoæa. In the lobsters, which hare, throughout life, a large abdomen provided with swimmerets, the Zoæa, after going through a Mysis or Schizopod stage, passes into the adult form.

In the crab, the young leaves the egg as a Zoæa (fig. 74, A and B). But this is not followed by a Schizopod stage, inasmuch as the five hinder pair of thoracic limbs are apparently, from the first, devoid of exopodites. But the Zoæa, after it has acquired stalked eyes and a complete set of thoracic and abdominal members, and has passed into what is called the Megalopa stage (fig. 74, C and D), suffers a more complete metamorphosis. The carapace widens, the fore part of the head is modified so as to bring about the formation of the characteristic metope: and the abdomen, losing more or fewer of its posterior appendages, takes up its final position under the thorax.

In the Zoæa state, those thoracic limbs which give rise to the maxillipedes are provided with well-developed exopodites, and in the free Mysis state all these limbs have exopodites. In the Opossum-shrimps these persist throughout life; in Penceus, the rudiments of them only remain; in the lobster, they disappear altogether.

Thus, in these animals, there is no difficulty in demonstrating that embryological uniformity of type of all the 
limbs, complete evidence of which was not furnished by the development of the crayfish. In this crustacean, in fact, it would appear that the process of development has undergone its maximum of abbreviation. The embryo presents no distinct and independent Nauplius or Zoæa stages, and, as in the crab, there is no Schizopod or Mysis stage. The abdominal appendages are developed very early, and the new born young, which resembles the Megalopa stage of the crab, differs only in a few points from the adult animal.

Guided by comparative morphology, we are thus led to admit that the whole of the Arthropoda are connected by closer or more remote degrees of affinity with the crayfish. If we were to study the perch and the pondsnail with similar care, we should be led to analogous conclusions. For the perch is related by similar gradations, in the first place, with other fishes; then more remotely, with frogs and newts, reptiles, birds, and mammals; or, in other words, with the whole of the great division of the Vertebrata. The pond-snail, by like reasoning upon analogous data, is connected with the Mollusca, in all their innumerable kinds of slugs, shellfish, squids, and cuttlefish. And, in each case, the study of development takes us back to an egg as the primary condition of the animal, and to the process of yelk division, the formation of a blastoderm, and the conversion of that blastoderm into a more or less modified 
gastrula, as the early stages of development. The like is true of all the worms, sea-urchins, starfishes, jellyfishes, polypes, and sponges; and it is only in the minutest and simplest forms of animal life that the germ, or representative of the ovum becomes metamorphosed into the adult form without the preliminary process of division.

In the majority even of these Protozoa, the typical structure of the nucleated cell is retained, and the whole animal is the equivalent of a histological unit of one of the higher organisms. An Amoba is strictly comparable, morphologically, to one of the corpuscles of the blood of the crayfish.

Thus, to exactly the same extent as it is legitimate to represent all the crayfishes as modifications of the common astacine plan, it is legitimate to represent all the multicellular animals as modifications of the gastrula, and the gastrula itself as a peculiarly disposed aggregate of cells; while the Protozoa are such cells either isolated, or otherwise aggregated.

It is easy to demonstrate that all plants are either cell aggregates, or simple cells; and as it is impossible to draw any precise line of demarcation, either physiological or morphological, between the simplest plants, and the simplest of the Protozoa, it follows that all forms of life are morphologically related to one another; and that in whatever sense we say that the English and the Californian crayfish are allied, in the same sense, though not to the same degree, must we admit that all living things 
286 THE COMPARATIVE NIORPHOLOGY OF THE CRAYFISH.

are allied. Given one of those protoplasmic bodies, of which we are unable to say certainly whether it is animal or plant, and endow it with such inherent capacities of self-modification as are manifested daily under our eyes by developing ova, and we have a sufficient reason for the existence of any plant, or of any animal.

This is the great result of comparative morphology; and it is carefully to be noted that this result is not a speculation, but a generalisation. The truths of anatomy and of embryology are generalised statements of facts of experience; the question whether an animal is more or less like another in its structure and in its development, or not, is capable of being tested by observation; the doctrine of the unity of organisation of plants and animals is simply a mode of stating the conclusions drawn from experience. But, if it is a just mode of stating these conclusions, then it is undoubtedly conceivable that all plants and all animals may have been evolved from a common physical basis of life, by processes similar to those which we every day see at work in the evolution of individual animals and plants from that foundation.

That which is conceivable, however, is by no means necessarily true; and no amount of purely morphological evidence can suffice to prove that the forms of life have come into existence in one way rather than another.

There is a common plan among churches, no less than 
THE MIORPHOLOGICAL UNITY OF LIVING THINGS. 287

among crayfishes; nevertheless the churches have certainly not been developed from a common ancestor, but have been built separately. Whether the different kinds of crayfishes have been built separately, is a problem we shall not be in a position to grapple with, until we have considered a series of facts connected with them, which have not jet been touched upon. 


\section{CHAPTER VI.}

THE DISTRIBUTION AND THE ETIOLOGY OF THE CRAYFISHES.

So far as I have been able to discover, all the crayfishes which inhabit the British islands agree in every point with the full description given above, at p. 230 . They are abundant in some of our rivers, such as the Isis, and other affuents of the Thames; and they hare been obserred in those of Devon; * but they appear to be absent from many other's. I cannot hear of any, for example, in the Cam or the Ouse, on the east, or in the rivers of Lancashire and Cheshire, on the west. It is still more remarkable that, according to the best information I can obtain, they are absent in the Severn, though they are plentiful in the Thames and Serern canal. Dr. II'Intosh, who has paid particular attention to the fauna of Scotland, assures me that crayfish are unknown north of the Tweed. In Ireland, on the other hand, they occur in many localities; + but the question whether their diffusion, and eren their introduction into this

* Moore. Mragazine of Natural History. New Series, III., 1839.

+ Thompson. Annals and Magazine of Natural History, XI., 1843. 
island, has or has not been effected by artificial means, is involved in some obscurity.

English zoologists have always termed our crayfish Astacus fuviatilis; and, up to a recent period, the majority of Continental naturalists have included a corresponding form of Astacus under that specific name.

Thus M. Milne Edwards, in his classical work on the Crustacea, ${ }^{*}$ published in 1837, observes under the head of "Ecrevisse commune. Astacus fluviatilis:" "There are two varieties of this crayfish; in the one, the rostrum gradually becomes narrower from its base onwards, and the lateral spines are situated close to its extremity; in the other, the lateral edges of the rostrum are parallel in their posterior half and the lateral spines are stronger and more remote from the end."

The "first variety," here mentioned, is known under the name of "Écrevisse à pieds blancs" $\dagger$ in France, by way of distinction from the "second variety," which is termed "Écrevisse à pieds rouges," on account of the more or less extensive red coloration of the forceps and ambulatory limbs. This second variety is the larger, commonly attaining five inches in length, and sometimes reaching much larger dimensions; and it is more highly esteemed for the market, on account of its better flavour.

In Germany, the two forms have long been popularly distinguished, the former by the name of "Steinkrebs,"

* "Histoire Naturelle des Crustacés."

† Carbonnier. "L'Écrevisse," p. 8. 
or "stone crayfish," and the latter by that of "Edelkrebs," or " noble crayfish."

Milne Edwards, it will be observed, speaks of these two forms of crayfish as "varieties" of the species Astacus fuviatilis; but, even as far back as the year 1803 some zoologists began to regard the "stone crayfish" as a distinct species, to which Schrank applied the name of Astacus torrentium, while the "noble crayfish" remained in possession of the old denomination, Astacus fuviatilis; and, subsequently, various forms of "stonecrayfishes" have been further distinguished as the species Astacus saxatilis, A. tristis, A. pallipes, A. fontinalis, \&c. On the other hand, Dr. Gerstfeldt,* who has devoted especial attention to the question, denies that these are anything more than varieties of one species; but he holds this and Milne Edwards's "second variety" to be specifically distinct from one another.

We thus find ourselves in the presence of three riews respecting the English and French crayfishes.

1. They are all varieties of one species-A. fluviatilis.

2. There are two species-A. fluviatilis, and $A$. torrentium, of which last there are several varieties.

3. There are, at ferrest, five or six distinct species.

Before adopting the one or the other of these views, it is necessary to form a definite conception of she meaning of the terms "species" and "variety."

* "Ueber die Flusskrebse Europas." Miém. de l'Acad. de St. Peters. burg, 1859 . 
The word "species" in Biology has two significations; the one based upon morphological, the other upon physiological considerations.

A species, in the strictly morphological sense, is simply an assemblage of individuals which agree with one another, and differ from the rest of the living world in the sum of their morphological characters; that is to say, in the structure and in the development of both sexes. If the sum of these characters in one group is represented by $A$, and that in another by $\mathrm{A}+n$; the two are morphological species, whether $n$ represents an important or an unimportant difference.

The great majority of species described in works on Systematic Zoology are merely morphological species. That is to say, one or more specimens of a kind of animal having been obtained, these specimens have been found to differ from any previously known by the character or characters $n$; and this difference constitutes the definition of the new species, and is all we really know about its distinctness.

But, in practice, the formation of specific groups is more or less qualified by considerations based upon what is known respecting rariation. It is a matter of observation that progeny are never exactly like their parents, but present small and inconstant differences from them. Hence, when specific identity is predicated of a group of individuals, the meaning conveyed is not that they are all exactly alike, but only that their differences are so 
small, and so inconstant, that they lie within the probable limits of individual variation.

Observation further acquaints us with the fact, that, sometimes, an individual member of a species may exhibit a more or less marked variation, which is propagated through all the offspring of that individual, and may even become intensified in them. And, in this manner, a variety, or race, is generated within the species; which variety, or race, if nothing were known respecting its origin, might have every claim to be regarded as a separate morphological species. The distinctive characters, of a race, however, are rarely equally well marked in all the members of the race. Thus suppose the species $\mathrm{A}$ to develope the race $\mathrm{A}+x$; then the difference $x$ is apt to be much less in some individuals than in others; so that, in a large suite of specimens, the interval between $\mathrm{A}+x$ and $\mathrm{A}$ will be filled up by a series of forms in which $x$ gradually diminishes.

Finally, it is a matter of observation that modification of the physical conditions under which a species lives favours the derelopment of varieties and races.

Hence, in the case of two specimens having respectively the characters $\mathrm{A}$ and $\mathrm{A}+n$, although, prim $\hat{a}$ facie, they are of distinct species; yet if a large collection shows us that the interval between $A$ and $A+n$ is filled up by forms of $\mathrm{A}$ having traces of $n$, and forms of $\mathrm{A}+n$ in which $n$ becomes less and less, then it will be con- 
cluded that $\mathrm{A}$ and $\mathrm{A}+n$ are races of one species and not separate species. And this conclusion will be fortified if $\mathrm{A}$ and $\mathrm{A}+n$ occupy different stations in the same geographical area.

Even when no transitional forms between $\mathrm{A}$ and $\mathrm{A}+n$ are discoverable, if $n$ is a small and unimportant difference, such as of average size, colour, or ornamentation, it may be fairly held that $\mathrm{A}$ and $\mathrm{A}+n$ are mere varieties; inasmuch as experience proves that such variations may take place comparatively suddenly; or the intermediate forms may have died out and thus the evidence of variation may have been effaced.

From what has been said it follows that the groups termed morphological species are provisional arrangements, expressive simply of the present state of our knowledge.

We call two groups species, if we know of no transitional forms between them, and if there is no reason to believe that the differences which they present are such as may arise in the ordinary course of variation. But it is impossible to say whether the progress of inquiry into the characters of any group of individuals may prove that what have hitherto been taken for mere varieties are distinct morphological species; or whether, on the contrary, it may prove that what have hitherto been regarded as distinct morphological species are mere varieties.

What has happened in the case of the crayfish is this: 
294 DISTRIBUTION AND ETIOLOGY OF THE CRAYFISHES.

the older observers lumped all the Western European forms which came under their notice under one species, Astacus furiatilis; noting, more or less distinctly, the stone crayfish and the noble crayfish as races or varieties of that species. Later zoologists, comparing crayfishes together more critically, and finding that the stone crayfish is ordinarily markedly different from the noble crayfish, concluded that there were no transitional forms, and made the former into a distinct species, tacitly assuming that the differential characters are not such as could be produced by variation.

It is at present an open question whether further investigation will or will not bear out either of these assumptions. If large series of specimens of both stone crayfishes and noble crayfishes from different localities are carefully examined, they will be found to present great variations in size and colour, in the tuberculation of the carapace and limbs, and in the absolute and relative sizes of the forceps.

The most constant, characters of the stone crayfish are :-

1. The tapering form of the rostrum and the approximation of the lateral spines to its point; the distance between these spines being about equal to their distance from the apex of the rostrum (fig. $61, \mathrm{~A}$ ), $\mathrm{P} 239-$

2. The development of one or two spines from the ventral margin of the rostrum.

3. The gradual subsidence of the posterior part of 
THE STONE CRAYFISH AND THE NOBLE CRAYFISH. 295

the post-orbital ridge, and the absence of spines on its surface.

4. The large relative size of the posterior division of the telson $(G)$.

On the contrary, in the noble crayfish :-

1. The sides of the posterior two-thirds of the rostrum are nearly parallel, and the lateral spines are fully a third of the length of the rostrum from its point; the distance between them being much less than their distance from the apex of the rostrum (B).

2. No spine is developed from the ventral margin of the rostrum.

3. The posterior part of the post-orbital ridge is a more or less distinct, sometimes spinous elevation.

4. The posterior division of the telson is smaller relatively to the anterior division $(\mathrm{H})$.

I may add that I have found three rudimentary pleurobranchiæ in the noble crayfish, and never more than two in the stone crayfish.

In order to ascertain whether no crayfish exist in which the characters of the parts here referred to are intermediate between those defined, it would be necessary to examine numerous examples of each kind of crayfish from all parts of the areas which they respectively inhabit. This has been done to some extent, but by no means thoroughly; and I think that all that can be safely said, at present, is that the existence of intermediate forms is not proven. But, whatever the constancy of the 
differences betreen the two kinds of crayfishes, there can surely be no doubt as to their insignificance; and no question that they are no more than such as, judging by analogy, might be produced by variation.

From a morphological point of view, then, it is really impossible to decide the question whether the stone crayfish and the noble crayfish should be regarded as species or as varieties. But, since it will, hereafter, be convenient to have distinct names for the two kinds, I shall speak of them as Astacus torrentium and Astacus nobilis."*

In the physiological sense, a species means, firstly, a group of animals the members of which are capable of completely fertile union with one another, but not with the members of any other group; and, secondly, it means all the descendants of a primitive ancestor or ancestors, supposed to have originated otherwise than by ordinary generation.

It is clear that, even if crayfishes had an unbegotten ancestor, there is no means of knowing whether the stone crayfish and the noble crayfish are descendants of the same, or of different ancestors, so that the second sense of species hardly concerns us. As to the first sense, there is no evidence to show whether the two

* According to strict zoological usage the names should be written A. Auviatrlis (var. torrentium) and A. fluviatilis (var. nobilis) on the hypothesis that the stone crayfish and the noble crayfish are varieties; and A.torrentium and A. furiatilis on the hypothesis that they are species; but as I neither wish to prejudge the species question, nor to employ cumbrously long names, I take a third course 
kinds of crayfish under consideration are capable of fertile union or whether they are sterile. It is said, however, that hybrids or mongrels are not met with in the waters which are inhabited by both kinds, and that the breeding season of the stone crayfish begins earlier than that of the noble crayfish.

M. Carbonnier, who practises crayfish culture on a large. scale, gives some interesting facts bearing on this question in the work already cited. He says that, in the streams of France, there are two very distinct kinds of crayfishes-the red-clawed crayfish (L'Écrevisse à pieds rouges), and the white-clawed crayfish (L'Écrevisse à. pieds blancs), and that the latter inhabit the swifter streams. In a piece of land converted into a crayfish farm, in which the white-clawed crayfish existed naturally in great abundance, 300,000 recl-clawed crayfish were introduced in the course of five years; nevertheless, at the end of this time, no intermediate forms were to be seen, and the "pieds rouges" exhibited a marked superiority in size over the "pieds blancs." M. Carbonnier, in fact, says that they were nearly twice as big.

On the whole, the facts as at present known, seem to incline rather in favour of the conclusion that $A$. torrentium and $A$. nobilis are distinct species; in the sense that transitional forms have not been clearly made out, and that, possibly, they do not interbreed.

As I have already remarked, the very numerous 
specimens of English and Irish crayfishes which have passed through my hands, have all presented the character of Astacus torrentium, with which also the description given in works of recognised authority coincides as far as it goes.* The same form is found in many parts of France, as far south as the Pyrenees, and it is met with as far east as Alsace and Switzerland. I have recently $\dagger$ been enabled, by the kindess of Dr. Bolivar, of Madrid, who sent me a number of crayfishes from the neighbourhood of that city, to satisfy myself that the Spanish peninsula contains crayfishes altogether similar to those of Britain, except that the subrostral spine is less developed. Further, I have no doubt that Dr. Heller $\ddagger$ is right in his identification of the English crayfish with a form which he describes uncler the name of $A$. saxatilis. He says that it is especially abundant in Southern Europe, and that it occurs in Greece, in Dalmatia, in the islands of Cherso and Veglia, at Trieste, in the Lago di Garda, and at Genoa. Further, Astacus torrentium appears to be widely distributed in North Germany. The eastern limit of this crayfish is uncertain; but, according to Kessler, $\S$ it does not occur within the limits of the Russian empire.

* See Bell. " "British Stalk-eyed Crustacea," p. 237.

+ Since the statement respecting the occurrence of crayfishes in Spain on $\mathrm{p} .44$ was printed.

† "Die Crustaceen des Südlichen Europas," 1863.

\ "Die Russischen Flusskrebse." Bulletin de la Société Impériale des Naturalistes de MLoscow, 1874. 
Astacus torrentium appear's to be particularly addicted to rapid highland streams and the turbid pools which they feed.

Astacus nobilis is indigenous to France, Germany, and the Italian peninsula. It is said to be found at Nice and at Barcelona, though I cannot hear of it elsewhere in Spain. Its south-eastern limit appears to be the Lake of Zirknitz, in Carniola, not far from the famous caves of Adelsberg. It is not known in Dalmatia, in Turkey, nor in Greece. In the Russian empire, according to Kessler, this crayfish chiefly inhabits the watershed of the Baltic. The northern limit of its distribution lies between Christianstad, in the Gulf of Bothnia $\left(62^{\circ} 16^{\prime} \mathrm{N}\right)$, and Serdobol, at the northern end of Lake Ladoga. "Eastward of Lake Ladoga it is found in the Uslanka, a tributary of the Swir. It appears to be the only crayfish which exists in the waters which flow from the south into the Gulf of Finland and into the Baltic; except in those streams and lakes which have been artificially connected with the Volga, and in which it is partially replaced by $A$. leptodactylus." It still inhabits the Lakes of Beresai and Bologoe, as well as the affluents of the Msta and the Wolchow; and it is met with in affluents of the Dnieper, as far as Mohilew. Astacus nobilis is also found in Denmark and Southern Sweden; but, in the latter country, its introduction appears to have been artificial. This crayfish is said occasionally to be met with on the Lironian coast in the waters of the Baltic, which, however, it must 
be remembered, are much less salt than ordinary sea water:

It will be observed that while the two forms, $A$. torrentium and $A$. nobilis, are intermixed over a large part of Central Europe, $A$. torrentium has a wider north-westward, south-westward, and south-eastward extension, - being the sole occupant of Britain, and apparently of the greater part of Spain and of Greece. On the other. hand, in the northern and eastern parts of Central Europe, $A$. nobilis appears to exist alone.

Further to the east, a new form, Astacus leptodactylus (fig. 75), makes its appearance. Whether A. leptodactylus exists in the upper waters of the Danube, does not appear, but in the lower Danube and in the Theiss it is the dominant, if not the exclusive, crayfish. From hence it extends through all the rivers which flow into the Black, Azov, and Caspian Seas, from Bessarabia and Podolia on the west, to the Ural mountains on the east. In fact, the natural habitat of this crayfish appears to be the watershed of the Pontocaspian area, excluding that part of the Black Sea which lies southward of the Caucasus on the one hand, and of the mouths of the Danube on the other.*

It is a remarkable circumstance that this crayfish not only thrives in the brackish waters of the estuaries of the rivers which debouche into the Black Sea and the Sea of Azov, but that it is found even in the salter

* These statements rest on the authority of Kessler and Gerstfeldt, in their memoirs already cited. 


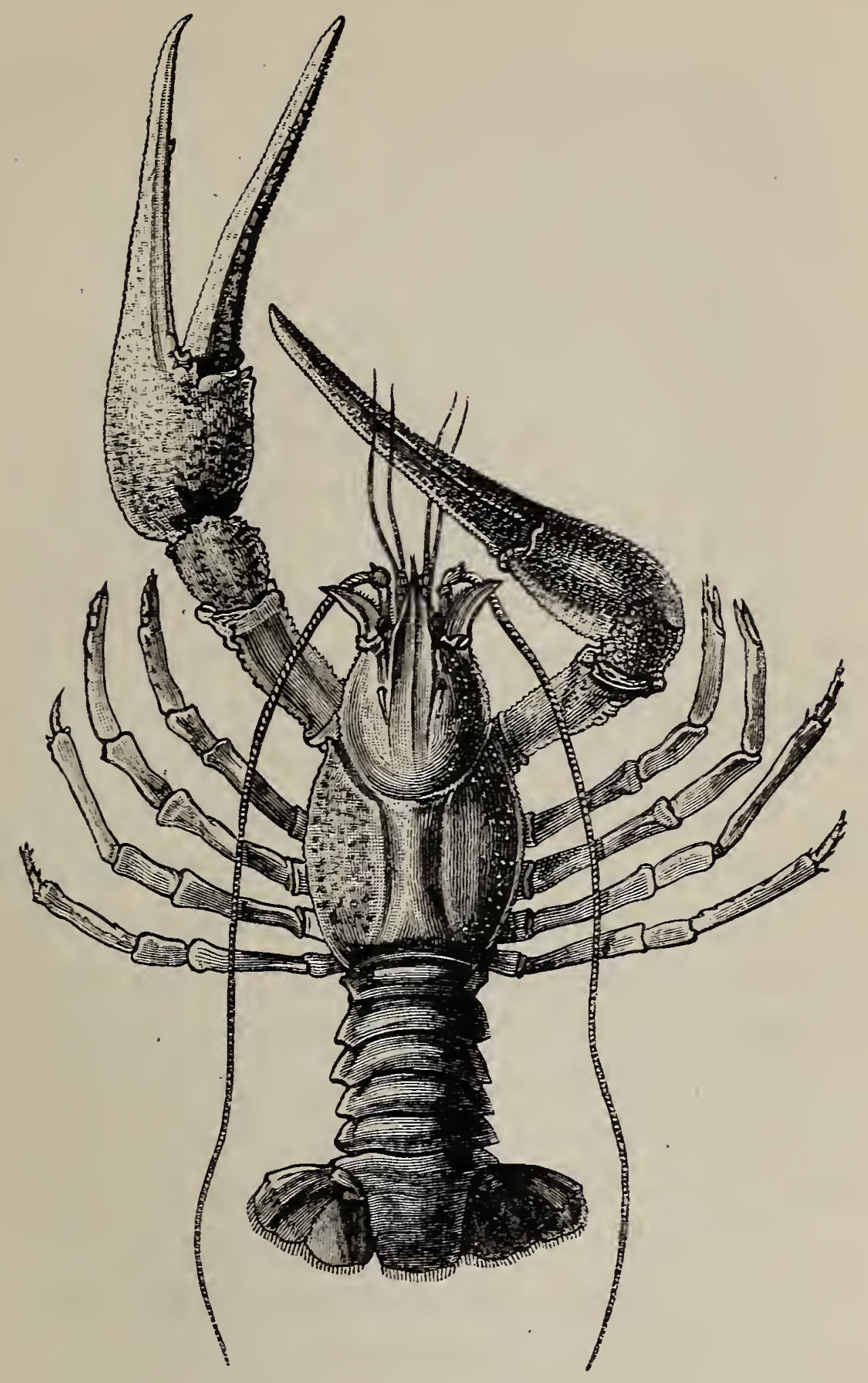

FIG. 75.-Astacus leptodactylus (after Rathke, $\frac{1}{3}$ nat. size). 
302 DISTRIBUTION AND ETIOLOGY OF THE CRAYFISHES.

southern parts of the Caspian, in which it lives at considerable depths.

In the north, Astacus leptodactylus is met with in the rivers which flow into the White Sea, as well as in many streams and lakes about the Gulf of Finland. But it has probably been introduced into these streams by the canals which have been constructed to connect the basin of the Volga with the rivers which flow into the Baltic and into the White Sea. In the latter, the invading $A$. leptodactylus is everywhere overcoming and driving out A. nobilis in the struggle for existence, apparently in virtue of its more rapid multiplication.*

In the Caspian and in the brackish waters of the estuaries of the Dniester and the Bug, a somewhat different crayfish, which has been called Astacus pachypus, occurs; another closely allied form (A. angulosus) is met with in the mountain streams of the Crimea and of the northern face of the Caucasus; and a third, A. colchicus, has recently been discovered in the Rion, or Phasis of the ancients, which flows into the eastern extremity of the Black Sea.

With respect to the question whether these Pontocaspian crayfishes are specifically distinct from one another, and whether the most widely distributed lind, A. leptodactylus, is distinct from $A$. nobilis, exactly the same difficulties arise as in the case of the west European

* Kessler (Die Russischen Flusskrebse, 1. c. p. 369-70), has an in. teresting discussion of this question. 
crayfishes. Gerstfeldt, who has had the opportunity of examining large series of specimens, concludes that the Pontocaspian crayfishes and $A$. nobilis are all varieties of one species. Kessler, on the contrary, while he admits that $A$. angulosus is, and $A$. pachypus may be, a variety of $A$. leptodactylus, affirms that the latter is specifically distinct from $A$. nobilis.

Undoubtedly, well marked examples of $A$. leptodactylus are very different from $A$. nobilis.

1. The edges of the rostrum are produced into five or six sharp spines, instead of being smooth or slightly serrated as in $A$. nobilis.

2. The fore part of the rostrum has no serrated spinous median keel, such as commonly, though not universally, exists in $A$. nobilis.

3. The posterior end of the post-orbital ridge is still more distinct and spiniform than in A. nobilis.

4. The abdominal pleura of $A$. leptodactylus are narrower, more equal sided, and triangular in shape.

5. The chelæ of the forceps, especially in the males, are more elongated; and the moveable and fixed claws are slenderer and have their opposed edges straighter and less tuberculated.

But, in all these respects, individual specimens of A. nobilis vary in the direction of $A$. leptodactylus and vice versâ; and if $A$. angulosus and $A$. pachypus are varieties of $A$. leptodactylus, I cannot see why Gerstfeldt's conclusion that $A$. notilis is another variety of 
304 DISTRIBUTION AND ETIOLOGY OF THE CRAYFISHES.

the same form need be questioned on morphological grounds. However, Kessler asserts that, in those 10calities in which $A$. leptodactylus and $A$. nobilis live together, no intermediate forms occur, which is presumptive evidence that they do not intermix by breeding.

No crayfishes are known to inhabit the rivers of the northern Asiatic watershed, such as the Obi, Yenisei, and Lena. None are known * in the sea of Aral, or the great rivers Oxus and Jaxartes, which feed that vast lake; nor any in the lakes of Balkash and Baikal. If further exploration verifies this negative fact, it will be not a little remarkable; inasmuch as two $t$, if not more, kinds of crayfishes are found in the basin of the great river Amur, which drains a large area of north-eastern Asia, and debouches into the Gulf of Tartary, in about the latitude of York.

Japan has one species (A. japonicus), perhaps more; but no crayfish has as yet been made known in any part of eastern Asia, south of Amurland. There are certainly none in Hindostan; none are known in Persia, Arabia, or Syria. In Asia Minor the only recorded locality is the Rion. No crayfish has yet been discovered in the whole continent of Africa.t.

* It would be hazardous, however, to assume that none exist, especi. ally in the Oxus, which formerly flowed into the Caspian.

$\dagger$ A. dauricus and A. Schrenckii.

\# Whatever the so-called Astacus capcnsis of the Cape Colony may be, it is certainly not a crayfish. 
Thus, on the continent of the old world, the crayfishes are restricted to a zone, the southern limit of which coincides with certain great geographical features; on the west, the Mediterranean, with its continuation, the Black Sea; then the range of the Caucasus, followed by the great Asiatic highlands, as far as the Corea on the east. On the north, though there is no such physical boundary, the crayfishes appear to be entirely excluded from the Siberian river basins; while east and west, though a sea-barrier exists, the crayfishes extend beyond it, to reach the British islands and those of Japan.

Crossing the Pacific, we meet with some half-a-dozen kinds of crayfishes, ${ }^{*}$ different from those of the old world, but still belonging to the genus Astacus, in British Columbia, Oregon, and California. Beyond the Rocky Mountains, from the Great Lakes to Guatemala, crayfishes abound, as many as thirty-two different species having been described, but they all belong to the genus Cambarus (fig. 63, p. 248). Species of this genus also occur in Cuba, $\uparrow$ but, so far as is at present known, not in any of the other West Indian islands. The occurrence of a curious dimorphism among the male Cambari has been described by Dr. Hagen; and a blind Cambarus

* Dr. Hagen in his "Monograph of the North American Astacidæ," enumerates six species ; A. Gambelii, A. klamathensis, A. leenisculus, A. nigrescens, $A$. oreganus, and $A$. Tronbridgii.

† Von Martens. Cambarus cubensis. Archiv. für Naturgeschichte, sxxviii. 
306 DISTRIBUTION AND ETIOLOGY OF THE CRAYFISHES.

is found, along with other blind animals, in the subterranean caves of Kentucky.

All the crayfishes of the northern hemisphere belong to the Potamobiida, and no members of this family are known to exist south of the equator. The crayfishes of the southern hemisphere, in fact, all belong to the division of the Parastacida, and in respect of the number and variety of forms and the size which they reach, the head-quarters of the Parastacidce is the continent of Australia. Some of the Australian crayfishes (fig. 76) attain a foot or more in length, and are as large as full-sized lobsters. The genus Engaus of Tasmania comprises small crayfish which, like some of the Cambari, live habitually on land, in burrows which they excavate in the soil.

New Zealand has a peculiar genus of crayfishes, Paranephrops, a species of which is found in the Fiji Islands, but none are known to occur elsewhere in Polynesia.

Two kinds of crayfish have been obtained in southern Brazil, and have been described by Dr. v. Martens,* as A. pilimanus and $A$. brasiliensis. I have shown that they belong to a peculiar genus, Parastacus. The former was procured at Porto Alegre, which is situated in $30^{\circ}$ S. Latitude, close to the mouth of the Jacuhy, at the north end of the great Laguna do Patos, which communi-

* Südbrasilische Süss- und Brackwasser Crustaceen, nach den Sammlungen des Dr. Reinh. Hensel. Archiv. für Naturgeschichte, xxxv. 1869. 


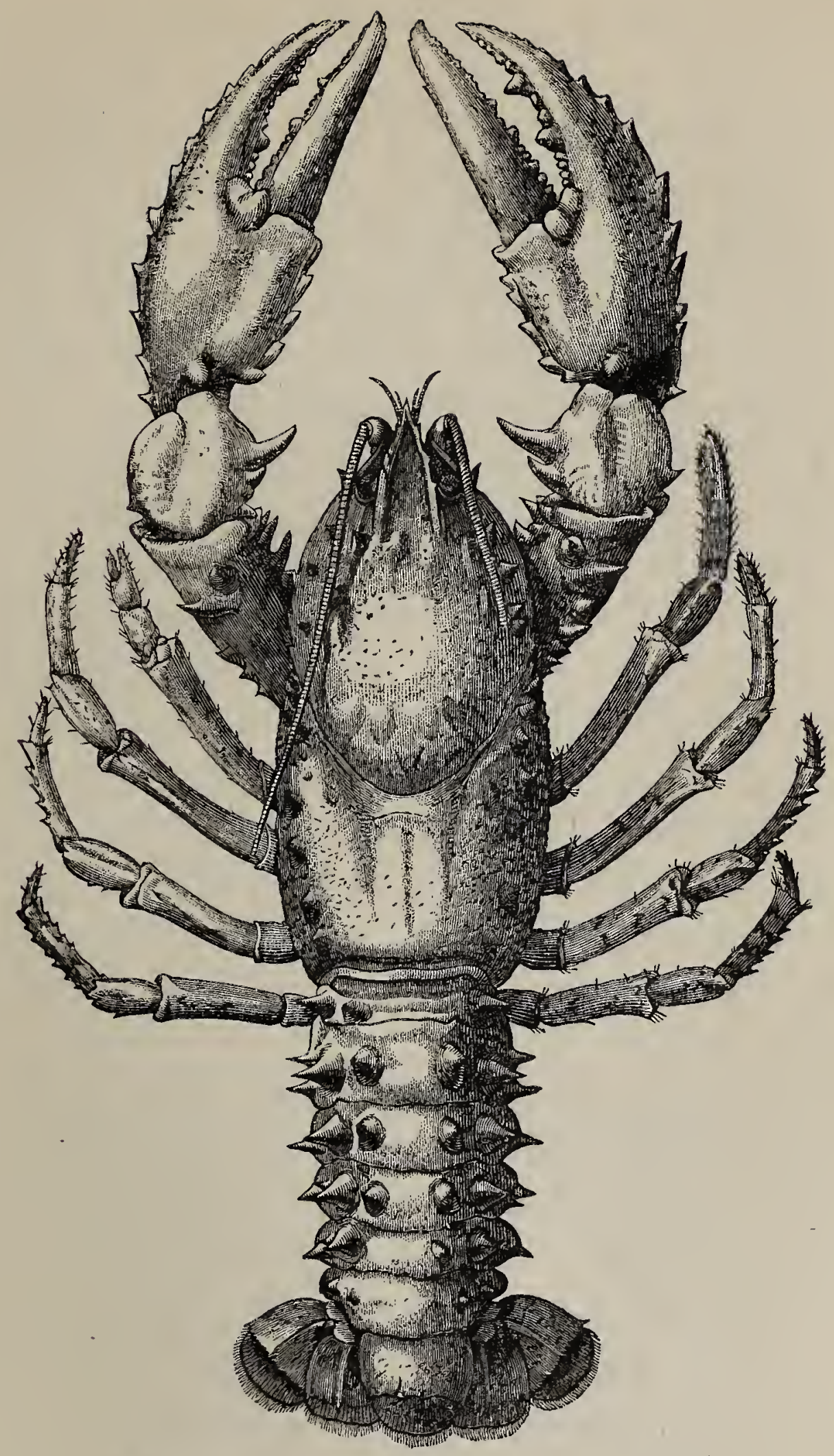

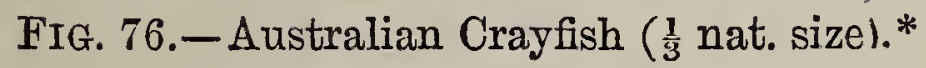

* The nomenclature of the Australian crayfishes requires thorough revision. I therefore, for the present, assign no name to this cray- 
cates by a narrow passage with the sea; and also at Sta. Cruz in the upper basin of the Rio Pardo, an affluent of the Jacuhy, "by digging it out of holes in the ground." The latter (P. brasiliensis, fig. 64) was obtained at Porto P. 250. Alegre, and further inland, in the region of the primitive forest at Rodersburg, in shallow streams.

In addition to these, no crayfish have as yet been found in any of the great rivers, such as the Orinoko; the Amazon, in which they were specially sought for by Agassiz; or in the La Plata, on the eastern side of the Andes. But, on the west, an "Astacus" chilensis is described in the "Histoire Naturelle des Crustacées," (vol. ii. p. 333). It is here stated that this crayfish "habite les côtes du Chili," but the freshwaters of the Chilian coast are doubtless to be understood.

Finally, Madagascar has a genus and species of crayfish (Astacoides madagascariensis, fig. 65) peculiar to itself. P. 250 .

On comparing the results obtained by the study of the geographical distribution of the crayfishes with those brought to light by the examination of their morphological characters, the important fact that there is a broad and general correspondence between the two becomes apparent. The wide equatorial belt of the earth's surface which separates the crayfishes of the northern from those of the southern hemisphere, is a sort of geographical

fish. It is probably identical with the A. notilis of Dana and the $A$. armatus of Von Martens. 


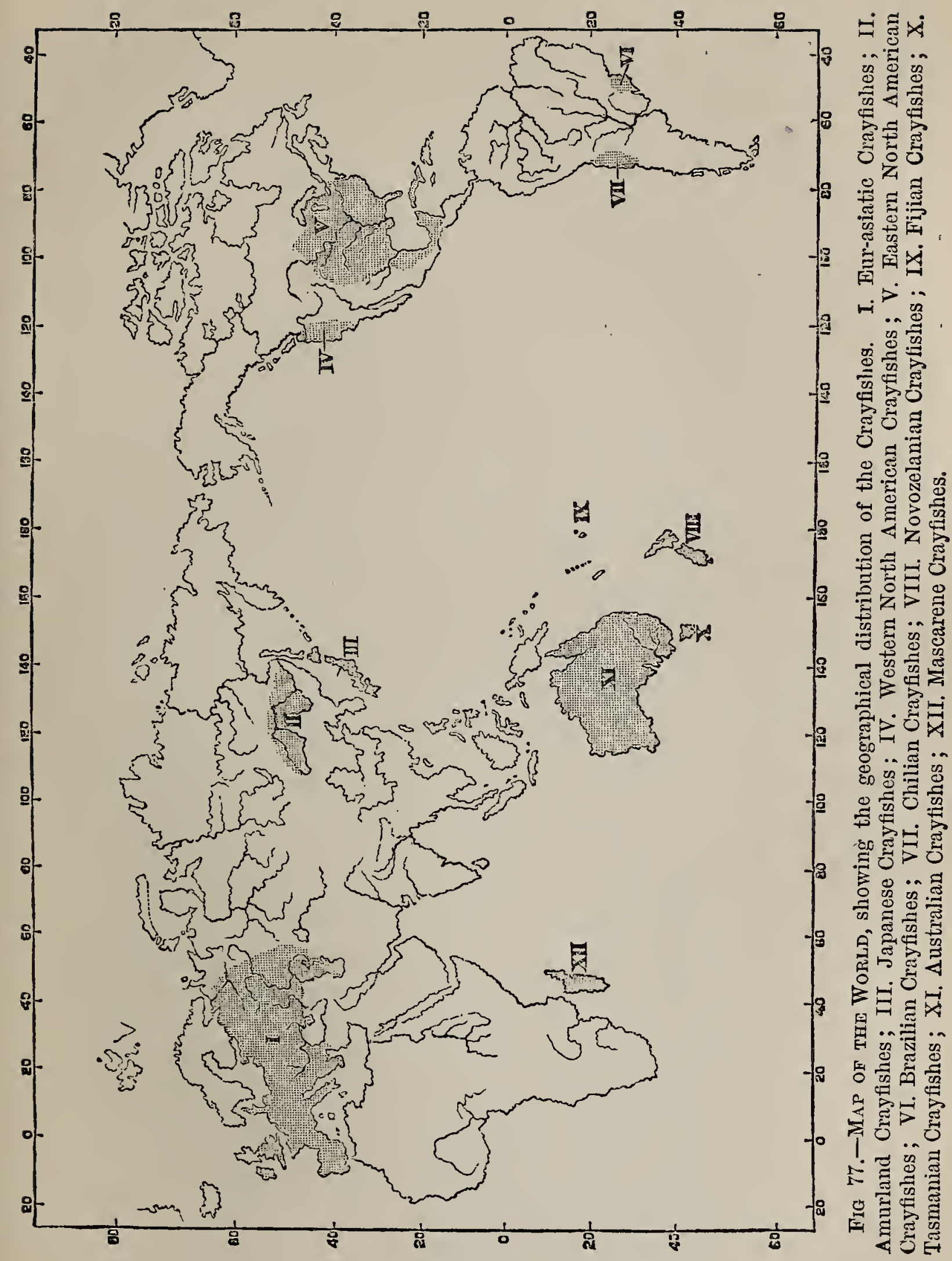




\section{DISTRIBUTION AND ETIOLOGY OF THE CRAYFISHES.}

representation of the broad morphological differences which mark off the Potamobiida from the Parastacida. Each group occupies a definite area of the earth's surface, and the two are separated by an extensive border-land untenanted by crayfishes.

A similar correspondence is exhibited, though less distinctly, when we consider the distribution of the genera and species of each group. Thus, among the Potamobiidce, Astacus torrentium and nobilis belong essentially to the northern, western, and southern watersheds of the central European highlands, the streams of which flow respectively into the Baltic and the North Seas, the Atlantic and the Mediterranean (fig. 77, I.); A. leptodactylus, pachypus, angulosus, and colchicus, appertain to the Pontocaspian watershed, the rivers of which drain into the Black Sea and the Caspian (I.); while Astacus dauricus and $A$. Schrenckii are restricted to the widely separated basin of the Amur, which sheds its waters into the Pacific (II.). The Astaci of the rivers of western North America, which flow into the Pacific (IV.), and the Cambari of the Eastern or Atlantic water-shed (V.) are separated by the great physical barrier of the Rocky Mountain ranges. Finally, with regard to the Parastacida, the widely separated geographical regions of New Zealand (VIII.), Australia (IX.), Madagascar (XII.), and South America (VI. and VII.), are inhabited by generically distinct groups.

But when we look more closely into the matter, it will 
be found that the parallel between the geographical and the morphological facts cannot be quite strictly carried out.

Astacus torrentium, as we have seen, inhabits both the British Islands and the continent of Europe; nevertheless, there is every reason to believe that twenty miles of sea water is an insuperable barrier to the passage of crayfishes from one land to the other. For though some crayfishes live in brackish water, there is no evidence that any existing species can maintain themselves in the sea. A fact of the same character meets us at the other side of the Eurasiatic continent, the Japanese and the Amurland crayfishes being closely allied; although it is not clear that there are any identical species on the two sides of the Sea of Japan.

Another circumstance is still more remarkable. The West American crayfishes are but little more different from the Pontocaspian crayfishes, than these are from Astacus torrentium. On the face of the matter, one might therefore expect the Amurland and Japanese crayfishes, which are intermediate in geographical position, to be also intermediate, morphologically, between the Pontocaspian and the West American forms. But this is not the case. The branchial system of the Amurland Astaci appears to be the same as that of the rest of the genus; but, in the males, the third joint (ischiopodite) of the second and third pair of ambulatory limbs is provided with a conical, recurved, hook-like process; while, in the females, the hinder edge of the penultimate thoracic 
sternum is elevated into a transverse prominence, on the posterior face of which there is a pit or depression.*

In both these characters, but more especially in the former, the Amurland and Japanese Astaci depart from both the Pontocaspian and the West American Astaci, and approach the Cambari of Eastern North America.

In these crayfishes, in fact, one or both of the same pairs of legs in the male are provided with similar

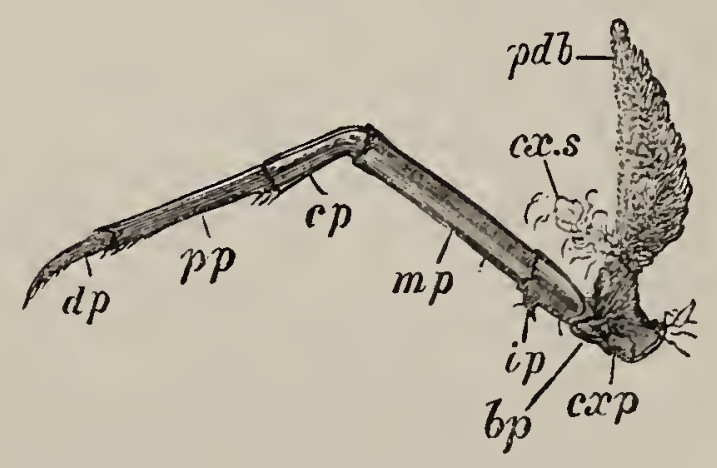

FIG. 78. - Cambarus (Guatemala) penultimate leg. exp, coxopodite; $c x . s$, coxopoditic setæ ; $p d b$, podobranchia ; $b_{p}$, basipodite ; ip, ischiopodite; $m p$, meropodite; $c p$ carpopodite; $p p$, propodite; $d p$, dactylopodite.

hook-like processes; while, in the females, the modification of the penultimate thoracic sternum is carried still further and gives rise to the curious structure described by Dr. Hagen as the "annulus ventralis."

In all the Cambari, the pleurobranchix appear to be entirely suppressed, and the hindermost podobranchia has no lamina; while the areola is usually extremely narrow. The proportional size of the areola in the Amurland

* Kessler, 1. c. 
crayfishes is not recorded; in the Japanese crayfish, judging by the figure given by De Haan, it is about the same as in the western Astaci. On the other hand, in the West American crayfishes it is distinctly smaller; so that, in this respect, they perhaps more nearly approack the Cambari. Unfortunately, nothing is known as to the branchiæ of the Amurland crayfishes. According to De Haan, those of the Japanese species resemble those of the western Astaci: as those of the West American Astaci certainly do.

With respect to the Parastacida; in the remarkable length and flatness of the epistoma, the crayfishes of Australia, Madagascar, and South America, resemble one another. But in its peculiar truncated rostrum (see fig. 65) and in the extreme modification of its branchial system, which I have described elsewhere, the Madagascar genus stands alone.

The Puranephrops of New Zealand and the Fijis, with its wide and short epistoma, long rostrum, and large antennary squames, is much more unlike the Australian forms than might be expected from its geographical position. On the other hand, considering their wide separation by sea, the amount of resemblance between the New Zealand and the Fiji species is very remarkable.

If the distribution of the crayfishes is compared with that of terrestrial animals in general, the points of 
314 DISTRIBUTION AND ÆTIOLOGY OF THE CRAYFISHES.

difference are at least as remarkable as the resemblances.

With respect to the latter, the area oocupied by the Potamobiida, corresponds roughly with the Palæarctic and Nearctic divisions of the great Arctogæal provinces of distribution indicated by mammals and birds; while distinct groups of crayfishes occupy a larger or smaller part of the other, namely, the Austro-Columbian, Australian, and Norozelanian primary distributional provinces of mammals and birds. Again, the peculiar crayfishes of Madagascar answer to the special features of the rest of the fauna of that island.

But the North American crayfishes extend much further South than the limits of the Nearctic fauna in general; while the absence of any group of crayfishes in Africa, or in the rest of the old world, south of the great Asiatic table-land, forms a strong contrast to the general resemblance of the North African and Indian fauna to that of the rest of Arctogra. Again, there is no such vast difference between the crayfishes of New Zealand, Australia, and South America, as there is between the mammals and the birds of those regions.

It may be concluded, therefore, that the conditions which have determined the distribution of crayfishes have been very different from those which have governed the distribution of mammals and birds. But if we compare with the distribution of the crayfishes, not that of ter. restrial animals in general, but only that of freshwater 
THE DISTRIBUTION OF FRESHWATER CRAYFISHES. 315

fishes, some very curious points of approximation become manifest. The Salmonidce, or fishes of the salmon and trout kind, a few of which are exclusively marine, many both marine and freshwater, while others are confined to fresh water, are distributed over the northern hemisphere, in a manner which recalls the distribution of the Potamobine crayfishes, ${ }^{*}$ though they do not extend so far to the South in the new world, while they go a little further, namely, as far as Algeria, Northern Asia Minor, and Armenia, in the old world. With the exception of the single genus Retropinna, which inhabits New Zealand, no true salmonoid fish occurs south of the equator; but, as Dr. Günther has pointed out, two groups of freshwater fishes, the Haplochitonidae and the Galaxide, which stand in somerwhat the same relation to the Salmonidce as the Parastacidce do to the Potamobiida, take the place of the Salmonidce in the fresh waters of New Zealand, Australia, and South America. There are two species of Haplochiton in Tierra del Fuego; and of the closely allied genus Prototroctes, one species is found in South Australia, and one in New Zealand; of the Galaxida, the same species, Galaxias attennuatus, occurs in the streams of New Zealand, Tasmania, the Falkland Islands, and Peru.

Thus, these fish avoid South Africa, as the crayfishes

* According to Dr. Günther their southern range is similarly limited by the Asiatic Highlands. But they abound in the rivers both of the old and new worlds which flow into the Arctic sea; and though those on 
do; but I am not aware that any member of the group is found in Madagascar, and thus completes the analog 5 .

The preservation of the soft parts of animals in the fossil state depends upon favourable conditions of rare occurrence; and, in the case of the Crustacea, it is not often that one can hope to meet with such small hard parts as the abdominal members, in a good state of preservation. But without recourse to the branchial apparatus, and to the abdominal appendages, it might be very difficult to say whether a given crustacean belonged to the Astacine, or to the closely allied Homarine group. Of course, if the accompanying fossils indicated that the deposit in which the remains occur, was of freshwater origin, the presumption in favour of their Astacine nature would be very strong; but if they were inhabitants of the sea, the problem whether the crustacean in question was a marine Astacine, or a true Homarine, might be very hard to solve.

Undoubted remains of crayfishes have hitherto been discorered only in freshwater strata of late tertiary age. In Idaho, North America, Professor Cope ${ }^{*}$ found, in association with Mastodon mirificus, and Equus excelsus, several species, which he considers to be distinct from the western side of the Rocky Mountains are different from the Eastern American forms, yet there are species common to both the Asiatic and the American coasts of the North Pacific.

* On three extinct Astaci from the freshwater Tertiary of Idaho. Proceedings of the American Philosophical Society, 1869-70. 
the existing American crayfishes; whether they are Cambari or Astaci does not appear. But, in the lower chalk of Ochtrup, in Westphalia, and therefore in a marine deposit, Von der Marck and Schlüter* have obtained a single, somewhat imperfect, specimen of a crustacean, which they term Astacus politus, and which, singularly enough, has the divided telson found only in the genus Astacus. It would be very desirable to know more about this interesting fossil. For the present it affords a strong presumption that a marine Potamobine existed as far back as the earlier part of the cretaceous epoch.

Such are the more important facts of Morphology, Physiology, and Distribution, which make up the sum of our present knowledge of the Biology of Crayfishes. The imperfection of that knowledge, especially as regards the relations between Morphology and Distribution, becomes a serious drawback when we attack the final problem of Biology, which is to find out why animals of such structure and active powers, and so localized, exist?

It would appear difficult to frame more than two fundamental hypotheses in attempting to solve this problem. Either we must seek the origin of crayfishes in conditions extraneous to the ordinary course of natural

* Teue Fische und Krebse aus der Kreide von Westphalen. Palæontographica, Bd. XV., p. 302 ; tab. XLIV., figs. 4 and 5. 


\section{DISTRIBUTION AND ETIOLOGY OF THE CRAYFISHES.}

operations, by what is commonly termed Creation; or we must seek for it in conditions afforded by the usual course of nature, when the hypothesis assumes some shape of the doctrine of Evolution. And there are two forms of the latter hypothesis; for, it may be assumed, on the one hand, that crayfishes have come into existence, independently of any other form of living matter, which is the hypothesis of spontaneous or equirocal generation, or abiogenesis; or, on the other hand, we may suppose that crayfishes have resulted from the modification of some other form of living matter; and this is what, to borrow a useful word from the French language, is known as transformism.

I do not think that any hypothesis respecting the origin of crayfishes can be suggested, which is not referable to one or other of these, or to a combination of them.

As regards the hypothesis of creation, little need be said. From a scientific point of view, the adoption of this speculation is the same thing as an admission that the problem is not susceptible of solution. Moreover, the proposition that a given thing has been created, whether true or faise, is not capable of proof. By the nature of the case direct evidence of the fact is not obtainable. The only indirect evidence is such as amounts to proof that natural agencies are incompetent to cause the existence of the thing in question. But such eridence is out of our reach. The most that 
can be proved, in any case, is that no known natural cause is competent to produce a given effect; and it is an obvious blunder to confound the demonstration of our own ignorance with a proof of the impotence of natural causes. However, apart from the philosophical worthlessness of the hypothesis of creation, it would be a waste of time to discuss a view which no one upholds. And, unless I am greatly mistaken, at the present day, no one possessed of knowledge sufficient to give his opinion importance is prepared to maintain that the ancestors of the various species of crayfish were fabricated out of inorganic matter, or brought from nothingness into being, by a creative fiat.

Our only refuge, therefore, appears to be the hypothesis of evolution. And, with respect to the doctrine of abiogenesis, we may also, in riew of a proper economy of labour, postpone its discussion until such time as the smallest fragment of evidence that a crayfish can be evolved by natural agencies from not living matter, is brought forward.

In the meanwhile, the hypothesis of transformism remains in possession of the field; and the only profitable inquiry is, how far are the facts susceptible of interpretation, on the hypothesis that all the existing kinds of crayfish are the product of the metamorphosis of other forms of living beings; and that the biological phenomena which they exhibit are the results of the interaction, through past time, of two series of 
factors: the one, a process of morphological and concomitant physiological modification ; the other, a process of change in the condition of the earth's surface.

If we set aside, as not worth serious consideration, the assumption that the Astacus torrentium of Britain was originally created apart from the Astacus torrentium of the Continent; it follows, either that this crayfish has passed across the sea by voluntary or involuntary migration; or that the Astacus torrentium existed before the English Channel, and spread into England while these islands were still continuous with the European mainland; and that the present isolation of the English crayfishes from the members of the same species on the Continent is to be accounted for by those changes in the physical geography of western Europe which, as there is abundant evidence to prove, have separated the British Islands from the mainland.

There is no evidence that our crayfish has been purposely introduced by human agency into Great Britain; and from the mode of life of crayfish and the manner in which the eggs are carried about by the parent during their development, transport by birds or floating timber would seem to be out of the question. Again, although Astacus nobilis is said to venture into the brackish waters of the Gulf of Finland, and $A$. leptodactylus, as we have seen, makes itself at home in the more or less salt Caspian, there is no reason to believe that Astacus torrentium is capable of existing in sea- 
water, still less of crossing the many miles of sea which separate England from even the nearest point of the Continent. In fact, the existence of the same kind of crayfish on both sides of the Channel appears to be only a case of the general truth, that the Fauna of the British Islands is identical with a part of that of the Continent; and as our foxes, badgers, and moles certainly have neither swum across, nor been transported by man, but existed in Britain while it was still continuous with western Europe, and have been isolated by the subsequent intervention of the sea, so we may confidently explain the presence of Astacus torrentium by reference to the same operation.

If we take into account the occurrence of Astacus nobilis over so large a part of the area occupied by Astacus torrentium; its absence in the British Islands, and in Greece; and the closer affinity which exists between $A$. nobilis and $A$. leptodactylus, than between $A$. nobilis and $A$.torrentium; it seems not improbable that Astacus torrentium was the original tenant of the whole western European area outside the Ponto-Caspian watershed; and that $A$. nobilis is an invading offshoot of the Ponto-Caspian or leptodactylus form which has made its way into the western rivers in the course of the many changes of level which central Europe has undergone; in the same way as $A$. leptodactylus is now passing into the rivers of the Baltic provinces of Russia.

The study of the glacial phenomena of central Europe 
322 DISTRIBUTION AND ETIOLOGY OF THE CRAYFISHES.

has led Sartorius von Waltershausen * to the conclusion that at the time when the glaciers of the Alps had a much greater extension than at present, a vast mass of freshwater extended from the valley of the Danube to that of the Rhone, around the northern escarpment of the Alpine chain, and connected the head-waters of the Danube with those of the Rhine, the Rhone, and the northern Italian rivers. As the Danube debouches into the Black Sea, and this was formerly connected with the Aralo-Caspian Sea, an easy passage would thus be opened up by which crayfishes might pass from the AraloCaspian area to western Europe. If they spread by this road, the Astacus torrentium may represent the first wave of migration westward, while $A$. nobilis answers to a second, and $A$. leptodactylus, with its varieties, remains as the representative of the old Aralo-Caspian crayfishes. And thus the crayfishes would present a curious parallel with the Iberian, Aryan, and Mongoloid streams of westward movement among mankind.

If we thus suppose the western Eurasiatic crayfishes to be simply varieties of a primitive Aralo-Caspian stock, their limitation to the south by the Mediterranean and by the great Asiatic highlands becomes easily intelligible.

The extremely severe climatal conditions which obtain in northern Siberia may sufficiently account for the

* "Untersuchungen ueber die Klimate der Gegenwart und der Vorwelt." Natuurkundige Verhandelingen van de Hollandsshe Maatschappij der Wetenschappen te Haarlem, 1865. 
absence of crayfishes (if they are really absent) in the rivers Obi, Yenisei, and Lena, and in the great lake Baikal, which lies more than 1,300 feet above the sea, and is frozen over from November to May. Moreover, there can be no doubt that, at a comparatively recent period, the whole of this region, from the Baltic to the mouth of the Lena, was submerged beneath a southward extension of the waters of the Arctic ocean to the AraloCaspian Sea and Lake Baikal, and a westward extension to the Gulf of Finland.

The great lakes and inland seas which stretch, at intervals, from Baikal, on the east, to Wenner in Sweden, on the west, are simply pools, isolated partly by the rising of the ancient sea-bottom and partly by evaporation; and often completely converted into fresh water by the inflow of the surrounding land-drainage. But the population of these pools was originally the same as that of the Northern Ocean, and a few species of marine crustaceans, mollusks, and fish, besides seals, remain in them as living evidences of the great change which has taken place. The same process which, as we shall see, has isolated the Mysis of the Arctic seas in the lakes of Sweden and Finland, has shut up with it other arctic marine crustacea, such as species of Gammarus and Idothea. And the very same species of Gammarus is imprisoned, along with arctic seals, in the waters of Lake Baikal.

The distribution of the American crayfishes agrees equally well with the hypothesis of the northern origin of 


\section{DISTRIBUTION AND ATIOLOGY OF THE CRAYFISHES.}

the stock from which they have been evolved. Ever under existing geographical conditions, an affuent of the Mississippi, the St. Peter's rirer, communicates directly, in rainy weather, with the Red river, which flows into Lake Winnipeg, the southernmost of the long series of intercommunicating lakes and streams, which occupy the low and flat water-parting between the southern and the northern watersheds of the North American Continent. But the northernmost of these, the Great Slare Lake, empties itself by the Mackenzie river into the Arctic Ocean, and thus provides a route by which crayfishes might spread from the north orer all parts of North America east of the Rocky Mountains.

The so-called Rocky Mountain range is, in reality, an immense table-land, the edges of which are fringed by two principal lines of mountainous elevations. The tableland itself occupies the place of a great north and south depression which, in the cretaceous epoch, was occupied by the sea and probably communicated with the ocean at its northern, as well as at its southern end. During and since this epoch it became gradually filled up, and it now contains an immense thickness of deposits of all ages from the cretaceous to the pliocene-the earlier marine, the later more and more completely freshwater. During the tertiary epoch, rarious portions of this area have been occupied by rast lakes, the more northern of which doubtless had outlets into the Northern sea. "That crayfish existed in the vicinity of the Rocky Mountains 
in the latter part of the tertiary epoch is testified by the Idaho fossils. And there is thus no difficulty in understanding their presence in the rivers which have now cut their way to the Pacific coast.

The similarity of the crayish of the Amurland and of Japan is a fact of the same order as the identity of the English crayfish with the Astacus torrentium of the European Continent, and is to be explained in an analogous fashion. For there can be no doubt that the Asiatic continent formerly extended much further to the eastward than it does at present, and included what are now the islands of Japan. Even with this alteration of the geographical conditions, however, it is not easy to see how crayfishes can have got into the Amur-Japanese fresh waters. For a north-eastern prolongation of the Asiatic highlands, which ends to the north in the Stanovoi range, shuts in the Amur basin on the west; while the Amur debouches into the sea of Okhotsk, and the Pacific ocean washes the shores of the Japanese islands.

But there are many grounds for the conclusion that, in the latter half of the tertiary epoch, eastern Asia and North America were connected, and that the chain of the Kurile and Aleutian islands may indicate the position of a great extent of submerged land. In that case, the sea of Okhotsk and Behring's sea may occupy the site of inland waters which formerly placed the mouth of the Amur in direct communication with the Northern Ocean, just as the Black Sea, at present, brings the basin of the 
Danube into connection, first with the Mediterranean and then with the western Atlantic; and, as in former times, it gave access from the south to the rast area now drained by the Volga. When the Black Sea communicated with the Aralo-Caspian sea, and this opened to the north into the Arctic sea, a chain of great inland waters must have skirted the eastern frontier of Europe, just such as would now lie on the eastern frontier of Asia if the present coast underwent elevation.

Supposing, howerer, that the ancestral forms of the Potamobiidce obtained access to the river basins in which they are now found, from the north, the hypothesis that a mass of fresh water once occupied a great part of the region which is now Siberia and the Arctic Ocean, would be hardly tenable, and it is, in fact, wholly unnecessary for our present purpose.

The vast majority of the stalk-eyed crustaceans are, and always have been, exclusively marine animals; the crayfishes, the Atyida, and the fluviatile crabs (Thelphusidce), being the only considerable groups among them which habitually confine themselves to fresh waters. But even in such a genus as Pcnaus, most of the species of which are exclusively marine, some, such as Penaus brasiliensis, ascend rivers for long distances. Moreover, there are cases in which it cannot be doubted that the descendants of marine Crustacea have gradually accustomed themselves to fresh water conditions, and have, at the same time, become more or less modified, 
so that they are no longer absolutely identical with those descendants of their ancestors which have continued to live in the sea.*

In several of the lakes of Norway, Sweden and Finland, and in Lake Ladoga, in Northern Europe; in Lake Superior and Lake Michigan, in North America; a small crustacean, Mysis relicti, occurs in such abundance as to furnish a great part of the supply of food to the fresh water fishes which inhabit these lakes. Now, this Mysis relicta is hardly distinguishable from the Mysis oculata which inhabits the Arctic seas, and is certainly nothing but a slight variety of that species.

In the case of the lakes of Norway and Sweden, there is independent evidence that they formerly communicated with the Baltic, and were, in fact, fiords or arms of the sea. The communication of these fiords with the sea having been gradually cut off, the marine animals they contained have been imprisoned; and as the water lias been slowly changed from salt to fresh by the drainage of the surrounding land, only those which were able to withstand the altered conditions have survived. Among these is the Mysis oculata, which has in the meanwhile undergone the slight variation which has converted it into Mysis relicta. Whether the same explanation ap-

* See on this interesting subject: Martens, "On the occurrence of marine animal forms in fresh water." Annals of Natural History, 1858: Lovèn. "Ueber einige im Wetter und Wener See gefundene Crustaceen." Halle Zeitschrift für die Gesammten Wissenschaften, xix., 1862: G. O. Sars, "Histoire Naturelle des Crustacés d'eau douce du Norvège," 1867. 
plies to Lakes Superior and Michigan, or whether the Mysis oculata has not passed into these masses of fresh water by channels of communication with the Arctic Ocean 'which, no longer exist, is a secondary question. The fact remains that Mysis relicta is a primitively marine animal which has become completely adapted to fresh-water life.

Several species of prawns (Palcmon) abound in our orm seas. Other marine prawns are found on the coasts of North America, in the Mediterranean, in the South Atlantic and Indian Oceans, and in the Pacific as far south as New Zealand. But species of the same genus (Palcmon) are met with, living altogether in fresh water, in Lake Erie, in the rivers of Florida, in the Ohio, in the rivers of the Gulf of Mexico, of the West India Islands and of 'eastern South America, as far as southern Brazil, if not further; in those of Chili and those of Costa Rica in western South America; in the Upper Nile, in West Africa, in Natal, in the Islands of Johanna, Mauritius, and Bourbon, in the Ganges, in the Molucca and Philippine Islands, and probably elsewhere.

Many of these fluviatile prawns differ from the marine species not only in their great size (some attaining a foot or more in length), but still more remarkably in the vast development of the fifth pair of thoracic appendages. These are always larger than the slender fourth pair (which answer to the forceps of the crayfishes); and, in the males especially, they are very long and strong, and 
are terminated by great chelæ, not unlike those of the crayfishes. Hence these fluviatile prawns (known in many places by the name of "Cammarons") are not unfrequently confounded with true crayfishes; though

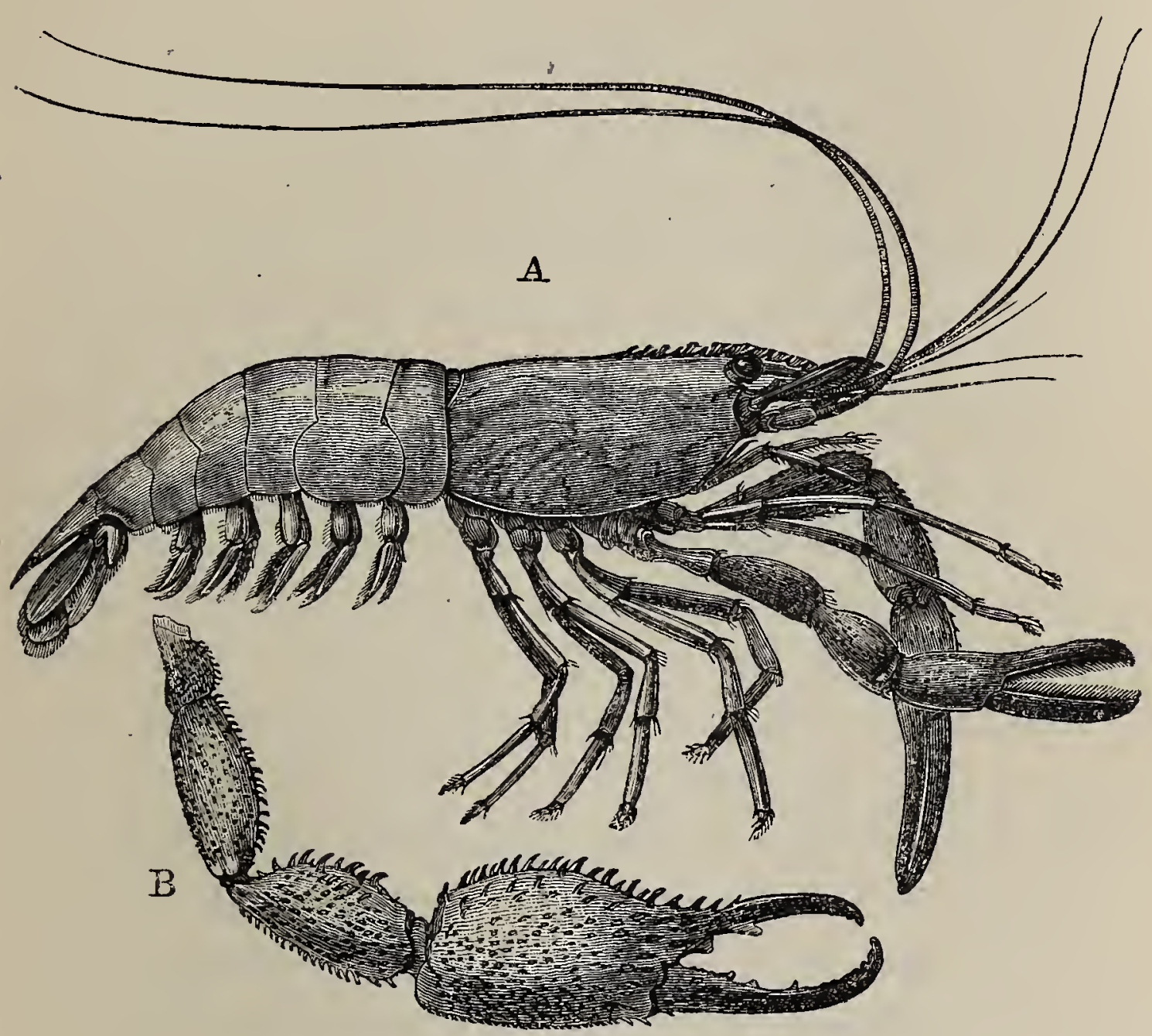

FIG. 79. Palcemon jamaicensis (about $\frac{5}{7}$ nat. size). A, female; $B$, fifth thoracic appendage of male.

the fact that there are only three pair of ordinary legs behind the largest, forceps-like pair, is sufficient at once to distinguish them from any of the Astacida.

Species of these large-clawed prawns live in the 
brackish water lagoons of the Gulf of Mexico, but I am not aware that any of them have yet been met with in the sea itself. The Palcmon lacustris (Anchistia. migratoria, Heller) abounds in fresh-water ditches and canals between Padua and Venice, and in the Lago di Garda, as well as in the brooks of Dalmatia; but its occurrence in the Adriatic or the Mediterranean, which has been asserted, appears to be doubtful. So the Nile prawn, though very similar to some Mediterranean prawns, does not seem to be identical with any at present linown.*

In all these cases, it appears reasonable to apply the analogy of the Mysis relicta, and to suppose that the fluviatile prawns are simply the result of the adaptive modification of species which, like their congeners, were primitively marine.

But if the existing sea prawns were to die out, or to be beaten in the struggle for existence, we should have, scattered over the world in isolated river basins, more or less distinct species of freshwater prawns, $\uparrow$ the areas inhabited by which might hereafter be indefinitely enlarged or diminished, by alteration in the elevation of the

* Heller, "Die Crustaceen des südlichen Europas," p. 259. Klunzinger, "Ueber eine Süsswasser-crustacee im Nil," with the notes by von Martens and von Siebold: Zeitschrift für Wissenschaftliche Zoologie, 1866.

$\dagger$ This seems actually to have happened in the case of the widelyspread allies and companions of the fluviatile prawns, Atya and Caridina. I am not aware that truly marine species of these genera are known. 
land and by other changes in physical geography. And, indeed, under these circumstances, the freshwater prawns themselves might become so much modified, that, even if the descendants of their ancestors remained unchanged in structure and habits in the sea, the relationship of the two might no longer be obvious.

These considerations appear to me to indicate the direction in which we must look for a rational explanation of the origin of crayfishes and their present distribution.

I have no doubt that they are derived from ancestors which lived altogether in the sea, as the great majority of the Myside and many of the prawns do now ; and that, of these ancestral crayfishes, there were some which, like Mysis oculata or Pencus brasiliensis, readily adapted themselves to fresh water conditions, ascended rivers, and took possession of lakes. These, more or less modified, have given rise to the existing crayfishes, while the primitive stock would seem to have vanished. At any rate, at the present time, no marine crustacean with the characters of the Astacide is known.

As crayfishes have been found in the later tertiaries of North America, we shall hardly err in dating the existence of these marine crayfishes at least as far back as the miocene epoch; and I am disposed to think that, during the earlier tertiary and later mesozoic periods, these Crustacea not only had as wide a distribution as the Prawns and Penai have now, but were differentiated into two groups, one with the general characters of the 


\section{DISTRIBUTION AND AETIOLOGY OF THE CRAYFISHES.}

Potamobiidce in the northern hemisphere, and another, with those of the Parastacida, in the southern hemisphere.

The ancestral Potamobine form probably presented the peculiarities of the Potamobiidce in a less marked degree than any existing species cloes. Probably the four pleurobranchiæ were all equally well developed; the laminæ of the podobranchiæ smaller and less distinct from the stem; the first and second abdominal appenclages less specialised; and the telson less distinctly divided. So far as the type was less specially Potamobine, it must have approached the common form in which Homarus and Nephrops originated. And it is to be remarked that these also are exclusively confined to the northern hemisphere.

The wide range and close affinity of the genera Astacus and Cambarus appear to me to necessitate the supposition that they are derived from some one already specialised Potamobine form; and I have already mentioned the grounds upon which I am disposed to believe that this ancestral Potamobine existed in the sea which lay north of the miocene continent in the northern hemisphere.

In the marine primitive crayfishes south of the equator, the branchial apparatus appears to have suffered less modification, while the suppression of the first abdominal appendages, in both sexes, has its analogue among the Palinuride, the headquarters of which are in the southern hemisphere. That they should have ascended 
the rivers of New Zealand, Australia, Madagascar, and South America, and become fresh water Parastacida, is an assumption which is justified by the analogy of the fresh-water prawns. It remains to be seen whether marine Parastacide still remain in the South Pacific and Atlantic Oceans, or whether they have become extinct.

In speculating upon the causes of an effect which is the product of several co-operating factors, the nature of each of which has to be divined by reasoning backwards from its effects, the probability of falling into error is very great. And this probability is enhanced when, as in the present case, the effect in question consists of a multitude of phenomena of structure and distribution about which much is yet imperfectly known. Hence the preceding discussion must rather be regarded as an illustration of the sort of argumentation by which a completely satisfactory theory of the rtiology of the crayfish will some day be established, than as sufficing to construct such a theory. It must be admitted that it does not account for the whole of the positive facts which have been ascertained; and that it requires supplementing, in order to furnish even a plausible explanation of rarious negative facts.

The positive fact which presents a difficulty is the closer resemblance between the Amur-Japanese crayfish and the East American Cambari, than between the 
334 DISTRIBUTION AND ETIOLOGY OF THE CRAYFISHES.

latter and the West American Astaci; and the closer resemblance between the latter and the Pontocaspian crayfish, than either bear to the Amur-Japanese form. If the facts had been the other way, and the West American and Amur-Japanese crayfish had changed places, the case would have been intelligible enough. The primitive Potamobine stock might then have been supposed to have differentiated itself into a western astacoid, and an eastern cambaroid form; * the latter would have ascended the American, and the former the Asiatic rivers. As the matter stands, I do not see that any plausible explanation can be offered without recourse to suppositions respecting a former more direct communication between the mouth of the Amur, and that of the North American rivers, in favour of which no definite evidence can be offered at present.

The most important negative fact which remains to be accounted for is the absence of crayfishes in the rivers of a large moiety of the continental lands, and in numerous islands. Differences of climatal conditions are obviously inadequate to account for the absence of crayfishes in Jamaica, when they are present in Cuba; for their absence in Mozambique, and the islands of Johanna and Mauritius, when they are present in Madagascar; and for their absence in the Nile, when they exist in Guatemala.

* Just as there is an American form of Idothea and an Asiatic form in the Arctic ocean at the present day. 
At present, I confess that I do not see my way to a perfectly satisfactory explanation of the absence of crayfishes in so many parts of the world in which they might, a priori, be expected to exist; and I can only suggest the directions in which an explanation may be sought.

The first of these is the existence of physical obstacles to the spread of crayfishes, at the time at which the Potamobine and the Parastacine stocks respectively began to take possession of the rivers, some of which have now ceased to exist; and the second is the probability that, in many rivers which have been accessible to crayfishes, the ground was already held by more powerful competitors.

If the ancestors of the Potamobine crayfishes originated only among those primitive crayfishes which inhabited the seas north of the miocene continent, their present limitation to the south, in the old world, is as easily intelligible as is their extension southward, in the course of the river basins of Northern America as far as Guatemala, but no further. For the elevation of the Eurasiatic highlands had commenced in the miocene epoch, while the isthmus of Panama was interrupted by the sea.

With respect to the Southern hemisphere, the absence of crayfishes in Mauritius and in the islands of the Indian Ocean, though they occur in Madagascar, may be due to the fact that the former islands are of comparatively late volcanic origin; while Madagascar is the remnant of 
a very ancient continental area, the oldest indigenous population of which, in all probability, is directly descended from that which occupied it at the beginning of the tertiary epoch. If Parastacine Crustacea inhabited the southern hemisphere at this period, and subsequently became extinct as marine animals, their preservation in the freshwaters of Australia, New Zealand, and the older portions of South America may be understood. The difficulty of the absence of crayfishes in South Africa* remains; and all that can be said is, that it is a difficulty of the same nature as that which confronts us when we compare the fauna of South Africa in general with that of Madagascar. The population of the latter region has a more ancient aspect than that of the former; and it may be that South Africa, in its present shape, is of very much later date than Madagascar.

With respect to the second point for consideration, it is to be remarked that, in the temperate regions of the world, the crayfishes are by far the largest and strongest of any of the inhabitants of freshwater, except the Vertcbrata; and that while frogs and the like fall an easy prey to them, they must be formidable enemies and competitors even to fishes, aquatic reptiles, and the smaller aquatic mammals. In warm climates, howerer, not only the large prawns which have been mentioned, but Atyce

* But it must be remembered that we hare as jet everything to learn respecting the fauna of the great inland lakes and river systems of South Africa. 
and fluviatile crabs (Thelphusa) compete for the possession of the freshwaters; and it is not improbable that under some circumstances, they may be more than a match for crayfishes; so that the latter might either be driven out of territory they already occupied, as Astacus leptodactylus is driving out $A$. nobilis in the Russian rivers; or might be prevented from entering rivers already tenanted by their rivals.

In connection with this speculation, it is worthy of remark that the area occupied by the fluviatile crabs is very nearly the same as that zone of the earth's surface from which crayfish are excluded, or in which they are scanty. That is to say, they are found in the hotter parts of the eastern side of the two Americas, the West Indies, Africa, Madagascar, Southern Italy, Turkey and Greece, Hindostan, Burmah, China, Japan, and the Sandwich Islands. The large-clawed fluviatile prawns are found in the same regions of America, on both east and west coasts, in Africa, Southern Asia, the Moluccas, and the Philippine Islands; while the Atyidce not only cover the same area, but reach Japan, extend over Polynesia, to the Sandwich Islands, on the north, and New Zealand, on the south, and are found on both shores of the Mediterranean; a blind form (Troglocaris Schmidtii), in the Adelsberg caves, representing the blind Cambarus of the caves of Kentucky.

The hypothesis respecting the origin of crayfishes 


\section{DISTRIBUTION AND ETIOLOGY OF THE CRAYFISHES}

which has been tentatively put forward in the preceding pages, involves the assumption that marine Crustacea of the astacine type were in existence during the deposition of the middle tertiary formations, when the great continents began to assume their present shape. That such was the case there can be no doubt, inasmuch as abundant remains of Crustacea of that type occur still earlier in the mesozoic rocks. They prove the existence of ancient crustaceans, from which the crayfishes may have been derived, at that period of the earth's history when the conformation of the land and sea were such as to admit of their entering the regions in which we now find them.

The materials which have, up to the present, time been collected are too scanty to permit of the tracing out of all the details of the genealogy of the crayfish. Nevertheless, the evidence which exists is perfectly clear, as far as it goes, and is in complete accordance with the requirements of the doctrine of evolution.

Mention has been made of the close affinity between the crayfishes and the lobsters-the Astacina and the Homarina; and it fortunately happens that these two groups, which may be included under the common name of the Astacomorpha, are readily distinguishable from all the other Podophthalmia by peculiarities of their exoskeleton which are readily seen in all well-preserved fossils. In all, as in the crayfish, there are large forceps, followed by two pairs of chelate ambulatory limbs, while 
the succeeding trro pairs of legs are terminated by simple claws. The exopodite of the last abdominal appendage is divided into two parts by a transverse suture. The pleura of the second abdominal somite are larger than the others, and overlap those of the first somite, which are very small. Any fossil crustacean which presents all these characters, is certainly one of the Astacomorpha.

The Astacina, again, are distinguished from the Homarina by the mobility of the last thoracic somite, and the characters of the first and second abdominal appendages, when they are present; or by their entire absence. But it is so difficult to make out anything about either of these characters in fossils, that, so far as I am aware, we know nothing about them in any fossil Astacomorph. And hence, it may be impossible to say to which division any given form belongs, unless its resemblances to known types are so minute and so close as to remove doubt.

For the present purpose, the series of the fossiliferous rocks may be grouped as follows:-1. Recent and Quaternary. 2. Newer Tertiary (Pliocene and Miocene). 3. Older Tertiary (Eocene). 4. Cretaceous (Chalk, Greensand and Gault). 5. Wealden. 6. Jurassic (Purbeck to Inferior Oolite). 7. Liassic. 8. Triassic. 9. Permian. 10. Carboniferous. 11. Devonian. 12. Silurian. 13. Cambrian.

Now the oldest known member of the group of the 


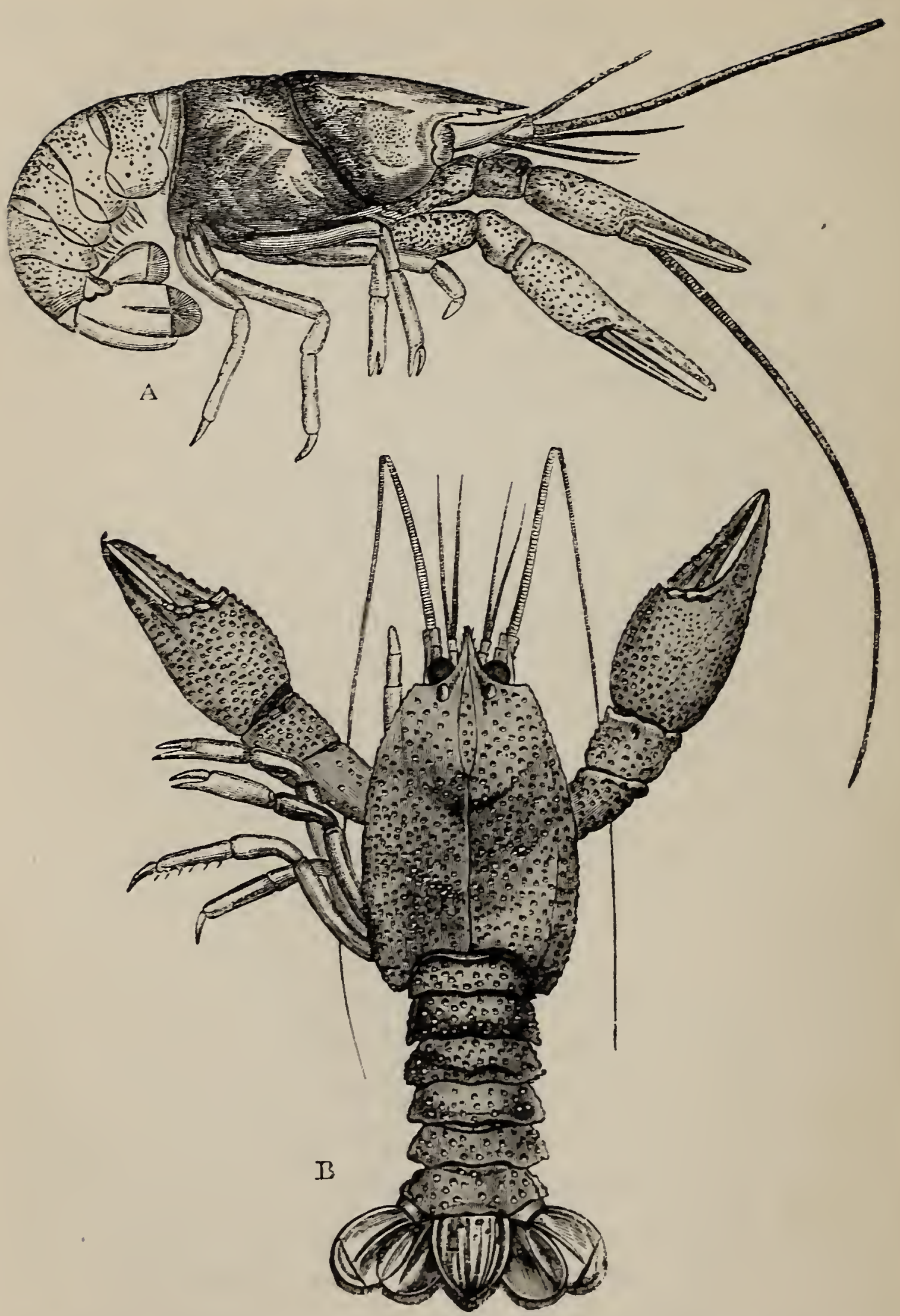

Fig. 80.-A, Pscudastacus pustulasus (nat. size). B, Eryma modestiformis $(\times 2)$. Both figures after Oppel. 
decapod Podophthalmia to which the Astacomorpha belong occurs in the Carboniferous formation. It is the genus Anthrapalamon-a small and very curious crustacean, about which nothing more need be said at present, as it does not appear to have special affinities with the Astacomorpha. In the later formations, up to the top of the Trias, podophthalmatous Crustacea are very rare; and, unless the Triassic genus Pemphix is an exception, no Astacomorphs are known to occur in them. The specimens of Pemphix which I have examined are not sufficiently complete to enable me to express any opinion about them.

The case is altered when we reach the Middle Lias. In fact this yields several forms of a genus, Eryma (fig. 80, B), which also occurs in the overlying strata almost up to the top of the Jurassic series, and presents so many variations that nearly forty different species have been recognised. Eryma is, in all respects, an Astacomorph, and so far as can be seen, it differs from the existing genera only in such respects as those in which they differ from one another. Thus it is quite certain that Astacomorphous Crustacea have existed since a period so remote as the older part of the Mesozoic period; and any hesitation in admitting this singular persistency of type on the part of the crayfishes, is at once removed by the consideration of the fact that, along with Eryma, in the Middle Lias, prawn-like Crustacea, generically identical with the existing Penceus, flourished in the sea 


\section{DISTRIBUTION AND, ETIOLOGY OF THE CRAYFISHES.}

and left their remains in the mud of the ancient sea bottom.

Eryma is the only crustacean, which can be certainly ascribed to the Astacomorpha, that has hitherto been found in the strata from the Middle Lias to the lithographic slates; which last lie in the upper part of the Jurassic series. In the freshwater beds of the Wealden, no Astacomorpha are known, and although no very great

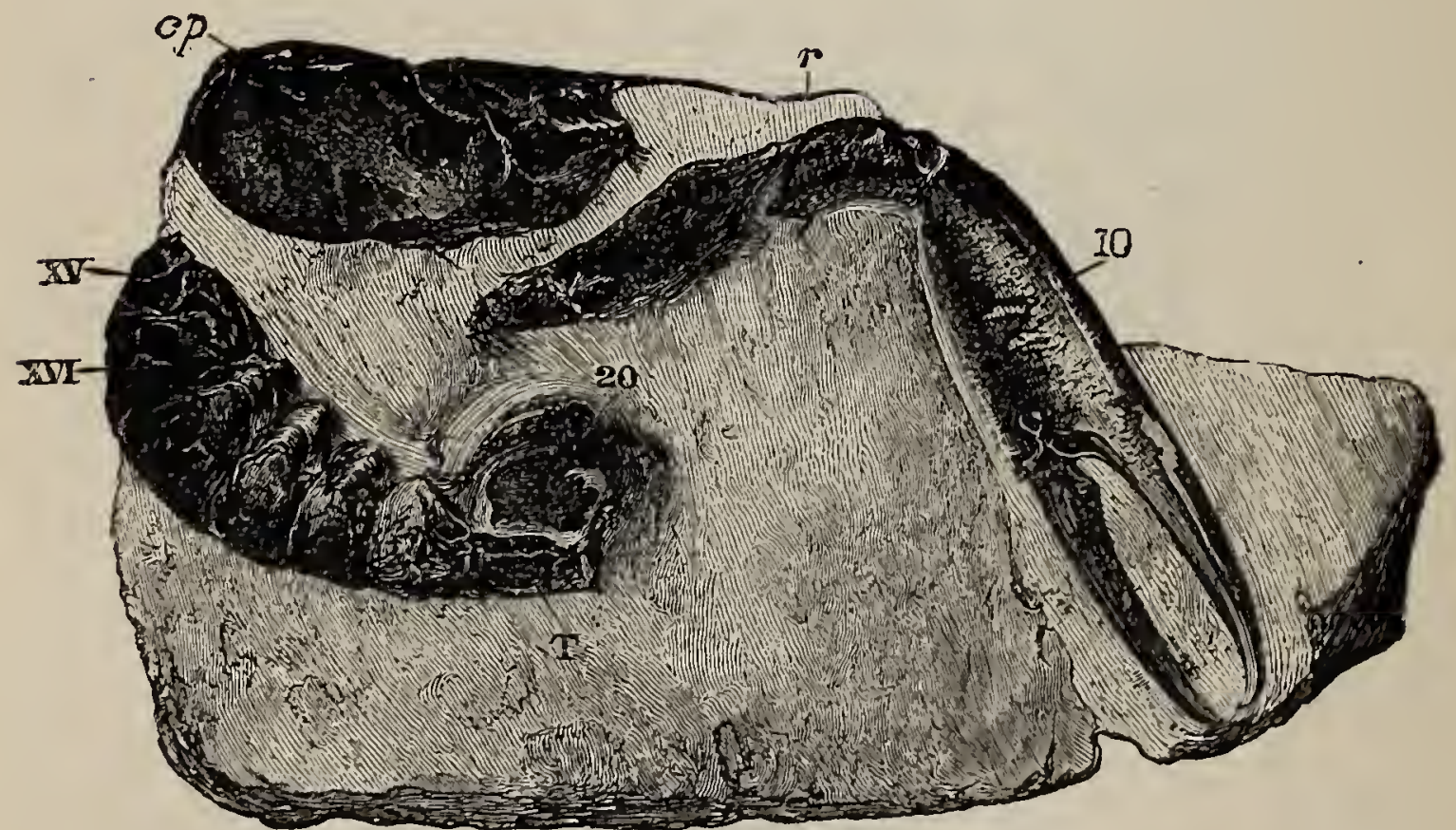

Fig. 81. - Hoploparia longimana ( $\frac{2}{3}$ nat. size). - cp, carapace ; $r$, rostrum, T, telson ; XV., XVI., first and second abdominal somites; 10, forceps ; 20, last abdominal appendage.

weight is to be attached to a negative fact of this kind, it is, so far, evidence that the Astacomorpha had not yet taken to freshwater life. In the marine deposits of the Cretaceous epoch, however, astacomorphous forms, which 
are known by the generic names of Hoploparia and Enoploclytia, are abundant.

The differences between these two genera, and between both and Eryma, are altogether insignificant from a broad morphological point of view. They appear to me to be of less importance than those which obtain between the different existing genera of crayfishes.

Hoploparia is found in the London clay. It therefore extends beyond the bounds of the Mesozoic epoch into the older Tertiary. But when this genus is compared with the existing Homarus and Nephrops, it is found partly to resemble the one and partly the other. Thus, on one line, the actual series of forms which have succeeded one another from the Liassic epoch to the present day, is such as must have existed if the common lobster and the Norway lobster are the descendants of Erymoid crustaceans which inhabited the seas of the Liassic epoch.

Side by side with Eryma, in the lithographic slates, there is a genus, Pseudastacus (fig. 80, A), which, as its name implies, has an extraordinarily close resemblance to the crayfishes of the present day. Indeed there is no point of any importance in which (in the absence of any knowledge of the abdominal appendages in the males) it differs from them. On the other hand, in some features, as in the structure of the carapace, it differs from Eryma, much as the existing crayfishes differ from Nephrops. Thus, in the latter part of the Jurassic epoch, the Astacine type 
344 DISTRIBUTION AND ÆTIOLOGY OF THE CRAYFISHES.

was already distinct from the Homarine type, though both were marine; and, since Eryma begins at least as early as the Middle Lias, it is possible that Pseudastacus goes back as far, and that the common protastacine form is to be sought in the Trias. Pseudastacus is found in the marine cretaceous rocks of the Lebanon, but has not yet been tracad into the Tertiary formations.

I am disposed to think that Pseudastacus is comparable to such a form as Astacus nigrescens rather than to any of the Parastacida, as I doubt the existence of the latter group at any time in northern latitudes.

In the chalk of Westphalia (also a marine deposit) a single specimen of another Astacomorph has been discovered, which possesses an especial interest as it is a true Astacus (A. politus, Von der Marck and Schlüter), provided with the characteristic transversely divided telson which is found in the majority of the Potamobiida.

If we arrange the results of palæontological inquiry which have now been stated in the form of a table such as that which is given on the following page, the significance of the succession of astacomorphous forms, in time, becomes apparent. 
Successive Forms of the Astacomorphous TrPe.

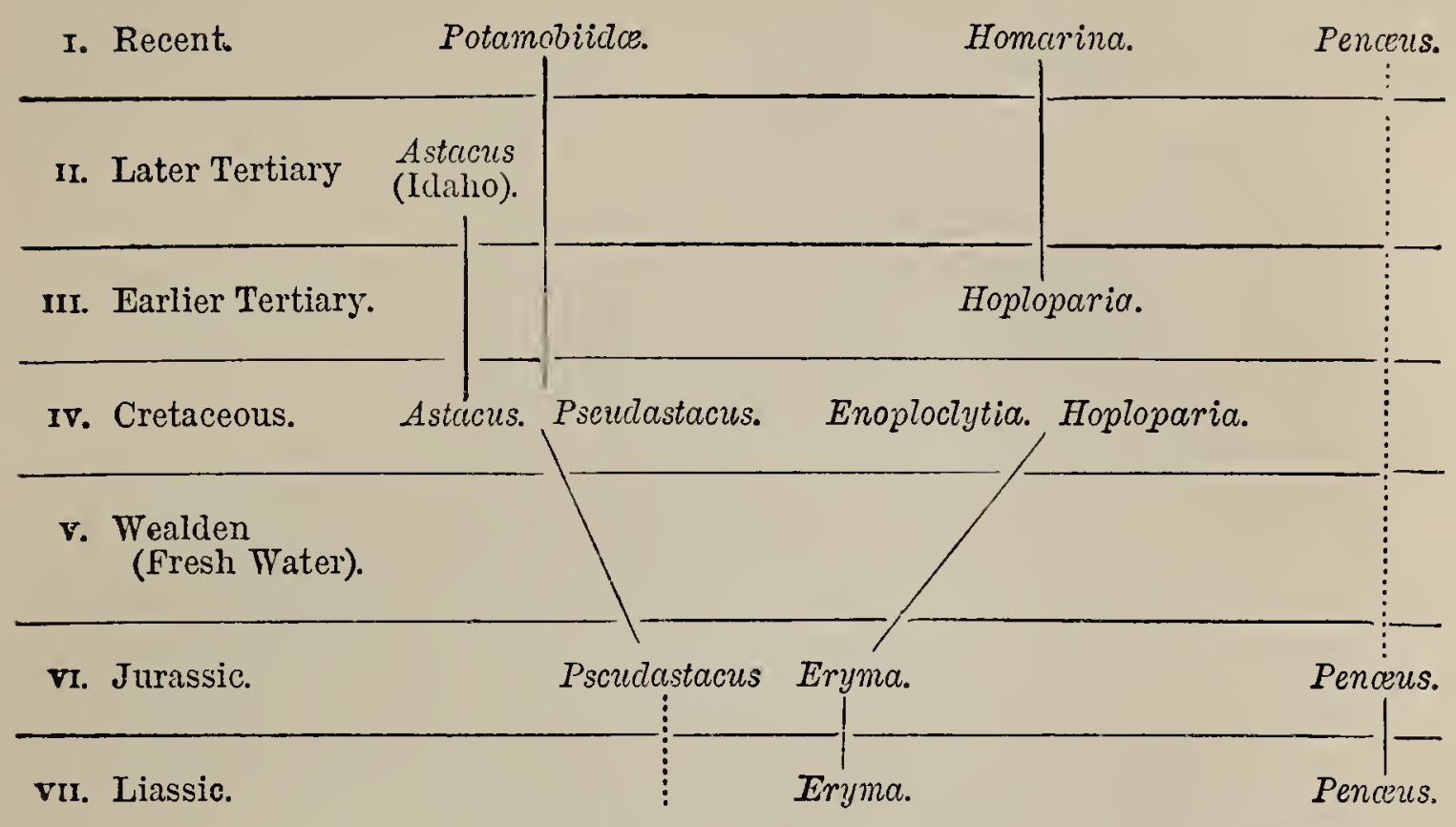

virr. Triassic.

Ix. Permian.

x. Carboniferous. Anthrapalcemon

xr. Devonian.

xrr. Silurian.

xır. Cambrian.

If an Astacomorphous crustacean, having characters intermediate between those of Eryma and those of Pseudastacus, existed in the Triassic epoch or earlier; if it gradually diverged into Pseudastacine and Erymoid forms; if these again took on Astacine and Homarine 
346 DISTRIBUtion AND ETIOLOGY OF THE CRAYFISHES.

characters, and finally ended in the existing Potamobiida and Homarina, the fossil forms left in the track of this process of evolution would be very much what they actually are. Up to the end of the Mesozoic epoch the only known Potamobiida are marine animals. And we have already seen that the facts of distribution suggest the hypothesis that they must have been so, at least up to this time.

Thus, with respect to the Aitiology of the crayfishes, all the known facts are in harmony with the requirements of the hypothesis that they have been gradually evolved in the course of the Mesozoic and subsequent epochs of the world's history from a primitive Astacomorphous form.

And it is well to reflect that the only alternative supposition is, that these numerous successive and coexistent forms of insignificant animals, the differences of which require careful study for their discrimination, have been separately and independently fabricated, and put into the localities in which we find them. By whatever verbal fog the question at issue may be hidden, this is the real nature of the dilemma presented to us not only by the crayfish, but by every animal and by every plant; from man to the humblest animalcule; from the spreading beech and towering pine to the Micrococci which lie at the limit of microscopic visibility. 


\section{NOTES.}

Note 1., Chapter I., p. 17.

\section{THE CEEMICAL COMPOSITION OF THE EXOSKELETON.}

THE harder parts of the exoskeleton of the crayfish contain rather more than half their weight of calcareous salts. Of these nearly seven-eighths consist of carbonate of lime, the rest being phosphate of lime.

The animal matter consists for the most part of a peculiar substance termed Chitin, which enters into the composition of the hard parts not only of the Arthropoda in general but of many other invertebrated animals. Chitin is not dissolved even by hot caustic alkalies, whence the use of solutions of caustic potash and soda in cleaning the skeletons of crayfishes. It is soluble in cold concentrated hydrochloric acid without change, and may be precipitated from its solution by the addition of water.

Chitin contains nitrogen, and according to the latest investigations (Ledderhose, "Ueber Chitin und seine Spaltungs-produkte :" Zeitschrift für Physiologische Chemie, II. 1879) its composition is represented by the formula $\mathrm{C}_{16} \mathrm{H}_{26} \mathrm{~N}_{2} \mathrm{O}_{10}$.

Note II., Chapter I., p. 29.

THE CRAB'S EYES, OR GASTROLITHS.

The "Gastroliths," as the "crab's eyes" may be termed, are found fully dereloped only in the latter part of the summer season, just before ecdysis sets in. They then give rise to rounded prominences, one on 
each side of the anterior part of the cardiac dirision of the stomach. The proper wall of the stomach is continued orer the outer surface of the prominence ; and, in fact, forms the outer wall of the chamber in which the gastrolith is contained, the inner wall being formed by the cuticular lining of the stomach. When the outer wall is cut through, it is readily detached from the convex outer surface of the gastrolith, with which it is in close contact. The inner surface of the gastrolith is usually flat or slightly concare. Sometimes it is strongly adherent to the chitonous cuticula; but when fully formed it is readily detached fro:n the latter. Thus the proper wall of the stomach invests only the outer face of the gastrolith, the inner face of which is adkerent to, or at any rate in close contact with, the cuticula. The gastrolith is by no means a mere concretion, but is a cuticular growth, having a definite structure. Its inner surface is smooth, but the outer surface is rough, from the projection of irregular ridges which form a kind of meshwork. A vertical section shows that it is composed of thin superimposed lasers, of which the inner are parallel with the flat inner surface, while the outer becomes gradually concentric with the outer surface. Moreorer, the inner layers are less calcified than the outer, the projections of the outer surface being particularly dense and hard. In fact, the gastroliths are very similar to other hard parts of the exoskeleton in structure, except that the densest layers are nearest the epithelial substratum, instead of furthest away from it.

When ecdysis occurs, the gastroliths are cast off along with the gastric armature in general, into the carity of the stomach, and are there dissolved, a new cuticle being formed external to them from the proper wall of the stomach. The dissolred calcareous matter is probably used up in the formation of the new exoskeleton.

According to the obserrations of M. Chantran (Comptes Rendus, LXXVIII. 1874) the gastroliths begin to be formed about forty days before ecdysis takes place in crayfish of four years' old; but the interval is less in younger crayfish, and is not more than ten days during the first year after birth. When shed into the stomach during ecdysis they are ground down, not merely dissolved. The process of destruction and absorption takes twenty-four to thirty hours in very young crayfish, serenty to eighty hours in adults. Unless the gastroliths are normally dereloped and re-absorbed, ecdysis is not healthily effected, and the craytish dies in the course of the process. 
According to Dulk ("Chemische Untersuchung der Krebsteine:" Müller's Archiv. 1835), the gastroliths have the following composition :-

Animal matter soluble in water . . . . 11.43

Animal matter insoluble in water (probably chitin) 4.33

Phosphate of lime . . . . . . . $18 \cdot 60$

Carbonate of lime $\quad$. $\quad$ • . . . . 6316

Soda reckoned as carbonate.$\quad$ • . 1.41

$\overline{98 \cdot 93}$

The proportion of mineral to animal matter and of phosphate to carbonate of lime is therefore greater in the gastroliths than in the exoskeleton in general.

\section{Note III., Chapter I., p. 31. \\ GROWTH OF CRAYFISH.}

The statements in the text, after the words "By the end of the year," regarding the sizes of the crayfish at different ages, are given on the authority of M. Carbonnier (L'Écrevisse. Paris, 1869); but they obviously apply only to the large "Écrevisse à pieds rouges" of France, and not to the English crayfish, which appears to be identical with the "Écrevisse à pieds blancs," and is of much smaller size. According to $\mathrm{Mr}$. Carbonnier (1. c. p. 51), the young crayfish just born is "un centimètre et demi environ," that is to say, three-fifths of an inch long. The young of the English crayfish still attached to the mother, which I have seen, rarely exceeds half this length.

M. Soubeiran ("Sur l'histoire naturelle et l'education des Écrevisses:" Comptes Rendus, IX. 1865) gives the result of his study of the growth of the crayfishes reared at Clairefontaine, near Rambouillet, in the following table :

\begin{tabular}{|c|c|c|c|c|c|}
\hline & $\begin{array}{l}\text { Nean length. } \\
\text { Metres. }\end{array}$ & & $\begin{array}{l}\text { Mean weight. } \\
\text { Grammes. }\end{array}$ \\
\hline Crayfis & of the year & • & 0.025 & • & 0.50 \\
\hline : & 1 year old & $\bullet$ & 0.050 & • & $1 \cdot 50$ \\
\hline " & 2 sears old & • & 0.070 & . & $3 \cdot 50$ \\
\hline " & 3 years, & • & 0.090 & . & 6.50 \\
\hline " & 4 jears ", & • & $0 \cdot 110$ & - & $17 \cdot 50$ \\
\hline " & 5 years :, & • & $0 \cdot 125$ & • & $18 \cdot 50$ \\
\hline " & indeterminate & • & $0 \cdot 160$ & . & $30 \cdot 00$ \\
\hline : & rery old & $\cdot$ & $0 \cdot 190$ & . & $125 \cdot 00$ \\
\hline
\end{tabular}

These obserrations must also app]y to the "Écrevisse à pieds rouges." 


\section{Note IV., Chapter I, p. 37. THE ECDYSES OF CRAYFISHES.}

There is a good deal of discrepancy between different obserrcrs as to the frequency of the process of ecdysis in crayfishes. In the text I hare followed M. Carbonnier, but M. Chantran ("Observations sur l'histoire naturelle des Écrevisses:" Comptes Rendus, LXXI. 1870, and LXXIII. 1871), who appears to have studied the question (on the "écrevisse a pieds rouges" apparently) very carefully, declares that the young crayfish moults no fewer than eight times in the course of the first twelve months. The first moult takes place ten dass after it is hatched; the second, third, fourth, and fifth, at intervals of from twenty to twenty-fire days, so that the young animal moults fire times in the course of the ninety to one hundred days of July, August, and September. From the latter month to the end of April in the following year, no ecdysis takes place. The sixth takes place in MIay, the seventh in June, and the eighth in July. In the second year of its age, the crayfish moults fire times, that is to say, in August and in September, and in May, June, and July following. In the third year, the crayfish commonly moults only twice, namely in July and in September. At a greater age than this, the females moult only once a Jear, from August to September; while the males moult twice, first in June and July; afterwards in August and September.

The details of the process of ecdysis are discussed by Braun, "Ueber die histologischen Torgänge bei der Häutung ron Astacus fuviatilis." Würzburg Arbeiten, Bd. II.

\section{Note V., Chapter I., p. 39. \\ REPRODUCTION IN CRAYFISHES.}

The males are said to approach the females in Norember, December, and January, in the case of the French crayfishes. In England they certainly begin as early as the beginning of October, if not earlier. According to M. Chantran (Comptes Rendus, 1870), and M. Gerbe (Comptes Rendus, 1858), the male seizes the female with his pincers, throws her on her back, and deposits the spermatic matter, firstly, on the external plates of the caudal fin ; secondly, cn the thoracic sterna around the external openings of the oviducts. During this operation, the appendages of the two first abdominal somites are carried backwards, 
the extremities of the posterior pair are inclosed in the groove of the anterior pair; and the end of the vas deferens becoming everted and prominent, the seminal matter is poured out, and runs slowly along the groove of the anterior appendage to its destination, where it hardens and assumes a vermicular aspect. The filaments of which it is composed are, in fact, tubular spermatophores, and consist of a tough case or sheath filled with seminal matter. The spoon-shaped extremity of the second abdominal appendage, working backwards and forwards in the groove of the anterior appendage, clears the seminal matter out of it, and prevents it from becoming choked.

After an interval which varies from ten to forty-five days, oviposition takes place. The female, resting on her back, bends the end of the abdomen forward over the hinder thoracic sterna, so that a chamber is formed into which the oviducts open. The eggs are passed into the chamber by one operation, usually during the night, and are plunged into a viscous greyish mucus with which it is filled. The spermatozoa pass out of the vermicnlar spermatophores, and mix with this fluid, in which the peculiarity of their form renders them readily recognisable. The spermatozoa are thus brought into close relation with the ova, but what actually becomes of them is unknown.

The origin of the viscous matter which fills the abdominal cnamber when the eggs are deposited in it, and the manner in which these become fixed to the abdominal limbs is discussed by Lereboullet ("Recherches sur le mode de fixation des œufs aux faux pattes abdominaux dans les Ëcrevisses." Annales des Sciences Naturelles, 4e Ee. T. XIV. 1860), and by Braun (Arbeiten aus dem Zoologisch-Zootomischen Institut in Würzburg, II.).

Note VI., Chapter I., p. 42.

\section{ATTACHMENT OF THE YOUNG CRAYFISH TO THE MOTHER.}

I observe that I had overlooked a passage in the Report on the award of the Prix Montyon for 1872, Comptes Rendus, LXXV. p. 1341, in which M. Chantran is stated to have ascertained that the young crayfishes fix themselves "en saisissant arec un de leurs pinces le filament qui suspend l'œuf à une fausse patte de la mère."

In the paper already cited from the Comptes Rendus for 1870, M. Chantran states that the young remain attached to the mother during ten days after hatching, that is to say, up to the first moult. Detached before this period, they die; but after the first moult, they sometimes leave the 
mother and return to her again, up to twenty-eight dass, when they become independent.

In a note appended to M. Chantran's paper, M. Robin states, that "the young are suspended to the abdomen of the mother by the intermediation of a chitinous hyaline filament, which extends from a point of the internal surface of the shell of the egg as far as the four most internal filaments of each of the lobes of the median membranous plate of the caudal appendage. The filaments exist when the embryos hare not yet attained three-fourths of their development." Is this a larral coat? Rathke does not mention it and I have seen nothing of it in those receutly hatched young which I have had the opportunity of examining.

Note VII., Chapter II., p. 64.

THE "SALIVARY" GLANDS AND THE SO-CALLED "LIVER" OF THE CRAYFISH.

Braun (Arbeiten aus dem Zoologisch-Zootomischen Institut in Würzburg, Bd. II. and III.) has described "salivary" glands in the walls of the œesophagus, in the metastoma, and in the first pair of maxillæ of the crarfish.

Hoppe-Seyler (Pflügers Archir, Bd. XIV. 1877) finds that the rellow fluid ordinarily found in the stomachs of crayfishes always contains peptone. It dissolves fibrin readily, without swelling it up, at ordinary temperatures; more quickly at $40^{\circ}$ Centigrade. The action is delayed by eren a trace of hrdrochloric acid, and is stopped by the addition of a few drops of water containing 0.2 per cent. of that acid. By adding alcohol to the rellow fluid, a precipitate is obtained, which is soluble in water and in glycerine. The aqueous solution of the precipitate has a strong digestive action on fibrin, which is arrested by acidulation with hydrochloric acid. These reactions show that the fluid is very similar to, if not identical with, the pancreatic fluid of vertebrates.

The secretion of the "liver" taken directly from that gland, has a more strongly acid reaction than the fluid in the stomach, but has similar digestive properties. So has an aqueous extract of the gland, and a watery solution of the alcoholic precipitate. The aqueous extract also possesses a strong diastatic action on starch, and breaks up olive oil. There is no more glycogen in the "liver" than is to be found in other organs, and no constituents of true bile are to be met with. 
NOTES.

Note VIII., Chapter II., p. 81.

ANAL RESPIRATION IN CRAYFISH.

Lereboullet ("Note sur une respiration anale observée chez plusieurs Crustacés ;" Mémoires de la Société d'Histoire Naturelle de Strasbourg, IV. 1850) has drawn attention to what he terms "anal respiration" in joung crayfish, in which he observed water to be alternately taken into and expelled from the rectum fifteen to seventeen times in a minute. I have never been able to observe anything of this kind in the uninjured adult animal, but if the thoracic ganglia are destroyed, a regular rhythmical dilatation and closing of the anal end of the rectum at once sets in, and goes on as long as the hindermost ganglia of the abdomen retain their integrity. I am much disposed to imagine that the rhythmical morement is inhibited, when the uninjured crayfish is held in such a position that the rent can be examined.

\section{Note IX. Chapter II., p. 82. THE GREEN GLAND.}

The existence of guanin in the green gland rests on the authority of Will and Gorup-Besanez (Gelehrte Anzeigen, d. k. Baienzschen Akademie, No. 233, 1848), who say that in this organ and in the organ of Bojanus of the freshwater mussel, they found "a substance the reactions of which with the greatest probability indicate guanin," but that they had been unable to obtain sufficient material to give decisive results.

Leydig (Lehrbuch der Histologie, p. 467) long ago stated that the green gland consists of a much convoluted tube containing granular cells disposed around a central carity. Wassiliew ("Ueber die Niere des Flusskrebses :" Zoologischer Anzeiger, I. 1878) supports the same view, giving a full account of the minute structure of the organ, and com. paring it with its homologues in the Copepoda and Phyllopoda.

Note X., Chapter III., p. 105.

\section{THE ANATOMY OF THE NERVOUS SYSTEM OF THE CRAYFISH.}

The details respecting the origin and the distribution of the nerves are intentionally omitted. See the memoir by Lemoine of which the title is giren in the "Bibliography." 
Note XI., Chapter III., p. 110.

\section{THE FUNCTIONS OF THE NERVOUS SYSTEM OF THE CRAYFISH.}

Mr. J. Ward, in his "Observations on the Physiology of the Nervous System of the Crayfish," (Proceedings of the Royal Society, 1879) has given an account of a number of interesting and important experiments on this subject.

Note XII., Chapter III. p. 124.

\section{THE THEORY OF MOSAIC VISION.}

Oscar Schmidt ("Die Form der Krystalkegel im Arthropoden Auge :" Zeitschrift für Wissenschaftliche Zoologie, XXX. 1878) has pointed out certain difficulties in the way of the universal application of the theory of mosaic vision in its present form, which are well worthy of consideration. I do not think, however, that the substance of the theory is affected by Schmidt's objections.

Note XIII., Chapter III.: p. 135.

THE SPERMATOZOA.

Since the discovery of the spermatozoa of the crayfish in 1835-36 by Henle and von Siebold, the structure and development of these bodies have been repcatedly studied. The latest discussion of the subject is contained in a memoir of Dr. C. Grobben ("Beiträgc zur Kenntniss der männlichen Geschlechtsorgane der Dekapoden:" Wien, 1878). There is no doubt that the spermatozoon consists of a flattened or hemispherical body, produced at its circumference into a greater or less number of long tapcring curved processes (fig. $34 \mathrm{~F}$ ). In the interior of this are two structures, one of which occupies the greater part of the body, and, when the latter lies flat, looks like a double ring. This may be called, for distinctncss' sake, the annulate corpuscle. The other is a much smaller oval corpuscle, which lies on one side of the first. The annulate corpuscle is dense, and strongly refracting; the oval corpuscle is soft, and less sharply defined. Dr. Grobben describes the annulate corpuscle as "napfartig," or cup-shaped ; closed below, open above, and with the upper edgc turned inwards, and applied to the inner side of the wall of the cup. It appeared to me, on the other hand, that the annulate corpuscle is really a hollow ring, somewhat 
like one of the ring-shaped air-cushions one sees, on a very small scale. Dr. Grobben describes the spermatoblastic cells of the testis and their nuclear spindles; but his account of the development of the spermatozoa does not agree with my own observations, which, so far as they have gone, lead me to infer that the annulate corpuscle of the spermatozoon is the metamorphosed nucleus of the cell from which the spermatozoon is developed. For want of material, however, I was unable to bring my investigations to a satisfactory termination, and I speak with reserve.

\section{No'Te XIV., Chapter IY., p. 174. THE MORPHOLOGY OF THE CRAYFISH.}

The founder of the morphology of the Crustacea, M. Milne Fdwards, counts the telson as a somite, and consequently considers that twentyone somites enter into the composition of the body in the Podophthalmia. Moreover, he assigns the anterior seven somites to the head, the middle seven to the thorax, and the hinder seven to the abdomen. There is a tempting aspect of symmetry about this arrangement; but as to the limits of the head, the natural line of demarcation between it and the thorax seems to me to be so clearly indicated between the somite which bears the second maxillæ and that which carries the first maxillipedes in the Crustacea, and between the homologous somites in Insects, that I have no hesitation in retaining the grouping which I have for many years adopted. The exact nature of the telson needs to be elucidated, but I can find no ground for regarding it as the homologue of a single somite.

It will be observed that these differences of opinion turn upon questions of grouping and nomenclature. It would make no difference to the general argument if it were admitted that the whole body consists of twenty-one somites and the head of seven.

\section{Note XV., Chapter IV., p. 199. THE HISTOLOGY OF THE CRAYFISH.}

In dealing with the histology of the crayfish I have been obliged to content myself with stating the facts as they appear to me. The discussion of the interpretations put upon these facts by other observers, especially in the case of those tissues, such as muscle, on which there is as yet no complete agreement even as to matters of observation, would require a whole treatise to itself. 
Note XVI., Chapter IV., p. 221.

\section{THE DEVELOPMENT OF THE CRAYFISH.}

The remark made in the last note applies still more strongly to the history of the development of the crayfish. Notwithstanding the masterly memoir of Rathke, which constitutes the foundation of all our knowledge on this subject ; the subsequent investigations of Lereboullet; and the still more recent careful and exhaustive works of Reichenbach and Bobretsky, a great many points require further investigation. In all its most important features I have reason to believe that the account of the process of development given in the text, is correct.

\section{Note XVII., Chapter VI., p. 297.}

\section{PARASITES OF CRAYFISHES.}

In France and Germany crayfishes (apparently, however, only A. nobilis) are infested by parasites, belonging to the genus Branchiobdella. These are minute, flattened, vermiform animals, somewhat like small leeches, from one-half to one-third of an inch in length, which attach themselves to the under side of the abdomen ( $B$. parasitica), or to the gills ( $B$. astaci), and live on the blood and on the eggs of the crayfish. A full account of this parasite, with reference to the literature of the subject, is given by Dormer ("Ueber die Gattung Branchiobdella:" Zeitschrift für Wiss. Zoologie, XV. 1865). According to Gay, a similar parasite is found on the Chilian crayfish. I have never met with it on the English crayfish. The Lobster has a somewhat similar parasite, Histriobdella. Girard, in the paper cited in the Bibliography, gives a curious account of the manner in which the little lamellibranchiate mollusk, Cyclas fontinalis, shuts the ends of the ambulatory limbs of crayfishes which inhabit the same waters, between its valves, so that the crayfish resembles a cat in walnut shells, and the pinched ends of the limbs become eroded and mutilated. 


\section{BIBLIOGRAPHY.}

The subjoined list indicates the chief books and memoirs, in addition to those mentioned in the text and in the Appendix, which may be advantageously consulted by any one who wishes to study more fully the biology of the crayfishes.

\section{1.-NATURAL HISTORY.}

Roesel vor RosenHof. Der Monatlich-herausgegeben Insekten Belustigung. 1755 .

CARBonnier. L'Écrevisse, Paris, 1869.

Brandt AND RA'IZEBURG. Medizinische Zoologie. Bd. II., pp. $58-70$.

BELl. British Stalk-eyed Crustacea, 1853.

SoubEIRAx. Sur l'Histoire naturelle et l'Éducation des Écrevisses. Comptes Rendus, LX., 1865.

Chaxtrax. Observations sur l'Histoire naturelle des Écrevisses. Comptes Rendus, LXXI., 1870.

_- Sur la Fécondation des Écrevisses. Ibid., LXXIV., 1872.

- Expériences sur la Régénération des Yeux chez les Écrevisses. Ibid., LXXVII., 1873.

- Observations sur la Formation des Pierres chez les Ecrevisses. Ibid., LXXVIII., 1874.

- Sur le Mécanisme de la Dissolution intrastomacale des Concrétions gastriques des Écrevisses. Ibid., LXXVIII., 1874.

STEFFENBERG. Bijdrag til kanne domen om flodkraftens natural historia, 1872. Abstract in Zoological Record, IX.

VALLOT. Sur l'Écrevisse fluviatile et sur son parasite l'Astacobdelle branchiale. Comptes Rendus Acad. Sciences, Dijon. Mémoires, 1843-44. Dijon, 1845.

Putray. On some of the Eabits of the Blind Crayfish. Proceedings

Boston Society of Nat. History, XVIII. 
Heller. Ueber einen Flusskrebs-albino. Verhand d. Z. Bot. Gesellschaft, Wien. Bd. 7, 1857, and Bd. 8, 1858.

Lereboullet. Sur les variétés Rouge et Bleue de l'Écrevisse fluviatile. Comptes Rendus, XXXIII., 1857.

GIRARd. Quelques Remarques sur l'Astacus fluriatilis. Ann. Soc. Entom. France, T. VII. 1859.

\section{[I.-ANATOMY AND PHYSIOLOGY.}

BraNdT aNd RATZEBURG. Op. cit.

Milne EdwaRds. Histoire naturelle des Crustacés. 1834.

Rolleston. Forms of Animal Life. 1870.

HUXLEY. Manual of the Anatomy of Vertebrated Animals. 1877. Huxley and Marisin. Elementary Biology. 1875.

Srckow. Anatomisch-Physiologische Untersuchungen. 1818.

KroHr. Verdauungsorgane des Krebses. Gefässsystem des Flusskrebses. Isis, 1834.

For BaER. Ueber die sogenannte Erneuerung des Magens der Krebse und die Bedeutung der Krebssteine. Müller's Archiv, 1835.

Oesterler. Ueber den Magen des Flusskrebses. Müller's Archiv, 1840.

T. J. PARKer. On the Stomach of the Freshwater Crayfish. Journal of Anatomy and Physiology, 1876.

BARTSCH. Die Ernährungs- und Verdauungsorgane des Astacus leptodactylus. Budapester Naturhistor. Hefte II. 1878.

Deszŏ. Ueber das Herz des Flusskrebses und des Hummers. Zoologischer Anzeiger, I. 1878.

LEREBOUlLET. Note sur une Respiration anale observée chez plusieurs Crustacées. Mém. de la Société d'Histoire Naturelle de Strasbourg, IV., 1850.

WAssiliew. Ueber dis Niere des Flusskrebses. Zoologischer $A \mathrm{n}$ zeiger, I. 1878.

LEMOINE. Recherches pour servir à l'histoire des systèmes nerveux, musculaire et glandulaire de l'Écrevisse. Annales des Sciences Naturelles, Sé. IV. T. 15, 1861.

DIETL. Die Organization des Arthropoden Gehirns. Zeitschrift für Wiss. Zoologie, XXVII., 1876.

ERIEGER. Ueber das centrale Nervensystem des Flusskrebses. Zoologischer Anzeiger, I., 1878.

LEYDIG. Das Auge der Gliederthiere. 1864. 
Max Schulze. Die Zusammengesetzten Augen der Krebse und Insekten, 1868.

BERGER. Untersuchungen über den Bau des Gehirns und der Retina der Arthropoden. 1878.

GRENACHER. Untersuchungen über das Sehorgan der Árthropoden. 1879.

O. Schмтdт. Die Form der Krystalkegel im Arthropoden Auge. Zeitschrift für Wiss. Zoologie, XXX., 1878.

FARRE. On the organ of hearing in the Crustacea. Phil. Trans. 1843.

LEYDIG. Ueber Geruchs- und Gehörorgane der Krebse und Insekten. Müller's Archiv, 1860.

Hensen. Studien über das Gehörorgan der Decapoden. Zeitschrift für Wissenschaftliche Zoologie, XIII. 1863.

GrobBex. Beiträge zur Kenntniss der männlichen Geschlechtsorgane der Dekapoden. 1878.

BRoccHI. Recherches sur les Organes génitaux mâles des Crustacés décapodes. Annales des Sciences Naturelles, Sé. VI. ii.

LExDIG. Zur feineren Bau der Arthropoden. Muiller's Archiv, 1855.

- Handbuch der Histologie. 1857.

HAECKEL. Ueber die Gewebe des Flusskrebses. Müller's Archiv, 1857.

BRAUN. Ueber die histologischen Vorgänge bei der Häutung von Astacus fluviatilis. Würzburg Arbeiten, II.

BAUR. Ueber den Bau der Chitinsehne am Kiefer des Flusskrebses und ihr Verhalten beim Schalenwechsel. Reichert $u_{\text {. }} \mathrm{Du}$ Bois Archiv, 1860.

COSTE. Faits pour servir à l'Histoire de la Fécondation chez les Crustacés. Comptes Rendus, XLVI. 1858.

LEREBo Ullet. Recherches sur la mode de Fixation des Gufs aux fausses pattes abdominales dans les Écrevisses. Annales des Sciences Naturelles, Sé. IV. T. 14, 1860.

\section{III.-DEVELOPMENT.}

RАтнKE. Ueber die Bildung und Entwickelung des Flusskrebses 1829.

Lereboullet. Recherches d'Embryologie comparée sur le développement du Brochet, de la Perche et de l'Écrevisse. 1862. 
BoBRetsky. (A Memoir in Russian, of which an abstract is giren in Hofmann and Schwalbe, Jahresbericht für 1873 (1875)).

REICHENBACH. Die Embryonanlage und erste Entwickelung des Flusskrebses. Zeitschrift für Wiss. Zoologie. 1877.

\section{T.-TAXONOMY AND DISTRIBUTION OF CRAYFISHES.}

A. General.

MILLE EDTARDs. Op. cit.

ERICHSON. Uebersicht der Arten der Gattung Astacus. Wiegmann's Archiv für Naturgeschichte, XII. 1846.

DANA. Crustacea of the United States Exploring Expedition. 1852.

De SAussure. Note carcinologique sur la Famille des Thalassinides et sur celle des Astacides. Rev. et Magazin de Zoologie, IX.

Huxlex. On the Classification and the Distribution of the Crayfishes. Proceedings of the Zoological Society. 1878.

B. European and Asiatic.

RATHKE. Zur Fauna der KrJm. 1836.

Gerstfeld and Kessler. Cited in the text.

DE HaAx. Fauna Japonica. 1850.

LEReboullet. Description de deux nouvelles Espèces d'Écrevisses (A. longicornis, A.pallipes). Ném. Soc. Science Nat. Strasbourg. V. 1858.

Heller. Crustaceen des siidlichen Europa. 1863.

KESsLer. Ein neuer russischer Flusskrebs, Astacus colchicus. Bulletin de la Soc. Imp. des Naturalistes de Moscou, L. 1876.

\section{American.}

Strmpson. Crustacea and Echinodermata of the Pacific shores of North America. Journal of Boston Society of Natural History VI. ; 1857-8.

De Sausstre. Mémoire sur divers Crustacées nouveaux des Antilles et du Méxique. Mém. de la Société de Physique de Genère T. XIV., 1857.

VoN MARTENS. Südbrasilische Sïss- und Brackwasser Crustaceen (A.pilimanus, A. brasiliensis), Wiegmann's Archiv, XXXV., 1869. - Ueber Cubansche Crustaceen. 1bid. XXXVIII.

HAGEN. Monograph of the North American Astacida. 1870. 
D. Madagascar.

AUDOUIN and MILNE EDWARDS. Sur une Espèce nouvelle du genre Écrevisse (Astacus). Écrevisse de Madagascar (A. Madagascariensis). Mém. du Muséum d'Hist. naturelle, T. II. 1841.

E. Austraiia.

Von Martess. On a new Species of Astacus. Annals \& Mag. of Natural History, 1866.

Heller. Reise der "Novara." Zool. Theil. Bd. II. 1865.

F. New Zealand.

Mrens. Notes on the Genera Astacoides and Paranephrops. Transactions of the New Zealand Institute, IX., 1876.

Paranephrops. Zoology of "Erebus" and "Terror," 1874. Catalogue of New Zealand Crustacea, 1876.

Annals of Natural History, 1876.

Wood-Mason. On the mode in which the Young of the New Zealand Astacida attach themselves to the Mother. Ann. \& Mag. Natural History, 1876.

G. Fossil Astacomorpha.

OPPEL. Palæontologische Mittheilungen, 1862.

BeLl. British Fossil Crustacea. Palæontographical Society.

P. VAN BeNEDEN. Sur la Découverte d'un Homard fossile dans l'Argile de Rupelmonde. Bulletin de l'Acad. Royale de Belgique. XXXIIII., 1872.

Vox DER MARCK und Schlüter. Neue Fische und Krebse von der Kreide von Westphalen. Palæontologica, XV. 1865.

COPE. On three extinct Astaci from the freshwater tertiary of Idaho. Proceedings of the American Philosophical Society, XI., 1869-70. 



\section{IN D E X.}

A.

Abdomen, 19, 141 development of, 213

Abdominal appendages, 143 derelopment of, 217

Abdominal somite, characters of, 142 Etiology, 47

AGASSIZ, 308

Alimentary canal, 51 development of, 213, 222

Ambulatory legs, 168

American Crayfishes, 243, 247

Amceba, 285

Amurland Crayfishes, 304

Antenna, 23, 172

development of, 214, 218

Antennule, 23, 173

development of, 214, 218

Anthrapalcemon, 341

Anus, 29

Apodeme, 99, 158, 175

Appendage, 24, 143, 161, 173

abdominal, 143

cephalic, 170

thoracic, 164

Archenteron, 211

Arctogæal province, 314

Areola, 235

ARISTOTLE, referred to, 4

Arteries, 71
Arteries, development of, 224

Arthrobranchia, 75

Arthrophragm, $15 \mathrm{~s}$

Arthropoda, 279, 284

Articulations, 95

Asiatic Crayfishes, $30 t$

Astacina, 254

Astacoides, 250, 313

Astacomorpha, 338

Astacopsis, 250, 264

Astacus, division into sub-genera, 290

Astacus angulosus, 302, 310

colchicus, 302,310

dauricus, 304, 310

fluviatilis,

anatomy, general account of, 17-31

attachment of young to mother, 40,351

branchial formula, 266

development, 205-226

distribution, geographical $44,288,298$

distribution, chronological, 44

ecdysis, 32,350

general characters, 6

growth, 31, 349

habits, 8 
Astacus fluviatilis-continued histology, 174

mortality, 127

muscular system, 90 myths concerning, 44

name, origin of, 13

nervous system, 101

newly hatched young, cha-

racters of, 219

nutrition, 48

occurrence, 5,8

organs of alimentation, 51

circulation, 68

excretion, 82,353

hearing, 116

reproduction, 128

respiration, 75,353

sight, 118

smell, 114

taste, 115

touch, 113

prehension of food, 49

putrid, effect of smell of,

45

reproduction of lost limbs, 38

reproduction, sexual, 39 , $128,135,350$

sexual characters, 7,20 ,

$32,145,241$

somites and appendages,

143

systematic description,

230

use as food, 10, 289

varieties, 289

fontinalis, 290

japonicus, 304

klamathensis, 305

leniusculus, 305
Astacus leptodactylus, 299, 302 $303,310,320$

nigrescens, 244

nobilis, 290, 295, 296, 299, 310

oreganus, 305

pachypus, 302, 310

pallipes, 290

politus, 344

saxatilis, 290

Schrenckii, 304, 310

torrentium, 290, 294, 298, 310, 311

tristis, 290

Tronbridgii, 305

Atya, Atyida, 331, 336

Auditory organ, 116

setæ, 116

Australian Crayfishes, 306

province, 314

Austrocolumbian province, 314

Axius, 271

B.

BALL, R., quoted, 36

Basipodite, 143

BELL, T., quoted, 37, 42

Bile-duct, 61,66

Biological sciences, scope of, 4

Blastoderm, 207

Blastomere, 205

Blastopore, 209

Blood, 31, 68, 176 corpuscles, 69,176

development of, 224

sinuses, 50, 69

BoBRETSKx, referred to, 356

Bolivar, Dr., 298

Branchiæ, Astacoides, 266

Astacopsis, 264 
Branchiæ-continued

Astacus, 25, 75, 265

development of, 224

Cancer, 276

Homarus, 257

Palamon, 270

Palinurus, 264

Penceus, 267

Branchial chamber, 25

formula,

Astacoides, 266

Astacopsis, 264

Astacus, 266

Cancer, 277

hypothetically complete, 268

Palamon, 270

Palinurus, 265

Penceus, 267

Branchiobdella, 356

Branchiostegite, 25

development of, 217

BRAUN, quoted, 352

Brazilian Crayfishes, 306

\section{C.}

Cæcum, 61

Calcification of exoskeleton, 197

Californian Crayfisines, 243

Cambarus, 44, 247, 310, 312

Cancer, 272, 283

Carapace, 19

development of, 214

CARbonnier, M., quoted,-297, 349, 350

Cardia, 52

Caridina, 330

Carpopodite, 165

Cell, 66, 199

Cell-aggregate, 190, 199

division, 200

theory, 202, 204
Cephalic appendages, 170 development of, 217

flexure, 163

somites, 154

Cephalon, 19, 141

Cephalothorax, 19

Cervical groove, 19

spines, 234

Chantran, M., quoted, 348, 350. 351

Chelæ, 22

Chilian Crayfishes, 308

Chitin, 50 composition of, 347

Charaps, 250

Chorology, 46

Circulation, 73 organs of, 68

Common knowledge and science, 3

Connective tissue, 178 development of, 224

Cope, Prof., quoted, 316

Cornea, 118

Coxopodite, 143

Coxopoditic setæ, 78

Crab, see Cancer

Crab's-eye, see Gastrolith

Crangon, 272

Crayfish, origin of name, 12

common, see Astacus fluviatilis

Crayfishes, Amurland, 304

Asiatic, 304

Australian, 306

Brazilian, 306

Californian, 243

Chilian, 308

definition of, 254

Eastern North American, 247, 305

European, 288, 297

evolution of, 331 . 
Craæfishes, Figian, 306, 313

Japanese, 304, 313

Mascarene, 308, 313

northern and southern, com. pared, 252

Novozelanian, 306, 313

southern, 249

Tasmanian, 306

Western North American, 305, 313

Crustacea, 271, 278

Crystalline cones, 121

Cuticle, 33, 50, 175, 192

Cyclas, 356

$D$.

Dactylopodite, 165

Daphnia, asexual reproduction of 128

DARWIs, C., referred to, 4

DE HAAx, quoted, 313

Development, 205

abdomen, 213

abdominal appendages, 217

alimentary canal, 213, 222

antennæ, 214, 218

antennules, 214,218

blood and blood ressels, 224

branchiostegite, 217

carapace, 214

cephalic appendages, 217, 219

connective tissue, 224

ear, 225

eye, 225

eyestalk, 214, 218

gills, 224

heart, 224

kidney, 224

labrum, 218

mandibles, 214
Derelopment of muscles, 224 nervous system, 213, 224 reproductire organs, 225 rostrum, 217

thoracic appendages, 217,219

Digestion, 63

Distribution, 46

chronological, of crayfishes, 44 , 316,339

table of, 345

geographical, of crayfishes, 44 , 288

causes of, 335

resuits of study of, 308,314

DORJIER, quoted, 3506

DuLK, quoted, 349

E.

Ear, 116

derelopment of, 225

Ecdysis, 32, 350

Écrevisse à pieds blancs, 289, 297

à pieds rouges, 289,297

Ectoderm, 141

Ectostracum, 194

Edelkrebs, 290

Endoderm, 141

Endophragmal system, 157

Endopleurite, 158

Endopodite, 145

Endoskeleton, 17

Endosternite, 158

Endostracum, 194

Engreus, 250, 306

Enoplocytia, 342

Epiblast, 211

Epidermis, 140

Epimeron, 143

Epiostracum, 192

Epipodite, 167 
Epistorna, 155

Epithelium, 140, 177

Equus excelsus, occurring with fossil crayfishes, 316

Eryma, 341

Evolution of crayfishes, 331

Excretion, organs of, 82

Exopodite, 145

Exoskeleton, 17 chemical composition, 347

Eye, 118

compound, 122

development of, 225

Eye-stalk, 24, 173

development of, 214

F.

Family, 252

Fat-cells, 180

Fibre, muscular, 185

Fibril, muscular, 185

Figian Crayfishes, 306

Filament, muscular, 185

Filter of stomach, 58

Flagellum, 167

Food-yelk, 206

Foot-jaws, see maxillipedes

Forceps, 22

Foregut, 61

development of, 213, 222

Fossil crayfishes, 316

Foster, Dr. M., referred to, 110

France, consumption of crayfish in, 10

Function, 22

Galaxida, 315

Gammarus, 323

Ganglion, 103, 105

Ganglionic corpuscle, 87, 103
Gastric mill, 53

Gastrolith, 29, 347

chemical composition, 349

Gastrula, 211

GAY, quoted, 356

Genus, 249

Geographical distribution, see Distribution

GERBE, M., quoted, 350

Germinal disc, 209

layer, 206

spot, 133

vesicle, 133

GERSTFELDT, Dr., quoted, 290

Gills, see Branchiæ

GIRARD, quoted, 356

GoRUP-BESANEZ, quoted, 353

Green-gland, 83, 353

development of, 224

GrobBen, Dr., quoted, 354

Growth of crayfish, 31, 349

Guanin, 82, 353

Gullet, see Esophagus

GüNTHER, Dr., quoted, 315

$\mathrm{H}$.

HAGEN, Dr., quoted, 305, 312

Haplochitonida, 315

HARVEx, quoted, 5

Head, see Cephalon

Hearing, organ of, 116

Heart, 27, 71

development of, 224

HeLLER, Dr., quoted, 298, 330

Hepatic duct, see Bile duct

Hind gut, 61

development of, 214, 223

Histology, 175

Histriohdella, 356

Homaridoe, 263 
Homarina, 261

Homarus, 13, 42, 257, 332

Homology, homologous, homolo. gue, 148

Hoploparia, 342

Hypoblast, 211

I.

Idothea. 323, 334

Impregnation, 135, 350

Integument, 50

Interseptal zone, 183

Intestine, 29, 61

Ischiopodite, 165

J.

Japanese Crayfishes, 213, 314

Jaws, 23

JoHxミTON, J., quoted, 42

K.

KESSLER, quoted, 298, 301

Kidnes: see Green gland

KLUNZINGER, referred to, 330

I.

Labrum, 51

development of, 218

LAMARCK, referred to, 4

LEREBO CLLET, quoted, 353

Legs, ambulatory, 168

LEMOIYE, referred to, 353

LEYDIG, referred to, 115,353

Liver, 30, 64

development of, 223

nature of secretion, 352

Lobster, common, see Homarus

Norway, see Nephrops
Lobster, Rock, see Palinurus

Lovis, referred to, 327

M.

Machine, living, 128

M'Lstosh, Dr. W. C., quoted, 288

Mandible, 23, 51, 170 development of, 214

Martens, Vox, 306

Mastodon mirificus, occurring with fossil crayfishes, 316

MIaxillæ, 23, 170

Maxillipedes, 23, 164

Medullary groove, 213

Megalopa stage of development, 283

Meropodite, 165

Mesoblast, 212

Mesoderm, 141

Mesophragm, 158

Metamere, 143

Metastoma, 51

Metope, 278

Midgut, 61

derelopment of, 211, 214, 223

Milde-EdWARDs, quoted, 13, 289

Mollusca, 284

Morphology: 46, 138

comparative, 230

Mortality of crayfishes, 123

Morula, 206

Mosaic rision, 122, 354

Motor plates, 189

Mouth, 51

Müller, JohanNes, referred to, 122

Miuscle, 57, 90, 175, 181

development of, 224

histology of, 90, 181

IIuscles of abdomen, 99 
INDEX.

Muscles of chela, 93 of stomach, 57

Myosin, 186

Myotome, 174

Mysis, 281, 323

relicta, origin of, from $M I$. oculata, 327

Mysis stage of derclopment, 280

\section{N.}

Natural History, 3

Philosophy, 3

Nauplius stage of development, 215,280

Nearctic province, 314

Nephrops, 259, 332

Nerve, 101

auditory, 117

optic, 118

Nerve-cells, 103, 187

fibres, 101, 188

Nervous system, 105

development of, 213,224

functions of, 354

Noble crayfish, see Astacus nobitis

Nomenclature, binomiał, 13, 15

Norway lobster, see Nephrops

Novozelanian province, 814

Nucleated cell, 199

Nucleolus, 187

Nucleus, 177, 200 changes of, in cell-division, 200

\section{O.}

Esophagus, 51

Olfactory organ, 114

Organ, 22

Origin of crayfish, evidence as to, 320,331
Ovary, 31,129

structure of, 131

Oviduct, 129

Oviposition, 351

Ovisac, 132

Orum, 129

structure of, 133

P.

Pal:arctic province, 314

Palamon, 268, 328

Palinuridce, 263

Palinu'

Palp, 171

Paranephrops, 250, 306, 313

Paraphragm, 158

Parasites of cragfish, $3 \tilde{5} 6$

Parastacida, 252, 256, 300, 313

Parastacus, 250, 306

Pempliix, 341

Penceus, 267, 280

Pericardium, 69

Perivisceral cavity, 50

Phyllobranchia, 271

Physiology, 46

Pleurobranchia, 79

Pleuron, 96, 143

Podobranchia, 75, 165

Podophthalmia, 279

Pore-canals, 195

Post-orbital ridge, 233

spinc, 232

Potamobiida, 252, 256

Prawn, see Palamon

Prehension of food, 49

Procephalic lobes, 160

development of, 213

Propodite, 165

Protopodite, 143

Prototroctes, 315 
Protozoa, 285

Psentastacus, 343

Pylorus, 52

\section{R.}

Race, 292

PATHKE, quoted, 356

RÉAUMUR, quoted, 33

Reflex action, 108

ReICHENBACH, quoted, 350

Renal organ, see Green-gland

Reproduction of lost limbs, 38

sexual, 39, 128, 135, 350

Reproductive organs, 128

development of, 225

Respiration, anal, 353

Respiratory organs, see Branchiæ

Retropinna, 315

RoBIs, quoted, 352

Rock lobster, see Palinurus

ROESEL vON ROSENHOF, quoted, 41,43

RONDOLETIUS, referreả to, 4

Rostrum, 157

development of, 217

\section{S.}

Salivary glands, 352

Salmonidce, parallel between their distribution, and that of Astacide, 315

Sarcolemma, 90, 182

SAPS, G. O.., referied to, 327

SARTORIUS VON WALTERHAUSEN, quoted, 322

Scaphognathite, 80,170

Schizopod stage of derelopment, 280

SCHLÜTER, 317
SCHMIDT, O., quoted, 35 s

SCHRANK, 290

Science, physical, 3

Science and common sensc, 1

Segmentation, 174

Self-causation, 112

Sensory organs, 113

Septal line, 183 zone, 183

Setæ, 197

Shrimp, see Crangon

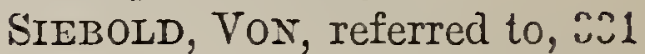

Sight, organ of, 118

Sinus, sternal, 69

Smell, organ of, 114

Somite, 143, 161, 355

abdominal, 142

cephalic, 154

thoracic, 150

SodbeIRar, MI., quoted, 349

Southern Crayfishes, $2 \frac{11}{x} 9$

Species, 243, 290

morphological, 291

physiological, 296

Spermatozoa, 129, 135, 35:

Spontaneous action, 112

Squame of antenna, 172

Steinkrebs, see Astacus torrentium

Sternum, 96, 143

Stomach, 29, 51

Stone-crayfish, see Astacus torrentium

Striated spindle, 121

Swimmeret, 20

$\mathrm{T}$.

Taste, organ of, 115

Teleology, 47, 137

Tendon, 92, 175 
Tergum, 96, 143

Terminal plates, 189

Terminology, scientific, 14

Testis, 129 structure of, 133

Thoracic appendages, 164 development of, 217 somites, 150

Thorax, 19, 141

Tissue, 175

Touch, organ of, 113

Transformism, 318

Treviranus, referred to, 4

Tribe, 252

Trichobranchiæ, 263

Troglocaris, 337

V.

Valves of heart, 73 of stomach, 59

VAN HELMONT, quoted, 45

Variety, 290, 292

Vas deferens, 130

Vent, see Anus

Vertebrata, 284
Vertebrata, eye of, 122, 125

Visual pyramid, 121 rod, 121

Vitelline membrane, 133

Vitellus, 133

Voluntary action, 112

VON DER MARCK, 317

W.

WARD, J., referred to, 354

WASSILIEW, quoted, 353

Whirlpool of life, 84

WrLl, quoted, 353

WoOD-MASON, quoted, 44

Y.

Yelk, 133

Yelk-division, 205

Young of Astacus, newly hatched, characters of, 219

$\mathrm{Z}$.

Zoæa stage of development, 280

TIIE END. 

A LIST OF

KEGAN PAUL, TRENCH \& CO.'S PUBLICATIONS. 


\title{
A LIST OF
}

\section{IXEGAN PAUL, TRENCH \& CO.'S PUBLICATIONS.}

\begin{abstract}
CON T ENTS.
GeNeral Literature page

Pulpit Commentary • . 23 Woriks of Fiction • 42

International Scientific Books for the Young • 43

SERIES . . . 30
\end{abstract}

\section{GENERAL LITERATURE.}

A. K. H. B. - From a Quiet Place. A Volume of Sermons. Crown 8vo, 5 s.

ALLEN, Rev. R., M.A.-Abraham: his Life, Times, and Travels $_{y} 3800$ years ago. With Map. Second Edition. Post 8vo, 6s.

ALLIES, T.W., MI.A.-Per Crucem ad Lucem. The Result of a Life. 2 vols. Demy 8vo, 25 s.

A Lifess Decision. Crown 8vo, 7s. $6 d$.

ALLNATT, F.J.B., B.D.-The Witness of St. Matthew. An Inquiry into the Sequence of Inspired Thought pervading the First Gospel, and into its Result of Unity, Symmetry, and Com. pleteness, as a Perfect Portrait of the Perfect Man. Crown 8ro, 5 s.

$A M O S$, Frofessor Sheldon. - The History and Principles of the Civil Law of Rome. An aid to the Study of Scientific and Comparative Jurisprudence. Demy 8vo. 16s.

Ancient and Modern Britons. A Retrospect. 2 vols. Demy 8 vo, $24 s$. 
ANDERDON, Rev. W. H.-Fasti A postolici ; a Chronology of the Years between the Ascension of our Lord and the Martyrdom of SS. Peter and Paul. Second Edition. Enlarged. Square 8 vo, 5 s.

Evenings with the Saints. Crown 8vo, 5s. ANDERSON, David.- "Scenes" in the Commons. Crown 8vo, 5 s. ARMSTRONG, Richard A., B.A.-Latter-Day Teachers. Six Lectures. Small crown $8 \mathrm{vo}, 2 s .6 d$.

AUBERTIN, F. F-A Flight to Mexico. With Seven full-page Illustrations and a Railway Map of Mexico. Crown 8vo, $7 s .6 d$.

BADGER, George Percy, D.C.L.-An English-Arabic Lexicon. In which the equivalent for English Words and Idiomatic Sentences are rendered into literary and colloquial Arabic. Royal 4to, 8os.

BAGEHOT, Walter. - The English Constitution. New and Revised Edition. Crown 8vo, 7s. 6d.

Iombard Street. A Description of the Money Market. Eighth Edition. Crown 8vo, $7 s .6 d$.

Essays on Parliamentary Reform. Cirown 8vo, 5 s.

Some Articles on the Depreciation of Silver ${ }_{y}$ and Topics connected wyith it. Demy 8vo, 5 s.

BAGENAL, Philip H.-The American-Irish and their Influence on Irish Politics. Crown 8vo, $5 s$.

BAGOT, Alan, C.E.-Accidents in Mines: their Causes and Prevention. Crown 8vo, 6s.

The Principles of Colliery Ventilation. Second Edition, greatly enlarged. Crown 8vo, 5 s.

The Principles of Civil Engineering in Estate Management. Crown 8vo, 7s. 6d.

$B A K E R$, Sir Sherston, Bart. - The Laws relating to Quarantine Crown 8vo, r2s. 6d.

BALDWIN, Capt. F. H.-The Large and Small Game of Bengal and the INorth- IN estern Provinces of India. With 20 Illustrations. New and Cheaper Edition. Small 4to, IOS. 6 .

$B A L L I N, A d d$ S. and F. L.-A Hebrew Grammar. With Exercises selected from the Bible. Crown 8vo, $7 s .6 d$.

BARCLAY, Edgar.-Mountain Life in Algeria. With numerous Illustrations by Photogravure. Crown 4 to, 16.

BARLOW, fames H.-The Ultimatum of Pessimism. An Ethical Study. Demy 8vo, 6 .

BARNES, William.-Outlines of Redecraft (Logic). With English Wording. Crown 8vo, 3 s. 
BAUR, Ferdinand, Dr. Ph.-A Philological Introduction to Greelk and Latin for Students. Translated and adapted from the German, by C. KEgan Paul, M.A., and E. D. Stone, M.A. Third Edition. Crown 8vo, $6 s$.

BELLARS, Rev. W.-The Testimony of Conscience to the Truth and Divine Origin of the Christian Revelation. Burney Prize Essay. Simall crown 8vo, $3 s .6 \%$.

BELLASIS, Edward.-The Money Jar of Plautus at the Oratory School. An Account of the Recent Representation. With Appendix and 16 Illustrations. Small 4to, sewed, $2 s$.

BELLINGHAM, Henry, M.P.-Social Aspects of Catholicism and Protestantism in their Civil Bearing upon Nations. Translated and adapted from the French of M. le BARON DE HAUllevilide. With a Preface by His Eminence Cardinal Manning. Second and Cheaper Edition. Crown 8vo, 3s. 6d.

BELLINGHAM, H. Belsches Graham.-Ups and Downs of Spanish Travel. Second Edition. Crown 8vo, 5 s.

$B E N N$, Alfred $W$.-The Greek Philosophers. 2 vols. Demy
8vo, $28 s$.

$B E N T$, F. Theodore-Genoa: How the Republic Rose and Fell. With 18 Illustrations. Demy 8vo, I 8 s.

Bible Folk-Lore. A Study in Comparative Mythology. Crown 8vo, IOs. $6 d$.

BIRD, Charles, F.G.S.-Higher Education in Germany and England. Being a brief Practical Account of the Organization and Curriculum of the German Higher Schools. With critical Remarks and Suggestions with reference to those of England. Small crown 8vo, 2s, $6 d$.

BLACKLEY, Rev. W. S.-Essays on Pauperism. I6mo. Cloth, Is. $6 d$. ; sewed, Is.

BLECKLY, Henry.-Socrates and the Athenians: An Apology. Crown 8vo, 2s. $6 d$.

BLOOMFIELD, The Lady.-Reminiscences of Court and Diplomatic Life. New and Cheaper Edition. With Frontispiece. Crown 8vo, 6s.

BLUNT, The Ven. Archdeacon. - The Divine Patriot, and other Sermons. Preached in Scarborough and in Cannes. New and Cheaper Edition. Crown 8vo, 4s. $6 d$.

BLUNT, Wilfred S.-The Future of Islam. Crown 8vo, 6s.

$B O D D Y$, Alexander $A_{0}$-To Kairwân the Holy. Scenes in Muhammedan Africa. With Route Map, and eight Illustrations by A. F. Jacassey. Crown 8 vo, $6 s$.

BOOLE, Mary.-Symbolical Methods of Study. Crown 8vo, 5 s. 
BOUVERIE-PUSEY, S. E. B.-Permanence and Evolution. An Inquiry into the Supposed Mutability of Animal Types. Crown 8 vo, 5 s.

BOWEN, H. C., M.A.- -Studies in English. For the use of Modern Schools. Seventh Thousand. Small crown 8vo, Is. 6d.

Engiish Grammar for Beginners. Fcap. 8vo, $1 s$.

Simple English Poems. English Literature for Junior Classes.

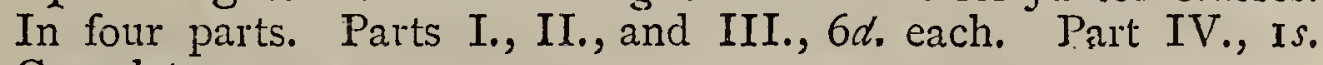
Complete, $3 s$.

BRADLEY, F. H. - The Principies of Logic. Demy 8vo, I6s. BRIDGETT, Rev. T. E.-History of the Holy Eucharist in Great Britain. 2 vols. Demy 8vo, $18 s$.

BRODRICK, the Hon. G. C.-Political Studies. Demy 8vo, I4s.

BROOKE, Rev. S. A.-Life and Letters of the Late Rev. F. WW. Robertson, M.A. Edited by.

I. Uniform with Robertson's Sermons. 2 vols. With Steel Portrait. 7 s. 6 .

II. Library Edition. With Portrait. 8vo, $12 s$.

III. A Popular Edition. In I vol., 8vo, $6 s$.

The Fight of Faith. Sermons preached on various occasions. Fifth Edition. Crown 8vo, $7 s .6 d$.

The Spirit of the Christian Life. Third Edition. Crown $8 \mathrm{vo}, 5$ s.

Theology in the English Poets.-Cowper, Coleridge, Wordsworth, and Burns. Fifth Edition. Post 8vo, $5 s$.

Christ in Modern Life. Sixteenth Edition. Crown 8vo, 5 s.

Sermons. First Series. Thirteenth Edition. Crown 8vo, 5 s.

Sermons. Second Series. Sixth Edition. Crown 8vo, $5 s$.

BROWN, Rev. F. Baldwin, B.A. - The Higher Life. Its Reality, Experience, and Destiny. Sixth Edition. Crown 8vo, 5 s.

Doctrine of Annihilation in the Light of the Gospel of Love. Five Discourses. Fourth Edition. Crown 8vo, 2s. 6d.

The Christian Policy of Life. A Book for Young Men of Business. Third Edition. Crown 8vo, $3 s .6 d$.

BROWN, S. Borton, B.A.-The Fire Baptism of all Flesh; or, The Coming Spiritual Crisis of the Dispensation. Crown $8 \mathrm{vo}, 6 s$.

BROWN, Horatio F. - Life on the Lagoons. With two Illustrations and Map. Crown 8vo, $6 s$.

BROWNBILL, Foln.-Principles of English Cancn LaW. Part I. General Introduction. Crown 8vo, $6 s$.

BROWNE, W. R.-The Inspiration of the Nex Testament. With a Preface by the Rev. J. P. Norris, D.D. Fcap. 8vo, 2s. $6 d$. 
BURDETT, Hcnry C.-Flelp in Sickness-Where to Go and What to Do. Crown 8ro, Is. 6 .

Helps to Health. The Habitation-The Nursery-The Schoolroom and-The Person. With a Chapter on Pleasure and Health Resorts. Crown 8ro, is. 6 .

BURTON, Mrs. Richard.-The Inner Life of Syria, Palestine, and the Holy Land. Post 8vo, 6s.

BUSBECQ, Ogier Griselin de.-His Life and Letters. By CHARLES Thorntor Forster, M.A., and F. H. Blacisbur.ie DaNiell, M.A. 2 rols. With Frontispieces. Demy 8ro, 24s.

CARPENTER, W. B., LL.D., M.D., F.R.S., etc.-The Principles of Mental Physiology. With their Applications to the Training and Discipline of the Mind, and the Study of its Morbid Conditions. Illustrated. Sixth Edition. 8ro, I2s.

Catholic Dictionary: Containing some Account of the Doctrine, Discipline, Rites, Ceremonies, Councils, and Religious Orders of the Catholic Church. By Willian E. Addis and THOMAs ARnold, M.A. Second Edition. Demy 8io, 2 Is.

CERVANTES.-Iourney to Parnassus: Spanish Text, with'Translation into English Tercets, Preface, and Illustrative Notes, by JAires Y. Gibsox. Crown 8ro, i2s.

CHEYNE, Rev. T. K.-The Prophecies of Isaiah. Translated with Critical Notes and Dissertations. 2 vols. Third Edition. Demy 8vo, 25 s.

CHICHELE, MIary.-Doing and Undoing. A Story. I vol. Crown 8vo.

CLAIRAUT. - Elements of Geometry. Translated by Dr. KaINES. With I45 Figures. Crown 8ro, 4s. $6 d$.

CLARKE, Rev. Henry Janes, A.K.C.-The Fuadamental Science. Demy 8ro, IOs. 6d.

CLAYDEN, P.W.-Samuel Sharpe. Egyptologist and Translator of the Bible. Crown 8vo, 6 s.

CLIFFORD, Samiel.-What Think Ye of the Christ? Crown 8 vo, 6s.

CLODD, Edivard, F.R.A.S. - The Childhood of the IXorld: a Simple Account of Man in Early Times. Serenth Edition. Crown 8vo, 35.

A Special Edition for Schools. Is.

The Childhood of Religions. Including a Simple Account of the Birth and Growth of Myths and Legends. Eighth Thousand. Crown 8ro, 5 s.

A Special Edition for Schools. Is. 6d.

Jesus of Nazareth. With a brief sketch of Jewish History to the Time of His Birth. Small crown 8vo, 6s 
COGHLAN, F. Cole, D.D.-The Modern Pharisee and other Sermons. Edited by the Very Rev. H. H. Dickinson, D.D., Dean of Chapel Royal, Dublin. New and Cheaper Edition. Crown 8vo, $7 s .6 \vec{a}$.

COLE, George R. Fitz-Roy.-The Peruvians at Home. Crown 8vo, $6 s$.

COLERIDGE, Sara.-Memoir and Letters of Sara Coleridge. Edited by her Daughter. With Index. Cheap Edition. With Portrait. $7 s .6 d$.

Collects Exemplified. Being Illustrations from the Old and New Testaments of the Collects for the Sundays after Trinity. By the Author of "A Commentary on the Epistles and Gospels." Edited by the Rev. JOSEPH TACKSON. Crown 8vo, 5 s.

CONNELL, A. K.-Discontent and Danger in India. Small crown 8vo, 3s. 6 .

The Economic Revolution of India. Crown 8vo, 4s. 6 d.

CORY, Willian.-A Guide to Modern English History. Part I. -MDCCCXV.-MDCCCXXX. Demy 8vo, 9s. Part II.MDCCCXXX.-MDCCCXXXV., I 5 s.

COTTERILL, H. B.-An Introduction to the Siudy of Poetry. Crown 8vo, 7s. 6d.

COUTTS, Francis Burdett Money. - The Training of the Instinct of Love. With a Preface by the Rev, Edward Thring, M.A. Small crown 8vo, 2s. $6 d$.

COX, Rev. Sir George W., M.A., Bart.-The Mythology of the Aryan Nations. New Edition. Demy 8vo, i6s.

Tales of Ancient Greece, New Edition. Small crown 8vo, $6 s$.

A Manual of Mythology in the form of Question and Answrer. New Edition. Fcap. 8vo, 3s.

An Introduction to the Science of Comparative Mythology and Folk-Iore. Second Edition. Crown 8vo. 7s.6d.

COX, Rev. Sir G. W., MT.A., Bart., and FONES, Eustace Hinton.Popular Romances of the Middle Ages, Third Edition, in I vol. Crown 8vo, 6 s.

COX, Rev. Samuel, D.D.-A Commentary on the Book of Job. With a Translation. Demy 8vo, I 5 .

Salvator Mundi ${ }_{3}^{*}$ or, "Is Christ the Saviour of all Men? Ninth Edition. Crown $8 \mathrm{vo}, 5$ s.

The Larger Hope. A Sequel to "Salvator Mundi." Second Edition. I6mo, Is.

The Genesis of Evil, and other Sermons, mainly expository. Third Edition. Crown 8vo, $6 s$.

Baiaam. An Exposition and a Study. Crown 8vo, 5 s.

Miracles. An Argument and a Challenge. Crown 8vo, 2s, $6 d$. 
CRAVEN, Mrs. - A Year's Meditations * Crown 8ro, 6s.

CRAWFURD, Oswald._Portugal, Old and New. With Illustra. tions and Maps. New and Cheaper Edition. Crown 8ro, 6 s.

Crime of Christmas Day. A Tale of the Latin Quarter. By the Author of "My Ducats and my Daughter." Is.

CROZIER, Fonn Beattic, M.B.-The Religion of the Future. Crown 8vo, 6s.

DANIELL, Clarmont. - The Gold Treasure of India. An Inquiry into its Amount, the Cause of its Accumulation, and the Proper Means of using it as Money. Crown 8vo, 5 .

Danish Parsonage. By an Angler. Crown 8vo, $6 s$.

Darkness and Dawn: the Peaceful Birth of a New Age. Small crown 8ro, 2s. 6d.

DAVIDSON, Rev. Samuel. D.D., LL.D.-Canon of the Bible: Its Formation, History, and Fluctuations. Third and Revised Edition. Small crown 8ro, 5 s.

The Doctrine of Last Things contained in the New Testament compared with the Notions of the Jews and the Statements of Church Creeds. Small crown 8vo, 3s. 6 d.

DAVIDSON, Thomas. - The Parthenon Frieze, and other Essays. Crown 8ro, 6s.

DAWSON, Geo., M.A. Prayers, with a Discourse on Prayer. Edited by his Wife. First Series. Eighth Edition. Crown 8ro, 6s.

*" Also a New and Cheaper Edition. Crown 8vo, $35.6 d$.

Prayers, with a Discourse on Prayer. Edited by George St. Clatr. Second Series. Crown 8vo, 6 s.

Sermons on Disputed Points and Special Occasions. Edited by his Wife. Fourth Edition. Crown 8vo, $6 s$.

Sermons or Daily Life and Duty. Edited by his Wife. Fourth Edition. Crown \&vc, 6 s.

The Authentic Gospel, and other Sermons. Edited by George St. Clatr. Third Edition. Crown 8vo, $6 s$.

Three Books of God: Nature, History, and Scripture. Sermons edited by George St. Clair. Crown 8vo, 6 s.

DE FONCOURT, Madame Marit.-Wholesome Cookery. Third Edition. Crown 8ro, 33. $6 \dot{d}$.

DE LONG, Licut. Conn. G. W.-The Voyage of the Jeannette. The Ship and Ice Journals ot. Edited by his Wife, EMMA DE LoNG. With Portraits, Maps, and many Illustrations on wood and stone. 2 vols. Demy 8ro, $36 s$.

Democracy in the Old World and the New. By the Author of "The Suez Canal, the Eastern Question, and Abyssinia," etc. Small crown 8vo, $2 s .6 \%$. 
DEVEREUX, W. Cope, R.N., F.R.G.S.-Fair Yraly, the Riviera, and Monte Carlo. Comprising a Tour through North and South Italy and Sicily, with a short account of Malta. Crown 8 vo, $6 s$.

Doing and Undoing. A Story. By MARy CHICHele. I vol. Crown 8vo.

DOWDEN, Edzurd, LL.D.-Shakspere: a Critical Study of his Mind and Art. Seventh Edition. Post 8vo, I2s.

Studies in Literature, 1789-1877. Third Edition. Large post $8 \mathrm{vo}, 6 s$.

DUFFIELD, $A$. F-Don Quixote: his Critics and Commentators. With a brief account of the minor works of MIGUEL DE Cervantes SaAvedra, and a statement of the aim and end of the greatest of them all. A handy book for general readers. Crown 8vo, 3s. $6 \%$.

DU MONCEL, Count. - The Telephone, the Microphone, and the Phonograph. With 74 Illustrations. Second Edition. Small crown 8vo, 5 s.

DURUY, Victor.-History of Rome and the Roman People. Edited by Prof. MAHAFFy. With nearly 3000 Illustrations. 4to. Vols. I. IT. and III. in 6 parts, 30s. each vol.

EDGEWORTH, F. Y.-Mathematical Psychics. An Essay on the Application of Mathematics to Social Science. Demy 8ro, $7 s .6 d$.

Educational Code of the Prussian Nation, in its Present Form. In accordance with the Decisions of the Common Provincial Law, and with those of Recent Legislation. Crown 8vo, $2 s .6 d$.

Education Library. Edited by Philip Magnus :-

An Introduction to the History of Educational Theories. By Oscar Browning, M.A. Second Edition. 3s. $6 d$.

Old Greek Education. By the Rev. Prof. MAHAfFy, M.A. Second Edition. 3s. $6 d$.

School Management. Including a general view of the work of Education, Organization and Discipline. By JOSEPH LANDON. Third Edition. $6 s$.

Eighteenth Century Essays. Selected and Edited by AustiN Dobson. With a Miniature Frontispiece by R. Caldecott. Parchment Library Edition, 6s.; vellum, 7s. $6 \mathrm{~d}$.

ELSD ALE, Henry.-Studies in Tennyson's Idylls. Crown 8vo, 5 s. ELYOT, Sir Thomas. - The Boke named the Gouernour. Edited from the First Edition of I53I by Henry Herbert Sterhen Croft, M.A., Barrister-at-Law. 2 vols. Fcap. 4to, 50 s. 
Emerson's (Ralph WValdo) Life. By Oliver TVendell Holmes. English Copyright Edition. With Portrait. Crown 8vo, 6s.

Enoch the Prophet. The Book of. Archbishop LAURENCE's Translation, with an Introduction by the Author of "The Evolution of Christianity." Crown 8vo, 5 s.

Eranus. A Collection of Exercises in the Alcaic and Sapphic Metres. Edited by F. W. Cornish, Assistant Master at Eton. Second Edition. Crown 8vo, 2s,

EVANS, Mark.-The Story of Our Father's Love, told to Children. Sixth and Cheaper Edition. With Four Illustrations. Fcap. 8vo, is. 6d.

"Fan IX wae ${ }^{33}$ at Canton before Treaty Days 1825-1844. By an old Resident. With Frontispiece. Crown 8vo, 5 s.

FEIS, Facob.-Shakspere and Montaigne. An Endeavour to Explain the Tendency of Hamlet from Allusions in Contemporary Works. Crown 8vo, 5 s.

FLECKER, Rev. Eliezer.-Scripture Onomatology* Peing Critical Notes on the Septuagint and other Versions. Second Edition. Crown 8vo, 3s. 6.

FLOREDICE, W. H.-A Month among the Mere Irish. Small crown 8vo, 5 s.

FOWLE, Rev. T. W.-The Divine Iegation of Christ. Crown $8 \mathrm{vo}, 7 \mathrm{~s}$.

Frank Leward. Edited by Charles Bampton. Crown 8vo, $7 s .6 d$. FULLER, Rev. Morris. - The Iord"S Day: or, Christian Sunday. Its Unity, History, Philosophy, and Perpetual Obligation. Sermons: Demy 8vo, Ios. 6d.

GARDINER, Sammel R., and F. BASS NIULLINGER, M.A.Introduction to the Study of English History. Second Edition. Large crown 8vo, 9s.

GARDNER, Dorsey.-Quatre Bras, Ligny, and WVaterloo. A Narrative of the Campaign in Belgium, 1815. With Maps and Plans. Demy 8ro, I6s.

Genesis in Advance of Present Science. A Critical Investigation of Chapters I.-IX. By a Septuagenarian Beneficed Presbyter. Demy 8vo. Ios. 6a.

GENNA, E.-Irresponsible Philanthropists. Being some Chapters on the Employment of Gentlewomen. Small crown 8 ro, $2 s .6 d$.

GEORGE, Henry.-Progress and Poyerty: An Inquiry into the Causes of Industrial Depressions, and of Increase of Vant with Increase of Wealth. The Remedy. Fifth Library Edition. Post $8 v o, 7 s .6 \pi$. Cabinet Edition. Crown 8vo, 2s. 6r. Also a Cheap Edition. Limp cloth, Is. 6d. Paper covers, Is. 
GEORGE, Henry-continued.

Social Problems, Fourth Thousand. Crown 8vo, 5s. Cheap

Edition. Paper covers, Is.

GIBSON, Fames $Y$. - Iourney to Parnassus. Composed by Miguel DE CERvantes SAavedra. Spanish Text, with Translation into English Tercets, Preface, and Illustrative Notes, by. Crown 8vo, I2s.

Glossary of Terms and Phrases. Edited by the Rev. I. PERcy SMith and others. Medium 8vo, I2s.

GLOVER, F., M.A.-Exempla Latina. A First Construing Book, with Short Notes, Lexicon, and an Introduction to the Analysis of Sentences. Second Edition. Fcap. 8vo, $2 s$.

GOLDSM1TD, Sir Francis Henry, Bart., Q.C., M.P.-Memoir of. With Portrait. Second Edition, Revised. Crown 8vo, $6 s$.

GOODENOUGH, Commodore F. G.-Memoir of with Extracts from his Letters and Journals. Edited by his Widow. With Steel Engraved Portrait. Third Edition. Crown 8vo, 5 s.

GOSSE, Edmund.-Studies in the Literature of IVorthern Europe. New Edition. Large crown 8vo, 6 s.

Seventeenth Century Studies, A Contribution to the History of English Poetry. Demy 8vo, Ios. $6 a^{7}$.

GOULD, Rev. S. Baring, M.A.-Germany, Present and Past. New and Cheaper Edition. Large crown 8vo, 7s. $6 d$.

GOWAN, Major Walter E.-A. Tvanoff's Russian Grammar. (I6th Edition.) Translated, enlarged, and arranged for use of Students of the Russian Language. Demy 8vo, $6 s$.

GOWER, Lord Ronald. MY Reminiscences. Cheap Edition. With Portrait. Large crown 8vo, 7 s. $6 d$.

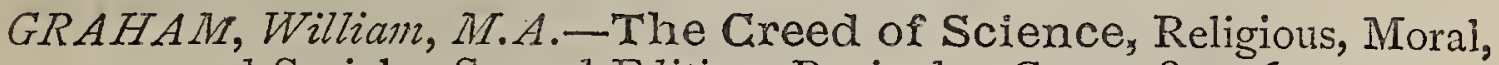
and Social. Second Edition, Revised. Crown 8 vo, $6 s$.

GREY, Rowland.-In Sunny Switzerland. A Tale of Six Weeks. Small crown 8vo, 5 s.

GRIFFITH, Thomas, A.M.-The Gospel of the Divine Life: a Study of the Fourth Evangelist. Demy 8vo, I4s.

GRIMLEY, Rev. H. N., M.A.-Tremadoc Sermons, chiefiy on the Spiritual Body, the Unseen Korld, and the Divine Humanity. Fourth Edition. Crown 8vo, 6 s.

G. S. B.-A Study of the Prologue and Epilogue in English Literature from Shakespeare to Dryden. Crown 8 vo, 5 s.

GUSTAFSON, Alex. - The Foundation of Death. Third Edition, Crown 8 vo, 5 . 
HAECKEL, Prof. Ernst. - The History of Creation. Translation revised by Professor E. RAy Lankester, M.A., F.R.S. With Coloured Plates and Genealogical Trees of the various groups of both Plants and Animals. 2 vols. Third Edition. Post 8 vo, $32 s$.

The History of the Evolution of Man. With numerous Illustrations. 2 vols. Post $8 \mathrm{vo}, 32 s$.

A. Visit to Ceylon. Post $8 \mathrm{vo}, 7 s .6 \%$.

Freedom in Science and Teaching. With a Prefatory Note by T. H. Huxley, F.R.S. Crown 8 vo, 5 s.

HALF-CROWN SERIES :-

A Lost Love. By AnNa C. Ogle [Ashford Owen].

Sister Dora : a Biography. By MARgaret Lonsdale.

True Words for Brave IMen: a Book for Soldiers and Sailors.

By the late Charles Kingsley.

Notes of Travel : being Extracts from the Journals of Count VoN MOLTIKE.

English Sonnets. Collected and Arranged by J. DeNnis.

London Lyrics. By F. Locker.

Home Songs for Quiet Hours. By the Rev. Canon R. H. BAYNES.

HARRIS, William.-The History of the Radical Party in Parliament. Demy 8vo, I5s.

HARROP, Robert.-Bolingbroke. A Political Study and Criticism. Demy 8ro, 14 s.

HART, Rev. F. W. T. - The Autobiography of Iudas Iscariot. A Character Study. Crown 8vo, 3s. $6 d$.

HAWEIS, Rev. H. R., M.A.-Current Coin. Materialism-The Devil-Crime-Drunkenness-Pauperism-Emotion-Recreation - The Sabbath. Fifth Edition. Crown 8ro, 5 s.

Arrows in the Air. Fifth Edition. Crown 8vo, 5 .

Speech in Season. Fifth Edition. Crown 8ro, 5 .

Thoughts for the Times. Thirteenth Edition. Crown 8vo, 5 s.

Unsectarian Family Prayers. New Edition. Fcap. Svo, is. 6 d.

HAWKINS, Edwarts Comerford.-Spirit and Form. Sermons preached in the Parish Church of Leatherhead. Crown 8ro, 6s.

HAWTHORNE, Nathaniel.-Works. Complete in Twelve Volumes. Large post 8 vo, $7 s .6 \%$. each volume.

VOL. I. TWICE-TOLd TALES.

II. MOSSES From AN Old MANSE.

III. The House of tile Seven Gables, and Tue Snow IMAGE. 
HAWTHORNE, Nathaniel-continued.

Vol. IV. The Wonderbook, Tanglewood Tales, and Grand FATHER'S CHAIR.

V. The Scarlet Letter, and The Blithedale Romince.

VI. The Marble Faun. [Transformation.]

VIII. $\}$ OUR Old HOME, aNd ENGlish NOTE-Boors.

IX. AMERICAN NOTE-BOOKS.

X. FRENCH AND ITALIAN NOTE-BOOKS.

XI. Septimius Felton, The Dolliver Romance, Fanshawe, and, in an Appendix, The Ancestral Footstep.

XiI. Tales and Essays, and other Papers, with a BioGRAPHICAL SKETCH OF HaWTHORNE.

HAYES, A. A., Funr--Newy Colorado, and the Santa Fé Trail. With Map and 6o Illustrations. Square 8vo, 9s.

HENNESSY, Sir John Pope--Ralegh in Ireland. With his Letters on Irish Affairs and some Contemporary Documents. Large crown $8 \mathrm{vo}$, printed on hand-made paper, parchment, IOs. $6 d$.

HENRY, Philip.-Diaries and Letters of. Edited by MATTHEW HenRY LeE, M.A. Large crown $8 \mathrm{vo}, 7 s .6 d$.

HIDE, Albert.-The Age to Come. Small crown 8vo, 2s. 6d.

HIME, Major H. W. L., R.A.-Wagnerism : A Protest. Crown $8 \mathrm{vo}, 2 s .6 d$.

HINTON, F--Life and Letters. With an Introduction by Sir W. W. GuLL, Bart., and Portrait engraved on Steel by C. H. Jeens. Fifth Edition. Crown 8vo, 8s. 6d.

Philosophy and Religion. Selections from the Manuscripts of the late James Hinton. Edited by Caroline HadDon. Second Edition. Crown 8vo, 5 .

The Laxy Breaker, and The Coming of the Law. Edited by Margaret Hinton. Crown 8vo, $6 s$.

The Mystery of Pain. New Edition. Fcap. 8vo, Is.

Hodson of Hodson's Horse ; or, Twelve Years of a Soldier's Life in India. Being extracts from the Letters of the late Major W. S. R. Hodson. With a Vindication from the Attack of Mr. Bosworth Smith. Edited by his brother, G. H. Hodson, M.A. Fourth Edition. Large crown 8vo, 5 s.

HOLTHAM, E. G. - Eight Years in Japan, 1873-1881. Work, Travel, and Recreation. With three Maps. Large crown $8 \mathrm{vo}, 9 s_{\text {. }}$

Homology of Economic Justice. An Essay by an East India Merchant. Small crown 8vo, 5 s.

HOOPER, Mary.--Little Dinners: How to Serve them writh Elegance and Economy. Eighteenth Erlition. Crown 8 vo, $2 s, 6 d$. 
HOOPER, Mary-continued.

Cookery for Invalids, Persons of Delicate Digestion, and Children. Fourth Edition. Crown 8vo, 2s. $6 d$.

Every-Day Meals; Being Economical and Wholesome Recipes for Breakfast, Luncheon, and Supper. Sixth Edition. Crown 8 vo, $2 s .6 d$.

HOPKINS, Ellice- - Work amongst Working Men. Fifth Edition. Crown 8vo, 3s. 6d.

HOSPITALIER, E.-The Modern Applications of Electricity. Translated and Enlarged by JULIUS MAIER, Ph.D. 2 vols. Second Edition, Revised, with many additions and numerous Illustrations. Demy 8vo, I2s. $6 d$. each volume.

VoI. I.-Electric Generators, Eilectric Light.

VoL. II.-Telephone: Various Applications: Electrical Transmission of Energy.

Household Readings on Prophecy: By a Layman. Small crown 8vo, 3s. $6 d$.

HUGFES, Henry,-The Redemption of the IXorld. Crown 8vo, 3s. $6 d$.

HUNTINGFORD, Rev. E., D.C.L.-The Apocalypse. With a Commentary and Introductory Essay. Demy 8vo, $5^{5}$.

HUTCHINSON, H.-Thought Symbolism, and Grammatic Illusions. Being a Treatise on the Nature, Purpose and Material of Speech. Crown 8vo, 5 s.

HUTTON, Rev. C. F.-Unconscious Testimony; or, The Silent Witness of the Hebrew to the Truth of the Historical Scriptures. Crown 8vo, 2s. $6 d$.

HYNDMAN, H. M.-The Historical Basis of Socialism in England. Large crown 8vo, 8s. $6 d$.

IM THURN, Everard F.-Among the Indians of Guiana. Being Sketches, chiefly anthropologic, from the Interior of British Guiana. With 53 Illustrations and a Map. Demy 8vo, I8s.

7ACCOUD, Prof. S.-The Curability and Treatment of Pulmonary Phthisis. Translated and edited by MONTAGU Lubbock, M.D. Demy 8vo, i 5 s.

Jaunt in a Junk: A Ten Days' Cruise in Indian Seas. Large crown 8 vo, $75.6 \%$.

FENKINS, E., and RAYMOND, F.-The Architect's Legal Handbook. Third Edition, revised. Crown 8vo, 6 s.

FENNINGS, MTrs. Vaughan.-Rahel: Her Life and Lelters. Large post 8 vo, $7 s .6 d$. 
GERVIS, Rev. W. Henley. - The Gallican Ghurch and the Revolution: A Sequel to the History of the Church of France, from the Concordat of Bologna to the Revolution. Demy 8vo, I8s.

FOEL, L.-A Consul's Manual and Shipowner"s and Shipmaster's Practical Guide in their Transactions Abroad: With Definitions of Nautical, Mercantile, and Legal Terms; a Glossary of Mercantile Terms in English, French, German, Italian, and Spanish; Tables of the Money, Weights, and Measures of the Principal Commercial Nations and their Equivalents in British Standards; and Forms of Consular and Notarial Acts. Demy 8vo, I2s.

FOHNSTONE, C. F., M.A.-Historical Abstracts: being Outlines of the History of some of the less known States of Europe. Crown 8 vo, $7 s .6 d$.

FOLLY, William, F.R.S.E., etc.-The Life of John Duncan, Scotch Weaver and Botanist. With Sketches of his Friends and Notices of his Times. Second Edition. Large crown 8vo, with Etched Portrait, 9s.

FONES, C. A.-The Foreign Freaks of Five Friends. With 30 Illustrations. Crown $8 \mathrm{vo}, 6 s$.

FOYCE, P. W., LL.D., etc.-Old Celtic Romances. Translated from the Gaelic. Crown 8vo, $7 s .6 d$.

KAUFMANN, Rev. M., B.A.-Socialism: its Nature, its Dangers, and its Remedies considered. Crown $8 \mathrm{vo}, 7 \mathrm{~s}, 6 a_{\text {。 }}$

Utopias : or, Schemes of Social Improvement, from Sir Thomas More to Karl Marx. Crown 8vo, $5^{5}$.

KAY, David, F.R.G.S.-Education and Educators: Crown 8vo, $7 s .6 d$.

KAY, Foseph. - Free Trade in Land. Edited by his Widow. With Preface by the Right Hon. JoHN BRIGHT, M.P. Seventh Edition. Crown 8vo, 5 s.

KEMIPIS, Thomas a. - Of the Imitation of Christ, Parchment Library Edition.-Parchment or cloth, 6s.; vellum, $7 s .6 d$. The Red Line Edition, fcap. 8vo, red edges, 2s. 6d. The Cabinet Edition, small $8 \mathrm{vo}$, cloth limp, Is. ; cloth boards, red edges, Is. $6 d$. The Miniature Edition, red edges, $32 \mathrm{mo}$, Is.

** All the above Editions may be had in various extra bindings.

KENT, C.-Corona Catholica ad Petri successoris Pedes Oblata: De Summi Pontificis Leonis XIII* Assumptione Epigramma. In Quinquaginta Linguis. Fcap. 4 to, $15 \mathrm{~s}$. 
FETTLEIVELL, Rev.S.-Thomas à Zempis and the Brothers of Common Life. 2 vols. With Frontispieces. Demy 8vo, $30 s$.

** Also an Abridged Edition, in one volume. With Portrait. Crown 8vo, 7 s. $6 d$.

KIDD, Foseph, M.D.-The Laws of Therapeutics ; or, the Science and Art of MIedicine. Second Edition. Crown Sro, $6 s$.

KINGSFORD, Anna, M.D.-The Perfect WWay in Diet. A Treatise advocating a Return to the Natural and Ancient Food of our Race. Small crown Sro, $2 s$.

KINGSLEY, Charles, M.A.-Letters and Memories of his Life. Edited by his Wife. With two Steel Engraved Portraits, and Vignettes on Wood. Fifteenth Cabinet Edition. 2 vols. Crown Sro, I2s.

** Also a People's Edition, in one volume. With Portrait. Crown Sro, $6 s$.

All Saints' Day, and other Sermons. Edited by the Rev. W. Harrisow. Third Edition. Crown 8vo, $75.6 \%$.

True Words for Brave Men. A Book for Soldiers' and Sailors' Libraries. Eleventh Edition. Crown 8vo, 2s. $6 d$.

KNOX, Alexander A.-The New Playground; or, Wanderings in Algeria. New and Cheaper Edition. Large crown 8vo, $6 s$.

LANDON, Foseph.-School Management; Including a General View of the Work of Education, Organization, and Discipline. Third Edition. Crown 8vo, 6s.

LAURIE, S. S.-The Training of Teachers, and other Educational Papers. Crown 8ro, $75.6 d$.

LEE, Rev.F. G., D.C.L.-The Other World; or, Glimpses of the Supernatural. 2 vols. A New Edition. Crown 8vo, I5s.

Letters from an Unknown Friend. By the Author of "Charles Lowder." With a Preface by the Rev. W. H. ClEaver. Fcap. 8ro, Is.

Letters from a Young Emigrant in Manitoba. Second Edition. Small crown 8vo, 3s. $6 d$.

Leward, Frank. Edited by Charles BAMpton. Crown 8vo, 7 s. $6 d$. LEWIS, Edward Dillon.-A Draft Code of Criminal Law and Procedure. Demy 8vo, 2Is.

LILLIE, Arthur, M.R.A.S.-The Popular Life of Buddha. Containing an Answer to the Hibbert Lectures of I88I. With Illustrations. Crown 8vo, 6s.

LLOYD, Walter.-The Hope of the World: An Essay on Universal Redemption. Crown 8vo, 5 s.

LONSDALE, Margaret.-Sister Dora: a Biography. With Portrait. Cheap Edition. Crown 8vo, 2s. $6 d$. 
LOUNSBURY, Thomas R.-Iames Fenimore Cooper. With Portrait. Crown 8ro, 5 s.

LOWDER, Charles. - A Biography. By the Author of "St. Teresa."

New and Cheaper Edition. Crown 8vo. With Portrait. 3s. 6d.

LÜCKES, Eva C. E.-Lectures on General Nursing, delirered to the Probationers of the London Hospital Training School for Nurses. Crown 8vo, 2s. 6d.

LYALL, William Rowe, D.D. - Propædeia Prophetica $\hat{\xi}$ or, The Use and Design of the Old Testament Examined. New Edition. With Notices by George C. Pearson, M.A., Hon. Canon of Canterbury. Demy 8 vo.

LYTTON, Edward Bulwer, Lord.-Life, Letters and Literary Remains. By his Son, the EARL of LyTTON. With Portraits, Illustrations and Facsimiles. Demy 8ro. Vols. I. and II., 32s.

MACAULA Y, G. C.-Francis Beaumont : A Critical Study. Crown Bro, 5 s.

MAC CALLUM, M. W.-Studies in Loxx German and High German Literature. Crown 8vo, 6s.

MACHIAVELLI, Niccold. - Lile and Times. By Prof. Villarr. Translated by LINDA VILLARI. 4 vols. Large post, 8vo, 48 s.

MACHIAVELLI, Niccolo.-Discourses on the First' Decade of Titus Livius, Translated from the Italian by NINIAN HILL THOMSon, M.A. Large crown 8ro, I2s.

The Prince. Translated from the Italian by N. H. T. Small crown 8 vo, printed on hand-made paper, bevelled boards, $6 s$.

MACKENZIE, Alexander-Hovy India is Governed. Being an Account of England's Work in India. Small crown 8vo, 2s.

MACNAUGHT, Rev. Fohn. - Cœna Domini : An Essay on the Lord's Supper, its Primitive Institution, Apostolic Uses, and Subsequent History. Demy 8ro, I 4 s.

MACWALTER, Rev. G. S.-Life of Antonio Rosmini Serbati (Founder of the Institute of Charity). 2 vols. Demy 8vo. [Vol. I. now ready, price I $2 s$.

MAGNUS, Mrs.-A bout the Jewrs since Bible Times. From the Babylonian Exile till the English Exodus. Small crown 8ro, $6 s$.

MAIR, R. S., M.D., F.R.C.S.E.-The Medical Guide for AngloIndians. Being a Compendium of Advice to Europeans in India, relating to the Preservation and Regulation of Health. With a Supplement on the Management of Children in India. Second Edition. Crown 8vo, limp cloth, 3s. $6 d$.

MALDEN, Henry Elliot.-Yienna, 1683. The History and Consequences of the Defeat of the Turks before Vienna, September I2th, I683, by Joln Sobieski, King of Poland, and Charles Leopold, Duke of Lorraine. Crown 8vo, $4, s .6 d$. 
Many Voices. A volume of Extracts from the Religious Writers of Christendom from the First to the Sixteenth Century. With Biographical Sketches. Crown 8vo, cloth extra, red edges, 6s.

MARKHAM, Capt. Albert Hastings, R.N.-The Great Frozen Sea : A Personal Narrative of the Voyage of the Alert during the Arctic Expedition of $1875^{-6}$. With 6 Full-page Illustrations, 2 Maps, and 27 Woodcuts. Sixth and Cheaper Edition. Crown 8ro, 6s.

A Polar Reconnaissance: being the Voyage of the Isbjörn to Novaya Zemlya in 1879 . With Io lllustrations. Demy 8 vo, $16 s$.

Marrlage and Maternity; or, Scripture Wives and Mothers. Small crown 8vo, 4s. $6 d^{\text {. }}$.

MARTINEAU, Gertrude.-Outline Iessons on Morals. Small crown 8 vo, 3 s. $6 d$.

MAUDSLEY, H., M.D.-Body and WXill. Being an Essay concerning Will, in its Metaphysical, Physiological, and Pathological Aspects. 8vo, I2s.

McGRATH, Terence.-Pictures from Ireland. New and Cheaper Edition. Crown 8vo, $2 s$.

MEREDITH, M.A.-Theotokos, the Example for WToman. Dedicated, by permission, to Lady Agnes Wood. Revised by the Venerable Archdeacon Denison. 32mo, limp cloth, Is. $6 d$.

MILLER, Edward.-The History and Doctrines of Irvingism; or, The so-called Catholic and Apostolic Church. 2 vols. Large post $8 \mathrm{vo}, 25$ s.

The Church in Relation to the State. Large crown 8vo, $75.6 d$.

MINCHIN, F. G.-Bulgaria since the WVar: Notes of a Tour in the Autumn of 1879. Small crown 8vo, 3s. 6d.

MITCHELL, Lucy M.-A History of Ancient Sculpture. With numerous Illustrations, including 6 Plates in Phototype. Super royal 8vo, 42s.

Selections from Ancient Sculpture. Being a Portfolio containing Reproductions in Phototype of 36 Masterpieces of Ancient Art to illustrate Mrs. Mitchell's "History of Ancient Sculpture." I $8 s$.

MITFORD, Bertran.-Through the Zulu Country. Its Battle fields and its People. With Five Illustrations. Demy 8vo, I 4 s.

MOCKLER, E.-A Grammar of the Baloochee Language, as it is spoken in Makran (Ancient Gedrosia), in the Persia-Arabic and Roman characters. Fcap. 8vo, $5^{s .}$

MOLESWORTH, Rev. W. Nassau, M.A.-History of the Church of England from 1660. Large crown 8vo, 7s. 64 
MORELL, F.R.-Euclid Simplified in INethod and Language. Being a Manual of Geometry. Compiled from the most important French Works, approved by the University of Paris and the Minister of Public Instruction. Fcap. 8vo, 2s. $6 d$.

MORRIS, George.-The Duality of all Divine Truth in our Lord Yesus Christ. For God's Self-manifestation in the Impartation of the Divine Nature to Man. Large crown 8vo, $7 s .6 d$.

MORSE, E. S., Ph.D.-First Book of Zoology. With numerous Illustrations. New and Cheaper Edition. Crown 8vo, 2s. 6 d.

MULL, Mathias. -Paradise Lost. By John MilTon. Books I-VI. The Mutilations of the Text emended, the Punctuation revised, and all collectively presented, with Notes and Preface; also a short Essay on the Intellectual Value of Milton's Works, etc. Demy 8vo, 6s.

MURPHY, Fohn Nicholas. - The Chair of Peter; or, The Papacy considered in its Institution, Development, and Organization, and in the Benefits which for over Eighteen Centuries it has conferred on Mankind. Demy 8vo, I8s.

Naturess Nursling. A Romance from Real Life. By Lady Ger. TRUDE STOCK. 3 vols. Crown.8vo, 3Is. $6 d$.

NELSON, F. H., M.A.-A Prospectus of the Scientiflc Study of the Hind û Lary. Demy 8vo, 9s.

NEWMAN, Cardinal.-Characteristics from the WMritings of. Being Selections from his various Works. Arranged with the Author's personal Approval. Sixth Edition. With Portrait. Crown 8vo, $6 s$.

*** A Portrait of Cardinal Newman, mounted for framing, can be had, $2 s .6 d$.

NEWMAN, Francis William.-Essays on Diet. Small crown 8vo, cloth limp, $2 s$.

New Truth and the Old Faith: Are they Incompatible? By a Scientific Layman. Demy 8vo, Ios. $6 d$.

Nexy Werther. By Loki. Small crown 8vo, 2s. 6d.

NICHOLSON, Edward Byron.-The Gospel according to the Hebrevys. Its Fragments Translated and Annotated, with a Critical Analysis of the External and Internal Evidence relating to it. Demy 8vo, 9s. $6 d$.

A INew Commentary on the Gospel according to Matthexx. Demy 8vo, I2s.

NICOLS, Arthur, F.G.S., F.R.G.S.-Chapters from the Physical History of the Earth: an Introduction to Geology and Palæontology. With numerous Illustrations. Crown 8vo, 5 s.

NOPS, Marianne.-Class Lessons on Euclid. Part I. containing the First Two Books of the Elements. Crown 8vo, 2s. $6 d$.

Nuces: Exercises on the Syntax of the Public School Latin Primer. New Edition in Three Parts. Crown 8vo, each Is.

** The Three Parts can also be had bound together, $3 s$. 
UATES, Frank, F.R.G.S.-Matabele Land and the Victoria Falls. A Naturalist's Wanderings in the Interior of South Africa. Edited by C. G. OATES, B.A. With numerous Illustrations and 4 Maps. Demy 8vo, 2Is.

OGLE, W., M.D., F.R.C.P.-Aristotle on the Parts of Animals. Translated, with Introduction and Notes. Royal 8vo, 12s. 6d.

O'HAGAN, Lord, K.P. - Occasional Papers and Addresses. Large crown 8vo, 7 s. $6 d$.

OKEN, Lorenz, Life of. By Alexander Ecker. With Explanatory Notes, Selections from Oken's Correspondence, and Portrait of the Professor. From the German by Alfred Tulk. Crown 8vo, 6s.

O'MEARA, Kathleen.-Frederic Ozanam, Professor of the Sorbonne : His Life and Work. Second Edition. Crown 8vo, 7s. $6 d$.

Henri Perreyve and his Counsels to the Sick. Small crown $8 \mathrm{vo}, 5^{s}$.

OSBORNE, Rev. W. A.-The Revised Version of the New Testament. A Critical Commentary, with Notes upon the Text. Crown 8vo, 5 s.

OTTLEY, H. Bickersteth.-The Great Dilemma. Christ His Own Witness or His Own Accuser. Six Lectures. Second Edition. Crown 8vo, 3s. $6 d$.

Our Public Schools-Eton, Harrow, Winchester, Rugby, Westminster, IMarlborough, The Charterhouse. Crown 8vo, 6 s.

OWEN, F. M.-John IKeats: a Study. Crown 8vo, $6 s$.

Across the Hills. Small crown 8vo, is. $6 \pi$.

OWEN, Rev. Robert, B.D.-Sanctorale Catholicum; or, Book of Saints. With Notes, Critical, Exegetical, and Historical. Demy 8vo, I8s.

OXENHAM, Rev. F. Nutcombe. - Wh hat is the Truth as to Everlasting Punishment. Part II. Being an Historical Inquiry into the Witness and Weight of certain Anti-Origenist Councils. Crown 8vo, 2s. $6 d$.

OXONIENSIS. - Romanism, Protestantism, Anglicanism. Being a Layman's View of some questions of the Day. Together with Remarks on Dr. Littledale's "Plain Reasons against joining the Church of Rome." Crown 8ro, 3s. $6 \pi$.

PALMER, the late Willian.-Notes of a Visit to Russia in 18<0-1841. Selected and arranged by JoHN H. CARDINAL Newman, with portrait. Crown 8vo, 8s. 6 d.

Early Christian Symbolism. A Series of Compositions from Fresco Paintings, Glasses, and Sculptured Sarcophagi. Edited by the Rev. Provost NorThCote, 1).D., and the Rev. Canon Brownlow, M.A. With Coloured Plates, folio, 42s, , or with Plain Plates, folio, 25 s. 
Parchment Library. Choicely Printed on hand-made paper, limp parchment antique or cloth, $6 s$. ; vellum, $7 s .6 d$. each volume.

Selections from the Prose WXritings of Jonathan Swift. With a Preface and Notes by Stanley LANE-Poole and Portrait.

English Sacred Lyrics.

Sir Joshua Reynolds"s Discourses. Edited by EDMund Gosse.

Selections from Mrilton"s Prose Wrritings. Edited by ERNEST MYERS.

The Book of Fsalms. Translated by the Rev. T. IK. CHeynt, M.A.

The Vicar of Wwakefield. With Preface and Notes by Austin DoBson.

English Comic Dramatists. Edited by Ostwatd Crawfurd. English Lyrics.

The Sonnets of John Milion. Edited by Mark Pattison. With Portrait after Vertue.

French Lyrics. Selected and Annotated by GeORGe SAInT'sBURY. With a Miniature Frontispiece designed and etched by H. G. Glindoni.

Fables by Mr. John Gay. With Memoir by Austin Dobson, and an Etched Portrait from an unfinished Oil Sketch by Sir Godfrey Tneiler.

Select Letters of Percy Bysshe Shelley. Edited, with an Introduction, by Richard GarNetT.

The Christian Year. Thoughts in Verse for the Sundays and Holy Days throughout the Year. With Miniature Portrait of the Rev. J. Keble, after a Drawing by G. Richmond, R.A.

Shakspere's WXorks. Complete in Twelve Volumes.

Eighteenth Century Essays; 'Selected and Edited by Austin DoBson. With a Miniature Frontispiece by R. Caldecott.

Q. Horati Flacci Opera. Edited by F. A. Cornish, Assistant Master at Eton. With a Frontispiece after a design by L. Alma Tadema, etched by Leopold Lowenstam.

Edgar Allan Poe's Poems. With an Essay on his Poetry by ANDREiv LANG, and a Frontispiece by Linley Sambourne.

Shakspere's Sonnets. Edited by EDward Dowden. With a Frontispiece etched by Leopold Lowenstam, after the Death Mask.

English Odes. Selected by Edirund Gosse. With Frontispiece on India paper by Frmo Thomycroft, A.I.A.A. 
Parchment Library-continued.

Of the Imitation of Christ. By Thomas A Kempis. A revised Translation. With Frontispiece on India paper, from a Design by W. B. Richmond.

Poems: Selected from Percy Byssie Shelley. Dedicated to Lady Shelley. With a Preface by Richard Garnet and a Niniature lirontispiece.

** The above volumes may also be had in a variety of leather bindings. PARSLOE, Foseph.-Our Railways. Sketches, Historical and Descriptive. With Practical Information as to Fares and Rates, etc., and a Chapter on Railway Reform. Crown 8vo, 6 s.

FASCAL, Blaise.-The Thoughts of. Translated from the Text of Auguste Molinier, by C. Kegan PaUl. Large crown 8vo, with Frontispiece, printed on hand-made paper, parchment antique, or cloth, I2s.; vellum, I 5 s.

PAUL, Alexander.-Short Pariiaments. A History of the National Demand for frequent General Elections. Small crown 8vo, 3s. $6 d$.

PAUL, C. Kegan.-Biographical Sketches, Printed on hand-made paper, bound in buckram. Second Edition. Crown 8vo, $7 s .6 d$.

PEARSON, Rev. S.-W Week-day Living. A Book for Young Men and Women. Second Edition. Crown 8vo, 5 s.

PESCHEL, Dr. Oscar.-The Races of Man and their Geographical Distribution. Second Edition. Large crown 8vo, 9 s.

PETERS, F. H.-The Nicomachean Ethics of Aristotle. Translated by. Crown 8vo, 6s.

PHIPSON, E.-The Animal Iore of Shakspeare's Time. Including Quadrupeds, Birds, Reptiles, Fish and Insects. Large post 8vo, 9s.

PIDGEON, D.-An Engineer's Holiday; or, Notes of a Round Trip from Long. $0^{\circ}$. to $0^{\circ}$. New and Cheaper Edition. Large crown 8vo, $75.6 \%$.

Old World Questions and New World Answers: Large crown 8ro, 7s. 6d.

POE, Edgar Allan. - W Works of. With an Introduction and a Memoir by RICHARD HENRY StOddaRd. In 6 vols. With Frontispieccs and Vignettes. Large crown 8vo, 6s, each.

POPE, F. Buckingham. - Railway Rates and Racical Rule. Trade Questions as Election Tests. Crown 8vo, 2s. 6d.

PRICE, Prof. Bonamy. - Chapters on Practical Political Economy. Being the Substance of Lectures delivered before the University of Oxford. New and Cheaper Edition. Large post 8 ro, 5 s. 
Pulpit Commentary, The. (Old Testament Series.) Edited by the Rev. J. S. ExelL, M.A., and the Rev. Canon H. D. M. Speisce.

Genesis. By the Rev. T. Whitrelaw, M.A. With Homilies by the Very Rev. J. F. Montgomery, D.D., Rev. Prof. R. A. Redford, M.A., LL.B., Rev. F. Hastings, Rev. W. RoberTs, M.A. An Introduction to the Study of the Old Testament by the Venerable Archdeacon FARrar, D.D., F.R.S. ; and Introductions to the Pentateuch by the Right Rev. H. CoTTERILL, D.D., and Rev. T. Whitelaw, M.A. Eighth Edition. I vol., I 5 s.

Exodus. By the Rev. Canon Rawlinson. With Homilies by Rev. J. OrR, Rev. D. Young, B.A., Rev. C. A. Goodhart, Rev. J. URQUitart, and the Rev. H. T. ROBJoHns. Fourth Edition. 2 vols., I8s.

Leviticus. By the Rev. Prebendary Meyricir, M.A. With Introductions by the Rev. R. Collins, Rev. Professor A. CAVE, and Homilies by Rev. Prof. Redford, LL.B., Rev. J. A. Macdonald, Rev. W. Clarkson, B.A., Rev. S. R. Aldridge, LL.B., and Rev. McCheyne EDGAR. Fourth Edition. I5s.

Numbers. By the Rev. R. Winterbotham, LL.B. With Homilies by the Rev. Professor W. Binnie, D.D., Rev. E. S. Prout, M.A., Rev. D. Young, Rev. J. Waite, and an Introduction by the Rev. Thomas Whitelaw, M.A. Fourth Edition. I5s.

Deuteronomy. By the Rev. W. L. Alexander, D.D. With Homilies by Rev. C. Clemance, D.D., Rev. J. ORr, B.D., Rev. R. M. Edgar, M.A., Rev. D. Davies, M.A. Third edition. I 5 s.

Joshua. By Rev. J. J. LiAs, M. A. With Homilies by Rev. S. R. Aldridge, LL.B., Rev. R. Glover, Rev. E. DE Pressensé, D.D., Rev. J. Waite, B.A., Rev. W. F. Adenney, M.A.; and an Introduction by the Rev. A. Plummer, M.A. Fifth Edition. I2s. $6 d$.

Iudges and Ruth. By the Bishop of Bath and Wells, and Rev. I. Morison, D.D. With Homilies by Rev. A. F. MUir, M.A., Rev. W. F. Adeney, M.A., Rev. W. M. Statham, and Rev. Professor J. Thomson, M.A. Fourth Edition. Ios. $6 d$.

1 Samuel. By the Very Rev. R. P. Smith, D.D. With Homilies by Rev. Donald Fraser, D.D., Rev. Prof. Chapman, and Rev. B. DALE. Sixth Edition. I 5 s.

1 Kings. By the Rev. Joseph Hammond, LL.B. With Homilies by the Rev. E. DE Pressensé, D.D., Rev. J. Waite, B.A., Rev. A. Rowland, LL.B., Rev. J. A. Macdonald, and Rev. J. URquharT. Fourth Edition. I 5 s.

1 Chronicles. By the Rev. Prof. P. C. Barker, M.A., LL.B. With Homilies by Rev. Prof. J. R. Thomson, M.A., Rev. R. Tuck, B.A., Rev. W. Clarkson, B.A., Rev. F. Whitfirld, M.A., and Rev. Richard Glover. I $5 s$ 
Pulpit Commentary, The-continued.

Ezra, Nehemiah, and Esther. By Rev. Canon G. RAwilinson, M.A. With Homilies by Rev. Prof. J. R. Thomson, II.A., Rev. Prof. R. A. Redford, LL. B., M.A., Rev. W. S. Lewis, M.A., Rev. J. A. Macdonald, Rev. A. Mackennal, B.A., Rev. WV. Ciarisson, B.A., Rev. F. Hastings, Rev. W. Dinwiddie, LL.B., Rev. Prof. Rowlands, B.A., Rev. G. Wood, B.A., Rev. Prof. P. C. BARKER, M.A., LL.B., and the Rev. J. S. ExelL, M.A. Sixth Edition. I vol., I2s. $6 d$.

Jeremiah. (Vol. I.) By the Rev. T. K. Cheyne, M.A. With Homilies by the Rev. W. F. Adeney, M.A., Rev. A. F. Muir, M.A., Rev. S. Conway, B.A., Rev. J. WAIte, B.A., and Rev. D. Young, B.A. Second Edition. I5s.

Jeremiah (Vol. II.) and Lamentations. By Rev. T. K. Cheyne, M.A. With Homilies by Rev. Prof. J. R. Thomson, M.A., Rev. W. F. Adeney, M.A., Rev. A. F. Muir, M.A., Rev. S. Convay, B.A., Rev. D. Young, B.A. I5s.

Pulpit Commentary, The. (New Testament Series.)

St. Mark. By Very Rev. E. Bickersteth, D.D., Dean of Lichfield. With Homilies by Rev. Prof. Thomson, M.A., Rev. Prof. Grven, M.A., Rev. Prof. Johnson, M.A., Rev. A. Rowland, B.A., LL.B., Rev. A. Muir, ant Rev. R. Green. Fourth Edition. 2 vols., 2 Is.

The Acts of the A postles. By the Bishop of Bath and Wells. With Homilies by Rev. Prof. P. C. BARKer, M.A., LL.B., Rev. Prof. E. Johnson, M.A., Rev. Frof, R. A. REDFord, M.A., Rev. R. Tucr, B.A., Rev. W. Clarkson, B.A. Second Edition. 2 vols., 2 Is.

1 Corinthians. By the Ven. Archdeacon FArRar, D.D. With Homilies by Rev. Ex-Chancellor LiPSCONi, LL.D., Rev. David Thomas, D.D., Rev. D. Fraser, D.D., Rev. Prof. J. R. Thomson, M.A., Rev. J. Waite, B.A., Rev. R. Tucis, B.A., Rev. E. Hurndall, M.A., and Rev. H. Brfinner, B.D. Second Edition. Price I5s.

PUSEY, Dr.-Sermons for the Church"s Seasons from Advent to Trinity. Selected from the Published Sermons of the late Edward Bouverie Pusey, D.D. Crown 8vo, 5 s.

RADCLIFFE, Frank R. Y.-The New Politicus. Small crown Sio, $2 s .6$.

RANKE, Leopold von.-Universal History. The oldest Historical Group of Nations and the Greeks. Edited by G. W. Protirero. Demy 8vo, I6s.

Realities of the Future Life. Small crown Svo, is. 6a.

RENDELL, $¥$. MT.-Concise Handbook of the Island of Madeira. With Plan of Funchal and Map of the Island. Fcap. Sio, is. $6 \%$. 
REYNOLDS, Rev. F. W.-The Supernatural in Nature. A Verification by Free Use of Science. Third Edition, Revised and Enlarged. Demy 8vo, I4s.

The Mystery of Miracles. Third and Enlarged Edition. Crown 8ro, $6 \mathrm{~s}$.

The IMystery of the Universe; Our Common Faith. Demy $8 \mathrm{vo}, \mathrm{I} 4 \mathrm{~s}$.

RIBOT, Prof. Th.-Feredity: A Psychological Study on its Phenomena, its Laws, its Causes, and its Consequences. Second Edition. Large crown Sro, $9 s$.

RIMMER, Willian, M.D.-Art Anatomy. A Portfolio of 8I Piates. Folio, 7os., nett.

ROBERTSON, The late Rev. F. W., M.A.-Iife and Leiters of. Edited by the Rev. STOPFORD BROOKE, M.A.

I. Two vols., uniform with the Sermons. With Steel Portrait. Crown 8vo, $7 s .6 d$.

II. Library Edition, in Demy 8vo, with Portrait. i2s.

III. A Popular Edition, in I vol. Crown 8vo, $6 s$.

Sermons. Four Series. Small crown 8vo, 3s. 6d. each.

The Human Race, and other Sermons. Preached at Cheltenham, Oxford, and Brighton. New and Cheaper Edition. Small crown 8 vo, $3 s .6 \pi$.

INotes on Genesis. Nerw and Cheaper Edition. Small crown 8ro, 3 s. $6 d$.

Expository Lectures on St. Paul's Epistles to the Corinthians. A New Edition. Small crown 8ro, 5 s.

Lectures and Addresses, with other Literary Remains. A New Edition. Small crown 8vo, 5 s.

An Analysis of Tennyson"s "In Memoriam." (Dedicated by Permission to the Poet-Laureate.) Fcap. 8vo, 2s.

The Education of the Kuman Race. Translated from the German of GotThold EpHraim Lessing. Fcap. 8vo, 2s. $6 d$.

The above Works can also be had, bound in half morocco.

** A Portrait of the late Rev. F. W. Robertson, mounted for framing, can be had, $2 s .6 d$.

ROMANES, G. F.- Mental Evolution in Animals. With a Posthumous Essay on Instinct by Charles Darwin, F.R.S. Demy 8vo, I2s.

ROSMINI SERBATI, A., Founder of the Institute of Charity. Life. By G. Stuart MACWalter. 2 vols. 8vo.

[Vol. I. now ready, I2s.

Rosmini's Origin of Ideas. Translated from the Fifth Italian Edition of the Nuovo Saggio Sull origine delle idee. 3 vols. Demy 8vo, cloth, I6s, each.

Rosmini's Psychology: 3 vols. Demy 8ro. [Vol. I. now rendy, i6s. 
Rosmini's Philosophical System. Translated, with a Sketch of the Author's Life, Bibliography, Introduction, and Notes by Thomas Davinson. Demy \&vo, I6s.

RULE, Martin, M.A. - The Life and Times of St. Anselm, Archbishop of Canterbury and Primate of the Britains. 2 vols. Demy 8vo, $32 s$.

SAMUEL, Sydney M.-Jewish Life in the East. Small crown 8vo, 3s. 6d.

SARTORIUS, Emestine.-Three Months in the Soudan. With II Full-page Illustrations. Demy 8vo, I 4 s.

SAYCE, Rev. Archibald Henry. - Introduction to the Science of Language. 2 vols. Second Edition. Large post 8vo, $21 s$.

Scientific Layman. The New Truth and the Old Faith : are they Incompatible? Demy 8vo, ros. 6 .

SCOONES, IV. Baptistc.-Four Centuries of English Letters: A Selection of 350 Letters by 150 Writers, from the Period of the Paston Letters to the Present Time. Third Edition. Large crown 8 vo, $6 s$.

SEE, PROF. GERMAIN.-Bacillary Phthisis of the Lungs. Translated and edited for English Practitioners by WilliaM Henry Weddeli, M.R.C.S. Demy 8vo.

SHILLITO, Rev. Foseph.-WKomanhood: its Duties, Tempiations, and Privileges. A Book for Young Women. Third Edition. Crown 8vo, 3s. 6 d.

SHIPLEY, Rev. Orby, M.A.-Principles of the Faith in Relation to Sin. Topics for Thought in Times of IRetreat. Eleven Addresses delivered during a Retreat of Three Days to Persons living in the World. Demy 8vo, I2s.

SIDNEY, Algemon.-A Review. By Gertrude M. Ireland BlackBURNE. Crown 8 vo, $6 s$.

Sister Augustine, Superior of the Sisters of Charity at the St. Johannis Hospital at Bonn. Authorised Translation by HANS TharaU, from the German "Memorials of AMalie voN LASAULX." Cheap Edition. Large crown 8vo, 4s. 6 \%.

STINNER, Fames.-A Memoir. By the Author of "Charles Lowder." With a Preface by the Rev. Canon Carter, and Portrait. Large crown, $7 s .6 d$.

** Also a cheap Edition. With Portrait. Crown Sro, 3s. 6

SMITII, Edward, M.D., LL.B., F.R.S.-Tubercular Consumption in its Early and Remediable Stages. Second Edition. Crown 8vo, 6s.

SPEDDING, Fames.-Reviews and Discussions, Literary, Political, and Historical not relating to Bacon. Demy Svo, 12s. $6 d$.

Evenings with a Reviewer; or, Bacon and Macaulay. With a Prefatory Notice by G. S. Venables, Q.C. 2 vols. Demy Sro, r8s. 
STAPFER, Paul.-Shakespeare and Classical Antiquity: Greek and Latin Antiquity as presented in Shakespeare's Plays. Translated by EmILY J. CAREY. Large post 8vo, i2s.

STATHAM, F. Reginald.-Free Thought and Truth Thought. A Contribution to an Existing Argument. Crown 8vo, 6s.

STEVENSON, Rev. W. F.-Hymns for the Church and Home. Selected and Edited by the Rev. W. FLEMing STEvenson.

The Hymn Book consists of Three Parts :-I. For Public Worship.-II. For Family and Private Worship.-III. For Children. Small Edition. Cloth limp, iod.; cloth boards, is. LARGe Type Edition. Cloth limp, Is. $3 d$; ; cloth boards, Is. 6 .

Stray Papers on Education, and Scenes from School Life. By B. H. Second Edition. Small crown 8vo, 3s. $6 \pi$.

STREATFEILD, Rev. G. S., M.A.-Lincolnshire and the Danes. Large crown 8vo, 7s. $6 d^{\circ}$.

STRECKER-WISLICENUS.-Organic Chemistry. Translated and Edited, with Extensive Additions, by W. R. HoDGKINson, Ph.D., and A. J. Greenaway, F.I.C. Demy 8vo, 2 Is.

Study of the Prologue and Epilogue in English Literature. From Shakespeare to Dryden. By G. S. B. Crown 8vo, $5 s$.

SULLY, Fames, M.A.-Pessimism: a History and a Criticism. Second Edition, Demy 8vo, I 4 s.

SUTHERST, Thomas. - Death and Disease Behind the Counter. Crown 8vo, Is. 6d.; sewed, Is.

SWEDENBORG, Eman.-De Cultu et Amore Dei ubi Ágitur de Telluris ortu, Paradiso et Vivario, tum de Primogeniti Seu Adami Nativitate Infantia, et Amore. Crown $8 v 0,6 s$.

SYME, David.-Representative Government in Engiand. Its Faults and Failures. Second Edition. Large crown 8vo, $6 s$.

Tacitus"s Agricola. A Translation. Small crown $8 \mathrm{vo}, 2 s .6 d$.

TAYLOR, Rev. Isaac. - The Alphabet. An Account of the Origin and Development of Letters. With numerous Tables and Facsimiles. 2 vols. Demy 8vo, 36 s.

TAYLOR, Feremy. - The Marriage Ring. With Preface, Notes, and Appendices. Edited by Francis BURDETT MONEY CoutTs. Small crown 8vo, 2s. $6 d$.

TAYLOR, Sedley. - Profit Sharing between Capital and Labour. To which is added a Memorandum on the Industrial Partnership at the Whitwood Collieries, by ARCHIBALD and HENRY BRIGGS, with remarks by SEDLEY TAYLOR, Crown 8 ro, $2 s .6 d$. 
Thirty Thousand Thoughts. Edited by the Rev. CAron SPENcE, Rer. J. S. Exell, and Rev. Charles Neil. 6 rols. Super royal 8ro.

[Vols. I., II., and III. now ready, I6s, each.

THOM, F. Hamitton.-Iarys of Life after the Inind of Christ. Second Edition. Crown 8vo, 7s. 6l.

THOMSON, F. Tumbull. Social Problems; or, An Inquiry into the Laws of Influence. With Diagrams. Demy 8ro, ros. 6\%.

TIDMAN, Paul F.-Gold and Silver Money. Part I.-A Plain Statement. Part II._Objections Answered. Third Edition. Crown 8vo, is.

TIPPLE, Rev. S. A.-Sunday Mornings at Norwood. Prayers and Sermons. Crown 8ro, $6 s$.

TODHUNTER, Dr. F-A Siudy of Shelley. Crown 8ro, 75.

TRANT, William.-Trade Unions: Their Origin, Objects, and Efficacy. Small crown 8ro, Is. 6d.; paper covers, Is.

TREMENHEERE, Hugh Seymour, C.B.-A Manual of the Principles of Governments as set forth by the Authorities of Ancient and Modern Times. New and Enlarged Edition. Crown 8vo, 3s. 6\%.

TUKE, Daniel Hack, M.D., F.R.C.P.-Chapters in the Existory of the Insane in the British Isles. With Four Illustrations. Large crown 8ro, I2s.

TWINING, Lonisa.-Workhouse Visiting and Management during Twenty-Five Years. Small crown 8ro, $2 s$.

TYLER, F.-The I.iystery of Being: or, Withat Do WWe IXnowy? Small crown 8vo, 3s. 6\%.

UPTON, Major R. D.-Gleanings from the Desert of Arabia. Large post $8 \mathrm{ro}$, IOs. $6 \pi$.

VACUUS VIATOR.-Flying South. Recollections of France and its Littoral. Small crown 8vo, 3s. 6i.

VAUGHAN, H. Halford. -New Readings and Renderings of Shakespeares's Tragedies. 2 vols. Demy 8ro, 25 s.

VILLARI, Professor.-Niccolò IvIachiavelli and his Times. Translated by LiNDA VilLARI. 4 vols. Large post 8vo, 48 s.

VILLIERS, The Right IIon. C. P.-Free Trade Speeches of. With Political Memoir. Edited by a Member of the Cobden Club. 2 vols. With Portrait. Demy 8vo, $25 s$.

*** Pcople's Edition. I vol. Crown 8ro, limp cloth, 2s. 6 d.

VOGT, Lieut.-Col. IIcrmann.-The Egyptian War of 1882. A translation. With Map and Plans. Large crown $80^{\circ} 0,6 s$.

VOLCKXSOM, E. W. :-Catechism of Elementary Modern Chemistry. Small crown 8ro, 35. 
VYNER, Lady Mary.-Every Day a Portion. Adapted from the Bible and the Prayer Book, for the Private Devotion of those living in Widowhood. Collected and Edited by Lady Mary Vyner, Square crown 8 vo, 5 .

WALDSTEIN, Charles, Ph.D.-The Balance of Emotion and Intellect; an Introductory Essay to the Study of Philosophy. Crown $8 \mathrm{vo}, 6 s$.

WALLER, Rev. C. B.-The Apocalypse, reviewed under the Light of the Doctrine of the Unfolding Ages, and the Restitution of All Things. Demy 8vo, I $2 s$.

WALPOLE, Chas. George.-A Short History of Ireland from the Earliest Times to the Union with Great Britain. With 5 Maps and Appendices. Second Edition. Crown 8vo, 6s.

WALSHE, Walter Hayle, NK.D.-Dramatic Singing Physiologically Estimated. Crown 8vo, 3 s. $6 d$.

WARD, William George, Ph.D.-Essays on the Philosophy of Theism. Edited, with an Introduction, by WILFRID WARD. 2 vols. Demy 8vo, 2Is.

WARD, Wilfrid.-The Wish to Believe $\mathrm{A}$ Discussion Concerning the Temper of Mind in which a reasonable Man should undertake Religious Inquiry. Small crown 8vo, 5 s.

WEDDERBURN, Sir David, Bart., M.P.-Life of . Compiled from his Journals and Writings by his sister, Mrs. E. H. PERCIVAL. With etched Portrait, and facsimiles of Pencil Sketches. Demy 8vo, I 4 s.

WEDMORE, Frederick.-The Masters of Genre Painting* With Sixteen Illustrations. Post $8 \mathrm{vo}, 7 s .6 d$.

What to Do and How to Do It. A Manual of the Law affecting the Housing and Sanitary Condition of Londoners, with special Reference to the Dwellings of the Poor. Issued by the Sanitary Laws Enforcement Society. Demy 8vo, Is.

WHEWELL, William, D.D.- His Life and Selections from his Correspondence. By Mrs. Stair Douglas. With a Portrait from a Painting by Samuel Laurence. Demy 8vo, 2 Is.

WHITNEY, Prof. William Dwight. - Essentials of English Grammar, for the Use of Schools. Second Edition. Crown $8 \mathrm{vo}, 3 s .6 d$.

WILLIAMS, Rowland, D.D.-Psalms, Litanies, Counsels, and Collects for Devout Persons. Edited by his Widow. New and Popular Edition. Crown 8vo, 3s. $6 d$.

Stray Thoughts Collected from the Writings of the late Roxxland $W$ illiams, $D . D$, Edited by his Widow. Crown 8vo, 3s. 6d.

WILSON, Lieut.-Col. C. T. - The Duke of Berxyick, Marshal of France, 1702-1734. Demy 8vo, I5s. 
WILSON, Mrs. R. F.-The Christian Brothers. Their Origin and Work. With a Sketch of the Life of their Founder, the Ven. Jean Baptiste, de la Salle. Crown 8vo, $6 s$.

WOLTMANN, Dr. Alfred, and WOERMANN, Dr. Karl.-History of Painting. Edited by Sidney Colvis. Vol. I. Painting in Antiquity and the Middle Ages. With numerous Illustrations. Medium 8vo, 28s. ; bevelled boards, gilt leaves, 30 s.

Word was Made Flesh. Short Family Readings on the Epistles for each Sunday of the Christian Year. Demy 8ro, Ios. 6d.

WREN, Sir Christopher.-His Family and His Times. With Original Letters, and a Discourse on Architecture hitherto un. published. By Lucy Phillimore. Demy 8vo, Ios. $6 d$.

YOUMANS, Eliza A.-First Book of Botany. Designed to Cultivate the Observing Powers of Children. With 300 Engravings. New and Cheaper Edition. Crown 8vo, 2s. 6d.

YOUMANS, Edward L., M.D.-A Class Book of Chemistry, on the Basis of the New System. With 200 Illustrations. Crown 8 ro, 5 s.

\section{THE INTERNATIONAL SCIENTIFIC SERIES.}

I. Forms of Water: a Familiar Exposition of the Origin and Phenomena of Glaciers. By J. Tyndall, LL.D., F.R.S. IVith 25 Illustrations. Eighth Edition. Crown 8vo, 5s.

II. Physics and Politics; or, Thoughts on the Application of the Principles of "Natural Selection" and "Inheritance" to Politicai Society. By Walter Bagehot. Sixth Edition. Crown 8ro, 4s.

III. Foods. By Edward Smith, M.D., LL.B., F.R.S. With numerous Illustrations. Eighth Edition. Crown 8vo, 5s.

IV. Mind and Body: the Theories of their Relation. By Alexander Bain, LL.D. With Four Illustrations. Seventh Edition. Crown 8 vo, 4 s.

V. The Study of Sociology. By Herbert Spencer. Elerenth Edition. Crown 8ro, 5 s.

VI. On the Conservation of Energy. By Balfour Stewart, M.A., LL.D., F.R.S. With I4 Illustrations. Sixth Edition. Crown Sro, 5 s.

VII. Animal Locomotion; or Walking, Swimming, and Flying. By J. B. Pettigrew, M.D., F.R.S., etc. With I 30 Illustrations. Third Edition. Crown 8vo, 5 s.

VIII. Responsibility in Mental Disease. By Henry Maudsley, M.D. Fourth Edition. Crown 8ro, $5^{s}$. 
IX. The INew Chemistry. By Professor J. P. Cooke. With 3I Illustrations. Eighth Edition, remodelled and enlarged. Crown 8vo, 5 s.

X. The Science of Law * By Professor Sheldon Amos. Fifth Edition. Crown 8vo, 5 s.

XI. Animal Mechanism : a Treatise on Terrestrial and Aerial Locomotion. By Professor E. J. Marey. With II7 Illustrations, Third Edition. Crown 8vo, 5 s.

XII. The Doctrine of Descent and Darwinism. By Professor Oscar Schmidt. With 26 Illustrations. Sixth Edition. Crown 8 ro, 5 s.

XIII. The History of the Conflict betwreen Religion and Science. By J. W. Draper, M.D., LL.D. Eighteenth Edition. Crown 8vo, $5^{s}$.

XIV. Fungi : their Nature, Influences, Uses, etc. By M. C. Cooke, M.D., LL.D. Edited by the Rev. M. T. Berkeley, M.A., F.L.S.

With numerous Illustrations. Third Edition. Crown 8vo, 5 s.

XV. The Chemical Effects of Light and Photography. By Dr. Hermann Vogel. Translation thoroughly Revised. With Ioo Illustrations. Fourth Edition. Crown 8vo, $5^{s}$.

XVI. The Life and Growth of Language. By Professor William Dwight Whitney. Fourth Edition. Crown 8ro, 5 s.

XVII. Money and the Mechanism of Exchange. By W. Stanley Jevons, M.A., F.R.S. Sixth Edition. Crown 8vo, 5 s.

XVIII. The Nature of Light. With a General Account of Physical Optics. By Dr. Eugene Lommel. With I88 Illustrations and a Table of Spectra in Chromo-lithography. Third Edition. Crown 8 vo, 5 s.

XIX. Animal Parasites and Messmates By P. J. Van Beneden. With 83 Illustrations. Third Edition. Crown 8ro, 5 s.

XX. Fermentation. By Professor Schiitzenberger. With 28 Illustrations. Fourth Edition. Crown 8vo, 5s.

XXI. The Five Senses of Man. By Professor Bernstein. With 9I Illustrations. Fourth Edition. Crown 8vo, 5 s.

XXII. The Theory of Sound in its Relation to IMusic. By Pro: fessor Pietro Blaserna. With numerous Illustrations. Third Edition. Crown 8vo, 5 s.

XXIII. Studies in Spectrum Analysis. By J. Norman Lockyer, F.R.S. With six photographic Illustrations of Spectra, and numerous engrarings on Wood. Third Edition. Crown 8ro, $6 s .6 d$.

XXIV. A History of the Growth of the Steam Engine. By Professor R. H. Thurston. With numerous Illustrations. Third Edition. Crown 8vo, $6 s, 6 \pi$. 
XXV. Education as a Science. By Alexander Bain, LL.D. Fourth Edition. Crown 8ro," 5 s.

XXVI. The Iuman Species. By Professor A. de Quatrefages. Third Edition. Crown 8ro, 5 s.

XXVII. Modern Chromatics. With Applications to Art and Industry. By Ogden N. Rood. With I3O original Illustrations. Second Edition. Crown 8vo, 5 s.

XXVIII. The Crayfish: an Introduction to the Study of Zoology. By Professor T. H. Huxley. With 82 Illustrations. Fourth Edition. Crown 8ro, 5 s.

XXIX. The Brain as an Organ of Mind. By H. Charlton Bastian, M.D. With numerous Illustrations. Third Edition. Crown 8 vo, 5 s.

XXX. The Atomic Theory. By Prof. Wurtz. Translated by G. Cleminshaw, F.C.S. Third Edition. Crown 8vo, 5 s.

XXXI. The Natural Conditions of Existence as they affect Animal Life. By Karl Semper. With 2 Maps and 106 Woodcuts. Third Edition. Crown 8vo, 5 s.

XXXII. General Physiology of Muscles and Nerves. By Prof. J. Rosenthal. Third Edition. With Illustrations. Crown 8vo, 5 .

XXXIII. Sight: an Exposition of the Principles of Monocular anci Binocular Vision. By Joseph le Conte, LL.D. Second Edition. With I32 Illustrations. Crown 8vo, 5 s.

XXXIV. Illusions: a Psychological Study. By James Sully. Second Edition. Crown 8vo, $5^{s}$.

XXXV. Volcanoes: what they are and what they teach. By Professor J. W. Judd, F.R.S. With 92 Illustrations on Wood. Third Edition. Crown 8vo, 5 s.

XXXVI. Suicide : an Essay on Comparative Moral Statistics. By Prof. H. Morselli. Second Edition. With Diagrams. Crown 8vo, $5 s$.

XXXVII. The Brain and its Functions. By J. Lilys. With Illustrations. Second Edition. Crown 8ro, 5 s.

XXXVIII. Myth and Science : an Essay. By Tito Vignoli. Second Edition. Crown 8vo, 5 s.

XXXIX. The Sun. By Professor Young. With Illustrations. Second Edition. Crown 8vo, 5 s.

XL. Ants, Bees, and W asps: a Record of Observations on the Habits of the Social Hymenoptera. By Sir John Lubbock, Bart., M.P. With 5 Chromo-lithographic Illustrations. Seventh Edition. Crown 8 vo, $5^{s}$. 
XLI. Animal Intelligence. By G. J. Romanes, LL.D., F.R.S. Third Edition. Crown 8vo, 5 s.

XLII. The Concepts and Theories of Modern Physics. By J. B. Stallo. Third Edition. Crown 8vo, 5 s.

XLIII. Diseases of the Memory; An Essay in the Positive Psychology. By Prof. Th. Ribot. Second Edition. Crown 8vo, $5 s$.

XLIV. Man before Metals. By N. Joly, with 148 Illustrations. Third Edition. Crown 8vo, 5 s.

XLV. The Science of Politics. By Prof. Sheldon Amos. Third Edition. Crown 8vo, 5 s.

XLVI. Elementary Meteorology: By Robert H. Scott. Third Edition. With Numerous Illustrations. Crown 8vo, 5 .

XLVII. The Organs of Speech and their Application in the Formation of Articulate Sounds. By Georg Hermann Von Meyer. With 47 Woodcuts. Crown 8vo, $5 s$.

XLVIII. Fallacies. A View of Logic from the Practical Side. By Alfred Sidgwick. Crown 8vo, $5^{s}$.

XLIX. Origin of Cultivated Plants. By Alphonse de Candolle. Crown 8vo, 5 s.

L. Jelly-Fish, Star-Fish, and Sea-Urchins, Being a Research on Primitive Nervous Systems. By G. J. Romanes. Crown $8 \mathrm{vo}, 5 s$.

\section{MILITARY WORKS.}

BARRINGTON, Capt. F. T.-England on the Defensive; or, the Problem of Invasion Critically Examined. Large crown 8vo, with Map, $7 s .6 d$.

BRACKENBUR Y, Col. C. B., R.A. - Military Kandbooks for Regimental Officers.

I. Military Sketching and Reconnaissance. By Col. F. J. Hutchison and Major H. G. MacGregor. Fourth Edition. With 15 Plates. Small crown 8vo, $4 s$.

II. The Elements of Modern Tactics Practicaliy applied to English Formations. By Lieut.-Col. Wilkinson Shaw. Fifth Edition. With 25 Plates and Maps. Small crown 8vo, 9 s.

III. Field Artillery. Its Equipment, Organization and Tactics. By Major Sisson C. Pratt, R.A. With I2 Plates. Second Edition. Small crown 8vo, $6 s$. 
Military Handbooks-continued.

IV. The Elements of Military Administration. First Part: Permanent System of Administration. By Major J. W. Buxton. Small crown 8vo. $7 s .6 d$.

V. Military Law: Its Procedure and Practice. By Major Sisson C. Pratt, R.A. Second Edition. Small crown 8vo, 4 s. $6 d$.

VI. Cavalry in Modern War. By Col. F. Chenevix Trench. Small crown 8vo, $6 s$.

VII. Field Works* Their Technical Construction and Tactical Application. By the Editor, Col. C. B. Brackenbury, R.A. Small crown 8vo.

BROOKE, Major, C. K.-A System of Field Training. Small crown 8vo, cloth limp, 2s.

CLERY, C., Lieut.-Col.-Minor Tactics. With 26 Maps and Plans. Sixth and Cheaper Edition, Revised. Crown 8vo, 9 s.

COLVILE, Lieut.-Col. C. F.-Military Tribunals. Sewed, $2 s .6 \pi$. CRAUFURD, Capt. H. F.-Suggestions for the Military Training of a Company of Infantry. Crown 8vo, is. $6 d$.

HARRISON, Lieut.-Col. R.-The Officer's Memorandum Book for Peace and WNar. Third Edition. Oblong 32mo, roan, with pencil, $3 s .6 d$.

Notes on Cavalry Tactics, Organisation, etc. By a Cavalry Officer. With Diagrams. Demy 8vo, I2s.

PARR, Capt. H. Hallam, C.M.G.-The Dress, Horses, H $_{3}$ and Equipment of Infantry and Staff Officers, Crown 8vo, is.

SCHAW, Col. H. - The Defence and Attack of Positions and Localities. Third Edition, Revised and Corrected. Crown 8vo, 3s. $6 d$.

WILKINSON, H. Spenser, Capt. 20th Lancashire R.V.-Citizen Soldiers. Essays towards the Improvement of the Volunteer Force. Crown 8 vo, $2 s .6 d$.

\section{POETRY.}

ADAM OF ST: VICTOR.-The Liturgical Poetry of Adam of St. Victor. From the text of GAUTIER. With Translations into English in the Original Metres, and Short Explanatory Notes, by DigBy S. Wrangitam, M.A. 3 vols. Crown 8vo, printed on hand-made paper, boards, $2 \mathrm{I}$ s.

AUCHMUTY, A. C.-Poems of English Heroism : From Brunanburh to Lucknow; from Athelstan to Albert. Small crown 8vo, Is. 6 . 
AVIA. - The Odyssey of Homer: Done into English Verse by. Fcap. 4to, I5s.

BARING, T. C., M.P.-The Scheme of Epicurus A Rendering into English Verse of the Unfinished Poem of Lucretius, entitled "De Rerum Naturâ." Fcap. 4to, $7 s$.

BARNES, William.-Poems of Rural Life, in the Dorset Dialect. New Edition, complete in one vol. Crown 8vo, 8s. $6 d$.

BAYNES, Rev. Canon H. R.-Home Songs for Quiet Hours. Fourth and Cheaper Edition. Fcap. 8vo, cloth, 2s. $6 d$.

$B E N D A L L$, Gerard.-Musa Silvestris. I6mo, Is. $6 \mathrm{~d}$. BEVIAGTON, L. S.-Wey Notes: Small crown 8vo, 5 s. BILLSON, C. F.-The Acharnians of Aristophanes. Crown 8vo, 3 s. $6 d$.

BLUNT, Wilfrid Scaven. - The Wind and the Whirlwind. Demy $8 \mathrm{vo}, \mathrm{r} s .6 d$.

BOWEN, H. C., M.A.-Siraple English Poems: English Literature for Junior Classes. In Four Parts. Parts I., II., and III., $6 d$. each, and Part IV., Is. Complete, 3 s.

BRASHER, Alfred.-Sophia * or, the Viceroy of Valencia. A Comedy in Five Acts, founded on a Story in Scarron. Small crown 8vo, $2 s .6 d$.

BRYANT, W. C.-Poems: Cheap Edition, with Frontispiece. Small crown 8 vo, 3 s. $6 \%$.

BYRNNE, E. Fairfax.-Milicent: a Poem. Small crown 8vo, 6s.

CAILLARD, Emma Marie.-Charlotte Corday, and other Poems. Small crown 8vo, 3 s. $6 d$.

Calderon's Dramas: the Wonder-Working Magician-Life is a Dream-the Purgatory of St. Patrick. Translated by DeNis Florence MacCarthy. Post 8vo, ros.

Camoens Lusiads: - Portuguese Text, with Translation by J. J. Aubertin. Second Edition. 2 vols. Crown 8vo, I2s.

CAMPBELL, Lewis. -Sophocles. The Seven Plays in English Verse. Crown 8vo, $7 s .6 d$.

Castilian Brothers (The), Chateaubriant, WXaldemar: Three Tragedies; and The Rose of Sicily: a Drama. By the Author of "Ginevra," etc. Crown 8vo, 6 s.

Christian (Owen) Poems. Small crown 8vo, 2s. 6\%.

Chronicles of Christopher Columbus. A Poem in 12 Cantos. By M. D. C: Crown 8vo, 7s. 6 6 . 
CLARKE, Mary Cowden.-Honey from the IWeed. Verses. Crown 8vo, $7 s$.

Cosmo de Medici; The False One; Agramont and Beaum mont: Three Tragedies; and The Deformed: a Dramatic Sketch. By the Author of "Ginevra," etc., etc. Crown 8vo, 5 s.

COXHEAD, Ethel.-Birds and Babies. Imp. 16mo. With 33 Illustrations. Gilt, 2s. $6 d$.

David Rizzio, Bothwell $y$ and the Witch Lady: Three Tragedies. By the author of "Ginevra," etc. Crown 8vo, $6 s$.

DAVIE, G.S., M.D. - The Garden of Fragrance. Being a complete translation of the Bostán of Sádi from the original Persian into English Verse. Crown 8vo, $7 s .6 d$.

DAVIES, T. Hart.-Catullus. Translated into English Verse. Crown 8vo, $6 s$.

DENNIS, F.-English Sonnets. Collected and Arranged by. Small crown 8vo, 2s. $6 d$.

DE VERE, Aubrey.-Poetical WXorks.

I. The Search after Proserpine, etc. 6s.

II. The Legends of St. Patrick, etc. $6 s$.

III. Alexander the Great, etc. 6s.

The Foray of Queen Meave and other Legends of Ireland's Heroic Age. Small crown 8vo, 5 s.

Legends of the Saxon Saints. Small crown 8ro, $6 s$.

DILLON, Arthur.-River Songs and other Poems. With $\mathrm{I}_{3}$ autotype Illustrations from designs by Margery May. Fcap. 4to, cloth extra, gilt leaves, Ios. $6 d$.

DOBELL, Mrs. Horace.Ethelstone, Eveline, and other Poems. Crown 8vo, $6 s$.

DOBSON, Austin.-Old World Idylls and other Verses. Fourth Edition. I8mo, cloth extra, gilt tops, 6 .

DOMET, Alfred.-Ranolf and Amohia. A Dream of Two Lives. New Edition, Revised. 2 vols. Crown 8vo, I2s.

Dorothy: a Country Story in Elegiac Verse. With Preface. Demy 8 vo, 5 s.

DOWDEN, Edward, LL.D.-Shakspere's Sonnets. With Intro. duction and Notes. Large post 8ro, $7 s .6 \pi$.

DUTT, Ton. - A Sheaf Gleaned in French Fields. New Edition. Demy 8vo, Ios. $6 d$.

EDMONDS, E. IT. - Hesperas. Rhythm and Rhyme. Crown 8vo, 4 s. EDWARDS, Miss Betham.-Poems. Small crown 8vo, 3s. 6\%. 
ELDRYTH, Maud.-Margaret, and other Poems. Small crown 8ro, 3s. $6 d$.

All Soul's Eve, "No God," and other Poems. Fcap. 8vo, 3 s. $6 \pi$.

ELLIOTT, Ebenezer, The Corn Law Rhymer.-Poems. Edited by his son, the Rev. EDwin Elliotr, of St. John's, Antigua. 2 vols. Crown 8 ro, i $8 s$.

English Verse. Edited by W. J. Linton and R. H. Stoddard. 5 rols. Crown 8 vo, cloth, 5 s. each.

I. Chaucer to Burns,

II. Translations.

iII. Lyrics of the Nineteenth Century.

IV. Dramatic Scenes and CharaCters.

V. BALlads AND ROMANCES.

ENIS.-Gathered Leaves. Small crown 8vo.

EVANS, Anne-Poems and Music. With Memorial Preface by ANn Thackeray Ritchie. Large crown 8ro, $7 s$.

FORSTER, the late William.-Midas. Crown 8vo, 5 s.

GINNER, Isaac B.-The Death of Otho and other Poems. Small crown 8vo, 5 s.

GOODCHILD, fohn A.-Somnia Medici. Small crown 8vo, $5^{s}$.

GOSSE, Edmund W.-Nexy Poems. Crown 8vo, 7 s. $6 \mathrm{~d}$.

GRAHAM, William. Two Fancies, and other Poems. Crown 8ro, 5 s.

GRINDROD, Charles. Plays from English History. Crown 8ro, $75.6 d$.

The Stranger's Story, and his Poem, The Lament of Love: An Episode of the Malvern Hills. Small crown 8ro, 2s. $6 d$.

GURNEY, Rev. Alfred. - The Vision of the Eucharist, and other Poems. Crown 8vo, 5 s.

A Christmas Faggot. Small crown 8ro, 5 s.

HELLON, H. G.-Daphnis: a Pastoral Poem. Small crown 8vo, 3 s. 6 d.

HENR Y, Daniel, Funr. - Under a Fool's Cap. Songs. Crown 8vo, cloth, bevelled boards, 5 s.

Herman Waldgrave: a Life's Drama. By the Author of "Ginevra," etc. Crown 8 vo, $6 s$.

HEYWOOD, 7. C.-Herodias, a Dramatic Poem. New Edition, Revised. Small crown 8vo, 5 s.

HICKEY, E. H. A Sculptor, and other Poems. Small crown 8 vo, 5 s. 
HONEYWOOD, Patty.-Poems. Dedicated (by permission) to Lord Wolseley, G.C.B., etc. Small crown 8vo, 2s. $6 d$.

FENKINS, Rev. Canon-Alfonso Petrucci, Cardinal and Conspirator: an Historical Tragedy in Five Acts. Small crown 8vo, 3 s. $6 d$.

FOHNSON, Emle S. W.-Ylaria and other Poems. Small crown 8vo, 3s. $6 d$.

KEATS, Fohn.-Poetical WXorks. Edited by W. T. ArNoLd. Large crown 8vo, choicely printed on hand-made paper, with Portrait in eau-forte. Parchment or cloth, I2s.; vellum, I 5 s.

KENNEDY, Captain A. W. M. Clark.-Robert the Bruce. A Poem: Historical and Romantic. With Three Illustrations by James Faed, Jun. Printed on hand-made paper, parchment, bevelled boards, crown 8 vo, Ios. $6 d$.

$K I N G$, Edward.-Echoes from the Orient. With Miscellaneous Poems. Small crown 8vo, 3 s. $6 d$.

$K I N G, M r s$. Hamilton.-The Disciples. Sixth Edition, with Portrait and Notes. Crown 8vo, 5 s.

A Book of Dreams. Crown 8vo, 3s. 6 .

KNOX, The Hon. Mrs. O. N.-Four Pictures from a Life, and other Poems. Small crown 8vo, 3s. $6 d$.

$L A N G, A$-XXXII Ballades in Blue China. Elzovir 8vo, parchment, 5 s.

Rhymes à la Mode. With Frontispiece by E. A. Abbey. I8mo, gilt tops, 5 s.

LAWSON, Right Hon. Mr. Justice.-Hymni Usitati Latine Redditi : with other Verses. Small 8vo, parchment, 5 s.

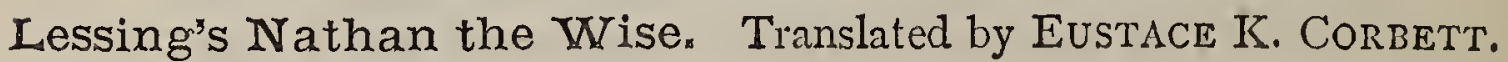
Crown 8vo, 6 s.

Life Thoughts. Small crown 8vo, 2s. $6 d$.

Living English Poets MDCGCLXXXIY. With Frontispiece by Walter Crane. Second Edition. Large crown 8vo. Printed on hand-made paper. Parchiment or cloth, I2s. ; vellum, I5s.

LOCKER, F.-London Lyrics. New Edition. With Portrait, I $8 \mathrm{mo}$. Cloth extra, gilt tops, 5 .

Love in Idleness. A Volume of Poems. With an Etching by W. B. Scott. Small crown 8vo, 5 s.

Love Sonnets of Proteus. With Frontispiece by the Author. Elzevir $8 \mathrm{vo}, 5$ s.

LUMSDEN, Lieut.-Col. H. W.-Beowulf: an Old English Poem. Translated into Modern Rhymes. Second and Revised Edition. Small crown 8vo, 5 s. 
Lyre and Star. Poems by the Author of "Ginevra," etc. Crown $8 \mathrm{vo}, 5$ s.

MACGREGOR, Duncan.-Clouds and Sunlights Poems. Small crown 8vo, $5^{5}$.

MAGNUSSON, Eirikr, M.A., and PALMER, E. H., M.A.-Johan Ludvig Runeberg's Lyrical Songs, Idylls, and Epigrams. Fcap. 8vo, 5 s.

M.D.C.-Chronicles of Christopher Columbus: A Poem in Twelve Cantos. Crown 8vo, $7 s .6 d$.

MEREDITH, Owen [The Earl of Lytton].-Lucile. New Edition. With 32 Illustrations. I6mo, $3 s$. $6 d$. Cloth extra, gilt edges, 4s. $6 d^{2}$.

MORRIS, Lewis.-Poetical Works of. New and Cheaper Editions, with Portrait. Complete in 3 vols., 5 s, each.

Vol. I. contains "Songs of Two Worlds." Eleventh Edition.

Vol. II. contains "The Epic of Hades." Eighteenth Edition.

Vol. III. contains "Gwen" and "The Ode of Life." Sixth Edition.

The Epic of Hades. With I6 Autotype Illustrations, after the Drawings of the late George R. Chapman. 4to, cloth extra, gilt leaves, $2 \mathrm{i} s$.

The Epic of Hades. Presentation Edition. 4to, cloth extra, gilt leaves, Ios. $6 \%$.

Songs Unsung: Fourth Edition. Fcap. 8vo, 6s.

The Lewis Morris Birthday Book. Edited by S. S. CopeMAN, with Frontispiece after a Design by the late George R. Chapman. 32mo, cloth extra, gilt edges, $2 s$. ; cloth limp, Is. $6 d$.

MORSHEAD, E. D. A. - The House of Atreus. Being the Agamemnon, Libation-Bearers, and Furies of Æschylus. Translated into English Verse. Crown 8vo, $7 s$.

The Suppliant Maidens of 2 Eschylus. Crown $8 \mathrm{vo}, 3 s .6 \pi$.

NADEN, Constance W.-Songs and Sonnets of Spring Time. Simall crown 8vo, 5 s.

NEWELL, E. F.-The Sorrows of Simona and Lyrical Verses. Small crown 8vo, $3 s .6 d$.

NOEL, The Hon. Roden. - A Little Ghild's Monument. Third Edition. Small crown 8vo, 3s. 6d.

The Red Flag, and other Poems. New Edition. Small crown 8 vo, $6 s$.

O'HAGAN, folm.-The Song of Roland. Translated into English Verse. New and Cheaper Edition. Crown 8vo, 5 .

PFEIFFER, Emily. - The Rhyme of the Lady of the Rock. and How it Grexy. Small crown 8vo, $35.6 d$. 
PFEIFFER, Emily-continued.

Gerard's Monument, and other Poems. Second Edition. Crown 8ro, 6s.

Under the Aspens: Lyrical and Dramatic. With Portrait. Crown 8vo, 6s.

PIATT, F. F.-Idyls and Iyrics of the Ohio Valley. Crown
8ro, 5s. RAFFALOVICH, Mark André. - Cyril and Lionel, and other Poems. A rolume of Sentimental Studies. Small crown Sro, 3. $6 d$.

Rare Poems of the 16 th and 17 th Centuries. Edited V. J. LiNTON. Crown 8ro, 5 s.

RHOADES, Fames. - The Georgics of Virgil. Translated into English Verse. Small crown 8ro, 5 s.

ROBINSON, A. Mary F.-A Handful of Honeysuckle. Fcap. 8vo, 3 s. $6 \pi$.

The Crowned Hippolytus. Translated from Euripides. With New Poems. Small crown Sro, 5 s.

ROUS, Lieut.-Col.-Conradin. Small crown 8ro, 2s.

Schiller's Mary Stuart. German Text, with English Translation on opposite page by LeEdhair White. Crown 8 ro, $6 s$.

SCOTT, E.J. L.-The Eclogues of Virgil. - Translated into English Verse. Small crown 8vo, 3s. $6 \pi$.

SCOTT, George F. E.-Theodora and other Poems. Small crown 8vo, 3s. 6 .

SEAL, W. H.-Tone, and other Poems. Second and Cheaper Edition, revised, crown 8 ro, $3 s .6 d$.

SELKIRK, J. B.-Poems. Crown 8ro, $75.6 \%$

SHARP, William.-Euphrenia: or, The Test of Lore. A Poem Crown 8ro, 5 s.

SKINNER, H. F.-The Lily of the Lyn, and other Poems. Small crown 8ro, 3s. $6 d$.

SLADEN, Douglas B.-Frithjof and Ingebjorg, and other Poems. Small crown 8ro, 5 s.

SMITH, F. W. Gilbart. - The Loves of Vandyck. A Tale of Genoa. Small crown 8ro, 2s. $6 d$.

The Log o" the "Norseman." Small crown 8ro, 5 s.

Sophocles: The Seven Plays in English Verse. Translated by LEwIs CaMpbeli. Crown 8ro, 7s. $6 \mathrm{~d}$. 
SPICER, Henry.-Haska : a Drama in Three Acts (as represented at the Theatre Royal, Drury Lane, March Ioth, I877). Third Edition. Crown 8vo, 3s. $6 d$.

SYMONDS, fohn Addington.-Vagabunduli Libellus. Crown 8vo, 6s.

Tares. Crown 8 vo, is. 6 \%

Tasso's Jerusalem Delivered. Translated by Sir John Kingston JAmES, Bart. Two Volumes. Printed on hand-made paper, parchment, bevelled boards. Large crown 8vo, 21s.

TAYLOR, Sir H.-WOorks. Complete in Five Volumes. Crown $8 \mathrm{vo}, 30 \mathrm{~s}$.

Philip Van Artevelde. Fcap. 8vo, 3s. 6\%.

The Virgin Widox $W_{3}$ etc. Fcap. 8vo, $3 s .6 d$.

The Statesman. Fcap. 8vo, 3s. 6d.

TAYLOR, Augustus.-Poems. Fcap. 8vo, 5 s.

TAYLOR, Margaret Scott.- "Boys Together, ${ }_{3}$ " and other Poems. Small crown 8vo, 6s.

THORNTON, L. M. - The Son of Shelomith. Small crown 8vo, 3s. $6 d$.

TODHUNTER, Dr. F.-Laurella, and other Poems. Crown 8vo, 6s. 6 .

Forest Songs . Small crown 8vo, 3 s. $6 d$.

The True Tragedy of Rienzi : a Drama. $3 s .6 d$.

Alcestis: a Dramatic Poem. Extra fcap. 8vo, 5 s.

TYLER, M. C.-Anne Boleyn. A Tragedy in Six Acts. Small crown 8vo, 2s. $6 d$.

-WALTERS, Sophia Lydia.-A Dreamer's Sketch Book. With 2 I Illustrations by Percival Skelton, R. P. Leitch, W. H. J. Boot, and T. R. Pritchett. Engraved by J. D. Cooper. Fcap. 4to, I2s. $6 d$.

Wandering Echoes.-By J. E. D. G. In Four Parts. Small crown 8vo, $5^{s}$.

WATTS, Alaric Alfred and Anna Mary Horvitt.-Aurora. A Medley of Verse. Fcap. 8vo, bevelled boards, 5 .

WEBSTER, Augusta. - In a Day: a Drama. Small crown 8vo, 2s. 6\%.

Disguises: a Drama. Small crown 8vo, 5 s.

Wet Days. By a Farmer. Small crown 8 vo, $6 s$.

WILLIAMS, F.-A Story of Three Years, and other Poems. Small crown 8 vo, $3 s .6 d$.

Wordsworth Birthday Book, The. Edited by ADELAIDE and VIOLET WORDSWORTH. $32 \mathrm{mo}$, limp cloth, Is. $6 d_{\text {. ; }}$ cloth extra, $2 s$.

YOUNGMAN, Thomas George.-Poems. Small crown 8vo, 5 s. 
YOUNGS, Ella Sharpe.-Paphus s $_{\text {and }}$ other Poems. Small crown 8vo, 3 s. $6 d$.

A Heart's Life, Sarpedon, and other Poems, Small crown $8 \mathrm{vo}^{2} 3,6 d$.

\section{WORKS OF FICTION IN ONE VOLUME.}

BANKS, Mrs. G. L.-God's Providence House. New Edition. Crown 8vo, 3s. $6 \%$.

HUNTER, Hay. - The Crime of Christmas Day. A Tale of the Latin Quarter. By the Author of "My Ducats and my Daughter." Is.

HUNTER, Hay, and WHYTE, Walter.-MY Ducats and MY Daughter. New and Cheaper Edition. With Frontispiece. Crown 8vo, 6s.

INGELOW, fean.-Off the Skelligs : a Novel. With Frontispiece. Second Edition. Crown 8vo, 6 s.

KIELLAND, Alexander.-Garman and Worse. A Norwegian Novel. Authorized Translation, by W. W. Kettlewell. Crown 8vo, 6s.

MACDONALD, G.-Donal Grant. A Norel. New and Cheaper Edition. With Frontispiece. Crown 8vo, 6 s.

Castle WXarlock. A Norel. New and Cheaper Edition. Crown 8 vo, $6 s$.

Malcolm. With Portrait of the Author engraved on Steel. Sixth Edition. Crown 8vo, 6s.

The Marquis of Lossie. Fifth Edition. With Frontispiece. Crown 8vo, 6s.

St. George and St. Michael, Fourth Edition. With Frontispiece. Crown 8ro, 6s.

PALGRAVE, W. Gifford.-Hermann Agha: an Eastern Narrative. Third Edition. Crown 8vo, 6s.

SHAW, Flora L.-Castle Blair; a Story of Youthful Days. New and Cheaper Edition. Crown 8vo, 3s. $6 d$.

STRETTON, Hesba.--Through a Needle's Eye: a Story. New and Cheaper Edition, with Frontispiece. Crown 8vo, 6s.

TAYLOR, Col. Meadows, C.S.I., M.R.I.A.-Seeta: a Novel. New and Cheaper Edition. With Frontispiece. Crown 8vo, $6 s$.

Tippoo Sultaun: a Tale of the Mysore War. New Edition, with Frontispiece. Crown 8vo, 6s.

Ralph Darnell. New and Cheaper Edition. With Frontispiece. Crown 8vo, 6s. 
TAYLOR, Col. Meadows, C.S.T., M.R.T.A.-continued.

A Noble Queen. New and Cheaper Edition. With Frontispiece. Crown 8vo, 6s.

The Confessions of a Thug. Crown 8vo, 6 .

Tara: a Mahratta Tale. Crown 8vo, $6 s$.

Within Sound of the Sea. New and Cheaper Edition, with Frontispiece. Crown 8 ro, 6 s.

\section{BOOKS FOR THE YOUNG.}

Brave Men's Footsteps. A Book of Example and Anecdote for Young People. By the Editor of "Men who have Risen." With 4 Illustrations by C. Doyle. Eighth Edition. Crown 8ro, 3s. 6d.

COXHEAD, Ethel.-Birds and Babies. Imp. I6mo. With 33 Illustrations. Cloth gilt, $2 s .6 d$.

DAVIES, G. Christopher.-Rambles and Adventures of our School Field Club: With 4 Illustrations. New and Cheaper Edition. Crown 8vo, 3s. 6d.

EDMONDS, Herbert.-Well Spent Lives: a Series of Modern Biographies. New and Cheaper Edition. Crown 8vo, 3s. 6d.

EVANS, Mark.-The Story of our Fathers's Love, told to Children. Sixth and Cheaper Edition of Theology for Children. With 4 Illustrations. Fcap. 8vo, Is. 6d.

FOHNSON, Virginia W.-The Catskill Fairies. Illustrated by Alfred Fredericks. $5 s$.

MAC KENNA, S. F.-Plucky Fellowxs. A Book for Boys. With 6 Illustrations. Fifth Edition. Crown 8vo, 3s. $6 d$.

REANE Y, Mrs. G. S.-WWaking and WXorking ; or, From Girlhood to Womanhood. New and Cheaper Edition. With a Frontis. piece. Crown 8vo, 3s. 6d.

Blessing and Blessed: a Sketch of Girl Life. New and Cheaper Edition. Crown 8vo, 3s. 6 0

Rose Gurney"s Discovery: A Book for Girls. Dedicated to their Mothers. Crown 8ro, 3s. 6d.

English Girls: Their Place and Power. With Preface by the Rev. R. W. Dale, Fourth Edition. Fcap. 8vo, 2s. 6 $d$.

Iust Anyone, and other Stories. Three Illustrations. Royal I6mo, Is. 6d.

Sunbeam WXillie, and other Stories. Three Illustrations. Royal $16 \mathrm{mo}, \mathrm{Is} .6 d$.

Sunshine Jenny, and other Stories. Three Illustrations Royal $\mathrm{I} 6 \mathrm{mo}, \mathrm{I} s, 6 d$. 
44 A List of Kegan Paul, Trench \& Co's Publications.

STOCKTON, Frank R.-A Jolly Fellowship. With 20 Illustrations. Crown 8 vo, 5 s.

STORR, Francis, and TURNER, Hawes.-Canterbury Chimes; or, Chaucer Tales re-told to Children. With 6 Illustrations from the Ellesmere Manuscript. Third Edition. Fcap. 8vo, 3s. 6d.

STRETTON, Hesba.-David Lloyd's Last XXill. With 4 Illustrations. New Edition. Royal 16 mo, 2s. $6 d$.

Tales from Ariosto Re-told for Children. By a Lady. With 3 Illustrations. Crown 8vo, 4s. 6 d.

WHITAKER, Florence-Christy's Inheritance. A London Story. Illustrated. Royal $16 \mathrm{mo}^{2}$ is. $6 d_{3}$ 



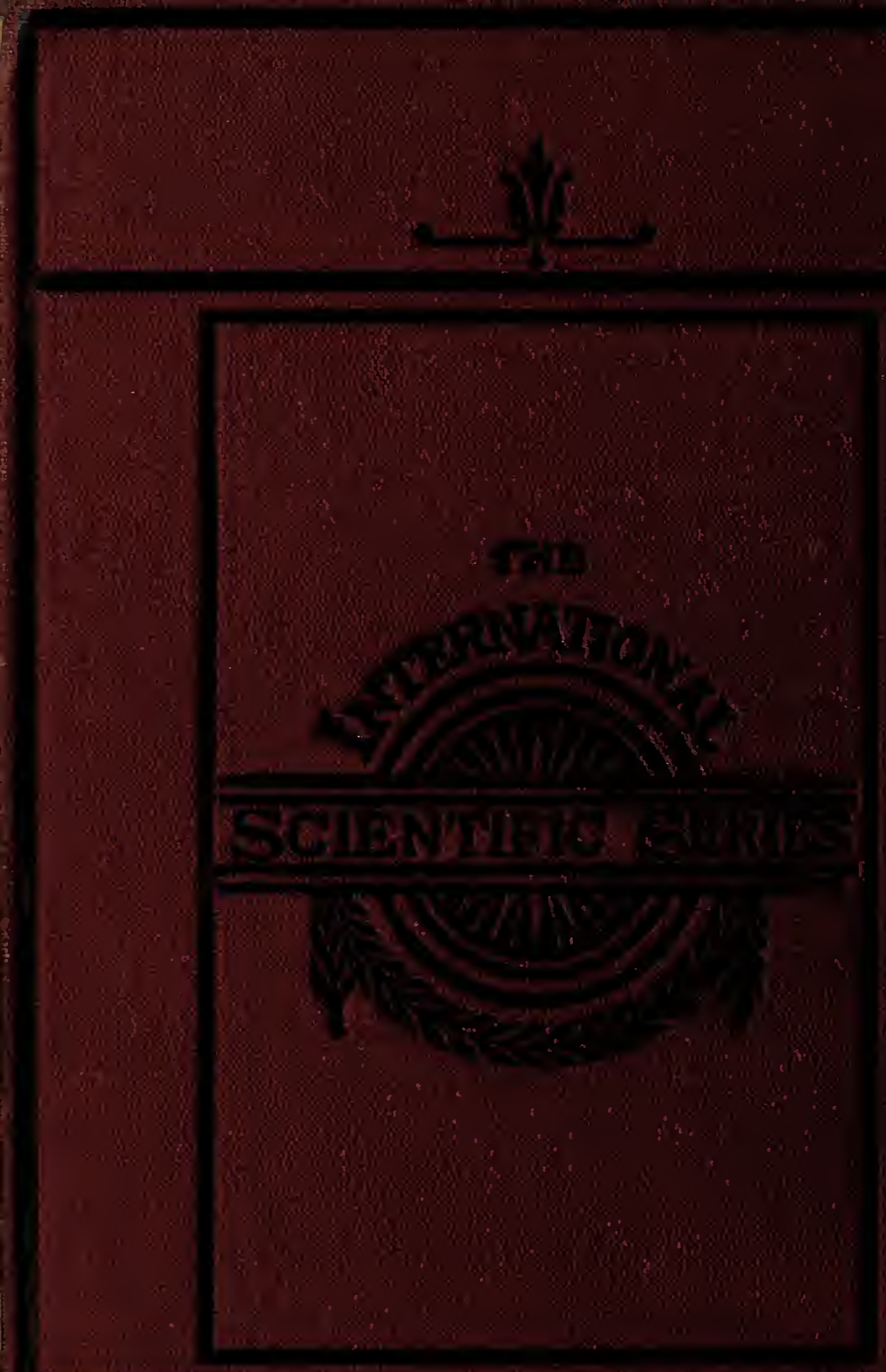

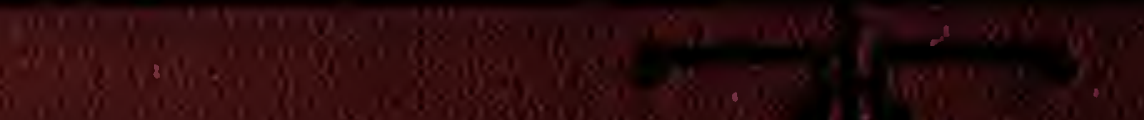

